\title{
Bangladesh: Poverty Reduction Strategy Paper
}

Poverty Reduction Strategy Papers are prepared by member countries in broad consultation with stakeholders and development partners, including the staffs of the World Bank and the IMF. Updated with annual progress reports, they describe the countries macroeconomic, structural, and social policies in support of growth and poverty reduction, as well as associated external financing needs and major sources of financing. This country document for Bangladesh is being available on the IMF website by agreement of the member country as a service to users of the IMF website.

Copies of this report are available to the public from

International Monetary Fund • Publication Services $70019^{\text {th }}$ Street, N.W. • Washington, D.C. 20431

Telephone: (202) 623-7430 • Telefax: (202) 623-7201

E-mail: publications@imf.org Internet: http://www.imf.org

\section{International Monetary Fund Washington, D.C.}




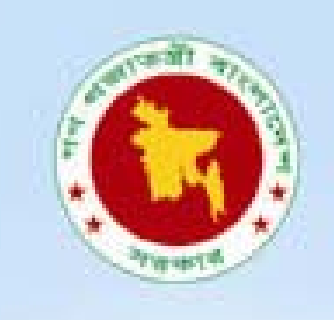

\section{Steps Towards Change}

National Strategy for Accelerated Poverty Reduction II

(Revised)

FY 2009-11

General Economics Division

Planning Commission

Government of the People's Republic of Bangladesh

December 2009 


\section{Steps Towards Change}

National Strategy for Accelerated Poverty Reduction II FY 2009-11

(Prepared in the light of Election Manifesto of the Bangladesh Awami League 2008)

General Economics Division

Planning Commission

Government of the People's Republic of Bangladesh

December 2009 
Cover Design: GED, Planning Commission Copies Printed: 3,500 (English) 

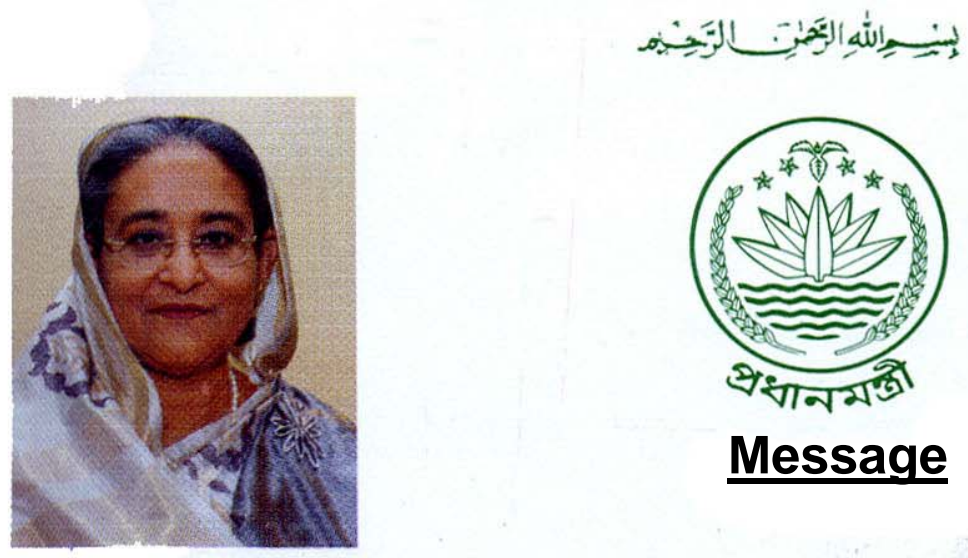

PRIME MINISTER

GOVERNMENT OF THE PEOPLE'S REPUBLIC OF

BANGLADESH

\section{Message}

Our government's aim is to achieve Vision 2021 by implementing economic policies delineated in our Awami League Party's Election Manifesto. Vision 2021 envisages Bangladesh as a middle income country, free from poverty and with healthy growth, stable commodity prices, reduced income and social disparity, secured health and education, entrenched democracy, and capacity to meet the challenges of climate change. The endeavors would be aided by modern information and technology, which also would realize our goal of a "Digital Bangladesh" by 2021.

Since independence, our effort to free Bangladesh from poverty was hindered by disruption of democracy a number of times. The short periods of democracy we experienced, saw some progress in our struggle against poverty, and appreciable success in respect of some of our Millennium Development Goals (MDGs). Now with democracy restored in Bangladesh, our government is confident of freeing our people from poverty and meeting the targeted MDGs, by implementing our economic policies as promised to the people in our Election Manifesto.

In our government's bid to overcome poverty, the General Economics Division (GED) of the Planning Commission has revised the second Poverty Reduction Strategy Paper (PRSP) in the light of our Election Manifesto. The document entitled "Steps Towards Change: National Strategy for Accelerated Poverty Reduction II (FY 2009-11)," or "NSAPR II" is in consonance with Vision 2021 of a middle income Bangladesh with qualitative change in the lives of the people. However, the success of NSAPR II depends on implementation of action plans by all government Ministries and agencies.

I am confident all Ministries and agencies of the government would succeed in achieving the targets of the revised NSAPR II. They would, however, need resource support of our development partners, whom I urge to come forward and join hands with the government in achieving our common goals. Let us together all move forward on the road to a poverty free Bangladesh, to "Sonar Bangladesh" as was envisioned by the Father of the Nation, Bangabandhu Sheikh Mujibur Rahman.

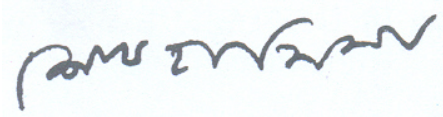

(Sheikh Hasina) 

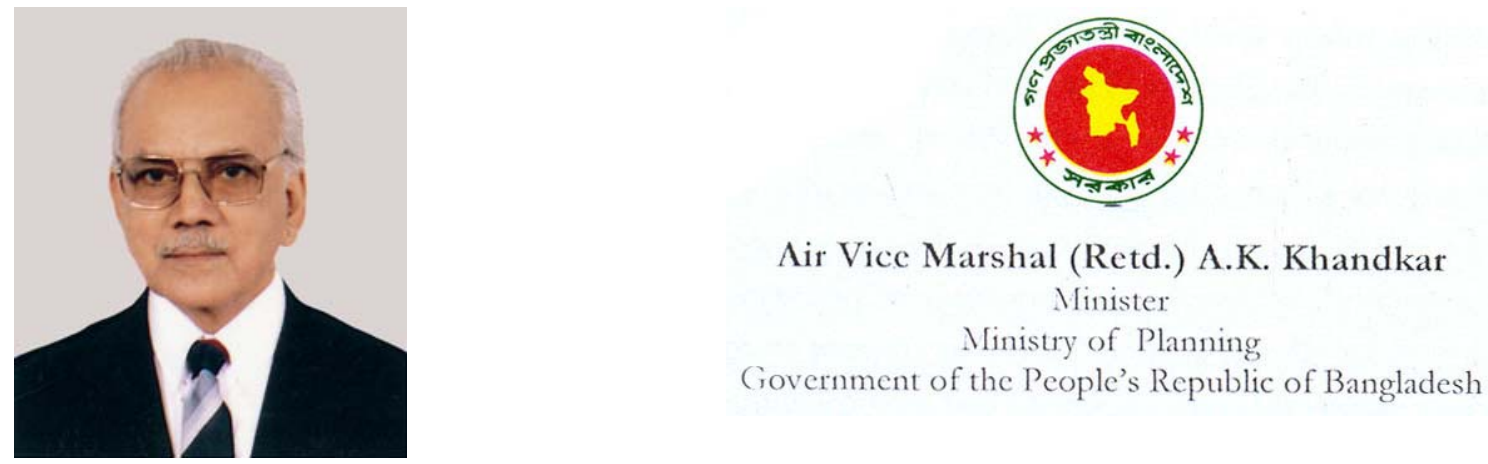

\section{Message}

The second Poverty Reduction Strategy Paper (PRSP-2) of Bangladesh titled 'Steps Towards Change: National Strategy for Accelerated Poverty Reduction (FY 2009-11)' has been revised in the light of the government's development vision and Election Manifesto of the Awami League. It embodies policies as well as strategies for achieving accelerated poverty reduction during FY 2009-11. The revised NSAPR II outlines a comprehensive medium-term strategy for poverty reduction through faster pro-poor economic growth through pro-poor macroeconomic management, creating decent employment opportunities, enhancing productivity and efficiency through science and technology and also in development of small as well as medium scale enterprises. The document also emphasizes on protection of the vulnerable people, regional balance, fundamental human rights, good governance and effective public service delivery. The firm commitment of the government to the Millennium Development Goals (MDGs), the South Asian Development Goals (SDGs) and other international agreements relevant to economic and social development was taken into due consideration during formulating the strategies.

It is evident that the incidence of poverty has been declining in Bangladesh over time. The national head count index of poverty measured by the upper poverty line declined from 56.6 percent in 1991-92 to 40.0 percent in 2005. During the period, urban poverty reduced at a faster rate than rural poverty. At the same time, all indicators of human poverty like life expectancy at birth, infant mortality rate, population having access to drinking water, and adult literacy rate have shown improvements. However, the absolute values of many of the indicators are still high. Household income for all groups has improved, though the distribution has become more unequal.

In achieving faster poverty reduction, the revised NSAPR II puts emphasis on the activities that are targeted to benefit the extreme poor, women in poverty, landless poor and other vulnerable groups. To protect the poor from falling into deeper poverty, five priority areas have been identified in the strategy paper, which include social safety net programmes, food security, disaster management, micro-credit and rural non-farm activities. In this regard, significant budgetary allocation has been made in the revised NSAPR II to expand the Social Safety Net Programmes (SSNPs). 
During recent years, climate change has been posing a critical threat to the fight against poverty in Bangladesh. The prevailing high incidence of poverty and population density makes Bangladesh more vulnerable to climate change. Climate change and variability have already been creating adverse impact on the life and livelihoods of a vast population, particularly those who are living in the coastal areas and in the arid and semi-arid regions of the country. A significant proportion of population of the country is likely to be displaced because of climate-induced flooding, tropical cyclones and storm surges. Revised NSAPR II thus emphasizes mainstreaming and strengthening climate change adaptation across various sectors- improved crop production practices, watershed and coastal zone management including aforestation, building cyclone shelters, embankments, improving salinity control measures, public awareness, emphasize climate research, and data collection. Accordingly, a Climate Change Fund with domestic resources has already been created. A multi-donor Trust Fund has also been under process to supplement the government initiatives.

The estimated total resource requirement for implementing the goals and targets set out in revised NSAPR II is Tk. 2,814.81 billion at FY08 prices, most of which will be met from the domestically generated resources. However, there will be a resource gap of around Tk.874.84 billion at FY08 prices or around US\$ 12.50 billion for three years which has to be mobilized from external sources and increasing domestic revenues.

The revised NSAPR II has been prepared after extensive consultations with the stakeholders, academia, researchers, NGOs and civil societies both at the national and regional levels. It is prepared by the General Economics Division (GED) of the Planning Commission as the National Poverty Focal Point (NPFP) with active cooperation from all the Ministries/Divisions and government agencies. Short-term local consultants were hired to assist at the GED for revision of NSAPR II. Since the NSAPR II (FY2009-11) is a policy and strategy document, its implementation will be continuously monitored and it will be updated and adjusted drawing lessons from the practical field.

I congratulate the General Economics Division (GED) of the Planning Commission for successfully revising the document, 'Steps Towards Change: National Strategy for Accelerated Poverty Reduction (FY2009-11)'. I thank BIDS and the members of the 'Independent Committee for monitoring and evaluation of PRS and attainment of MDGs' for their valuable suggestions and cooperation. I am most grateful to the Finance Minister and the Economic Affairs Adviser to the Honorable Prime Minister for their valuable guidance and concerns. I am also grateful to all the participants in the NSAPR II consultation meetings at the national and regional level. I gratefully acknowledge the encouragement of the Honorable Prime Minister towards completing the revised NSAPR II.

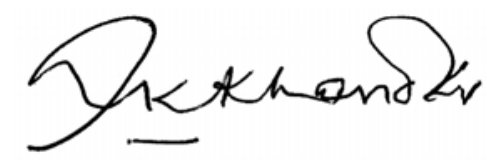

Air Vice Marshal (Retd.) A.K. Khandkar 


\section{Foreword}

Following completion of the Fifth Five Year Plan in 2002, the Government of Bangladesh changed its development strategy and adopted PRSP in an attempt to reduce poverty on a fast track basis. The Government vision for 'a Poverty free Bangladesh' is to reduce poverty within the shortest possible time through attaining higher economic growth. In line with its objectives, NSAPR II (FY 2009-11) was approved by the then Caretaker Government in 2008. Present Democratic Government came to power in January, 2009 and decided to align the NSAPR II in line with its development vision and election manifesto in terms of poverty reduction, economic growth, efficiency through use of science and technology as well as other socioeconomic goals. In this regard, General Economics Division (GED) of the Planning Commission as the National Poverty Focal Point with cooperation from all the Ministries/Divisions and government agencies has revised the NSAPR II.

The poverty reduction strategy framework of the revised NSAPR II is based on the reality of multidimensionality of poverty and takes into account the dynamics of the socio-economic factors that reinforce and perpetuate poverty in the country. The strategy framework consists of five strategic blocks and five supporting strategies, these are: (i) macroeconomic environment for pro-poor growth; (ii) critical areas for pro-poor growth; (iii) essential infrastructure for propoor growth; (iv) social protection for the vulnerable; and (v) human development. The supporting strategies, on the other hand, comprise of: (i) ensuring participation, social inclusion, and empowerment; (ii) promoting good governance; (iii) ensuring efficient delivery of public services; (iv) caring for environment and tackling climate change; and (v) enhancing productivity and efficiency through science and technology.

The NSAPR II which has been revised in the light of the government's development vision and the Election Manifesto also emphasizes the aspect of policy continuity. In this respect, due considerations have been given to the Millennium Development Goals (MDGs) and the SAARC Development Goals (SDGs) as well as the need for sustained efforts towards achieving these goals.

The revised NSAPR II has been prepared after extensive consultations with the members of 'Independent PRS and MDGs Monitoring Committee', Ministries/Divisions and Sector Divisions of the Planning Commission, academia, researchers, NGOs, civil societies and other relevant stakeholders. Draft NSAPR II was placed in the Cabinet on 9 Sept 2009. It was also placed in the National Parliament on 15 Sept 2009 for comments and discussion by the people's representatives. This is the first time in Bangladesh that a national document of this kind has been placed before the Parliament. 
I am most grateful to the Hon'ble Planning Minister and the Economic Affairs Adviser to the Hon'ble Prime Minister for their valuable guidance in revising the NSAPR II and encouragement to complete the document in line with government's development philosophy. I am also very much grateful to the Hon'ble Finance Minister for his valuable suggestions. My heartfelt gratitude goes to the members of 'Independent Committee for Monitoring and Evaluation of PRS and Attainment of MDGs' for their effective guidance and suggestions. I extend my tributes to the concerned members of the Parliament for their discussion and suggestions on revised NSAPR II. I also appreciate the thoughtful comments provided by the development partners in Bangladesh. Finally, I express my deep gratitude to the BIDS for their active support in finalizing the revised NSAPR II. Thanks are also due to my colleagues in the Division who worked hard to make the document available in time. I owe to all of them.

December, 2009

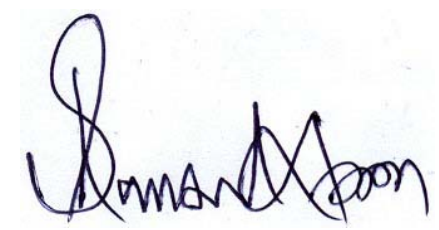

\section{Professor Dr. Shamsul Alam}

Member

General Economics Division (GED)

Planning Commission 


\section{Contents}

Contents

Tables

Figure

Boxes

Abbreviations

Executive Summary

Chapter 1: The Development Vision and Poverty Reduction Framework 1

1.1 The Development Vision

1.2 Attainment of MDGs

1.3 Poverty Reduction Strategy Framework

1.4 Key Issues in Generating Pro-Poor Growth

1.5 Implementation Challenges

1.6 Participatory Formulation Process

Chapter 2: Poverty Situation and the Medium Term Macroeconomic Framework 9

2.1 Achievements in Poverty Reduction

2.2 Trends in Income Inequality

2.3 Women's Poverty

2.4 Regional Differences in Poverty

2.5 Extreme and Chronic Poverty

2.6 Poverty Scenario Beyond 2005

2.7 Medium Term Macroeconomic Framework

2.7.1 Growth and Investment

2.7.2 Fiscal Policy

2.7.3 Monetary Policy

2.7.4 External Sector

Chapter 3: Roadmap for Pro-Poor Economic Growth: Strategic Blocks 17

3.1 Strategic Block I: Macroeconomic Environment for Pro-Poor Economic Growth 17

3.1.1 Recent Macroeconomic Performance

3.1.2 Current Macroeconomic Challenges

3.1.3 Key Thrusts for Macroeconomic Policy

3.2.2 Promoting Decent Employment

3.2.3 Improving the Environment for Private Sector Development (PSD) 25

3.2.4 Agriculture

3.2.5 Water Resources Development and Management 33

3.2.6 Land Use Policy and Management

3.2.7 Urban Development

3.3 Strategic Block III: Essential Infrastructure for Pro-Poor Economic Growth 38

3.3.1 Power and Energy

$\begin{array}{ll}\text { 3.3.2 Transport } & 42\end{array}$

3.3.3 Post and Telecommunication $\quad 44$

3.3.4 Housing $\quad 45$

3.4 Strategic Block IV: Social Protection for the Vulnerable 45

3.4.1 Social Safety Net Programmes 46

3.4.2 Food Security $\quad 46$

$\begin{array}{ll}\text { 3.4.3 Disaster Management } & 47\end{array}$

$\begin{array}{ll}\text { 3.4.4 Microcredit } & 48\end{array}$

3.4.5 Rural Non-Farm Activities 
3.5 Strategic Block V: Human Resources Development 50

3.5.1 Improving Knowledge Base: Education, Training and Research $\quad 50$

3.5.2 Improving Health, Nutrition and Population Planning: Taking a Holistic Approach 54

Chapter 4: Roadmap for Accelerated Poverty Reduction: Supporting Strategies 61

4. 1 Strategy I: Ensuring Participation, Social Inclusion and Empowerment 61

4.1.1 Women's Advancement and Rights 61

4.1.2 Children's Advancement and Rights $\quad 65$

4.1.3 Indigenous Communities $\quad 68$

4.1.4 Persons with Disabilities

4.1.5 Disadvantaged and Extreme Poor Groups 70

4.2 Strategy II: Promoting Good Governance $\quad 71$

4.2.1 Making Parliamentary Process Effective 72

4.2.2 Strengthening Local Government $\quad 72$

4.2.3 Reforming and Strengthening Public Services 73

4.2.4 Reforming Legal and Judicial System 74

4.2.5 Promoting E-governance $\quad 75$

$\begin{array}{ll}\text { 4.2.6 Combating Corruption } & 75\end{array}$

4.2.7 Ensuring Human Rights 76

4.2.8 Accessing Information $\quad 76$

4.2.9 Improving Project Implementation Capacity 76

4.2.10 Improving Sectoral Governance 76

4.3 Strategy III: Ensuring Efficient Delivery of Public Services 77

4.3.1 Priorities in Urban/Rural Service Delivery 78

4.3.2 Safety, Security and Protection of Life, Liberty and Wealth 78

$\begin{array}{ll}\text { 4.3.3 Safe Water and Sanitation } & 79\end{array}$

4.3.4 Power and Energy $\quad 80$

4.3.5 Transportation 80

4.3.6 ICT, Post and Telecommunication $\quad 81$

4.3.7 Development of Tourism 81

4.4 Strategy IV: Caring for Environment and Tackling Climate Change 82

4.4.1 Recent Progress

4.4.2 Current Challenges to Environment 83

4.4.3 Types of Pollution-Institutional Arrangements 84

4.4.4 Tackling Climate Change for Poverty Reduction 90

4.4.5 Forestry 92

4.5 Strategy V: Enhancing Productivity and Efficiency through Science and 93

Technology

4.5.1 Vision and Strategic Goals 93

4.5.2 Assessment of Recent Progress 94

4.5.3 Current Challenges 94

4.5.4 Future Policies and Strategies 94

Chapter 5: Indicative Costs of Achieving Goals and Targets 97

5.1 Methodology for Calculating Resource Needs for revised NSAPR-II 97

5.2 Estimated Resource Gap 99

Chapter 6: Strengthening Implementation, and Monitoring and Evaluation 101

6.1 Implementation Arrangements 101

6.2 Monitoring and Evaluation 102

6.2.1 Evolution of Monitoring and Evaluation 103

6.2.2 Monitoring and Evaluation of NSAPR-II (revised) 103

6.2.3 Data Generation for M \& E 104

6.2.4 Institutional Strategy of M \& E System 105

6.2.5 M \& E Indicators 106

6.2.6 Capacity Building for M \& E 106 
Annexes

$\begin{array}{ll}\text { Table of Policy Matrices } & 107\end{array}$

$\begin{array}{lr}\text { Annex 1: Policy Matrices } & 108\end{array}$

Annex 2: Social Safety Net Budget FY 2008 - $09 \quad 229$

Annex 3: Monitoring and Evaluation Indicators 237

Annex 4: Thematic Committees and their Composition 264

Annex 5: Summary Proceedings of NSAPR II Consultation Meetings 268

\section{Tables}

Page

2.1 Head Count Ratio of Poverty, 1991/92 to 2005

$2.2 \quad$ Income Distribution, 2000 and $2005 \quad 10$

2.3 Medium Term Macroeconomic Framework 13

3.1 Employment Projections for the 2008-09 to 2010-11 Period 22

3.2 Performance of Health, Nutrition and Population Sector 54

4.1 Women's Risks and Vulnerabilities 63

4.2 Targets and Achievements of NSAPR Policy Agenda 82

4.3 Ecologically Critical Areas (ECAs) in Bangladesh 84

5.1 Indicative Cost of Achieving revised NSAPR II Goals and Targets 99

5.2 Estimate of Domestic Resource Gap for NSAPR II (revised) Implementation 100

$\begin{array}{lll}\text { 6.1 Institutional Process of revised NSAPR II Monitoring and Evaluation } & 105\end{array}$

Figure

$1.1 \quad$ Poverty Reduction Strategy Framework 4

6.1 Monitoring and Evaluation System of NSAPR II 104

\section{Boxes}

1.1 Macroeconomic Targets based on Vision 2021

3.1 Power Sector Vision and Policy Statement 39 
ACC

ADB

ADP

ADR

AIDS

AMC

ANC

AQMP

ARI

ARISE

ASA

BADC

BAEC

BANBEIS

BANSDOC

BAPEX

BARC

BARD

BARI

BAU

BB

BBS

BCAS

BCC

BSCIC

BCSIR

BDHS

BERC

BFTI

BGMEA

BIDS

BIFT

BIM

BIMAN

BIMSTEC

BINP

BITAC

BIWTA

BIWTC

$\mathrm{BKB}$

BMA

BMD

BMDC

BMET

BNC

BNS

BOI

BOT
Anti- Corruption Commission

Asian Development Bank

Annual Development Programme

Alternative Dispute Resolution

Acquired Immune Deficiency Syndrome

Alternative Medical Care

Ante-Natal Care

Air Quality Monitoring Project

Acute Respiratory Infection

Appropriate Resources for Improving Street Children Improvement Project

Association for Social Advancement

Bangladesh Agricultural Development Corporation

Bangladesh Atomic Energy Commission

Bangladesh Bureau of Educational Information and Statistics

Bangladesh National Scientific \& Technical Documentation Centre

Bangladesh Petrolem Exploration and Production Company Limited

Bangladesh Agricultural Research Council

Bangladesh Academy for Rural Development

Bangladesh Agricultural Research Institute

Bangladesh Agricultural University

Bangladesh Bank

Bangladesh Bureau of Statistics

Bangladesh Centre for Advanced Studies

Behaviour Change Communication

Bangladesh Small \& Cottage Industries Corporation

Bangladesh Council of Scientific and Industrial Research

Bangladesh Demographic and Health Survey

Bangladesh Energy Regulatory Commission

Bangladesh Foreign Trade Institute

Bangladesh Garments Manufacturers and Exporters Association

Bangladesh Institute of Development Studies

Bangladesh Institute of Fashion and Technology

Bangladesh Institute of Management

Biman Bangladesh Airlines

Bay of Bengal Initiative for Multi-Sectoral Technical and Economic Cooperation

Bangladesh Integrated Nutrition Programme

Bangladesh Industrial and Technical Assistance Centre

Bangladesh Inland Water Transport Authority

Bangladesh Inland Water Transport Corporation

Bangladesh Krishi Bank

Bangladesh Medical Association

Bangladesh Metrological Department

Bangladesh Medical and Dental Council

Bureau of Manpower, Employment and Training

Bangladesh Nursing Council

Bangladesh Naval Ship

Board of Investment

Build, Operate \& Transfer 


\begin{tabular}{|c|c|}
\hline BPC & Bangladesh Pharmacy Council \\
\hline BPC & Bangladesh Petroleum Corporation \\
\hline BPDB & Bangladesh Power Development Board \\
\hline BPI & Bangladesh Parjatan Institute \\
\hline $\mathrm{BPO}$ & Bangladesh Post Office \\
\hline BR & Bangladesh Railway \\
\hline BRAC & Bangladesh Rural Advancement Committee \\
\hline BRDB & Bangladesh Rural Development Board \\
\hline BRRI & International Rice Research Institute \\
\hline BRTC & Bangladesh Road Transport Corporation \\
\hline BSCIC & Bangladesh Small \& Cottage Industries Corporation \\
\hline BSTI & Bangladesh Standards and Testing Institute \\
\hline BTRC & Bangladesh Telecom Regulatory Commission \\
\hline BTTB & Bangladesh Telephone and Telegraph Board \\
\hline BUET & Bangladesh University of Engineering and Technology \\
\hline BWDB & Bangladesh Water Development Board \\
\hline CBD & Convention on Biological Diversity \\
\hline $\mathrm{CBN}$ & Cost of Basic Needs \\
\hline $\mathrm{CBO}$ & Community Based Organization \\
\hline CBR & Community Based Rehabilitation \\
\hline CC & Community Clinic \\
\hline CCCI & Chittagong Chamber of Commerce and Industries \\
\hline CCD & Convention to Combat Desertification \\
\hline CCDB & Christian Commission for Development in Bangladesh \\
\hline CDs & Communicable Diseases \\
\hline CDD & Control of Diarrhoeal Disease \\
\hline CDMP & Comprehensive Disaster Management Programme \\
\hline CDSP & Char Development and Settlement Project \\
\hline CEDAW & Convention on the Elimination of All Forms of Discrimination Against Women \\
\hline CEGIS & Centre for Environmental and Geographic Information Services \\
\hline CEmOC & Comprehensive Emergency Obstetrical Care \\
\hline CETP & Common Effluent Treatment Plant \\
\hline CFL & Compact Fluorescent Lamp \\
\hline CGAP & Consultative Group to Assist the Poor \\
\hline $\mathrm{CHT}$ & Chittagong Hill Tracts \\
\hline CICS & Computerized Inventory Control System \\
\hline CIPRAD & Centre for Indigenous Peoples Research and Development \\
\hline CL & Child Labour \\
\hline CMCA & Case Management and Court Administration \\
\hline CMSD & Central Medical Store Depots \\
\hline $\mathrm{CNC}$ & Community Nutrition Centre \\
\hline CNG & Compressed Natural Gas \\
\hline CNP & Community Nutrition Programme \\
\hline CPA & Chittagong Port Authority \\
\hline CPD & Centre for Policy Dialogue \\
\hline СРP & Cyclone Preparedness Programme \\
\hline CPR & Contraceptive Prevalence Rate \\
\hline CPRs & Common Property Resources \\
\hline
\end{tabular}




\begin{tabular}{|c|c|}
\hline CRA & Community Risk Assessment \\
\hline $\mathrm{CRC}$ & Convention on the Rights of the Child \\
\hline CSBA & Community Skilled Birth Attendants \\
\hline CSDDWS & Committee for Speedy Dissemination of Disaster Related Warning Signal \\
\hline CSE & Chittagong Security Exchange \\
\hline $\mathrm{CSO}$ & Community Support Organisation \\
\hline CSR & Corporate Social Responsibility \\
\hline CTMS & Computerized Terminal Management \\
\hline CZPDC & Central Zone Power Distribution Company \\
\hline DAE & Department of Agricultural Extension \\
\hline DAM & Department of Agricultural Marketing \\
\hline DCCI & Dhaka Chamber of Commerce and Industries \\
\hline DDA & Department of Drug Administration \\
\hline DDC & Development Design Consultants \\
\hline DEA & Decentralised Action Research \\
\hline DESA & Dhaka Electric Supply Authority \\
\hline DESCO & Dhaka Electric Supply Company \\
\hline DFP & Department of Films and Publications/Directorate of Family Planning \\
\hline DGFP & Directorate General of Family Planning \\
\hline DGHS & Directorate General of Health Services \\
\hline DHS & Demographic and Health Survey \\
\hline DIFE & Department of Inspection for Factories and Establishments \\
\hline DLS & Department of Livestock Services \\
\hline $\mathrm{DM}$ & Disaster Management \\
\hline $\mathrm{DMB}$ & Disaster Management Bureau \\
\hline DMFAS & Debt Management Financial Analysis System \\
\hline DMIC & Disaster Management Information Centre \\
\hline DMTATF & Disaster Management Training and Public Awareness Building Task Force \\
\hline DOE & Directorate of Environment \\
\hline $\mathrm{DOF}$ & Department of Fisheries \\
\hline DOTS & Directly Observed Treatment Short course \\
\hline DPDT & Department of Patent, Design and Trademark \\
\hline DPHE & Department of Public Health Engineering \\
\hline DPP & Development Project Proforma \\
\hline DRR & Disaster Risk Reduction \\
\hline DSL & Digital Subscriber Line \\
\hline DTW & Deep Tube Well \\
\hline DYD & Department of Youth Development \\
\hline ECA & Ecologically Critical Area \\
\hline ECC & Environmental Clearance Certificate \\
\hline ECDP & Early Childhood Development Programme \\
\hline ECNWRC & Executive Committee of the National Water Resources Council \\
\hline E-governance & Electronic governance \\
\hline EGWS & Electricity, Gas and Water Sector \\
\hline EIA & Environmental Impact Assessment \\
\hline EMP & Environmental Management Plan \\
\hline EMTAP & Economic Management of Technical Assistance Project \\
\hline EmOC & Emergency Obstetrical Care \\
\hline
\end{tabular}




\begin{tabular}{|c|c|}
\hline EPB & Export Promotion Bureau \\
\hline EPZ & Export Processing Zone \\
\hline ERD & Economic Relations Division \\
\hline ESD & Essential Service Delivery \\
\hline ETP & Effluent Treatment Plant \\
\hline EU & European Union \\
\hline EPI & Expanded Programme on Immunization \\
\hline FCD & Flood Control and Drainage \\
\hline FD & Finance Division \\
\hline FDI & Foreign Direct Investment \\
\hline FEMA & Federal Emergency Management Agency \\
\hline FFW & Food For Works \\
\hline FIAC & Farmer's Information and Advisory Centre \\
\hline FIQC & Fish Quality Control \\
\hline FMD & Foot-and-Mouth Disease \\
\hline FP & Family Planning \\
\hline GCM & Growth Centre Market \\
\hline GDP & Gross Domestic Product \\
\hline GED & General Economics Division \\
\hline GHG & Green House Gas \\
\hline GIS & Geographic Information Systems \\
\hline GM & Genetically Modified \\
\hline GMP & Growth Monitoring and Promotion \\
\hline GMOs & Genetically Modified Organisms \\
\hline GNP & Gross National Product \\
\hline GOB & Government of Bangladesh \\
\hline GPWM & Guideline for Participatory Water Management \\
\hline GR & Gratuitous Relief \\
\hline GW & Ground Water \\
\hline $\mathrm{H} \& \mathrm{FWC}$ & Health and Family Welfare Centre \\
\hline HIES & Household Income and Expenditure Survey \\
\hline HIV & Human Immune Virus \\
\hline HNPSP & Health, Nutrition and Population Sector Programme \\
\hline HQ & Headquarter \\
\hline HRD & Human Resources Development \\
\hline HSC & Higher Secondary Certificate \\
\hline HYV & High Yielding Variety \\
\hline IAEA & International Atomic Energy Authority \\
\hline ICD & Inland Container Depot. \\
\hline ICT & Information and Communication Technology \\
\hline ICT & Inland Container Terminal \\
\hline ICTPs & International Conventions, Treaties and Protocols \\
\hline ICZM & Integrated Coastal Zone Management \\
\hline IDCOL & Infrastructure Development Company Limited. \\
\hline IEM & Information, Education and Monitoring \\
\hline IFC & International Finance Corporation. \\
\hline IGAs & Income Generating Activities \\
\hline ILO & International Labour Organization \\
\hline
\end{tabular}




\begin{tabular}{|c|c|}
\hline IMCI & Integrated Management of Child Illness \\
\hline IMDMCC & Inter Ministerial Disaster Management Co-ordination Committee \\
\hline IMED & Implementation Monitoring and Evaluation Division \\
\hline IMR & Infant Mortality Rate \\
\hline IMTP & Integrated Multi-Modal Transport Plan \\
\hline IOC & International Oil Companies \\
\hline IPEC & International Programme on the Elimination of Child Labour \\
\hline IPHN & Institute of Public Health Nutrition \\
\hline IPM & Integrated Pest Management \\
\hline IPR & Intellectual Property Rights \\
\hline IRIs & Industrial Relations Institutes \\
\hline IT & Information Technology \\
\hline IWM & Institute of Water Modelling \\
\hline IWT & Inland Water Transport. \\
\hline JCS & Joint Coopeartion Strategy \\
\hline JPUF & Jatiya Pratibandhi Unnayan Foundation \\
\hline KGF & Krishi Gabeshana Foundation \\
\hline $\mathrm{km}$ & Kilo meter \\
\hline KWh & Kilowatt hours \\
\hline LAN & Local Area Network \\
\hline LDC & Least Developed Countries \\
\hline LFPR & Labour Force Participation Rate \\
\hline LG & Local Government \\
\hline LGD & Local Government Division \\
\hline LGED & Local Government Engineering Department \\
\hline LMIS & Logistics Management Information System \\
\hline LPG & Liquefied Petroleum Gas \\
\hline LGIs & Local Government Institutions \\
\hline MDGs & Millennium Development Goals \\
\hline $\mathrm{M} \& \mathrm{E}$ & Monitoring and Evaluation \\
\hline MFA & Ministry of Foreign Affairs \\
\hline MFA & Multi-Fibre Arrangements \\
\hline MFI & Micro Finance Institution \\
\hline MIDAS & Micro Industries Development Assistance Society \\
\hline MIS & Management Information System \\
\hline MLE & Ministry of Labour and Employment \\
\hline MMR & Maternal Mortality rate \\
\hline MNCs & Multinational Corporations \\
\hline MoA & Ministry of Agriculture \\
\hline MoCAT & Ministry of Civil Aviation and Tourism \\
\hline $\mathrm{MoC}$ & Ministry of Communication \\
\hline $\mathrm{MoC}$ & Ministry of Commerce. \\
\hline MoCHTA & Ministry of Chittagong Hill Tracts Affairs \\
\hline MoE & Ministry of Establishment \\
\hline MoE & Ministry of Education \\
\hline MoEWOE & Ministry of Expatriates Welfare and Overseas Employment \\
\hline MoEF & Ministry of Environment and Forest \\
\hline MoPEMR & Ministry of Power, Energy and Mineral Resources \\
\hline
\end{tabular}


$\mathrm{MoF}$

MoFDM

MoFL

MoHA

MoHFW

MoIn

MoI

MoTJ

MoL

MoLE

MoLGRD\&C

MoLJ\&PA

$\mathrm{MoP}$

MoPME

MoRA

MoP\&T

$\mathrm{MoS}$

MoSICT

MoSW

$\mathrm{MoU}$

MoWCA

MoWR

MPA

MP

MSME

MT

MTBF

MTMF

MV

MW

NAP

NAPA

NARS

NBR

NBSAP

NCBs

NCDs

NCSDT

NCT

NCTB

NCWD

NDMC

NDP

NEMAP

NEMEW

NEP

NER

NFE
Ministry of Finance

Ministry of Food and Disaster Management

Ministry of Fisheries and Livestock

Ministry of Home Affairs

Ministry of Health and Family Welfare

Ministry of Industries

Ministry of Infromation

Ministry of Textiles and Jute

Ministry of Land

Ministry of Labour \& Employment

Ministry of Local Government, Rural Development and Cooperatives

Ministry of Law, Justice \& Parliament Affairs

Ministry of Planning

Ministry of Primary and Mass Education

Ministry of Religious Affairs

Ministry of Post and Telecommunication

Ministry of Shipping

Ministry of Science and Information \& Communication Technology

Ministry of Social Welfare

Memorandum of Understanding

Ministry of Women \& Children Affairs

Ministry of Water Resources

Mongla Port Authority

Member of Parliament

Micro, Small, and Medium Enterprise

Metric Ton

Medium Term Budgetary Framework

Medium Term Macroeconomic Framework

Motor Vessel

Mega Watt

National Action Plan

National Adaptation Programme of Action

National Agricultural Research System

National Board of Revenue

National Bio-diversity Strategy and Action Plan

Nationalized Commercial Banks

Non-Communicable Diseases

National Council for Skill Development and Training

Newmooring Container Terminal

National Curriculum \& Textbook Board

National Council for Women's Development

National Disaster Management Council

National Drug Policy

National Environment Management Action Plan

National Electro-Medical Equipment Workshop

National Emergency Policy

National Enrollment Rate

Non Formal Education 


\begin{tabular}{|c|c|}
\hline NGO & Non-Government Organization \\
\hline NGOAB & Non Governmental Organization Affairs Bureau \\
\hline NGOCC & Non Governmental Organization Coordination Committee \\
\hline NHRC & National Human Rights Commission \\
\hline NIB & National Institute of Biotechnology \\
\hline NMC & National Monitoring Centre \\
\hline NNP & National Nutrition Programme \\
\hline NPA & National Plan of Action \\
\hline NPFP & National Poverty Focal Point \\
\hline NPL & Non Performing loan \\
\hline NPWA & National Policy for Women's Advancement \\
\hline NRDC & National Rural Development Council \\
\hline NSAPR & National Strategy for Accelerated Poverty Reduction \\
\hline NSC & National Steering Committee \\
\hline NWMP & National Water Management Plan \\
\hline NWP & National Water Policy \\
\hline NWR & National Water Resources \\
\hline O\&M & Operation and Maintenance \\
\hline OMS & Open Market Sales \\
\hline $\mathrm{OSH}$ & Occupational Safety and Health \\
\hline PAs & Protected Areas \\
\hline PBS & Palli Bidhyut Samity \\
\hline РCB & Printed Circuit-Board \\
\hline PCJSS & Parbatya Chattagram Jana Sanghati Samiti \\
\hline PCU & Project Coordination Unit \\
\hline PDB & Power Development Board \\
\hline PDBF & Palli Daridra Bimochon Foundation \\
\hline PFA & Platform for Action \\
\hline PFIs & Partner Finance Institutions \\
\hline PGD & Post Graduate Degree \\
\hline PHC & Primary Health Care \\
\hline PKSF & Palli Karma Sahayak Foundation \\
\hline PLAGE & Policy Leadership and Advocacy for Gender Equality \\
\hline PLC & Public Limited Company \\
\hline PLMC & Procurement and Logistics Management Cell \\
\hline PNC & Post-Natal Care \\
\hline PM & Prime Minister \\
\hline PPP & Public Private Partnership \\
\hline PRA & Participatory Rural Appraisal \\
\hline PRS & Poverty Reduction Strategy \\
\hline PRSP & Poverty Reduction Strategy Paper \\
\hline PSC & Public Service Commission: \\
\hline PSC & Production Sharing Contract \\
\hline PSD & Private Sector Development \\
\hline PSI & Pre-Shipment Inspection \\
\hline PSTN & Public Service Telephone Network \\
\hline PV & Photovoltaic \\
\hline $\mathrm{R} \& \mathrm{D}$ & Research and Development \\
\hline
\end{tabular}




\begin{tabular}{|c|c|}
\hline RCC & Reinforced Cement Concrete \\
\hline REB & Rural Electrification Board \\
\hline REOPA & Rural Employment Opportunity for Protection of Public Property \\
\hline RHD & Roads And Highways Department \\
\hline $\mathrm{RMC}$ & Rural Mother Centre \\
\hline RMG & Readymade Garments \\
\hline RNFA & Rural Non-Farm Activities \\
\hline RNFE & Rural Non-Farm Enterprises \\
\hline RNFS & Rural Non-farm Sector \\
\hline $\mathrm{RO}-\mathrm{RO}$ & Roll On Roll Off \\
\hline RRAP & Risk Reduction Action Planning \\
\hline RRC & Regulatory Reforms Commission \\
\hline RRI & River Research Institute \\
\hline SAARC & South Asian Association for Regional Cooperation \\
\hline SAFTA & South Asia Free Trade Agreement \\
\hline SBA & School Based Assessment \\
\hline SBA & Skilled Birth Attendants \\
\hline SCITI & Small and Cottage Industries Training Institute \\
\hline SDGs & SAARC Development Goals \\
\hline SDNBD & Sustainable Development Networking Programme \\
\hline SEC & Security Exchange Commission \\
\hline SEDF & Small Enterprise Development Facility \\
\hline SEF & Small Enterprise Fund \\
\hline SEID & Socio Economic Infrastructure Division \\
\hline SEZ & Special Economic Zone \\
\hline SHED & Society for Environment and Human Development \\
\hline SHS & Solar Home System \\
\hline SIA & Social Impact Assessment \\
\hline SICT & Support to ICT Task Force \\
\hline SIDR & Name of the disastrous cyclone (Bangladesh, 2007) \\
\hline SME & Small and Medium Enterprises \\
\hline SMEF & Small and Medium Enterprises Fund \\
\hline SMESDP & Small and Medium Enterprises Support and Development Programme \\
\hline SMEWP & Small Enterprise Web Portal \\
\hline SMF & State Medical faculty \\
\hline SMTQ & Standard, Metrology, Test and Quality \\
\hline SOD & Standing Orders on Disaster \\
\hline SOEs & State-Owned Enterprises \\
\hline SOP & Standing Operating Procedure \\
\hline SPM & Suspended Particulate Matters \\
\hline SPS & Samitac... and Phyto S \\
\hline SPM & Sanitary and Phyto-Sanitary \\
\hline SSC & Secondary School Certificate \\
\hline SSEP & Smiling Sun Franchise Program \\
\hline SSNP & Social Safety Net Programme \\
\hline STD & Sexually Transmitted Disease \\
\hline SZPDC & South Zone Power Distribution Company Limited \\
\hline TB & Tuberculosis \\
\hline
\end{tabular}


UHC

UHFWC

UN

UNCAC

UNDP

UPHCP

VAT

VAW

VGD

VGF

WARPO

WASA

WEDP

WEEH

WEF

WFCL

WFP

WHO

WID

WMF

WMG

WMIP

WMO

WSIS

WTO

WWF

WZPDC
Twenty Equivalent Unit

Total Factor Productivity.

Training Needs Assessment

Table of Equipments

Tripartite Productivity Committee

Technical Project Proforma/Proposal.

Test Relief

Tidal River Management

Technical Schools and Colleges

Technical Training Centres

Technical and Vocational Education and Training

Unaccounted for Gas

University Grants Commission

Upazila Health Complex

Union Health and Facmily Welfare Centre

United Nations

United Nations Convention Against Corruption

United Nations Development Programme

Urban Primary Health Care Project

Value Added Tax

Violence against Women

Vulnerable Group Development

Vulnerable Group Feeding

Water Resources Planning Organization

Water Supply and Sewerage Authority

Women Entrepreneurs Development Programme

Women's Empowerment through Employment and Health

Women Entrepreneurs Forum

Worst Form of Child Labour

World Food Programme

World Health Organization

Women in Development

Water Management Federation

Water Management Group

Water Management Improvement Project

Water Management Organization

World Summit on the Information Society

World Trade Organization

Workers Welfare Fund

West Zone Power Distribution Company Limited 


\section{Executive Summary}

\section{The Development Vision}

The present government has placed elimination of poverty and inequity at the forefront of its development strategy. The development vision of the current government as reflected in its Election Manifesto necessitated a revision of the second NSAPR (FY2009-FY11) prepared by the immediate past interim government. An unelected government, its task was to hold election and hand over power to a democratic government; it lacked the public mandate to commit to any long term policy.

In accordance with the Election Manifesto, the thrust has now shifted to putting Bangladesh into a trajectory of high performing growth, stabilizing commodity prices, minimizing income and human poverty, securing health and education for all, enhancing creativity and human capacity, establishing social justice, reducing social disparity, achieving capacity to tackle the adverse effects of climate change, and firmly rooting democracy in the political arena. It is stipulated that developments in information and communication technology will take the country to new heights of excellence, giving a new identity branded as Digital Bangladesh. These wide ranging social, economic, political and technological changes constitute the Charter of Change as enunciated in the Election Manifesto.

The government has also adopted a long term vision for the development of the country which will be reflected in the long term Perspective Plan (2010-2021), under preparation by the government. For realizing the Vision, the government would start the implementation of the Sixth Five Year Plan (FY:2011-2015) from July 2010. The present NSAPR II (revised) shall remain in force until FY11 and its performance will be reviewed each year in normal course. Eventually, the time frame for MTBF (medium term budget framework) shall be extended from three to five years, which shall facilitate continuation of spill over projects or programmes as well as inclusion of new ones.

In the light of the long term vision, the government has identified five priority areas for medium term action: (i) maintenance of macroeconomic stability and control over commodity price hike in the face of the present global economic crisis; (ii) effective action against corruption; (iii) sufficiency in power and energy; (iv) elimination of poverty and inequality; and (v) establishment of good governance.

\subsection{Progress in Attaining MDGs}

Bangladesh has made significant progress towards attaining the MDGs by 2015. Bangladesh has successfully achieved gender parity in primary and secondary education. The country is on track to achieve the targets of halving the proportion of people living below the poverty line and suffering from hunger, net enrolment ratio in primary education, and reduction of child mortality. There are some lagging areas like primary school completion rate, adult literacy rate, access to safe drinking water by the rural people, and maternal mortality ratio which indicate the need for sustained government efforts and generous donor support.

\subsection{Poverty Reduction Strategy Framework}

The poverty reduction strategy framework of NSAPR II (revised) consists of five strategic blocks and five supporting strategies. The strategic blocks are: (i) macroeconomic environment for pro-poor growth; (ii) critical areas for pro-poor growth; (iii) essential infrastructure for pro-poor growth; (iv) social protection for the vulnerable; and (v) human 
development. The supporting strategies comprise: (i) ensuring participation, social inclusion, and empowerment; (ii) promoting good governance; (iii) ensuring efficient delivery of public services; (iv) caring for environment and tackling climate change; and (v) enhancing productivity and efficiency through science and technology. The critical concern of the strategy is to achieve higher growth as well as equity and poverty reduction simultaneously. In this context, the focus is on agriculture and rural life, expansion of social safety nets for the ultra poor and targeted approach towards employment generation.

\subsection{Key Issues for Pro-Poor Growth}

The strategy will be sustained by defining appropriate roles of the public and private sectors and encouraging public private partnerships (PPP); focusing on the key sources of growth and providing fiscal stimulus to counter the effects of global recession; ensuring regional balance in development; promoting decentralized growth with broad public participation, growth of rural towns and semi-urban areas outside the municipal areas and growth of the meso-economy; reducing population growth and reaping the benefit of demographic dividend; focusing on women's advancement and rights; strengthening safety nets programmes; and ensuring environmental protection and protection from the adverse effects of global warming and climate change.

\section{Progress in Poverty Reduction}

The incidence of poverty has been declining in Bangladesh. The national head count index of poverty measured by the upper poverty line declined from 56.6 percent in 1991-92 to 40.0 percent in 2005 . During the period, urban poverty reduced at a faster rate than rural poverty. At the same time, all indicators of human poverty like life expectancy at birth, infant mortality rate, population having access to drinking water, and adult literacy rate have shown improvements. However, the absolute values of many of the indicators are still high. Household income for all groups has improved, though the distribution has become more unequal.

\subsection{Vulnerability of Women}

There are some special aspects to women's poverty. The total number of poor women is higher than that of poor men. Various micro studies indicate that the 'hardcore' poor are

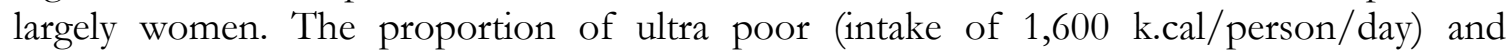
extreme poor (intake of $1,805 \mathrm{k} . \mathrm{cal} / \mathrm{person} / \mathrm{day}$ ) is higher for female-headed households than male-headed ones. The special features of women's poverty require a gender perspective in the pro-poor growth strategy.

\subsection{Persistence of Regional Variation}

Sharp regional contrasts exist in the incidence of poverty. In 2005, the poverty headcount ranged from a low of 32 percent in Dhaka and 34 percent in Chittagong and Sylhet divisions to over 50 percent in Barisal and Rajshahi divisions. Poverty measured by the lower poverty line gives a similar picture. Special policy measures are needed to accelerate poverty reduction in the regions lagging behind.

\subsection{Extreme and Chronic Poverty}

The latest BBS data show that 19.5 percent of the country's population suffers from extreme poverty. People living in remote and vulnerable areas like river banks and char areas, remote hilly areas, and certain groups of indigenous and disadvantaged people are the usual victims of extreme poverty. About 25-30 million people live in chronic poverty. 
Investment in infrastructure, creation of employment opportunities in the lean period, and increased coverage of social safety net programmes will improve their poverty situation.

\subsection{Medium Term Macroeconomic Framework}

The medium term macroeconomic framework takes into account the adverse impact of the global economic slowdown and reflects the election pledges of the government to tackle the impact of global recession, maintain macroeconomic stability, and steer the economy to recovery and move to higher growth. The projections reflect a cautiously optimistic scenario that is consistent with recent trends and takes into account the commitment of the government to reduce poverty and inequity.

Annual GDP growth is projected to be 6.0 percent in FY10, 6.7 percent in FY11, and 7.2 percent in FY12. These growth targets are consistent with the Election Manifesto, which sets GDP growth at 8.0 percent by 2013 and 10.0 percent by the year 2017 . Inflation rate is projected to decline during the revised NSAPR II period, investment/GDP is projected to improve in FY11 after sluggish growth in FY10, revenue/GDP and government expenditure/GDP are projected to improve in FY10 and FY11. However, the budget deficit will also increase in next two years. In the external sector, both import and export growth would be higher in FY10 and FY11.

\section{Roadmap for Pro-Poor Growth: Strategic Blocks}

\subsection{Macroeconomic Environment for Pro-poor Economic Growth}

The macroeconomy faces several risks and challenges in the coming two years- reversing the slide in the growth rate, increasing the investment/GDP ratio, sustaining the momentum in revenue growth, improving export performance, sustaining remittance growth, providing productive employment to the growing labour force, and ensuring food security.

The government has taken steps to balance its policies to meet short term exigencies and long term development needs. A fiscal stimulus package was undertaken in April 2009 to support agriculture, export and power sector and provide enhanced social security. The FY10 budget has adopted special measures and support package for minimizing the adverse impact of the global economic slowdown. The Bangladesh Bank has advised the commercial banks to reduce their lending rate to 13 percent to support agriculture, large and medium enterprises, housing and trade finance. The government will continue to provide such support to mitigate the impact of recession in the short term.

3.2 Key Thrusts of Macroeconomic Policy: Higher economic growth will require (i) increased accumulation of capital facilitated by reductions in the cost of borrowing and improvement in total factor productivity; (ii) promoting growth of sectors(broadly defined) like agriculture, industry and services focusing on the more pro-poor segments of the sectors; and (iii) improved business and investment climate.

The fiscal policy will focus on macroeconomic stability and pro-poor economic growth while safeguarding the economy from international shocks like the current global melt down, ensuring food security, and encouraging social inclusion. This will be achieved through raising revenue, reordering public expenditure to more productive and social sectors, and improving efficiency of expenditure.

Financial sector will be reformed to make financial intermediation in the development process more efficient. The Bangladesh Bank will continue to pursue such monetary policy that would reduce inflation and promote higher growth through maintaining an adequate flow of credit to productive activities and providing refinance support for income and employment generating priority sectors including agriculture and SMEs. The efforts will also 
aim at keeping bank's lending rate as well as interest rate spread lower, and maintaining a stable and competitive real exchange rate avoiding undesirable fluctuations.

The external sector policy will be geared to sustain export growth, enhance remittance flows, and ensure increasing flow of imports required to attain the targeted growth rate of the economy and meet consumer demand.

\subsection{Critical Areas for Pro-Poor Growth}

Small and Medium Enterprises (SMEs) Development: The SMEs will play a pivotal role in achieving the national goal of accelerated pro-poor growth. The government will, through its policy support to the SMEs, play the role of a facilitator to provide them a level playing field. The policies and strategies for promoting SMEs growth and competitiveness will be formulated to address the multiple constraints and challenges facing SMEs based on a comprehensive and inclusive credit policy, human resources development focusing on fostering the entrepreneurial spirit, technology and product quality and standards, subcontracting, production networking, access to markets, gender sensitivity, regional spread, and policy coordination and cooperation.

Promoting Decent Employment: The government will undertake job creation programmes for those who are by-passed by the normal growth process. The government will introduce a programme entitled Employment Generation for the Hard Core Poor in FY10 which is estimated to create 4.9 million man-months of employment. The government is also planning to widen the existing SSN programmes. Employment will be created also through public works programmes, micro-credit and employment-based social safety nets.

A comprehensive employment guideline will be formulated with the following core components: (i) creating employment opportunities in rural economy, (ii) creating employment opportunities for wage labour in industries, (iii) providing credit and training for self-employment, (iv) promoting subcontracting arrangements between large and SMEs, and (v) providing special training arrangements for facilitating export of labour. The labour policy will be reviewed with a view to re-defining minimum wage, removal of discrepancy between male and female wages for same work and productivity, and better protection of the rights of workers and trade unions.

Environment for Private Sector Development: The government has introduced a broad range of policy and institutional changes having positive impact on private sector development. Enhanced efforts will be made to support the private sector-led development during the revised NSAPR II through maintaining macroeconomic stability to provide a conducive environment for private investment, removing infrastructural constraints, creating a deeper and more efficient financial sector, developing best practices for microfinance, developing the capital market, addressing skills shortages in the labour market, promoting regulatory transparency, improving access to land for private enterprises, promoting development of economic zones, technology development, women entrepreneurship development, promoting corporate social responsibility, promoting publicprivate dialogue, and competition.

Agriculture: The challenges of improved performance in the agricultural sector will be addressed through a set of policies and strategies in the NSAPR II (revised) period. In the crop sub-sector, the strategies will focus on productivity gains, diversification to high value crops, market based input distribution along with effective monitoring, biotechnology research and development, technology generation and dissemination, strengthening of NARS institutes, demand-driven agricultural extension, revamping the agricultural marketing system, agro-processing activities, creating employment opportunities especially for women, increasing cropping intensity through diversification to high value crops, creating enabling agri-business development services and market opportunities both for 
domestic and international markets, promoting small and medium enterprises, export promotion and development of AEZ-based technology, climate change adaptive technology, extension of irrigation, flood protection and drainage coverage, and agricultural subsidy.

The overall strategy of fisheries sub-sector development envisages intensification of aquaculture by species and ecosystems, addition of export-oriented species, ensuring biodiversity and preserving natural breeding grounds, product diversification, value addition, development of appropriate marketing infrastructure strengthening the capacity of the Department of Fisheries (DoF), promoting cooperation among the key actors such as NGOs, private sector entrepreneurs and community based fishing groups and enhancing productivity of all khas ponds and water bodies.

Livestock: In the livestock subsector strategies will focus on dairy development and meat production, poultry development, veterinary services and animal health, feeds and animal management, breed development, hides and skins, marketing of livestock products, demand-led extension services and assured marketing facilities for poultry and milk products, international trade management, access to credit and insurance and institutional development for research and extension, for livestock and poultry development in the country. The Department of Livestock Services (DLS) and Bangladesh Livestock Research Institute (BLRI) will play a supportive role for private sector development in the subsector.

Forestry: In the forestry subsector strategies will focus on development and management of protected areas (PAs), eco-parks, botanical gardens and safari parks under a reformed legal framework, ensuring both in-situ and ex-situ conservation in the country, co-management in five out of $19 \mathrm{PAs}$, wildlife protection, sustainable management of enhancing access of the poor to public commons, conducting National forest assessment and periodic forest inventory, and building forest resources through afforestation.

Rural Development: The National Rural Development Council (NRDC), headed by the Prime Minister, will be formed to provide guidelines for implementing the rural development policy. A national steering committee will be formed to assist the NRDC and follow up policy implementations. Steps are underway to set up the Policy and Strategy Formulation Unit (PSFU) to implement the National Rural Development Policy 2001 for which a project has been undertaken for the period 2009-2013.

Water Resources Development and Management: The strategies of water resources development and management will be grouped under six major heads: (i) dredging the main rivers and their development for the multipurpose use of water resources, management for navigation, erosion control, and development of hydropower; (ii) flood protection and storm-water drainage measures will be undertaken with the rehabilitation and maintenance of existing FCD and FCDI systems in a participatory manner and protection of rural and urban areas from floods; (iii) disaster management programmes will include provisions of cyclone protection, early warning and forecasting systems with adequate lead time, flood proofing shelters, control of riverbank erosion, drought management and rationalization of groundwater resources and climate change adaptation; (iv) adequate provisions will be made for water management for agriculture through public sector irrigation development and flood management and drainage; ( $v$ ) protection of the natural environment and aquatic resources will be ensured with water pollution monitoring and control, water management for fisheries and ecologically sensitive areas and raising awareness of all stakeholders to support environmental measures; and (vi) development of institutions in the water sector will be ensured. 
Land Use Policy and Management: Land use policy will ensure optimal use of land resources and delivery of land related services to the people through modernized and efficient land administration. The strategies are: (a) computerisation of the land records and land management system, (b) allotment of agricultural Khas land to landless and asset less people to improve their living conditions, (c) ensuring planned use of land through enforcement of the provisions of the existing laws and promulgation of new laws, $(d)$ ensuring proper management of jalmahal, balumahal and other mahals for poverty reduction, (e) protection and conservation of wet lands, hilly areas, tea gardens, and rubber gardens, and (f) taking measures to help accretion of coastal land.

Urban Development: Urbanization has incidental growth promotion and poverty reduction potential but puts heavy pressure on the development of utilities to meet demand for a rapidly growing urban population. The urbanization policy would encompass spatial, economic, social, cultural, aesthetic and environmental aspects of urban life directed towards achieving an urban society free from hunger and poverty with ample access to education, health, shelter, and basic services and a secure and liveable environment at home and workplace. It will be a society sensitive to women, children and the aged.

\subsection{Essential Infrastructure for Pro-Poor Growth}

Power and Energy: The supply of quality and reliable power at affordable prices to the people will be ensured through system expansion with a prudent least cost plan, efficiency improvement through institutional and structural reform and establishment of commercial arrangements among the sector entities. Balanced development of generation, transmission and distribution of electricity will be ensured. Electricity generation will focus on completion of under construction plants, installation of new plants, utilization of full capacity of existing plants through rehabilitation, scheduled maintenance and overhauling, and human resource development., review of Captive Power Policy to remove all barriers.

The vision of the power sector is to provide access to affordable and reliable electricity to all citizens of Bangladesh by 2021. The supply of quality and reliable power at an affordable price will be ensured through system expansion with a prudent least cost plan, efficiency improvement through institutional and structural reform and establishment of commercial arrangement among the sector entities. Electricity generation will be raised to 7,000 MW by 2013, 8,000 MW by 2015 and 20,000 MW by 2021 .

The existing National Energy Policy (NEP) is being updated to provide guidelines for achieving energy security for the country. An action plan will be worked out to improve the operational and financial performance of Petrobangla and its subsidiaries. The policy for public-private partnership for operating companies of Petrobangla will be formulated so that both domestic and foreign entrepreneurs may participate.

The major strategies to meet the demand for petroleum products will include increasing the LPG bottling capacity and increasing the refining capacity, expansion of the storage capacity of petroleum products, improvement of the distribution system by putting a second oil installation, and enhancement of the capability to handle large vessels to reduce losses in import operations.

For renewable energy, the main goal is to develop, disseminate, promote and extend the renewable energy technology to the rural people to meet their energy needs for lighting and cooking purposes by using sustainable and inexhaustible environment friendly renewable 
energy sources. The National Coal Policy is being formulated for development of coal to meet the growing energy demand.

Transport: The goal of road transport is to achieve a well-maintained, cost effective and safe road network connecting all parts of the country and to establish cross-border links. The development of road sector emphasizes: (i) capacity expansion through construction of tunnel, (ii) four laning of existing important highways. (iii) Construction of major bridges, (iv) development of road corridor and border roads to facilitate sub-regional trade, and (v) regional balance in road development. The development of rural road communication will emphasize linking growth centres, union parishad headquarters, upazilla parishad headquarters, social service institutions like schools, and hospitals with the national road network.

The planned construction of Padma Multipurpose Bridge will be completed by 2013. Steps have been taken to implement the construction of Padma Bridge project at Mawa and the construction of Karnaphuli Hanging Bridge project on a priority basis. Feasibility studies for construction of the four-lane Dhaka-Chittagong Expressway are underway.

The main goal of Bangladesh Railway is to sustain its growth momentum to contribute to the development efforts of the country through providing wider connectivity and mass transportation facilities at a comparatively cheap price. A Master Plan for the development of $\mathrm{BR}$ is under preparation by the Planning Commission to overcome the problems and expand and modernize the railway. The measures include double tracking the DhakaChittagong corridor, establishing rail link with neighbouring countries under the Asian Rail and Highways Scheme, undertaking a three-year maintenance rolling plan, and rehabilitation of railway. Feasibility studies will be undertaken to construct underground rail, circular rail, circular and elevated rail in Dhaka. In order to modernise railways, a reform project called Bangladesh Railway Sector Improvement is being implemented.

The main goal of water transport is to ensure the smooth and safe navigation of cargo and passenger vessels. In order to overcome the current and emerging problems programmes will be undertaken for dredging all major river routes and the construction of inland river container terminals. Besides, the IWTA will make provision for providing facilities at different landing ports, landing facilities in the coastal area, and pontoons at wayside landings.

The main goal related to ports is to enhance efficiency and productivity against pre-set indicators through improving the quality of services and facilities to the port users and stakeholders at competitive prices. Mongla and Chittagong sea ports will be developed and will be opened to all regional users.

Post and Telecommunication: In order to realize the vision of building Digital Bangladesh the main thrust will be to extend ICT facilities to those who are living in rural areas. The strategies for the development of BPO will focus on the introduction of an ICTbased postal network to keep it connected with customers, bringing qualitative changes in postal services, establishing e-centers in the post offices, continuous improvement of products, work process reengineering, creating a business development cell and providing quality services to the people.

Housing: The priorities of housing development are: (i) create an enabling environment for adequate and affordable housing for different income groups, especially low-income and extreme poor and vulnerable groups; (ii) provide housing for rural and urban homeless, landless and vulnerable groups; (iii) ensure maximum utilization of land in rural areas through developing "growth centre" centric housing in every union and Upazilla and 
housing with modern amenities in urban areas; and (iv) facilitate private sector house building and house building by NGOs and CBOs. The government's goal is to provide housing for all by 2015 .

\subsection{Social Protection for the Vulnerable}

In achieving faster poverty reduction, attention will be given to activities that are targeted to benefit the extreme poor, women in poverty, landless poor and other vulnerable groups. To protect the poor from falling into deeper poverty, priority will be given to at least five areas. These are: social safety net programmes; food security; disaster management; micro-credit and rural non-farm activities.

Social Safety Net Programmes: A strong and expanded social safety net programme (SSNP) is the main emphases of Vision 2021, which will protect the poor from all sorts of social, economic and natural shocks. The major goals of SSNPs are: (i) safety net interventions will achieve the protection of all types of poor people and the prevention of chronic poverty as well as transient poverty. It will target the extreme poor first; (ii) the government will encourage NGOs, CBOs and the private sector to augment their role and contributions to expand the social safety net; and (iii) attempts will be made to increase coverage through increased budgetary allocation each year.

Food Security: Food security encompasses three broad aspects, namely, availability, access and utilization. Food security and nutrition will (i) ensure adequate and stable supply of safe and nutritious food; (ii) enhance the purchasing power of the people for increased access to food; and (iii) ensure adequate nutrition for all, especially women, children and persons with disabilities.

Disaster Management: The goal for disaster management (DM) is prevention and protection of lives and properties from any kind of hazards with priority given to disaster risk management along with mitigation. DM will include (i) improving the cyclone signal system to make it clear to common people and improving flood forecasting to be able to make forecasts 6-7 days ahead instead of 3-4 days as currently made; (ii) strengthening coordination among the government agencies, NGOs and civil society institutions and coordination and management at grassroots level; (iii) developing insurance system to cover disaster-related losses of property; (iv) avoiding overlap in relief distribution and rehabilitation initiatives, (v) providing adequate health facilities for the disaster victims, quick transportation of the affected people and instant treatment of the injured people, and (vi) improving capacity for adequate and quick response to emerging and potential disaster like sea-level rise, bird flu, etc.

Microcredit: Microcredit programme will seek to increase the coverage to a larger number of deserving households; introduce a uniform approach of operation both by NGOs and the public sector; and introduce a regulatory framework for streamlining the activities of the microcredit programme in the country. A national microcredit policy will be framed to provide guidelines about the operation of microcredit. It is also necessary to rationalize interest rates. Necessary mechanism will be devised to ensure that microcredit reaches the ultra poor and the hard to reach areas especially those located in regions with higher incidence of poverty. Local governments will be involved in microcredit delivery. It will rationalize interest, reducing the wide variations and the exorbitant rates.

Rural Non-Farm Activities: Rural non-farm activities have the potential of becoming leading areas of growth in the rural economy. The strategies will focus on two broad areas: (i) improving the rural investment climate; and (ii) supporting institutional framework. 


\subsection{Human Resources Development}

Knowledge Base: Education, Training and Research: The country's education system comprising primary, secondary, tertiary, and non-formal education will be developed to build a knowledge-based society. Utmost priority will be given to quality of education to increase the employability. Attention will be given to increase people's access to information, research capacity and awareness among people, particularly at the grassroots level. The commitment of the government is to achieve 100 percent literacy by 2014 .

Health, Nutrition and Population Planning: Taking a Holistic Approach: Health, nutrition and population (HNP) are intimately related and complementary to other sectors of the economy. The government is committed to ensure quality health, nutrition and family welfare services, which are affordable, attainable and acceptable to its citizens. The government focuses on increasing health status, reducing health inequalities, expanding access to social safety network and encouraging affordable service delivery systems for everybody. For the poor and vulnerable, existing facilities will be further expanded and consolidated to ensure access of the poor to public health care services as well as establish ownership through community participation. The health policy will be reevaluated and adjusted according to the goals set by the government.

The current commitment of spending at least 60 per cent of the total budgetary allocation of the HNP sector at upazila level and below will continue to be pursued to improve the quality of PHC and make it accessible and acceptable to the people, especially the poor and vulnerable. Functioning of the Upazila Health Complexes (UHCs), Union Health \& Family Welfare Centers (UHFWCs) and the Community Clinics (CCs) will be strengthened and further consolidated through providing adequate manpower, drugs and other medical aids. The Community Clinics will provide PHC services, maternal and child care, family planning services, nutrition and venereal disease related services to the rural people. The government is committed to reactivate 10,723 community clinics (CCs) which were established during 1996-2001. The MOHFW will run at least 8,000 CCs under government management. The government is committed to providing universal access to pure drinking water by 2011 and sanitation by 2013 .

\section{Roadmap for Accelerated Poverty Reduction: Supporting Strategies}

\subsection{Participation, Social Inclusion, and Empowerment}

The vision for women's advancement and rights is to create a society where men and women will have equal opportunities and will enjoy all fundamental rights on an equal basis. To achieve this vision, the aim is to ensure women's advancement and rights in the activities of all sectors of the economy. Women Development Policy formulated by the present government in 1997 will be revived to ensure women's empowerment and equality in rights and opportunities.

Differential treatment of children, the extreme poor, persons with disabilities and indigenous people is all pervasive and will be addressed in an effective manner for poverty reduction and development to benefit all. Proper attention is given in the NSAPR II (revised) to the hopes and aspirations of these groups of people.

\subsection{Good Governance}

Improving governance and reducing corruption are crucial to helping poor people escape poverty and achieving the MDGs. The promotion of good governance will focus on the following issues: (i) making parliamentary process effective; (ii) reforming and strengthening the public service system; (iii) reforming the legal and judicial system to ensure judicial help for the poor and women; (iv) changing roles of law enforcing agencies; (v) strengthening of 
local government; (vi) promoting e-governance; (vii) combating corruption; (viii) ensuring human rights; (ix) accessing information; (x) improving project implementation capacity; and (xi) improving sectoral governance. Devolving governance to root level, the upazila parishads would be gradually strengthened assigning more functions and responsibilities as they are able to act independently. The zila parishad system would be reviewed within 3-4 years to ensure a reformed and functional structure.

\subsection{Efficient Delivery of Public Services}

The main goal of public services delivery is to ensure adequate, effective and low-cost services relating to safety, security, and protection of life, liberty and wealth, safe water and sanitation for all, power and energy, transportation, solid waste management, and ICT, post and telecommunication to the people. Efforts will be made to develop public-private partnership and government-NGO cooperation to improve efficiency in the management of delivery in some essential utility services, where such modalities are feasible and bring additional value or enhances efficiency.

\subsection{Caring for Environment and Tackling Climate Change}

The environmental challenges in the forms of water and air pollution, land degradation, extreme degradation of terrestrial and aquatic ecosystems, unsustainable agricultural practices and unplanned urban growth will be met by undertaking measures in the areas of policies, planning, regulations and capacity building. Appropriate measures will be taken to adapt to and mitigate the impact of climate change. Climate adaptation will be strengthened by undertaking sectoral, multi-sectoral and cross-sectoral measures.

\subsection{Enhancing Productivity and Efficiency through Science and Technology}

The major goal of the science and technology policy is to make Bangladesh a knowledgebased society, which accelerates growth and reduce poverty. The quality of life of people of the disadvantaged strata will be improved through enhancing quality of education and health care by innovative application of ICT, enhancing productivity in agriculture through the application of biotechnology and inspiring the creation of jobs through technological growth induced by a more reliable availability of power through the promotion and application of atomic energy. Development of modern biotechnology will be promoted on the areas of bio-fuel, biomedical and agricultural research.

\subsection{Official Development Assistance (ODA)}

The Government recognizes that effective and efficient utilization of Official Development Assistance (ODA) is critical to the achievement of development goals. Accordingly, Bangladesh is fully committed to implementation of the Paris Declaration (PD) on Aid Effectiveness of 2005 and the Accra Agenda for Action (AAA) of 2008. Consequent upon PD, Bangladesh prepared a Harmonization Action Plan (HAP) and currently, in collaboration with the development partners, has been working on a Joint Cooperation Strategy (JCS). The leadership role of the Government is increasingly gaining strength in utilization of development assistance.

\section{Indicative Costs of NSAPR II}

In estimating the resource requirement for implementing revised NSAPR II, the cost of completing all the activities to achieve the desired goals and targets in each thematic area has been taken into consideration. The estimated cost of achieving the strategic goals and targets set out in revised NSAPR II is Tk. 2,814.81 billion. Non-discretionary expenditure comprising interest payment obligations (both domestic and foreign interest payments) of the public sector and national defence expenditure needs amounted to Tk. 642.59 billion at 
FY08 prices. The total public expenditure in the NSAPR II (revised) period thus comes to Tk. 3,457.40 billion. The total domestic resource that can be mobilized is in the amount of Tk. 2,582.56 billion at FY08 prices. The estimated total resources gap is Tk. 874.84 billion or USD 12.50 billion which has to be mobilized from external sources.

\section{Implementation Monitoring and Evaluation}

The implementation arrangements and monitoring and evaluation mechanism of NSAPR II (revised) have been clearly articulated. The major responsibility for the implementation of the strategy lies with the concerned ministries and their agencies comprising different thematic groups as well as other ministries and agencies responsible for the implementation of the crosscutting issues. Other actors that will play an active role in the implementation include the private sector, civil society organizations (CSOs), NGOs, and regulatory commissions. The development partners will play a supportive role in the implementation of the NSAPR II (revised). There would be regular dialogues with development partners based on mutually agreed JCS paper with clear aid effectiveness outcomes in support of a prioritised and operational national poverty strategy. A list of indicators has been developed for monitoring. For carrying out M\&E effectively, capacity building of concerned institutions will be undertaken. 
NSAPR II (Revised) 


\section{Text Quote}

“...implementation responsibility of NSAPR II (revised) lies with the concerned lead ministries and their agencies as well as other associate ministries and their agencies. Ministries/Divisions who will be responsible for preparing their respective detailed prioritized action plans/road maps based on NSAPR II (revised) policy agenda for the implementation of the strategies to achieve sectoral and crosscutting targets for the FY 2009-11 period."

Page: 101 
NSAPR II (Revised) 


\section{Chapter 1}

\section{The Development Vision and Poverty Reduction Framework}

\subsection{The Development Vision}

The present government has placed poverty reduction at the forefront of its development strategy. Elimination of poverty and inequity is central to the development vision laid out in the Election Manifesto of the government. The Manifesto has set specific poverty reduction targets to be attained during the current tenure of the government and identified faster agricultural growth, broad based rural development, targeted employment generation, and strengthening of social safety nets as some of the major strategies for attaining poverty reduction objectives.

A Poverty Reduction Strategy Paper (PRSP) titled "Unlocking the Potential: National Strategy for Accelerated Poverty Reduction (NSAPR I)" was prepared in 2005. The NSAPR I was put into implementation during FY2005-FY07 and subsequently it was extended up to June 2008. The second NSAPR (FY2009-FY11) was prepared by the immediate past caretaker government. Because of the unelected and interim nature of the caretaker government, the NSAPR II document prepared by it could not adequately reflect the genuine wishes of the people.

The current elected government has carried out a comprehensive evaluation of the NSAPR II document in accordance with its commitments in the Election Manifesto. While retaining policy continuity, the document has been recast in the light of the government's development vision and the Election Manifesto. In line with the aspirations of the people, the thrust has now shifted to making Bangladesh a happy and prosperous nation supported by mutually reinforcing development in social, economic and political front. In accordance with the Election Manifesto, this will entail putting Bangladesh into a trajectory of high performing growth, stabilizing commodity prices, minimizing income and human poverty, securing health and education for all, enhancing creativity and building capacity, establishing social justice, reducing social disparity, achieving capacity to tackle the adverse effects of climate change, and firmly rooting participatory democracy in the political arena.

A critical element in bringing about the envisaged social and economic development will be the adoption of advanced and innovative technology. It is stipulated that developments in information and communication technology will take the country to new heights of excellence, giving a new identity branded as Digital Bangladesh.

The government's commitment to bringing about the above mentioned developments in social, economic, political and technology fields constitute the Charter of Change as enunciated in the Election Manifesto.

The NSAPR II (revised) prepared in the light of the government's development vision and the Election Manifesto also emphasizes the aspect of policy continuity. In this respect, due considerations have been paid to the Millennium Development Goals (MDGs) and the SAARC Development Goals (SDGs) and the need for sustained efforts towards achieving these goals.

The government has also adopted a long term vision for the development of the country. For the purpose, the long term Perspective Plan (2010-2021), under preparation by the government, would provide goals for the future and chart out the course of action to 
achieve these goals by 2021, which will coincide with the Golden Jubilee of Independence of Bangladesh. For realizing the Vision, the government would start the implementation of the Sixth Five Year Plan (2010-2015) from July 2010. The plan document will project goals and targets and explore alternative strategies for reaching these goals and targets. This medium-term plan will contribute to the process of implementing the Perspective Plan and provide an indicative forecast for the nation reflecting the government's development philosophy. The present NPAPR II shall remain in force until FY11 and its performance will be reviewed each year in normal course. Eventually, the three year medium term budget framework (MTBF) followed by the line ministries in developing their annual budgets will be converted into a five year MTBF.

In the light of the long term vision, the government has identified five priority areas for medium term action: (i) maintenance of macroeconomic stability and control over commodity price hike in the face of the present global economic crisis; (ii) effective action against corruption; (iii) power and energy; (iv) elimination of poverty and inequality; and (v) establishment of good governance.

In the pursuit of achieving the Vision, some important targets have been set for the macroeconomy (Box 1). The NSAPR II incorporates these and other priority areas necessary for achieving the poverty reduction and other social goals. The NSAPR II also integrates the responses to the risks to the economy arising out of the current global economic recession.

\section{Box 1.1: Macroeconomic Targets based on Vision 2021}

- Secure and sustain an annual level of GDP growth of 8 percent by 2013 and raise it to 10 percent from 2017;

- Bring down the percentage of disadvantaged people living below the poverty line to 15 percent by 2021 ;

- Ensure a minimum of $2,122 \mathrm{k} . \mathrm{cal} /$ person/day of food to all poor people and standard nutritional food to at least 85 percent of the population by 2021;

- Ensure 100 percent net enrolment at primary level by 2010, provide free tuition up to the degree level by 2013, attain full literacy by 2014, and ensure that Bangladesh is known as a country of educated people with skills in information technology;

- Achieve self sufficiency in food by 2012;

- Ensure living accommodation for the entire population by 2015, supply of pure drinking water for the entire population by 2011, and bring each house under hygienic sanitation by 2013;

- Eliminate all kinds of contagious diseases and increase life expectancy of citizens to 70 years by 2021;

- Reduce maternal mortality to 1.5 percent, raise the use of birth control methods to 80 percent, and bring down infant mortality to 15 per thousand live births by 2021;

- Change the sectoral composition of output with the shares of agriculture, industry, and services standing at 15 percent, 40 percent, and 45 percent respectively in 2021;

- Reduce underemployment rate to 15 percent along with changing employment shares of agriculture, industry, and services to 30 percent, 25 percent, and 45 percent respectively in 2021;

- Generate 7,000 megawatt of electricity by 2013 , raise it to 8,000 megawatt in 2015 , and make provision to the expected demand for power of 20,000 megawatt in 2021.

\subsection{Attainment of MDGs}

Bangladesh has made significant progress towards attaining the MDGs by 2015. In case of majority of the indicators, Bangladesh is on track with prospect for earlier attainment of targets for some indicators. Bangladesh has successfully achieved gender parity in 
primary and secondary education. The country is on track to achieve the targets of halving the proportion of people living below the poverty line and suffering from hunger, net enrolment ratio in primary education, and reduction of child mortality. However, several lagging areas are there like primary school completion rate, adult literacy rate, access to safe drinking water by the rural people, and maternal mortality ratio. Similarly, participation of women in wage employment, access to tenurial security and essential drugs is still low. Access to Personal Computers (PCs) and Internet services has also been quite limited. Bangladesh thus needs to put sustained efforts to attain the MDGs by 2015. There is also the critical need for complementary external resources for financing the progress towards these goals. Historically, the gap between commitment of financial support by development partners for meeting MDGs and the actual availability of such resources has been quite glaring.

\subsection{Poverty Reduction Strategy Framework}

The poverty reduction strategy framework of NSAPR II is based on the reality of multidimensionality of poverty and takes into account the dynamics of the socio-economic factors that reinforce and perpetuate poverty in the country. The strategy framework consists of five strategic blocks and five supporting strategies (Figure 1.1). The strategic blocks are: (i) macroeconomic environment for pro-poor growth; (ii) critical areas for propoor growth; (iii) essential infrastructure for pro-poor growth; (iv) social protection for the vulnerable; and (v) human development. The supporting strategies, on the other hand, comprise of: (i) ensuring participation, social inclusion, and empowerment; (ii) promoting good governance; (iii) ensuring efficient delivery of public services; (iv) caring for environment and tackling climate change; and (v) enhancing productivity and efficiency through science and technology. For poverty reduction, it would be critical to address all these areas in order to derive mutually supportive interactions.

The critical concern of the strategy is to achieve higher growth and make the growth propoor such that the poorer sections get a proportionately greater share of the benefits of growth helping them move out of poverty. The reduction of inequality in income and opportunities is required for making growth more pro-poor apart from its value in creating a more egalitarian and stable society. In line with the pro-poor growth strategy of the present government, the NSAPR II addresses the issues of poverty reduction and equity simultaneously. In this context, major elements include: (i) bringing vibrancy in agriculture and rural life; (ii) expanding the social safety nets for the ultra poor; and (iii) targeted approach towards employment generation. 
Figure 1.1: Poverty Reduction Strategy Framework

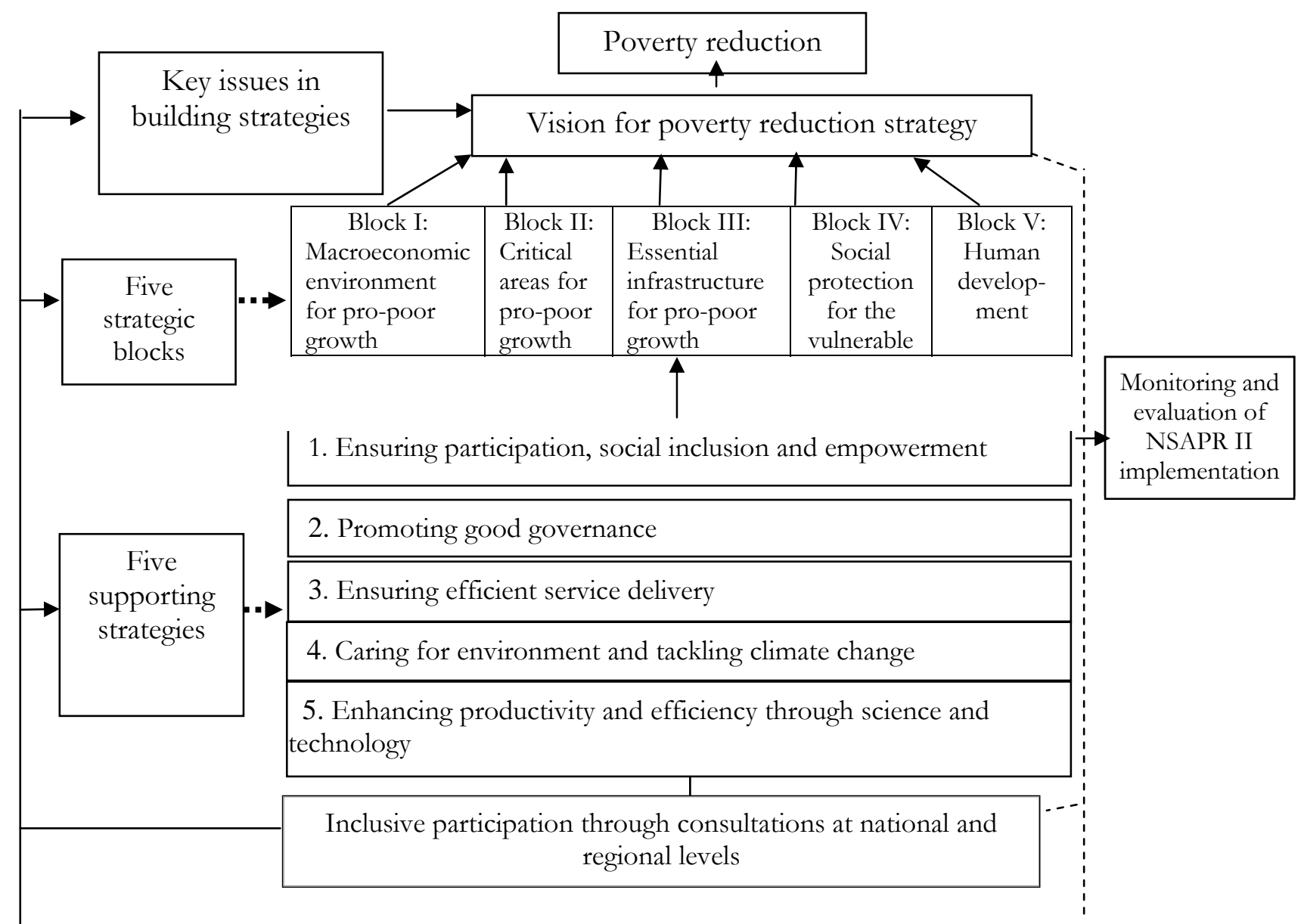

\subsection{Key Issues in Generating Pro-Poor Growth}

In the poverty reduction strategy, the role of the public sector in generating growth is important for several reasons. First, public investment in infrastructure like transport and communication, power and energy, ports, and human capital would be critical to enhance the efficiency of private investment. Second, the government needs to support the private sector through facilitating development-friendly institutions- property rights, rule of law, market-oriented incentives, sustainable public finances, sound monetary and trade policy, strong and efficient financial sector and good governance. Finally, public investment will determine the structure of growth by allocating resources to the social sectors like education, health, and rural infrastructure. The role of the public and the private sector would assume renewed importance through the explicit adoption of public private partnership (PPP) by the present government.

\section{Sources of Growth}

Since the 1990s, the growth of total factor productivity (TFP) has been low, growing at only 1.2 percent. For enhancing the growth of the economy during NSAPR II, the focus therefore would be on increasing TFP growth and the essential elements of this approach would be (i) pursuit of supportive macroeconomic policy, (ii) removal of infrastructural bottlenecks including electricity, gas, telecommunication, transport and port services, (iii) enhancing the supply of effective labour through investment in health, nutrition and education of all people especially people living in poverty, women, indigenous people, and persons with disabilities, (iv) generation, adaptation and diffusion of technology, through emphasis on R\&D and inflow of FDI, (v) minimizing the negative productivity shocks of 
natural disaster through better management of such disaster, enhancement of the poor's capacity to cope with the disaster and supporting the efforts of the entrepreneurs to overcome damages to production, plants and machinery, (vi) improving the quality of governance, (vii) lowering regulatory and administrative burden on business, (vii) promoting openness to trade and devising appropriate fiscal stimulus and policy responses to international shocks like global recession; (viii) improving the quality of financial sector intermediation, (ix) improving the performance of the tax system, and (x) bringing about institutional reforms to make them more market oriented and growth friendly.

\section{Ensuring Regional Balance}

The sharp regional difference in the incidence of poverty between the eastern and western regions of the country will be addressed through introducing regional dimension in allocation and utilization of resources. Special attention will be given to bring dynamism in the economy of the western region through provision of infrastructural facilities, credit and fiscal incentives, encouraging locational dispersion of industries and creating regional growth centres, providing training and upgrading skills, promoting rural non-farm activities and increasing the coverage of social safety nets.

\section{Decentralizing Growth}

Decentralized growth with participation in the most inclusive manner will have greater impact on poverty reduction. Rural towns or semi-urban areas growing outside the municipal areas have shown dynamism of non-farm activities. Growth of rural towns will be promoted through improved provision of public utilities, better connectivity, planned development of towns and land use planning.

The meso-economy, consisting of formal and informal activities in service, trade, construction and small industries provides scope for decentralized employment generation. These activities are often characterized by low asset base and limited scale and informal nature of operation. Hence, traditional policy interventions having a sectoral focus do not always serve well the growth requirements of these activities.

The meso-economy will be supported through appropriate credit facilities, skills training and technology upgradation to enable this vibrant component of the economy to integrate with the growing formal sector and contribute towards decentralized growth.

\section{Gaining from Demographic Dividend}

Bangladesh's population is likely to increase to 233 million in 2051 from the current estimate of 144.2 million in 2009. In this context, population planning will take a number of initiatives to reduce the growth rate such as (i) creating awareness about the population problem and enlisting public support for population planning and development; (ii) implementing family planning and reproductive health programmes more efficiently; and (iii) strengthening inter-ministerial coordination. The demographic transition that the country has undergone resulting in a higher proportion of young and working age population and a lower dependency ratio would create virtuous cycles of growth. Macroeconomic and sectoral policies will be geared towards providing productive employment to the growing labour force to reap the demographic dividend. 


\section{Focusing Women's Advancement and Rights}

Women in Bangladesh have made important gains along with changes in social attitudes towards women's economic participation. Further progress in women development will be achieved by including women's advancement and rights issues in all mainstream activities. Although women and men share many of the burdens of poverty, women frequently experience poverty differently, have different poverty reduction priorities, and are affected differently by development interventions. The NSAPR II will address the gender dimensions of poverty and implement gender responsive interventions to enhance the likelihood of success of poverty reduction efforts.

\section{Strengthening Safety Nets Programmes}

An effective, extensive, and development oriented social protection and safety nets programme will form an integral part of the poverty reduction strategy. The existing programmes will be consolidated and strengthened in terms of targeting and coverage. Social safety nets will be extended for the ultra poor. Social safety nets will also be extended for the urban poor who are often not reached by existing measures. Some previous programmes such as one house one farm, rural housing, ideal village, and returning home will be revived, and the coverage of old age allowance and destitute women allowance programmes will be substantially increased. Moreover, the

\section{Strengthening Financial Sector}

An efficient financial sector plays a crucial role in accelerating economic growth process. Therefore, reform initiatives implemented in the financial sector so far would be carried forward during NSAPR-II period to propel Bangladesh's economy on a higher trajectory. The government will carry out financial sector reforms to catalyse economic growth and will step up public expenditure to make a significant breakthrough in poverty eradication program.

The supervisory capacity of the Bangladesh Bank to oversee the commercial banks' activities will be further strengthen, and the NCB's privatization process will be expedited. Prudent credit policy will followed to avoid concentration of wealth to few group/companies. A cap on the credit limit of up to 35 percent of any bank's paid up capital has been imposed. The overall activities of the Bangladesh Bank and the NCBs will be fully automated. Meanwhile power of the Boards of Directors of SCBs has been enhanced. A 5-year business strategic plan has been prepared and expected to be put in to operation with the NSAPR II period. This will infuse dynamism in banking operation.

The Bangladesh Shilpa Bank and Bangladesh Shilpa Rin Shangtha will be merged to create a wholly-owned public limited company to strengthen the operational efficiency of a unified investment bank. The Government has recapitalized Bangladesh Krishi Bank (BKB), Rajshahi Krishi Unnayan Bank (RAKUB) and Karmashanghstan Bank in order to expand agricultural loans program as well as micro-credit.

The Money Laundering Prevention Act 2009 has been enacted in order to effectively prevent money laundering activities. Through this Act, the banks, financial institutions, moneychangers and insurance companies have been brought under accountability regime of Bangladesh Bank. 
Sovereign credit rating plays a supporting role in mobilizing capital from international capital market at a reduced cost and at favorable terms. Bangladesh Bank has taken steps to execute an agreement with two international rating agencies. This may expedite foreign investment and open up alternative ways of mobilizing capital.

\section{Ensuring Environmental Protection}

Operationally, poverty-environment linkages are evident at two levels - one is conservation of nature and natural resources for sustainable livelihood and the other is controlling/combating pollution for the maintenance of biodiversity and protection of human health. An integrated policy and plan will be formulated under the strategy to ensure environmental protection and protection from the adverse effects of global warming and climate change. Effective regional and international cooperation will be sought to ensure environmental protection and to cope with the effects of climate change.

\subsection{Implementation Challenges}

Ensuring efficient implementation of the NSAPR II is the key challenge. All ministries would be urged to undertake activities and actions to achieve the strategic objectives that are spelled out in the document, especially in the policy matrix. Accordingly, the line ministries and agencies will formulate and implement their activities and actions through allocations under the annual budgets.

In order to improve the efficiency and effectiveness of public expenditure and ensure that the goals set out in NSAPR II are attained, the government has been implementing a move away from the traditional incremental budgeting towards a medium term budget framework (MTBF) process. The MTBF is intended to support the implementation of NSAPR II through ensuring that (i) the government's fiscal management contributes to macroeconomic stability and supports an enabling environment for economic growth and poverty reduction; and (ii) adequate public resources are allocated through a more strategic and policy-led budget planning process directed towards priority programmes identified in the strategy and in supporting complementary sector level strategies.

Successful implementation of NSAPR II and achievements of the goals require a welldesigned monitoring and evaluation process in place both at macro and micro levels. Monitoring the implementation progress will consist of continuous assessment of the flow of inputs/expenditure for the fulfilment of specific objectives and appropriate utilization of the inputs. This will be accompanied by periodic assessment of actual progress in various input, output, and outcome indicators at the macro, sectoral, programme and project levels. For the purpose, effective measures will be undertaken to create capacity of concerned Ministries / Agencies to generate data and information relevant to monitoring. This would require capacity building of the concerned Ministries and implementing Agencies in implementation monitoring and evalution.

\subsection{Participatory Formulation Process}

The General Economics Division (GED) of the Planning Commission is the National Poverty Focal Point (NPFP) for coordination of activities leading to the preparation of NSAPR II. The National Steering Committee identified 18 thematic areas of the economy which would contribute to accelerated poverty reduction in the next three years. Accordingly, 18 thematic groups comprising the lead ministry and associate ministries/ 
divisions/agencies were formed to prepare thematic reports which formed the basis of NSAPR II (Annex 1).

The GED undertook a process of intensive consultation with the stakeholders in the formulation of NSAPR II. National level consultation was held in Dhaka on draft thematic reports and a second consultation was held at Barisal with participation of academics, researchers, NGOs, CBOs, the media and government officials. The thematic reports were finalised reflecting the findings and recommendations of both consultations.

Several consultations were held on draft NSAPR II. First, a two-day national level consultation was held in Dhaka with NGOs, CBOs, representatives of CCIs, academics, researchers and thematic groups. A second consultation was held in Dhaka with the development partners. Two regional consultations were held - one at Rajshahi and the other at Rangamati, with participation of NGOs, CBOs, representatives of local government, representatives of chambers of commerce and industry, the media and government officials. In addition, useful written comments were provided by NGOs, development partners and various ministries. The draft NSAPR II was finalised giving due consideration to the comments received at different consultation meetings. A summary of the recommendations made in different consultation meetings is presented in Annex 2.

To ensure ownership of the poverty reduction strategy, the NSAPR II document has been prepared incorporating the aspirations of the people as reflected in the Election Manifesto of the government. The subsequent consultation process carried out with stakeholders and the Honourable Members of the Parliament has contributed towards further strengthening the ownership of the strategy document. 


\section{Chapter 2}

\section{Poverty Situation and the Medium Term Macroeconomic Framework}

\subsection{Achievements in Poverty Reduction}

The incidence of poverty has been declining in Bangladesh (Table 2.1). The national head count index of poverty measured by the upper poverty line declined from 56.6 percent in 1991-92 to 40.0 percent in $2005 .{ }^{1}$ During the period, urban poverty reduced at a faster rate than rural poverty. On the other hand, headcount index measured by the lower poverty line declined from 41.0 percent in 1991-92 to 25.1 percent in 2005. The trend has been similar in both rural and urban areas. At the same time, all indicators of human poverty like life expectancy at birth, infant mortality rate, population having access to drinking water, and adult literacy rate have shown improvements over time. However, the absolute values of many of these indicators are still unacceptable and the challenge is to improve the situation rapidly.

Table 2.1: Head Count Ratio of Poverty, 1991-92 to 2005

(Percent)

\begin{tabular}{|l|c|c|c|c|}
\hline \multirow{2}{*}{} & \multicolumn{2}{|c|}{ Upper poverty line } & \multicolumn{2}{c|}{ Lower poverty line } \\
\cline { 2 - 5 } & $1991-92$ & 2005 & $1991-92$ & 2005 \\
\hline National & 56.6 & 40.0 & 41.0 & 25.1 \\
\hline Rural & 58.7 & 43.8 & 43.7 & 28.6 \\
\hline Urban & 42.7 & 28.4 & 23.6 & 14.6 \\
\hline
\end{tabular}

Source: BBS, Household Income and Expenditure Survey (HIES) 2005.

\subsection{Trends in Income Inequality}

Despite rises in household income, income distribution has become more unequal over time (Table 2.2). The bottom 5 percent of the population received 0.77 percent of the total income in 2005, down from 0.93 percent in 2000. The bottom 40 percent of the population which coincides with the share of the poor in total population received only 14.4 percent of the total income in 2005. On the other hand, the top 5 percent received nearly 27 percent of the total income in 2005.

\subsection{Women's Poverty}

One aspect of women's poverty is that the total number of poor women is higher than that of poor men. Various micro studies indicate that the 'hard-core' poor are largely women. The number of ultra poor (measured by food intake of 1,600 k.cal/person/day) and extreme poor (food intake of $1,805 \mathrm{k} . c a l / p e r s o n / d a y)$ is higher in female headed households than in male headed households. The HIES 2005 shows that about 29.6 percent of divorced/widowed women live below the lower poverty line against the national average of 25.1 percent.

\footnotetext{
1 The head count index gives the number of people living below the poverty line as a ratio of the total number of population. The upper poverty line is taken as the cost of a representative bundle of food that provides $2,122 \mathrm{kcal} /$ person/day plus the cost of a minimum bundle of non-food items. In the case of lower poverty line, the allowance for non-food items is lower than in the case of upper poverty line.
} 
Customary biases and intra-household inequalities lead to lower consumption by and fewer benefits for women and girls among low-income households. Intra-household inequalities exacerbate the vulnerability of women and girls. Skewed sex ratio showing a higher male population relative to female population (105 males for 100 females in 2008) suggests the presence of discrimination against women in health, nutrition and other aspects of well being originating within the households.

Table 2.2: Income Distribution, 2000 and 2005

(Percentage of total household income)

\begin{tabular}{|l|c|c|c|c|c|c|}
\hline \multirow{2}{*}{\multicolumn{1}{|c|}{ Income accruing to }} & \multicolumn{3}{|c|}{2005} & \multicolumn{3}{c|}{2000} \\
\cline { 2 - 7 } & Total & Rural & Urban & Total & Rural & Urban \\
\hline Bottom 5 percent & 0.77 & 0.88 & 0.67 & 0.93 & 1.07 & 0.79 \\
\hline Bottom 10 percent & 2.00 & 2.25 & 1.80 & 2.41 & 2.80 & 2.02 \\
\hline Next 40 percent & 18.32 & 20.02 & 17.16 & 19.65 & 22.35 & 17.19 \\
\hline Middle 40 percent & 42.03 & 43.82 & 39.97 & 39.93 & 42.03 & 39.48 \\
\hline Top 10 percent & 37.64 & 33.92 & 41.08 & 38.01 & 32.81 & 41.32 \\
\hline Top 5 percent & 26.93 & 23.03 & 30.37 & 28.34 & 23.52 & 31.32 \\
\hline Gini coefficient (income) & 0.467 & 0.428 & 0.497 & 0.451 & 0.393 & 0.497 \\
\hline
\end{tabular}

Source: BBS, Household Income and Expenditure Survey (HIES) 2005.

Women's social subordination makes them more vulnerable to poverty. Women have few rights and choices in taking personal decisions regarding education, marriage, child bearing, family expenditure pattern, and participation in labour market and income generating activities. Discrimination against women at the social level is reflected in their movement limited within the homestead, lack of mobility in the public space, early marriage (average age at marriage for women is 20.2 years while that for men is 27.6 years) and the practice of dowry. Women have weak protection socially and legally in the event of break-up of marriages. They fall easily in the trap of trafficking.

\subsection{Regional Differences in Poverty}

Regional differences in the incidence of poverty need in-depth analysis so that the problem can be addressed adequately. The reasons for lower incidence of poverty in the country's eastern region compared with the western region are important to consider in designing appropriate strategies to overcome the problem.

Regional poverty differences in the country persists due to many factors including location of the capital city and the major port, concentration of administrative powers, availability of power and gas, and easier access of people living in this part of the country to these cities. The impact of rapid growth of these cities is also spreading to the nearby rural areas. People in the country's western region have limited access to the growth poles because of lesser connectivity. Faster poverty reduction in the western region needs greater investments in infrastructure, especially roads and bridges. The construction of the Padma bridge taken up by the present government would increase connectivity between the two regions and will help increase returns to household activities in the lagging regions. This needs to be supported by building better access to the Mongla port, and expansion of power and energy networks. The policy thrust also requires more investments in human capital and improvements in employment opportunities in the region. In addition, investment in infrastructure and services in urban areas in the western region will help improve diversified household activities and increase their returns. 


\subsection{Extreme and Chronic Poverty}

The Household Income and Expenditure Survey (HIES) 2005 data show that about 27.0 million people, constituting 19.5 percent of the total population, live in extreme poverty in Bangladesh, while 31 percent of the rural population suffer from chronic poverty. ${ }^{2}$ Adverse changes in household structure (e.g. increase in the dependency ratio among the poor relative to the non-poor households), pursuit of traditional agriculture as a means of livelihood due to inability to adopt improved practices, decline in availability of natural and common property resources, limited access to financial and human resources, and incidence of multiple shocks including natural and health shocks, and similar other factors are responsible for the non-poor to slip into poverty and the poor into extreme and chronic poverty. Women of these households are also more vulnerable to violence. Helping these households to deal with such shocks more effectively through social protection schemes, better governance, and changing attitudes (e.g. health behaviour and dowry) could keep many households out of chronic poverty.

Further, maternal nutritional status is a strong predictor of child nutritional status (and thus development of child's mental faculties and productivity). Women's health and well-being are therefore important factors for breaking the transmission of poverty over generations. It is important to ensure the access of the extreme poor and the chronic poor households to education, health care, credit, and other support services and remove market barriers to help them move out of poverty.

The persistence of extreme poverty in some specific geographic locations has been a stark reality in Bangladesh. People living in remote char areas with few assets and limited employment opportunities especially during the lean seasons become the usual victims of persistent poverty. Besides, people living in remote areas of the hill tracts region and indigenous people are also victims of extreme poverty. Investments in infrastructure, creation of employment opportunities during the lean periods, and increased coverage of social safety nets programmes (SSNPs) will improve the poverty situation of these disadvantaged groups.

\subsection{Poverty Scenario Beyond 2005}

Since the household income and expenditure surveys--the only source of poverty data in the country--are conducted at intervals, official statistics on poverty are not available beyond 2005. Based on past economic growth and associated trends in poverty, some poverty estimates for recent years can be derived. Two scenarios have been drawn: one based on high poverty elasticity; and the other using low poverty elasticity of growth. ${ }^{3}$ Using the

\footnotetext{
2 Extreme poverty is taken as a situation where people persist in deep poverty that is at the bottom of the poverty ladder. On the other hand, chronic poverty is defined as a situation in which people live in poverty for a prolonged period of time, often spanning generations. These people have low consumption, and suffer from hunger and under-nutrition, lack of access to basic health services, illiteracy, and other deprivations.

${ }^{3}$ One estimate is based on recent trends while the other uses a somewhat longer trend. The growth elasticity of poverty is estimated at 0.45 during $2000-2005$ while the value is 0.38 for $1992-2005$. The first value implies that if the economy grows by 1 percent then the head count ratio would decline by 0.45 percent. A similar interpretation holds for the second value. Given the growth of the economy between 2005 and 2009, the head count ratio declines by 8.9 percentage points if elasticity value of 0.45 is used while the decline is by 7.5 percentage points for assuming a growth elasticity of poverty of 0.38 .
} 
above methodology, the head count ratio in 2009 is estimated to have declined by 8.9 percentage points if the high value of poverty elasticity of growth is used while the decline is by 7.5 percentage points in the case of low poverty elasticity of growth. Thus, the headcount ratio of poverty could vary between 31.1 percent and 32.5 percent in 2009 .

The gain in poverty reduction during the period may, however, have eroded to some extent because of the sharp increase in the prices of rice and other essential commodities especially during the early months of 2008. Given the relatively high weight of food in the consumption basket (nearly 61 percent in rural areas and 45 percent in urban areas), high food prices during 2008 may have made the poor poorer and pushed some above the poverty line into poverty. Although the impact of the present global economic crisis in Bangladesh is relatively low, the growth of the real economy has been adversely affected including exports. The sensitivity has been heightened by the export led growth strategy that Bangladesh follows thereby affecting export related production and investment as well as softening of domestic demand. The GDP growth rate has fallen in 2009 leading to increased fiscal stress, unemployment, poverty, and deprivations especially for the vulnerable groups.

\subsection{Medium Term Macroeconomic Framework}

The global economy experienced robust growth of 4.2 per cent during 2002-07 against an average growth of 3.0 percent during the 1990s. In 2007, the growth rate reached a peak of 5.2 percent. This higher growth of the world economy also helped Bangladesh to improve its growth performance during the period.

However, the debacle of the sub-prime mortgage market in the United States (US) triggered a downturn in the US economy in 2008 which quickly engulfed the world economy leading to a deep global recession. The global economy, which grew by 3.1 percent in 2008, is projected to shrink by 1.4 percent in 2009 , before the growth rate modestly rises to 2.5 percent in 2010.

Despite the effects of global economic slowdown and adverse impacts of two consecutive floods and cyclone Sidr that hit Bangladesh in FY08, the economy remained mostly stable and growth in FY2009 is estimated at 5.9 percent showing high resilience of the economy. Nevertheless, the aftermath of the deepened global economic crisis and the apprehension that the crisis might linger for a while pose great challenge for the Bangladesh economy at least until FY 2010.

The medium term macroeconomic framework (MTMF) for NSAPR II has been drawn against this backdrop (Table 2.3). The framework reflects the election pledges of the government to tackle the impact of global recession, maintain macroeconomic stability, and steer the economy through to recovery and a trajectory of higher growth. The projections reflect a cautiously optimistic scenario that is consistent with recent trends and takes into account the commitment of the government to reduce poverty and inequality. Policies will be geared to preserve the desired macroeconomic environment which will be evaluated in terms of pre-specified indicators. 
Table 2.3: Medium Term Macroeconomic Framework

\begin{tabular}{|c|c|c|c|c|c|c|}
\hline Indicator & Actual & Actual & $\begin{array}{l}\text { Provisional/ } \\
\text { Actual }\end{array}$ & Revised & Projection & Projection \\
\hline & $2006-07$ & $2007-08$ & 2008-09 & $2009-10$ & $2010-11$ & 2011-12 \\
\hline Nominal GDP (billion Taka) & 4724.8 & 5458.2 & 6149.4 & 6910.9 & 7802.9 & 8834.4 \\
\hline Nominal Growth (\%) & 13.7 & 15.5 & 12.7 & 12.4 & 12.9 & 13.2 \\
\hline Real Growth (\%) & 6.4 & 6.2 & 5.9 & 6.0 & 6.7 & 7.2 \\
\hline Deflator (\% change) & 6.8 & 8.8 & 6.4 & 6.0 & 5.8 & 5.6 \\
\hline Inflation $(\%)$ & 7.2 & 9.9 & 6.7 & 6.5 & 6.1 & 6.0 \\
\hline \multicolumn{7}{|l|}{ Investment $\&$ Saving ( $\%$ of GDP) } \\
\hline Gross Investment & 24.5 & 24.2 & 24.2 & 24.6 & 26.1 & 27.4 \\
\hline Private & 19.0 & 19.3 & 19.5 & 19.4 & 20.7 & 21.7 \\
\hline Public & 5.4 & 5.0 & 4.6 & 5.2 & 5.4 & 5.6 \\
\hline Gross Domestic Savings & 20.4 & 20.3 & 20.0 & 20.5 & 20.9 & 21.3 \\
\hline Gross National Savings & 28.7 & 30.2 & 32.4 & 32.8 & 33.5 & 34.0 \\
\hline \multicolumn{7}{|l|}{ Aggrr. Budgetary Position ( $\%$ of GDP) } \\
\hline Total Revenue & 10.2 & 10.8 & 10.4 & 11.4 & 11.9 & 12.2 \\
\hline NBR Tax & 7.7 & 8.4 & 8.2 & 8.8 & 9.3 & 9.6 \\
\hline Non-NBR Tax & 0.4 & 0.4 & 0.4 & 0.4 & 0.4 & 0.4 \\
\hline Non-Tax Revenue & 2.2 & 2.0 & 1.8 & 2.2 & 2.2 & 2.2 \\
\hline Total Expenditure & 13.4 & 15.9 & 13.8 & 16.5 & 16.9 & 17.0 \\
\hline Revenue Expenditure & 9.4 & 12.6 & 12.1 & 12.0 & 11.9 & 11.7 \\
\hline Annual Development Expenditure & 4.0 & 3.3 & 3.2 & 4.5 & 5.0 & 5.3 \\
\hline Overall Balance & -3.2 & -5.1 & -3.4 & -5.1 & -5.0 & -4.8 \\
\hline Primary Balance & -1.2 & -2.6 & -1.0 & -2.6 & -2.7 & -2.5 \\
\hline Financing & 3.2 & 5.1 & 3.4 & 5.1 & 5.0 & 4.8 \\
\hline Net Foreign Financing & 1.0 & 1.6 & 0.6 & 2.4 & 2.3 & 2.2 \\
\hline Gross Borrowing & 1.6 & 1.9 & 1.2 & 2.1 & 2.1 & 2.1 \\
\hline Grants & 0.2 & 0.4 & 0.2 & 0.9 & 0.9 & 0.9 \\
\hline Amortization & 0.8 & 0.8 & 0.7 & 0.6 & 0.7 & 0.8 \\
\hline Domestic Financing & 2.1 & 3.5 & 2.8 & 2.7 & 2.7 & 2.6 \\
\hline Banking System & 1.2 & 3.0 & 2.2 & 2.2 & 2.2 & 2.1 \\
\hline Non Bank & 0.9 & 0.5 & 0.6 & 0.5 & 0.5 & 0.5 \\
\hline \multicolumn{7}{|l|}{ Money and Credit ( $\%$ change) } \\
\hline Net Domestic Assets & 12.6 & 18.1 & 17.8 & 13.9 & 14.8 & 15.5 \\
\hline Domestic Credit & 14.3 & 21.8 & 15.8 & 17.5 & 18.0 & 18.3 \\
\hline Credit to Private Sector/1 & 15.0 & 24.9 & 14.6 & 15.0 & 16.5 & 17.8 \\
\hline Broad Money (M2) & 17.1 & 17.6 & 19.2 & 15.5 & 15.8 & 16.0 \\
\hline \multicolumn{7}{|l|}{ Balance of Payments ( $\%$ of Change) } \\
\hline Export & 15.8 & 17.4 & 10.1 & 13.0 & 14.5 & 16.0 \\
\hline Import & 16.6 & 25.6 & 4.2 & 13.5 & 16.0 & 17.5 \\
\hline Remittance & 24.5 & 32.4 & 22.4 & 16.0 & 16.5 & 16.5 \\
\hline Current Account Balance (\% of GDP) & 1.4 & 0.9 & 2.8 & 2.3 & 1.6 & 1.1 \\
\hline \multicolumn{7}{|l|}{ Debt ( $\%$ of GDP) } \\
\hline Outstanding Total Debt & 49.6 & 46.8 & 45.1 & 48.3 & 46.9 & 45.3 \\
\hline Domestic Debt & 19.3 & 20.0 & 20.6 & 23.6 & 23.6 & 23.4 \\
\hline External Debt & 30.3 & 26.8 & 24.4 & 24.7 & 23.3 & 21.9 \\
\hline Interest Payment & 2.0 & 2.5 & 2.4 & 2.5 & 2.3 & 2.3 \\
\hline
\end{tabular}

Source: Ministry of Finance, Bangladesh Bank, and Planning Commission. 


\subsubsection{Growth and Investment}

Annual GDP growth is projected to be 6.0 percent in FY2010 before it rises to 6.7 percent in FY2011. These growth targets are consistent with the Election Manifesto of the government, which sets GDP growth of 8 percent to be achieved by FY2013 and 10 percent by FY2017. The achievement of projected growth will be facilitated by several strategic thrusts to be adopted by the government. The main strategy will be to keep domestic demand buoyant along with exports and facilitate adequate investment so that the required supply response could be forthcoming to meet rising demands. Emphasis will be laid on agriculture and rural development, power and energy, small and medium enterprises (SMEs), human resource development, and social safety nets. The thrust will be on creating employment opportunities, expanding public expenditure, and increasing investment.

The depressed investment rate, which resulted mainly from the impact of global recession, is expected to reverse in FY11. Investment is estimated to account for 24.2 percent of GDP in FY2009 and projected to be 24.6 percent in FY2010 and 26.1 percent in FY2011. To take the economy to a higher trajectory of growth as envisaged by the government, qualitative changes in the investment strategy will be introduced. As a vehicle to attaining the projected growth, investment in infrastructure development, especially power and energy, ports, communication, and education and health will be given priority.

For mobilizing the required investments, complementary use of public and private capital with provision for public private partnership (PPP) in infrastructure, health and education and other sectors will be given emphasis. The government has allocated Tk. 2.5 billion in the FY10 budget to accelerate the process of investment through PPP. The allocation will be used for setting up an Infrastructure Investment Fund from which the government will provide equity or loan to private investors to ensure government's participation. In addition, different financial incentives will be extended from the Fund to encourage investments. The aim is to set up an institution for preparation and implementation of the PPP budget through innovative ways, independent operation, and accountability of planning and budget process of the private sector. This will also provide incentives to PPP initiatives in different sectors and expedite project approval process.

\subsubsection{Fiscal Policy}

During the NSAPR II period, the fiscal policy would focus on maintaining macroeconomic stability and promoting pro-poor growth while safeguarding the economy from international shocks like the current global meltdown, ensuring food security, and encouraging social inclusion. The government aims to achieve this through raising revenue, reordering public expenditure to more productive and social sectors, and improving efficiency of public expenditure.

The revenue/GDP ratio is projected to grow from 10.4 percent in FY2009 to 11.4 percent in FY2010 and 11.9 percent in FY2011 and would rise at higher rates afterwards. Improvements in revenue collection will be achieved through expanding the tax base; curbing tax evasion; checking leakage in the tax collection system; enhancing transparency, accountability and efficiency in the revenue administration and tax collection system; simplifying tax rules to create a tax friendly environment and providing more client oriented services; reducing discretionary power in tax laws; and undertaking reforms and capacity building of revenue administration.

The achievement of the government's long term commitment to reduce the incidence of poverty to 15 percent in FY21 requires a fast track poverty reduction strategy which in its turn requires continued increase in government expenditure. Total expenditure/GDP ratio is estimated to be 13.8 percent of GDP in FY2009. This will rise to 16.5 percent in FY2010 and 19.9 percent in FY2011 and would be higher thereafter. The size of ADP as share of GDP will rise from the estimated level of 3.2 percent in FY2009 to 4.5 percent in FY2010 
and 5.0 percent in FY2011. The rising trend in public expenditure will be in accordance with the need to implement fiscal support measures to meet the adverse impact of the global economic crisis and the government's emphasis on agriculture, support to sectors affected by world recession, infrastructure especially power and energy, regional parity, and social safety net programmes. Emphasis will be put on mobilizing grants and concessional foreign development assistance in support of public investment in social and infrastructural sectors and for programmes designed to counter the negative fallout of the global meltdown.

For improving ADP implementation, planning and budgeting have largely been decentralized under MTBF system. To ensure satisfactory working of the system, priority will be given to strengthening the budget and planning wings in the ministries along with more effective supervision and monitoring. Measures will be taken for more effective and efficient use of available budgetary resources.

Overall budget deficit is estimated to stand at 3.4 percent of GDP in FY2009 of which 2.8 percent will be financed from domestic sources and the rest from external sources. In FY2010, budget deficit is estimated at 5.1 percent of GDP of which 2.3 percent will be financed from external sources and 2.7 percent from domestic sources. In FY 2011, budget deficit is projected to be slightly lower at 5.0 percent.

\subsubsection{Monetary Policy}

Bangladesh Bank will continue to pursue a monetary policy that would contain inflation at low levels and promote higher growth through adequate flow of credit from the banks to productive activities and refinance support to income and employment generating priority sectors including agriculture and SMEs, keeping lending rate and interest rate spread low, and maintaining a competitive real exchange rate.

The growth of broad money is projected to decline in the NSAPR II period in support of the inflation objective. Similarly, growth of domestic credit is projected to decline. However, growth of credit to the private sector is expected to rise to facilitate private sector growth. The recent downward trend in inflation is likely to continue during the NSAPR II period. Annual inflation is estimated at 6.4 percent in FY2009 which will come down to 6.0 percent in FY2010 and 5.8 percent in FY2011.

\subsubsection{External Sector}

The external sector has started to show some impact of the global recession. Exports of raw jute, jute products, frozen food, leather goods, and pharmaceuticals have registered negative growth during the FY09 and the growth of RMG exports has decelerated. Export growth is estimated at 10.1 percent in FY2009. Export growth is likely to be 13.0 percent in FY2010 before it picks up to 14.5 percent in FY2011. The government has constituted a Task Force involving all concerned agencies to monitor developments in the global economy and make necessary policy recommendations. The government has also declared a stimulus package including additional export subsidies to the worst hit sectors, lowering interest rate on import credit for raw materials and capital machinery, and enhancing borrowing facilities from the Export Development Fund.

The growth of imports has declined sharply in FY09 because of lower food imports and fall in prices of petroleum and other commodities. Import growth is projected to increase in the remaining years of NSAPR II to support growth through higher imports of industrial raw materials, capital machinery, and intermediate goods.

Remittance growth is estimated at 22.4 percent in FY2009 and projected to decline to 16.0 percent in FY2010 due to economic decline in labour importing countries and rise again to 16.5 percent in FY2011. The comfortable remittance inflow will help to keep the real effective exchange rate stable and thereby maintain Bangladesh's export competitiveness. 
The above macroeconomic outcomes will depend significantly on the speed of global recovery from the current economic slowdown. If the recovery falters and the recession prolongs, it may become difficult to sustain the export growth and remittance inflow may also weaken. Assuming the current positive pace of global recovery will continue the economy will start moving to higher growth reaching 6.7 percent in FY11 as projected in the MTMF. 


\section{Chapter 3 \\ Roadmap for Pro-Poor Economic Growth: Strategic Blocks}

Five strategic blocks provide the key components of the present strategy for accelerated poverty reduction:

Strategic Block I: $\quad$ Macroeconomic environment for pro-poor economic growth

Strategic Block II: Critical areas for pro-poor economic growth

Strategic Block III Essential infrastructure for pro-poor economic growth

Strategic Block IV: Social protection for the vulnerable

Strategic Block V: Human resources development

\subsection{Strategic Block I: Macroeconomic Environment for Pro-Poor Economic Growth}

The government is committed to maintaining stable macroeconomic environment. Macroeconomic stability will be maintained through managing the fiscal, monetary and exchange rate policies, providing effective safeguards against adverse external or domestic shocks and creating an enabling environment for pro-poor private sector-led economic growth.

\subsubsection{Recent Macroeconomic Performance}

In the recent past, Bangladesh has maintained an average annual growth rate of around 6 percent. There has been a continuous robust growth of both exports and imports. These developments coupled with phenomenal growth in remittances resulted in a positive current account balance and comfortable foreign exchange reserves. The inflation rate has been moderate though it increased by more than 1 percentage point during the period FY04-FY07. The inflation rate peaked to 9.9 percent in FY08 fuelled mainly by domestic and international supply shocks causing the prices of food grains, fuel, fertilizer, and other essential commodities to soar.

The macroeconomic situation changed for the better in FY09. The inflation rate declined sharply with enhanced domestic production of food grains which has been facilitated by concerted government efforts at raising agricultural output. These developments in the domestic economy were complemented by improved international supply situation of food and other essential goods as well as declining commodity prices.

The deepening world recession exerted negative effect on growth rate through contraction of export demand for some goods. Although the external sector has maintained robust growth but it is lower than the previous year. The performance of export of individual products has varied and export growth is mainly propelled by garments.

The flow of remittance has remained buoyant though the outflow of migrant workers has declined and there is return flow of workers who have lost jobs in the foreign market.

In view of the changed developments, the government has already undertaken fiscal measures to mitigate any negative influence. The government has constituted a Task Force involving all concerned agencies as well as civil society representatives to monitor the development in the global economy and would continue to adopt measures to overcome the impact of recession on growth, employment and poverty.

\subsubsection{Current Macroeconomic Challenges}

The macroeconomy faces several risks and challenges in the coming two years. The major challenge is to reverse the slide in the growth rate. This will require the economy to increase the investment/GDP ratio which stagnated at around 24.4 percent over the last five years. 
The ratio needs to increase to nearly 30 percent over the next few years in order to meet economic growth and other targets. Sustaining the momentum in revenue growth will be a challenging task in macroeconomic management. Export performance in the future faces uncertainties arising from prolonged recession in the global economy which has already affected the export of frozen fish, leather and jute. Similarly, the risk of declining remittance growth due to recession in developed countries looms on the macroeconomy. Providing productive employment to the growing labour force, especially the poor, will remain a major challenge. Finally, falling prices has provided relief to the consumers, particularly to the low income and the poor. However, the sharp fall in rice price may exert a dampening effect on farmers' incentives to produce with negative effect on poverty reduction.

The government has taken steps to balance its policies to meet short term exigencies and long term development needs. A fiscal stimulus package was undertaken in April 2009 to support agriculture, export and power sectors and provide enhanced social security. The FY10 budget has adopted special measures and support package for minimizing the adverse impact of the global economic slowdown. The Bangladesh Bank has instructed the commercial banks to reduce their lending rate to 13 percent to support agriculture, large and medium enterprises, housing and trade finance. Export subsidy for three worst affected sectors has been increased by 2.5 percent. The government has also introduced austerity measures in other areas of public expenditure to free up resources for creation of jobs, increase in aggregate demand, and implementation of social safety nets and poverty reduction programmes. The government will continue to provide such support to mitigate the impact of recession in the short term.

\subsubsection{Key Thrusts for Macroeconomic Policy}

\section{Growth Policy}

For achieving higher economic growth, emphasis will be put on several areas: (i) increased accumulation of capital facilitated by reductions in the cost of borrowing and improvement in total factor productivity; (ii) promoting growth of sectors like agriculture, industry and services focusing on the more pro-poor segments of the sectors; and (iii) improved business and investment climate. Other aspects of the growth policy will include channelling an increasing share of government expenditure to social and infrastructural sectors and directly poverty reducing programmes/projects and fostering growth through complementary use of public and private capital with provision for public private partnership (PPP) in infrastructure, health and education. Successful application of PPP will open up new avenues for increased flow of investment from both local and foreign investors. To gain the confidence of private investors regarding the government's commitment in the PPP initiative, an allocation of Tk. 2.5 billion has been made in FY10 budget for loan and equity, PPP viability gap funding as subsidy, and PPP technical assistance. The government is taking steps to set up an institution for preparation and implementation of PPP budget which will ensure innovative ways, independent operation, and accountability of planning and the budget process.

Attempts will be made to attract higher volume of FDI by addressing its bottlenecks related to policy discontinuity, bureaucratic red-tape, corruption, underdeveloped infrastructure, poor port management, and deficiencies of the legal system. The Government will establish special economic zones in different parts of the country. Further, efforts will be made to project Bangladesh as a viable, profitable and secure investment destination and come up with well-advertised business support services aimed at reducing the cost of doing business.

\section{Fiscal Policy}

The fiscal policy will focus on maintaining macroeconomic stability and promoting propoor economic growth while safeguarding the economy from international shocks like the 
current global melt down, ensuring food security, and encouraging social inclusion. This will be achieved through raising revenue, reordering public expenditure to more productive and social sectors, and improving efficiency of expenditure.

Improvements in revenue collection will be achieved through expanding the tax base, curbing tax evasion, checking leakage in the tax collection system, and ensuring more transparency, accountability and efficiency in the revenue administration and tax collection system. The tax base will be broadened by collecting VAT from items to which law applies as well as bringing new persons/businesses under tax net.

For financing the budget deficit, the government intends to keep domestic borrowing restrained within acceptable levels to avoid crowding out effect and probable inflationary pressure. In this context, the government puts emphasis on global development partnership that has been made an integral part of MDGs under the UN framework under which the government expects to receive more untied and concessional aid especially to support social and infrastructural sectors. The government, jointly with the development partners, is developing a Joint Cooperation Strategy (JCS) in the interest of enhancing aid effectiveness following the Paris Declaration and the Accra Agenda for Action (AAA). The JCS will focus on, among other things, alignment of aid with national priorities, systems and procedures, increasing accountability, eliminating duplication of efforts and rationalizing donor activities, reforming and simplifying donor policies and procedures, and better monitoring of utilization of development aid.

\section{Monetary Policy}

The Bangladesh Bank will continue to pursue such monetary policy as would reduce inflation and promote higher growth through maintaining an adequate flow of credit from the banks to productive activities and providing refinance support for income and employment generating priority sectors including agriculture and SMEs. The efforts will also aim at keeping lending rate low, containing spread, and maintaining a competitive real exchange rate avoiding undesirable fluctuations.

\section{Trade Related Policies}

The external sector policy will be geared to sustain export growth, enhance remittance flows, and ensure increasing flow of imports required to attain the targeted growth rate of the economy and meet consumer demand. The government's efforts will focus on reduction of the trade transaction cost and delivery time through effective trade facilitation measures, one-stop export facilities including the issue of export registration certificates at EPB, graduation to higher valued products, increased quality of the products, and initiatives for recognition from international accreditation bodies to increase exports. Focus will also be given on problems related to lack of production and trade policy to satisfy high quality and standard requirements in the developed countries, narrow supply base and its poor response to changing international demand, lack of investment funds, weak physical infrastructure including lack of connectivity with neighbouring countries, high port and transport costs, low technological and R\&D level to address the problems of international competitiveness, and low entrepreneurship and management skills.

The government will continue to enhance its capacity to address the demand side issues. The pertinent issues include increased preferential market access, complex rules of origin and restrictive trade policies and non-tariff barriers, social movements inappropriate to the context which impede export, discriminatory market access granted to competitors e.g. under AGOA, and lack of adequate market information. The government will take further steps to reduce the anti-export bias through rationalization of tariffs and removal of nontariff barriers to trade. Efforts will be made to avoid negative effective protection to 
industries and to provide a stable duty structure. The various incentive schemes for export promotion will be examined to make them more effective, results focused and transparent.

The flow of remittances will be enhanced by addressing issues relating to migration of workers and the flow of remittances through the formal channel. The government plans to start the Prabashi Kalyan Bank (Expatriate Welfare Bank) as a public sector bank with provisions to provide loans to labour migrants. Additional banks will also be allowed to float by the non-resident Bangladeshis. The inflow of remittance through formal channels will be encouraged by improving access to Bangladeshi banks and exchange houses in selected areas in the Middle East and new migrant destinations like Greece, Italy, Republic of Korea, and Spain, creating a legal framework that is conducive to using formal channels, increasing access to banks and post offices in remote areas with concentration of remittance receiving households, and imparting knowledge of remittance process and investment opportunities to migrant workers.

Bangladesh is a member of the WTO and a number of regional trading arrangements like SAFTA and BIMSTEC. Under the regional trading arrangements, Bangladesh will continue to seek duty free access for its exports to other developing country markets. Trading arrangements involve a shift from existing to changed pattern of trade, production, investment and employment leading to gains and losses for a particular country. Bangladesh can enhance its gains and minimize its losses if it negotiates skilfully. The need for an improved capacity for negotiation has been considered a critical aspect of trade agreements. Under the regional trading arrangements, Bangladesh will continue to seek duty free access for its exports to other developing country markets.

Bangladesh will negotiate, along with other LDCs, with EU for relaxing the rules of origin and take measures to fulfil the sanitary and phyto-sanitary (SPS) provisions in developed country markets especially in EU. Along with seeking assistance for building infrastructure for export development, Bangladesh will seek liberalization of movement of natural persons under mode 4 under services trade liberalization.

\subsection{Strategic Block II: Critical Areas for Pro-Poor Economic Growth}

\subsubsection{Small and Medium Enterprise (SME) Development}

The SME sector will play a pivotal role in achieving the national goals of accelerated propoor growth, sustained poverty alleviation and faster rate of economic and social progress. The SMEs account for over 99 percent of private sector industrial establishments providing job opportunities to around 70 to 80 percent of the non-agricultural labour force. The SME share in manufacturing value added varies from 28 to 30 percent. Their contribution to national exports is also significant. The greater proportion of the SMEs (58 percent of establishments and 55 percent of jobs created by them in 2006) is in rural locations which offer better prospects for industrial dispersal. However, their location in certain administrative divisions/districts reflects regional concentration. There has been increased women's involvement in SMEs, especially home-based micro enterprises engaged in the production of clothing and textiles (boutiques and handicrafts, weaving and spinning) livestock and dairy, and retail sales. Relatively small enterprises owned by women entrepreneurs are mostly of the sole proprietorship type which needs low investments.

Constraints and Challenges to SME Growth: The SME sector continues to suffer from lack of access to finance, infrastructural bottlenecks (especially unreliable power), low levels of technological competence, difficult market access and regulatory barriers. Other important challenges include sharp market competition both in existing and new markets. Sophisticated consumer preferences and market standards and various non-price factors such as quality, health and safety and ecological compatibility of products and processes which determine competitive advantage also pose significant challenges. In the changed 
market perspectives, introduction of new products and processes, more innovative design, shorter product cycles and smaller output batches, greater mass customization, and more just-in-time delivery etc. have become the critical determinants of survival and growth of the SMEs

Policies and Strategies for Future Development of SMEs: The government's policy support to SMEs is to play the role of the facilitator to remove operational bottlenecks, neutralize market failures and provide necessary promotional support.

A comprehensive and inclusive credit policy will be formulated emphasizing increase in the flow of formal credit into the sector focusing on micro enterprises and women entrepreneurs through introduction of new and innovative credit schemes and financial instruments. In this context, collateral requirements for SME loans will be scaled down and a switch from immovable assets to movable assets for collaterals needs will be introduced. Bangladesh Bank will refinance credit facilities for SMEs. For enhancing entrepreneurial skills, suitable courses on entrepreneurial skill development can be introduced at school and college levels.

Strengthening of partnership between private entrepreneurs and R\&D institutions, universities, and other stakeholders will be fostered by the government to facilitate supply of quality products through progressive assimilation of new and more sophisticated technologies. Inter-firm linkages and networking through subcontracting would be encouraged to enhance external competitiveness. In order to get integrated with the global and regional economies (ASEAN and SAARC in particular) through the international value chains of productions, special efforts would be taken. The development of horizontal production networking among firms of identical size would be another new initiative to achieve efficiency in mass production irrespective of the size of units.

The SMEF web portal would be made cost-effective and user-friendly to SME entrepreneurs. The SMEs would be encouraged to make the most use of the ICT and ecommerce facilities and services in production, marketing and networking. Measures to enhance international competitiveness of the agro-based food products would include making the producers aware of the international food safety standards, strengthening of the BSTI product certification system and establishment of one national Referral Centre for Certification and a Food Agro-Processing Park containing quality and standards certification facilities. Further, provision of incentives in both cash and kind (i.e. air cargo facilities, refrigerators and vans etc. for food products preservation and transportation) would be considered to facilitate entry into export market.

The SME policies and strategies would be made sensitive to needs of woman entrepreneurs in SMEs. The WEF in the SMEF would be used as a channel to safeguard women's interests as equal partners in business development activities. Special incentives e.g. enterprises of weavers, blacksmiths and clay potters and silk, Jamdani and Benarasi villages would be considered for SMEs in economically depressed regions. Effective coordination at the national level will be fostered through dialogue among relevant stakeholders while formulating SME policies and implementation strategies.

\subsubsection{Promoting Decent Employment}

The labour market in Bangladesh is characterized by (i) high rate of labour force growth, (ii) low rate of unemployment but high under-employment rate, (iii) predominance of employment in agriculture followed by the services sector, (iv) smaller share of female employment, and (v) low wage rates. The number of people out of work in Bangladesh climbed to 2.1 million in 2005-06 from 1.7 million in 1999-2000, with an unemployment rate of 4.2 percent. The unemployment rate provides a partial picture of the labour market performance because unemployment rate does not take into account labour who are 
underemployed e.g. who work less than 35 hours a week. There are large variations in unemployment rate by region, age, sex, and education levels. The share of the informal sector (including agriculture) in total employment increased from 75.3 percent in 1999-2000 to 78.5 percent in 2005-06. The enhanced employment share reflects in part the fact that the informal sector is a refuge sector for those who fail to get absorbed in formal employment. The participation in the labour force even below the age of 15 years is quite high and this needs to be taken into account in promoting decent employment in the country.

Labour Force Projections: With the current labour force growth rate of 3.3 percent annually, the labour force is estimated to grow to 56.4 million in 2009-10, and 58.3 million in 2010-11, resulting in an incremental labour force of 5.4 million during 2009-11. Similarly, if the prevailing employment growth trend continues, total employment will increase to 53.97 million in 2009-10, and 55.75 million in 2010-11, with an incremental employment of 5.27 million during the same period (Table 3.1). It means that given the existing trends of labour force and employment growth, 7.32 million additional jobs (including a backlog of 1.88 million unemployed) will have to be created during 2009-11 requiring an employment growth rate of 4.7 percent. Besides, if the existing trend of underemployment continues, underemployed persons will amount to 26.58 million during 2009-11. To create productive employment for at least 75 percent of these underemployed people (19.94 million), 27.26 million additional productive employment will have to be created during 2009-11.

Table 3.1: Employment Projections for the 2008-09 to 2010-11 Period

\begin{tabular}{|c|c|c|c|c|c|}
\hline Sector & $\begin{array}{l}\text { GDP } \\
\text { (billion Tk) } \\
2008-09\end{array}$ & \begin{tabular}{|l} 
GDP \\
(billion Tk) \\
$2010-11$
\end{tabular} & $\begin{array}{l}\Delta \mathrm{Y} \\
\text { (billion Tk) }\end{array}$ & $\eta \mathrm{i} \lambda \mathrm{i}$ & $\begin{array}{l}\Delta \mathrm{E} \\
(000)\end{array}$ \\
\hline Agriculture & 652.13 & 746.60 & 94.47 & 23.40 & $2,210.55$ \\
\hline Mining \& quarrying & 39.79 & 45.73 & 59.40 & 1.60 & 9.50 \\
\hline Manufacturing & 581.32 & 665.54 & 84.23 & 8.27 & 696.57 \\
\hline Electricity, gas \& water & 57.02 & 65.44 & 8.42 & 1.68 & 14.14 \\
\hline Construction & 318.71 & 364.75 & 46.04 & 3.93 & 180.94 \\
\hline Trade, hotel \& restaurant & 490.46 & 561.44 & 70.97 & 11.38 & 807.65 \\
\hline Transport, storage \& communication & 340.30 & 389.66 & 49.36 & 10.68 & 527.19 \\
\hline $\begin{array}{l}\text { Finance \& business services and real } \\
\text { estate }\end{array}$ & 296.76 & 339.84 & 43.08 & 4.80 & 206.77 \\
\hline $\begin{array}{l}\text { Health, education, public admin. \& } \\
\text { defence }\end{array}$ & 250.00 & 286.30 & 36.29 & 5.33 & 193.44 \\
\hline Community \& personal services & 221.06 & 253.20 & 32.15 & 13.20 & 424.35 \\
\hline All sectors & $3,247.55$ & $3,718.49$ & 470.94 & $\ldots$ & $5,271.10$ \\
\hline
\end{tabular}

Notes: (i) All values in 1995-96 million Taka; employment in thousands of workers; and incremental labour intensity in workers per million Taka; (ii) The following method is used for projecting increases in sectoral employment: $\Delta \mathrm{Ei}=(\eta \mathrm{i})\left(\lambda_{\mathrm{i}}\right) \Delta \mathrm{Yi}$, where, $\Delta \mathrm{Ei}$ is the incremental employment in the $\mathrm{i}$-th sector, $\eta \mathrm{i}$ is the elasticity of employment in the $i$-th sector, $\lambda i$ is the average labour intensity (employment per unit of value added) in the $\mathrm{i}$-th sector and $\Delta \mathrm{Yi}$ is the change in value added in sector $\mathrm{i}$ over the period of projection.

The projected increase in employment will account for 96.9 percent of increase in the labour force, making a not-so-significant dent into the existing unemployment and underemployment in the economy. This indicates the challenge of employment generation is to absorb the labour force. Several approaches can be adopted to ease the unemployment problem: (i) introducing policies for making growth more employment-friendly; 
(ii) undertaking special schemes for job creation (especially through micro-credit), (iii) employment-based safety nets through public works programmes; and (iv) increasing overseas migration of workers.

Job Creation Programmes: The government undertakes job creation programmes for those who are by-passed by the normal growth process. Existing labour market policies and programmes underline the importance of a rights-based approach to employment and of guaranteeing employment promotion especially through micro-credit and employmentbased social safety nets through public works programmes. The government has different programmes for creating employment for the larger labour force as estimated above. The coverage, funding and effectiveness of the existing employment generation programmes appear to be limited. The existing programmes cannot guarantee jobs and income security to the poor.

The government introduced the 100 days Employment Generation Programme in FY08 for the rural people. In view of the implementation experience, a changed programme entitled Employment Generation for the Hard Core Poor will be introduced in FY10 which will create 56 lakh man-months of employment.

Skill Development Programmes: Skill training is provided by various levels and types of institutions offering a variety of courses under Ministry of Education and Ministry of Labour and Employment. At the highest level, the engineering and technology universities offer undergraduate and graduate programmes and some specialized institutes offer undergraduate programmes like glass and ceramics, textile, leather and graphic arts. At the next lower level, skill training is being imparted through public sector polytechnic institutes and private sector polytechnics. Similarly, there are agricultural training institutes in both the public sector and the private sector.

Under the Ministry of Education, public sector technical schools and colleges (TSCs) offer courses to meet the requirements of the National Skill Standard Grade III (semi-skilled level), Grade II (skilled level) and Grade I (professional or highly skilled level). Besides, there are textile institutes, specialised textile vocational centres, technical training centres, and nurses training institutes. A number of private textile institutes are in place, but very few of the RMG workers are trained there.

Vocational training facilities for women have been expanded and diversified over the years. Part-time, short-term and ad hoc courses are also organised by these institutes to meet the needs of local industries. Some courses are also organised for the housewives and others in trades like the repair of common domestic appliances, hair and skin care, dressmaking etc.

Technical Training Centres (TTCs) under BMET offer regular 2-year vocational training courses and 6-month special courses whose demand is increasing. Besides, T'TCs offer many other special short-term skill upgrading courses at the request of the employers. The Department of Youth Development (DYD) has imparted skill development training to youths in different trades.

The government will expand and diversify training facilities, especially for women and upgrade and reorient the quality and content of vocational training in general to cater to the emerging needs of the economy. TSCs that can train the school dropouts can be expanded from current 64 upazillas to other upazillas. Vocational training schools at upazila level will be established with some courses of six months' duration.

To the extent that a sizeable proportion of employment would have to be self-employment in small units in various sectors, the training system would include entrepreneurship, management and marketing skills. Steps towards this end may include revision of courses, introduction of new courses like computer hardware, medical electronics, consumer 
electronics and industrial electronics, revising space norms for workshops and activating the NCSDT.

Foreign Employment: Annual flow of migrant workers has increased from 6,087 in 1976 to $1,407,705$ in 2008 with an annual rate of growth of 18.5 percent. The sustained growth of migrant workers has been marked by few dips caused by external demand contraction. The current world recession has posed challenges for migrant workers which may persist in the future.

According to MoEWOE, the long-term strategies for expanding overseas employment include: (i) entering new markets for overseas employment, (ii) expanding representation in existing overseas labour markets, (iii) improving skill training for exporting skilled workers, (iv) undertaking special initiative for exporting workers from Monga and other ecologically vulnerable areas, (v) managing welfare programmes for migrant workers, (vi) controlling the recruiting agencies and bringing transparency in the migration process, (vii) increasing the inflow of remittances and ensuring their proper use, (viii) undertaking a special initiative for exporting women workers, and (ix) increasing the skill and role of Bangladesh missions abroad in exporting workers.

A substantial number of the expatriate wage earners are victims of unscrupulous manpower agents who extract substantial sums of money from job seekers for arranging employment abroad. In this context, innovative schemes for funding the prospective job seekers abroad are needed. The government is improving regulation of the recruitment process. More importantly, the government will set up Prabashi Kalyan Bank (Expatriate Welfare Bank) which will lend money to those who go abroad, which they will repay from their wages. The Bank will be owned by the expatriate workers. Some banks/financial institutions have initiated an expatriate lending project whereby the bank will advance money to the prospective job seekers who will repay the loan from their remittances. Similarly, PKSF has introduced a programme for migrant workers targeting people from monga areas. A Skill Development Fund will be created for retention and expansion of foreign labour market.

The government has taken a number of measures for the welfare of remittance earning workers. The Wage Earners' Welfare Fund is being used for several important activities like repatriation of mortal remains of workers from host countries, burials, and financial assistance to the sick and distressed and to heirs of the deceased who are not getting any compensation from the employer. To recognize the contributions of middle and lowermiddle class expatriates-wage-earners, a new policy for giving the remitters special citizens' privileges has been formulated in 2008. The Expatriates Welfare Desk has been set up in districts with concentration of migrant workers. Ministry of Labour plans to set up technical training facilities in each upazila. Awareness creation programmes have been strengthened among potential workers willing to have overseas employment.

Employment Guidelines: A comprehensive employment guideline will be formulated with the following core components: (i) creating employment opportunities in rural economy, (ii) creating employment opportunities for wage labour in industries, (iii) providing credit and training for self-employment, (iv) promoting subcontracting arrangements between big and small and medium scale industries, and (v) providing special training arrangements for facilitating export of labour.

Mainstreaming Employment into Development Policies: Employment generation needs to be taken into account while formulating both macroeconomic and sectoral policies and programmes. Employment considerations can be factored into the works of different ministries through (i) sector-based analytical work for employment generation, (ii) selectively moving ahead with operational details, and (iii) building the analytical capacity of the MoLE, Ministry of Industries, Ministry of Agriculture and all other ministries for addressing issues on employment generation. Private sector employment will be promoted with supportive policies and programmes. 
Sector Level Policies for Higher Employment, Productivity, and Real Wages: Agriculture is still the main employer in the economy. Accordingly, greater emphasis is needed on rural development, with a view to expanding market access, employment and productivity. Most of Bangladesh's poor and underemployed live in the rural areas or work in urban informal sectors. The formidable challenge facing the government is to increase opportunities for these people to engage in productive employment and enable them to earn a decent wage. At the same time, employment in the formal sector must expand in manufacturing activities. To make this happen, issues relating to easy entry and expansion of private firms in the formal sector, providing financial and fiscal incentives, increasing productivity through activating the National Productivity Organization (NPO) and the Tripartite Productivity Committee (TPC) will be addressed.

The government will continue to pursue the creation of a conducive environment for enterprise development in both the rural and the urban areas through simplification of the process of registration of small businesses, enhanced access to micro finance, expanding social security systems, access to information on markets and new technology, and regulatory reforms. The major features of rural employment are high levels of underemployment, low productivity, and low wages. The rural employment policy will focus on investment and access to capital to increase productivity and earnings, reduction of the vulnerability of agricultural labourers, fostering access to markets and business development services for rural enterprises, creating institutions of the rural poor to ensure decent working conditions.

Labour Market Policies: The labour policy will be reviewed with a view to re-defining minimum wage based on current subsistence income, removal of discrepancy between male and female wages for same work and productivity, removal of child labour, and better protection of the rights of workers and trade unions.

Policies Relating to Labour Welfare: The programmes for labour welfare will lay emphasis on the promotion of harmonious industrial relations, social protection, improvement of occupational safety and health $(\mathrm{OSH})$, elimination of child labour with emphasis on elimination of worst form of child labour (WFCL), enforcement of labour laws especially those relating to unorganised labour and women and child labour, and promotion of the welfare of migrant workers and returned migrant workers. Rationing system has been introduced for labourers including garment workers, ultra poor and rural landless farm labourers.

\subsubsection{Improving the Environment for Private Sector Development (PSD)}

Deregulation and liberalization of the economy have opened up significant opportunities for the private sector. A vibrant private sector is visible in manufacturing, especially exportoriented textiles and ready made garments, frozen fish and shrimp, leather, tea, plastic products, toy making, furniture, light engineering, agro-based products and more recently in pharmaceuticals, consumer durables, telecommunication, ICT, banking and insurance, ship building, transportation, tourism, and electricity.

Notwithstanding the continued efforts of the government to facilitate private sector development, some critical problems still persist. Infrastructure constraint in the form of shortage of electricity, inefficient port, lack of proper repair and maintenance of roads due to inadequate $\mathrm{O} \& \mathrm{M}$ allocation especially the Dhaka-Chittagong highway, underutilized railway system due to poor management and lack of investment, inadequate air cargo services, and a lack of high-speed Internet access is having a unfavourable impact on productivity and investment in the private sector. Other problems affecting private sector growth include shortage of skilled labour, high interest rates and high service charges in the financial sector; shallow equity market, governance issues involving corruption, 
dysfunctional bureaucracy and procedural complexity, lack of, or delay in, contract enforcement and dispute resolution, inadequate bankruptcy laws, legal impediments to corporate operations, complex procedure for determining ownership or registration of land transfer; and regulatory barriers.

\section{Policies and Strategies for Private Sector Development}

Systematic Dialogue between Public and Private Sectors: The Board of Investment (BOI) was set up as a high profile private sector friendly institution and to ensure effective public private dialogue. Since BOI could not serve its purpose adequately, the government established the Better Business Forum (BBF) for systematic, results-oriented dialogue between the public and private sectors. The consultation process, however, needed back up services of Regulatory Reform Commission (RRC) and a number of subcommittees cochaired by the representatives of the private sector and government counterparts.

The present government gives high priority to the consultation process but it does not look favourably to the multiplicity of subcommittees. The government believes that special problems should be handled by subject specific task forces. In order to handle the impact of global recession, it promptly set up a Task Force which is active now. The government has taken stock of $\mathrm{BBF}$ recommendations and plans to use BBF as the mother platform for the consultation process. The government is considering restructuring and streamlining of the multiplicity of subordinate bodies. It is also considering establishing focal points for private investment in related public agencies through which regulatory reforms, streamlining of procedures, transparency of operations, and speedy provision of services can be ensured. The ultimate objective is reducing the cost of doing business and securing investment in the fastest possible time. Open and free consultation between the government on the one hand and stakeholders in any operation, related business associations, civil society, and public interest interlopers on the other is essential to resolve issues and expedite solutions.

The expected impacts are measurable improvements in the business environment, higher levels of foreign and local investment activity leading to improvement in peoples' lives. In practical terms, these goals will be achieved through the establishment of government and private sector secretariats, as well as through thematic task forces. The task forces would prioritize the issues, perform necessary background research and analysis, and bring forward the issues with concrete recommendations for actions.

Continuing Sound Macro-economic Management: The government will continue to maintain macroeconomic stability in the face of domestic and external shocks. Fiscal stimulus package, appropriate monetary and credit policy and effective Social Safety Net Programmes (SSNPs) have been undertaken to overcome the impact of global recession.

Overcoming Infrastructure Constraints: Traffic congestion in Dhaka has reached nightmarish proportions. It is also becoming problematic in Chittagong. The main factor is the lack of public transport services. In Dhaka, transport planning needs high priority along with special attention to driving regulations. A combination of elevated expressway, underground railway, over-bridges, ring road, and circular railway needs to be planned for metropolitan Dhaka in the near future. This can be a project under PPP.

The specific measures to be undertaken for infrastructure development are to (a) ensure reliable supply of electricity, (b) adopt appropriate policy and project implementation in infrastructure, (c) construction of Padma and Karnaphuli bridge/tunnel, Dhaka-Chittagong four-lane express way, expansion and modernization of railway, (d) construction of deep sea ports and modernization of Chittagong and Mongla ports, (e) restructuring of Bangladesh Biman and construction of modern international airport : Bangabandhu Sheikh Mujib International Airport at Trishal, Mymensingh and expansion of Cox's Bazar Airport, 
(f) reform in the telecommunications sector to extend services to villages. (f) modernize the railway transport system for industrial transportation through integrating it with other surface modes, and $(\mathrm{g})$ expedite reform of the parastatal bodies of the infrastructure sector. Efforts will also be taken to improve traffic management in Dhaka city and construction of elevated expressway and tube-trains (underground metro) in the city.

To promote the private sector, the government had earlier prepared Bangladesh Private Sector Infrastructure Guidelines that spelt out necessary steps for private sector investment in infrastructure facilities in the economy. Presently BOI is looking after private sector investment but it is not functioning well. The government has introduced a PPP budget this year and is considering revamping the entire institutional arrangement for private investment. The interrelationships between BOI, a newly established PPP Cell, and a system of approval of private investments in public goods and services are presently being defined. Private investment with public support is not only being considered for infrastructure facilities such as power plants and energy resource development enterprises, wireless or other telecommunication projects, roads, expressways, railways, tunnels, or ports but also for programmes and projects in education, health, and social welfare. Recognizing the limited availability of public resources, the government is keen on generating private investment for public goods and services. The PPP budget process and processing of PPP programmes and activation of the BOI are likely to be put in place by September 2009 .

Creating a More Efficient Financial Sector: The banks have reset their interest rates to maintain credit growth as the economy faces the impact of global recession. Further, interest rate spread has declined and various charges for banking services have also been reduced. The Bangladesh Bank will continue to undertake measures to ensure availability of bank credit to the private sector at reasonable interest rate along with prudent regulation and sound management.

Developing Capital Market: The government policies will focus on: (i) restoring investor confidence through greater transparency and accountability in the working of the Stock Exchanges and other supportive measures, (ii) more efficient operations of the Central Depository System, (iii) enhancing capacity and power of the SEC to monitor and enforce compliance of the rules, (iv) undertaking measures to enhance the supply of good shares in the market, (v) encouraging MNCs to be listed in Bangladesh, (vi) setting up Bangladesh Institute of Capital Market to train investors and intermediary agencies, and (vii) examining the possibilities of state owned good companies to go public share. Other measures will include encouraging institutional buyers to buy more shares from the market, introduction of derivative market, encouraging foreign investors to buy shares, proper and quick action against companies not complying with the rules and regulations of SEC.

Regulatory Transparency and Streamlining: The BOI in an effort to streamline sanctions, expedite processing of investment proposals, and reduce cost of business has been planning one stop service station for a while. The effort has not been very successful yet. The government set up BBF and various subcommittees under it virtually for the same purpose. In addition, it set up a Regulatory Reforms Commission (RRC) for simplification of procedures and ensuring transparency of operations in the public sector. The reform programme will focus on (i) streamlining and simplification of business regulations; (ii) establishment of effective screening mechanisms for new regulations; (iii) development of comprehensive e-registry of business related laws, regulations and rules in Bangladesh; and (iv) strengthening and development of institutional capacities to implement and sustain procompetitive and investor friendly regulatory reform in Bangladesh. While the objectives are laudable, there are questions relating to the manner in which they can be best achieved. The issues are under review of the government within the overall context of promotion of investment and its institutional apparatus for the purpose. 
Improving Access to Land for Private Enterprises: The paucity of land and the worsening land/man ratio makes it imperative that utmost economy be practised for industrial (and other non-agricultural) use of land. This calls for a greater emphasis on better land use planning and improvements in the land administration system in order to facilitate efficient land markets and development of a modern economic zones regime.

Special Economic Zones: The export processing zones (EPZs) as well as industrial estates have contributed a great deal to industrialization in Bangladesh. However, looking at the future it seems obvious that in a globalized world of free trade and uniform industrial incentives which is virtually knocking at the door, some different strategies are called for developing relatively backward economies like Bangladesh and more so for its backward areas. We are looking at experiences of other countries and notably China in developing special economic zones (SEZs) covering not simply enclaves of limited areas but really wider areas of upazilas. These areas will be selected based on prescribed criteria and would cover both developed and backward regions and arrangements will be made by harnessing the elements of strengths as well as mitigating the weaknesses of the selected areas to make them attractive to development enterprises.

No further EPZs or industrial estates will be developed but the existing and the planned or committed ones will continue to operate under the existing laws and rules up to 2013.

The new SEZs will be established by developing infrastructure facilities there so that energy and power sources, transport and communication links, travel and banking facilities, and trained manpower supply can be easily found. The development of an area will take advantage of the comparative advantage of the location. If it is an area where large scale industries can be developed so will it be. If, on the other hand, it is good for agriculture, farming will be its main activity. If it is endowed for service industry, then that is the sector that will take hold there. If the area is good for some cottage industry such as quilt making, the efforts will be organize the activities in such a way that the area and its artisan can respond to large global demand.

The government will not acquire land to develop any particular estate or farm but would assist intending parties to get land for its business and other facilities to set up their individual enterprises. The investors will be ensured of a stable system of tax laws and fiscal measures for a well defined time horizon.

Development of Technology: Policies will focus on (i) monitoring technological developments in the world, acquire the best practice technologies and adapt them to local needs, (ii) resolving technological difficulties faced by local enterprises through appropriate research and process development, (iii) supporting main public institutions in Bangladesh dealing with technology-related matters such as BCSIR, BAEC, BITAC, and public universities including engineering and agriculture, (iv) private organizations for innovative research, and (v) digital Bangladesh as major initiative for modernization and upgrading/catching up of technology.

Corporate Social Responsibility (CSR): Strategies to be followed for promotion of CSR, among others, are (i) creating a common platform for understanding and practicing CSR in Bangladesh, (ii) strengthening the CSR dimension for economic empowerment of the poor, (iii) engaging the socially responsible private investors in development initiatives, (iv) dialogue and cooperation with multilateral organizations and NGOs working with codes of conduct and ethical issues related to business activities, (v) continue to develop sustainable partnerships with value driven private sector organizations under their CSR schemes to organize pilot projects addressing development issues, and (vi) favourable tax treatment of CSR expenditure. 
Ensuring Competition: The government has decided to break cartels (business syndicates) which are responsible for hoarding and abnormal profit. Market developments will be closely monitored and barriers to competition will be removed. Promotion of competition will benefit the consumers.

\subsubsection{Agriculture}

The vision of this sector is to enhance growth through development and dissemination of sustainable technologies which are ecologically adaptable, economically profitable, and capable of generating productive employment, diversification of both crop and non-crop, development of agri-business services, and human resource development and ensure "food for all" by taking all possible measures and to make Bangladesh self-sufficient in food by 2013.

In this context, some of the important challenges are: (i) maximise production in the face of decreasing farm size, degradation of soil quality, loss of agricultural land and limited water resources; (ii) harness productivity gains by making a breakthrough in yield technology, (iii) efficiently use water in rice production and shift to water efficient food crops; (iv) creating a level playing field to compete with others and reap the benefits of a globalized world; (v) strike a balance between ensuring adequate incentives for the numerous small producers (rice, poultry, dairy, fish, nursery etc.) on the one hand, and keeping food prices low for the poor consumers on the other; (vi) ensure intra-household food entitlement between men and women (especially lactating women) and between adults and children; (vii) ensure increased production of fish, milk, meat and eggs for a balanced diet for the growing population; (viii) cope with climate change, maintain ecological balance and conserve biodiversity; (ix) to provide greater support to domestic agricultural research; and (x) address increasing volatility in international food market.

\section{Future Agricultural Policies and Strategies Crop Production}

Increasing yield: To increase yield, more investment will be made for the development of crop varieties, quality seed, soil health, pest management, and agronomic practices, development of local service providers (LSP), strengthening of the value chain, market development, improving agricultural research and mechanization, improving capacity of scientists and extension workers, and flood control, irrigation and water management.

Broad-based support to agriculture: The government will ensure access to reliable, affordable, adequate and timely supply of major inputs like fertilizers, fuel and irrigation through appropriate support measures especially subsidies and effective distribution system. Any distortion in market for fertilizers and pesticides with regard to dealership, quota and restricted movement of fertilizers will be addressed to ensure timely availability at fair prices.

Other broad-based support includes access to quality seeds (HYV, hybrid), output price support, credit for small farmers and sharecroppers, promoting commercial agriculture and genetic engineering, subsidizing the installation and maintenance of electricity connections to irrigation pumps, maintenance of rural roads enabling storage, processing and marketing of perishable high-value farm products in the private sector, and enhanced extension, and agricultural education with particular focus on quality improvement in all production environments. Public-private partnership will be encouraged in providing broad-based support to agriculture. The approach includes the promotion of private service providers, public-private coordination in research and development, seed production, and business development. For quality control and reliable supply of seeds, the existing regulatory framework needs improvement through better coordination among different agencies 
concerned. The amount of agricultural loan will be increased and the loan giving procedure simplified. Loan will be made available for the sharecroppers.

Diversification of high value crops: Emphasis will be given on increasing production of non-rice cereal crops, especially maize and oilseeds, and also of fruits, vegetables, flowers, and ornamental and medicinal plants. Infrastructure and marketing supports will be provided to develop integrated supply chains including processing, storage and transportation at the local and national levels. Several issues such as product standardisation, food safety, sanitary and phyto-sanitary measures will be taken up. Various methods like relay cropping, mixed cropping, and zero tillage will be considered in different agroecological zones.

Agricultural research and technology generation: Agricultural research will remain largely in the public domain, but efforts will be made to develop programmes involving NGOs and the private sector. The capacity of the ten NARS institutions will be further strengthened through supporting quality research including biotechnology research, human resource development, strengthened MIS/ICT facilities, prioritizing farmers' demand-led research and adequate incentive structures for the scientists. Increased attention will be given to $\mathrm{R} \& \mathrm{D}$ in the non-crop sector including livestock, poultry, fisheries and forestry. The National Institute of Biotechnology (NIB) will conduct research on crop varieties to serve farmers located in deeply flooded areas, char land, flash flood-prone areas, coastal tidal surge and salinity prone areas, and hilly areas.

Technology dissemination: There will be emphasis on participatory extension services involving wider rural communities i.e. farmers, landless households, different occupation groups and women. These will be implemented as per Plan of Action with necessary amendments and clarifications in response to changing demands of commercialization. Emphasis will be given on partnership of DAE, DLS, DoF and BRDB cooperatives with the private sector and NGOs, which have evolved many successful approaches to disseminating promising technologies. Under NATP, FIAC (Farmers' Information and Advisory Centre) will play an important role at union level.

Revamping agricultural marketing system: The ongoing programme will continue to develop marketplaces and market outlets. Credit facilities will be provided to private initiatives for small and medium-scale agri-businesses in processing and packaging. Formation of farmers' groups will be encouraged to ensure their direct participation in the marketing of agricultural produce. Fair price for agricultural crops and products will be ensured. Incentives will be provided for development of rural warehousing. The Department of Agricultural Marketing (DAM) will be strengthened to enable it to take modern marketing services for crops and high value agro-products and provide advice and information on prices, processing, handling, and storage and transportation services. DAM will promote an innovative marketing system such as contract growing integrated with a supply chain of high value agro-products. Emphasis will be given to improving marketing environment for agri-inputs and products as well as increasing storage and warehouse facilities. A price Commission will be established for forecasting prices of essential commodities, analysing changes in demand and supply, cost of production of agricultural products, analysing export-import trends and international prices of essential commodities. This Commission will help formulate and up-date regional production planning based on price trends.

Agro-processing activities: Agri-business and agro-processing will be given top priority as a thrust sector to promote value addition to crops, livestock, fish and horticultural products. The government will provide support to the agro-entrepreneurs through infrastructure development, and fiscal benefits including export incentives and tax concessions. The private sector will also get support for technical training, technology development, and 
improvement of standards of hygiene, handling and packaging of processed products. Food safety would be improved as a means of strengthening export outlet of agricultural products. Agro-economic zones will be established with appropriate support services, quality control laboratories and by developing communication and transportation facilities.

Climate change adaptive technology: Some efforts have been made to cope with climate change through development of salinity resistance, drought resistance, short duration, cold tolerant rice varieties. In future, more emphasis will be given to develop technologies which are environment friendly in coping with climatic change. The brick burning system will be modernized by 2011 for no smoke condition kiln; solar technology will be encouraged for household power supply; and rain water harvesting will be encouraged to develop in all public and private buildings/establishments.

Irrigation and flood protection: Deregulation and market liberalization have encouraged private sector participation in minor irrigation. The suggested interventions include facilitating tube well and surface water irrigation, and revival of rivers through dredging and the Ganges Barrage. Channels will be identified for drainage and also for water retention to be used during the dry season. Capital dredging will be conducted for maintaining navigability and maintaining water flows. Navigability and drainage will be tied up and water bodies will be established in townships and rural areas for surface water supply in dry seasons. The government has already adopted the National Water Policy (1999) for efficient management of water resources in the country. The government plans to increase irrigation coverage from 14.30 lakh hectares in 2007-08 to 14.80 lakh hectares in 2010-11 for additional food grain production. Flood protection and drainage has been planned to cover an area of 46.21 lakh hectares by 2010-11.

\section{Fisheries}

The overall strategy of fisheries sub-sector development envisages intensification of aquaculture by species and ecosystems, addition of export-oriented species, ensuring biodiversity and preserving natural breeding grounds, product diversification, value addition, and development of appropriate marketing infrastructure. For increasing fish production, emphasis will be given on (i) making people more conscious about conservation for augmenting natural fish stock and protecting fish habitats through publicizing Fish Conservation Act and new fisheries policies; (ii) protecting breeding and nursery grounds of major fishes through establishment of sanctuary and re-excavation of canals, beels and baors under different programmes; (iii) encouraging alternate income generating activities for fishermen; (iv) protecting beels and haors from the use of pesticides in contagious lands through more coordinated efforts with relevant ministries/agencies; (v) encouraging ricecum-fish culture and aquaculture and intensifying poly culture; (vi) emphasizing management of aquaculture in floodplains involving local community; (vii) ensuring disease control and quality control of fry and fingerlings; and (viii) prioritizing research and development to meet new changes in the sector. The capacity of the Department of Fisheries (DoF) will be strengthened so that it can support inland aquaculture. Cooperation among the key actors such as NGOs, private sector entrepreneurs and community based fishing groups shall be promoted. Necessary steps will be undertaken for increasing productivity of all khas ponds and water bodies used for fish culture.

\section{Livestock}

The National Livestock Policy identifies ten critical policy areas: dairy development and meat production, poultry development, veterinary services and animal health, feeds and animal management, breed development, hides and skins, marketing of livestock products, international trade management, access to credit and insurance and institutional development for research and extension, for livestock and poultry development in the country. 
The strategy is to harness the full potentials of the sub-sector through creating an enabling environment, opening up opportunities, and reducing risk and vulnerability. The private sector will remain the main actor, while the Department of Livestock Services (DLS) and Bangladesh Livestock Research Institute (BLRI) will play a supportive role. Capacity of DLS will be enhanced in terms of skill development through training and personnel. Increased provision of trained manpower will be linked to the expanded nationwide outfit of DLS. Necessary steps will be undertaken to increase the production of milk, meat, eggs, and chicken to meet growing domestic demand.

Husbandry of poultry and dairy: The private sector operated poultry and dairy farming are generally capital intensive, knowledge-based and risky, and therefore need technological, financial and marketing support. Some private sector entrepreneurs have ventured into the contract growing of poultry and milk products, supporting small farms with improved poultry and dairy breeds, quality input supplies, demand-led extension services and assured marketing facilities for poultry and milk products. Cattle development for meat production is also important. Strategies will also focus on cost-effective quality feed supply, human resource development to ensure exclusive monitoring and supervision and continuous technical support at village level, women's employment in livestock, mitigation of disease incidence, export of livestock products and bio-security against highly pathogenic diseases such as Avian Influenza and FMD.

\section{Forestry}

The development and management of protected areas (PAs), eco-parks, botanical gardens and safari parks will be brought under a legal framework by amending existing wildlife laws. Necessary measures will be undertaken to ensure both in-situ and ex-situ conservation in the country. Policy intervention is already in place to adopt co-management in five out of 19 PAs in Bangladesh. More areas of natural forest and PAs will be brought under comanagement. Due to limited scope for conserving the habitat for mega wildlife and the comparatively small areas left as shelter for small cats and other herbivores total wildlife protection is under threat. Therefore, wildlife protection would be a priority concern for conservation.

Public commons: Public commons including natural resources such as land, wetlands, forests, grasslands, grazing land, reed land, khas land, peat land, rivers, estuaries and the open seas may be one of the most important safety nets available to the poor particularly in the rural areas, provided these are managed in a sustainable manner. In order to increase access to natural resources for the rural poor, participatory social forestry for degraded and encroached forestland and co-management for PAs have been introduced by the Forest Department. It will continue to allow better access of the poor to the public commons.

National forest assessment: National forest assessment and periodic forest inventory will be conducted using MIS and GIS to generate quality and reliable data for future planning and better management. Technical support for developing GIS and training of remote sensing specialists in the Forest Department will be considered in future interventions.

Afforestation: Building forest resources through afforestation will be emphasised. Efforts will be made to establish climate change resilient afforestation in the denuded hill forests and coastal land by accretion.

\section{Rural Development}

Both the government and the NGOs are implementing various programmes for rural development covering microcredit, social security, development of rural infrastructure, women's empowerment, education, health, family welfare, nutrition, and environmental conservation. The National Rural Development Policy 2001 provides a comprehensive 
framework for sustained improvements in rural life and accelerating the pace of rural poverty reduction.

The government will constitute the National Rural Development Council (NRDC), headed by the Prime Minister, to provide guidelines for implementing the rural development policy. Also a national steering committee will be formed to assist the NRDC and follow up policy implementations. Steps are underway to set up the Policy and Strategy Formulation Unit (PSFU) to implement the National Rural Development Policy 2001 for which a project has been undertaken covering 2009-2013.

\subsubsection{Water Resources Development and Management}

The vision for the water resources sector as indicated in the National Water Policy (1999) is to ensure continued progress towards achieving the national goals of development and MDGs through development of water resources, optimizing its various uses, managing resources for sustainable development including securing the lives and properties of people from water related disasters.

The challenge for the water sector is to discourage the use of groundwater and to increase surface water use until a threshold of groundwater storage is achieved for all hydrological regions. However, upstream abstraction or diversion of water from common rivers by India is apprehended to cast adverse impact on the flow of surface water in Bangladesh.

The job of managing water resources is problematic because of controversy over allocation rights and the difficulty of enforcing rules and regulations on conservation arising mainly from its public good nature. A balanced set of policies and institutional reforms are required that will harness market forces while at the same time strengthen the capacity of the government to carry out its essential roles. It is imperative for Bangladesh that it relies on the alternative system of administered control that allocates water resources and charges according to set social, environmental, and economic criteria. Water resource development during the lean season has been geared toward the expansion of irrigation to promote foodgrain production. It gives rise to conflicts in the presence of its increasing competing uses due to population growth, urbanization, and industrialization. The government needs to shift the focus from water resource development to water resources management.

The combination of high rainfall during the monsoon and full-flowing rivers from our neighbouring country result in extensive inundation of floodplains (about 20-30 percent of the country). The flooding occurs over 6 million hectares to depths ranging from $30 \mathrm{~cm}$ to $2 \mathrm{~m}$. This situation creates both opportunities for highly productive farming and fishing systems and risks from deep flooding, riverbank erosion and drainage problems creating greater sufferings for poor households. Bangladesh desperately needs measures against these disasters in terms of developing resilience and adaptation.

Lack of adequate and regular allocation of funds has been a perennial problem in BWDB's conducting of annual O\&M activities. Failure to recover part of the capital and O\&M cost accentuated the problem. Needs, priorities and implementability have to be judged for estimating O\&M needs for projects with long-term benefits of water sector projects. Similarly, adequate environmental considerations in project preparation have been a consistent problem in water sector projects. The government's capacity to assess the environmental impact of water sector projects will be enhanced as part of the overall strategy to respond to climate change including setting up of a central climate change unit and/or climate change cells in important ministries. The NWMP has divided the country into eight regions for which principal water-related issues have been identified. These issues constitute problems under short, medium and long term regarding hydrological resources as per natural endowments in respective regions. Distribution of poverty by hydrological 
region could display a striking feature that needs attention. Water projects need to take account of the poverty situation to prioritize projects in locations where poverty can be reduced most.

\section{Strategies and Institutional Development}

The strategies of water resources development and management are to (i) develop the main rivers of Bangladesh for the multipurpose use of water resources, managed for navigation and erosion control and developing hydropower; (ii) undertake flood protection and storm water drainage measures with the rehabilitation and maintenance of existing FCD and FCD/I systems in a participatory manner; (iii) include provisions of cyclone protection, an early warning and forecasting system, flood shelters, control of riverbank erosion, drought management and rationalization of groundwater in disaster management programmes; (iv) make adequate provision for water management for agriculture through public sector irrigation development, flood management and drainage; (v) ensure protection of the natural environment and aquatic resources with monitoring and controlling water pollution, water management for fisheries and ecologically sensitive areas, (vi) undertake dredging of rivers for flood control, navigation, drainage and irrigation, (vii) take initiatives to implement the Ganges barrage project to expand irrigation facilities, prevent salinity, and to solve the problem of scarcity of sweet water in the Sundarban region, (viii) seek regional and international cooperation for development of water resources, and (ix) raise awareness among all stakeholders about scarcity of water and the economic use of the resource.

Considering the economic importance of the river systems, the government has decided to implement river channel stabilization through capital dredging in the major rivers of the country. The BWDB is working on formulating a comprehensive plan for capital dredging, primarily covering 13 rivers with a cumulative length of 1,392 km. The pilot dredging of a reach of Jamuna River from upstream of Sirajganj Hard Point to downstream of Dhaleswari off take covering a length of about $20 \mathrm{~km}$ would be started soon and, in the light of the experience of this pilot capital dredging, a nationwide capital dredging programme would be finalized.

Institutional Development: The highest body for the formulation of national water policy is the National Water Resources Council. The government has set-up WARPO as a secretariat of the Executive Committee of the National Water Resources Council (ECNWRC). WARPO is responsible for three main assignments: prepare and update the National Water Management Plan, update and maintain a National Water Resource database and act as a clearing house for all water sector projects undertaken by any agency. The ECNWRC needs to be effective and regular monitoring of the three activities has to be ensured.

The Joint Rivers Commission has to continue its efforts to effectively establish the country's water shares and negotiate accordingly. Specialized Institutions such as RRI, CEGIS and IWM and other relevant research institutions need to pursue professional and technological breakthroughs in view of the challenges in the water sector in future. The Bangladesh Water Development Board (BWDB), the Local Government Engineering Department (LGED) and the Bangladesh Agricultural Development Corporation (BADC) have continued to carry out major responsibilities of conducting activities concerning investment and operation \& maintenance (O\&M).

\subsubsection{Land Use Policy and Management}

The main goal of land use policy and management is to ensure best possible use of land resources and delivery of land related services to the people through modernized and efficient land administration for sustainable development with accelerated poverty reduction. 
Because of diversion of agricultural land to multiple uses and river erosion the per capita availability of land is declining and the loss of agricultural land is going on the rate of about 1 percent per year. The poor have very little access to government land like char land, khas land, water bodies etc. There are land laws and policies to allot such land to the poor and the landless, but the interest of the poor is rarely preserved. The vested interest groups in both rural and urban areas are in de facto and de jure possession with the help of money and muscle. The adivashi (the indigenous people) of the CHT and other areas are losing their common property rights in land. In the cities, the slum dwellers pay high rent for staying in the slums and they remain under threat of eviction.

Land is being degraded by soil salinity, soil contamination, deforestation, water pollution, falling water table and drainage congestion. Financial constraints, lack of awareness, reluctance to obey rules and enforce laws, piece-meal efforts to deal with these issues, implementation of contradictory and ineffective policies are the main reasons for such degradation. The government will address the problems, including higher allocation consistent with public expenditure programme and improving quality/efficiency of expenditure by government departments. Government agencies responsible for preventing land degradation do not get enough funds to tackle these problems.

The Ministry of Land formulated a National Land Use Policy in 2001 to prevent land degradation and to ensure its best utilization for all purposes. The policy also highlights the need, and the importance of carrying out National Land Zoning for integrated planning and management of the country's land resources. However, the institutional structure for implementation is lacking. Illegal encroachment on rivers, canals and water bodies for housing, industries etc. is common in both rural and urban areas. This leads to obstruction of the flow of water, reduction in flood plain areas and increased flooding. The imperative for raising food production is so urgent that agricultural expansion often neglects the consequential loss of wetland water bodies and biodiversity.

The Ministry of Land is implementing a programme under which at least 20 landless families are being given khas land in each upazila. A total of 6,397 landless families in 436 upazilas have been given nearly 2,185 acres of khas land till July 2009. In addition, 71,032 landless families have been rehabilitated through providing khas land including houses under Ideal Village I and II projects. Similar rehabilitation programme has been targeted for 10,650 landless households under Climate Victims Rehabilitation Project within January 2009 to June 2012. In addition, rehabilitation of 9,500 households is in progress under Char Development and Settlement-3 Project.

\section{Strategies to Overcome Land Related Policy and Management Problems}

The lack of coordination between different departments responsible for preparation and maintenance of Record of Rights (ROR) often leads to confusion, conflicts and many instances of litigation causing suffering of the people especially the small and marginal farmers. The Ministry of Land has already undertaken projects to conduct digital surveys and introduce e-governance. Land records will be computerized/digitized and land mutation will be made automatic.

Necessary measures would be initiated to ensure sound coordination of the activities undertaken by department of registration, A.C. Land and DLRS. Through appropriate delineation of supervisory responsibility of settlement activities, better coordination of the two offices in dealing with the preparation and maintenance of land records at the upazila level will be achieved. The Directorate of Registration will be directed to remove inconsistency in land records management and also for immediate updating of land titles. 
A database including all land resources, land zoning information and other resources in selected areas such as Char land and other ecologically endangered areas will be developed. The Ministry of Land is implementing a coastal land zoning project to ensure proper use of land and mitigate land degradation. There will be provision for a participatory and joint monitoring system with government employees and the local people for overseeing the activities of land classification, and land record modernization for effective land management. The participation of the poor in the whole process, from formulation to implementation of laws and policies will be instituted.

The land in CHT is administrated under the relevant Acts, Rules and Regulations of the Manual of 1900. The customary common property rights of the ethnic people are to be protected. Laws and policies would be framed for the proper management of the land in the Chittagong Hill Tracts. The provisions of Rangamati/Khagrachhori/Bandarban Hill District Local Government Council Act 1989 have been amended according to the CHT Peace Accord. Laws and policies will also be introduced to avoid environmental degradation such as stopping hill-cutting, tree-felling while using available land for development of resources such as tea and rubber plantation.

The modification and simplification of all land-related laws are expected to remove many of the land related disputes. A special committee will be set up to come up with recommendations in this regard.

Land Use Management: Planned use of land according to Land Zoning Maps prepared on the basis of present and potential land uses will be ensured through enforcement of the provisions of relevant laws. The provisions of the Town Improvement Act of 1953 will also be more strictly enforced. The government will take up project for development of rural townships where specific areas are to be earmarked for housing, marketplaces, industries and infrastructure.

Land acquisition act and policy would be rationalized. Unused acquired land or acquired land not used for the declared purposes would be resumed by the Deputy Commissioner. Unused land of Bangladesh Railway may be given to Roads and Highways and Local Government Engineering Department for construction of roads if needed. In case of big public sector projects like the Padma Bridge (for which the government has already approved the resettlement plan) affected persons would be motivated to make their resettlement voluntary. They would be compensated for their land at the price suggested in the National Involuntary Resettlement Policy.

While building rural roads, highways, bridges and culverts, the government departments do not keep enough space for the natural flow of water. In the big cities, the land grabbers are filling up the water bodies, thus creating drainage problems. Provisions are to be made for free flow of water. The natural flow of rivers and canals is to be restored by removing the land grabbers. The water bodies and the flood plain areas in Dhaka and other big cities would be freed from illegal occupants.

The rivers, canals, haors, etc. would be leased out to poor and genuine fishermen. This will be ensured with the involvement of the MOFL, DOF and major stakeholders including NGOs. The Jalmahal Management Policy 2009 has already been finalized and gazetted in June 2009. Similarly, Balumahals and other Sairat Mahals would be managed in a way which will benefit the poor.

Inspections of industries would be conducted more frequently to strictly enforce the construction of ETPs and their due continuous operation. The relevant provisions of EBSATA would be strictly enforced to stop degradation of crop land by neighbouring industries. Projects would be taken to develop perennially inundated areas like Bhabadaha. The conflict between the growers of shrimp and crops would be resolved by involving the 
Union Parishads, DOE, DOF, DAE and stakeholders' representative organizations including local NGOs.

The Ministry of Land would continue with its programme of housing for the urban poor. Khas land in urban areas (i.e. non-agricultural) would be utilized for housing the slum dwellers. Non-agricultural khas land would be provided to the Ministry of Food and Disaster Management and Ministry of Social Welfare for constructing (i) houses for women, marginalized people and endangered communities, and (ii) vagrant homes and night shelters in the cities for the uprooted population.

\subsubsection{Urban Development}

Bangladesh is experiencing rapid urbanization. In 2007, the estimated total population was 142.6 million of which 25.0 percent ( 35.7 million) was urban. Urbanization is characterized by over centralization in few cities like Dhaka and Chittagong resulting in overcrowding and a severe lack of basic facilities in almost all spheres of life. The major challenges of urbanization in Bangladesh are: (i) unplanned and unguided urbanization with mounting problems; (ii) absence of strong planning outfit centrally and in urban centres; (iii) lack of advance planning for utility services, shelter and infrastructure; (iv) absence of an integrated approach to urbanization embracing cluster development of adjacent towns or provision for satellite towns; (v) lack of comprehensive urbanization comprising all civic amenities like parks, lakes, and other recreation facilities; (vi) absence of a regulatory framework for utilization of urban public land and waterways to prevent their misuse; (vii) inadequate environmental concern for protection of urban waterways, disposal of solid wastes and industrial sludge; (viii) lack of concern for urban poor and slum dwellers; and (ix) absence of statistical database for urban planning. The high population density calls for a spatial pattern of urbanization composed of urban and peri urban areas. Planned urbanization will ensure growth and equity taking into consideration a futuristic scenario. The specific goals are to: (i) promote urban development for balanced growth across the country; ii) finalization of national urban development policy and (iii) promote sustainable urbanization for poverty reduction and development.

\section{Strategies}

The following strategies will be followed for urban development: (i) planning, guiding and promoting urban development with adequate services for all; (ii) creating strong planning outfit in relevant ministries and all city corporations; (iii) making advance planning for utility services, shelter and infrastructure in all urban centres; (iv) planning road infrastructure development and public transportation for a number of cities and towns in a cluster; (v) adopting an integrated approach to urbanization embracing cluster development of adjacent towns or provision for satellite towns; (vi) developing comprehensive urbanization comprising all civic amenities like parks, lakes and other recreation facilities; (vii) developing policy framework and creating a regulatory framework for utilization of urban public land and rivers for building parks, lakes and civic amenities; (viii) improving urban environment by protecting urban rivers, regulating disposal of solid wastes and industrial sludge; (ix) creating an enabling environment including social protection systems and safety nets for urban poor and slum dwellers by building appropriate institutions like cooperatives, micro credit organizations, easy access to credit, improved health facilities, etc; (x) building regulatory authority for citizens' protection against exploitation by home developers and other private utility providers; (xi) creating strong mechanism for coordination of infrastructure development and provision of utilities in all urban centres; (xii) creating a framework for operation of private sector, NGOs, CBOs, PVOs etc. for building infrastructure, recreation facilities and utility services for urban inhabitants; (xiii) building institutions in collaboration with the BBS for creating statistical database for urban planning; 
and (xiv) build democratic institutions for effective urban governance with the participation of the civil society, NGOs, and CBOs. In developing the growth centres, areas will be earmarked for community housing including social forestry.

\subsection{Strategic Block III: Essential Infrastructure for Pro-Poor Economic Growth}

Infrastructure development contributes to growth in general and pro-poor growth in particular. Infrastructure includes electricity, gas, renewable energy, roads, railway, inland waterways, sea ports, land ports, airports, and post and telecommunication links.

\subsubsection{Power and Energy}

The government will adopt a comprehensive long term policy on electricity and energy to develop the power and energy sector, and promote energy efficiency and conservation. Sustainable energy will be promoted as a strategic priority for poverty reduction.

\section{Power}

The vision of the power sector is to provide access to affordable and reliable electricity to all citizens of Bangladesh by 2021. The supply of quality and reliable power at an affordable price will be ensured through system expansion with a prudent least cost plan, efficiency improvement through institutional and structural reform and establishment of commercial arrangement among the sector entities. Electricity generation will be raised to 7,000 MW by 2013, 8,000 MW by 2015 and 20,000 MW by 2021 .

As power projects are highly capital intensive, developing adequate generation, transmission and distribution facilities to provide reliable and quality power supply to the population poses a formidable challenge for the government. Absence of clear organizational goals, adequate financial and commercial autonomy and lack of adequate incentives resulted in inefficiency in the utility management. High maintenance cost and overhauling time for the existing power plants in the public sector is a serious concern. Limited autonomy and financial power to the concerned authority, long approval procedures, and bureaucratic interference cause delay in the maintenance of power plants. In the distribution system, poor quality of power supply causes serious problem to the customers due to a low voltage profile and presence of harmonics as the system is overloaded, inadequate network capacity, lack of reactive power compensation, poor maintenance and absence of proper response from the operators.

Policies and Strategies: In order to meet the projected demand for electricity, necessary investments will be made in a timely manner. This will require careful planning and timely resource mobilization involving both public and private sectors. Balanced development of generation, transmission and distribution of electricity will be ensured. The entities shall enjoy operational autonomy along with responsibility for eliminating loss, wastage and theft, and for efficiency in operation. The possibility of trading power within the region will be explored, and the potential of coal will be fully utilized.

Electricity generation will focus on completion of under construction plants, installation of new plants, utilization of full capacity of existing plants through rehabilitation, scheduled maintenance and overhauling, and human resource development., review of Captive Power Policy to remove all barriers. Transmission infrastructure will be expanded by PGCB in conformity with the generation expansion. The government will adopt a three year crash programme for quick implementation of ongoing and under consideration power generation stations, ordering 500/1500 MW rental power plant on urgent basis, and initiatives for construction 800 MW Peaking Power Plant, IPP of 1250 MW on gas and duel fuel and 2000-2600 MW imported coal based power stations. A schedule for repair, maintenance and overhauling or salvaging of old power stations will be made to increase and stabilize power 
production. gas turbine projects on urgent basis, and reactivation of initiatives for construction of 10, 20 and 30 megawatt power stations. A schedule for repair, maintenance and overhauling or salvaging of old power stations will be made to increase and stabilise power production.

The performance of distribution utilities will be improved through reduction of system loss from current 18.5 percent to 14 percent in 2014, arrear reduction, ensuring reliability of electricity supplies, ensuring affordable price, use of pre-paid metering system, and bill payment system through mobile phone operators. For demand side management, the government has already adopted daylight saving time (effective from 19 June, 2009) and in addition will focus on adjusting shopping hours, holiday staggering for industries and creating awareness of CFL bulbs.

There is significant difference between per unit generation cost (BPDB's own generation cost and purchase cost of power from IPPs and bulk supply cost). The BPDB's bulk supply tariff for urban utilities and rich PBSs is Taka 0.30 less per unit than its supply cost. For poor PBSs, this difference is as high as Taka 0.64 per unit. As a result, BPDB is incurring a loss of more than Tk. 1,000 crore annually. This indicates the need for rationalization of tariff for the sustainability of the sector. The Bangladesh Energy Regulatory Commission (BERC) is responsible for regulation of the sector. The government issues policy directives on matters concerning the electricity sector including measures necessary for its overall planning and coordination. The process of unbundling and corporatization of sector entities is on-going.

\section{Box 3.1: Power Sector Vision and Policy Statement}

- $\quad$ Bring the entire country under electrification by year 2020

- Make the power sector financially viable with ability to facilitate growth

- Increase the sectors' efficiency

- Make the sector commercially oriented

- Improve the quality and reliability of electricity supply

- Use available domestic natural gas for power generation and also explore other alternatives like LNG for the same.

- Increase private sector participation

- Ensure reasonable and affordable price for electricity by pursuing least cost options and explore options for power trading

- Promote competition among various entities

- Promote regional and sub-regional cooperation

Rural Electricity Supply: The overall goal of REB programme is improvement of socioeconomic conditions of the rural people by providing reliable and affordable electricity. The rural electricity network is the fastest growing and most efficiently operated entity within the Bangladesh electricity industry. But it is experiencing serious operational problems due to power shortage and loss of revenue due to non-availability of power and an increase in system losses due to customer backlash from frequent and prolonged load shedding. The REB is facing financial problems in its expansion programme.

The REB strategies for future development are: (a) augment power generation, (b) upgrade and rehabilitate old system for capacity building and reliable supply, (c) implement divisionwise programmes and Chittagong Hill Tracts Rural Electrification Project to ensure regional balance, (d) disseminate renewable energy technologies (solar, wind, small hydro, bio-mass etc.), (e) ensure additional assistance for expansion of network, (f) hand over BPDB rural 
distribution systems to REB, (g) reduce system loss, (h) enhance performance, (i) rationalize tariffs and (j) replace incandescent lamp by compact fluorescent lamp (CFL).

Nuclear Power: In view of the need for diversifying energy sources for long-run energy security, a nuclear power plant will be installed at Rooppur as soon as possible, with generation capacity between $700 \mathrm{MW}$ and 1,000 MW. In this respect, a MOU has been recently signed between Russia and Bangladesh.

\section{Energy}

The main goals of the non-renewable energy sector are: (a) assessment of non-renewable indigenous energy sources; (b) exploration and development of new oil/gas and coal fields; (c) appraisal and conversion of probable and possible reserve to proven reserve; (d) development of the fields considering their capacity and market demand; (e) strengthening institutional capacity of Petrobangla and its companies to make them more effective and financially viable; and ( $f$ ) installation of adequate transmission and distribution network to cater to customers' need.

The major challenges of the natural gas sector are to: (a) minimise gas demand and supply gap; (b) improve reliable estimation of gas reserves through extended exploration and development programmes; (c) optimize production from the existing gas fields; (d) conserve and make efficient use of gas; (e) make Petrobangla and its companies operationally and financially sound; and (f) reduce disparity of supply of gas to different areas of the country.

Serious considerations are being given for using coal along with gas for power generation. The government will set up coal-fired power plant using environment-friendly technology for extraction of coal. The major challenges are to: (a) explore and develop new coal fields and (b) conserve and make efficient use of coal.

Policies and Strategies: The existing National Energy Policy (NEP) is being updated to provide guidelines for achieving energy security for the country. An action plan will be worked out to improve the operational and financial performance of Petrobangla umbrella. The Gas Act will be enacted providing action-plans for proper accountability targeting to reduce un-accounted for Gas (UFG) and outstanding gas bill. Strengthening the Hydrocarbon Unit has already been undertaken to provide adequate and appropriate staff and expertise to assist in policy formulation. The policy for public-private partnership for operating companies of Petrobangla will be formulated so that both domestic and foreign entrepreneurs may participate. Gas marketing companies are going to introduce meters for domestic gas supply and will take measures for zonal isolation. Procurement and supply of domestic meters will also be opened to the private sector. To save trees and the environment, use of LPGs in rural households will also be encouraged for which provision of subsidy for buying of cylinder may be encouraged while the price of gas will be paid by the user.

Efforts to convert possible and probable reserve into proven reserve will involve IOCs especially in offshore exploration, supporting BAPEX with funds to strengthen its exploration and seismic survey activities and engage drilling crew through outsourcing, and exploration activities in both onshore and offshore under PSC.

The National Coal Policy is being formulated for concomitant development of coal to meet the growing energy demand. Special initiatives will be taken to ensure economic use of coal available so far and also to develop coal based power plants. Priorities will be given to the exploration and exploitation of new coal fields. Research and development has been strengthened to ensure economically viable extraction of coal at deeper layers.

The BPI as the Energy Research Institute will ensure continuous training and skill development of professionals working in the oil, gas and mineral sector. The capability of 
the existing training institute of the Bangladesh Petroleum Corporation (BPC) has been strengthened to provide training to the downstream segments of oil refining and marketing.

With a view to meeting the demand of petroleum products, the specific strategies/policies to be pursued are: (a) expansion of the storage capacity of petroleum products, (b) improvement of the distribution system by putting in place a second oil installation, (c) enhancement of capability of handling large vessels to reduce losses in import operations, (d) increase of the LPG bottling capacity, and (e) increase of the refining capacity from the existing 1,400,000 MT to about 4,500,000 MT.

In view of the mismatch between supply and demand, leading to acute scarcity of gas not only to power plants, but also to other customers, thereby constraining future economic growth, EMRD has decided to explore alternative sources of gas supply. In that context Government has decided (a) to establish a Liquefied Natural Gas (LNG) terminal to import initially about $500 \mathrm{mmcfd}$, (b) also to explore the possibility of reviving the inter-regional gas pipeline.

\section{Renewable Energy}

Renewable energy complements other forms of energy. The popular or relatively widely used sources include hydro power, biogas and solar photovoltaic. Other potential energy sources include wind energy, bio-diesel from jatropha plantations, gasohol from molasses, wave and tide power and geothermal power. However, the most promising source may be nuclear energy. All possible efforts would be made to tap renewable clean energies.

The main goal of the renewable energy sector is to develop, disseminate, promote and extend the renewable energy technology to the rural people to meet their energy needs for lighting and cooking purposes by using sustainable inexhaustible environment friendly renewable energy sources. The specific goals of the sector are to: (a) increase access to electricity among the people living in off-grid, isolated and inaccessible remote areas of Bangladesh by solar home systems (SHSs), (b) supply clean bio-gas to meet the energy needs for cooking purpose in rural areas by constructing bio-gas plants, (c) improve the standard of living and increase income by introducing solar power and bio-gas in rural areas, (d) use slurry of the bio-gas plant as bio-fertilizer to minimize use of chemical fertilizer and boost agricultural products as well as increase fish production, (e) explore the potential of other forms of renewable energy, such as wind energy, micro hydro, tidal energy, bio-mass and bio-diesel to meet the power and energy demand of the rural people and ( $\mathrm{f}$ ) explore the potential of municipal wastes to generate electricity as well as for safe disposal of the wastes.

The major challenges of the renewable energy sector are: (a) absence of a government institutional set-up to co-ordinate the renewable energy activities under government and NGOs, (b) absence of proper management in the government agencies to deal with the renewable energy projects/programmes, (c) financial and economic constraints to promote the renewable energy (RE) programmes, (d) lack of proper technical knowledge of the employees dealing with the RE programme, and (e) social barrier and information gap in promoting the RE programmes.

Policies and Strategies: The government agencies involved in RE programmes will provide institutional support including procurement of equipment and training to the employees participating in the RE programmes. The Renewable Energy Policy will be finalized by the government. All duties and taxes would be reconsidered for imported solar panels to encourage NGOs in their renewable energy programmes. The government will consider giving grants to NGOs for enhancing their programmes, particularly solar power and bio-gas plant programmes. The Bangladesh Bank will refinance loans provided by commercial banks to solar energy and biogas. 


\subsubsection{Transport}

\section{Road Transport}

The goal of road transport is to achieve a well-maintained, cost effective and safe road network connecting all parts of the country and facilitating links with neighbouring countries.

The development of road and road transport faces a number of challenges: (i) road construction requires a raised earth embankment because of low-lying topography and construction of bridges and culverts at frequent intervals because of rivers and canals; (ii) torrential rains during the monsoon period wash away road surfaces, particularly the shoulders and earth embankments of the road network; (iii) road network is still broken at many places by a number of river gaps requiring ferry services for the movement of vehicular traffic; (iv) a large segment of the road network has narrow pavement width, lower axle-load design, detour alignment, horizontal curvature and unstable shoulders requiring correction and improvement; (v) the presence of mixed traffic on the road network creates a problem for economic and efficient operation of mechanised vehicles and is to a large extent responsible for traffic accidents on roads. This particular aspect needs special attention while planning and designing the construction of a road; (vi) the principal inadequacies in the system of building a suitable road network in Bangladesh relate largely to the poor quality of available construction materials and poor construction practices.

Policies and Strategies: The development of road sector emphasizes: (i) capacity expansion through construction of tunnel, (ii) four laning of existing important highways. (iii) construction of big bridges, (iv) development of road corridor and border roads to facilitate regional trade, and (v) regional balance in road development.

An Integrated Multi-Modal Transport Plan (IMTP) is being formulated emphasising the maintenance of existing assets and infrastructure and encouraging more investment in rail and inland water transport. Once finalised and implemented, this will help sustain an integrated communication network in the country. A legal and financial framework will be created to encourage private investment in road sector development. Asian Highway Routes will be completed according to international standards. The resourceful coastal areas will be brought under the road network system. Regional balance will be established in the road sector development programme. Construction of missing links particularly on the national and regional highway network will be expedited.

The planned construction of Padma Multipurpose Bridge will be completed by 2013. Steps have been taken to implement the construction of Padma Bridge project at Mawa and the construction of Karnaphuli Hanging Bridge project on a priority basis. Feasibility studies for construction of the four-lane Dhaka-Chittagong Expressway are underway.

The government has approved a Strategic Transport Plan (STP) for Dhaka. A feasibility study project for the construction of an elevated expressway, a tunnel between Tejgaon and the airport and a tunnel under river Karnaphuli is under consideration. Steps are being taken to construct the Dhaka eastern bypass. It is felt that the feasibility studies of the two will be taken up in an integrated manner, and that these should be built up in PPP modality.

\section{Rural Road Connectivity}

The main goal of LGED is development of road communication to link growth centres, union parishad headquarters, upazilla parishad headquarters, social service institutions like schools, and hospitals with the national road network. The problems in the development of roads by the LGED are: (a) lack of availability of land, (b) local conflict in prioritizing roads for development, (c) shortage of skilled manpower at union level, (d) inadequate flow of funds, (e) overloaded trucks causing early damage to the pavement, (f) number of gaps in 
road network increasing road development costs, (g) non-availability of good quality construction materials, and (h) frequent inundation by annual floods.

The strategies and policies for the development of the road system of LGED include finalization and adoption of a Road Master Plan, adoption of a maintenance plan and according higher priority to maintenance over new construction, exploring technological options to construct quality roads with available construction materials, introduction of measures to stop overloading, adoption of procedures to maximize generation of employment for the poor, ensuring quality of construction, more involvement of local government institutions (LGIs) and ensuring utilisation and maintenance of constructed facilities.

\section{Railway Transport}

The main goal of the Bangladesh Railway is to provide wider connectivity throughout the country including the capital city and mass transportation facilities at a comparatively cheap price.

The current problems of the Bangladesh Railway (BR) include lack of capacity building, lack of proper servicing facilities and delay in finalization of tenders. The current performance of BR is unsatisfactory owing to a number of reasons: lack of upward adjustment of passengers and freight fares since 1992 against about 400 percent increase in fuel and operation costs, lack of investment to re-orient the railway network towards the capital city, shorten the distance between Chittagong port and other cities and connect Mongla port or other areas where rail network does not exist, lack of matching expansion of the rail network in the face of increase in the competitive road network and lack of an adequate maintenance budget leading to deteriorating rail tracks \& other infrastructures resulting in poor performance of BR.

A Master Plan for the development of BR is under preparation by the Planning Commission to overcome the problems and expand and modernize the railway. The measures include double tracking the Dhaka-Chittagong corridor, establishing rail link with neighbouring countries under the Asian Rail and Highways Scheme, undertaking a three-year maintenance rolling plan, and rehabilitation of railway. Feasibility studies will be undertaken to construct underground rail, circular rail, circular and elevated rail in Dhaka. In order to modernise railways, a reform project called Bangladesh Railway Sector Improvement is being implemented.

\section{Water Transport}

The main goal of BIWTA is to ensure smooth, fast and safe navigation for the movement of cargo and passenger vessels at low cost. The improvement of inland waterways will reduce time and transport cost (Tk. 1.50 per ton km against Tk. 2.70 for road and Tk. 1.70 for rail) which will help expand trade and commerce and related activities with favourable impacts on the overall economy. It will particularly benefit the people in the coastal areas where no alternative mode of transport is available. .

Due to reduction in stream flows and cross-boundary flows, siltation of rivers, and reduction of tidal volume, the navigability of inland waterways has been gradually deteriorating. As a result, the length of navigable inland waterways has declined in recent years, hindering the smooth plying of IWT vessels and creating obstructions to the drainage of flood water. The other problem is the lack of integration with other modes of transport.

In order to overcome current and emerging problems prevailing in inland water transport, an IWT sector strategy will develop an integrated plan for dredging for phased 
implementation. A comprehensive but affordable programme for dredging of the major rivers is needed to maintain their navigability round the year. IWT infrastructure will be constructed to handle the growing volume of traffic. The construction of an inland river container terminal at Pangaon on the river Buriganga near Dhaka, which will reduce the congestion of container traffic of maritime ports, is underway. The feasibility of constructing more river-based container terminals needs to be studied. Besides, the IWTA has to make provision for providing port facilities at different landing ports, landing facilities at coastal areas, and pontoons at way-side landings and introducing circular waterways in and around Dhaka city

Sea Ports: For Chittagong port, the main strategy to overcome the problems is to increase port capacity and port efficiency through construction of a container terminal at the New Mooring area, construction of back-up facilities, implementation of the Chittagong Port Trade Facilitation Project, capital dredging of Karnaphuli river, construction of container terminals and implementation of the Port Efficiency Improvement Plan. Plans for setting up a deep seaport at Sonadia are well in progress.

The Mongla port has enough potential to turn it into a fully utilized port but still lags behind due to infrastructural constraints of transportation by road and inadequate railway links with its hinterland, lack of silos and absence of oil bunkering facilities. Moreover, the decline of the jute industries of the south-western region of the country has caused a significant decline in the export of jute and jute-goods through this port. The main development goals of Mongla port are optimum utilization of existing infrastructure facilities, overcoming the bottlenecks of port operation, provision of quality and efficient services to the port users and the business community and developing the necessary back-up facilities. With a view to modernising the Mongla port, a plan has been taken up to construct a multi-purpose jetty with sophisticated facilities. The government plans to develop Mongla as a sea port for regional use.

Land Ports: The Government of Bangladesh formed the Bangladesh Land Port Authority (BLPA) under Act 10 of 2001 and gave the responsibility for 13 land ports to the Authority. Later, the government decided to hand over the 12 land ports (except the Benapole Land Port) to private entrepreneurs to carry out the day to day operations of the ports under the Private Sector Investment Guidelines.

Air Transport: The physical work to upgrade Osmani International Airport for the operation of wide bodied aircraft has been completed. The physical work of extension, modernization and construction of passenger terminal buildings at Osmani International Airport is in progress. Besides, a plan has been taken up for upgradation of Zia International Airport. Bangladesh Biman will be restructured to enable it to operate on commercial and profitable basis. Aviation services in the private sector will be encouraged.

\subsubsection{Post and Telecommunication}

In order to realize the vision of building Digital Bangladesh, ICT facilities need to be extended to rural areas where the majority of people live. To this end, internet connectivity and opportunities for the best use of information and communication technology would have to be ensured. Over the years, the government implemented a number of projects to install digital exchanges, introduce pre-paid service, distribute one million T\&T mobile telephones, install digital telephone lines, and establish an international telecommunication system through submarine cables. Providing telecommunication services and developing 
telecom and internet infrastructure will be the prime objectives of all the service providers in this sector. More emphasis will be given on ICT development.

The strategies for the development of BPO will focus on the introduction of an ICT-based postal network to keep it connected with customers, bringing qualitative changes in postal services, establishing e-centers in the post offices, continuous improvement of products, work process reengineering, creating a business development cell and providing quality services to the people.

\subsubsection{Housing}

"Housing for all by 2015" has been incorporated in Vision 2021 for developing housing and shelter in urban and rural areas of Bangladesh. The other goals of housing development are: (i) create an enabling environment for adequate and affordable housing for different income groups, especially low-income and extreme poor and vulnerable groups; (ii) provide housing for rural and urban homeless, landless and vulnerable groups; (iii) ensure maximum utilization of land in rural areas through developing "growth centre" centric housing in every union and upazila and housing with modern amenities in urban areas; and (iv) facilitate private sector house building, and house building by NGOs and CBOs as supplementary to private developers for certain category of housing development. In housing construction, use of aggregates will be promoted instead of bricks.

Assuming that the population will grow to about 25 crore in 2025 , a system will have to be established whereby housing for 25 lakh families is made available annually. Further, the quality of housing and affordability and accessibility will have to be considered since data reveal that only one-third of dwellings are built of concrete and semi-concrete material. The main problem lies in land prices, which has become prohibitive in both rural and urban areas, especially for housing. Thus there arises a need to resort to strategies like 'compact townships' for the rural areas.

Policies and Strategies: The major policies and strategies are: (i) prepare a comprehensive data base that relates to an updated list of authentic landless, marginal, ethnic, vulnerable, disaster prone, food insecure communities, especially distressed women with children, and (ii) adopt a land management policy, in conjunction with the data base and existing Land Use Policy for delineating the land that could be allocated for housing, particularly for the poor. The Land Acquisition Act will be modified and rationalized to formulate a rational strategy under the auspices of the land acquisition policy. This policy will attempt to make available a minimum quantity of relatively less fertile and unusable land if non-agricultural khas land is not available. In the urban sphere, the provisions of the Town Improvement Act of 1953 and the Land Zoning Laws will be enforced while in the rural areas, necessary acts will be enforced.

The emerging concerns to prioritize are housing and infrastructure standards, housing finance, drainage, maintenance of conservancy services and alleviation of substandard urban living bereft of green belts and water bodies. The government will also integrate planning of linked activities; strengthen institutions concerned with urban management and development through local resource mobilization, delegation of authority and community involvement.

\subsection{Strategic Block IV: Social Protection for the Vulnerable}

Social security, empowerment, and employment generation are indispensable elements of poverty reduction programmes. Strong and expanded social safety nets will protect the poor from different social, economic, and natural shocks and poverty will certainly reduce through social empowerment. In achieving faster poverty reduction, attention needs to be given to activities that are directly targeted to benefit the extreme poor and disable, women in poverty, landless poor and other vulnerable groups like urban poor. To protect the poor 
from falling into deeper poverty, attention has to be given to at least five areas. These are: social safety net programmes; food security; disaster management; micro-credit and rural non-farm activities.

\subsubsection{Social Safety Net Programmes}

A strong and expanded social safety net programme (SSNP) is the main emphases of Vision 2021, which will protect the poor from all sorts of social, economic and natural shocks. The social safety net may be defined operationally to include all kinds of cash and kind transfers to the poor, all welfare activities, unemployment benefits for retrenched workers, subsidized health care, shelters for the homeless, and pension benefits, which prevent individuals from falling into poverty.

The major goals of SSNPs are: (i) safety net interventions will achieve the protection of all types of poor people and the prevention of chronic poverty as well as transient poverty. It will target the extreme poor first; (ii) the government will encourage NGOs, CBOs and the private sector to augment their role and contributions to expand the social safety net; and (iii) attempts will be made to increase coverage through increased budgetary allocation each year.

All the programmes undertaken under the social safety net at present will continue. The old age allowances, allowance for insolvent persons with disabilities, stipend programme for students with disabilities, allowance for widows and distressed women, maternity allowance for poor mothers, and small ethnic groups would be expanded. The present government gives more emphasis on SSNPs as a means to reduce poverty. Social safety nets will be extended for the ultra poor and the number of recipients of old age allowances and destitute women allowance would, at least, be doubled. Besides, other programmes such as one house one farm, rural housing, ideal village and returning homes will be taken up.

\subsubsection{Food Security}

Food security is a core issue in the struggle against poverty. Food security encompasses three broad aspects, namely, availability, access and utilization. The government has formulated several national policies highlighting various aspects of food security. The National Food and Nutrition Policy and the National Plan of Action for Nutrition are more comprehensive and these have served as starting points for the implementation of the policies. These policies focus on objectives such as: (i) ensure adequate and stable supply of safe and nutritious food; (ii) enhance the purchasing power of the people for increased access to food; and (iii) ensure adequate nutrition for all, especially women, children and persons with disabilities.

Despite significant progress in domestic food grains production, Bangladesh is still facing food insecurity. Nearly 40 percent of the population lacks the resources to acquire enough food. The government operates a number of programmes to ensure food security in the country. These include: (i) open market sales (OMS); (ii) FFW programme; (iii) VGD programme; (iv) VGF programme; (v) test relief (TR); (vi) gratuitous relief (GR); (vii) food aid to CHT area people; (viii) food subsidy; and (ix) employment in char areas.

Main problems of access to food relate to lack of purchasing power among poor people, which has seasonality and spatial dimension. Considerable intra-household disparity and discrimination persist in food consumption. Further, Increasing food availability and household access to food alone will not be adequate to satisfactorily address the malnutrition problem. Nutritional issues will need to be addressed more directly and comprehensively. Comprehensive programmes involving nutrition education, food fortification, improvement in water quality and public health will be undertaken. Further, awareness of nutrition will be created through mass communication. The government is 
committed to ensure quality and safe food to the people. To this end, in addition to enacting laws, the government has taken initiatives to strengthen the Bangladesh Standard and Testing Institution (BSTI).

To ensure food security for the nation and particularly for the extreme poor, the government will (i) maintain an optimum level of food stock; (ii) ensure access to food at an affordable price for the hardcore poor, the disadvantaged groups and persons with disabilities; (iii) operate special food programme in the poverty/disaster prone areas; (iv) increase awareness about safe and nutritious food through the mass media and school education; (v) ensure food security by strengthening the public procurement system; (vi) distribute food under VGD cards area-wise in proportion to the population living below poverty line; (vii) ensure adequate coverage under VGD; (viii) strengthen OMS for increasing access to food for the urban poor; (ix) encourage domestic cereal production; (x) encourage building of cold storage plants, giving guidance to banks for assessing the scope of financing these; (xi) encourage supply of nutritious food including pulses and oil seeds through high quality seeds, technology and credit support to the farmers; (xii) encourage cooperative agricultural marketing to maintain stable prices of food; (xiii) introduce crop insurance; (xiv) increase storage capacity for food grains; (xv) provide incentives for construction of rural warehousing; and (xvi) improve food management and monitoring in the domestic and world markets to avert future crises.

\subsubsection{Disaster Management}

In November 2007, a devastating cyclone 'Sidr' hit the coastal belts of Bangladesh which was followed by another cyclone 'Aila' in May 2009. Although the cyclones devastated large areas, the death toll was relatively low (3,406 in 2007 and 190 in 2009) because of the improved early warning system and its ability to mobilize organizational and community actions in a timely manner and relief and early recovery systems.

The goal for disaster management (DM) is prevention and protection of lives and properties from any kind of hazards with priority given to disaster risk management along with mitigation. The government emphasises disaster risk management in a cost effective manner. The draft Disaster Management Act has identified a group of broad-based strategies, which focus on management of risk and consequences, community involvement in protecting lives and properties with greater involvement of local government bodies and emphasis on non-structural mitigation. The government has taken a number of steps for building up institutional capacity from national to union levels for effective and systematic disaster management.

DM will include (i) improving the cyclone signal system to make it clear to common people and improving flood forecasting to be able to make forecasts 6-7 days ahead instead of 3-4 days as currently made; (ii) strengthening coordination among the government agencies, NGOs and civil society institutions and coordination and management at grassroots level; (iii) creation of a disaster relief fund to support victims of natural disasters; (iv) developing insurance system to cover disaster-related losses of property; (v) avoiding overlap in relief distribution and rehabilitation initiatives, (vi) providing adequate health facilities for the disaster victims, quick transportation of the affected people and instant treatment of the injured people, and (vii) improving capacity for adequate and quick response to emerging and potential disaster like sea-level rise, bird flu, etc.

The strategies for DM will focus on: (i) collective action of public sector, NGOs and community organisations to reduce the risk of disasters in the country, (ii) increase the mitigation capacity of the community and NGOs, (iii) promoting optimum coordination and best utilization of resources along with ensuring community participation so that they 
are aware of what they can do for protecting their lives and property, and (iv) undertaking measures for dealing with disasters such as Tsunami and earthquake.

The DM needs to be continuously upgraded and strengthened. Various actions to be taken in this area are: (i) mainstreaming disaster management into national policies, planning, and institutional development; (ii) increasing community involvement in disaster management; (iii) ensuring protection of women, children, the aged, and people with disabilities giving due attention to their special needs; (iv) creating a coping capacity at global, regional, national, local, community, household and individual levels; (v) continuing risk assessment to address the new risks arising from the changing national, regional and global situations; (vi) strengthening attention to environmental management, land-use and urban planning, protection of critical facilities, application of science and technology, and partnership and networking in disaster risk reduction and mitigation; (vii) increasing capacity of disaster forecasting by introducing community radio throughout the coastal belt and adjoining districts; (viii) undertaking construction of multipurpose shelters in the cyclone prone coastal areas and flood prone areas; (ix) undertaking structural interventions such as construction of embankment, regulator, and flood control mechanism; (x) implementing a coastal disaster management policy; (xi) ensuring quick transportation of the victims from the affected areas; and (xii) introduction of property insurance to cover disaster- related damages.

\subsubsection{Microcredit}

Microcredit has helped address poverty by providing loan in small amounts without collateral and has helped in particular women who are the target borrowers of micro lending. Over the years, various challenges with regard to microcredit have emerged. These are: (i) prevalence of high interest rates which are being reduced, but further reduction of interest rate is necessary; (ii) vicious cycle of microcredit - the poor are borrowing from one microcredit organization to repay another; (iii) microcredit programmes have not been very successful in including the hardcore poor; (iv) rate of graduation to above the poverty line among the microcredit borrowers is low, indicating persistent dependency on microcredit; (v) most of the microcredit recipients being women, bear the burden of repayment; (vi) microcredit organizations compete with each other and often put pressure on the potential clients to borrow; (vii) profitability of micro enterprises is small and often is not sustainable on a long-term basis because of enterprise decapitalization, saturation of markets for products that are traditionally produced by microcredit borrowers, weak coordination among NGOs and MFIs and a weak financial system. Efforts will be made to upscale the technology base in utilizing micro credits and bring transparency in interest rate fixation and in offering micro credits.

Currently the emphasis is to increase the coverage of the programme to a larger number of deserving households; introduce a uniform approach of operation both by NGOs and the public sector; and introduce a regulatory framework for streamlining the activities of the microcredit programme in the country. The government would channel more resources for microcredit operations, increase effectiveness of microcredit for poverty alleviation, avoid overlapping and reduce seasonal vulnerability through microcredit. Local governments will be involved in microcredit delivery.

A Microfinance Regulatory Authority (MRA) has been established to provide appropriate regulatory framework. A national microcredit policy will be framed to provide guidelines about the operation of microcredit. It is also necessary to rationalize interest rates. Necessary mechanism will be devised to ensure that microcredit reaches the ultra poor and the hard to reach areas especially those located in regions with higher incidence of poverty. 


\section{Up-scaling Microcredit}

Up-scaling microcredit is a natural consequence of microcredit programme as the progressive microcredit recipients demonstrate their entrepreneurial ability to handle larger size loans requiring expansion, deepening and diversification of loan products. Some of the microcredit organizations, notably some partner organizations with support of PKSF have increased their loan ceilings to Tk. 300,000 for microenterprise programme and to Tk. 30,000 for all other programmes. The microenterprise loan not only helps reduce poverty of the borrowing household but also creates employment opportunity for other poor people. It is expected that as more and more borrowers graduate out of the regular microcredit programme the demand for larger size loans will increase.

\subsubsection{Rural Non-Farm Activities}

The vision for rural non-farm activities (RNFA) is to foster such activities as an important and effective poverty reduction activity for women in particular. Therefore it is important to identify activities for RNFA and the roles of both public and private sectors and to encourage entrepreneurs to promote RNFA.

The following problems/challenges have been identified for RNFA: (i) since RNFA includes a diverse group of activities, it is difficult to define it as a sector and hence it lacks any baseline assessment; (ii) activities in RNFA are often financed by microcredit, which can only support very small-sized activities. There is a limitation in accessing finances for larger sized activities; (iii) people engaged in RNFA activities, particularly women, lack capacity and skill for producing quality products; have inadequate access to information in determining what to produce and often they lack skills in marketing their products; (iv) as institutional financing is mainly urban biased, problems arise since the NGOs are not very effective in providing business advice because they themselves are not well-equipped to provide such support; (v) management capacity of small enterprises operating in RNFA is rather poor; and (vi) RNFA suffers from inadequate infrastructural facilities particularly energy and communication;

Future strategies will focus on two broad areas: (i) improving the rural investment climate; and (ii) supporting institutional framework. Measures for improving investment climate will include ensuring more energy supply in the rural areas with emphasis on bio-fuel and solar energy use; emphasis on routine maintenance of the existing roads, development of waterways and railway communication; up-scaling and technology upgradation of small enterprises focusing on product development and quality improvement; provision of training for workers based on market demand and also for entrepreneurs in improved business method; promoting linkage with agriculture and greater value addition of farm products through a boost in agro-processing, arranging local-level fairs on routine basis to promote RNF products, skill development training and internship facilities, in-country and international tours through public-private financial participation.

In order to mainstream RNF issues in rural development, an institutional set-up will be formed with different stakeholders, including local government institutions, private entrepreneurs in RNF and providers of financing and other support services. These stakeholders shall identify the strategic policy and investment priorities. The government will consider instituting a monitoring unit to monitor implementation of the initiative and the results.

The RNFAs are undertaken mainly within the informal sector and it is desirable to keep them informal under the present settings. However, creation of an enabling environment for them and provision of some support services would make this sector more vibrant and will contribute substantially to poverty reduction. Some interventions that would be considered 
are: improving marketing capacity by providing sales centres in the GCM and other periurban markets where the government can provide supports and entrepreneurs can undertake a buy-back system; training and awareness building about hygienic agroprocessing and food processing activities; strengthening SME Foundation to allow it to serve more effectively, providing women with basic skills about business management and steps linking them to markets, setting up of more vocational institutes in the rural and periurban areas, allocating more funds under microcredit and microfinance, improving the management of this sector through organising training, orientation, and workshops, disseminating market information and providing institutional and logistic support to entrepreneurs, taking initiatives by the government to create ICT villages in rural areas and taking initiatives by government and NGOs to bring diversification in products and upgrading product designs.

\subsection{Strategic Block V: Human Resources Development}

\subsubsection{Improving Knowledge Base: Education, Training and Research}

\section{Education}

Education is one of the key elements for building the knowledge base of the people. It is expected that the country's education system comprising primary, secondary, tertiary, and non-formal education will establish a truly empowered knowledge-based society to meet the challenges of the 21 st century. There is general agreement that the number of institutions and enrolments have grown at all levels, but the quality of education has deteriorated, especially in institutions where the children of the poor family go. The declining quality of education reduces the employability of the learners creating a disincentive for the poor people to send their children to school. The commitment of the government is to achieve 100 percent literacy by 2014 .

Early childhood and pre-school education: The government recognizes the value of and demand for pre-schools and has been encouraging NGOs and communities to set up preschools within the premises of or near public primary schools. Children from poor families, especially the first generation learners, can benefit greatly from ECDP programmes. A large number of government and non-government agencies are running pre-primary schools. While government funding may not be available for large-scale provision of ECD services, government support can take the form of facilitation and encouragement of donor assistance. All pre-schools may be registered with the government.

Primary education: The Constitution of the People's Republic of Bangladesh directs the State "to adopt effective measures for establishing universal system of education and extending free and compulsory education to all children and removing illiteracy." Accordingly, the government has taken multi-faceted actions in accelerating the pace of providing primary and mass education. The compulsory primary education programme now covers the whole country. The government has undertaken primary education development programmes to improve the quality of education through the introduction of primary school quality level standards, increased access, participation and completion of the primary education cycle and adoption of a child-centred approach in the classroom.

One of the important election pledges of the government is to enrol all children of 6-10 years age by 2011. The School Survey Report 2007 shows a net enrolment rate (NER) of 91.1 percent. Under the Primary Education Stipend Project (Phase II), 40 percent (4.8 million) students have been covered under stipend facilities and the need is to extend its coverage to increase the enrolment rate.

A project is targeted to the children who are outside the formal stream with provisions for education allowances. The government started a school feeding programme under which a child is provided with 75 grams of fortified biscuits in eight poverty-stricken upazilas of 
three selected districts. Other government measures include completion of first round of the national assessment programme, providing supplementary reading materials and teachinglearning materials, imparting training to the teachers and the members of SMCs and PTAs, and introduction of terminal examination at grade five.

Future actions will focus on: (i) ensuring one primary school for every 1,500 population, (ii) developing and funding programmes to extend the coverage, in cooperation with NGOs, (iii) reorienting madrasha education to develop productive students for the real world of skills and knowledge, (iv) applying quality standards like physical facilities, learning aids, formation of the managing committee, student-teacher ratio, and involvement of the community in all primary institutions, (v) reviewing the teaching-learning model so that the foundation of literacy and numeracy skills and basic knowledge can be built at the primary level, (vi) continuing English language teaching from class one, (vii)ensuring a higher salary scale for teachers, and (viii) effective implementation of primary education development programme, and (ix) Capacity development of institutions like the National Curriculum and Textbook Board to ensure quality improvement in primary education.

Secondary Education: Secondary education (grade VI to XII) is provided through collaboration between the government and non-government providers within a regulatory framework. Poverty is a deterrent to secondary school access because, in addition to the tuition fees, there are high additional costs for transportation, uniforms, books and materials and private tutoring. Retention of the students in secondary education is one of the major challenges. A positive development has been the closing of the gender gap in secondary school enrolment with 52.3 percent share of girl students. Stipends and exemption of tuition fees for girls in rural areas have made a difference.

The quality of secondary education remains a major challenge. The curriculum does not relate to prospects of employment, entrepreneurship and practical skills. Examinations mostly test ability to recall information and do not test the ability to reason, or apply, analyse and synthesise information. Expansion in enrolment has not been matched by increase in physical capacity and human resources. Students both per class and per teacher are around 60. Almost half of the teachers do not have any professional training. Academic supervision of secondary schools is weak and almost non-functional.

Future actions will include: (i) making secondary education up to class $\mathrm{X}$ into one unified stream within five years with adequate focus on communication skills, science and mathematics for all students; (ii) undertaking a sub-sector development programme for the under-served groups; (iii) building more government schools in the capital, construction of government secondary schools at every upazilla headquarter and developing and expanding government secondary schools at every district headquarter in phases; (iv) ensuring that NCTB is restricted to only curriculum development and has permanent professional staff; (v) ensuring common minimum standards of inputs and performance in all types of schools; (vi) ensuring that the student-teacher ratio does not exceed 50, competent teachers are appointed, schools have libraries, laboratories, toilets, drinking water and other facilities, all teachers have periodic in-service professional upgrading; (vii) restricting/eliminating private tutoring by teachers and at the same time enhancing their salaries; (viii) making public examinations and internal assessment mutually complementary and more oriented towards the diagnosis of weaknesses of individual learners, institutions and the system for taking remedial measures rather than branding a large number of students as failures;(ix) providing stipend for both girls and boys from poor families; (x) increasing the stipend rate for both poor boys and girls; (xi) taking particular care of disadvantaged students; (xii) expand coverage of schools teaching ICT course in the secondary and higher secondary level, and (xiii) putting emphasis on science education. 
The Government will take the initiative for assistance to secondary schools for introducing computer courses; introduction of computer training and internet facilities for rural secondary and higher secondary institutions; development of SSC (ICT) and HSC (ICT) curriculum in schools and colleges; introduction of Olympiads for primary, secondary and university levels in science and ICT; establishment of six IT training institutions, one in each divisional headquarters; and training of the teachers of schools and colleges in using computers and ICT.

Technical and Vocational Education and Training (TVET): The technical and vocational education and training (TVET) programmes offer courses of one to four years duration after the junior secondary level (class VIII). Vocational training institutes, polytechnics, commercial institutes, technical training centres and specialised institutes offer such courses.

Stated government policies and goals are to increase the proportion of participants in TVET to 20 percent of the students enrolled in the secondary stage by 2020 from the present proportion of around 3 percent. The objectives of TVET are to expand it for the poor, particularly for adolescents, young adults, adults, males and females and make provision for TVET after class VI, VII and equivalent grades. The expansion will be achieved through introducing double shifts in the technical institutions and a special stipend programme for women's education in science and TVET, establishing more polytechnic institutions at divisional headquarters for girls, assessing the market demand for jobs, and providing skill training to the underprivileged and ultra poor for getting jobs and getting self-employment. The equity effect of this expansion depends on the proportion of the clientele of the programmes from disadvantaged and poor sections of the population; how effective the programmes are in marketable skills, and whether there is an expansion in employment opportunities. Emphasis will be given on high quality technical education for industrial growth.

It is essential that TVET courses are flexible in terms of duration, time-table and curriculum and should be flexible in terms of age structure and academic qualification of the students. TVET institutions should develop cooperation with micro-credit providers to support selfemployment of trainees. Particular attention should be given to introducing computer (software and hardware) and ICT related courses. Standard computer training courses at the divisional headquarters have been introduced, and learning packages for students of different levels have been developed. It is important to give emphasis on medical technical training.

Tertiary Education: The main issues regarding access to tertiary education are two-fold: (a) equity of access to universities and prestigious institutions leading to potentially high private return from higher education, and (b) the balance of enrolment in different fields.

Gender disparity in higher education persists, despite progress at the primary and the secondary levels. In tertiary education, increase of enrolment of male and female students in professional degree education must be improved in accordance with the domestic needs and also according to the needs of the countries importing human resources. This sub-sector needs to achieve better balance in enrolment among humanities, applied and pure sciences, technology and commerce. In terms of performance, it is imperative to improve the examination performance of the general undergraduate and graduate students. Internal efficiency of public sector higher education must be improved and the knowledge generation role of the universities must be strengthened.

Actions to be taken for tertiary education are: (i) revise the Private University Act 1992 and establish an Accreditation Council to improve and maintain the quality of education; (ii) install effective governing boards in government and non-government colleges in accordance with the rules of the National University; (iii) institute a permanent pay 
commission and a separate service commission for teachers; (iv) appoint sufficient numbers of teachers for all subjects to maintain a reasonable teacher-student ratio; (v) assess physical facilities and human resources of colleges and apply its rules before authorizing opening of honours and masters courses in colleges; (vi) increase the effectiveness of National University in supervising the network of degree colleges, enforcing accreditation standards, assisting colleges to improve quality of education, and maintaining the integrity of public examinations through decentralizing its functions by establishing National University at division levels; (vii) consider regional disparity in establishing new universities and provide adequate resources to ensure quality higher education and research; (viii) introduce new practice of assessment where teachers and students will evaluate each other; (ix) arrange professional upgradation and pedagogic training programmes; (x) create job placement centres on every campus; (xi) ensure access to computer facilities with internet connections, library etc for the teachers and the students; (xii) remove terrorism and session backlogs from educational institutions; (xii) expand the scope of science education and research; (xiii) introduce free education up to bachelors level; (xiv) pay higher salary to teachers; and (xv) institute a permanent pay commission and a separate commission for teachers in due course in future.

Adequate resource for assuring quality is a central concern in the future development of higher education. The expansion of capacity will be contingent upon availability of required resources for ensuring acceptable quality, rather than more of the same "low cost low outcome" provisions. Public-private collaboration, cost-sharing and cost recovery will be considered as strategies for dealing with resource constraints, enhancing resources for quality improvement, and contributing to equality of opportunity in the education system and the higher education sub-system.

Non-formal Education (NFE): The Bureau of Non Formal Education (BNFE) under MoPME is responsible for non-formal education programmes which are implemented through NGOs. The basic goal of adult literacy programme is to provide them with literacy, life skills, and income generating skills which will help reduce rural poverty and empower the rural poor. It is necessary that an initiative be launched, involving the stakeholders in NFE, to develop a vision and policy framework.

The aim of NFE will be to build a nationwide network of community-based, communitymanaged and multi-purpose non-formal and adult learning centres, to meet the diverse learning demands. The role of NFE in offering a "second chance" primary education for adolescents who missed or dropped out from primary class and establishing link of the second chance programmes with skill development and formal education will be emphasized. Parental continuing education opportunities will be developed and made accessible through the network of community learning centres. It will be necessary to target marginal sections of the population to address their specific needs. Education and training need to be linked with credit and business advice.

Continuing Training: Skills and the knowledge base of people that are created through formal education can be maintained, reinforced, upgraded and strengthened through continuous training. In the already existing educational institutes, evening and night courses would be introduced for need-based skill retraining programmes. The duration of these courses can vary to meet the varied situations and needs of the clients.

Building Research Capacity: Research creates new knowledge and information, discovers hidden or forgotten knowledge, creates scope for better understanding of various issues, and helps in dispelling myths and prejudices. Supporting research activities, particularly of action and applied types, which will help the poor, women and disadvantaged groups would be encouraged. At the higher education institutes, the teachers will be encouraged to undertake research on subjects that will lead to better understanding of issues at national 
and local levels and provide solutions to problems. Involvement of large NGOs in financing such research activities will be encouraged. The government will constitute a knowledge council with adequate support.

\subsubsection{Improving Health, Nutrition and Population Planning: Taking a Holistic Approach}

Health, nutrition and population (HNP) are intimately related and complementary to other sectors of the economy. Improvements in health and nutrition would translate into higher incomes, higher economic growth and decline in poverty. Moreover, increase or decrease of population size and change in the age composition has direct bearing on socio-economic development. It is noteworthy that Bangladesh has made significant progress in the health outcomes and some of the major gains have been achieved through low-cost solutions.

Infant and child mortality rates have been markedly reduced (Table 3.2). Life expectancy has risen steadily. Reversing past trends, women now live longer than men. The total fertility rate has been more than halved. Maternal mortality and under-nutrition rates, though still high, are registering decline. The development of countrywide network of healthcare infrastructure in public sector is remarkable.

Table 3.2: Performance of Health, Nutrition and Population Sector

\begin{tabular}{|l|c|c|c|c|}
\hline Indicators & $1992-1995$ & $1995-1999$ & $1999-2003$ & $2003-2006$ \\
\hline Neonatal mortality rate/ 1000 LB & 48 & 42 & 41 & 37 \\
\hline Infant mortality rate / 1000 LB & 82 & 66 & 65 & 52 \\
\hline Under-5 mortality rate/1000 LB & 116 & 94 & 88 & 65 \\
\hline Children's vaccination (\%) & 54 & 60 & 73 & 82 \\
\hline ANC by trained provider (\%) & 28 & 33 & 48 & 52 \\
\hline Delivery by trained person (\%) & 9 & 12 & 13 & 43 \\
\hline Children short for age (\%) & $\ldots$ & $\ldots$ & 43 & 13 \\
\hline $\begin{array}{l}\text { Children underweight for height } \\
(\%)\end{array}$ & $\ldots$ & $\ldots$ & 17 & 41 \\
\hline Children underweight for age (\%) & $\ldots$ & $\ldots$ & 48 & 2.7 \\
\hline Total fertility rate (TFR) & 3.3 & 3.3 & 3.0 & \\
\hline
\end{tabular}

Source: MoHFW, Successive BDHSs

The HNP activities, however, face several challenges:

- There are major differences in health conditions and health care consumption between different groups. Improvements in some areas are relatively more difficult to sustain while there are indications of stagnation in others.

- Though maternal mortality is declining, it is still one of the highest in the world. So also the neonatal mortality. Bangladesh's current challenge is to improve effective service delivery, health sector governance (especially in primary and maternal health services), and increase the number of trained birth attendants.

- Further sharp reduction in fertility rate might demand new ways of interventions for which concerted inter and multi-sectoral efforts would be required.

- The challenge of reducing child mortality is to address the district and regional variations. Though diarrhoea has been managed quite successfully, still it is a great killer.

- Threats of HIV/AIDS, particularly from injectable drug users, pockets of malaria, kal-azar and filaria and multi-drug resistant $T B$ are also emerging as challenges. 
- Emerging and changing pattern of threats include arsenic related diseases, avian flu, childhood disabilities, mental health problems, road-railway-river accidents and violence (particularly against women).

- The challenge of reducing malnutrition essentially that of women needs coordinated multi-sectoral interventions on sustained basis.

- Meeting the health needs of the fast growing urban poor including the slum dwellers will continue to pose major challenge.

- Demographic and life-style changes give rise to emerging health threats: more youths, more females, more ageing population, and rise of non-communicable diseases. The inevitable effect of climate change over health poses additional challenges.

- With increasing dominance of technologies in health care, the requirement of human resources in health in appropriate number and skill-mix will continue to remain another challenge.

- The development of appropriate strategies to handle the large number of informal semi or un-qualified health care providers (village doctors, drug sellers, kobiraj, totka, herbalist, faith healers, untrained traditional birth attendants etc.) catering to the needs of majority of the population particularly of poor and women poses some challenge.

- Centralized management system of the government health services and prevalent practices at the facility levels result in absenteeism of service providers. These are emerging as major obstacles to effective and efficient utilization of the countrywide health care infrastructure network.

The goal is sustainable improvement in health, nutrition and family welfare status of the people, particularly of the poor and vulnerable groups, including women, children and elderly with ultimate aim of their economic and social emancipation and physical and mental well being.

The government is committed to ensure quality health, nutrition and family welfare services, which are affordable, attainable and acceptable to its citizens. The government focuses on increasing health status, reducing health inequalities, expanding access to social safety network and encouraging affordable service delivery systems for everybody. For the poor and vulnerable, existing facilities will be further expanded and consolidated not only to ensure access of the poor to public health care services but also to raise their voices and establish ownership through community participation. In this context the health policy will be reevaluated and adjusted according to the demands of the time.

Child Health: Expanded Programme on Immunization (EPI) will be further strengthened and special activities will be undertaken for maintenance of zero polio status, measles catchup and neonatal tetanus campaigns, introduction of hepatitis $B$ vaccine throughout the country, strengthened disease surveillance, etc. The control of acute respiratory infection and diarrhoeal diseases and school health programmes will be further strengthened. The integrated management of childhood illness (IMCI) programme will be further expanded. The new initiatives in child health area include (i) introduction of hepatitis $B$ vaccine throughout the country; and (ii) expansion of community and facility based IMCI.

Maternal and Reproductive Health: The life-cycle approach will be undertaken to address the need of women for general and reproductive health and to ensure reproductive health in phases. The vast network of state facilities will be further strengthened for appropriate women, adolescents and reproductive health. The on-going national nutrition 
programme will continue to cater to the need of adolescents as its special target groups. Comprehensive emergency obstetrical care (EmOC) facilities will be expanded by establishing such facilities in more upazila health complexes. More community skilled birth attendants (SBA) will be trained. The demand of ante-natal care (ANC), institutional delivery or delivery by trained personnel, post-natal care (PNC) will be created through strengthened health promotion involving community and different stakeholders. Ongoing demand side financing through providing maternity health vouchers will be expanded based on lessons learnt.

Control of Communicable Diseases: The existing programmes will be further expanded and strengthened to intensify prevention and control of communicable diseases (CDs), such as, acute respiratory tract infection, diarrhoea, dengue, etc. Special measures will be initiated for combating tuberculosis, leprosy, malaria, filariasis and kal-azar, which are concentrated in specific pockets of the country.

Control of Non-communicable Diseases: The government will, in partnership with local government administration and private sector create greater awareness of, and provide services for the control of unhealthy diet and lifestyle related major NCDs like - cardiovascular diseases, cancer, diabetes, mental illness, etc. It will also take steps to combat common NCDs, such as, hypertension, asthma, blindness, etc., which particularly afflict the poor. Existing preventive and curative measures with respect to all NCDs will further be expanded and strengthened to increase access of all to health care services.

Nutrition: The National Nutrition Programme (NNP) will be expanded to all upazillas in phases. The ongoing micro-nutrient programmes will be continuously reviewed for their refinement and expansion with particular emphasis on access of poor and vulnerable women and children. Nutrition activities will be reinforced by forging links with other activities in the health sector like community-centred immunization, community-based integrated management of childhood illness and hospital services for referral of severely malnourished. The multi-sectoral links of the MOHFW's nutrition initiatives with programmes by other ministries for food fortification, income and food security would be further strengthened. The value of women status in reducing malnutrition and dissemination of knowledge about nutrition amongst the citizens will be promoted. Monitoring and surveillance systems will be strengthened to improve nutrition of the poorer and vulnerable sections of the society. Nutrition of children and mother's welfare will be ensured. The target is to ensure the minimum daily intake of 2,122 k cal of food for all by the year 2021 .

Food Quality: The problem of major health hazards stems from unsafe drinking water and consuming unhygienic and low quality food. Definitive food standards would be established to serve as benchmark for evaluating and maintaining standards. Initiatives will be undertaken for reviewing all existing food safety laws and upgrading laboratories with clear assignment of responsibilities for different entities within public and private sectors. The government will examine the need for an authority for food (independently or integrate with existing drug administration) to take necessary follow-up action with the aim of removing threat to health of the citizens from substandard and/or adulterated food. By removing food deficit, nutrition needs of 85 percent of the population will be ensured by the year 2012.

Population Planning: Recognizing the significance of the population problem, the government will bring appropriate changes in the population policy to reflect recent realities and ensure effective delivery of population control and reproductive health services. The community clinics will be reopened to address the challenges in the population sector. Target-oriented population planning programmes will be strengthened to achieve the goals. All issues related to population control and family planning (FP) will be guided by the national population policy which will be updated. Contraceptives along with FP services will 
continue to be made widely available and further expanded to the poor and the marginalized population in both rural and urban areas and different regions and to meet the un-met need. Efforts are underway to popularize the slogan of having one child per couple. The existing FP programme will be expanded and strengthened involving both men and women, and will be popularized through an intensive motivational campaign under the Behaviour Change Communication (BCC) programme. Clinical, long acting and permanent methods will be emphasized wherever possible in order to increase contraceptive prevalence rate (CPR) and ensure further decline in total fertility rate (TFR).

Health Education and Promotion: A major strategy to ensure better health would be to promote public health through health education within MOHFW and channels outside it. The existing institutions of MOHFW will be strengthened for providing effective health messages. Coalition will be built with mass media for providing health education to the population on a continuing basis regarding methods of preventing communicable and noncommunicable diseases, caring practices for children, adolescents and the old aged, and creating awareness on nutrition and proper sanitation. Steps will also be taken to reach basic health and reproductive health information through school curricula and utilize NGOs and different religious centers to influence health behaviour of the people.

Control of Emerging Threats: Existing counselling and treatment services for mental health, drug abuse, avian flu, STD and HIV/AIDS, arsenic diseases, injuries, trauma sufferers, women and child victims of violence, road-railway-river accidents, etc., would be improved and introduced where not available. Attention will also be paid to provide health services for other emerging and changing patterns of threats such as, childhood disabilities and geriatric care. Ongoing emergency preparedness and response programme will be further strengthened to manage the disasters like flood, cyclone, tornado, Sidr etc. By 2021, minimum daily intake of 2,122 $\mathrm{k}$ cal of food, elimination of contagious diseases, and primary health care and sanitation for all will be ensured. Average longevity will be raised to 70 years, and efforts will be made for reducing child and maternal mortality.

Urban Health Services: The existing practice of providing urban primary health care (UPHC) services through contracted NGOs for the city corporations and selected municipalities under the LG Division will continue to be pursued. In addition, MOHFW will continue to provide Primary Health Care (PHC) services in urban areas not covered by the UPHC project. The establishment of an 'Urban Health Unit' in each Division would be considered. Similarly, it will also continue to provide secondary and tertiary level health care in urban areas and try to improve both coverage and quality in response to demand. A priority objective for improving urban health services will be to facilitate access and effective use of available essential services packages (ESP) delivery by urban poor and slum dwellers. The LG Division will also be strengthened for urban disease surveillance and monitoring including management information system (MIS), capacity development and quality assurance. Moreover, MOHFW will strengthen its policy directive and stewardship roles in providing effective urban health care services.

Primary Health Care: The current commitment of spending at least 60 per cent of the total budgetary allocation of the HNP sector at upazila level and below will continue to be pursued to improve the quality of PHC and make it accessible and acceptable to the people, especially the poor and vulnerable. The provision of ESP delivery will be strengthened and popularized. Functioning of the Upazila Health Complexes (UHCs), Union Health \& Family Welfare Centers (UHFWCs) and the Community Clinics (CCs) will be strengthened and further consolidated through providing adequate manpower, drugs and other medical aids. The Community Clinics will provide PHC services, maternal and child care, family planning services, nutrition and venereal disease related services to the rural people. There 
will be involvement of local government bodies and NGOs for greater participation of the community with a view to ensuring community driven PHC services.

Secondary and Tertiary Health Care: The services offered by secondary and tertiary hospitals will, depending on bed capacity, be standardized along with human resource needs and table of equipments (TOE) linked to the services. Appropriate manpower development and management structure will be developed for the existing hospitals. New branches of sub-specialization will be created in all medical college hospitals, so that patients do not need to rush to the capital city. Hospital autonomy will be introduced initially for the tertiary level specialized hospitals and gradually extended to medical college and district hospitals. Management Committees at hospitals will be strengthened for better monitoring and monitoring and vigilance team for hospitals will be further strengthened and its jurisdiction will be expanded. Government will establish new specialized hospitals under its private public partnership initiative. Death audit will be introduced for establishing accountability and quality of care.

Alternate Medical Care: Homeopathy, ayurvedic and unani are included in alternate medical care (AMC). Necessary actions will be taken for improvement of the standard of alternate medicine, increase the demand for quality care and thereby reduce unsound practices. Capacity building of the AMC providers and proper monitoring and evaluation of the AMC provided will be undertaken.

Affordable Health Care Services: Existing system of affordable health care services will be further expanded and consolidated ensuring proper safety net for the poor. Facilities providing health care outside the public sector (but receiving government fund) will ensure that at least 30 per cent of their all types of services are kept for free treatment for those who cannot pay. Necessary fund will be mobilized through user fees, government allotment, social organizations, private contributions, corporate social responsibility, community financing schemes, and social insurance. Fees for providing medical advice or diagnostic service will be reviewed and regulated as necessary. The government will also encourage establishment of network of evenly spread specialist and super-specialist services through private investment for patients who can pay.

Community Clinics: The government is committed to reactivate 10,723 community clinics (CCs) which were established during 1996-2001. The MOHFW will run at least 8,000 CCs under government management. The government plans to establish 18,000 CCs in phases to deliver maternal and child health care including family planning services and limited curative care.

Surveillance of Diseases: The existing disease surveillance system will be reviewed for its updating to incorporate NCDs along with CDs and keeping in view the international health regulation system. Disease information monitoring and management system will be strengthened not only to issue public alert and increase availability of adequate information concerning the incidence and prevalence of diseases at regional and national levels, but also to establish a network with the global disease information system. Maps of all major diseases, on the basis of their incidence and prevalence, will be constructed for each district.

Health Governance: Good governance in the health sector will be strengthened through skilled staff deployment, preventing malpractices, and creating a more customer friendly health service delivery system in the public facilities in partnership with all stakeholders. The stewardship capacity of public sector will be improved for monitoring quality of care and safety of patients in both public and private sectors. New initiatives in health governance include:

- Consolidation of public-private partnership in management of health services; 
- Citizens charter for health service delivery;

- Better regulation of the non-public health care providers;

- Better monitoring in medical colleges and specialized hospitals for ensuring management efficiency and establishing increased attention to patients;

- Decentralization of health administration; and

- Formulation of national health policy.

Sector Reforms: The ongoing health sector reforms will be carried out under the HNPSP. The on-going reform measures would be closely monitored and reviewed for their successful implementation. Efforts will be taken to re-establish functioning of the Bangladesh Medical and Dental Council (BMDC). Laws relating to the regulatory bodies will be reviewed and strengthened. Both administrative and financial authority, as far as possible, will be decentralized with a view to increasing accountability and establishing quality health care services at all levels. A system of collection, retention and utilization of user fees and local resources at all public health facilities (ensuring adequate safety net for the poor) will be established for which a set of guidelines will be developed.

Gender Equality in Health: Efforts will focus on (i) ensuring rights of women for a better physical and mental health at all stages of their life cycle, (ii) strengthening PHC for women with emphasis on reducing maternal and infant mortality, (iii) strengthening reproductive rights and reproductive health of women at all stages of population planning and implementation, (iv) preventing women from HIV/AIDS and sexually transmitted diseases (STD) through awareness raising, and (v) creating women-friendly facilities at all pubic health complexes.

Stewardship Role of the Public Sector: The government has been emphasizing wider involvement of the private sector including non-state institutions for enhancing effective health service delivery. To this end, the stewardship role of the MOHFW will be strengthened. The following are some of the important areas where effective regulatory mechanism of the government will be established.

I. MOHFW will gradually assume strategic stewardship and governance roles for policy management in the following and related areas.

- Setting up a coordinating system for synergistic, effective and efficient contribution from state and non-state including private sector and health related NGOs for extending and improving health services.

- Necessary steps will be taken for formulation, implementation, review and periodic updating of comprehensive health and population strategies.

II. MOHFW will strengthen its regulatory and supervisory roles.

- Regulatory bodies such as BMDC, State Medical Faculty (SMF), Bangladesh Nursing Council (BNC), and Bangladesh Pharmacy Council (BPC) will be made more effective and functional through revising their mandate, structure and capacity building for enforcement of standards.

- The existing structure and capacity of DGHS, Directorate of Family Planning (DFP) and Department of Drug Administration (DDA) will be reviewed and strengthened for increasing supervisory performance.

- Professional medical ethics and code of conduct will be established among the service providers through enforcement of regulatory framework in consultation with the professional associations. 
- The need for separate regulatory body for effective service delivery system for both the public and private sectors will be reviewed.

III. Public sector will increasingly focus on ensuring proper safety net for the poor, vulnerable and marginalized.

- Existing health delivery system in both public and private sectors will be further expanded and strengthened, ensuring proper safety net for the poor, vulnerable and marginalized.

- Alternative health delivery systems will be explored leading to an eventually self managed system with community participation in managing the facilities on pilot basis and then scaled-up, based on lessons learnt.

IV. Proper information generation, collection and effective management feeding into policy formulation and planning.

- Develop comprehensive plan including performance indicators for monitoring and evaluation of health interventions with sound demographic and socio-economic data including those on burden of disease, inequality and gender disparity.

- Formulation of an improved planning and budget through pilot introduction of local level planning.

Human Resources for Health: The comprehensive long-term HR strategy under preparation by MOHFW would address the issues of shortages, maldistribution of personnel, skill-mix imbalance, negative work environment and weak knowledge base. MOHFW would also address some medium term actions like recruitment and training of nurses and medical technicians.

Drug Issues: All drug related issues will be guided by the actions incorporated into the National Drug Policy (NDP) which will be updated with the objective of ensuring easy access to essential drugs at fair prices, promoting competition among the local pharmaceutical industries and supporting and strengthening the existing regulatory measures to ensure quality drugs. Moreover, increased attention will be given to 'rational use of drugs' by educating both prescribers and +users. For all these to be materialized, the Department of Drug Administration (DDA) will be strengthened, expanded and modernized. Updating list of essential drugs will be completed.

Water and Sanitation: Access to safe and adequate water and hygienic sanitation with its proper use is fundamental for health. The government is committed to providing universal access to pure drinking water by 2011 and sanitation by 2013. Access of water would be ensured in urban areas particularly to slums and water scarce areas like arsenic affected areas, saline areas, char-haor-coastal belt, CHT, and barind tract areas. Emphasis would be provided for stopping open defecation along with installation of sanitary toilets at home and all public places. Proper management of waste water and solid waste would be given priority attention.

Telemedicine and E-Health: The government will make health services especially specialist services accessible to all people irrespective of their geographical location at low cost through provision of telemedicine and e-health services related to consultation and labservices. E-health will also confer other benefits in the health sector. To achieve this goal, wireless internet connections will be provided to 800 points in the government health sector and mobile phones will be provided to upazilla health projects. 


\section{Chapter 4}

\section{Roadmap for Accelerated Poverty Reduction: Supporting Strategies}

The supporting strategies are needed for accelerating economic growth and ensuring its long-term sustainability and inclusiveness. These strategies are mostly crosscutting in nature. Five supporting strategies would be adopted to complement the strategic blocks:

Strategy I: Ensuring Participation, Social Inclusion and Empowerment

Strategy II: Promoting Good Governance

Strategy III: Ensuring Efficient Delivery of Utility Services

Strategy VI: Caring for Environment and Tackling Climate Change

Strategy V: Enhancing Productivity and Efficiency through Science and Technology

\section{1 Strategy I: Ensuring Participation, Social Inclusion and Empowerment}

The development framework of NSAPR II is centred on people which comprises of heterogeneous groups having different realities, obstacles, and opportunities. As such, the poverty reduction strategies need to take such differences into consideration. According to Article 27 of the Constitution, all citizens are equal before the law and are entitled to equal protection of the law. Article 28 states that the State shall not discriminate against any citizen on the grounds of religion, race, caste, sex, or region. With respect to women, Article 28 states that 'women shall have equal rights with men in all spheres of state and public life nothing shall prevent the State from making special provision in favour of women or for the advancement of any backward section of the population'.

\subsubsection{Women's Advancement and Rights}

Women frequently experience poverty differently, have different poverty reduction priorities and are affected differently by development interventions. In addressing gender based discrimination, NSAPR II follows a two-pronged approach. Firstly, gender is integrated into all thematic policy matrices covering sectoral interventions. Secondly, there is a specific matrix dealing with gender equality commitments entitled 'Women's Advancement and Rights'.

\section{Vision and Goals}

The vision for women's advancement and rights is to create a society where men and women will have equal opportunities and will enjoy all fundamental rights on an equal basis. To achieve this vision, the mission is to ensure women's advancement and rights in activities of all sectors of the economy.

The Bangladesh Government adopted the 'National Policy for Women's Advancement' (NPWA) 2008 that aims at eliminating all forms of discrimination against women by empowering them to become equal partners of development. The overall development goal for women's empowerment covers: (i) promoting and protecting women's rights; (ii) eradicating the persistent burden of poverty on women; (iii) eliminating discrimination against women; (iv) enhancing women's participation in mainstream economic activities; (v) creating opportunities for education and marketable skills training to enable them to participate and be competitive in all economic activities; (vi) incorporating women's needs and concerns in all sectoral plans and programmes; (vii) promoting an enabling environment at the work-place: setting up day care centres for the children of working mothers, career women hostels, safe accommodation for working women; (viii) providing safe custody for women and children victims of trafficking and desertion, and creating an enabling 
environment for their integration in the mainstream of society; (ix) ensuring women's empowerment in the field of politics and decision making; (x) taking action to acknowledge women's contribution in social and economic spheres; (xi) ensuring women's social security against all vulnerability and risks in the state, society and family; (xii) eliminating all forms of violation and exploitation against women; (xiii) developing women's capacity through health and nutrition care; (xiv) facilitating women's participation in all national and international bodies; (xv) strengthening the existing institutional capacity for coordination and monitoring of women's advancement; (xvi) taking action through advocacy and campaigns to depict positive images of women; (xvii) taking special measures for skills development of women workers engaged in the export-oriented sectors; (xviii) incorporating gender equality concerns in all trade-related negotiations and activities; and (xix) ensuring gender sensitive growth with regional balance; and $(\mathrm{xx})$ protecting women from the adverse effects of environmental degradation and climate change.

\section{Current Challenges}

Bangladesh has made measurable progress in women's advancement and rights in a number of areas including education, participation in labour force, health and nutrition, and participation in public services. In the area of women's advancement and rights, the government has made strong commitments and undertaken various initiatives to reduce the gap between men and women. However, on the path towards achieving the desired goals of gender equality and gender mainstreaming, some challenges remain.

Female Faces of Poverty: The female-headed households usually earn less income since poor women have low earning capacity and their wages are lower than male wages. Women are more susceptible to becoming poor when they lose the male earning member of the family because of abandonment, divorce, or death.

Women's Participation in Mainstream Economic Activities: Women's economic participation is low but increasing. However, there is still a large difference between female and male participation. Labour force participation rate of males is 86.8 percent against 29.2 percent for females.

Violence against Women (VAW) and Exploitation: Violence against women is pervasive. Physical and sexual assaults, including acid throwing, are common. In addition, trafficking is also reported. Poverty, dowry, early marriage, superstition, social attitude etc. are the major causes of violence against women.

Early Marriage: The negative consequences of early marriage are multiple, including loss of education, employment opportunities, decision-making power, and leading to early childbirth. The rates of maternal and infant mortality are high among adolescent mothers.

Gender Dimension of Vulnerabilities and Risks: As gender discrimination in a long social process, women face constraints that result in vulnerability and risks in all spheres and stages of women's lives (Table 4.1).

Coping Mechanism for Disaster and Climate Change: With higher incidence of droughts, floods, cyclones and other natural calamities due to looming threat of climate change, women are affected differently than men indicating the need to introduce gender sensitivity in coping mechanisms and strategies. 
Table 4.1: Women's Risks and Vulnerabilities

\begin{tabular}{|c|c|}
\hline $\begin{array}{l}\text { Life cycle } \\
\text { stage }\end{array}$ & Associated risks and vulnerabilities \\
\hline $\begin{array}{l}\text { Children } \\
\text { under } 12\end{array}$ & $\begin{array}{l}\text { Girl children face specific hazard of not attending school owing to income-earning or } \\
\text { domestic responsibilities } \\
\text { Indivisibility of work, which is done as part of normal household or agricultural } \\
\text { responsibilities. } \\
\text { Double burden of education and work (or care-giving in family) and therefore increased } \\
\text { vulnerabilities of low productivity and fewer opportunities }\end{array}$ \\
\hline Adolescents & $\begin{array}{l}\text { Girl children are particularly vulnerable to withdrawal from school } \\
\text { Double burden of education and work } \\
\text { Entry into high-risk employment categories, hazardous industries, prostitution }\end{array}$ \\
\hline Adults & Lack of access to financial institutions and asset building opportunities \\
\hline Unmarried & $\begin{array}{l}\text { Restricted access to the labour market owing to societal norms } \\
\text { Societal/family pressure for getting married }\end{array}$ \\
\hline Marriage & $\begin{array}{l}\text { Bearing the cost of dowry } \\
\text { Tortured by in-laws and husband }\end{array}$ \\
\hline $\begin{array}{l}\text { Parenthood } \\
\text { and career }\end{array}$ & $\begin{array}{l}\text { Bearing cost of childbearing and rearing } \\
\text { Loss of employment or job insecurity owing to pregnancy, child and elderly care } \\
\text { Social expenses of marriage, rituals }\end{array}$ \\
\hline Divorce & $\begin{array}{l}\text { Stigmatisation } \\
\text { Double burden of family and income generation }\end{array}$ \\
\hline Widowhood & $\begin{array}{l}\text { Loss of assets to late husband's family claims } \\
\text { Sexual harassment by in-laws, family members and others }\end{array}$ \\
\hline Old people & $\begin{array}{l}\text { Lack of income source and people who can look after them } \\
\text { No shelter, become a burden to the family } \\
\text { Abandoned by family members }\end{array}$ \\
\hline
\end{tabular}

Budget, Programme and Project Formulation: Currently 16 ministries spending 60 percent of the total national budget are under the medium term budgetary framework (MTBF) which requires them to answer questions on how their spending would affect women and poverty in the budget call circular (BC1) of the Ministry of Finance. Thus the capacity strengthening issues of engendering programmes and project formulation and answering BC1 have now come to the forefront.

Sex Disaggregated Data: Strengthening the capacity of the national statistical system and the ministries in generating and reporting data, especially sex disaggregated data, in understandable forms remains a challenge for which concerted actions would be needed. There will be dialogues among stakeholders for identifying when and what types of sex disaggregated data should be collected by the statistical system.

Governance: The main problem with gender governance is the implementation of the existing laws, rules and regulations and stated policies. In addition, reforms of some laws, rules and regulations, policies and the institutional mechanism are needed to make governance gender sensitive.

\section{Strategic Objectives}

In order to overcome the challenges, eleven strategic objectives would be adopted: (i) putting a policy and legal framework in place to facilitate achieving equal rights for women, (ii) ensuring women's full participation in mainstream economic activities, (iii) ensuring social protection for women against vulnerability and risk, (iv) enhancing women's political empowerment and participation in decision making, (v) eliminating all forms of violence and exploitation against women, (vi) strengthening institutions for ensuring gender mainstreaming, (vii) capacity building in making available sex disaggregated data, 
(viii) integrating gender concern in all national policies/programmes/projects, (ix) building women's capacity through health and nutrition services, $(\mathrm{x})$ building women's capacity through education and knowledge dissemination, and (xi) ensuring women's participation in international forums.

Policy and Legal Framework: Taking the constitution as the basis, the government's commitment to various international forums (CEDAW, Beijing Platform for Action etc.) would be taken into consideration in addressing women's advancement and rights issues

Productive Employment: To create more jobs, action would be taken to improve women's employment opportunities and wages outside the household and also ensure equal pay for equal work. An enabling environment would be created in the workplace by establishing day care centres. Provision would be made for life and disability insurance for workers, especially women workers. Steps would be taken to ensure secure jobs and decent working conditions for women in the formal and informal sectors.

Enabling Environment: Measures would be taken to develop advocacy for treating girl child and boy child equally and promote equal sharing of household and productive work. Necessary legal and administrative measures would be taken for ensuring a safe workplace, transportation facilities, and infrastructure like separate toilets, lunch rooms and lunchtime.

Social Protection: The existing programmes for social protection for disadvantaged women would be continued. Gender sensitive measures would be taken to protect women from economic vulnerability and risk due to natural disasters. The effect of the emerging problems of climate change on women would be assessed for designing coping strategies and mitigation measures. Banks and micro-credit providers would be encouraged to extend small and micro-credit to the poor and the vulnerable.

Political Empowerment and Participation: In this context, the main targets are to ensure participation of women in the National Parliament and the local political institutions, influence political decisions in favour of women, ensure direct election in the reserve seats in the National Parliament and ensure women's representation in the local bodies with authority and responsibility. Initiatives would be taken to make women politically more conscious, encourage women to participate in politics and to build leadership among women at all levels.

Violence Against Women: The major targets for elimination of VAW are to ensure reporting of all VAW incidence, reduce reported VAW at least by half, consolidate the "One-Stop Crisis Centre" in medical college hospitals at divisional levels to provide medical treatment, legal and psycho-social counselling to women and children victims of violence, and providing shelter facilities and making efforts for their reintegration and rehabilitation in society. The police, the administration and the judiciary will be sensitized to apply CEDAW with provisions in cases of VAW and women's rights.

Gender Mainstreaming: Laws, rules and regulations, institutional mechanisms, policies, projects and programmes which are not gender sensitive would be reformed. The intuitional mechanism for coordination and monitoring of gender equality issues would be strengthened.

Institutional Strengthening: The National Council for Women's Development (NCWD) would oversee women's advancement-related activities in NSAPR II through providing guidance and policy support. The Women's Development Implementation and Evaluation Committee, MoWCA, will regularly review, evaluate and co-ordinate women's development activities and assist NCWD by reporting on progress of implementation. The WID Focal 
Point Mechanism would be strengthened to play an effective role in leading the coordination and monitoring the implementation of women's advancement and rights in policies, projects and programmes.

Integration of Women's Advancement and Rights: For integration, capacity building of relevant government officials on gender responsive budgeting and planning will be undertaken. The poverty and gender impact assessment criteria and yardsticks will be adopted in line with NSAPR II policy agenda.

In order to improve women's general health, the planned targets are to: improve women's life expectancy from 66 in 2006 to 70 years by 2011, reduce women's morbidity rate by 27 percent by 2011, reduce women's mortality rate from 5.2 per thousand in 2006 to 4.5 per thousand in 2011, and reduce maternal mortality ratio from 3.37 per thousand live births in 2006 to 2.4 per thousand live births in 2011.

In the education sector, the targets are to have all girls complete a full course of primary schooling, and achieve gender balance in higher secondary and tertiary education. Steps will be taken to introduce special stipend programmes for women's education at the higher secondary and university levels in science and technical and vocational education.

Measures would be taken for ensuring participation of women producers, women trade unions and women entrepreneurs in trade negotiations and in various committees of the Ministry of Commerce, ensuring coherence between the dominant international economic agenda and the international legal obligations, making arrangements for market access to goods where women are 'behind the label', planning for market access to women in the secret services under Mode 4, encouraging FDI in women labour intensive industries, and ensuring women's voice in international forums.

Special programme for ethnic women including poor, destitute and elderly will be undertaken to address their needs. In order to increase productivity and diversification of activities, the ethnic women's capacity would be enhanced through health, education and services.

The media will be sensitized to promote positive images of women. In order to make the media more gender friendly, effort will be taken to establish increased linkages between women's groups and the broadcasting agencies.

Disability and Gender Issues: The issues of disability will be addressed in NSAPR II not only as humanitarian but also as a development issue. Measures will be taken for ensuring proper housing and accessibility to all physical facilities for them. In order to provide special support for women with severe disabilities, shelter homes will be built. Women with disabilities will be given preference under the safety net measures.

\subsubsection{Children's Advancement and Rights}

Bangladesh has made significant progress in the area of child rights' promotion, survival, and development. Nevertheless, the general situation of the children in Bangladesh needs to improve further since the survival and development of many Bangladeshi children is still threatened by malnutrition, disease, poverty, illiteracy, abuse, exploitation, and natural disaster. 


\section{The Vision}

The vision regarding children's advancement and rights is to create 'a world fit for children'. The goals to be achieved are: (i) ensuring children's rights and advancement through the implementation of government policies and legislations; (ii) providing health services the children need; (iii) ensuring access to food and nutrition they need; (iv) providing access to girls to education, training and development opportunities; (v) ensuring access to urban poor children to early childhood development, education, sports and cultural activities providing knowledge and life skill; (vi) protecting children from all forms of abuse, exploitation and violence; (vii) providing access to children particularly in urban and remote settings to clean water and sanitation, and a healthy environment; (viii) ensuring participation of children in defining their needs, developing programmes, implementing interventions, and evaluating their success; (ix) ensuring support of duty bearer, parents and other care givers on whom children have to depend; and (x) ensuring widespread public support for survival and development of children.

\section{Proposed Actions}

Intervention and actions for achieving the strategic objectives are indicated below:

Child Health and Nutrition: The programme areas include eradication of polio, elimination of measles and neonatal tetanus, improvement of nutrition and strengthening the school health programme. The actions will include maximizing the efficiency and costeffectiveness of health expenditure and improving governance. The specific activities will include sensitizing primary and secondary students about critical child health and reproductive health issues, healthy practices and worm infestation, and supplying iron and folic acid tablets for schoolgirls. Activities will be undertaken to develop an adolescent health strategy including counselling, building awareness for adolescents on hygienic practices, nutrition, puberty, RTI/STD and HIV/AIDS.

Food and Nutrition: To control vitamin A deficiency and contain the prevalence of night blindness, vitamin A supplements will be distributed to children with vitamin A deficiency, measles, persistent diarrhoea or severe malnutrition and to postpartum women within 6 weeks of delivery. Ongoing efforts to control iodine deficiency disorders through universal salt iodization will continue. To address the causes of anaemia, strategies will be used to control anaemia, including iron-foliate supplementation, anathematic treatment, fortification, and BCC to increase the consumption of iron-rich foods and promoters of iron absorption. A strategy will be developed to address the health care needs of children with physical and mental disabilities.

Child Education: The intervention for early childhood development will include an awareness raising programme for parents to make them aware of early childhood development's benefits, promote community-based childcare centres for clusters of families where literate mothers are trained to become caregivers and design facilities for early learners. Efforts will be made to increase enrolment rate and decrease dropout rate, train primary teachers, increase the attendance rate, increase contact hours, and maintain gender parity in access and achievement. Non-formal education (NFE) will be provided to diverse types of children deprived of education, like un-enrolled or drop-out children and hard to reach children to enhance their employability and productivity through skill training.

Effectiveness of primary schools will be ensured by increasing community involvement; creation of a child-friendly teaching/learning environment; promoting access, competence, relevance, efficiency and equity in education and also by developing a strong life skills 
component including mental, cultural and physical development. Quality of primary education will be achieved by improving the quality of learning materials and instructions, strengthening capacity of teachers; developing infrastructure facilities and including sports and cultural activities in the curriculum. Opportunities for vocational training will be created in secondary schools for improving their income-generating capacity. The curricula of Madrasha education will be reviewed to improve quality of learning and increase market relevance of Madrasha education.

Access to Water and Sanitation: The specific objectives are to: mitigate arsenic problem in drinking water by providing alternative systems, increase rural and urban slum access to sanitary latrines, expand water and sanitation services to cover currently underserved pourashava areas, provide improved water supply to underserved, un-served and difficult to reach areas by 2011 . The primary schools will be ensured access to sanitation and safe drinking water. Environmental hazards for children (sound, air, water pollution, etc) would be reduced and standards for sound, air and water pollution would be implemented.

Child Empowerment: Children would be empowered to have a voice in the socioeconomic decision-making process in the family, society and national levels. In this respect, it would be necessary to create a national platform for allowing children to express opinions on their needs and expectations and means of addressing them.

Child Protection: All children, particularly those who are vulnerable, would be ensured right to protection from abuse, exploitation and violence. The policies of existing NPA would be used against sexual abuse and exploitation of children and trafficking. Laws affecting children will be harmonized and enforced. Awareness amongst law enforcing officials and judicial officers and the development of a diversion scheme involving the courts, social workers and probation officers as an alternative to custodial sentences will be undertaken.

The Municipal Corporations and Pourashavas will be mobilized to register all births. Awareness raising programmes through union parishad members, and leaders of social opinion including Imams will be conducted to eliminate the practice of early marriage. A widespread social awareness campaign and community mobilization on protection issues will be undertaken to foster positive attitudes towards children, particularly girls, and bolster the positive attitude of parents and decision-makers on the need to protect children regardless of the socio-economic environment.

Effective measures will be taken to reduce child labour, and eliminate worst forms of child labour with a particular focus on child domestic workers, migrants, refugees and other vulnerable groups. In this context, a policy for children in the formal sector focusing on those caught up in the worst forms of child labour will be formulated. Street children will be assisted in accessing their rights and protecting them from all forms of abuse and exploitation. Working children such as waste collectors, leather workers, brick breakers, auto-workshop workers and tempo helpers will have access to learning opportunities in formal and non-formal facilities.

To recover and remove children from abusive and exploitative circumstances, the interventions will include developing community support for these children; providing livelihood alternatives, basic services and adoption, and implementing policies and legislation necessary for the prevention of abuse, discrimination, exploitation and violence. 
Steps will be taken to increase efficiency to combat sexual abuse, exploitation and trafficking of children through enhanced coordination and cooperation.

Management and Coordination: The Ministry of Women and Children Affairs will conduct public advocacy and coordinate interventions for children's well-being and rights. An inter-ministerial coordination committee consisting of government ministries with children's portfolios and organizations representing children's mandate will be chaired by the Secretary of the Ministry of Women and Children Affairs and will coordinate the implementation of CRC, CEDAW, and the World Fit for Children Plan of Action.

\subsubsection{Indigenous Communities}

Bangladesh has around forty-five different small ethnic communities i.e. indigenous communities-- and 2 million indigenous people. Some of the 'hardcore poor' of Bangladesh are found among the indigenous communities.

\section{The Vision}

For the indigenous people, the vision is to ensure their social, political and economic rights; ensure security and fundamental human rights; and preserve their social and cultural identity. They will be ensured access to education, health care, food and nutrition, employment and protection of rights to land and other resources.

The crucial provisions of the CHT accord of 1997 have mostly been implemented. A separate Ministry of CHT Affairs has been created, a Land Commission Act passed by the Parliament, withdrawal of army camps has been started and the Land Commission constituted to resolve land disputes in the three hill districts. The District and Sessions Courts have started functioning in the three districts of CHT. The government programmes have also incorporated the needs and concerns of the indigenous people. The unimplemented provisions of the peace accord would be considered for implementation by the government. The Land Commission will be reconstituted and land survey carried out.

\section{Areas of Future Action}

The challenges with respect to addressing social and economic conditions of indigenous communities cover: (i) living in remote areas and far away from each other making it difficult to reach, mobilize and organize them, (ii) partial operationalization of the 'Land Disputes Resolution Commission' to prevent land grabbing and displacement of indigenous people, (iii) lack of specific objectives concerning needs and concerns of indigenous people in mainstream policies of respective ministries/divisions, (iv) absence of an alphabet and dearth of students hindering development of curriculum in indigenous languages at schools, (v) low food production resulting in food insecurity, (vi) inadequate institutional mechanism to establish linkage and coordination with NGOs and the private sector to address issues related to indigenous people in a comprehensive manner, (vii) lack of comprehensive understanding of the problems of the indigenous communities, and (viii) absence of detailed information on indigenous population with ethnic disaggregation.

Major areas of interventions would include:

UN Declaration: The government would consider implementing the UN Declaration on the Rights of Indigenous Peoples 2007 and ratify the ILO Convention 1969.

Rights on Land: An appropriate land policy will be formulated which can deal with land disputes involving indigenous peoples. A secure land tenure system will be introduced in 
CHT. Representatives of the indigenous people will be included in undertaking development projects in areas inhabited by indigenous communities.

Empowering Indigenous Community: The government will ensure participation of local governments in the management of natural resources and will recognize the traditional knowledge of indigenous peoples. The government will ensure community involvement in the adoption of technologies without competing with their traditional food production system.

Human Development Programmes: Existing human development programmes will address the special needs of indigenous people. Monitoring and supervision will be strengthened so that education, health and maternal child health services, and nutrition and housing facilities reach the indigenous people.

Language and Children's Access to Education: A national language policy will be formulated to safeguard the languages of indigenous peoples. An action plan on mainstreaming the education of indigenous children will be implemented.

Electrification and Telecommunication: The national power grid and distribution system for electricity supply in different upazilas of hill districts will be expanded. The government will consider the feasibility of raising electricity generation capacity of the Kaptai Hydroelectric Power Station and setting up a grid substation in the hill districts to meet the demand for electricity

Safety Nets and Food Assistance Programmes: Assistance will be provided in hill districts to strengthen their capacities and increase employment opportunities to cope with any sudden decrease of their income due to damage to Jhum crops caused by floods and droughts.

Rural Development and Non-farm Economic Activities: In the hill districts, income generating activities through small and cottage industries, trading, and poultry and livestock rearing will be expanded. The income of poor people will be enhanced through social forestry in hilly areas and cultivation of fruits and medicinal plants. Measures will be taken to support EPB's 'one district one product' initiative under which 'Textiles for Rangamati', 'Pineapples for Khagrachari' and 'Rubber for Bandarban' have been finalized.

Expansion of Micro Credit: Micro credit activities for the poor people will be expanded and vocational training will be provided to the poor. The development of rural roads, hats, and bazars for marketing of agricultural products will continue. Action will be taken to eliminate barriers so that agriculture and local products have easy access to national and international markets.

Development of Tourism: Private investment will be encouraged to develop sustainable tourist facilities in Rangamati, Bandarban, and Khagrachari.

\subsubsection{Persons with Disabilities}

The government envisions promoting and protecting rights of persons with disabilities and facilitate their full participation and inclusion in mainstream social, political and cultural lives. They will be enabled to lead productive and meaningful lives through access to education, health care, food and nutrition, employment and protection, and security in society. 
The government is strongly committed to the advancement and rights of persons with disabilities by virtue of the Constitution which enshrines equal rights and status for every citizen and by signing the UN Convention on Rights of Persons with Disabilities and the Beijing Proclamation on the Full Participation and Equality with Disability in Asia and the Pacific Region.

A National Disability Action Plan has been formulated involving all related ministries. The Ministry of Social Welfare has taken up programmes for enabling and integrating persons with disabilities with mainstream of society through various programmes including stipend programmes for students, subsistence allowance, skill training, and interest free micro credit. In addition to its own initiatives, the government provides funds to NGOs to provide education facilities to persons with mental disability.

Despite some progress, access to special education, training and rehabilitation, equal opportunities, creation of employment and income generating opportunities, social security, accessibility to physical facilities, fixation of quota, and prevention of disabilities are not yet fully ensured since different ministries are not legally responsible for addressing disability issues in their action plans. Proper supervision and monitoring of NGO activities is essential.

\section{Proposed Actions}

Along with expansion of integrated education programme for visually impaired children, existing institutions for hearing impaired and mentally retarded children will be expanded. New institutions will be established to provide access to more children with disabilities at primary, secondary and tertiary levels.

A collaborative effort among the government, NGOs and the private sector will be encouraged to expedite the expansion of the existing institutions, establish new institutions, undertake teachers' training and action researches on disability.

Action will be taken in the health sector to (i) strengthen early detection of symptoms of disability and provide primary medical rehabilitation; (ii) undertake a nutrition programme for pregnant women; (iii) appoint trainee doctors, nurses and other caregivers to deal with disability issues; and (iv) introduce support services of assistive devices and equipment at the health centres.

Measures will be taken so that persons with disabilities can have access to all physical facilities and information and communication. Inclusion of persons with disabilities in various national and community level decision making processes that affect their lives would be ensured. Services like early detection and timely medical intervention, fitment of artificial aids and appliances, educational services in special and integrated schools, vocational rehabilitation and micro credit will be provided to persons with disabilities through community based rehabilitation (CBR) programme in the rural areas.

The Bangladesh Disability Welfare Act would be amended to clarify definitions of disability and make it consistent with standards set out internationally on disability rights. The National Coordination Committee for persons with disabilities would be strengthened to monitor and coordinate activities of different ministries/divisions.

\subsubsection{Disadvantaged and Extreme Poor Groups}

There are some disadvantaged and stigmatized groups (such as dhopa, muchi, napit, and other traditional low caste people) who are subject to social injustice and are marginalized, and have little opportunities for overcoming their harsh realities. The vision for these disadvantaged and extreme poor groups is to include them into the mainstream of society by ensuring their participation in socioeconomic activities and to promote and protect their 
human rights, reduce their persistent poverty, and ensure education and skill training for income generating activities.

Several actions are already in progress for the development of the disadvantaged groups. Among the coastal fishing communities various activities such as savings/credit schemes, promotion of alternative income generating schemes for men and women, improving access to social services and building their capacity to face and survive natural disasters have been introduced. Development activities for the sweeper community have been undertaken by NGOs. The owners of tea gardens have entered into agreement with the trade union of tea garden workers to enhance their wages and provide subsidized food. Similarly, communities like kaibarta/namasudra, jalo (fishermen), dhopas, napits and other groups face decaying occupations. The Ministry of Social Welfare has implemented capacity and livelihood development programme for socially disadvantaged women with a view to creating employment/self-employment of sex-workers and their children in selected cities

\section{Proposed Actions}

Coordination and Monitoring: The cooperation and involvement of local bodies i.e. Upazila and Union Parishads and NGOs will help to locate/ identify the disadvantaged people to enable them to participate in development activities. Government functionaries at upazila, district, divisional/national level will coordinate their activities.

Housing Facilities: The Ministry of Land would give priority to allotting khas land to people of the disadvantaged communities for settlement under the Asrayan project. For the tea garden workers, planters/owners would be encouraged to earmark land within the estates so that they can build their own dwellings.

\subsection{Strategy II: Promoting Good Governance}

Unless governance improves, poor people will continue to suffer from inadequate security, poor public services and lack of economic opportunities. A range of factors, including transparency, accountability, responsiveness, efficiency, organizational performance and technical capacity, have impact on good governance. Improving governance and reducing corruption are crucial to helping poor people escape poverty and achieving the MDGs.

\section{The Vision}

The vision is to ensure an effective parliamentary process, sound law and order, pro-people public services, improved legal and judicial system, strengthened local governance, and a corruption-free society with social justice.

A number of important steps have taken place in recent years to enhance transparency and accountability in all financial transactions. The government is trying to ensure transparency in the service delivery system of the state institutions. A number of crosscutting initiatives have also been taken:

(i) Streamlining and simplifying institutions (establishments, conventions and rules), eliminate administrative barriers, deregulate bureaucratic procedures, develop one-stop services, modernize administration through administrative and regulatory reform;

(ii) Providing support for legal drafting and advocacy for judicial sector reforms, improvement in court administration, investigation and prosecution, judicial ethics and legal clinics for victims of corruption; 
(iii) Increasing transparency and accountability in the budget and procurement processes, government auditing and customs and tax administration, e.g. Public Finance Reform initiatives are on board;

(iv) Improving the quality and predictability of public service delivery, expand citizens' participation in local government, promote open hearings, restructure permit and licensing procedures and ensure that local government is responsive to citizens' needs;

(v) Working with the business community to implement codes of conduct and undertake deregulation and legal/procedural reforms;

(vi) Reducing corruption in health, education, environment and energy sectors;

(vii) Building coalition with the media and civil society and the private sector to strengthen their role as watchdog and also undertake public awareness campaigns and advocacy programmes;

(viii) Prevention of money laundering, action against international corruption, promoting anti-corruption legislation, and enhancing accounting and auditing standards for ensuring private sector accountability through signing the UN Convention Against Corruption (UNCAC);

(ix) Introducing the 'Citizen Charter' by the ministries and agencies to ensure that their services reach the people;

(x) Opening BG Press website for uploading gazettes and laws for public use;

(xi) Amending the rules of business of the Secretariat to encourage the use of IT in administration through e-governance;

(xii) National ID card has been introduced as one of the basic identity for different public service delivery; and

(xiii) Birth registration has been initiated through municipalities, pourashava and union council.

The promotion of good governance requires attention to different issues connected to each other. The issues cover: (i) making parliamentary process effective; (ii) reforming and strengthening the public service system; (iii) reforming the legal and judicial system to ensure judicial help for the poor and women; (iv) changing roles of law enforcing agencies; (v) strengthening of local government; (vi) promoting e-governance; (vii) combating corruption; (viii) ensuring human rights; (ix) accessing information; (x) improving project implementation capacity; and (xi) improving sectoral governance.

\subsubsection{Making Parliamentary Process Effective}

The Parliament plays a key role in promoting accountability and good governance. The Parliament would hold the government accountable through legislative debates, articulating citizens' feedback and strengthening democratic institutions including the media. The ninth Parliament has already brought several changes in rules and procedures in order to make the Parliament more effective. The representation of opposition bench members in Standing Committees has been raised along with chairmanship in several important committees. The Parliamentary Committees has been formed in the first session of the Parliament with some chairs given to the opposition. However, continued absence of the opposition on the issue of having more seats in the front row and failure to ratify the party charter within six months weaken the democratic and parliamentary systems. The law has now been amended extending the time for ratification to one year.

\subsubsection{Strengthening Local Government}

Local governance initiatives currently underway in the country hold much promise for developing effective systems of public participation as well as accountability that will ensure that government servants are responsible to elected officials, and elected officials are in turn 
responsible to their constituency. The government is taking steps to strengthen local government so that it can respond to the needs of the people and bring services to the doorsteps of the people. Strengthening of local government and decentralisation of power imply delegating powers of the central government with the aim to address major issues like poverty reduction, good governance, infrastructure development and disaster management. Efficient and dedicated local government bodies can deliver services and generate social and economic awareness to achieve the national goals. In this respect, the following actions are contemplated:

(i) Capacity building of the local government bodies and providing adequate fiscal authority and incentives for mobilization of resources at the local level;

(ii) introducing a clear mandate of authority and responsibility including job description of women members of the local government institutions;

(iii) sensitizing the members of the local government institutes about poverty, gender balance and citizens' rights issues through leadership training;

(iv) introducing a system of reward and recognition for the members of the local government institutions for undertaking commendable work;

(v) creating a culture of developing partnership with local-level NGOs/CBOs and ensuring their accountability to the local people;

(vi) ensuring uniform application of rules and procedures;

(vii) gradually introducing ICT and e-governance at the local government level;

(viii) allowing flexibility and operational independence to local governments to suit the local needs;

(ix) ensuring full access to information on service delivery to the users;

(x) introducing a system of monitoring the performance of local government bodies and subject them to performance and financial auditing;

(xi) providing technical and consultancy support by nation building departments; and

(xii) introducing local-level planning and budgeting and ensuring budget implementation.

The upazila parishads would be gradually strengthened assigning more functions and responsibilities as they are able to act independently. The zila parishad system would be reviewed within 3-4 years to ensure a reformed and functional structure.

\subsubsection{Reforming and Strengthening Public Services}

In the case of public services, the goal is to raise the quality of public services delivered to citizens and enhance the capacity to carry out core government functions, which are essential for sustaining rapid development. The civil service must be able to attract high calibre entrants with high standard of integrity. The public service reform will be a defining priority, as governance cannot improve without a high-performing civil service. Several areas of intervention have been identified to bring efficiency, transparency and accountability in public service management:

(i) Improving the recruitment procedure.

(ii) Undertaking human resource development through training at the entry level and continuous on-the-job training and postings to ensure a match between competence and job requirements and improve public service delivery.

(iii) Defining civil service code of conduct to address issues of corruption and harassment.

(iv) Developing institutional mechanisms to eliminate, or at least reduce to the minimum, patronage, political pressure and nepotism. 
(v) Bringing procedural change so that civil servants would work with clear terms of reference, job description, delegated authority, simplified procedures and a clear line of accountability. Proper audit and public reporting on the public service will be undertaken which could make accountability of public servants effective.

(vi) Creating a healthy and enabling work environment taking into consideration increases in pay-scale, relating them to skill and responsibilities; streamlining non-financial benefits, introducing performance-based promotion, and punishment.

(vii) Strengthening and reforming the role of the Public Service Commission (PSC), which is vital for promoting excellence in public administration and governance. The quota system will be reviewed.

(viii) Strengthening parliamentary and public oversight needs, with public dissemination of audit findings and scrutiny by a Parliamentary Audit Committee.

\subsubsection{Reforming Legal and Judicial System}

The judicial system needs strengthening particularly with respect to the poor, women and other vulnerable groups. In the civil justice system, the case management processes have been excruciatingly slow, costly and time consuming, which restricts access to justice for the poor and the disadvantaged groups of society.

The government has implemented the Legal and Judicial Capacity Building Project to improve the quality and pace of the civil justice delivery system; reduce backlog; make the system more accessible to the users, particularly to the disadvantaged, women and children; and institutionalize the resolution of disputes out of court. Other key reform programmes include the alternative dispute resolution (ADR) mechanism, legal aid services and training programmes for the judges and court support staff. There has also been an attempt to bring the legal community including the judges and the people of the legal profession under the canopy of the National Legal Aid Organization having the responsibility of offering propoor services to the impoverished and the vulnerable people.

The judiciary has been separated from the executive with effect from 1 November 2007. All courts have been placed under the Supreme Court. The government has started construction of courts for the judicial magistrates. While most judicial functions and executive functions are clearly demarcated, there is a grey area of functions which requires legal training.

Suggested reforms for improving the judicial system are:

(i) Appointing a court Ombudsman, according to Article 77 of the Constitution.

(ii) Introducing a recruitment and selection system that ensures that competent judges are chosen in a transparent, independent, fair and inclusive manner. The Judicial Service Commission and its Secretariat will be equipped to monitor the performance of all judges and undertake evaluation on the basis of objective criteria.

(iii) Improving the work environment in the courts with proper office equipment and required support staff.

(iv) Establishing a separate pay commission to formulate a separate salary structure for officials of judicial services reflecting the nature of their job and consistent with public sector compensation policy.

(v) Introducing a system where judges have to reveal assets and properties belonging to them and their family members at the time of entry, during the tenure intermittently and after leaving the office. It is also important that such disclosures of assets are 
verified and monitored on a regular basis by some independent and authorized functionary and made available for public knowledge.

(vi) Streamlining administrative procedure of the court so that they are easily understood, and arbitrary decision making by court staff is minimised.

(vii) Introducing a computerized court case recording and tracking system and make the information accessible to people through the website.

(viii) The NGOs will work to facilitate access to the judicial system by the poor, women and vulnerable people and in building awareness among them.

(ix) Alternative dispute settlement mechanisms will be strengthened by regulating them by formal and traditional laws. Formal alternative dispute resolution mechanisms could be attached to courts or to government agencies, such as land and labour boards.

\subsubsection{Promoting E-governance}

Despite some successes during the last few years in the ICT sector, the adoption of ICT in all sectors has so far been minimal. Recently, a national broadband policy has been framed, bandwidth price has been reduced and arrangements for an alternative fibre optic connection between Dhaka and Cox's Bazaar have been made. Efforts are on to have a second submarine cable. The second submarine cable will act as an additional physical backup for its connectivity with the information superhighway. These will create an opportunity to extensively use e-governance. For the purpose, consideration would be given to several actions: (i) undertake a strategy to get information online; (ii) publicise policy issues online; (iii) create a user-friendly portal for allowing interactive transacts services; (iv) regularly update web pages for incorporating most recent information; (iv) compose a legal framework for e-governance requiring public notice and comment in legislative and regulatory processes; (v) set up office to monitor e-governance implementation in the government and update the e-governance policy; (vi) gradually introduce e-governance in local government bodies; and (vii) establish a nationwide third generation wireless broadband network to ensure high-speed down link packet access (HSDPA).

\subsubsection{Combating Corruption}

The government has heightened its focus on anti-corruption considering the beneficial impact of a corruption free administration on poverty reduction, development, and equity. In the short run, the government is focusing on enforcement and sanctions against corruption to directly address the culture of impunity and to build public trust in the ability of government institutions in reducing corruption. In the medium-term, the aim is to strengthen the core institutions of governance, including the Anti-Corruption Commission (ACC). At the same time, the government will initiate a sustained campaign to create public awareness and education in preventive measures, creating the right conditions for the public sector to enhance public service delivery. Eventually the policy will be managing development in a qualitatively better way and make governance compliant with the UN Convention against Corruption (UNCAC), which has been ratified by the government.

The government will carry out activities to enhance monitoring mechanisms to prevent wrongdoings and actively follow up to sanction the same. Anti-corruption institutions will be empowered with more investigative powers to detect and act on corrupt practices within the system as a whole. The Anti-Corruption Commission (ACC) has been made operational, independent and effective. The ACC will develop a strategic plan through a consultation process on how to address the challenges of combating corruption in the short, medium and long terms while restructuring rule of law and the constitutional obligations. 
The government will put in place some key reforms, such as introducing legislation and practices that will enhance the transparency of fiscal operations of the government. The Right to Information Act gives the citizens the right to obtain information from the government

\subsubsection{Ensuring Human Rights}

There are many laws and regulations, which specifically prohibit discrimination in any form. But due to lack of enforcement and oversight, the weaker sections of the society bear the brunt of the injustice. The state and its institutions are the guarantors of human rights for citizens and non-citizens. The role of the state remains central, both in undertaking reforms and ensuring compliance with protective legislation. Rights can be best protected through adequate legislation, independent judiciary, enactment and enforcement of individual safeguards and remedies, and the establishment of democratic institutions. The government has approved the National Human Rights Commission Ordinance 2007 and set up the National Human Rights Commission (NHRC).

\subsubsection{Accessing Information}

Access to information creates opportunities that generate resources and making information available to the poor people and people in remote areas is essential for poverty reduction. The NGOs and CBOs can play an important role in providing information on health, family planning, violence against women, child abuse, civic rights and responsibilities, various legal issues, market information, environment and other critical areas to the poor and women. Electronic media can deliver information in an effective manner. The government will consider employing a TV channel to disseminate information in an effective manner to a wide range of people on various issues which are particularly relevant to the poor and women. In this respect, ICT will serve as a powerful tool to give equal access to information to the poorest of the poor and women and thereby help to create sustainable human development.

The Right to Information Act 2009 has been passed and the Information Commission has been established. The government will take measures to adequately equip the mass media and provide training facilities to disseminate information at the grass roots level.

\subsubsection{Improving Project Implementation Capacity}

The government will take necessary steps to improve the capacity of project implementation. Following actions are being considered: (i) improving project quality; (ii) shifting from the existing project approach to a programme approach linked with national and/or sectoral development policies and strategies; (iii) delegating needed authority to project directors for accelerating ADP implementation; (iv) simplifying and further streamlining the procedure of aid disbursement; (v) timely procurement of goods and services; (vi) strengthening the capacity of the officials from ministry/division on procurement and implementation of projects; and (vii) introducing a management information system (MIS) for monitoring the implementation status every three months so that authorities can hold implementing agencies accountable.

\subsubsection{Improving Sectoral Governance}

At the sectoral level, poor governance is typically manifested in different forms of corruption. The design of sectoral level anti-corruption strategies would consider where risks are highest along the goods and service flow and how they might be minimized. The 
nature, degree, causes and implications of misgovernance and corruption for people would be analysed within each sector's perspective as these will vary across sectors.

\subsection{Strategy III: Ensuring Efficient Delivery of Public Services}

Bangladesh still needs to go a long way in delivering utilities to people and in meeting their demand efficiently, especially in terms of safe water supply and sanitation, effective mass transportation system, reasonable energy supply and widely diffused telecom facilities for the people. Poor infrastructural facilities are causing market rigidities, increasing cost, affecting labour mobility and hurting the poor most.

The government has initiated reforms in key areas like transport, energy and telecommunications, paving the way for private sector operations to make the delivery system more effective and efficient. In transport, the government has endorsed the National Land Transport Policy, Integrated Multimodal Transport Policy and National Shipping Policy. It has liberalized the domestic civil aviation market to allow private competition. In telecommunications, improved sector outcomes resulted from important initiatives by the BTRC and other sectoral reforms.

Strengthening the planning outfits of the Local Government Division and city corporations is needed to move ahead with reform initiatives for creating urban facilities to cater to the needs of a rapidly growing urban population. Some key principles would be followed to ensure the welfare of the service recipients such as (i) quality or standard of the services must be maintained; (ii) delivery of services have to be designed to reduce inequality; and (iii) the private sector would be encouraged to increase their involvement in service delivery, which will help to create a fiscal space by relieving pressure on the government budget and subsequent redirecting of government resources to social spending.

Scope of Public-Private Partnership: The government has put emphasis on publicprivate partnership (PPP) to ensure expeditious development of infrastructure and utility services by attracting local and foreign investment and improving the expertise and technology. Through a well-laid out policy mechanism, private initiative would be encouraged to promote quality service delivery in the area of essential economic infrastructure. The government is keen to encourage private investments in energy and power, roads, waterways, railways, ports, water and sanitation, telecommunications/ICT, housing and tourism.

The government will consider expanding the scope of PPP further in different areas, such as the private sector can work closely with state enterprises to improve the management of government assets such as idle land and other assets of railway stations, bus terminals and postal centres close to market places. The expansion of provisions of PPP in augmenting services of essential economic infrastructure will enhance the quality of services to the people and relieve some of the strain on the government budget.

Bangladesh has demonstrated significant success in augmenting private investment and fostering public-private partnership to render efficient delivery of utility services. The private sector has its presence in road and waterways to cater to the need of transportation of passengers and cargo. Power generation and petroleum exploration have been opened to private operation since the 1990s. Almost one-third of power generation comes from the IPPs. The PSC companies together supply one-third of gas to the national gas grid. The energy sector will be further liberalized for improving its service delivery to consumers. In the telecommunications sector, 12 PSTN and six mobile phone companies were given licenses for extending telephone connections. Private operators are encouraged to extend 
fibre optic lines across the country for the development of speedy internet facilities nationwide on BOO-BOT basis. The VOIP licensing is also under process for development of cheap internet telephony across the country. Certain functions of rail transportation are already privatized. Closed branch lines will be offered to the private sector for resumption of services in those sections. The government is considering allowing profit-operations of providers of water and sanitation services in pourashavas and urban slums.

Government-NGO Cooperation: The government-NGO cooperation is fruitful in areas where expectation of profit is not high to attract profit-making private operators. More importantly, government-NGO cooperation can improve efficiency in the management of service delivery of some essential utilities. The NGOs are involved in the delivery of several basic services such as education, health, water supply and sanitation. These experiences in the social sectors can be utilized to forge wider cooperation in other areas, such as providing water in pourashavas and slums, cleaning and waste disposal in cities, rural energy supply programmes, creation of service facilities in the urban cities, development of recreational facilities around urban river banks, and building shelter houses for the poor.

The NGO-PVO cooperation has been made successful in activities like cleaning city roads and disposal of waste under the Clean Dhaka initiative. Some NGOs are processing city wastes for making composts for farming. Several government organizations (REB, BPDB, LGED and IDCOL) and NGOs (Grameen Shakti) have been engaged in popularizing and prorating renewable energy projects/programmes in the rural areas. Cities and pourashavas can undertake joint venture with NGOs for development of urban service facilities like sanitary toilets, auditoriums and libraries. River banks adjacent to cities and towns could be leased out through open solicitation to NGOs and private operators for plantation and development of park and recreational facilities.

\subsubsection{Priorities in Urban/Rural Service Delivery}

In spite of improvement in utility services delivered by public and private sectors and NGOs, significant social inequality still exists which cuts across all key social targets. The rich-poor divide is striking, but more worrying is the gap between the poorest and the rest of society in terms of receiving utility services. This is more pronounced in discrepancy between utility services in rural and urban areas. This obviously calls for greater priority to development of utility services in rural areas through effective policy intervention, regulation and direction. With a view to reducing inequalities of access and opportunity, a balanced development strategy would be undertaken to improve utility services in rural and urban areas. The urban localities have some advantages because of their high population density which help reduce cost. But most of the people live in rural areas where the provision of utility services is inadequate and costly.

\subsubsection{Safety, Security and Protection of Life, Liberty and Wealth}

The main goal of providing services for the safety, security and protection of life, liberty and wealth is to create a safe habitable human environment ensuring peace and security for all. There remains widespread concern about law and order, access to justice and public safety at different levels of society. The Police Reform Programme (PRP) aims at improving the efficiency and effectiveness of Bangladesh Police by supporting key areas such as (a) access to justice including crime prevention, (b) investigation, police operation and prosecution, (c) human resource management and training, (d) strategic capacity and oversight, and (e) communication and action against trafficking of human beings. 
The Fire Service and Civil Defence Directorate is the major first responder in disasters like fire hazards, road accidents, shipwreck, drowning, collapsed structure, landslide etc. In order to increase fire safety, rescue and ambulance facilities across the country, fire stations will be set up in all pourasavas, upazilas and important industrial and commercial centres. Efforts will be made to raise a strong volunteer cadre comprising of local civil societies, NGOs, students, and educational institutions to supplement government initiatives.

\subsubsection{Safe Water and Sanitation}

The government intends to achieve the targets of safe water by 2011 and sanitation for all by 2010. Currently 97 percent of the population have access to pathogen free water. But arsenic contamination presents a new challenge which has reduced safe water availability to 80 percent in urban and 70 percent in rural areas. On the other hand, sanitation coverage is 84-97 percent in urban areas and 86 percent in rural areas.

Rural Water Supply: It is estimated that the total number of different types of tube wells in the country is about 7.0 million. The government and private initiatives account for most tube wells (some 96 percent) and NGOs played a supplementary role (4 percent). However, leaving out the arsenic contaminated and other non-functional ones, the number of usable tube wells is 5.7 million. There has not been much progress in mitigating the arsenic problem. Some hydro-geological factors (e.g. arsenic, salinity and low groundwater levels), and deep-rooted poverty prevent market forces from reaching all users. Preventative measures like water safety plans are needed in both rural and urban areas to deliver good quality water. Programmes will undertaken to encourage rain water harvest and identify low lying areas for making water reservoirs which can be used during the dry season.

Rural Sanitation: The government initiated a national sanitation campaign together with DPHE, LGED, local governments, the government's administrative units in upazilas and districts and the NGOs. Since the initiation of the coordinated community-led total sanitation (CLTS) approach in 2003, rural sanitation coverage has increased to nearly 86 percent (as of June 2007). If the current progress is maintained, the country is likely to reach its desired sanitation coverage to all by 2010 .

Urban Water Supply: The present urban water supply coverage is about 71 percent of which the coverage by piped water supply is 39 percent and the remaining 32 percent is by hand pump tube wells. The National Water Management Plan estimates that in the next 30 years the urban population will outnumber the rural population. The future urban water supply has to rely on the piped system as the presently used hand pump tube wells are suspected to be contaminated from leaching from pit latrines and septic tanks. Moreover they will no longer be appropriate for the densely populated areas.

Urban Sanitation: Conventional sewerage systems are absent in all urban areas except Dhaka city. Only 20 percent of the population of Dhaka city is served by a highly expensive sewerage network, the rest use septic tanks, pit latrines, unhygienic latrines or none at all. The sanitary conditions of urban slum dwellers are deplorable having no other option than drains, open fields, roadsides or riverbanks. Providing the urban households with sanitation by the conventional sewerage system is very expensive as compared with other off-site sanitation options such as modified sewerage and settled sewerage, which are particularly suitable for small to medium size townships. The option would be to go for multiple technologies adapted to local conditions and affordability. 
Solid Waste Management: At present daily waste generation in Dhaka city amounts to around $3,200 \mathrm{MT} /$ day which is expected to rise to $4,624 \mathrm{MT} /$ day by 2015 . The present solid waste collection rate is 44 percent.

For addressing the water, sanitation and waste management issues, the government's strategies and actions would focus on: (a) multi-agency involvement, (b) comprehensive monitoring and quality control of water sources throughout the country, (c) development of new water sources including use of surface water, (d) GO-NGO partnership particularly for waste disposal and water for slum dwellers, (e) development and replication of hygienic waste disposal, (f) promoting waste composting including where possible by NGOs/PVOs, and $(\mathrm{h})$ protecting rivers.

\subsubsection{Power and Energy}

The main goal is to ensure adequate and reliable power and energy supply at an affordable cost for development and livelihood. Despite its importance, only 43 percent of the population has access to electricity in the country, the coverage in the rural areas is much below the national average. Gas is the prime supplier of energy but its availability in the western zone is limited. Most importantly, the country is facing serious supply constraints in providing gas to power plants, fertilizer and other industries. The priority in energy and power would be given to (a) augmenting electricity generation, (b) providing un-interrupted power, (c) improving coverage, (d) addressing urban concerns, (e) ensuring power for agriculture, (f) improving customer service, and (f) augmenting the gas supply.

Policies and Strategies: A number of policies and strategies would be taken up to improve energy and power supply and ensure their service quality. The strategies for developing services in the fields of power and energy are (a) implement the ongoing three-year road map with a time-bound action plan to achieve electricity for all by 2020, (b) develop and improve the transmission and distribution network, (c) enforce a well-designed load management plan to maximize customer satisfaction by the optimal use of the existing supply, (d) consider developing service standards for power and gas and introducing service contract, (e) efficient usages of gas both in power generation and other uses including gas based industries, machine, tools and appliances, ( $\mathrm{f}$ ) consider introducing cooperative management of power supply in slums, (g) introduce a functional one-stop service in power and gas utilities, (h) expand the gas network to the western, north-western and south western zones, (i) develop renewable energy for un-served and remote areas through partnership with NGOs and PVOs, (j) improve billing and collection and minimise systems loss; (k) popularize and expand CNG use by promoting establishment of CNG pumps on highways adjacent to district towns depending on the gas grid, (l) promote R \& D in power and gas by strengthening the power cell, the hydro-carbon unit and the Bangladesh Petroleum Institute, and (m) make the Energy Regulatory Commission fully functional.

\subsubsection{Transportation}

The main goal of providing public support in the transport sector is to ensure a cost effective, affordable and efficient transportation system for all. Bangladesh has witnessed rapid expansion in the transport network resulting in rapid growth of transportation services. The commendable achievement in building an extensive rural network of roads had a significant impact on ensuring affordable transport services in the rural sector and improving the living conditions of the rural poor. However, problems arising out of congestion, inefficient management practices, cumbersome procedures, and labour union 
pressure need to be addressed to realize the full benefit of the road network and develop many of the vital utilities in the transport sector. The benefits of recent initiatives in the privatization of certain services and streamlining of procedures shall be evaluated with a view to considering their extension.

Policies and Strategies: The government would follow strategies and policies to promote an efficient, adequate, effective and reliable transportation system to facilitate movement of passengers and goods through all modes of transport without neglecting any to promote others. Free and fair competition would be ensured among competing modes for their healthy development. The role of the government will be to promote, regulate and provide facilities, particularly to those areas where the required services are not forthcoming. Strategies for the improvement of service delivery in the transport sector include (a) develop a comprehensive master plan for the transportation of passengers and goods by different modes of transports; (b) develop an efficient road network connecting major cities with secondary towns by the upgrade of roads; (c) develop viable public transportation in districts and cities connecting surrounding growth centres; (d) expand and intensify railway operations connecting ports and towns; (e) develop railway time-tables taking into account public requirement; (f) develop and maintain roads, railways and waterways on a routine basis; (g) promote commercialization of all public transportation; (h) build and strengthen public-private partnership in rail transportation; (i) expand affordable air links with other towns; (j) take regulatory and monitoring measures to reduce road accidents; $(\mathrm{k})$ make roads, railways and water transportation accessible and safe for women and persons with disabilities.

\subsubsection{ICT, Post and Telecommunication}

The main goal of the sector is to improve access to ICT, telecom and postal services. Bangladesh has a tele-density of nearly 32 percent. Till July 2008, there were about 1.3 million telephone connections and 44.8 million mobile phones under 12 PSTN and 6 mobile phone operators in the country. Fixed internet connectivity started in 1996 but its growth suffered because of high cost. With subsequent reduction of costs, the use of internet services grew faster. There are 72 ISPs and internet connections rose to around 450 thousand users by 2007 from a mere 1,000 in 2000. With the operation of BTRC and the liberalization of the sector, tele-density including mobile telephones has risen. Recent VOIP licensing will have further impetus for augmenting services in the sector. The postal department would be reorganized and reoriented to support the rural economy and act as a centre of information in rural Bangladesh to benefit farmers and small vendors.

\subsubsection{Development of Tourism}

The main goal of the tourism sector is to develop tourism for providing accessible, comfortable and safe tourism services to people, both local and foreign.

A well-conceived strategy for the development of tourism includes an integrated approach for the creation and development of tourist sites, a tourist attraction-centred infrastructure (transportation and accommodation) and a robust promotional campaign. Specific strategies are (i) upgrading the tourism policy, (ii) preparing a tourism master plan to identify focused areas, (iii) creating tourism facilities at important natural and historical sites including hill tracts districts, (iv) promoting private sector involvement in tourism in a coordinated way, (v) designing an incentive mechanism to promote and direct investment into desired tourism areas, especially those in the western region of the country, (vi) developing low-cost, affordable tourism in collaboration with local and foreign airlines, and (vii) developing a regulatory framework to protect tourist interests and to provide an enabling environment for the tourism industry. 


\subsection{Strategy IV: Caring for Environment and Tackling Climate Change}

The challenges to attaining environmental sustainability are in the forms of water and air pollution, land degradation, extreme degradation of terrestrial and aquatic ecosystems, unsustainable agricultural practices and unplanned urban growth. There is the further challenge of overcoming weak environmental governance. Climate change has compounded problems of environmental degradation and has led to serious deterioration of ecosystems, adding yet another dimension to poverty.

In this area, the vision is to achieve poverty-free environmental sustainability in Bangladesh, that is, to meet the needs of current and future generations by ensuring environmental friendly development to enable common peoples' access to public lands and resources and tackling pollution of various kinds that harms mainly the poor, particularly poor women and children.

The government has adopted the Bangladesh Climate Change Strategy and Action Plan 2009 which is built on six pillars: (i) food security, social protection and health; (ii) comprehensive disaster management; (iii) infrastructure to ensure that existing assets are well maintained and fit-for-purpose and that urgently needed infrastructure is put in place to deal with likely impacts of climate change; (iv) research and knowledge management; (v) mitigation and low carbon development; and (vi) capacity building and institutional strengthening. The Climate Change Action Plan comprises immediate, short, medium, and long term programmes with priority given to the needs of the poor and vulnerable, including women and children, in all activities implemented under the Action Plan.

Table 4.2: Targets and Achievements of NSAPR Policy Agenda

\begin{tabular}{|c|c|c|}
\hline Strategic Goal & Target & Achievement \\
\hline \multirow[t]{2}{*}{$\begin{array}{l}\text { Conservation of } \\
\text { bio-diversity of the } \\
\text { country }\end{array}$} & \multirow{2}{*}{$\begin{array}{l}\text { Community empowerment through } \\
\text { formation of groups, capacity building, } \\
\text { trainings, and, inter alia, creation of } \\
\text { alternative income generation activities } \\
\text { to reduce pressure on biodiversity } \\
\text { resources. }\end{array}$} & $\begin{array}{l}\text { Formation of ECA Coordination } \\
\text { Committees through Ministerial } \\
\text { Gazette notification }\end{array}$ \\
\hline & & $\begin{array}{l}\text { Management plan developed for } \\
\text { biodiversity resource management } \\
\text { and ensured access right of the poor } \\
\text { to the CPRs. }\end{array}$ \\
\hline \multirow{2}{*}{$\begin{array}{l}\text { Control of air } \\
\text { pollution in major } \\
\text { metropolitan cities } \\
\text { and rural settings }\end{array}$} & $\begin{array}{l}\text { Reduce air pollution impacted burden } \\
\text { of human diseases. }\end{array}$ & $\begin{array}{l}\text { Achievement made in } 2003 \text { after the } \\
\text { withdrawal of two-stroke baby taxi. }\end{array}$ \\
\hline & $\begin{array}{l}\text { Daily air pollution level to be informed } \\
\text { to the public. }\end{array}$ & $\begin{array}{l}\text { A data bank of air pollution has been } \\
\text { created. }\end{array}$ \\
\hline $\begin{array}{l}\text { Increase access of } \\
\text { the poor to CPRs. }\end{array}$ & $\begin{array}{l}\text { CPRs are to be managed and } \\
\text { conserved. }\end{array}$ & Process has been initiated. \\
\hline \multirow[t]{3}{*}{$\begin{array}{l}\text { Improve solid waste } \\
\text { management system }\end{array}$} & $\begin{array}{l}\text { Manage the medical and hazardous } \\
\text { waste. }\end{array}$ & nitiated. \\
\hline & Manage solid wastes properly. & $\begin{array}{l}\text { Involvement of NGOs and private } \\
\text { sectors in SWM. }\end{array}$ \\
\hline & Impose effective regulatory measures. & $\begin{array}{l}\text { Regulatory measures are in place } \\
\text { (reduce, reuse and recovery). }\end{array}$ \\
\hline \multirow[t]{3}{*}{$\begin{array}{l}\text { Control of } \\
\text { industrial pollution }\end{array}$} & $\begin{array}{l}\text { Bring all the amber-b and red } \\
\text { categories industries under ECA } 1997 \\
\text { rules }\end{array}$ & Initiative has been taken. \\
\hline & $\begin{array}{l}\text { Move tanneries and other polluting } \\
\text { industries to environmental } \\
\text { management sites immediately. }\end{array}$ & Process going on. \\
\hline & Strengthen regulatory measures. & Process has been initiated. \\
\hline
\end{tabular}




\subsubsection{Recent Progress}

Major achievements in the area of environment are summarized in Table 4.2. The following initiatives have either been implemented or are being implemented:

(i) National Environmental Management Action Plan (NEMAP): The National Environment Management Action Plan (NEMAP), developed in 1996, has prioritized 57 actions on the environmental front and the government is in the process of creating a second-order priority list for immediate implementation.

(ii) Sustainable Environment Management Programme (SEMP): The Sustainable Environment Management Programme (SEMP) consisted of 26 projects (components) executed by the Ministry of Environment and Forest (MoEF) and was implemented by 22 government/ non-government agencies. The 26 components fell into five categories: (a) policy and institutions; (b) participatory eco-system management; (c) community-based environmental sanitation; (d) advocacy and awareness; and (e) training and education. The SEMP was successful in mainstreaming environmental issues in the national policy discourse, and ensuring grassroots participation in policy making.

(iii) Bangladesh National Adaptation Programmes of Action (NAPA): The NAPA intends to identify the urgent and immediate needs of the country to adapt to present threats from climate change. Addressing these needs would expand the current coping range and enhance resilience in a way that would promote the capacity to adapt to current climate variability and extremes, and consequently to future climate change as well.

(iv) Bangladesh National Capacity Self-Assessment (NCSA) for Global Environmental Management: The overall goal of NCSA is to provide Bangladesh with the opportunity to identify priority capacity needs in order to effectively address crosscutting global environmental issues and the development of the corresponding strategy and action plan for capacity building in the environmental sector in the context of the three Conventions relevant for NCSA: the Convention on Biological Diversity; the United Nations Framework Convention for Climate Change and United Nations Conventions for Combating Desertification.

\subsubsection{Current Challenges to Environment}

With expanding population, the demand for food would increase while food production will be adversely affected by natural calamities. The linkage between poverty and conservation of natural resources is a mutually reinforcing process. For the purpose, it is important to address issues related to several interlinking factors, such as common property rights; crop, fisheries, forestry, and livestock sustainability; conservation of protected and ecologically critical areas (Table 4.3); ecosystem and biodiversity loss; land degradation and river erosion; coastal zone management; drought and floods; and ground water depletion. There are also issues like illegal and unauthorized hill cutting in greater Chittagong, especially in Rangamati, Bandarban and Khagrachhari. 
Table 4.3: Ecologically Critical Areas (ECAs) in Bangladesh

\begin{tabular}{|l|l|c|}
\hline \multicolumn{1}{|c|}{ Ecologically Critical Areas } & \multicolumn{1}{|c|}{ Districts } & \multicolumn{1}{c|}{ Total area in hectares } \\
\hline The Sundarbans & Bagerhat, Khulna, Satkhira & $\begin{array}{l}10 \mathrm{~km} \text { area surrounded the } \\
\text { Sundarbans reserved forest }\end{array}$ \\
\hline Cox's Bazar (Teknaf, Sea beach) & Cox's Bazar & 10,465 \\
\hline St. Martin Island & Cox's Bazar & 590 \\
\hline Sonadia Island & Cox's Bazar & 4,916 \\
\hline Hakaluki Haor & Maulavi Bazar & 18,383 \\
\hline Tanguar Haor & Sunamganj & 9,727 \\
\hline Marjat Baor & Jhinaidah & 200 \\
\hline Gulshan-Banani-Baridhara Lake & Dhaka & Gulshan-Baridhara Lake area \\
\hline $\begin{array}{l}\text { River ECAs (Buriganga, Turag, } \\
\text { Balu and Sitalakhya) }\end{array}$ & $\begin{array}{l}\text { Dhaka, Narayangonj and } \\
\text { Gazipur }\end{array}$ & $\begin{array}{l}\text { The rivers and the foreshore } \\
\text { areas of the rivers Buriganga, } \\
\text { Turag, Balu and Sitalakhya }\end{array}$ \\
\hline
\end{tabular}

\subsubsection{Types of Pollution-Institutional Arrangements}

Pollution has a strong negative impact on health, is a major cause of erosion of human productivity and even death, particularly among the poor and marginalized communities. Bangladesh faces environmental pollution such as water, air, soil, and noise, along with the contamination of food.

Air pollution: In dealing with air pollution, the strategy is to address both outdoor and indoor sources of pollution. The air pollution level has reduced especially in the cities because of the introduction of lead-free gasoline in Bangladesh. However, in recent times the emission of lead has increased due to suspended particulate matters (SPM) due to rise in vehicular traffic and increase in population density in the cities. The most vulnerable groups subjected to air pollution are the children and women of urban and rural areas, especially from indoor air pollution. Indoor air pollution is mainly caused by cooking fuels. Brickfields and recently developed shallow engine-based vehicles are important sources of air pollution in the rural areas.

Water pollution: Water pollution can be in terms of surface water and groundwater pollution. Flowing water is mainly polluted because of the disposal of untreated wastes into the river system from industries and also from cities, whereas the non-flowing water pollution is caused by excessive use of pesticides and soil erosion. The ship building industry contributes significantly to marine oil pollution, though in a few areas of concentration of the industry. The other sources of oil pollution are the ships and mechanized boats all over the country.

Noise pollution: The noise pollution level in the major urban centres exceeds the legal and safe standards. This is mainly an urban phenomenon caused by vehicular congestion and affects the poor who work outdoors. Another aspect of noise pollution is occupational exposure to industrial noise, which affects poor workers.

Soil pollution: Polluted soil builds up persistent toxic compounds, chemicals, salts, radioactive materials, or disease-causing agents in soils that have adverse effects on plant growth and animal health. Use of chemical fertilizers, herbicides and pesticides in agriculture and industrial effluents from tannery, textile, fertilizer, sugar, paper and pulp and other relevant industries are causing the problem. Also litter/leachate from solid wastes/landfill and salinity intrusion in coastal belts are the causes of soil pollution. 
Radioactive pollution: Industrial wastes, both solid and liquid, having radioactive elements and other toxic materials are dumped into the water bodies in and around the big cities. The radiation from medical X-rays, colour TV, luminous dials of clocks and watches, X-ray fluoroscopes also contribute to the risks

Solid Waste/Sludge Management: There is a lack of sufficient sanitary landfills for the disposal of all solid waste and the waste products from energy and bio-fertilizer plants. The disposal of hazardous and medical wastes in urban areas is a major cause of concern for urban life, particularly for the poor who are engaged in scavenging activities.

Urbanization: Unplanned high-rise buildings, inadequate drainage and sewage infrastructure, growth of slums, poor transport network, improperly planned land development, lack of urban land use control and unplanned industrial activities in residential areas, construction of roads without appropriate environmental mitigation measures and poor solid-waste management are the main factors responsible for unsustainable urban growth.

\section{Contamination}

Contamination causes both degradation of environment-based resources and adds to pollution. Some of the contamination issues are:

Sustainable Waste Management: Waste management is a major problem because these wastes are dumped in open sites. From the solid waste 'leachate' is produced and mixes with surface and ground water and poses a threat to the environment. In waste management, there are various stakeholders who are involved in waste-to-resource recovery systems without any health safety. In addition, hospital/medical waste is a serious threat to public health.

Bio-safety and Quarantine Management: Bangladesh has adopted bio-safety protocol to maintain the environmentally friendly genetically modified organisms (GMOs)/living modified organisms (LMOs) and safe application of modern biotechnology in medicine, agriculture, fisheries and livestock.

Exotic Aquatic Organisms: There are at least 32 fish species that have been introduced in the country. The impact of alien species on indigenous species has not been studied. Among the exotics, tilapia of two species, Oreochromis mosambicus and niloticus introduced in the 1950s and 1960s have caused concerns because these species have invaded all available habitats.

Exotic Plants and Trees: Many tree and plant species have invaded Bangladesh, and some are a threat to native varieties. Eupatorium odoratum (Ayapan) and Mikania cordata (Assam lata) are two invaders that overtop the canopy of shrubs and young tree saplings. Croton bonplandianum (Bon khira) and Lantana camara (Nak phul) grow along the edges of forest and wastelands and invade local vegetation.

Vector Epidemic: Various flue viruses have attacked Bangladesh over centuries. The recent attack of bird flu is not new but of a different dimension. There is a strong possibility of the virus mutating so that it can be transferred from bird to human and then human to human.

Environmental Governance: Bangladesh is committed to the cause of global environmental sustainability and has signed and ratified various international conventions, treaties and protocols (ICTPs). Such ICTPs include: United Nations Framework 
Convention on Climate Change (UNFCCC) and Kyoto Protocol, United Nations Convention on Biological Diversity (CBD) and Cartagena Protocol on Bio Safety, Montreal Protocol on Substances that Deplete the Ozone Layer, Basel Convention on the Control of Trans Boundary Movements of Hazardous Wastes and their Disposal, Stockholm Convention on POPs, and United Nations Convention to Combat Desertification (CCD). The Rules have been updated and, accordingly, responsibilities assigned to appropriate agencies and departments. The policies, plans, acts and rules supporting environmental activities are: The Environment Policy 1992 and Implementation Programme; The National Environment Management Action Plan (NEMAP) 1995; The Environment Conservation Act 1995 and its subsequent amendments; The Environment Conservation Rules 1997 and its subsequent amendments; The Environment Court Act 2000 and its subsequent amendments; Sustainable Environment Management Programme (SEMP); Bangladesh National Adaptation Programmes of Action (NAPA); Bangladesh National Capacity Self-Assessment (NCSA) for Global Environmental Management.

Institutional Arrangements: The MOEF is the focal point for several environment-related ICTPs. As the technical arm of the ministry on environment-related affairs, the Department of Environment (DOE) has been taking necessary steps toward ensuring compliance to these ICTPs. Some of the important tools used for environmental protection with emphasis on poverty reduction are the Environmental Impact Assessment (EIA)/Environmental Management Plan (EMP)/ Effluent Treatment Plant (ETP) to be applied to all policies, programmes and projects. The government's capacity for assessing professional impact and enforcement needs augmentation.

\section{Policies and Strategies}

The policies and strategies to be adopted cover four broad headings:

(i) Policy: Integrate principles of sustainable development in national and sectoral plans, policies and programmes and the regulatory framework.

- Ensure sustainable livelihood of the poor, especially women and disadvantaged groups. Develop the regulatory frameworks that recognize the user rights of people on CPRs.

- Establish user rights through licensing/leasing/participatory systems to CPRs in NRM of water bodies and forests.

- Finalize the Wetlands Policy, upgrade Forestry Sector Master Plan and Bangladesh Wild Life Amendment Act 1974 with provision for access of the local poor and women.

- Undertake new projects and programmes to preserve rights of the poor and women on CPRs

- Organize meetings with relevant ministries to resolve conflicts among those involved in shrimp, salt, paddy production, afforestation etc. in the coastal districts.

- Develop demonstration projects for sustainable resources management.

\section{Integration of environmental issues into policies and plans}

- Continue dialogue among and between the sectoral ministries/agencies on integration of environmental issues.

- Arrange coordination meetings among and between the sectoral ministries/agencies/ departments/organizations.

- Undertake local, regional and national training workshops. 
- Establish a policy support unit within MoEF.

Improve living environment in the slums

- Set up a strategy for a participatory slum improvement centre in all municipality and urban areas.

- Extend the solid waste collection service, water points and sanitary latrines in slums.

- Continue the awareness programmes in slum areas for water supply and sanitation facilities.

- Recover the slum areas that are illegal encroachment on wetlands, riverbank/river, canals, etc by land-grabber/encroacher and establish the natural flow of water/drainage system.

(ii) Planning: Ensure good governance in environment and natural resources management.

- Improve technical and managerial compliance by improving professional competence.

- Develop a well-defined organogram.

- Develop accountability and transparency in all sectoral issues.

- Develop a participatory and co-management approach in all CPRs.

- Develop networking with different stakeholders.

Strengthen the process of environmental analysis such as EIA in project design and implementation.

- Recruit professional staff in DoE.

- Continue awareness programmes among scientific, technical and managerial personnel

- Expand the DoE activities focusing on environmentally hazardous areas.

- Develop a website for environmental clearance certificate (ECC) and EMP procedures.

- Establish public consultation process in all EIA, EMP, ETP and other relevant activities.

\section{Sustainable land management}

- Continue the community-based earth excavation work under the food-for-work programme for more integration of poor people.

- Increase the extension activities to produce improved seeds of local plant species.

- Establish monitoring and evaluation systems with the help of concerned authorities.

(iii) Regulations: Enforcement and regulation of pollution, contamination and invasion of harmful organisms.

\section{Control of industrial pollution}

- Continue to enforce all environmental policies, rules and regulations with the polluting industries.

- Introduce mandatory environment friendly solid and other waste management systems.

- Develop sector specific EIA guidelines.

- Amend Environment Conservation Rules 1997 providing for public participation in EIA wherever possible and necessary.

- Enforce Common Effluent Treatment Plant (CETP) in all private sector-run industrial parks.

- Develop the Environmental Management Programme in consultation with relevant environmental management experts (EMP and ETP experts). 
- Set up a strong networking system among all relevant industries to establish a database.

\section{Control of air pollution in major metropolitan cities and rural settings}

- Implement the procedures of Air Quality Standard (AQS) in the vehicles of urban centres and all polluting industries.

- Ensure the mandatory use of four-stroke engines in all cities of the country.

- Arrange campaigns for owners, drivers of vehicles and managers of polluting industries for utilizing clean energy.

- Establish vehicle inspection and maintenance programmes in all metropolitan cities.

- Identify industries including brick kilns which are responsible for air pollution and set a permissible limit for polluted air emissions.

- Continue tree plantation and development of green belt around industries.

- Develop an appropriate dust control system in each major city.

- Ensure adequate CNG stations to rise to 70 percent of total vehicular fuel stations, as well as conversion facilities consistent with availability of gas.

- Establish refinery stations for lead and sulphur free vehicular fuel oil.

- Establish the compulsory annual tests of vehicle emission levels.

- Set up pollution emission tax.

- Introduce energy efficient cooking stoves in rural areas.

\section{Control of radioactive pollution}

- Develop and implement a search committee for the assessment of existing radioactive pollution. Develop a monitoring and evaluation system in the major metropolitan cities.

- Develop guidelines of the training programmes for the safe use of radioactive matters at least once a year in major metropolitan cities.

\section{Control of noise pollution}

- Complete all procedures to implement the Noise Level Standard (NLS) in metropolitan cities, vehicles and industries.

- Continue awareness and motivational activities through campaign and training programmes for maintaining the NLS for vehicles and industries.

- Ban the use of hydraulic horns in all types of vehicles and apply full restrictions on the use of horns in some selected areas like those around academic and religious institutions and completely ban the use of horns in residential areas.

- Develop a nationalized noise inventory and database along with a strong networking system.

- Consider fiscal measures to discourage use of machines that pose health risk.

\section{Improvement of solid waste management system}

- Develop and implement awareness and motivational programmes in each urban and semi-urban area for efficient and effective solid waste collection, resource recovery and recycling along with safe disposal of solid waste through CBO-based participatory comanagement system approach.

- Develop pilot project for integrated waste-to-energy, biogas and bio-fertilizer production system in major metropolitan cities.

- Develop regulations and guidelines for segregation at source and safe disposal of hazardous wastes.

- Develop the public-private partnership for environmentally friendly SWM system in all metropolitan cities. 
- Complete the formulation of SWM master plan for all metropolitan and urban cities.

- Introduce a framework for building up capacity for handling trans boundary hazardous waste management under the Basel Convention.

- Develop a national database of SWM system along with a strong networking set-up among all relevant organizations with coordination of relevant information.

\section{Control of water pollution and contamination}

- Reduce the use of chemical fertilizer and pesticide along with the phase-out of persistent organic pollutants (POPs).

- Introduce less water polluting substances and improvement technologies in industrial processes.

- Establish monitoring and evaluation activities by concerned authorities and organizations to reduce effluent discharges (e.g. discharges from mechanized vessels) and strict implementation of ECA 1997 along with other regulations in all water pollution and land degradation activities.

- Promote the use of organic compost.

- Set up polluter-to-pay approach to reclaim, clean up and rehabilitate the damaged ecosystem.

- Enforce the mandatory installation of effluent treatment plants for industries.

\section{Control of river erosion and hill cutting}

- Continue the community-based earth excavation work under the food-for-work programme for more integration of poor people in river-bed excavation programmes.

- Establish monitoring and evaluation systems with the help of concerned authorities.

(iv) Capacity Building: Enhance environmental education, awareness and motivational programmes

Enhance education and awareness activities for sustainable development

- Complete process for all regulatory procedures for enhancing professionalism in environmental management including new recruitment.

- Arrange environmental management training, seminar and symposium in districts.

- Advertise the environmental awareness and motivational activities through roadside posters and electronic and print media.

- Develop a national network of environmental management curriculum, modules and books.

\section{Improve research and development activities}

- Develop collaborative research programmes involving academic and research organizations and MoEF.

- Publish and distribute the research-based periodicals and journals on a regular basis.

- Organize training on research methodology on innovative poverty reduction tools on SWM and air quality development.

\subsubsection{Tackling Climate Change for Poverty Reduction}


Climate change and its variability have already impacted on the life and livelihoods of the people in the coastal areas and in the arid and semi-arid region of Bangladesh. Climate change will exacerbate many of the current problems and natural hazards the country faces. It is expected to result in increasingly frequent and severe tropical cyclones; heavier and more erratic rainfall resulting in higher river flows, river bank erosion, and increased sedimentation; rising sea level leading to submergence of low lying coastal areas and saline water intrusion up coastal rivers and into ground water aquifers; and other problems.

\section{Climate Change Impact on Bangladesh}

The coastline of Bangladesh is about $710 \mathrm{~km}$ long and the coastal zone covers about 23 percent of the country and is home to 30 million people. Such a low-lying country with a funnel-shaped coast exposing the land to cyclones, storm surges, seasonal flooding and drought, salinity intrusion, widespread poverty, a large population base and poor governance have made Bangladesh most vulnerable to climate change.

The anticipated climate change impact in Bangladesh will be manifested in two ways in contrasting regions, such as, (i) in the Southern part towards the sea there will be drainage congestion due to higher water and river-bed levels, salinization of the soil and water resources due to lower river flows, sea-level rise and more intense disasters including cyclones and storm surges with higher risks because of the higher water level; and (ii) the other part of the country in the North-Western region will be subject to scarcity of water leading to drought condition and aridity with less rainfall and higher temperature.

Bangladesh has adopted the Bangladesh Climate Change Strategy and Action Plan (BCCSAP) 2009 which will be the basis to combat climate change impacts. The Climate Change Action Plan is built on six pillars: (i) food security, social protection and health; (ii) comprehensive disaster management; (iii) infrastructure; (iv) research and knowledge management; (v) migration and low carbon development; and (vi) capacity building and institutional strengthening. The BCCAP 2009 is based on the four building blocks of the Bali Action Plan-adaptation to climate change, mitigation, technology transfer, and adequate and timely flow of funds for investment within an inviolate framework of food, energy, water, livelihoods and health security. The strategy is to integrate climate change constraints and opportunities into the overall plan and programmes involving all sectors and processes for economic and social development.

\section{Climate Change Trust Fund}

Over the last three decades, the Government has invested over \$ 10 billion to make the country more climate resilient and less vulnerable to natural disaster. Presently the Government of Bangladesh has established a National Climate Change Fund of 700 crore Taka with its own revenue. The principle of the operation of the fund shall be based to finance activities under the Bangladesh Climate Change Strategy and Action Plan 2009.

\section{Adapting to Climate Change to Reduce Poverty}

Agro-ecological zones have been delineated for select agro-climatic appropriate crops and soil conservation has been promoted for the enhancement of agricultural productivity. A GIS based national data bank has been created to assist in planning appropriate cropping patterns. Moreover, programmes of the Barind Multipurpose Development Authority (BMDA) on risk reduction in drought prone areas have commenced implementation, the National Watershed Development under the MACH programme and the Flood Action Plan has commenced, the gazetting of the forest Conservation Act, Wild Life Act, Protected Areas and other policies which lead to forest and biodiversity conservation and reduction of 
forest fragmentation have been implemented. Bangladesh has extensive experience in involving local communities in forest protection and regeneration as well as the creation of long-term interests in maintaining forestry resources through, for example, a Social Forestry Programme that promotes a unique benefit-sharing arrangement. Finally, the Coastal Islands (char) Development and Settlement Programme (CDSP) is under implementation.

\section{Strengthening Climate Adaptation}

Sectoral Measures relate to specific adaptation options existing for each of the sectors that could be affected by climate change.

- Mainstreaming adaptation to climate change into policies and programmes in different sectors (focusing on disaster management, water, agriculture, health and industry).

- Enhancing resilience of urban infrastructure and industries to impacts of climate change.

- Development of eco-specific adaptive knowledge (including indigenous knowledge) on adaptation to climate variability to enhance adaptive capacity for future climate change.

- Promoting adaptation to coastal crop agriculture to combat increased salinity.

- Adaptation to agriculture systems in areas prone to enhanced flash flooding in the North-Eastern and Central regions.

- Adaptation to fisheries in areas prone to enhanced flooding in the North-Eastern and Central regions through adaptive and diversified fish culture practices.

- Promoting adaptation to coastal fisheries through the culture of salt tolerant fish especially in the coastal areas of Bangladesh.

Multi-sectoral Measures relate in particular to the management of natural resources that span several sectors:

- Reduction of climate change hazards through coastal afforestation with community participation.

- Providing drinking water to coastal communities to combat enhanced salinity due to sea- level rise.

- Capacity building for integrating climate change in planning, designing of infrastructure, conflict management and land-water zoning for water management institutions.

- Construction of flood shelter, and information and assistance centres to cope with enhanced recurrent floods in major floodplains.

Coastal zone management is also considered as the appropriate framework to consider technical adaptation measures like dike building, beach nourishment, etc. The ecosystem approach to adaptation to climate change is a strategy for the integrated management of land, water and living resources that promote their conservation and sustainable use in an equitable way.

Cross-sectoral Measures apply to different sectors, such as:

- Education and training: introduction of climate change issues at different levels of the educational system is an ongoing process that will ensure a continuity of the process, the development of research activities, and greater awareness of the citizens. Training will address different stakeholders involved in the management of resources sensitive to climate change (soils, water, etc.) who will need to understand the nature of climate change as well as potential adaptation options.

- Public awareness campaigns: Raising awareness and information dissemination in order to have the stakeholders involved and concerned. These campaigns would also give the 
opportunity to understand what the perception and views of the public on climate change and adaptation are. Finally, user's networks would be established to ensure the follow-up and exchange of experiences between different stakeholders.

- Insurance development: An insurance system for coastal flooding and other natural disasters consequent on climate change would contribute to the involvement of the private sector in adaptation strategies.

- Changes in institutional, administrative and organizational arrangements would be necessary to enhance the effectiveness of political decisions. This would be preceded by an examination of the existing bodies in charge of climate change issues: national climate change committees, their degree of representativeness and their power and functions. Links between these committees and those, for example, in charge of sustainable development would be considered; and better coordination/integration of the different sectoral departments would be encouraged.

- Strengthening the legal system: Since many environmental problems are partly due to non-enforcement of existing laws, the legal system would be strengthened.

- Strengthening fiscal measures: The introduction of public policies to encourage and support adaptation of individuals and the private sector, particularly through the establishment of fiscal incentives or subsidies, would be used as an option.

- Risk/disaster management measures include the development of early warning systems, in particular for extreme events like cyclones, and for climate variability like droughts and floods. Emergency plans, extreme events relief and recovery measures also belong to this type of measures. The success of these measures depends upon good communication systems and a certain level of trust from users.

- Science, research and development $(\mathrm{R} \& \mathrm{D})$ and technological innovations are particularly needed for climate change processes in general, for economic valuation of adaptation options, for technological adaptation options (development of drought or salt-resistant crop varieties), or for investigations of new sources of groundwater resources and better resource management.

- Monitoring, observation and communication systems would be strengthened, created or improved, not only for climate-related parameters but also for other indicators of climate change and impacts. This monitoring would allow policymakers to adjust the adaptation strategy based on confirmed changes in the climate.

\subsubsection{Forestry}

Bangladesh is a densely populated country having 14.757 million hectares of land where forest area is 2.52 million hectares representing $17 \%$ surface area of the country. The forest is an integral part of our environment that maintains the ecological balance by controlling soil erosion, water and air quality. It also contributes to our national economy by providing timber, fuel wood, food like honey, wax, medicine, fodder, industrial raw materials etc. Poverty reduction through social forestry is now a success story within forestry sector of Bangladesh. About 0.335 million rural poor are now engaged as participants of the social forestry programme.This sector is contributing $4 \%$ of the nations's GDP. Under the social forestry programme about Tk. 1206.05 million so far distributed among 81402 participants as part of their benefit share. This programme is marked as a milestone in the national economy for poverty reduction in Bangladesh. 


\section{5 Strategy V: Enhancing Productivity and Efficiency through Science and Technology}

Bangladesh with insignificant natural resources, small land area, and large population, cannot accelerate its growth rate unless the benefits of technology in every conceivable area are harvested and productivity and efficiency are increased by using technology.

\subsubsection{Vision and Strategic Goals}

Bangladesh will be made a poverty-free prosperous digital country through the application of science and technology. The quality of life of the disadvantaged people will be improved through enhancing the quality of education and health care by the innovative application of ICT, enhancing productivity in the agricultural sector through the application of biotechnology and inspiring the creation of jobs through technological growth supported by more reliable availability of power through promotion and application of atomic energy.

To achieve the vision of a poverty-free prosperous Bangladesh, several strategic goals will be achieved:

a. Make quality education accessible to disadvantaged sections of the population by innovative application of ICT;

b. Create a stimulating environment for educational excellence by introducing Olympiads at all levels of education;

c. Use advanced data mining techniques to extract useful information from past public examinations and use this feedback to improve upon educational policies and create a healthy environment of competition conducive to achieving excellence;

d. Create opportunities in disadvantaged areas of the country for acquiring technical skill;

e. Create scope of employment through making ICT literacy available particularly to young men and women of disadvantaged areas;

f. Enhance quality of healthcare of the rural poor through the development of computerbased medical consultation systems;

g. Introduce and strengthen biotechnological research for increasing crop and drug production;

h. Increase electricity generation substantially by use of nuclear energy and inspire industrial growth;

i. Inspire increased transparency, reduced scope for corruption, more efficient governance and save illiterate and disadvantaged sections of the population from harassment by the application of e-governance;

j. Establish a centre of excellence in science and technological research that will formulate solutions to our technological problems and reduce dependence on foreign experts;

k. Improve tele-density to bring a greater proportion of the population into the streams of ICT activities;

1. Introduce community e-centres and other e-facilities;

m. Start vigorous research on devising structures that will be least affected by Sidr-like cyclones and tidal waves;

n. Reformulate import and export policies that encourage technological development in the country and generate jobs;

o. Keeping poverty reduction as the goal, reformulate science and technology policy in the light of recent developments in ICT and bio-technology; and

p. Establish Bangladesh as a BPO outsourcing destination. 


\subsubsection{Assessment of Recent Progress}

Several policies and actions have been taken to adapt science and technology for sustainable development:

a. National Policy on Science and Technology (S\&T) has been formulated.

b. National Policy on ICT has been adopted.

c. National Task Force on ICT has been formed.

d. Coordinating Committee for the implementation of World Summit on Information Society (WSIS) Declaration of Principles and Plan of Action has been formed.

e. Copyright Act has been amended.

f. Several measures, like exemption of VAT and taxes on ICT related equipment, tax holidays, creation of equity funds, ICT incubator centre, opening of shared office in the Silicon Valley, have been taken to inspire growth of the sector.

g. E-governance strategy is being formulated.

h. Measures have been taken to establish a High-Tech Park.

i. Actions have been taken to connect Bangladesh with the Information Superhighway through submarine fibre-optic cable.

j. ICT Business Promotion Council has been established to oversee the development of IT industries in Bangladesh.

k. Voice over Internet Protocol (VoIP) has been opened up to the private sector.

\subsubsection{Current Challenges}

Inadequate Educational Facilities: Bangladesh is yet to develop an education system that inspires creativity among young people. Lack of quality teachers and laboratory facilities hampers science education especially in rural schools. High rate of illiteracy is a major constraint on use of the education system to develop computer skills.

Shortage of Manpower: There exists acute shortage of skilled manpower required to propel the country through harvesting the benefits of science and technology.

Insufficient ICT Infrastructure: Communication infrastructure in the country is poor especially in the rural areas.

Lack of Job Opportunities: There do not exist enough job opportunities in science and technical areas. Unless considerable number of industrial enterprises are established, education in science and technology will not appear lucrative to the population.

Inadequate Research Initiatives/Financial Support in Science: The expenditure on $\mathrm{R} \& \mathrm{D}$ in Bangladesh does not constitute more than 0.3 percent of its GNP. The National Science and Technology Policy recommends that special efforts be given to ensure 1 percent of GNP for R\&D activities. Bangladesh is yet to build an institution for ICT education and research.

\subsubsection{Future Policies and Strategies}

In order to overcome the challenges, some immediate steps would be taken to build a strong base for education, health and technology including ICT and biotechnology. Sufficient trained manpower has also to be produced to maintain the scientific infrastructure and use it effectively so that people from all sectors can benefit from the application of science and 
technology. Scientists with proven track record and visionary approaches would be put at the helm to run science and technology institutes.

Strengthening Education through ICT: As the establishment of an adequate number of schools staffed with qualified teachers will take time, ICT would be used to provide quality education especially in the rural areas. The introduction of computer aided learning packages would not only reduce the gap between demand and supply of teachers but also allow rural young people acquire scientific knowledge and technical skill more efficiently, and contribute to nation building.

Computer Rooms in Educational Institution: The BCC has taken up plans to provide computers and establish ICT training centres especially in schools/colleges in remote areas. The process will continue especially in terms of establishing computer laboratories in educational institutes.

Computer Assisted Health Care System: An effective health care system especially for the rural poor needs to be ICT driven. The development of a computerized medical expert system would be complemented and strengthened with internet connectivity.

Expanding Internet Facilities: For effective application of ICT technologies, availability of internet connectivity to disadvantaged areas with higher incidence of poverty would be given priority especially for effective e-learning, e-health and e-governance.

\section{Biotechnology for National Development}

In order to give impetus to the development of modern biology and biotechnology, setting up of a separate Biotechnology Cell under the Ministry of Science, Communication and Information Technology would be considered. When established, this Cell will be responsible for up-scaling proven technologies and demonstrating the same at the field level. It will be instrumental in technology transfer to industries and maintaining close interactions.

Bioinformatics is an emerging and enabling technology for several fields of biomedical and agricultural research. The scientists of Bangladesh will be able to significantly contribute to the progress of this field since the capital investment needed for bioinformatics research is much smaller than for experimental biological sciences. The newly established National Institute of Biotechnology needs visionary leadership to play its due role. The cutting edge technologies such as bioinformatics, proteomics, computational chemistry and synthetic chemistry (for design and synthesis of new drugs) would be given priority. Efforts will be given to create crops of high yield and capable of withstanding drought, salinity and floods.

Promoting Science Education: To meet the demand for quality human resources, measures would be taken to popularize science and technical education by introducing stimulating events like science clubs, and creating science and technology based jobs and introducing science competitions.

Promoting SME and Indigenous Technology: The SMEs would be expanded through adopting appropriate technologies and encouraging productive indigenous technologies. Material research, testing and quality control for SME products will be institutionalized along with creating opportunities for experienced workers, formalizing their knowledge and enabling them to produce products of international standards. Technology Transfer Centres 
for SMEs and SME incubation centres would be introduced. The SME sector will also be enriched with ICT technologies to improve their quality and productivity.

Introducing Olympiads: Olympiads would be initiated throughout the country to challenge the merit and creativity of our students at all levels. The Bangladesh Computer Council may be given the responsibility of administering Olympiads for different classes and subjects, in particular science subjects, in close coordination with the Ministry of Education.

Technology for Community Housing in Coastal Areas: The development of appropriate technologies for community housing in coastal areas is a priority under which structures would be constructed that could be used for community purposes, like schooling in normal times and shelter homes at times of tornadoes or upsurge of sea water.

Effectiveness of ICT Usage: In order to harness the power of ICT and generate awareness among all concerned persons, a massive campaign in clearly comprehensible term would be undertaken in collaboration with the print and electronic media, both locally and nationally, in order to build momentum and support for telecommunication initiatives especially in rural areas and develop awareness and engagement of all stakeholders. 


\section{Chapter 5}

\section{Indicative Costs of Achieving Goals and Targets}

The revised NSAPR II (FY2009 - FY2011) provides the medium term operational strategy to achieve the goal of accelerated poverty reduction and the MDGs. It is also the stepping stone towards achieving the vision, as articulated by the government, of turning Bangladesh into a middle income country by 2021 characterized by drastically reduced poverty, high rate of growth, and fulfilment of basic needs by every citizen. The goals and targets in the thematic policy matrices are set out in a way that is consistent with the priorities adopted by the government in respective thematic areas. The prioritization reflects the collective efforts of the policy makers, thematic committees, and consultation with stakeholders including officials of various ministries and agencies.

The costing of goals and targets covers all thematic areas. The adjustment of NSAPR II, prepared during the caretaker government, to reflect the vision and commitments of the newly elected government necessitates new assessment of resources required to achieve the revised set of goals and targets. The development vision and commitment of the present government lay heavy emphasis on certain sectors and identifies specific strategies and policies to achieve the goals and targets within stipulated time. The estimated costs of the additional activities to be undertaken to achieve these goals and targets have been determined following the adopted methodology used in preparing NSAPR II earlier. Accordingly, the estimated total resource requirement includes the original estimated resource requirement plus the estimated additional resource requirement arising from the commitment of the present government.

\subsection{Methodology for Calculating Resource Needs for revised NSAPR-II}

In estimating the resource requirement for implementing revised NSAPR II, the cost of completing all the activities to achieve the desired goals and targets in each thematic area was taken into consideration. These costs are indicative and were identified in consultation with relevant stakeholders in the ministries and agencies. Due to the crosscutting nature of some thematic areas, there are some overlaps of goals and activities. For example, ICT is a stand alone issue in itself but at the same time various sectors or activities such as education, health, and governance also include ICT components. Thus the cost of enhancing efficiency through ICT does not give the full picture of the resource need in the ICT thematic area. Similarly, water resource management is addressed as a separate sector and is also included under "environment". However, efforts have been made to avoid these overlaps and double/multiple counting as far as possible. Efforts have also been made not to overestimate the implementation needs.

The estimated costs basically represent four components:

(i) costs of activities of ongoing projects and programmes that have spilled over from NSAPR I (FY2005-FY08);

(ii) costs of activities that have to be undertaken during the period of implementation of NSAPR II to achieve the goals and targets of thematic areas;

(iii) additional recurring costs over and above the normal increase of existing items that have to be incurred for running the activities to achieve the goals and targets of revised NSAPR II; and 
(iv) maintenance costs necessary for newly completed projects and programmes during the period of NSAPR II.

It is important to recognize that the cost estimates of activities and strategies of NSAPR II are incremental costs of projects and programmes over and above the existing budget allocations of the government, i.e. allocation to existing projects and programmes in the ADP and Revenue Budget. The activities to be undertaken to achieve the goals and targets of NSAPR II through ongoing and new projects and programmes are in the process of identification. The unit costs of these activities are already available with the concerned ministries and agencies. It may be mentioned that cost estimates of activities to be implemented through new projects and programmes are based on average unit costs of similar activities available in the ministries and agencies. All activities covered by themes and strategic goals have been brought under the umbrella of costing. By and large, the costs represent estimates of total input costs required for completing the activities within the strategic goals of a theme.

\section{Revision of Cost Estimates}

The additional costs of implementing the commitment of the present government have been determined at three stages: First, the commitment of the government which is target and outcome specific in terms of medium term and long term scenario has been identified. Second, the ministries and concerned agencies were requested to provide information on activities, projects and programmes needed to achieve the goals and targets during the NSAPR II period along with their estimated costs. Third, the concerned thematic committees arrived at the final estimates of costs for three years. The estimated costs of activities have been deflated to arrive at costs at base year prices of FY2008 and have been aggregated.

The estimated cost of achieving the strategic goals and targets set out in NSAPR II is Tk. 2814.81 billion (Table 5.1).

The resource requirement reflects the government's commitment to the people in addressing the priority issues to overcome the problems that the country faces including the present crisis of the global economy. The resource needs are quite large in certain areas such as education including ICT, infrastructure including energy and power, agriculture, governance including action against corruption, health, and social protection. 
Table 5.1: Indicative Cost of Achieving revised NSAPR II Goals and Targets

\begin{tabular}{|c|c|c|c|}
\hline $\begin{array}{l}\text { Sl. } \\
\text { No }\end{array}$ & $\begin{array}{l}\text { Thematic areas (strategic blocks and supporting } \\
\text { strategies) }\end{array}$ & $\begin{array}{l}\text { Cost (billion } \\
\text { Taka at FY08 } \\
\text { prices ) }\end{array}$ & $\begin{array}{l}\text { Percent of } \\
\text { total }\end{array}$ \\
\hline 1 & $\begin{array}{l}\text { Macroeconomic management for pro-poor } \\
\text { economic growth }\end{array}$ & 31.43 & 1.12 \\
\hline 2 & Resource mobilization & 29.75 & 1.06 \\
\hline 3 & Agricultural growth towards poverty reduction & 180.00 & 6.39 \\
\hline 4 & Water resources development and management & 42.49 & 1.51 \\
\hline 5 & $\begin{array}{l}\text { Small and medium enterprises (SMEs) } \\
\text { development }\end{array}$ & 14.04 & 0.50 \\
\hline 6 & Employment generation and labour welfare & 38.10 & 1.35 \\
\hline 7 & Private sector development (PSD) & 54.76 & 1.95 \\
\hline 8 & Land use policy and management & 3.78 & 0.13 \\
\hline 9 & Housing development & 80.81 & 2.87 \\
\hline 10 & $\begin{array}{l}\text { Infrastructure development including Power, } \\
\text { Energy and Communication }\end{array}$ & 536.66 & 19.07 \\
\hline \multirow[t]{6}{*}{11} & Social protection & & \\
\hline & Safety nets for poverty reduction & 140.00 & 4.97 \\
\hline & Food security & 110.00 & 3.91 \\
\hline & Disaster management & 9.19 & 0.33 \\
\hline & Scaling up Micro-Credit for poverty reduction & 50.00 & 1.78 \\
\hline & Rural non-farm activities & 10.20 & 0.36 \\
\hline 12 & Education, training and research & 582.30 & 20.69 \\
\hline 13 & Health nutrition and population planning & 207.94 & 7.39 \\
\hline \multirow[t]{4}{*}{14} & Social inclusion and empowerment & & \\
\hline & Women's advancement and rights & 35.55 & 1.26 \\
\hline & Children's advancement and rights & 0.46 & 0.02 \\
\hline & $\begin{array}{l}\text { Indigenous people, people with disability, and } \\
\text { other disadvantaged and extreme poor groups }\end{array}$ & 12.65 & 0.45 \\
\hline 15 & Promoting good governance and public services & 300.95 & 10.69 \\
\hline 16 & $\begin{array}{l}\text { Utility services delivery including water, } \\
\text { sanitation and urban services }\end{array}$ & 168.00 & 5.97 \\
\hline 17 & $\begin{array}{l}\text { Caring for environment and tackling climate } \\
\text { change }\end{array}$ & 125.03 & 4.44 \\
\hline \multirow[t]{2}{*}{18} & $\begin{array}{l}\text { Technology policy including ICT and } \\
\text { biotechnology }\end{array}$ & 50.72 & 1.80 \\
\hline & Total & 2814.81 & 100.00 \\
\hline
\end{tabular}

\subsection{Estimated Resource Gap}

The estimated total domestic resources gap is Tk. 874.84 billion or US $\$ 12.5$ billion (Table 5.2). The gap has been calculated using the following approach:

First, resource requirements for achieving different thematic goals through providing inputs and outputs and undertaking reforms envisaged in all thematic areas have been estimated. This amount comes out to be Tk. 2814.81 billion at FY08 prices. 
Secondly, non-discretionary expenditure is calculated by adding interest payment obligations (both domestic and foreign interest payments) of the public sector and national defence expenditure needs which amounted to Tk. 642.59 billion at FY08 prices. The total public expenditure in the NSAPR II period thus comes to Tk. 3457.40 billion.

Thirdly, the maximum amount of domestic resources that can be mobilised during the NSAPR II implementation period was identified. The total domestic resource comes both from revenue collection and domestic borrowing possibilities as indicated in the MediumTerm Macroeconomic Framework (MTMF). For FY09, FY10 and FY11 projected revenue and domestic borrowing were deflated to measure them in terms of FY08 prices. The total domestic resource that can be mobilised is in the amount of Tk. 2,582.56 billion at FY08 prices.

Table 5.2: Estimate of Domestic Resource Gap for NSAPR II (revised) Implementation

(Billion Taka at FY08 constant prices)

\begin{tabular}{|l|r|r|}
\hline & High Case & Base Case \\
\hline $\begin{array}{l}\text { A. Resource needs for NSAPR II } \\
\text { implementation }\end{array}$ & $\mathbf{2 8 1 4 . 8 1}$ & $\mathbf{2 8 1 4 . 8 1}$ \\
\hline B. Non-discretionary expenditure & 642.59 & 642.59 \\
\hline Interest payment & 425.59 & 425.59 \\
\hline Defence expenditure & 217.00 & 217.00 \\
\hline C. Total expenditure (A+B) & 3457.40 & 3457.40 \\
\hline D. Total domestic resources & 2582.56 & 2567.52 \\
\hline Total revenue & 2077.94 & 2045.84 \\
\hline Domestic borrowing & 504.62 & 521.68 \\
\hline E. Domestic resource gap (C-D) & 874.84 & 889.88 \\
\hline F. Domestic Resource gap (billion US\$) & $\mathbf{1 2 . 5 0}$ & $\mathbf{1 2 . 7 1}$ \\
\hline
\end{tabular}

Finally, the resource gap is identified as a difference between domestic resources available and the total expenditure during the period. This amount has to be mobilized from external sources.

In recent years Bangladesh could mobilize nearly US $\$ 2.0$ billion per year as ODA from the development partners. Therefore, of the total domestic resources gap of US $\$ 12.5$ billion nearly half would be mobilised from external sources as ODA and another half would be mobilised through innovative measures like Public-Private Partnership (PPP) and FDI (Foreign Direct Investment). 


\section{Chapter 6}

\section{Strengthening Implementation, and Monitoring and Evaluation}

Implementation arrangements of NSAPR II (revised) and its monitoring and evaluation system need to be clearly articulated to ensure effective implementation. This chapter provides an outline of the implementation arrangements, and the roles and responsibilities of different actors. It also provides an outline of the monitoring and evaluation mechanism and the roles and responsibilities of different agencies.

\subsection{Implementation Arrangements}

The major implementation responsibility of NSAPR II (revised) lies with the concerned lead ministries and their agencies as well as other associate ministries and their agencies. Ministries/Divisions who will be responsible for preparing their respective detailed prioritized action plans/road maps based on NSAPR II (revised) policy agenda for the implementation of the strategies to achieve sectoral and crosscutting targets for the FY 2009-11 period. The lead ministries will be responsible for supervision, coordination, implementation and monitoring activities envisaged in NSAPR II (revised) in their sectors and crosscutting issues. Other actors that will play an active role in the implementation include the private sector, civil society organizations (CSOs), NGOs, and different regulatory commissions. The development partners will play a supportive role in the implementation of NSAPR II (revised).

The National Steering Committee will provide general guidance and coordinate the implementation of NSAPR II (revised). The Programming Committee of the Planning Commission with recommendation of the concerned sector divisions of the Planning Commission will ensure selection of programmes/projects by the ministries, which are consistent with NSAPR II (revised). The GED/NPFP will check the consistency of the programmes/projects with NSAPR II (revised) in terms of criteria developed by GED/NPFP in consultation with concerned sector division of the Planning Commission and ministries. The Ministry of Finance will ensure that MTBF reflects the priorities in NSAPR II (revised) and the overall expenditure framework contributes to the achievement of the goals of NSAPR II (revised).

The private sector has an important role in achieving the poverty reduction outcomes by virtue of its central role as an engine of growth in the economy. While the private sector will be driven by its own compulsions, it will create employment opportunities and an avenue for using the savings of the people. The government will undertake measures to remove the factors hindering active private sector participation in the economy and facilitate socially responsible behaviour by the private sector.

The CSOs and NGOs will continue to play an important role independently as well as in partnership with the government in the implementation of NSAPR II (revised) through various programmes related to areas like micro-credit, literacy, health and sanitation, and empowerment. The development partners will use the agreed national systems and processes to provide adequate funding and other support in the implementation of NSAPR II (revised). They will also facilitate capacity building initiatives within the framework of NSAPR II (revised). In view of the slow progress in the implementation of the ADP in recent years, an important area will be capacity building in different phases of the project cycle. 
For successful implementation of NSAPR II (revised) the government will take the following measures: (i) awareness building and PRS orientation for the members of the Parliament, government officials of the line ministries/divisions, and departments/ directorates; (ii) communication between the National Poverty Focal Point and all line ministries/divisions emphasising that activities undertaken by the ministries/divisions have to be consistent with NSAPR II (revised); (iii) wide dissemination of the NSAPR II (revised) document to the officials of all ministries/divisions, and departments/directorates. The awareness building and skill acquisition will be provided through appropriate mechanisms like workshops and training programmes.

Joint Cooperation Strategy for Aid Effectiveness: The Government of Bangladesh (GoB) and fifteen donors signed a Statement of Intent to Develop a Joint Cooperation Strategy (JCS) in support of the national poverty strategy (Revised NSAPR II) in August 2008. The overall goal of a JCS is to make aid in Bangladesh more effective by creating common platforms for national and sector dialogues and a national owned change process for improving delivery of aid. Specifically it aims at:

- Reducing aid fragmentation and high transaction costs for all partners due to weak lead and coordination, including streamlining project approval processes;

- Improving national capacity for ownership of cooperation activities through improved human resource management;

- Strengthening donor alignment to national systems, which are felt by many partners to be lacking the necessary solidity to move towards more aid-effective modalities, such as budget support

- Improving accountability for development results and enhancing predictability of aid flows

- Agreeing on a common framework for expected development outcomes at national and sector levels for the coming years.

In order to make aided projects/programme effectively implemented, Bangladesh would take the lead to make real structural and behavioural changes on aid policies and implementation. The GoB led JCS Working Group has started various JCS related consultations and recently drafted a JCS outline and a detailed JCS Action Plan. There would be regular dialogues with development partners based on mutually agreed JCS with clear aid effectiveness outcomes in support of a prioritised and operational national poverty strategy.

\subsection{Monitoring and Evaluation}

Monitoring and evaluation is an important component of NSAPR II (revised) because it helps the government to measure the quantity, quality and targeting of the outputs (goods and services) that it aims to provide and to measure the outcomes and impacts resulting from these outputs. The mechanism allows the government to measure its performance and understand the causes of good or poor performance. Performance will be measured through a set of monitoring and evaluation indicators such as inputs, outputs, outcomes and impact indicators. Performance indicators serve multiple purposes:

- They are used for informed decision making, for re-setting priorities and revision of the targets, if necessary.

- Public knowledge of performance indicators helps improve transparency and accountability of the government.

- They provide a better understanding of the linkages between the processes of implementation of NSAPR II (revised) and the outcomes in terms of achievements of the poverty reduction target. 
- They facilitate checking the consistency of programme/project choices with NSAPR II (revised).

- Choice of a set of $\mathrm{M} \& \mathrm{E}$ indicators for poverty reduction leads to conceptual clarity and puts in place a data generation system which can help other related research and policy adoption.

- They provide a vehicle for monitoring the performance of the government by other stakeholders including the civil society who can put pressure to improve performance.

\subsubsection{Evolution of Monitoring and Evaluation}

The National Poverty Focal Point (NPFP) of GED took initiatives to monitor the first NSAPR implementation at two levels. First, the National Steering Committee constituted the Independent Monitoring Committee comprising civil society representatives to provide a balanced and impartial assessment of the progress towards targets and causes of lack of progress with appropriate guidance for performance improvement. Secondly, GED/NPFP initiated the institutionalization of the government monitoring system focusing on the formation of working groups at the ministry/division level for all the thematic areas and their common terms of reference. The Independent Monitoring Committee interacted with GED/NPFP whenever it was felt necessary.

The ministries/divisions formed working groups and initiated the monitoring process but the work did not proceed very far. Two obvious reasons for such an outcome have been identified: (i) lack of persuasion for information on the performance indicators by GED/NPFP, the working groups did not feel the urge to pursue the monitoring task. Lack of interest of the working groups in carrying out the task is derived to some extent from the lack of capacity of the planning wing/units in the thematic ministries in the form of lack of adequate institutional strength and skilled manpower. (ii) up-to-date data, which is at the heart of monitoring, was not available. The NSAPR contained a host of indicators with the expectation that the demand for data would lead to an appropriate response from the BBS in generating outcome and impact indicators. It was also expected that the research organisations including the private research bodies and NGOs would seize this opportunity of data generation with support from the donors. Institutional weakness and lack of funding inhibited the demand led process. Future attempts at monitoring will have to address these issues.

During the preparation of NSAPR II, the GED/NPFP collected information on the indicators from different ministries and the BBS to evaluate the progress of first NSAPR. Data gaps in terms of lack of data and up-to-date data were identified, which constrained thorough assessment of the implementation progress.

\subsubsection{Monitoring and Evaluation of NSAPR-II (revised)}

The process of monitoring and evaluation of NSAPR II (revised) will be a continuous one, involving a number of overlapping sets of activities. As mentioned in Section 6.1, working groups at the ministry/division level will be activated/formed shortly and they will prepare their action plans/road maps to implement the policy matrix relevant to them. Side by side with the action plan for implementation, they will also formulate an action plan for monitoring and evaluation based on the terms of reference provided by the GED/NPFP. Major steps of the monitoring and evaluation process will include the following:

- Development of conceptually sound and empirically feasible performance indicators; 
- Establishing benchmarks on indicators to facilitate evaluation of progress toward target achievement;

- Institutionalizing a flexible and effective monitoring strategy based on clarity of the monitoring tasks;

- Progress monitoring on the action agenda spelled out in the policy matrices;

- Data generation for target achievements: census, surveys, qualitative studies and participatory poverty assessments. BBS, relevant agencies, academic and research institutions will have the responsibility and opportunity to generate relevant data;

- Evaluation of the achievement of targets of poverty reduction and MDGs; and

- Dissemination of results and interaction with the civil society, business community, media and other groups.

The M \& E system for NSAPR II (revised) is shown in Figure 6.1.

\subsubsection{Data Generation for M \& E}

Data on M\&E indicators of revised NSAPR II (Annex-3) and attainment of MDGs will come from both government and non-government sources. Data on inputs and outputs will come primarily from concerned ministries/divisions. While some data on outcome/impact indicators may come from different ministries/divisions, the Bangladesh Bureau of Statistics (BBS) will be mainly responsible for generating data on these indicators.

The BBS is the major source of national sample surveys; it conducts HES/HIES, which is the major source of poverty statistics. There are also some MDG-related surveys, namely, DHS, VRS, and CLS. Data quality and the details of the definitions and methodology used in the major surveys conducted by the BBS should receive appropriate attention. There is a need for a review of all data sources that can be used for monitoring NSAPR II (revised) and MDGs. Need for special surveys and studies will have to be identified by the GED/NPFP, and BBS will need to align its data generation schedules with the requirements of GED/NPFP.

Figure 6.1: Monitoring and Evaluation System of NSAPR II (revised)

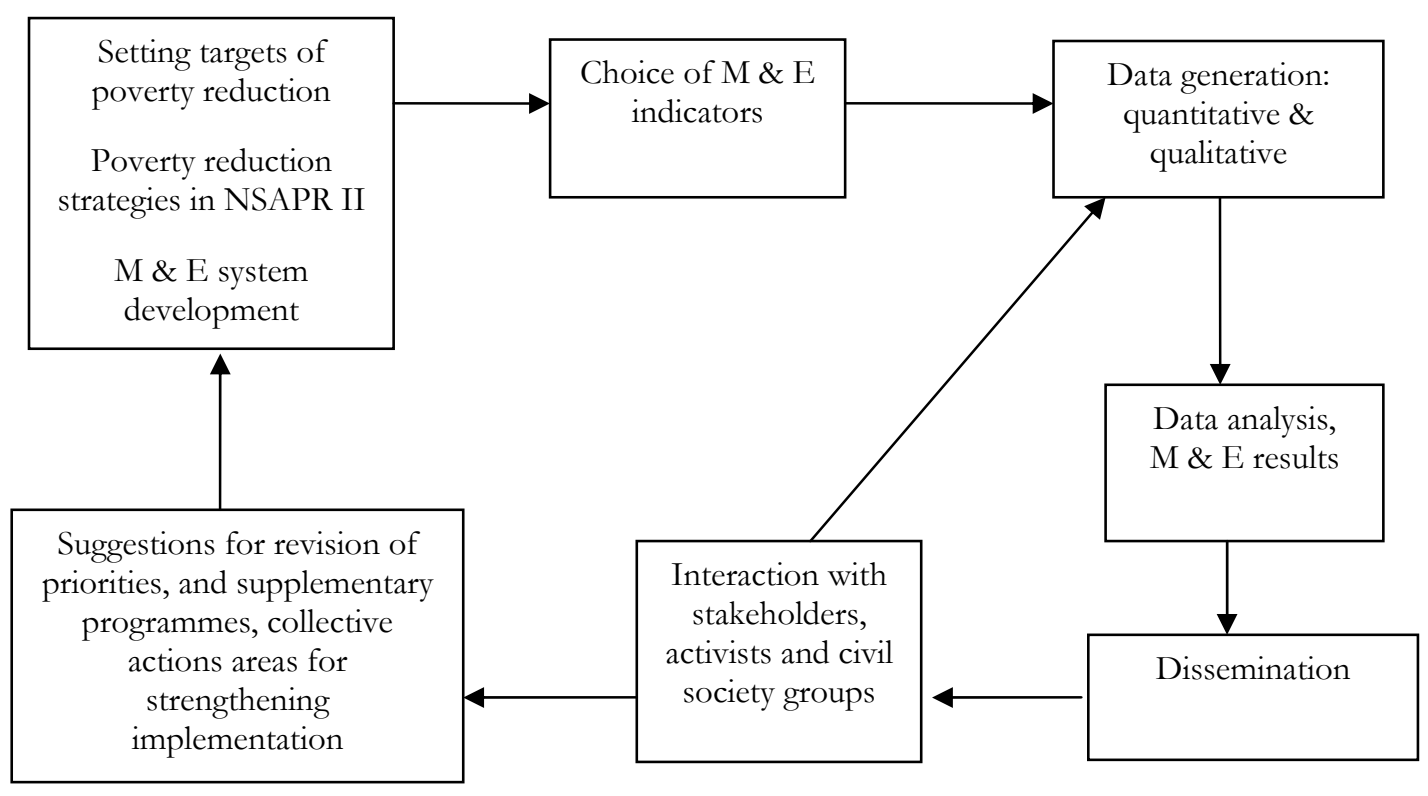


New rounds of surveys cannot be conducted simultaneously with HIES, because it will overburden BBS with consequent decline of quality. However, separate modules for NSAPR II (revised) and MDGs may be included in future HIES. In addition to the usual surveys, an effective monitoring system will require data from other appropriately designed special surveys. Some new surveys and specially designed evaluation studies may be conducted by research organizations like BIDS and other public and private research organizations.

Clear identification of indicators followed by streamlining of the mechanisms for generating reliable data is necessary, but not sufficient for poverty assessment and the monitoring of NSAPR II (revised) programme implementation. Proper utilization of such data and analysis of the linkages between policies, programmes and resulting outcome and impact are essential for understanding the poverty reduction process. To achieve this, capacity building within the appropriate government institutions is an urgent need.

\subsubsection{Institutional Strategy of M \& E System}

Monitoring implementation of NSAPR II (revised) and evaluation of actual poverty reduction will require a well-designed institutional mechanism. Such a mechanism has been outlined in Table 6.1. This includes, on the one hand, the primary role of the government, with the GED/NPFP having a central role, and, on the other hand, an independent and supplementary role for academic/research organizations and civil society groups. The GED/NPFP will have the primary responsibility for developing the detailed strategies for NSAPR II (revised) monitoring. Responsibilities will include:

a) collating official data on PRS monitoring,

b) coordinating monitoring efforts within and outside the government,

c) facilitating effective resolution of debates on indicators and methodologies and developing new indicators where necessary,

d) undertaking relevant research and studies in collaboration with independent academic/research institutions and civil society groups, and

e) facilitating feed back of outcome monitoring into policy making.

Working groups at the ministry/division level will undertake measures for generating performance indicators relevant to the group. Progress towards attainment of targets will be assessed and the report will be sent to the GED/NPFP for coordination at the national level.

Table 6.1: Institutional Process of revised NSAPR II Monitoring and Evaluation

\begin{tabular}{|l|l|}
\hline \multicolumn{1}{|c|}{ Task/Function } & \multicolumn{1}{|c|}{ Responsible entity } \\
\hline $\begin{array}{l}\text { 1. Review of progress of NSAPR II } \\
\text { (revised) implementation and } \\
\text { attainment of MDGs. }\end{array}$ & $\begin{array}{l}\text { The National Steering Committee (NSC) on Poverty } \\
\text { Reduction Strategy (PRS) }\end{array}$ \\
\hline $\begin{array}{l}\text { 2. Preparation of document on } \\
\text { NSAPR II (revised) implementation } \\
\text { and attainment of MDGs. }\end{array}$ & $\begin{array}{l}\text { The National Poverty Focal Point (NPFP), General } \\
\text { Economics Division (GED), Planning Commission }\end{array}$ \\
\hline $\begin{array}{l}\text { 3. Monitoring consistency of } \\
\text { programmes and projects with } \\
\text { NSAPR II (revised). }\end{array}$ & $\begin{array}{l}\text { A Technical Committee headed by the Member, } \\
\text { Programming Division, Planning Commission and } \\
\text { comprising all other members of the Planning } \\
\text { Commission, secretaries of Finance Division, ERD, } \\
\text { Planning Division, IMED and technical experts selected } \\
\text { by the government }\end{array}$ \\
\hline $\begin{array}{l}\text { 4. Annual evaluation of poverty } \\
\text { reduction and causal factors, special } \\
\text { studies on poverty and MDGs and } \\
\text { public dialogue }\end{array}$ & $\begin{array}{l}\text { GED/NPFP, independent academic/research } \\
\text { institutions/ civil society/private sector organizations. }\end{array}$ \\
\hline
\end{tabular}




\subsubsection{M \& E Indicators}

A list of indicators for M\&E of revised NSAPR II and attainment of MDGs has been appended at Annex 3. The list is suggestive and will be refined by the working groups in consultation with NPFP/GED in the actual process of monitoring. Information on all indicators may not be available at the desired level of disaggregation. On certain dimensions of poverty reduction policies, indicators may be drawn from a number of sources. Therefore, some degree of overlap in the characteristics of indicators may be inevitable. This is especially true for 'pro-poor growth' strategies, 'women's advancement and rights' and 'children's advancement and rights'.

\subsubsection{Capacity Building for $M \& E$}

Capacity building is necessary at all levels and in all institutions involved in the monitoring and evaluation task. The highlights of capacity building are:

- Capacity of BBS will be strengthened to enable it to conduct surveys, census and special surveys to produce quality data. The timing of these activities will match that of monitoring and evaluation of NSAPR II (revised) as well as preparation of future NSAPR;

- Suitable capacity-building of GED/NPFP will be achieved to enable it to guide the working groups and coordinate their activities and carry out the analytical work;

- The planning wings/units in the ministries/divisions will be strengthened with adequate manpower having appropriate skills; and

- A general awareness of preparation and monitoring and evaluation of NSAPR II (revised) will be created among the public officials through workshops and training programmes. 
Policy Matrices

\begin{tabular}{|l|l|c|}
\hline Sl. No. & & Page \\
\hline Policy Matrix 1 & Macroeconomic Environment for Pro-poor Growth & 108 \\
\hline Policy Matrix 2 & Resource Mobilisation & 115 \\
\hline Policy Matrix 3 & Agricultural Growth for Poverty Reduction & 116 \\
\hline Policy Matrix 4 & Water Resources Development and Management & 124 \\
\hline Policy Matrix 5 & Small and Medium Enterprise (SME) Development & 128 \\
\hline Policy Matrix 6 & Promoting Decent Employment & 133 \\
\hline Policy Matrix 7 & Private Sector Development (PSD) & 143 \\
\hline Policy Matrix 8 & Land Use Policy and Management & 151 \\
\hline Policy Matrix 9 & Housing Development & 153 \\
\hline Policy Matrix 10 & Infrastructure Development including Power, Energy and Communications & 155 \\
\hline Policy Matrix 11 & Social Safety Net, Food Security, Disaster Management, Micro-credit and Rural Non- & 166 \\
& farm Activities & \\
\hline Policy Matrix 12 & Improving Knowledge Base: Education, Training, and Research & 173 \\
\hline Policy Matrix 13 & Health, Nutrition, Population, and Food Safety & 183 \\
\hline \multirow{4}{*}{ Policy Matrix 14 } & Social Inclusion and Empowerment- Women's Advancement and Rights & 187 \\
\cline { 2 - 3 } & Social Inclusion and Empowerment- Children's Advancement and Rights & 193 \\
\cline { 2 - 3 } & Social Inclusion and Empowerment- Indigenous People, People with Disability, and & 202 \\
& Disadvantaged and Extreme Poor Groups & \\
\hline Policy Matrix 15 & Promoting Good Governance & 206 \\
\hline Policy Matrix 16 & Utility Services Development including Water, Sanitation and Urban Services & 211 \\
\hline Policy Matrix 17 & Caring for Environment and Tackling Climate Change & 218 \\
\hline Policy Matrix 18 & Technology Policy including ICT and Biotechnology & 224 \\
\hline
\end{tabular}


Policy Matrix 1: Macroeconomic Environment for Pro-poor Growth

\begin{tabular}{|c|c|c|c|}
\hline Strategic Goals & Key Targets & Actions Taken/ Underway & NSAPR II Policy Agenda (2009-2011) \\
\hline 1 & 2 & 3 & 4 \\
\hline \multicolumn{4}{|c|}{ I. Enhance growth, particularly pro-poor growth } \\
\hline \multicolumn{4}{|c|}{ Lead Responsibility: MoP and MoF Associate Responsibility: All other line ministries } \\
\hline 1. Maintaining stable growth & $\begin{array}{l}\text { - Maintain GDP growth rate of } 5.9 \% \text { in FY09, } \\
5.5 \% \text { in FY10 and } 6.0 \% \text { in FY11 } \\
\text { - Maintain the quality of the domestic sectors } \\
\text { - Performance of the tax system improved }\end{array}$ & $\begin{array}{l}\text { - Increased flow of concessionary and quality funds } \\
\text { - Measures/actions to improve governance } \\
\text { - Fiscal stimulus to counter effects of global recession }\end{array}$ & $\begin{array}{l}\text { - Increase investment in both private and public sectors } \\
\text { - Increase productivity through use of appropriate technology } \\
\text { - Human resources development } \\
\text { - Improve quality of public sector investment } \\
\text { - Continue fiscal stimulus to counter effects of global recession } \\
\text { - Promote fiscal discipline by DMFAS system }\end{array}$ \\
\hline \multicolumn{4}{|c|}{ Lead Responsibility: MoP, MoF Associate Responsibility: MoA, MoFL, MoI, MoLE } \\
\hline 2. Ensuring pro-poor growth & $\begin{array}{l}\text { - Increase agriculture growth rate to } 4 \% \\
\text { - Ensure rural non-farm sector to expand by } \\
10 \% \\
\text { - Ensure SME to grow by } 15 \%\end{array}$ & $\begin{array}{l}\text { - Providing subsidy to agriculture (Diesel, fertilizer, seeds } \\
\text { and power) } \\
\text { - Extended agricultural credit } \\
\text { - Introduced expenditure tracking for pro-poor and gender } \\
\text { sensitive budgeting } \\
\text { - Prepared guidelines for pro-poor and gender responsive } \\
\text { budget }\end{array}$ & $\begin{array}{l}\text { - Increase poverty reducing expenditure to } 8.5 \% \text { of GDP. } \\
\text { - Enhance subsidy to agriculture }\end{array}$ \\
\hline 3. Ensuring pro-women growth & $\begin{array}{l}\text { - Ensure women's employment to grow by } 7 \% \\
\text { per annum }\end{array}$ & & $\begin{array}{l}\text { - Give incentives to private sector to employ more women } \\
\text { - Ensure women's quota in public sector jobs }\end{array}$ \\
\hline \multicolumn{4}{|c|}{ Lead Responsibility: MoF, BB Associate Responsibility: MoC } \\
\hline 4. Reducing inflation & $\begin{array}{l}\text { - Reduce inflation rate gradually to } 6 \% \text { by } \\
\text { FY11 }\end{array}$ & $\begin{array}{l}\text { - Market monitoring } \\
\text { - Dialogues with business community } \\
\text { - Open market sale of essential goods for poor people } \\
\text { - Encourage agricultural production through timely } \\
\text { availability of inputs at subsidised prices } \\
\end{array}$ & $\begin{array}{l}\text { - Central Bank to maintain cautious monetary policy } \\
\text { - Ensure supply of essential commodities and smooth functioning of } \\
\text { market } \\
\text { - Undertake regular market monitoring and action against various } \\
\text { cartels and hoarding practices }\end{array}$ \\
\hline \multicolumn{4}{|c|}{ Lead Responsibility: MoF, BB Associate Responsibility: All Ministries } \\
\hline \multirow[t]{2}{*}{ 5. Maintaining fiscal discipline } & \multirow[t]{2}{*}{ • Keep budget deficit within $5 \%$ of GDP. } & - Budget deficit kept within a reasonable level. & $\begin{array}{l}\text { - Implement Public Resources and Budget Management Ordinance, } \\
2008 \\
\text { - Include quasi-fiscal expenditure in calculating budget deficit } \\
\text { - Undertake austerity measures to reduce waste in public expenditure } \\
\text { - Expand the use of DMFAS to all related agencies and data network } \\
\text { to ensure data concurrence and accuracy }\end{array}$ \\
\hline & & $\begin{array}{l}\text { - Prepared Internal Control Manual (ICM) to ensure greater } \\
\text { financial discipline in all line Ministries/ Divisions. }\end{array}$ & - Strengthening of Internal Control Mechanism of the line ministries \\
\hline \multicolumn{4}{|c|}{ sociate Responsibility: All Ministries } \\
\hline $\begin{array}{l}\text { 6. Enhancing efficient use of } \\
\text { resources }\end{array}$ & $\begin{array}{l}\text { - Ensure } 90 \% \text { implementation of ADP } \\
\text { - Bring } 75 \% \text { of the ministries/divisions under } \\
\text { MTBF } \\
\text { - Ensure that for all activities of the } \\
\text { government at least } 50 \% \text { of the beneficiaries } \\
\text { are poor and } 33 \% \text { of the beneficiaries are }\end{array}$ & $\begin{array}{l}\text { - Increased number of MTBF ministries from } 14 \text { in FY } 08 \text { to } \\
16 \text { in FY09 } \\
\text { - Constituted Budget Management Committees (BMCs) for } \\
\text { efficient budget preparation, implementation and } \\
\text { monitoring in MTBF ministries } \\
\text { - Public Expenditure Management Manual Published }\end{array}$ & $\begin{array}{l}\text { - Strengthen and deepen MTBF process to bring qualitative changes } \\
\text { in public financial management and link public resources with } \\
\text { government policies, strategies and priorities giving attention to } \\
\text { poverty reduction } \\
\text { - Ensure public allocation gives priority to poverty reduction and } \\
\text { women and child advancement }\end{array}$ \\
\hline
\end{tabular}




\begin{tabular}{|c|c|c|c|}
\hline Strategic Goals & Key Targets & Actions Taken/ Underway & NSAPR II Policy Agenda (2009-2011) \\
\hline 1 & 2 & 3 & 4 \\
\hline & $\begin{array}{l}\text { women } \\
\text { - Promote regional balance in resource } \\
\text { allocation }\end{array}$ & $\begin{array}{l}\text { - Promulgated regulation for audit survey } \\
\text { - Following guidance of the PAC to enhance effectiveness of } \\
\text { foreign aid utilization } \\
\text { - Harmonizing development partners' policies and } \\
\text { procedures } \\
\text { - Arranged bi-partite and tripartite meetings to settle audit } \\
\text { observations }\end{array}$ & $\begin{array}{l}\text { - Take into account the recommendations of the Public Expenditure } \\
\text { Review Commission in preparing budget. } \\
\text { - Roll out budgeting system linking to policy to all Ministries and } \\
\text { Divisions } \\
\text { - Put in place systems for effective follow-up of audit } \\
\text { recommendations } \\
\text { - Maintain regional and gender equity in budgetary resource } \\
\text { allocation } \\
\text { - Show revenue and capital expenditure separately in the budget }\end{array}$ \\
\hline \multicolumn{4}{|c|}{ Lead Responsibility: FD, all ministries } \\
\hline $\begin{array}{l}\text { 7. Promoting transparency in } \\
\text { resource use }\end{array}$ & & $\begin{array}{l}\text { - Established Performance Audit Directorate in } 2007 \text { and } \\
\text { audit activities have been undertaken following INTOSAI } \\
\text { Guidelines. } \\
\text { - Implemented separation of accounts from audit } \\
\text { - Introduced Public Financial Management Strategy (PFMS) } \\
\text { - Developed improved and transparent budget presentation }\end{array}$ & $\begin{array}{l}\text { - Prepare performance audit strategy } \\
\text { - Establish a framework for fiscal management reporting and control } \\
\text { through operationalisation of the ICM in all ministries } \\
\text { - Develop a standard consultation mechanism to get feedback for } \\
\text { quality and transparency in decision making for resource use }\end{array}$ \\
\hline \multicolumn{4}{|l|}{ Lead Responsibility: FD, C\&AG } \\
\hline $\begin{array}{l}\text { 8. Improving accountability in } \\
\text { resource use }\end{array}$ & & $\begin{array}{l}\text { - Adopted Entity Wide Audit Strategy and Entity Wide } \\
\text { activities are going on in four MTBF Ministries. } \\
\text { - Arranged exchange of views meetings for the MPs } \\
\text { - Undertook PAC strengthening project. Manual preparation } \\
\text { for strengthening PAC is going on }\end{array}$ & $\begin{array}{l}\text { - Strengthen Entity wide Audit } \\
\text { - Provide adequate support to the Public Accounts Committee } \\
\text { - Report NSAPR implementation to Parliament and media annually } \\
\text { in a transparent manner }\end{array}$ \\
\hline \multicolumn{4}{|c|}{ Lead Responsibility: PC, all ministries } \\
\hline $\begin{array}{l}\text { 9. Strengthening } \\
\text { programme/project formulation } \\
\text { and approval procedure }\end{array}$ & $\begin{array}{l}\text { - Ensure that all projects and programmes } \\
\text { specify how poor and women are going to } \\
\text { benefit and rank them accordingly }\end{array}$ & - Simplified project preparation formats & $\begin{array}{l}\text { - Take necessary steps to improve programme/project formulation } \\
\text { and approval procedure } \\
\text { - Integrate poverty reduction and women and child advancement } \\
\text { issues in the project preparation stage } \\
\text { - Ensure that every project/programme is designed to directly benefit } \\
\text { poor }\end{array}$ \\
\hline \multicolumn{4}{|c|}{ Lead Responsibility: IMED, all ministries } \\
\hline $\begin{array}{l}\text { 10. Strengthening public } \\
\text { procurement procedure }\end{array}$ & & - Formulated and put in place public procurement regulation & $\begin{array}{l}\text { - Identify and rectify weaknesses in PPR } \\
\text { - Continue training to the officials on PPR }\end{array}$ \\
\hline \multicolumn{4}{|c|}{ Lead Responsibility: FD, GED, IMED, Line Ministries } \\
\hline $\begin{array}{l}\text { 11. Strengthening overall and } \\
\text { sector level monitoring and } \\
\text { evaluation }\end{array}$ & & $\begin{array}{l}\text { - GoB is committed to design, initiate and implement } \\
\text { appropriate steps to achieve the MDGs by 2015, and to } \\
\text { strengthen its monitoring through MDG Progress Report } \\
\text { - MDG Progress Report was released in } 2005 \text { and } 2007\end{array}$ & $\begin{array}{l}\text { - Formulate mechanism to provide regular feedback to poverty } \\
\text { reduction projects/programmes formulation } \\
\text { - Conduct PRS monitoring and evaluation in a systematic manner } \\
\text { - Strengthen capacity of ministries and divisions to monitor } \\
\text { and evaluate progress of development projects }\end{array}$ \\
\hline \multicolumn{4}{|c|}{ Lead Responsibility: GED, FD Associate Responsibility: BBS } \\
\hline $\begin{array}{l}\text { 12. Enhancing analytical } \\
\text { capability in formulating national } \\
\text { policies }\end{array}$ & & $\begin{array}{l}\text { - Disaggregated data on recurrent, capital, gender and } \\
\text { poverty (RCGP) expenditure model developed } \\
\text { - Developed format to get more gender disaggregated data } \\
\text { on public expenditure }\end{array}$ & $\begin{array}{l}\text { - Strengthen information system, analytical ability and modelling } \\
\text { capability of the Finance Division and GED, Planning Commission } \\
\text { - Provide professional training to top officials engaged in fiscal } \\
\text { management }\end{array}$ \\
\hline
\end{tabular}




\begin{tabular}{|c|c|c|c|}
\hline Strategic Goals & Key Targets & Actions Taken/ Underway & NSAPR II Policy Agenda (2009-2011) \\
\hline \multirow[t]{2}{*}{1} & 2 & 3 & 4 \\
\hline & & $\begin{array}{l}\text { - Installation of Transaction Accounting System in accounts } \\
\text { offices and Wide Area Network in District Accounts } \\
\text { Offices, ministries/divisions and FD } \\
\text { - FD officers are being trained for improving the modelling } \\
\text { capability } \\
\text { - A web based integrated Budget and Accounting System } \\
\text { being introduced }\end{array}$ & $\begin{array}{l}\text { - Establish a Macro Fiscal Unit in the Finance Division } \\
\text { - Impart training to the staff of Finance Division and GED, Planning } \\
\text { Commission } \\
\text { - Strengthen technical capacity and inter-ministerial linkages of the } \\
\text { NPFP/GED }\end{array}$ \\
\hline $\begin{array}{l}\text { 13. Improving macroeconomic } \\
\text { and sectoral data }\end{array}$ & $\begin{array}{l}\text { - Undertake a smaller scale poverty survey } \\
\text { between two HIES } \\
\text { - Undertake labour force survey every three } \\
\text { years }\end{array}$ & & $\begin{array}{l}\text { - Strengthen the capacity of BBS and establish it as an autonomous } \\
\text { organization with sufficient human and financial resources }\end{array}$ \\
\hline \multicolumn{4}{|c|}{ II. Make Monetary Policy Effective } \\
\hline \multicolumn{4}{|l|}{ Lead Responsibility: $B B, N S D$} \\
\hline $\begin{array}{l}\text { 14. Improving monetary } \\
\text { management }\end{array}$ & $\begin{array}{l}\text { - Reduce inflation } \\
\text { - Support higher growth } \\
\text { - Maintain competitive real exchange rates }\end{array}$ & $\begin{array}{l}\text { - Recently revised the statutory liquidity ratio for scheduled } \\
\text { banks from } 16 \% \text { to } 18 \% \text { and cash reserve requirement } \\
\text { from } 4.5 \% \text { to } 5 \% \\
\text { - Reduced interest rate on National Savings Certificates and } \\
\text { the rate structure gradually linked to Treasury Bill rates } \\
\text { - Liberalised Treasury Bill rates and introduced Repo and } \\
\text { Reverse Repo facilities } \\
\text { - Introduced Auctions of } 5 \text {-year and 10-year term } \\
\text { Government Treasury Bonds bearing half-yearly interest } \\
\text { coupons } \\
\text { - Introduced long-term treasury bonds (2, } 3 \text { and } 5 \text { years) } \\
\text { - Promoted secondary market for government bonds } \\
\text { - Developed savings instruments for fixed income earners } \\
\text { - Undertook programmes to strengthen capacity of BB }\end{array}$ & $\begin{array}{l}\text { - Develop alternative savings instruments for the poor (Coupon bond } \\
\text { of lower denomination, long term bond of small amount) } \\
\text { - Ensure easier access of poor and women to bank } \\
\text { - Develop/deepen Inter-bank money market } \\
\text { - Modernize all aspects of BB's operations } \\
\text { - Strengthen BB's capability for effective supervision } \\
\text { - Increase quality of CAMEL rating } \\
\text { - Strengthen autonomy of Bangladesh Bank }\end{array}$ \\
\hline \multicolumn{4}{|l|}{ III. Make Capital Market Active } \\
\hline \multicolumn{4}{|c|}{ Lead Responsibility: MoF, SEC, BB } \\
\hline $\begin{array}{l}\text { 15. Developing domestic bond } \\
\text { market }\end{array}$ & & $\begin{array}{l}\text { - Promoted issuance of corporate bonds and securitization } \\
\text { by addressing regulatory and tax issues } \\
\text { - Achieved significant cost reduction in respect of issuance } \\
\text { of securities that includes all forms of debentures/bonds } \\
\text { - Reduced withholding tax on interest income of } \\
\text { Government Bond to } 10 \% \\
\text { - Popularized government and corporate bonds through } \\
\text { investor education programme and interaction with } \\
\text { stakeholders }\end{array}$ & $\begin{array}{l}\text { - Develop domestic bond market by encouraging securitization, and } \\
\text { corporate bond issuance through further legal/regulatory changes }\end{array}$ \\
\hline 16. Developing stock market & $\begin{array}{l}\text { - Increase capitalization/GDP rate to } 25 \\
\text { percent }\end{array}$ & $\begin{array}{l}\text { - Formulated different rules and regulations and developed } \\
\text { warning system to control irregularities of companies } \\
\text { - Undertook measures to increase transparency of } \\
\text { companies by enforcing requirements of publishing }\end{array}$ & $\begin{array}{l}\text { - Strengthen the surveillance system of SEC to protect the interest of } \\
\text { the investors in share market } \\
\text { - Extend share market and brokerage facilities in important cities and } \\
\text { towns }\end{array}$ \\
\hline
\end{tabular}




\begin{tabular}{|c|c|c|c|}
\hline Strategic Goals & Key Targets & Actions Taken/ Underway & NSAPR II Policy Agenda (2009-2011) \\
\hline 1 & 2 & 3 & 4 \\
\hline & & $\begin{array}{l}\text { financial statements in every six months } \\
\text { - Increase of facilities for investors in storing their share } \\
\text { scripts under a depository account and monitoring the } \\
\text { balance in BO Account } \\
\text { - New merchant banks registered }\end{array}$ & $\begin{array}{l}\text { - Strengthen capability of SEC in controlling and developing capital } \\
\text { market } \\
\text { - Provide facilities for investors for online transaction and } \\
\text { verification of the balance of their personal accounts } \\
\text { - Provide regular training and create awareness to increase knowledge } \\
\text { of the investors } \\
\text { - Bring foreign companies into the purview of stock market by } \\
\text { providing incentives and changing laws } \\
\text { - Establish Capital Market Institute to undertake research and } \\
\text { training }\end{array}$ \\
\hline \multicolumn{4}{|l|}{ IV. Reform Financial Sector } \\
\hline \multicolumn{4}{|l|}{ Lead Responsibility: BB,MOF } \\
\hline 17. Restructuring NCBs & & $\begin{array}{l}\text { - Three NCBs (Sonali, Janata and Agrani) converted into } \\
\text { public limited companies } \\
\text { - MoU signed with NCBs to restrict new lending, minimize } \\
\text { operating expenses, reduce non-performing loan (NPL), } \\
\text { and rationalize branch network } \\
\text { - Established Artha Rin Adalat to facilitate collection of } \\
\text { overdue loans } \\
\text { - Undertook special audits of four NCBs } \\
\text { - Appointed financial Adviser to Rupali Bank and published } \\
\text { international tender for its sale } \\
\text { - Appointed a management team for NCBs to improve } \\
\text { efficiency }\end{array}$ & $\begin{array}{l}\text { - Sell Rupali Bank/convert it into a public limited company } \\
\text { - Operate state owned banks under } 5 \text {-year business plan }\end{array}$ \\
\hline $\begin{array}{l}\text { 18. Improving bank regulation/ } \\
\text { supervision }\end{array}$ & & $\begin{array}{l}\text { - Strengthened prudential regulations and banking } \\
\text { regulations } \\
\text { - Setting up of effective internal control } \\
\text { - Increased capital adequacy requirements from } 8 \% \text { to } 9 \% \\
\text { on risk-weighted basis } \\
\text { - Increased minimum capital requirement for banks from } \\
\text { Tk. } 200 \text { million to Tk.1,000 million } \\
\text { - Dividend declaration by bank in excess of } 20 \text { percent is } \\
\text { allowed only if equivalent amount is set aside for reserve } \\
\text { - Reduced single borrower limit by half } \\
\text { - Bangladesh Bank issued regulations to control loan default } \\
\text { - Approval of amendments to enhance autonomy and } \\
\text { regulatory power of BB } \\
\text { - Introduced new risk analysis, lending policies, loan follow- } \\
\text { up and loan recovery process }\end{array}$ & $\begin{array}{l}\text { - Continue enhance skills of supervisors of BB l } \\
\text { - Build professional leadership in Bangladesh Bank } \\
\text { - Strengthen Bangladesh Bank with less government intervention } \\
\text { - Continue placement of right people in right job }\end{array}$ \\
\hline $\begin{array}{l}\text { 19. Improving corporate } \\
\text { governance of Banks } \\
\text { and NBFIs }\end{array}$ & & $\begin{array}{l}\text { - Reconstituted Boards of NCBs and SDBs with inclusion of } \\
\text { women } \\
\text { - Delegated some powers of the FD to the NCB Boards, and } \\
\text { decentralization has been implemented amongst different }\end{array}$ & $\begin{array}{l}\text { - Enhance and pursue more demanding accounting and disclosure } \\
\text { requirements for banks }\end{array}$ \\
\hline
\end{tabular}




\begin{tabular}{|c|c|c|c|}
\hline Strategic Goals & Key Targets & Actions Taken/ Underway & NSAPR II Policy Agenda (2009-2011) \\
\hline 1 & 2 & 3 & 4 \\
\hline & & $\begin{array}{l}\text { layers of management } \\
\text { - New incentive scheme has been introduced for improving } \\
\text { performance, including collection of NPLs } \\
\text { - Loan recovery department has been strengthened } \\
\text { - Powers and responsibilities of banks and management have } \\
\text { been made transparent } \\
\text { - Introduced appropriate qualifications for chief executives } \\
\text { of PCBs } \\
\text { - Implemented most of the recommendations made by the } \\
\text { Committee on Default Loans } \\
\text { - Qualifications of bank directors have been determined and } \\
\text { their number has been reduced }\end{array}$ & \\
\hline \multicolumn{4}{|l|}{ V. Promote Exports } \\
\hline \multicolumn{4}{|l|}{ Lead Responsibility: MoC, FD, BB } \\
\hline 20. Increasing exports & $\begin{array}{l}\text { - Increase export growth rate from } 12.0 \% \text { in } \\
\text { FY09 to } 16.5 \% \text { in FY11 }\end{array}$ & $\begin{array}{l}\text { - Formulated a three-year Export Policy (2009-2012) to } \\
\text { make the export sector more competitive } \\
\text { - Registrar of Joint Stock Companies has been } \\
\text { reorganised and automation is being introduced. } \\
\text { - Reorganisation of EPB, Bangladesh Tariff } \\
\text { - Skill-based training for entrepreneurship development is } \\
\text { being imparted to promote small and medium enterprises } \\
\text { - An action plan has been adopted to remove anti-export } \\
\text { bias } \\
\text { - Fiscal stimulus package to counter effects of global } \\
\text { recession } \\
\text { - Bank lending rate brought down to } 12 \text { to } 13 \text { percent } \\
\text { - Export development fund enhanced by } 50 \text { percent } \\
\end{array}$ & $\begin{array}{l}\text { - Undertake further measures to reduce trade transaction costs } \\
\text { - Effective implementation of Export policy 2009-12 } \\
\text { - Undertake actions on the basis of research and consultation with } \\
\text { the stakeholders for enhancing external competitiveness } \\
\text { - Strengthen one-stop-service for exports at EPB } \\
\text { - Improve productivity in export sector } \\
\text { - Fiscal stimulus package to counter effects of global recession to } \\
\text { continue }\end{array}$ \\
\hline $\begin{array}{l}\text { 21. Strengthening Compliance in } \\
\text { exports }\end{array}$ & $\begin{array}{l}\text { - Ensure that all enterprises adhere to } \\
\text { compliance standards }\end{array}$ & $\begin{array}{l}\text { - Compliance Measures in respect of social and } \\
\text { environmental standards are under implementation }\end{array}$ & $\begin{array}{l}\text { - Increase awareness of managerial people and entrepreneurs on } \\
\text { social and environmental compliance. } \\
\text { - Implementation of labour law }\end{array}$ \\
\hline \multicolumn{4}{|c|}{ 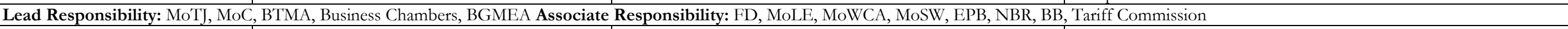 } \\
\hline $\begin{array}{l}\text { 22. Promoting backward linkage } \\
\text { in export activities }\end{array}$ & & $\begin{array}{l}\text { - Measures have been taken to encourage expansion of PTS } \\
\text { - Measures have been taken for improvement of ports and } \\
\text { customs procedures } \\
\text { - Shipping Ministry has undertaken a project on improving } \\
\text { the port's efficiency } \\
\text { - Actions initiated to provide support to strengthen the } \\
\text { capability of Institute of Fashion and Technology (BIFT) }\end{array}$ & $\begin{array}{l}\text { - Provide facilities to backward linking sectors } \\
\text { - Take steps for port development and simplification and reduction } \\
\text { of customs clearance and regulatory procedures } \\
\text { - Develop branding for Bangladesh Garments } \\
\text { - Analyse and address export barriers issues and coordinate efforts } \\
\text { with other LDCs } \\
\text { - Undertake initiatives for duty free and quota free access for RMG } \\
\text { to US market } \\
\text { - Undertake efforts for diversification of RMG exports } \\
\text { - Ensure preferential treatment in different country markets including } \\
\text { CIS, China and India }\end{array}$ \\
\hline
\end{tabular}




\begin{tabular}{|c|c|c|c|}
\hline Strategic Goals & Key Targets & Actions Taken/ Underway & NSAPR II Policy Agenda (2009-2011) \\
\hline 1 & 2 & 3 & 4 \\
\hline & & & $\begin{array}{l}\text { - Provide budgetary support for Skill Development Training of } \\
\text { workers, people at managerial level and entrepreneurs } \\
\text { - Provide support to strengthen the capability of BGMEA Institute } \\
\text { of Fashion and Technology (BIFT) } \\
\text { - Provide support in the context of withdrawal of safeguards from } \\
\text { China in EU and USA }\end{array}$ \\
\hline \multicolumn{4}{|c|}{ Lead Responsibility: MoC, EPB Associate Responsibility: MoI, Missions Abroad, BGMEA, BSTI } \\
\hline $\begin{array}{l}\text { 23. Diversifying export } \\
\text { destination }\end{array}$ & $\begin{array}{l}\text { - Increase export share to non-US and non- } \\
\text { Euro market to } 35.0 \text { percent from current } \\
28.5 \text { percent }\end{array}$ & $\begin{array}{l}\text { - Measures have been taken to explore markets in the East- } \\
\text { European countries } \\
\text { - Support to market exploring activities is being undertaken } \\
\text { - Quota/duty free access has been obtained to EU, Canada, } \\
\text { Australia, Norway, and New Zealand } \\
\text { - Joined three regional free trade blocks- SAFTA, BIMSTEC } \\
\text { and TPS-OIC } \\
\text { - Sending missions to Africa, South and South-East Asia } \\
\text { - BGMEA has employed lobbyist for obtaining duty free } \\
\text { access to USA for textile and RMG }\end{array}$ & $\begin{array}{l}\text { - Continue initiatives for diversification of exports including } \\
\text { diversification of garments and textiles } \\
\text { - Increase participation in international fairs and exhibitions in a } \\
\text { professional way } \\
\text { - Stregenthen Bangladesh Export Promotion Bureau (EPB) for } \\
\text { organizing international trade fairs in a more professional way } \\
\text { - Strengthen Bangladesh Standards and Testing Institute (BSTI) and } \\
\text { Bangladesh Accreditation Board (BAB) to control quality for } \\
\text { exports and for certification and accreditation }\end{array}$ \\
\hline 24. Diversifying export items & - Increase non-garment export share to $35 \%$ & $\begin{array}{l}\text { - More products like handicrafts, agro-processing, vegetables } \\
\text { and vegetable-processing, pharmaceutical and light } \\
\text { engineering products are under scrutiny for cash incentives } \\
\text { - To promote export of SMEs products and non-traditional } \\
\text { items, the Government is providing incentives including } \\
\text { credit and cash incentives }\end{array}$ & $\begin{array}{l}\text { - Enhance fiscal, monetary and other incentives to continue to } \\
\text { broaden the export base } \\
\text { - Undertake market studies in several buyers' countries to identify the } \\
\text { demand and the problems of existing products in marketing } \\
\text { - Establish Small Special Economic Zones in different parts of the } \\
\text { country for cluster development of products and facilities }\end{array}$ \\
\hline \multicolumn{4}{|l|}{ VI. Liberalize Imports } \\
\hline \multicolumn{4}{|c|}{ Lead Responsibility: MoC, Tariff Commission Associate Responsibility: MoI, FD, NBR, Business Chambers } \\
\hline $\begin{array}{l}\text { 25. Providing freer trade } \\
\text { environment }\end{array}$ & $\begin{array}{l}\text { - Reduce effective import protection further by } \\
25 \%\end{array}$ & $\begin{array}{l}\text { - An Import Policy Order (2006-09) has been formulated to } \\
\text { ensure greater degree of transparency and continuity } \\
\text { - Tariffs on intermediate inputs have been reduced } \\
\text { - There has been significant rationalization in the tariff- } \\
\text { structure with the number of tariff slabs reduced to } 4 \\
\text { - The number of banned and restricted items has been } \\
\text { brought down to } 24 \text { from } 122 \\
\text { - Rationalized supplementary duties from } 31 \text { to } 5 \\
\text { - Import license fee on all imports has been withdrawn }\end{array}$ & $\begin{array}{l}\text { - Reduce the average protective tariff to } 15 \text { percent } \\
\text { - Continue to rationalize quantitative restrictions } \\
\text { - Apply prudently duty escalation and rationalization } \\
\text { - Enhance revenue mobilization efforts to reduce the dependence on } \\
\text { import taxes } \\
\text { - Further rationalise supplementary duties } \\
\text { - Effectively implement Import Policy 2006-2009 }\end{array}$ \\
\hline \multicolumn{4}{|l|}{ VII. Promote Remittances } \\
\hline \multicolumn{4}{|c|}{ Lead Responsibility: MoEWOE Associate Responsibility: FD, NBR, BB } \\
\hline $\begin{array}{l}\text { 26. Augmenting } \\
\text { inflow of remittances }\end{array}$ & - Increase remittance inflow by $25.0 \%$ annually & $\begin{array}{l}\text { - Processing of remittances through official channels has } \\
\text { been streamlined by establishing banks/exchange houses in } \\
\text { different countries and setting remittance cells in all NCBs } \\
\text { - Task forces have been formed at national and regional } \\
\text { levels to monitor the implementation of the Money } \\
\text { Laundering Prevention Act } 2002 \\
\text { - A Monitoring Cell has been opened at FD to redress the } \\
\end{array}$ & $\begin{array}{l}\text { - Continue follow up measures to encourage flow of remittances } \\
\text { through the legal channel } \\
\text { - Take further actions to increase remittances through official } \\
\text { channel } \\
\text { - Continue to strengthen anti-money laundering surveillance } \\
\text { - Support Postal Department in transferring remittance in rural areas }\end{array}$ \\
\hline
\end{tabular}




\begin{tabular}{|c|c|c|c|}
\hline Strategic Goals & Key Targets & Actions Taken/ Underway & NSAPR II Policy Agenda (2009-2011) \\
\hline 1 & 2 & 3 & 4 \\
\hline & & $\begin{array}{l}\text { grievances of remitters } \\
\text { - Actions have been taken for identification, intensification } \\
\text { and diversification of external labour market } \\
\text { - Diplomatic initiatives adopted to prevent retrenchment of } \\
\text { labour and explore new labour markets abroad }\end{array}$ & \\
\hline \multicolumn{4}{|c|}{ VIII. Build Capacity for Trade Development } \\
\hline \multicolumn{4}{|c|}{ Lead Responsibility: MoC, EPB Associate Responsibility: MoFA, NBR, BB, Tariff Commission, BSTI, FBCCI, CPD, BFTI } \\
\hline $\begin{array}{l}\text { 27. Improving trade negotiation } \\
\text { capability }\end{array}$ & & $\begin{array}{l}\text { - Actions initiated to enhance trade negotiation capability by } \\
\text { strengthening WTO Cell in Ministry of Commerce and } \\
\text { Bangladesh Tariff Commission. } \\
\text { - Actions initiated to strengthen Bangladesh Foreign Trade } \\
\text { Institute (BFTI) }\end{array}$ & $\begin{array}{l}\text { - Strengthen WTO Cell and Bangladesh Tariff Commission } \\
\text { - Undertake measures to build capacity regarding trade negotiations } \\
\text { and WTO rules and regulations }\end{array}$ \\
\hline \multicolumn{4}{|c|}{ Lead Responsibility: EPB, MoS, MoCAT, MoEWOE Associate Responsibility: All service oriented ministries } \\
\hline $\begin{array}{l}\text { 28. Building capacity in trade } \\
\text { facilitation }\end{array}$ & & $\begin{array}{l}\text { - Trade Facilitation Project is in operation } \\
\text { - Automation introduced in Chittagong customs house } \\
\text { - Automation introduced in Dhaka customs house }\end{array}$ & $\begin{array}{l}\text { - Modernise Chittagong and Mongla ports } \\
\text { - Simplify trade related formalities } \\
\text { - Ensure effective monitoring of the performance of Trade } \\
\text { Facilitation project in different departments and ministries } \\
\text { - Strengthen the trade related information system } \\
\text { - Undertake needs assessment on trade facilitation for identifying key } \\
\text { measures and sequencing }\end{array}$ \\
\hline $\begin{array}{l}\text { 29. Building capacity for services } \\
\text { exports }\end{array}$ & $\begin{array}{l}\text { - Increase growth of exports of services by } 13.0 \\
\text { percent annually }\end{array}$ & & $\begin{array}{l}\text { - Invest for assessment of training needs for export of services } \\
\text { - Invest on training for development of tourism }\end{array}$ \\
\hline 30. Developing trade data base & & - A Trade Information Centre has been established at EPB & $\begin{array}{l}\text { - Develop human skill on Trade Information } \\
\text { - Develop trade related website }\end{array}$ \\
\hline \multicolumn{3}{|c|}{ Total Indicative Cost (in billion taka) } & Tk. 31.43 \\
\hline
\end{tabular}


Policy Matrix 2: Resource Mobilisation

\begin{tabular}{|c|c|c|c|}
\hline Strategic Goals & Key Targets & Actions Taken/ Underway & PRSP Policy Agenda (2009-2011) \\
\hline 1 & 2 & 3 & 4 \\
\hline \multicolumn{4}{|c|}{ Lead Responsibility: NBR, MoF Associate Responsibility: FD, MoE, and MoLJPA } \\
\hline 1. Enhancing tax effort & $\begin{array}{l}\text { - Increase total revenue to } 11.5 \% \text { of } \\
\text { GDP } \\
\text { - Increase the share of direct tax and } \\
\text { VAT } \\
\text { - Increase more transparency and anti- } \\
\text { corruption drive at all administrative } \\
\text { levels }\end{array}$ & $\begin{array}{l}\text { - Measures have been taken to implement the suggestions of the } \\
\text { Commission on Reforming the Public Revenue System } \\
\text { - Based on the recommendations of the Commission, measures have } \\
\text { been taken to further modernise and rationalise the taxation system } \\
\text { - Revision of the related laws of Customs, VAT \& Income Tax are } \\
\text { under process } \\
\text { - Introduce automated system of tax collection } \\
\text { - Withdraw irrational tax exemptions }\end{array}$ & $\begin{array}{l}\text { - Continue reforms and revenue enhancing measures } \\
\text { - Shorten VAT exemption list on production and imports } \\
\text { - Expand VAT net } \\
\text { - Expand Income tax net } \\
\text { - Introduce unified TIN for Income Tax and VAT } \\
\text { - Further modernise and rationalise the taxation system } \\
\text { - Undertake zero tolerance policy for the tax evaders }\end{array}$ \\
\hline 2. Improve tax administration & Tax ombudsman appointed & $\begin{array}{l}\text { - Necessary legal measures will be brought to make the NBR an } \\
\text { autonomous tax authority in line with other countries }\end{array}$ & $\bullet$ \\
\hline \multicolumn{4}{|c|}{ Lead Responsibility: NBR, MoF Associate Responsibility:: FD, MoE, and MoLJPA } \\
\hline $\begin{array}{l}\text { 3. Improving tax administration to } \\
\text { make the tax system more efficient }\end{array}$ & & $\begin{array}{l}\text { - Steps are under way to bring all wholesale and retail trade, } \\
\text { especially in urban areas, under VAT as well as to collect Income } \\
\text { Tax from them } \\
\text { - Automation of Accounts of those establishments are under way to } \\
\text { ensure correct record of transaction and therefore VAT \& Income } \\
\text { Tax } \\
\text { - Administration re-organisation has started with a view to reaching } \\
\text { all taxable units and individuals in the country } \\
\text { - A survey has been undertaken to ascertain the areas/individuals left } \\
\text { out of the tax-net }\end{array}$ & $\begin{array}{l}\text { - Reorganize VAT field administration on a functional basis } \\
\text { away from present territorial basis } \\
\text { - Complete necessary changes in VAT laws and procedures } \\
\text { and re-deploy officials } \\
\text { - Similar actions will be taken with respect to Customs, } \\
\text { Income tax and other taxes } \\
\text { - Re-organise NBR on a functional basis down to smallest } \\
\text { units at field level } \\
\text { - Strengthen tax collection departments by making } \\
\text { territorial and functional re-adjustments to ensure effective } \\
\text { presence of tax collection departments }\end{array}$ \\
\hline \multicolumn{4}{|c|}{ Lead Responsibility: NBR, MoF Associate Responsibility: FD, MoE, and MoLJPA } \\
\hline $\begin{array}{l}\text { 4. Generating more revenue from } \\
\text { non-tax sources }\end{array}$ & $\begin{array}{l}\text { - Ensure non-tax revenue's share in total } \\
\text { revenue to be } 18 \%\end{array}$ & $\begin{array}{l}\text { - Non-tax revenue rates on various items have substantially been } \\
\text { enhanced to augment revenue mobilization }\end{array}$ & - Undertake further measures to enhance non-tax revenue \\
\hline \multicolumn{4}{|c|}{ Lead Responsibility: ERD, MoF Associate Responsibility: PC, FD, IMED } \\
\hline $\begin{array}{l}\text { 5. Ensuring increased donor fund } \\
\text { inflow }\end{array}$ & - Make financing gap to be met & $\begin{array}{l}\text { - Efforts are being made to mobilise more official development } \\
\text { assistance } \\
\text { - Bangladesh Aid Harmonisation Action Plan has been prepared }\end{array}$ & $\begin{array}{l}\text { - Establish harmonisation, alignment and result-framework } \\
\text { between the GoB and the DPs } \\
\text { - Formulate Joint Cooperation Strategies (JCS) with DPs }\end{array}$ \\
\hline \multicolumn{3}{|c|}{ Total Indicative Cost (in billion taka) } & Tk. 29.75 \\
\hline
\end{tabular}


Policy Matrix 3: Agricultural Growth for Poverty Reduction

\begin{tabular}{|c|c|c|c|}
\hline Strategic Goals & Key Targets & Actions Taken/ Underway & PRSP Policy Agenda (2009-2011) \\
\hline 1 & 2 & 3 & 4 \\
\hline \multicolumn{4}{|l|}{ Sub-Sector: Crops } \\
\hline \multicolumn{4}{|c|}{ Lead Responsibility: MoA Associate Responsibility: DAE, NARS, BADC, DAM, BMDA, BCIC, FD and MoFDM } \\
\hline $\begin{array}{l}\text { 1. Increasing productivity and } \\
\text { profitability in crop sub-sector }\end{array}$ & $\begin{array}{l}\text { - Reduce yield gaps between on-farm and research } \\
\text { station } \\
\text { - Increase production of cereal crops from } 30.5 \\
\text { million tons to } 37.6 \text { million tons by } 2011 \\
\text { - Increase production of other field crops } \\
\text { including horticulture and plantation crops by } \\
10 \% \\
\text { - Increase production of major crops } \\
\text { - Diversify crop production }\end{array}$ & $\begin{array}{l}\text { - Formulated National Agriculture Policy and Plan of } \\
\text { - Action } \\
\text { - } 47 \text { HYVs and } 1 \text { hybrid rice variety developed and } \\
\text { adopted } \\
\text { - Innovative and profitable technologies of fruits, } \\
\text { vegetables, oilseeds, pulses, spices etc are being used } \\
\text { - Sixty eight HYVs \& } 70 \text { integrated crop management } \\
\text { technologies adopted by farmers } \\
\text { - Strengthened research-extension-farmers-private } \\
\text { sector linkages } \\
\text { - Ensured phytosanitary and quarantine measures } \\
\text { - Implemented integrated agricultural development } \\
\text { programme } \\
\text { - Recommended soil test based fertilizer application } \\
\text { - Recommended use of LCC, USG and drum seeders } \\
\text { - Programme undertaken for reducing yield gaps } \\
\text { - ADP allocation for agriculture sector has been raised } \\
\text { - Agricultural marketing services is strengthened by } \\
\text { implementing projects } \\
\text { - Expanded agriculture information network up to } \\
\text { Upazila } \\
\text { - Strengthened production and distribution of all classes } \\
\text { of seeds, seedlings and saplings } \\
\text { - Training on reduction of yield gap imparted to } \\
\text { extension personnel }\end{array}$ & $\begin{array}{l}\text { - Increase budget allocation for agriculture sector } \\
\text { - Increase subsidy for agricultural inputs } \\
\text { - Strengthen agricultural marketing services } \\
\text { - Undertake appropriate skill development programme for } \\
\text { - Reientists and extension workers } \\
\text { - Reform input (fertilizer, seed) supply policy } \\
\text { - Undertake Agricultural Sector Review } \\
\text { - Undertake action plan to increase production of major crops } \\
\text { - Enhance human resource development in agriculture sector } \\
\text { - Strengthen biotechnology research and development } \\
\text { - Reduce residual effect of pesticides } \\
\text { - Strengthen agricultural mechanization } \\
\text { - Accelerate development of improved technologies } \\
\text { - Provide agricultural credit and simplify lending procedure } \\
\text { - Provide loan to sharecroppers } \\
\text { - Reduce post-harvest loss } \\
\text { - Disseminate technology for rural women } \\
\text { - Target extension services (training, information and } \\
\text { demonstration) to women for promoting organic fertilizer, } \\
\text { food processing etc. on a commercial basis } \\
\text { - Ensure fair price for all crops and agricultural products } \\
\text { - Formulation of regional production plans based on past price } \\
\text { trends }\end{array}$ \\
\hline \multicolumn{4}{|c|}{ Lead Responsibility: MoA Associate Responsibility: DAE, NARS, BADC, DAM, BMDA, BCIC, FD and MoFDM } \\
\hline 2. Ensuring food security & $\begin{array}{l}\text { - Increase production of rice, wheat, maize, } \\
\text { potatoes, pulses, oilseeds, fruits, vegetables, } \\
\text { sugarcane, tuber crops and spices } \\
\text { - Improve nutrition intake of poor through } \\
\text { promotion of crop diversification } \\
\text { - Produce nutritious and safe food }\end{array}$ & $\begin{array}{l}\text { - 'National Food Policy 2006' and the National Food } \\
\text { Policy Plan of action 2008-2015' formulated } \\
\text { - } 600 \text { demonstrations of cereals, pulses, oilseeds, } \\
\text { vegetables, tuber crops and fruits and on-farm trials at } \\
21 \text { technology villages completed } \\
\text { - Action Plan for increasing yield of } 7 \text { crops undertaken } \\
\text { - Prepared crop suitability maps (rice, wheat, potatoes, } \\
\text { pulse) at } 40 \text { Upazila level }\end{array}$ & $\begin{array}{l}\text { - Reformulate Policy for Safety Net Programmes for poor } \\
\text { extreme poor and urban poor } \\
\text { - Implement 'National Food Policy Plan of Action' } \\
\text { - Formulate organic food production policy } \\
\text { - Strengthen research on salinity, sub-mergence and drought } \\
\text { tolerant variety development } \\
\text { - Ensure intra-household food security focusing on women } \\
\text { through targeted food and nutrition programmes } \\
\text { - Undertake awareness campaign on nutritional intake }\end{array}$ \\
\hline \multicolumn{4}{|c|}{ Lead Responsibility: MoA Associate Responsibility: DAE, NARS, BADC and BSFIC } \\
\hline $\begin{array}{l}\text { 3. Encouraging production of cash } \\
\text { crops }\end{array}$ & $\begin{array}{l}\text { - Increase production of jute, cotton and } \\
\text { sugarcane by } 8.5 \text { percent, } 2.6 \text { percent and } 16 \\
\text { percent respectively by } 2011 \\
\text { - Increase production of plantation crops (tea, }\end{array}$ & $\begin{array}{l}\text { - } 20 \text { new varieties of sugarcane are developed and } \\
\text { adopted } \\
\text { - One HYV of jute is developed and adopted } \\
\text { - Varietal development programme of high value crops }\end{array}$ & $\begin{array}{l}\text { - Continue research and extension development of cash crops } \\
\text { based on market demand } \\
\text { - Recast policy for encouraging cultivation of cash and } \\
\text { plantation crops }\end{array}$ \\
\hline
\end{tabular}




\begin{tabular}{|c|c|c|c|}
\hline Strategic Goals & Key Targets & Actions Taken/ Underway & PRSP Policy Agenda (2009-2011) \\
\hline 1 & 2 & 3 & 4 \\
\hline & rubber) & $\begin{array}{l}\text { undertaken } \\
\text { - Two jute mutants developed } \\
\text { - Two advanced mutants of tomato developed } \\
\text { - BSFIC is providing credit to the sugarcane producers } \\
\text { - Varietal development programme of jute, summer and } \\
\text { winter tomato taken up }\end{array}$ & $\begin{array}{l}\text { - Provide support to women to undertake production of cash } \\
\text { crops }\end{array}$ \\
\hline \multicolumn{4}{|c|}{ Lead Responsibility: MoA Associate Responsibility: DAE, BARI, BADC, Hortex Foundation, NGOs, Universities, Private Sectors and MoCAT } \\
\hline $\begin{array}{l}\text { 4. Accelerating production of high } \\
\text { value crops for domestic and export } \\
\text { market }\end{array}$ & $\begin{array}{l}\text { - Increase production of high value crops } \\
\text { (vegetables, fruits, flowers) by } 20 \% \text { per annum } \\
\text {-Increase production of medicinal, ornamental and } \\
\text { aromatic plants }\end{array}$ & $\begin{array}{l}\text { - Cash incentives for export of vegetables and fruits } \\
\text { given } \\
\text { - Contract growing of high value crops (vegetables, } \\
\text { fruits, flowers etc) encouraged } \\
\text { - More than } 20 \mathrm{HYVs} \text { of high value crops already in the } \\
\text { production system } \\
\text { - IPM technologies for high value crops adopted by } \\
\text { farmers } \\
\text { - Group marketing of high value crop fostered } \\
\text { - Quality-production- village of fruits and vegetables developed } \\
\text { for pre- and post harvest quality assurance } \\
\text { - Prepared maps and reports delineating potential areas } \\
\text { for high value crops at Upazila level and Mouza level } \\
\text { - A proposal for strengthening DAM submitted }\end{array}$ & $\begin{array}{l}\text { - Strengthen Hortex Foundation and DAM } \\
\text { - Strengthen coordination of research organizations, extension, } \\
\text { private and NGO participation } \\
\text { - Enhanced Public-Private partnership } \\
\text { - Develop market facilities focusing on poor farmers } \\
\text { - Strengthen research and development activities of BARI } \\
\text { relating to high value crops } \\
\text { - Strengthen Horticulture and ASC's programme of BADC, } \\
\text { DAE and other relevant organizations } \\
\text { - Explore export markets for high value crops } \\
\text { - Encourage and provide support to women to undertake } \\
\text { production of high value crops }\end{array}$ \\
\hline \multicolumn{4}{|c|}{ Lead Responsibility: MoA Associate Responsibility: SRDI, DAE, BARI, BARC and MoL } \\
\hline 5. Improving land resource base & $\begin{array}{l}\text { - Prevent crop land from non-agricultural uses } \\
\text { - Improve/sustain soil fertility through increasing } \\
\text { organic contents } \\
\text { - Encourage AEZ based cropping patterns }\end{array}$ & $\begin{array}{l}\text { - Use of balanced fertilizers and bio-fertilizers } \\
\text { encouraged } \\
\text { - Introduced soil health card on pilot basis } \\
\text { - Soil test based fertilizer recommendation through soil } \\
\text { mini lab at Upazila and union level continued } \\
\text { - Special programme for compost and green manure } \\
\text { production and use continued } \\
\text { - Soil survey completed in } 60 \text { Upazila } \\
\text { - Established } 11 \text { laboratories and modernized } 5 \text { existing } \\
\text { laboratories and } 2 \text { MSTL }\end{array}$ & $\begin{array}{l}\text { - Undertake further efforts to improve soil quality and land } \\
\text { administration } \\
\text { - Encourage use of balanced fertilizers based on soil test } \\
\text { - Encourage balanced use of inorganic and organic fertilizers }\end{array}$ \\
\hline \multicolumn{4}{|c|}{ Lead Responsibility: MoA Associate Responsibility: BARC, NARS, KGF, Universities, Associated Research Institutes and Private Sectors } \\
\hline $\begin{array}{l}\text { 6. Strengthening agricultural } \\
\text { research }\end{array}$ & $\begin{array}{l}\text { - Develop improved crop technologies for quick } \\
\text { dissemination } \\
\text { - Promote biotechnology research for crops }\end{array}$ & $\begin{array}{l}\text { - Allocation of research funds gradually increased } \\
\text { - Alternative sources of research funds on competitive } \\
\text { basis explored } \\
\text { - National Institute of Biotechnology (NIB) established } \\
\text { - } 47 \text { HYVs of rice and } 370 \text { HYVs of other crops } \\
\text { developed and disseminated } \\
\text { - Three jute varieties developed } \\
\text { - Developed and disseminated } 6 \text { farm machinery } \\
\text { (Reaper, HS rotary tiller, thresher, upland weeder, } \\
\text { power winnower and BARI plough) }\end{array}$ & $\begin{array}{l}\text { - Improve scientists' quality and incentive structure } \\
\text { - Allocate adequate funds for R\&D } \\
\text { - Adopt biotechnology policy for implementation } \\
\text { - Undertake socio-economic research and programme } \\
\text { - Strengthen soil management with emphasis on soil degradation } \\
\text { related research } \\
\text { - Strengthen human resource development and laboratory } \\
\text { facilities for transgenic research } \\
\text { - Conduct socio-economic research for problem identification, } \\
\text { technology generation and dissemination to women in }\end{array}$ \\
\hline
\end{tabular}




\begin{tabular}{|c|c|c|c|}
\hline Strategic Goals & Key Targets & Actions Taken/ Underway & PRSP Policy Agenda (2009-2011) \\
\hline 1 & 2 & 3 & 4 \\
\hline & & $\begin{array}{l}\text { - Soil management including soil degradation related } \\
\text { research initiated } \\
\text { - Research on biotechnology continued } \\
\text { - Biotechnology laboratory development undertaken }\end{array}$ & $\begin{array}{l}\text { participating income generating activities } \\
\text { - Ensure that research benefits poor and expands opportunities } \\
\text { for them }\end{array}$ \\
\hline \multicolumn{4}{|c|}{ Lead Responsibility: MoA Associate Responsibility: DAE, BADC, DAM, BMDA, FD and MoFDM } \\
\hline $\begin{array}{l}\text { 7. Strengthening agriculture } \\
\text { extension service }\end{array}$ & $\begin{array}{l}\text { - Ensure pro-poor and pro-women focus on } \\
\text { extension services } \\
\text { - Develop Local Service Providers from the poor } \\
\text { resource farmers } \\
\text { - Develop agri-business services } \\
\text { - Execute new extension policy }\end{array}$ & $\begin{array}{l}\text { - New Agricultural Extension Policy, Plan of Action for } \\
\text { - NAP and the strategic plan implemented } \\
\text { - Strengthened modern cultivation practices through } \\
\text { different extension approaches } \\
\text { - Farmers' Observation Trials (FOTs) /Block } \\
\text { Demonstrations have been conducted } \\
\text { - Different extension programmes for technology } \\
\text { transfer developed by research institutes } \\
\text { - Developed market chain through group based farming } \\
\text { - Developed market infrastructure } \\
\text { - Research-extension linkage through annual review } \\
\text { - Lrogramme implemented } \\
\text { - disseminated through BARC coordinated action plan } \\
\text { - Three year action plan for increasing rice production } \\
\text { undertaken }\end{array}$ & $\begin{array}{l}\text { - Continue the existing extension approaches } \\
\text { - Undertake door step extension service to support women's } \\
\text { participation in agricultural activities } \\
\text { - Update policies and action plans with changing conditions } \\
\text { - Strengthen capacity building of researchers, extension workers } \\
\text { and farmers } \\
\text { - Ensure revitalization of coordinated platforms (UECC, } \\
\text { DECC, RECC, NECC) for technology transfer } \\
\text { - Continue planning through bottom-up approach with the } \\
\text { - Implement demand driven decentralized extension approach } \\
\text { - Disseminate new technology through mass media } \\
\text { - Develop technologies to help women undertake more income } \\
\text { generation activities in agriculture } \\
\text { - Strengthen extension-research-farmers linkage }\end{array}$ \\
\hline \multicolumn{4}{|c|}{ Lead Responsibility: MoA Associate Responsibility: BADC, BMDA, DAE, BWDB, LGED, MoWR and Private Sectors } \\
\hline $\begin{array}{l}\text { 8. Expanding irrigation with } \\
\text { emphasis on efficient use of water } \\
\text { resources }\end{array}$ & $\begin{array}{l}\text { - Increase irrigation coverage, especially to less } \\
\text { developed areas } \\
\text { - Improve on-farm water management/water } \\
\text { productivity } \\
\text { - Emphasize conjunctive use of surface and } \\
\text { ground water for irrigation } \\
\text { - Re-excavate derelict canals, ponds for rain water } \\
\text { harvest }\end{array}$ & $\begin{array}{l}\text { - Policies towards deregulation and market liberalization } \\
\text { already encouraged private sector to participate in } \\
\text { minor irrigation } \\
\text { - Public sector irrigation systems are being rationalized } \\
\text { for improvement of performance and cost recovery. } \\
\text { - Expansion of irrigation facilities to } 5.35 \text { million } \\
\text { hectares of land by operating different irrigation } \\
\text { modes and equipments } \\
\text { - Facilities for conjunctive use of ground and surface } \\
\text { water for irrigation developed }\end{array}$ & $\begin{array}{l}\text { - Continue pro-market policies for irrigation development } \\
\text { - Improve efficiency of water use and on-farm water } \\
\text { management } \\
\text { - Emphasise private sector minor irrigation system } \\
\text { - Develop irrigation infrastructure through government } \\
\text { intervention } \\
\text { - Encourage efficient water management for more coverage }\end{array}$ \\
\hline \multicolumn{4}{|c|}{ Lead Responsibility: MoA Associate Responsibility: BADC, DAE, BARI, BJRI, BRRI, BINA, Universities, SCA, NGOs, BARC and Private Sectors } \\
\hline $\begin{array}{l}\text { 9. Promoting quality seed } \\
\text { development }\end{array}$ & $\begin{array}{l}\text { - Increase availability of quality seeds for cereals } \\
\text { and other crops } \\
\text { - Expedite private sector participation in seed } \\
\text { production and business development } \\
\text { - Promote increased use of bio-technologies in } \\
\text { variety development and planting material } \\
\text { propagation }\end{array}$ & $\begin{array}{l}\text { - Existing seed policy and seed rules updated } \\
\text { - BARI, BSRI and BJRI undertaken steps for providing } \\
\text { breeder seeds for multiplying into foundation seeds } \\
\text { - Private sector supported for seed development and } \\
\text { seed business } \\
\text { - Farmers' level quality seed production and storage } \\
\text { programme undertaken } \\
\text { - Quality seeds of cereals (66971 mt) produced and } \\
\text { distributed }\end{array}$ & $\begin{array}{l}\text { - Implement fully existing seed policy and seed rules } \\
\text { - strengthen use of bio-technologies in seed development } \\
\text { - Enhance involvement of private sector in seed production and } \\
\text { business } \\
\text { - Strengthen capacity building for seed technology research and } \\
\text { breeder/foundation, certified seed and TLS production } \\
\text { - Strengthen programme for restoration of and patenting local } \\
\text { variety seeds } \\
\text { - Provide support to women to undertake seed production and }\end{array}$ \\
\hline
\end{tabular}




\begin{tabular}{|c|c|c|c|}
\hline Strategic Goals & Key Targets & Actions Taken/ Underway & PRSP Policy Agenda (2009-2011) \\
\hline 1 & 2 & 3 & 4 \\
\hline & & $\begin{array}{l}\text { - } 1060 \mathrm{~kg} \text { jute breeder seeds supplied to BADC by BJRI } \\
\text { for producing certified and foundation seeds }\end{array}$ & conservation activities on a commercial basis \\
\hline \multicolumn{4}{|c|}{ Lead Responsibility: MoA Associate Responsibility: DAM, Hortex Foundation, BADC, DAE, NGOs, BARC and Private Sectors } \\
\hline $\begin{array}{l}\text { 10. Improving agricultural marketing } \\
\text { services }\end{array}$ & $\begin{array}{l}\text { - Reduce producer-consumer price spread } \\
\text { - Reduce marketing costs of crops } \\
\text { - Develop marketing facilities } \\
\text { - Improve value chain of specific product } \\
\text { - Ensure business development services (BDS) } \\
\text { - Strengthening forecasting system of prices of } \\
\text { agricultural inputs, products, supply and demand }\end{array}$ & $\begin{array}{l}\text { - Location-specific information about crop prices } \\
\text { provided by DAM } \\
\text { - Local market system strengthened } \\
\text { - BMDA constructed } 120 \mathrm{~km} \text { rural road and } 65 \\
\text { bridge/culverts } \\
\text { - Construction of } 45 \text { markets completed } \\
\text { - About } 100 \text { Farmers Marketing Group (FMG) being } \\
\text { formed in Rajshahi Division } \\
\text { - A interactive website launched by DAM linking } 42 \\
\text { districts for disseminating different market } \\
\text { information } \\
\text { - One cool chamber in Narshingdi and two processing } \\
\text { centres at Savar and in Comilla under construction } \\
\end{array}$ & $\begin{array}{l}\text { - Further strengthen capacity of DAM } \\
\text { - Establishment of Agricultural Price Commission } \\
\text { - Develop further the existing markets and establish new market } \\
\text { places } \\
\text { - Strengthen price analysis, forecasting, market research and } \\
\text { development } \\
\text { - Improve transport facilities } \\
\text { - Strengthen Agri-Business Development Services through } \\
\text { developing Local Service Providers (LSP) } \\
\text { - Strengthen agricultural marketing extensions services } \\
\text { - Ensure women farmer's access to farmers market }\end{array}$ \\
\hline \multicolumn{4}{|c|}{ Lead Responsibility: MoA Associate Responsibility: DAM, Hortex Foundation, DAE, BADC, NGOs, BARC and Private Sectors } \\
\hline $\begin{array}{l}\text { 11. Promoting agro-processing and } \\
\text { agri-business development }\end{array}$ & $\begin{array}{l}\text { - Increase opportunities for value addition to crops } \\
\text { - Strengthen linkages among farmers, traders, } \\
\text { processors and business service providers } \\
\text { - Introduce agri-insurance policy }\end{array}$ & $\begin{array}{l}\text { - Increased budget allocation and incentive package } \\
\text { declared for agro-entrepreneurs } \\
\text { - Agri-business development project undertaken } \\
\text { - Established cool chambers and processing centres } \\
\text { - Farmers training and trainers training undertaken } \\
\text { - Provided working capital through credit provision } \\
\text { - Agri-business development project implemented }\end{array}$ & $\begin{array}{l}\text { - Continue supports to agro-entrepreneurs } \\
\text { - Strengthen government-NGO-Private sector collaboration } \\
\text { - Provide Agri-credit at preferential rates to small and women } \\
\text { entrepreneurs } \\
\text { - Encourage agro-entrepreneurs for agro-processing and agri- } \\
\text { business development involving poor and women }\end{array}$ \\
\hline \multicolumn{4}{|c|}{ Lead Responsibility: MoA Associate Responsibility: DAM, Hortex Foundation, DAE, BADC, NGOs, BARC and Private Sectors } \\
\hline $\begin{array}{l}\text { 12. Promoting investment in } \\
\text { agriculture }\end{array}$ & $\begin{array}{l}\text { - Make provision for appropriate financial support } \\
\text { to research, extension and farmers to ensure level } \\
\text { playing field for them } \\
\text { - Encourage farmers for developing saving habits }\end{array}$ & $\begin{array}{l}\text { - Support provided to distribution of agricultural } \\
\text { inputs } \\
\text { - Investment in agricultural research increased } \\
\text { - Limited subsidy provided } \\
\text { - Credit facilities provided for small scale investment in } \\
\text { agriculture through DAE } \\
\text { - Women trained on post-harvest handling and } \\
\text { processing technologies by DAE }\end{array}$ & $\begin{array}{l}\text { - Rationalise level of subsidy for increasing efficiency and } \\
\text { competitiveness } \\
\text { - Develop savings policy for the rural poor particularly for poor } \\
\text { women } \\
\text { - Provide agricultural credit at lower interest rate particularly to } \\
\text { marginal and women farmers }\end{array}$ \\
\hline \multicolumn{4}{|c|}{ Lead Responsibility: MoA Associate Responsibility: DAE, DAM, Hortex Foundation, BADC, BARC, BINA, BRRI, Universities, Other Research Institutes, NGOs, and Private Sectors } \\
\hline $\begin{array}{l}\text { 13. Mainstreaming women in } \\
\text { agriculture sector }\end{array}$ & $\begin{array}{l}\text { - Enhance women's participation in crop } \\
\text { agriculture, fisheries, livestock and forestry }\end{array}$ & $\begin{array}{l}\text { - National Agriculture Policy emphasized participation } \\
\text { of women in agriculture } \\
\text { - Women targeted in extension and training } \\
\text { programme } \\
\text { - Nearly } 6000 \text { women trained in income generating } \\
\text { activities }\end{array}$ & $\begin{array}{l}\text { - Create further enabling environment for women in agriculture } \\
\text { - Encourage and provide assistance to women to undertake } \\
\text { farming activities on a commercial basis } \\
\text { - Encourage women as extension workers } \\
\text { - Providing agricultural credit to women farmers }\end{array}$ \\
\hline
\end{tabular}




\begin{tabular}{|c|c|c|c|}
\hline Strategic Goals & Key Targets & Actions Taken/ Underway & PRSP Policy Agenda (2009-2011) \\
\hline 1 & 2 & 3 & 4 \\
\hline \multicolumn{4}{|l|}{ Sub-Sector: Fisheries } \\
\hline \multicolumn{4}{|c|}{ Lead Responsibility: MoFL Associate Responsibility: DoF, BFRI, BFDC, Fish Farmers, Fish Traders, MiL, MoWR, NGOs and Private Sectors } \\
\hline $\begin{array}{l}\text { 14. Increasing productivity in inland } \\
\text { aquaculture }\end{array}$ & $\begin{array}{l}\text { - Increase aquaculture production up to } 13.7 \text { lakh } \\
\text { MT by } 2011 \\
\text { - Strengthen human resources development for } \\
\text { aquaculture } \\
\text { - Disburse micro credit for fish farmers and } \\
\text { disseminate improved aquaculture technologies } \\
\text { - Maximize pond aquaculture coverage and } \\
\text { encourage private sector }\end{array}$ & $\begin{array}{l}\text { - Formulated fisheries sub-sector road map } \\
\text { - Formulated inland aquaculture sub-strategy } \\
\text { - Imparted training on different aquaculture techniques } \\
\text { to fish farmers, hatchery, nursery operators and fishers } \\
\text { - Enhanced supply of quality brood and fish seed } \\
\text { - Developed water bodies through different projects } \\
\text { - Micro credit distributed to poor and marginal farmers } \\
\text { - Training and credit programme under Youth } \\
\text { Department }\end{array}$ & $\begin{array}{l}\text { - Undertake development programme in accordance with inland } \\
\text { aquaculture sub-strategy and fisheries sector road map } \\
\text { - Expand fisheries extension service up to union level and } \\
\text { ensure quality fish seed for the farmers } \\
\text { - Strengthen institutional capacity of DoF } \\
\text { - Update fisheries policy and strategies } \\
\text { - Strengthen intra and inter sector linkages including } \\
\text { government-NGO partnership } \\
\text { - Strengthen research-extension-farmers linkage } \\
\text { - Undertake massive programme for releasing fish fries in open } \\
\text { waters }\end{array}$ \\
\hline \multicolumn{4}{|c|}{ 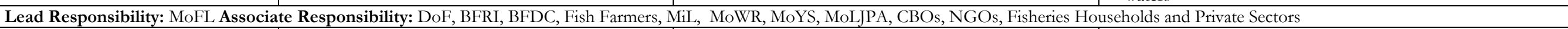 } \\
\hline $\begin{array}{l}\text { 15. Increasing productivity in inland } \\
\text { capture fisheries }\end{array}$ & $\begin{array}{l}\text { - Increase fish production from semi closed and } \\
\text { closed inland water bodies } \\
\text { - Reclaim and improve fish habitats and sanctuaries } \\
\text { - Restore and conserve indigenous and endangered } \\
\text { fish species }\end{array}$ & $\begin{array}{l}\text { - Formulated inland capture fisheries (ICF) sub-strategy } \\
\text { - Popularized Community Based Fisheries Management } \\
\text { - LEAF (Local Extension Agent for Fisheries) } \\
\text { promoted } \\
\text { - Restored fish habitat } \\
\text { - Established } 377 \text { fish sanctuaries } \\
\text { - Declared } 4 \text { protected areas for Jatka-Hilsa } \\
\text { - Hilsa action plan implemented } \\
\text { - Jatka protection programme executed. }\end{array}$ & $\begin{array}{l}\text { - Undertake development programme in accordance with inland } \\
\text { capture fisheries sub-strategy and fisheries sector road map } \\
\text { - Ensure that Jalmahals are handed over to DoF as per } \\
\text { requirement } \\
\text { - Consolidate regulatory framework } \\
\text { - Update Jalmahal management policy and ensure greater } \\
\text { involvement of poor and women } \\
\text { - Promote and expand CBMF activities } \\
\text { - Develop public-private partnership approach }\end{array}$ \\
\hline \multicolumn{4}{|c|}{ Lead Responsibility: MoFL Associate Responsibility: DoF, BFRI, Fish Farmers, Fish Traders, CBOs, NGOs and Private Sectors } \\
\hline 16. Raising income of poor fishers & $\begin{array}{l}\text { - Increase income from fish catch and improved } \\
\text { fish marketing } \\
\text { - Increase income from Alternate Income } \\
\text { Generating Activities (AIGAs) during the lean } \\
\text { season } \\
\text { - Strengthen value chain in fish/fish bi-product } \\
\text { marketing }\end{array}$ & $\begin{array}{l}\text { - Enhanced fish catch from open waters } \\
\text { - Micro credit provided for AIGAs } \\
\text { - VGD/VGF programme for Jatka fishers introduced } \\
\text { as a support for alternate livelihood } \\
\text { - Increased Hilsa catch } \\
\text { - Imparted training to poor fishers on different trades }\end{array}$ & $\begin{array}{l}\text { - Ensure poor fishermen's ownership of Khas Jalmahals } \\
\text { - Encourage women to participate in fishery production } \\
\text { activities } \\
\text { - Undertake activities for generation of fishermen's own capital } \\
\text { - Develop low cost and improved fish processing, packaging } \\
\text { and transportation systems } \\
\text { - Strengthen fish marketing policy }\end{array}$ \\
\hline \multicolumn{4}{|c|}{ Lead Responsibility: MoFL Associate Responsibility: DoF, DAE, BRRI, CBOs, NGOs and Private Sectors } \\
\hline 17. Promoting rice cum fish culture & $\begin{array}{l}\text { - Introduce fish production in rice field } \\
\text { concurrently and alternately }\end{array}$ & $\begin{array}{l}\text { - Imparted training on rice cum fish/shrimp culture } \\
\text { - Provided micro credit for rice cum fish/shrimp } \\
\text { culture } \\
\text { - Rice cum fish culture strategy is emphasized in } \\
\text { existing fishery research and extension policy } \\
\text { - Demonstrations on rice-fish culture undertaken } \\
\text { - Farmers' training, farmers' rally and motivational tour } \\
\text { for promoting rice fish culture conducted }\end{array}$ & $\begin{array}{l}\text { - Popularize rice cum fish/shrimp culture } \\
\text { - Emphasise rice cum fish culture in fishery curricula and } \\
\text { mainstream training programme } \\
\text { - Develop and disseminate technology for profitable rice cum } \\
\text { fish culture } \\
\text { - Encourage NGO and private sector collaboration in rice cum } \\
\text { fish/shrimp culture }\end{array}$ \\
\hline
\end{tabular}


Lead Responsibility: MoFL Associate Responsibility: BFRI, DoF, MoI, MoHFW, MoL, MoWCA, MoF, MoEMR, Fish Farmers, and Private Sector

18. Strengthening fisheries research $\quad$ • Accelerate fisheries research for higher

and extension

productivity

- Strengthen extension of new technologies

- Fisheries research arranged in BFRI, BAU and other universities

- DoF provides fisheries extension services
- Strengthen fisheries research in collaboration with the Universities and private sector

- Expand fisheries extension services up to Union level \begin{tabular}{l|l}
\hline 19. Increasing productivity of & $\bullet$ Increase sustainable marine and brackish water
\end{tabular}

marine and brackish water fisheries production
- Formulated marine fisheries sub-strategy

- Marine fishing regulations reviewed and amended

- Undertook initiatives for development of artisanal fisheries

\section{Lead Responsibility: MoFL Associate Responsibility: DoF, BFRI, BFFEA, BSFF, MoC, Fish/Shrimp Farmers, Processing Industries}

20. Assuring quality fish and fishery $\quad$ - Increase export of quality fish and fishery products for domestic and

international markets products

- Comply buyers
fishery products
- Formulated quality control sub-strategy

- Introduced HACCP and traceability in fish product

handling from production to consumption stages

- Imparted training on HACCP and traceability

- Established PCR lab and microbial/chemical lab

- Strengthened capacity of DoF quality control unit

- Undertaken campaign and enforcement of law to ensure formalin free fish and fish products

\section{Sub-Sector: livestock}

Lead Responsibility: MoFL Associate Responsibility: DLS, BLRI, MoC, BAU, Veterinary University and Colleges, Private Sector, NGOs

21. Increasing productivity in livestock sector

- Increase livestock production

- Increase income of livestock and poultry farmers

- Develop business services and market growth
- Livestock policy approved

- Critical areas identified for livestock development

- Tax and duty concessions allowed

- Graduates from universities and colleges trained

- Women and Youth employment training in livestock

\section{Lead Responsibility: MoFL Associate Responsibility: DLS, BLRI, BAU, MoC, MoYS, NGOs, Veterinary University and Colleges, Private Sector}

22. Promoting poultry sector

development
- Raise poultry production

- Raise income of poor and women poultry farmers

\section{$\bullet$}

- Poultry sector entrepreneurs encouraged through

favourable fiscal measures
- Strengthen capacity of DoF marine wing

- Establish fishing right for artisanal fishers

- Mitigate conflict between artisanal and commercial fishing

- Establish monitoring and controlling of marine fisheries

- Ensure quality and health hazard free fish and fishery products

- Emphasise traceability and HACCP regarding export and

domestic markets

- Review and strengthen export market policy

- Implement livestock policy related action plan

- Encourage community-based livestock service

- Encourage women's participation in market based livestock activities

- Increase budgetary allocation for livestock sector

- Continue strengthening capacity of DLS

- Develop livestock market development services

- Continue fiscal and technical support to private sector and NGOs

- Provide support to continue poultry hatching egg export

- Strengthen capacities of disease investigation network of DLS

- Strengthen bio-security measures to protect poultry industry

from infectious diseases

- Provide support to women to undertake poultry production on a commercial basis

Lead Responsibility: MoFL Associate Responsibility: DLS, BLRI, BAU, MoC, Veterinary University and Colleges, Private Sector, NGOs

23. Promoting milk and meat production
- Increase milk, meat and egg production

- Develop milk and meat processing facilities
- Breeds of dairy cows improved by breed up gradation programme and AI extension activities

- Training and extension services for goat and sheep rearing strengthened
- Encourage private sector and NGOs participation in dairy development through AI, embryo transfer and breed up gradation programme

- Encourage women to undertake livestock raising activities on a commercial basis 


\begin{tabular}{|c|c|c|c|}
\hline Strategic Goals & Key Targets & Actions Taken/ Underway & PRSP Policy Agenda (2009-2011) \\
\hline \multirow[t]{2}{*}{1} & 2 & 3 & 4 \\
\hline & & & $\begin{array}{l}\text { - Continue Buffalo, goat and sheep development activities } \\
\text { - Strengthen support to small scale dairy and poultry farmers } \\
\text { - Provide support for greater involvement of women in } \\
\text { livestock and poultry activities } \\
\text { - Strengthen market channels keeping focus on poor women } \\
\text { involved in this activities }\end{array}$ \\
\hline \multicolumn{4}{|c|}{ Lead Responsibility: MoFL Associate Responsibility: DLS, BLRI, BAU, MoC, Veterinary University and Colleges, Private Sector, NGOs } \\
\hline $\begin{array}{l}\text { 24. Strengthening livestock research } \\
\text { and extension }\end{array}$ & $\begin{array}{l}\text { - Increase production of livestock products } \\
\text { - Develop new breeds of livestock }\end{array}$ & $\begin{array}{l}\text { - Livestock Research arranged in BLRI and BAU } \\
\text { - Private sector, NGOs and CBOs being encouraged to } \\
\text { provide livestock extension services }\end{array}$ & $\begin{array}{l}\text { - Strengthen support to livestock research and extension } \\
\text { - Strengthen DLS to extend livestock services up to Union level } \\
\text { - Emphasise research on emerging diseases of livestock } \\
\text { - Develop improved animal husbandry practices and veterinary } \\
\text { services and disseminate them to poor and women }\end{array}$ \\
\hline \multicolumn{4}{|l|}{ Sub-Sector: Forestry } \\
\hline \multicolumn{4}{|l|}{ Lead Responsibility: MoEF Assc } \\
\hline $\begin{array}{l}25 \text {. Ensuring } \\
\text { sustainable livelihood of poor and } \\
\text { women }\end{array}$ & $\begin{array}{l}\text { - Improve access of the poor to natural resources } \\
\text { for production, nutrition and health } \\
\text { - Increase access of the poor to Common Property } \\
\text { Resources (CPR) through policy and project } \\
\text { interventions } \\
\text { - Ensure access of the poor in NRM especially in } \\
\text { forestry } \\
\text { - Raise awareness of the role of environment in } \\
\text { sustainable livelihood }\end{array}$ & $\begin{array}{l}\text { - Forestry Sector Master Plan is under revision } \\
\text { - Draft document prepared for Wildlife (Preservation) } \\
\text { Act, } 1974 \\
\text { - Social Forestry Rules } 2004 \text { approved } \\
\text { - Forestry Sector Development Projects including } \\
\text { Coastal Char Land Afforestation Project successfully } \\
\text { implemented }\end{array}$ & $\begin{array}{l}\text { - Introduce regulatory framework recognizing the rights of local } \\
\text { people including women on common property } \\
\text { - Establish and protect property rights } \\
\text { - Undertake projects/programme on CPR } \\
\text { - Continue and strengthen national tree fair programme } \\
\text { - Ensure public access to information on CPR } \\
\text { - Increase non-consumptive benefit of forest } \\
\text { - Increase scope for research and education } \\
\text { - Implement CBD, UNCCD, UNFCCC } \\
\text { - Strengthen capacity of MoEF and DF } \\
\end{array}$ \\
\hline \multicolumn{4}{|c|}{ Lead Responsibility: MoEF Associate Responsibility: MoF, BARI, FD, DOE, DAE, BMDA, NGOs } \\
\hline $\begin{array}{l}\text { 26. Increasing forest resources and } \\
\text { improving land quality }\end{array}$ & $\begin{array}{l}\text { - Bring } 20 \text { percent of land under forest by } 2015 \\
\text { - Implement National Forest Policy } \\
\text { - Improve organic contents and nutrients in soils of } \\
\text { affected areas } \\
\text { - Increase tree cover in the denuded lands } \\
\text { - Conserve and preserve soil }\end{array}$ & $\begin{array}{l}\text { The following projects being implemented: } \\
\text { - Reed Land Integrated Social Forest Project } \\
\text { - Social Forestry for Development and Management of } \\
\text { Forest Resources, Coastal Char Land Afforestation } \\
\text { Project } \\
\text { - Agar Plantation } \\
\text { - Projects on bamboo, cane and mutha plantation } \\
\text { - Poverty alleviation through participatory forestry } \\
\text { - Programme for use of organic manures through } \\
\text { farmer field schools (FFS) popularized } \\
\text { - IPM/ICM programme promoted } \\
\text { - Research on saline and drought tolerant varieties } \\
\text { undertaken } \\
\text { - Land quality through biogas technology enriched } \\
\text { - Ratification of Stockholm Convention undertaken } \\
\text { - National Implementation Plan (NIP) on Persistent } \\
\text { Organic Pollutants (POPs) formulated }\end{array}$ & $\begin{array}{l}\text { - Plant more indigenous species of trees } \\
\text { - Increase participation of people in social forestry } \\
\text { - Increase production of bamboo, cane, mutha and agar } \\
\text { - Encourage balanced use of fertilizers } \\
\text { - Extend and continue IPM/ICM } \\
\text { - Increase funds for saline and drought tolerant crop varieties } \\
\text { - Promote Integrated Plant Nutrient System (IPNS) and } \\
\text { adjustment of cropping patterns } \\
\text { - Increase tree-cover on denuded forest land with suitable native } \\
\text { - species } \\
\text { - Measure and stop illegal tree felling and encroachment } \\
\text { - Ensure massive plantation in fallow land and marginal land } \\
\text { - Develop market based incentive mechanism to prevent illegal } \\
\text { - Develing mechanism to involve local communities for } \\
\text { afforestaion activities } \\
\text { - Ensure women's greater involvement in afforestation activities }\end{array}$ \\
\hline
\end{tabular}




\begin{tabular}{|c|c|c|c|}
\hline Strategic Goals & Key Targets & Actions Taken/ Underway & PRSP Policy Agenda (2009-2011) \\
\hline 1 & 2 & 3 & 4 \\
\hline & & $\begin{array}{l}\text { - Sustainable Land Management Project formulated } \\
\text { - People started to receive benefits from participatory } \\
\text { forestry } \\
\text { - Coastal afforestation and homestead forestry } \\
\text { replication }\end{array}$ & for income generation \\
\hline \multicolumn{4}{|c|}{ Lead Responsibility: MoEF Associate Responsibility: MoF, MoSICT, MoA, FD, DoE, BFRI, NGOs, National Herbarium } \\
\hline 27. Conserving bio-diversity & $\begin{array}{l}\text { - Document and improve state of floral and faunal } \\
\text { biodiversity } \\
\text { - Implement biodiversity policies } \\
\text { - Involve people in co-management of PAs }\end{array}$ & $\begin{array}{l}\text { - } 19 \text { protected areas (PAs) established covering } 0.245 \\
\text { million ha of land } \\
\text { - Madhupur National Park developed } \\
\text { - Eco-park at Kuakata of Kalapara Uapazila established } \\
\text { - Botanical Garden and Eco-park in Chittagong } \\
\text { established } \\
\text { - Madhutila Eco-park established } \\
\text { - Safari Park in Cox's Bazar developed further } \\
\text { - Biodiversity of } 2 \text { Wildlife Sanctuary of Chittagong } \\
\text { developed } \\
\text { - } 2 \text { Eco-park in Greater Sylhet District established } \\
\text { - Dhanshiri Eco-park established and Ramsagar } \\
\text { National Park developed } \\
\text { - Nishorgo Support Project is being implemented to } \\
\text { establish co-management in } 5 \text { PAs } \\
\text { - Imposed moratorium on logging in natural forest up } \\
\text { to } 2010\end{array}$ & $\begin{array}{l}\text { - Bring more PAs under co-management and include poor and } \\
\text { women in co-management } \\
\text { - Strengthen and expand eco-parks and eco-tourism } \\
\text { - Formulate and implement biodiversity policy keeping the } \\
\text { interest of poor and women } \\
\text { - Conduct regular survey of flora and fauna }\end{array}$ \\
\hline \multicolumn{4}{|c|}{ Lead Responsibility: MoEF Associate Responsibility: MoF, ERD, MoP, FD, DoF } \\
\hline $\begin{array}{l}\text { 28. Adapting climate change and } \\
\text { mitigation }\end{array}$ & $\begin{array}{l}\text { - Plan for climate change adaptation } \\
\text { - Introduce CDM activities / Carbon trading }\end{array}$ & $\begin{array}{l}\text { - “Climate Change Resilient Afforestation in } \\
\text { Bangladesh' project proposed }\end{array}$ & $\begin{array}{l}\text { - Undertake studies on climate change impacts on livelihoods of } \\
\text { the poor } \\
\text { - Undertake action plan to minimise hazardous impact of } \\
\text { climate change on lives and properties }\end{array}$ \\
\hline \multicolumn{3}{|c|}{ Total Indicative Cost (in billion taka) } & Tk. 180.00 \\
\hline
\end{tabular}


Policy Matrix 4: Water Resources Development and Management

\begin{tabular}{|c|c|c|c|}
\hline Strategic Goals & Key Targets & Actions Taken/ Underway & PRSP Policy Agenda (2009-2011) \\
\hline 1 & 2 & 3 & 4 \\
\hline \multicolumn{4}{|c|}{ Lead Responsibility: MoWR, BWDB, WARPO, BHWDB, LGED, BADC, BMDA, CEGIS Associate Responsibility: MoEF } \\
\hline $\begin{array}{l}\text { 1. Expanding utilization of surface water, } \\
\text { including coastal polders and arsenic prone } \\
\text { areas }\end{array}$ & $\begin{array}{l}\text { - Extend surface water Irrigation } \\
\text { area by } 66,000 \text { ha. } \\
\text { - Increase supply of safe water for } \\
\text { domestic use } \\
\text { - Reduce ground water use by } \\
\text { optimizing surface water use } \\
\text { (conjunctive use) }\end{array}$ & $\begin{array}{l}\text { - Studies undertaken to determine utilization of the } \\
\text { flow of the main rivers } \\
\text { - Suitable locations identified for dual purpose } \\
\text { pump houses (to be used both for irrigation and } \\
\text { flood reduction) } \\
\text { - Irrigation components included in large flood } \\
\text { control projects } \\
\text { - BADC continued minor irrigation programmes as } \\
\text { usual } \\
\text { - LGED continued SSWRDSP-II for extending } \\
\text { small scale irrigation } \\
\text { - 3rd Small Scale Water Resources Development } \\
\text { Sector Project of LGED underway } \\
\text { - 2nd Small Scale Water Resources Sector } \\
\text { Development Sector Project of LGED is underway }\end{array}$ & $\begin{array}{l}\text { - Develop supplementary irrigation in coastal areas } \\
\text { - Extend Mahamaya Chhara Irrigation Project under Mirsarai upazila in } \\
\text { - Chittagong district } \\
\text { - Undertake Kurigram Irrigation Project (North and South Unit) } \\
\text { - Undertake Mathamuhuri Irrigation Project Phase-II } \\
\text { - Undertake Muhuri- Kahua FCDI Project } \\
\text { - Undertake North Rajshahi Irrigation Project } \\
\text { - Protect Chandpur Irrigation Project (CIP) area from erosion of the } \\
\text { - Ueghna River (Phase I) } \\
\text { - Undertake South Comilla-North Noakhali Comprehensive FCDI Project } \\
\text { - Urgentake Teesta Barrage Project Phase II (Unit I) } \\
\text { economic development }\end{array}$ \\
\hline \multicolumn{4}{|c|}{ Lead Responsibility: MoWR, BWDB, WARPO, JRC, RRI, BHWDB, LGED, BADC, BMDA, CEGIS, IWM Associate Responsibility: MoEF } \\
\hline $\begin{array}{l}\text { 2. Augmenting utilization of surface water for } \\
\text { efficient water management to ensure water } \\
\text { quality }\end{array}$ & $\begin{array}{l}\text { - Encourage rainwater } \\
\text { harvesting } \\
\text { - Excavate derelict ponds } \\
\text { - Excavate irrigation canal } \\
\text { - Re-excavate irrigation canal } \\
\text { - }(1220 \mathrm{~km}) \\
\text { - Excavate } / \text { Re-excavate } \\
\text { Drainage Canal }(1460 \mathrm{~km}) \\
\text { - Dredge } 53 \mathrm{~km} \text { of rivers } \\
\text { - Construct } 12 \text { rubber dam } \\
\text { - Ensure conjunctive use of } \\
\text { water }\end{array}$ & $\begin{array}{l}\text { - Undertaken d-siltation and re-excavation of } \\
\text { small rivers and canals using human labour } \\
\text { - Trans boundary water resources augmentation } \\
\text { through stronger regional cooperation } \\
\text { - Initiate study of Ganges Barrage, augmentation } \\
\text { of flow in the Gorai River. Replicate Tidal River } \\
\text { Management (TRM) } \\
\text { - Diverted surface water through small barrage } \\
\text { and large Water Control Structures (WCS) } \\
\text { - Rubber dam projects under the SSWRDSP-II, } \\
\text { LGED in underway }\end{array}$ & $\begin{array}{l}\text { - Extend Mahamaya Chhara Irrigation in Mirsarai upazila } \\
\text { - Undertake Kurigram Irrigation Project (North and South Unit) } \\
\text { - Undertake Mathamuhuri Irrigation Project Phase-II } \\
\text { - Undertake Teesta Barrage Project Phase II (Unit I) Undertake } \\
\text { Rehabilitation of G-K Pumping plants Kumar River Re-excavation } \\
\text { Project } \\
\text { - Construct Rubber Dam over Mahananda river in Chapainawabgonj } \\
\text { district } \\
\text { - Undertake Guptakhali Water Reservoir Irrigation Project } \\
\text { - Augment Burigonga flow by restoring links with the Jamuna river } \\
\text { - Undertake feasibility study and design of Ganges barrage } \\
\text { - Extend Chaddamadar Beel Embankment and Canal Excavation } \\
\text { - Uroject }\end{array}$ \\
\hline \multicolumn{4}{|c|}{ Lead Responsibility: MoWR, BWDB, WARPO, JRC, RRI, BHWDB, LGED, BADC, BMDA, CEGIS, IWM Associate Responsibility: MoEF } \\
\hline 3. Rationalizing utilization of groundwater & $\begin{array}{l}\text { - Groundwater management and } \\
\text { data collection, analysis and } \\
\text { distribution to concerned } \\
\text { agencies }\end{array}$ & $\begin{array}{l}\text { - National Water Policy for conjunctive use } \\
\text { surface and ground water where available \& } \\
\text { applicable } \\
\text { - Monitoring groundwater quality } \\
\text { - Maximum sustainable extraction (MSE) is } \\
\text { underway } \\
\text { - BADC continues minor irrigation programmes } \\
\text { - Ground Water data being collected }\end{array}$ & $\begin{array}{l}\text { - Undertake Barind rain water conservation and irrigation project } \\
\text { - Undertake Barind DTW installation project } \\
\text { - Undertake Barind command area development and training project } \\
\text { - Restrict GW abstraction by establishing threshold levels by GW } \\
\text { Circles of BWDB }\end{array}$ \\
\hline
\end{tabular}




\begin{tabular}{|c|c|c|c|}
\hline Strategic Goals & Key Targets & Actions Taken/ Underway & PRSP Policy Agenda (2009-2011) \\
\hline 1 & 2 & 3 & 4 \\
\hline \multicolumn{4}{|c|}{ Lead Responsibility: MoWR, BWDB, WARPO, JRC, RRI, BHWDB, LGED, BADC, BMDA, CEGIS, IWM Associate Responsibility: MoEF } \\
\hline $\begin{array}{l}\text { 4. Protecting from flood, improving drainage } \\
\text { and reducing vulnerability to water related } \\
\text { disasters including sea erosion and cyclonic } \\
\text { surges }\end{array}$ & $\begin{array}{l}\text { - Protect lives and properties } \\
\text { from flood hazards } \\
\text { - Rehabilitate polders for } \\
\text { protection of land from tidal } \\
\text { flood } \\
\text { - Replicate mechanism } \\
\text { developed under CAD projects }\end{array}$ & $\begin{array}{l}\text { - Increased allocation of O\&M resources } \\
\text { - Handing over management of the existing } \\
\text { projects to the beneficiaries started } \\
\text { - Replicate mechanism developed under } \\
\text { Command Area Development (CAD) Projects }\end{array}$ & $\begin{array}{l}\text { - Undertake Bemorta Project under Sadar \& Kachua upazila } \\
\text { - Undertake Chandpur Comilla Integrated FCDI Project } \\
\text { - Construct embankment and other ancillary works in Tannery } \\
\text { Industrial area in Savar upazila } \\
\text { - Ensure efficient O\&M of completed projects } \\
\text { - Institute appropriate environmental cell in agencies dealing with water } \\
\text { development and management } \\
\text { - Rehabilitate and maintain existing FCD/FCDI }\end{array}$ \\
\hline $\begin{array}{l}\text { 5. Protect wetland/Haor/Baor, Sunderban, } \\
\text { saline water intrusion and promote accretion } \\
\text { of land from the sea. }\end{array}$ & $\begin{array}{l}\text { - Income generation for the } \\
\text { poor from water resources }\end{array}$ & $\begin{array}{l}\text { - Community participation in multi-purpose use } \\
\text { of water and other facilities like irrigation canal, } \\
\text { fish-pass, regulators, irrigation inlets, cross dams, } \\
\text { embankment slops etc. } \\
\text { - Aquatic / wetland biodiversity preservation. }\end{array}$ & $\begin{array}{l}\text { - Hail Haor Rehabilitation } \\
\text { - Char Kukri Mukri FCD salinity control } \\
\text { - Char development and settlement } \\
\text { - Afforstation programme for ecological balance } \\
\text { - Barind environmental balance through afforestation. }\end{array}$ \\
\hline \multicolumn{4}{|c|}{ Lead Responsibility: MoWR, BWDB, WARPO, JRC, RRI, BHWDB, LGED, BADC, BMDA, CEGIS, IWM Associate Responsibility: MoEF } \\
\hline $\begin{array}{l}\text { 6. Managing erosion of major rivers and } \\
\text { protect large and small towns. }\end{array}$ & $\begin{array}{l}\text { - Protect habitation of poor } \\
\text { people on raised platforms in } \\
\text { char areas } \\
\text { - Make accreted land habitable } \\
\text { and suitable for crop } \\
\text { production } \\
\text { - Implement Integrated Coastal } \\
\text { Zone Management Plan } \\
\text { - Protect socio-economic } \\
\text { infrastructure at local level } \\
\text { against erosion }\end{array}$ & $\begin{array}{l}\text { - Coordinated efforts to make the accreted land } \\
\text { habitable and suitable for crop production in } \\
\text { ongoing } \\
\text { - Implementation of Integrated Coastal Zone } \\
\text { Management Plan (ICZM) is ongoing } \\
\text { - Protection of vulnerable areas from erosion, } \\
\text { especially saving places of economic importance } \\
\text { and densely populated areas is ongoing } \\
\text { - Activities to protect wet lands are being } \\
\text { undertaken }\end{array}$ & $\begin{array}{l}\text { - Undertake river bank protective works along the left bank of } \\
\text { Karnafuli River at Charandeep and Kadurkhil } \\
\text { - Undertake Bhola District Town Protection Project Phase II } \\
\text { - Undertake Border River Protection and Development Project, Phase } \\
\text { II } \\
\text { - Undertake Charfesson \& Monpura Town Protection Project } \\
\text { - Undertake Emergency Protection of Charlangta of Charelahi union in } \\
\text { Companigonj upazila in Polder-59/3C } \\
\text { - Undertake Jamuna Padma Left Bank Project } \\
\text { - Undertake Jamuna-Meghna River Erosion Mitigation Project } \\
\text { - Undertake Monno River Bank Protection and Rehabilitation Project } \\
\text { - Undertake Narasingdi Town Protection Project } \\
\text { - Undertake Patuakhali Town Protection Embankment Project } \\
\text { - Protect Meghai Bazar, Suvgacha \& Simla area, Baguria of Gaibandah } \\
\text { Sadar upazila and Sayedpur, Kanchipara and Balashighat of Fulchari } \\
\text { upazila, Bandarbari and adjacent area and Handloom enriched Betil \& } \\
\text { Enyetpur Bazar area from the Jamuna erosion } \\
\text { - Protect Bangladesh Navy's BNS Titumir Naval Station area from } \\
\text { erosion of Bhairab River } \\
\text { - Protect Brahmaputra River Right Bank at Bairagirhat and Chilmari } \\
\text { under Kurigram district -Phase I } \\
\text { - Protect Chapainawabgonj Sadar and Sibgonj upazila, Hasail- } \\
\text { Panchgaon-Garurgaon Bazar area under Tongibari upazila, Faridpur } \\
\text { Town and adjacent area, Charbhadrasion upazila, Lalpur upazila, } \\
\text { Chandpur town, Lauhojong upazila complex from erosion of the } \\
\text { Padma River } \\
\text { - Protect Goali Chhara, Kazirbazar chhara, Jangalia-Jugirgaon \& } \\
\text { Mahtabpur in Sylhet Sadar upazila }\end{array}$ \\
\hline
\end{tabular}




\begin{tabular}{|c|c|c|c|}
\hline Strategic Goals & Key Targets & Actions Taken/ Underway & PRSP Policy Agenda (2009-2011) \\
\hline 1 & 2 & 3 & 4 \\
\hline & & & $\begin{array}{l}\text { - Protection of Kadupur-Basantapur, Manik-kona, Velkona-Moinpur } \\
\text { area under Golapgonj and Fenchugonj upazila in Sylhet District from } \\
\text { erosion of the Kushiyara River } \\
\text { - Protect Raipur Coast Guard at Anowara upazila in Chittagong district } \\
\text { - Protect Soilbari and adjacent area of Sirajgonj Town from erosion of } \\
\text { the Jamuna River in Sirajgonj district } \\
\text { - Protect Teesta River Left Bank from Teesta Barrage to Chandimari } \\
\text { and upstream of Teesta River including Shoals Removal from the } \\
\text { Teesta River Bed near Teesta Barrage. } \\
\text { - Protect Jamuna river left bank from Horindhara to Hargila under } \\
\text { Islampur upazila in Jamalpur district } \\
\text { - Undertake Secondary Town Integrated Flood Protection Project } \\
\text { Phase II } \\
\text { - Undertake a study on Detailed Coastal Land Zoning with two Pilot } \\
\text { District Plain Lands (WARPO) } \\
\text { - Repair embankments on both banks of Gumti river } \\
\text { - Construct cross dam for land reclamation }\end{array}$ \\
\hline \multicolumn{4}{|c|}{ Lead Responsibility: MoWR, BWDB, WARPO, JRC, RRI, BHWDB, LGED, BADC, BMDA, CEGIS, IWM } \\
\hline $\begin{array}{l}\text { 7. Supporting revival, extension and } \\
\text { maintenance of safe navigation routes }\end{array}$ & $\begin{array}{l}\text { - Re-excavate rivers, canals and } \\
\text { Khals }\end{array}$ & $\begin{array}{l}\text { - Continuous survey of potential navigation routes } \\
\text { - BIWTA prioritizes excavation }\end{array}$ & $\begin{array}{l}\text { - Undertake dredging of rivers } \\
\text { - Undertake Khal Re-excavation project } \\
\text { - Undertake Gorai River Restoration Project } \\
\text { - Undertake Kumar River Re-excavation Project } \\
\text { - Extend Chaddamadar Beel Embankment and Canal Excavation } \\
\text { Project }\end{array}$ \\
\hline \multicolumn{4}{|c|}{ Lead Responsibility: MoWR, BWDB, WARPO, JRC, RRI, BHWDB, LGED, BADC, BMDA, CEGIS, IWM } \\
\hline $\begin{array}{l}\text { 8. Enhance access of the poor to water and } \\
\text { common water resources }\end{array}$ & $\begin{array}{l}\text { - BWDB's management to be } \\
\text { pro-IWRM in designing future } \\
\text { plans } \\
\text { - Bring women in mainstream } \\
\text { water management activities } \\
\text { - Provide support to common } \\
\text { water resources for sustaining } \\
\text { livelihood of poor and women }\end{array}$ & $\begin{array}{l}\text { - BWDB Act to authorize it for WMO } \\
\text { registration } \\
\text { - Need-based research for poverty reduction } \\
\text { through specialized institutions of GOB, } \\
\text { Universities } \\
\text { - People's participation at all stages of project } \\
\text { cycle }\end{array}$ & $\begin{array}{l}\text { - Undertake Integrated Planning for Sustainable Water Management } \\
\text { Project (IPSWAM) } \\
\text { - Undertake Water Management Improvement Project (WMIP) } \\
\text { - Undertake Char Development and Settlement Project (CDSP) Phase } \\
\text { III } \\
\text { - Undertake community based resource management project, LGED }\end{array}$ \\
\hline \multicolumn{4}{|l|}{ Lead Responsibility: MoWR } \\
\hline $\begin{array}{l}\text { 9. Developing human resource for BWDB, } \\
\text { WMOs and specialized Trusts }\end{array}$ & $\begin{array}{l}\text { Better Disaster Management } \\
\text { through advanced technology } \\
\text { \& people's participation }\end{array}$ & $\begin{array}{l}\text { - Trainings at home and abroad to update skill of } \\
\text { personnel engaged in water development and } \\
\text { management } \\
\text { - Community response to new technology }\end{array}$ & $\begin{array}{l}\text { - Remove Drainage congestion in Bhabadaha area } \\
\text { - Undertake Karotoya River Environmental Development Project } \\
\text { - Establish Environmental Cell in each agency dealing with water } \\
\text { development and management }\end{array}$ \\
\hline \multicolumn{4}{|c|}{ Lead Responsibility: MoWR, BWDB, WARPO, JRC, RRI, BHWDB, LGED, BADC, BMDA, CEGIS, IWM } \\
\hline $\begin{array}{l}\text { 10. Monitoring of hydrological (surface and } \\
\text { ground), climate and maritime data and } \\
\text { ensuring environmental management }\end{array}$ & $\begin{array}{l}\text { - Collect data from river } \\
\text { stations: } \\
\text { - } 2008-09-225 \text { nos } \\
\text { - } 2009-10-250 \text { nos }\end{array}$ & $\begin{array}{l}\text { - Data collection } \\
\text { - Discussion for maritime data exchange } \\
\text { - Climate Change Cell to monitor and guide } \\
\text { adaptation measures }\end{array}$ & $\begin{array}{l}\text { - Undertake Emergency Disaster Damage Rehabilitation (Sector) } \\
\text { Project } \\
\text { - Undertake emergency rehabilitation works damaged by Cyclone sidr } \\
\text { - Undertake Climate/Flood Forecast Application for Water related }\end{array}$ \\
\hline
\end{tabular}




\begin{tabular}{|c|c|c|c|}
\hline Strategic Goals & Key Targets & Actions Taken/ Underway & PRSP Policy Agenda (2009-2011) \\
\hline \multirow[t]{2}{*}{1} & 2 & 3 & 4 \\
\hline & - 2010-11 - 300 nos. & & $\begin{array}{l}\text { Disaster Mitigation in Bangladesh } \\
\text { - Undertake Climate/Flood Forecast Application for Water related } \\
\text { Disaster Mitigation } \\
\text { - Monitor and forecast water quality index }\end{array}$ \\
\hline \multicolumn{4}{|c|}{ Lead Responsibility: MoWR, BWDB, WARPO, JRC, RRI, BHWDB, LGED, BADC, BMDA, CEGIS, IWM } \\
\hline $\begin{array}{l}\text { 11. Reviewing existing policy and legislation } \\
\text { and finalization of National Water Act }\end{array}$ & $\begin{array}{l}\text { - Strengthen WARPO } \\
\text { - Engage experts on policy and } \\
\text { legislation } \\
\text { - Ensure adequate resources for } \\
\text { studies }\end{array}$ & $\begin{array}{l}\text { - Review of policy and laws } \\
\text { - Progress monitoring } \\
\text { - Water Act }\end{array}$ & $\begin{array}{l}\text { - Update national water management Plan and create provision for } \\
\text { women in policy and legislation of water development and } \\
\text { management } \\
\text { - Conduct Study on Surface water development for alternative source of } \\
\text { drinking water supply in Arsenic affected areas } \\
\text { - Institutionalise and operationalise coastal zone management } \\
\text { - Devise strategies for reducing vulnerabilities of floods } \\
\text { - Undertake flood zoning and risk mapping for floods } \\
\text { - Develop and updated digital elevation model for Bangladesh } \\
\text { - Establish haor/wetland database }\end{array}$ \\
\hline \multicolumn{3}{|l|}{ Total Indicative Cost (in billion taka) } & Tk. 42.49 \\
\hline
\end{tabular}


Policy Matrix 5: Small and Medium Enterprise (SME) Development

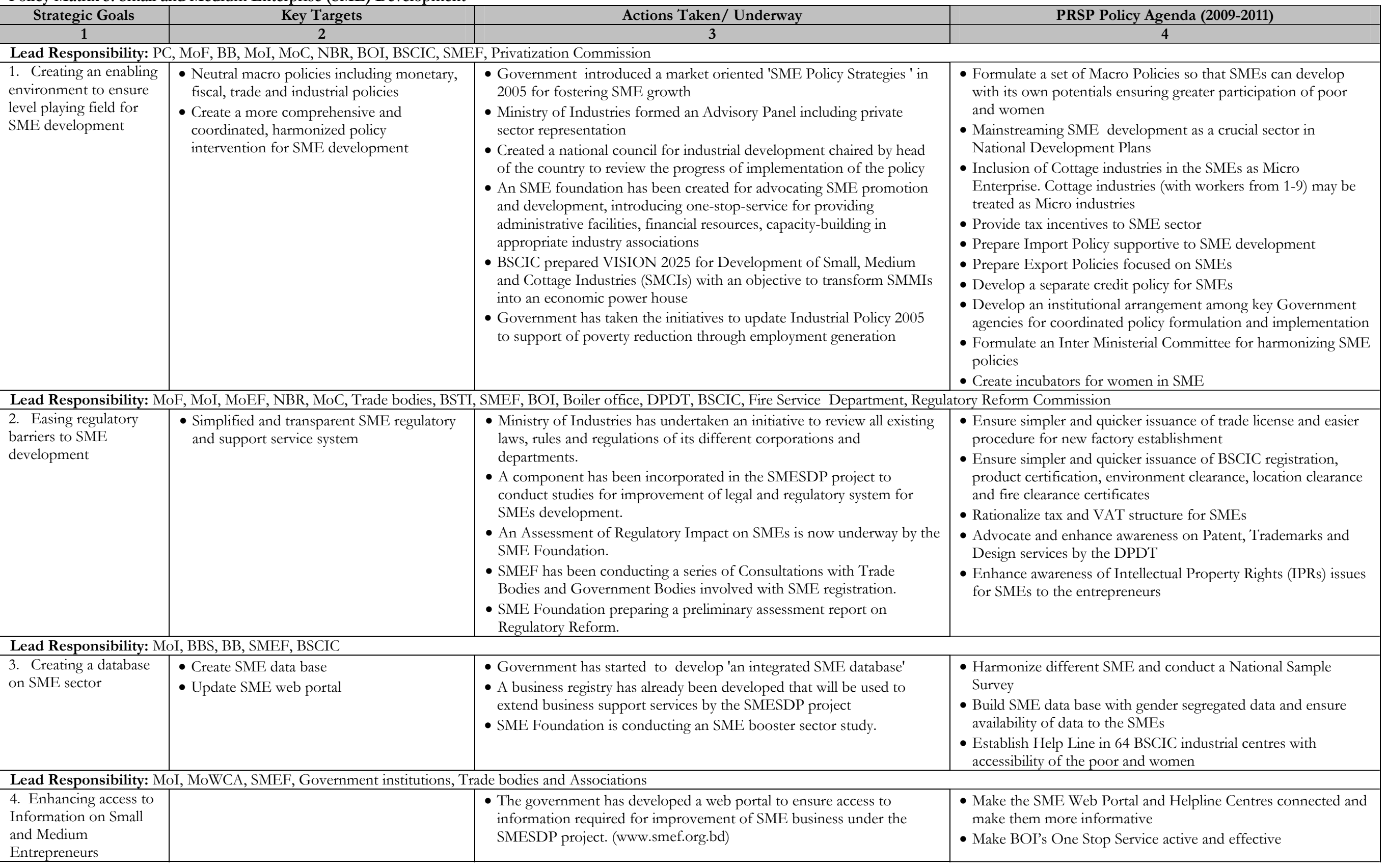




\begin{tabular}{|c|c|c|c|}
\hline Strategic Goals & Key Targets & Actions Taken/ Underway & PRSP Policy Agenda (2009-2011) \\
\hline 1 & 2 & 3 & 4 \\
\hline & & - SME foundation updates and maintain the Web portal & $\begin{array}{l}\text { - Expand Advisory Services by Industrial Estates Service Centres } \\
\text { (ISCs) of BSCIC with focus on women } \\
\text { - Expand Advisory Services by the SMEF particularly to women }\end{array}$ \\
\hline \multicolumn{4}{|c|}{ Lead Responsibility: BB, Commercial Banks, Leasing companies, SMEF, MoI, MoF, Other private sector banks } \\
\hline $\begin{array}{l}\text { 5. Increasing access to } \\
\text { finance for Small and } \\
\text { Medium Entrepreneurs }\end{array}$ & - $35 \%$ increase in flow of credit to SMEs & $\begin{array}{l}\text { - Refinancing scheme, Equity and Entrepreneurship Fund (EEF), and } \\
\text { Equity Development Fund (EDF) etc. are introduced for developing } \\
\text { SMEs. } \\
\text { - Tk. } 850 \text { million fund for refinancing SME loan is developed } \\
\text { - Many private banks have opened SME window for SME financing } \\
\text { - The government is encouraging banks and non-bank financial } \\
\text { institutions to disburse more credit by rationalising interest rates } \\
\text { - Bangladesh Bank has created Small Enterprise Fund (SEF) for } \\
\text { wholesaling credits to commercial banks } \\
\text { - BSCIC is providing collateral free loan to the underprivileged women } \\
\text { and unemployed youth to create self-employment } \\
\text { - MoI is conducting regular meeting with all Financial Institutions (PFIs) } \\
\text { to ensure credit to the SME at a discount rate }\end{array}$ & $\begin{array}{l}\text { - Formulate a separate credit policy for SMEs } \\
\text { - Advocate for reducing amount of collateral } \\
\text { - Introduce Venture Capital Financing for SMEs } \\
\text { - Enhance financing through Leasing companies } \\
\text { - Introduce Credit Guarantee Scheme } \\
\text { - Arrange Supplementation of credit flow to meet demand-supply } \\
\text { gap financing of SMEs } \\
\text { - Ensure medium and long term financing credits to SMEs by } \\
\text { - private banks } \\
\text { - Enhersify Financial Products by formal banking sector }\end{array}$ \\
\hline \multicolumn{4}{|c|}{ Lead Responsibility: NBR, MoF, MoC, SMEF, EPB } \\
\hline $\begin{array}{l}\text { 6. Providing different } \\
\text { types of incentives } \\
\text { (financial and fiscal) for } \\
\text { SMEs focusing on poor } \\
\text { and women } \\
\text { entrepreneurs }\end{array}$ & & $\begin{array}{l}\text { - Government has already provided export subsidy facilities to the } \\
\text { vegetables, agro-processing and agro-based products providers } \\
\text { - Cash-incentives are being provided to } 14 \text { exportable items at different } \\
\text { rates including vegetables. More products are under scrutiny for cash } \\
\text { incentives. }\end{array}$ & $\begin{array}{l}\text { - Provide fiscal incentives (for example VAT exemption, reducing } \\
\text { VAT rate etc.) } \\
\text { - Reduce the Import Duties of necessary Raw Materials for SMEs } \\
\text { - Set-up Industrial Parks for leading SMEs (Plastics, Electronics, } \\
\text { Electrical, Leather, Light Engineering) } \\
\text { - Set-up permanent physical facilities for SME trade fairs } \\
\text { - Ensure lower interest rates for poor women and disadvantaged } \\
\text { groups' entrepreneurs } \\
\text { - Introduce easier credit system for poor women }\end{array}$ \\
\hline \multicolumn{4}{|c|}{ Lead Responsibility: BCSIR, BITAC, Technical Institutes, Universities, Research Institutes, SMEF } \\
\hline $\begin{array}{l}\text { 7. Building new } \\
\text { technological capacity } \\
\text { and ensuring } \\
\text { technology up } \\
\text { gradation, adaptation } \\
\text { and diffusion }\end{array}$ & $\begin{array}{l}\text { - Preserve indigenous technology } \\
\text { - Upgrade technology } \\
\text { - Adapt new technology } \\
\text { - Diffuse new technology }\end{array}$ & $\begin{array}{l}\text { - SME Foundation has started stocktaking of the existing technologies } \\
\text { used in SMEs } \\
\text { - } 100 \text { indigenous technologies have been compiled and have been } \\
\text { uploaded in the SME Web Portal in Bangla } \\
\text { - National Institute of Bio-Technology has been set up } \\
\text { - Officials of BITAC are receiving overseas training regularly to improve } \\
\text { their technological knowledge. } \\
\text { - Experts from developed countries are regularly providing training to } \\
\text { the BITAC officials for development of technology } \\
\text { - BCSIR has set-up about } 22,000 \text { bio-gas plants in the country } \\
\text { - Six enterprises are producing Spirulina and two are exporting }\end{array}$ & $\begin{array}{l}\text { - Enhance R\&D for SMEs and increase funds to the research } \\
\text { institutes for innovation of new products } \\
\text { - Strengthen interaction between BCSIR and SMEF for } \\
\text { technology dissemination } \\
\text { - Encourage cooperation and partnership between the } \\
\text { universities, business and R\&D institutes } \\
\text { - A series of consultation meeting will be arranged by the SMEF } \\
\text { with the sector experts for } 6 \text { SME booster sectors } \\
\text { - Encourage invest on research and development for new product } \\
\text { innovation, product diversification and technology transfer } \\
\text { - Encourage joint venture/agreement/partnership on these areas }\end{array}$ \\
\hline \multicolumn{4}{|c|}{ Lead Responsibility: MoI Associate Responsibility: BOI, BSCIC, SMEF, Trade Bodies, Associations, WASA, PDB, TNT } \\
\hline $\begin{array}{l}\text { 8. Ensuring } \\
\text { Infrastructural facilities }\end{array}$ & $\begin{array}{l}\text { - Set-up SME Industrial Parks with all utility } \\
\text { connections }\end{array}$ & $\begin{array}{l}\text { - BSCIC has } 67 \text { industrial estates to provide infrastructural facilities for } \\
\text { establishment of industries throughout the country }\end{array}$ & $\begin{array}{l}\text { - Ensure adequate utility services (Electricity, water, gas etc.) } \\
\text { services for SMEs }\end{array}$ \\
\hline
\end{tabular}




\begin{tabular}{|c|c|c|c|}
\hline Strategic Goals & Key Targets & Actions Taken/ Underway & PRSP Policy Agenda (2009-2011) \\
\hline 1 & 2 & 3 & 4 \\
\hline $\begin{array}{l}\text { including basic utility } \\
\text { services for the SMEs }\end{array}$ & & & $\begin{array}{l}\text { - Strengthen telecommunication and ICT facilities especially for } \\
\text { small entrepreneurs } \\
\text { - Develop industrial parks for plastics, light engineering, } \\
\text { electronics and electrical products } \\
\text { - Build a Common Facility Centre including High End Mold } \\
\text { Making Factory and Design Centre }\end{array}$ \\
\hline \multicolumn{4}{|c|}{ Lead Responsibility: MoC, MoI Associate Responsibility: MoTJ, EPB, SMEF, BSTI, DPDT, NGOs, Chambers, Trade Bodies, SMED } \\
\hline $\begin{array}{l}\text { 9. Enhancing access to } \\
\text { market for SMEs } \\
\text { particularly for women } \\
\text { SME entrepreneurs }\end{array}$ & $\begin{array}{l}\text { - Arrange } 10 \text { SME product fairs every year } \\
\text { (both at national and international level) } \\
\text { - Arrange Product Fair for women } \\
\text { entrepreneurs } \\
\text { - Establish Display Centre for women SME } \\
\text { products }\end{array}$ & $\begin{array}{l}\text { - Started the process to establish International Standard Display Centre } \\
\text { - The Export Policy (2003-06) has identified } 5 \text { products as sectors with } \\
\text { the highest priority } \\
\text { - An Advisory Service Centre has been established by the SMEF to } \\
\text { provide information on the existing facilities by SEF of Bangladesh } \\
\text { Bank, training given by BSCIC Design centre, SCITI, BIM and BITAC } \\
\text { and Engineers Institution } \\
\text { - Business promotion councils on ICT, light engineering, herbal and } \\
\text { medicinal plant, leather sectors have been formed and councils on } \\
\text { pharmaceutical products, agro-processing products, poultry are in the } \\
\text { formation stage } \\
\text { - Hortex Foundation has been established for diversification into High } \\
\text { Value Crops } \\
\text { - EPB's 'One District One Product' scheme has already identified } 16 \\
\text { products from } 44 \text { districts for government approval } \\
\text { - EPB provides } 50 \% \text { concession for women entrepreneurs for } \\
\text { participating in the Trade Fair. } \\
\text { - SMEF organized } 2 \text { Women SME Product Fair in } 2007 \text { and } 2008\end{array}$ & $\begin{array}{l}\text { - Take further initiative to diversify products for SMEs } \\
\text { - Make EPB's 'One District One Product' programme effective } \\
\text { - Identify new products for SMEs } \\
\text { - Improve quality of SME products } \\
\text { - Build display centres for SME products } \\
\text { - Arrange fair for SME product at national and international } \\
\text { levels } \\
\text { - Enhance easy access to information on facilities given by the } \\
\text { EPB and other institutions } \\
\text { - Arrange more Product Fairs both in National and International } \\
\text { - Level } \\
\text { - Improve women entrepreneurs' capacity in proper pricing and } \\
\text { - Garketing skill of products }\end{array}$ \\
\hline \multicolumn{4}{|c|}{ Lead Responsibility: MoP, MoF Associate Responsibility: MoA, MoFL, MoI, MoL\&E MoI, MoEF, Ministry of Information, SMEF, DOE, NGOs, Media, Insurance Companies } \\
\hline $\begin{array}{l}\text { 10. Ensuring } \\
\text { environment friendly } \\
\text { SME development }\end{array}$ & - Make SMEs environmentally compliant & $\begin{array}{l}\text { - Restricted the new industry at approval stage which is harmful for } \\
\text { environment and introduced pollution control mechanism in the } \\
\text { existing industries. } \\
\text { - Industries, which are responsible for air pollution, are selected and air } \\
\text { pollutant emission permissible limit are established. } \\
\text { - Pilot schemes under Development of Reed based Textile Wastewater } \\
\text { Treatment are being carried out } \\
\text { - BSCIC has taken initiatives to relocate tanneries, garments and } \\
\text { pharmaceuticals industries to reduce pollution in Dhaka city } \\
\text { - Reduction of chemical fertilizer and pesticide use is encouraged, and } \\
\text { Persistent Organic Pollutants is phased out }\end{array}$ & $\begin{array}{l}\text { - Ensure installation of environment management system } \\
\text { - Build awareness in waste management system, regulatory } \\
\text { reforms on environment issues for small entrepreneurs } \\
\text { - Enhance supervision and monitoring by the BOILER office } \\
\text { - Ensure provision of CETP in the Savar Tannery Industrial Park } \\
\text { - Introduce SME insurance package to mitigate risks } \\
\text { - Create a Disaster Management Fund for rehabilitating calamity- } \\
\text { stricken SMEs with especial emphasis on SMEs owned by } \\
\text { women }\end{array}$ \\
\hline \multicolumn{4}{|c|}{ Lead Responsibility: MoP, MoF Associate Responsibility: MoA, MoFL, MoI, MoLE, SMEF, EPB, MoI, MoC } \\
\hline $\begin{array}{l}\text { 11. Assessing SME } \\
\text { booster Sectors' } \\
\text { performance and } \\
\text { expanding the list }\end{array}$ & $\begin{array}{l}\text { - Complete } 11 \text { Booster Sector Studies } \\
\text { - Successful completion of 'ONE DISTRICT } \\
\text { ONE PRODUCT' project }\end{array}$ & $\begin{array}{l}\text { - SME Foundation is conducting an SME booster sector study (6 } \\
\text { sectors). The studies will recommend policy strategies for } 6 \text { booster } \\
\text { sectors identified in the SME Policy Strategies } 2005 \text {. }\end{array}$ & $\begin{array}{l}\text { - Review the existing } 11 \text { booster sectors } \\
\text { - Develop comparative advantage-based, area-specific SMEs in } \\
\text { selected areas }\end{array}$ \\
\hline
\end{tabular}




\begin{tabular}{|c|c|c|c|}
\hline Strategic Goals & Key Targets & Actions Taken/ Underway & PRSP Policy Agenda (2009-2011) \\
\hline 1 & 2 & 3 & 4 \\
\hline \multicolumn{4}{|c|}{ Lead Responsibility: MoI, BSTI, Trade bodies, Chambers, SMEF } \\
\hline $\begin{array}{l}\text { 12. Improving quality } \\
\text { and standards of SME } \\
\text { products }\end{array}$ & $\begin{array}{l}\text { - Ensure and increase quality certification to } \\
\text { SMEs } \\
\text { - Ensure and increase product } \\
\text { standardization certificates to SMEs }\end{array}$ & $\begin{array}{l}\text { - Consumer Rights Protection Law has been approved in principle } \\
\text { - BSTI implemented a project called "Market Access and Trade } \\
\text { Facilitation Support for South Asia through strengthening institutional } \\
\text { and national capacity related to Standard, Metrology Testing and } \\
\text { Quality". } \\
\text { - BSTI is implementing project aiming to improve the quality } \\
\text { management system to be accepted at international level. } \\
\text { - BSTI branch offices in Chittagong, Rajshahi and Khulna are already } \\
\text { established and establishment of offices in Sylhet and Barisal are } \\
\text { underway }\end{array}$ & $\begin{array}{l}\text { - Popularize product certification system by BSTI and make it } \\
\text { easier for small entrepreneurs } \\
\text { - Enhance awareness in the field of product labelling services by } \\
\text { BSTI } \\
\text { - Strengthen product quality monitoring as per BSTI certification }\end{array}$ \\
\hline \multicolumn{4}{|c|}{ Lead Responsibility: MoE Associate Responsibility: BMET, BITAC, SCITI, BSCIC, SMEF, VTI, MoLE,, BIM, MoEWOE, MoTJ } \\
\hline $\begin{array}{l}\text { 13. Enhancing human } \\
\text { resource development } \\
\text { for SMEs }\end{array}$ & $\begin{array}{l}\text { - Conduct more entrepreneurship } \\
\text { development and workers' skill } \\
\text { improvement training } \\
\text { - Increase training on designing } \\
\text { - } 8,320 \text { women will trained in } 6 \text { trades each } \\
\text { year } \\
\text { - EDP training to } 1.58 \text { lakh person per year. } \\
\text { - Enhance Managerial Capabilities for SME } \\
\text { sectors }\end{array}$ & $\begin{array}{l}\text { - MoLE is providing technical training on different trades and creating } \\
\text { skilled human resources } \\
\text { - A project is being undertaken by BITAC to train poor women } \\
\text { especially in technical and vocational training } \\
\text { - A TTC of Ministry of Labour and Employment has been established in } \\
\text { Dhaka for women only } \\
\text { - Undertaken a project for establishment of } 5 \text { TTC for women in } 5 \\
\text { divisional head quarters } \\
\text { - Completed project on reproductive health and right, gender issues and } \\
\text { prevention of HIV/AIDS for tea plantation and garment workers by } \\
\text { the Ministry of Labour and Manpower } \\
\text { - SCITI of BSCIC is imparting training on entrepreneurship } \\
\text { development } \\
\text { - BSCIC imparted HRD training related to SMEs }\end{array}$ & $\begin{array}{l}\text { - Create a skilled labour force for SME development } \\
\text { - Strengthen job oriented and need based vocational training with } \\
\text { focus on women } \\
\text { - Ensure minimum wage rates for SME workers and make it } \\
\text { more rational } \\
\text { - Evaluate and follow up training provided by the TTCs } \\
\text { - Ensure and enhance market oriented and demand based training } \\
\text { - Consult with stakeholders for TTCs and MOLE trainings } \\
\text { - Increase training on different trades, basic technology, and work } \\
\text { safety issues } \\
\text { - Impart EDP training through SCITI, design centre, District } \\
\text { Based Industrial Service Centre etc. particularly to women } \\
\text { - Arrange for management development of private sector } \\
\text { entrepreneurs } \\
\text { - Prepare training needs assessments } \\
\text { - Organize training course on management development to public } \\
\text { and private sector stakeholders involved in providing business } \\
\text { services to SMEs }\end{array}$ \\
\hline \multicolumn{4}{|c|}{ Lead Responsibility: SMEF, MoWCA, MoI, Chambers, Associations, Trade bodies, Commercial banks, Training Institutes } \\
\hline $\begin{array}{l}\text { 14. Undertake policy } \\
\text { advocacy for women } \\
\text { SME entrepreneurs }\end{array}$ & $\begin{array}{l}\text { - Collect data on number of women } \\
\text { entrepreneur and monitor their growth } \\
\text { - } 10 \% \text { growth in the number of women } \\
\text { entrepreneur every year. }\end{array}$ & $\begin{array}{l}\text { - Industrial policy of } 2005 \text { emphasized women's participation in the } \\
\text { country's industrialization process }\end{array}$ & $\begin{array}{l}\text { - Mainstream gender issues in the Industrial Policy } \\
\text { - Implement Gender Action Plan by SMEF and WEEF } \\
\text { - Ensure mainstreaming women's advancement in all National } \\
\text { Policies } \\
\text { - Continue National SME women entrepreneurs conference } \\
\end{array}$ \\
\hline \multicolumn{4}{|c|}{ Lead Responsibility: SMEF, SCITI, BSCIC, Trade Bodies, Chambers } \\
\hline $\begin{array}{l}\text { 15. Executing capacity } \\
\text { building and skill } \\
\text { training for SME } \\
\text { women entrepreneurs }\end{array}$ & $\begin{array}{l}\text { - Training at least } 30 \% \text { of women } \\
\text { entrepreneurs }\end{array}$ & $\begin{array}{l}\text { - Ministry of Industries provided training on 'Business management' and } \\
\text { 'Entrepreneurship Development' to the rural potential women } \\
\text { entrepreneurs in all divisions and selected districts. }\end{array}$ & $\begin{array}{l}\text { - Enhance training on Management, Accounting and ICT } \\
\text { - Arrange entrepreneurship development training throughout the } \\
\text { country } \\
\text { - Introduce training on accounting, office management, } \\
\text { computer, spoken English etc. }\end{array}$ \\
\hline
\end{tabular}




\begin{tabular}{|c|c|c|c|}
\hline Strategic Goals & Key Targets & Actions Taken/ Underway & PRSP Policy Agenda (2009-2011) \\
\hline 1 & 2 & 3 & 4 \\
\hline \multicolumn{4}{|c|}{ Lead Responsibility: BB, Commercial Banks, MoF } \\
\hline $\begin{array}{l}\text { 16. Strengthening access } \\
\text { to finance for SME } \\
\text { women entrepreneurs }\end{array}$ & $\begin{array}{l}\text { - Successful implementation of SEF fund } \\
\text { - Expand credit to women entrepreneurs by } \\
\text { commercial banks }\end{array}$ & $\begin{array}{l}\text { - Bangladesh Bank created a fund called Small Enterprise Fund (SEF) for } \\
\text { providing credits. } 10 \% \text { of SEF fund has been allocated for the women } \\
\text { entrepreneurs. } \\
\text { - } 30 \% \text { Women entrepreneurs have received credit facilities } \\
\text { - Finance Division's 'RAKUB Small Enterprise Credit Programme' }\end{array}$ & $\begin{array}{l}\text { - Ensure implementation and monitoring of BB directives about } \\
\text { giving credit to women in SMEs } \\
\text { - Ensure more credit to women entrepreneurs } \\
\text { - Eliminate family conditions to ensure credit facilities } \\
\text { - Make credit available at reduced interest rate }\end{array}$ \\
\hline \multicolumn{4}{|c|}{ Lead Responsibility: BSCIC, SMEF, MoWCA, MoTJ } \\
\hline $\begin{array}{l}\text { 17. Providing } \\
\text { Infrastructural and } \\
\text { Institutional facilities } \\
\text { for women in SMEs }\end{array}$ & $\begin{array}{l}\text { - Ensure Plots in the Industrial Parks among } \\
\text { the real/potential women entrepreneurs }\end{array}$ & $\begin{array}{l}\text { - Women entrepreneurs has received } 20 \% \text { industrial plots in the } \\
\text { industrial estates }\end{array}$ & $\begin{array}{l}\text { - Allocate industrial plots to all potential women entrepreneurs on } \\
\text { a preferential basis } \\
\text { - Motivate women of all districts to start business }\end{array}$ \\
\hline \multicolumn{4}{|c|}{ Lead Responsibility: EPB, SMEF, NASCIB, Trade Bodies, Chambers } \\
\hline $\begin{array}{l}\text { 18. Supporting SME } \\
\text { women entrepreneurs } \\
\text { from indigenous groups }\end{array}$ & $\begin{array}{l}\text { - Introduce specialized women SME product } \\
\text { promotion }\end{array}$ & $\begin{array}{l}\text { - A total number of } 500 \text { women entrepreneurs of either rigid has been } \\
\text { created }\end{array}$ & $\begin{array}{l}\text { - Arrange specialized product/trade fairs of women from } \\
\text { indigenous groups } \\
\text { - Arrange a special window in the national display centre for the } \\
\text { indigenous groups }\end{array}$ \\
\hline \multicolumn{4}{|c|}{ Lead Responsibility: BITAC, BSTI, SCITI, SMEF, NASCIB, MoTJ } \\
\hline $\begin{array}{l}\text { 19. Ensuring technology } \\
\text { for SME women } \\
\text { entrepreneurs }\end{array}$ & $\begin{array}{l}\text { - Increase Training on designing } \\
\text { - Introduce Training on packaging } \\
\text { - Introduce Training on non traditional items }\end{array}$ & $\begin{array}{l}\text { - A total number of } 100 \text { indigenous technologies have been complied } \\
\text { under the SMESDP projects and been uploaded in the SME Web } \\
\text { Portal in Bangla }\end{array}$ & $\begin{array}{l}\text { - Enhance access to technology in } 11 \text { SME booster sectors } \\
\text { - Enhance training on Light Engineering and Electronics } \\
\text { Manufacturing for women } \\
\text { Organize demand driven training programmes } \\
\end{array}$ \\
\hline \multicolumn{4}{|c|}{ Lead Responsibility: MoI, MoF, MoP, BSCIC, BSTI, BB, SMEF } \\
\hline $\begin{array}{l}\text { 20. Enhancing } \\
\text { institutional capacity } \\
\text { and efficiency of SME } \\
\text { related institutions }\end{array}$ & $\begin{array}{l}\text { - Restructure BSCIC } \\
\text { - Evaluate projects implemented by BSCIC } \\
\text { - Capacity building of BSCIC } \\
\text { - Expand BSTI regional offices } \\
\text { - Strengthen SMEF }\end{array}$ & $\begin{array}{l}\text { - A project "Garments Shilpa Park" has been taken by MOI to relocate } \\
1200 \text { garments industries to Gojaria Upazila. } \\
\text { - A project named Women Entrepreneurship Development of BSCIC is } \\
\text { assisting women in } 50 \text { upazilas for self-employment } \\
\text { - Established district based } 24 \text { industrial estates } \\
\text { - BSTI plays vital role in maintaining SMEs products' standard and } \\
\text { quality } \\
\text { - BSTI is currently implementing two projects to upgrade the technical } \\
\text { infrastructure for standards development and harmonization, metrology } \\
\text { and testing laboratories for labelling and accreditation and enhance } \\
\text { national capacities for setting up of ISO } 9000 \text { and ISO } 14000 \text { schemes } \\
\text { - Established SME Foundation (SMEF) following the recommendations } \\
\text { of the National Task Force }\end{array}$ & $\begin{array}{l}\text { - Initiate diagnostic studies for recommendation and suggestions } \\
\text { for restructuring BSCIC } \\
\text { - Monitor performance of } 64 \text { BSCIC Industrial estate } \\
\text { - Modernise BSCIC design centres } \\
\text { - Make the help line centres established in the BSCIC estates } \\
\text { more user friendly } \\
\text { - Undertake cottage and rural industries project in CHTs } \\
\text { - Undertake skill development project through Skill Development } \\
\text { Centre } \\
\text { - Install Garments Shilpa Park } \\
\text { - Establish new regional BSTI offices and recruit qualified staff in } \\
\text { the regional offices } \\
\text { - Increase partnership building with private sector stakeholders }\end{array}$ \\
\hline \multicolumn{4}{|c|}{ Lead Responsibility: MoI, SMEF, Inter Ministerial Committee Associate Responsibility: Chambers, Associations, Trade Bodies, Research Institutes, Universities/technical institutes, NGOs, CBOs } \\
\hline $\begin{array}{l}\text { 21. Strengthening } \\
\text { public-private } \\
\text { partnership }\end{array}$ & $\begin{array}{l}\text { Enhance and harmonize activities by both } \\
\text { public and private sectors }\end{array}$ & $\begin{array}{l}\text { - 'Garments Shilpa Park' project is under implementation with public - } \\
\text { private partnership } \\
\text { - 'API Shilpa Park' project is under implementation with public - private } \\
\text { partnership }\end{array}$ & $\begin{array}{l}\text { - Develop a consultation process with business associations and } \\
\text { other stakeholders } \\
\text { - Assist SMEs to improve their competitiveness and access to } \\
\text { local and global markets } \\
\text { - Enhance partnership between NGOs and SMEs }\end{array}$ \\
\hline \multicolumn{3}{|c|}{ Total Indicative Cost (in billion taka) } & Tk. 14.04 \\
\hline
\end{tabular}


Policy Matrix 6: Promoting Decent Employment

\begin{tabular}{|c|c|c|c|}
\hline Strategic Goals & Key Targets & Actions Taken/ Underway & PRSP Policy Agenda (2009-2011) \\
\hline 1 & 2 & 3 & 4 \\
\hline \multicolumn{4}{|c|}{ Lead Responsibility: MoLE, MoEWOE Associate Responsibility: MoE, MoI, MoWCA, MoSW, BMET, BIMT, DoL, DIFE, BITAC, SCITI, BSCIC, SMEF, MF, TTCs, TSCs, DTE, BTEB } \\
\hline $\begin{array}{l}\text { 1.Enhancing Human Resource } \\
\text { Development (HRD) }\end{array}$ & $\begin{array}{l}\text { - Increase training on skill development by } 10 \\
\text { percent every year }\end{array}$ & $\begin{array}{l}\text { - TTCs, TSCs and polytechnic institutes are providing technical training on } \\
\text { different trades } \\
\text { - BITAC is providing training to women especially on technical and } \\
\text { vocational skills. } \\
\text { - One TTC in Dhaka and } 5 \text { TTCs in } 5 \text { divisional headquarters for women } \\
\text { were established by BMET. About } 8,320 \text { women will receive training } \\
\text { each year } \\
\text { - Curricula of some specific courses of TTCs and BIMT have been } \\
\text { updated. } \\
\text { - Training and employment programme in collaboration with BGMEA } \\
\text { organized for down-trodden people from Monga Area by BMET in } \\
\text { Bogra and Lalmanirhat TTCs. } \\
\text { - Modernization of TSCs/TTCs/BIMT/Polytechnic Institutes are } \\
\text { underway } \\
\text { - } 26 \text { additional TTCs constructed }\end{array}$ & $\begin{array}{l}\text { - Strengthen job oriented and need based } \\
\text { vocational training } \\
\text { - Advocate for a pollution free and healthy } \\
\text { working environment in small enterprises } \\
\text { - Assess the usefulness of training provided } \\
\text { by TTCs, TSCs and polytechnic institutes } \\
\text { - Provide special training to tea plantation } \\
\text { workers and workers involved in non- } \\
\text { traditional utility services } \\
\text { - Impart EDP training to } 0.16 \text { million } \\
\text { people with at least } 33 \% \text { women } \\
\text { - Organise entrepreneurship and skill } \\
\text { development training especially designed } \\
\text { for women. } \\
\text { - New courses will be introduced in BMET } \\
\text { - Train people in different vocational trades } \\
\text { in } 64 \text { TSCs } \\
\text { - Motivate the trained persons (NSSG-I, II } \\
\text { \& III) for self-employment by providing } \\
\text { bank loan } \\
\text { - Make all new TTCs operational } \\
\text { - Create training opportunities for school } \\
\text { dropouts and unemployed youths } \\
\text { - Course curricula of all emerging new } \\
\text { trades are updated. } \\
\text { - Training Programme for poor people of } \\
\text { Monga area continued } \\
\text { - Establish } 30 \text { TTCs at zilla level } \\
\text { - Establish } 5 \text { Marine Training Institutes }\end{array}$ \\
\hline \multicolumn{4}{|c|}{ Lead Responsibility: MoEWOE, MoL, MoFA Associate Responsibility: MoLE, MoE, MoI, MoWCA, MoHFW, MoSW, BMET, DoL, DIFE, BITAC, SCITI, BSCIC, SMEF, TSCs, TTCs, DTE, BTEB, MoYS } \\
\hline $\begin{array}{l}\text { 2. Providing training to the workforce } \\
\text { including women for overseas employment }\end{array}$ & $\begin{array}{l}\text { - Create skilled technicians and workers } \\
\text { among (a) people from Monga areas, and (b) } \\
\text { female population } \\
\text { - Promote overseas employment especially } \\
\text { safe migration for poor and women }\end{array}$ & $\begin{array}{l}\text { - Training on new courses in employable trades have started } \\
\text { - Introduced a course in housekeeping } \\
\text { - Training of } 22,000 \text { persons in } 2007 \text { as against } 16000 \text { in } 2006 \text { was given } \\
\text { - Overseas Employment Act, } 2008 \text { has been formulated } \\
\text { - Introduction of short courses in trades with potential demand } \\
\text { - Arrangement of public-private partnership for training } \\
\text { - Continuation of training programme in housekeeping. } \\
\text { - Identification of potential new areas of training for overseas employment, } \\
\text { and institutional set-up } \\
\text { - Credit to finance migration of workers introduced by PKSF and some } \\
\text { banks }\end{array}$ & $\begin{array}{l}\text { - Expand training programme in } \\
\text { housekeeping } \\
\text { - Provide one-stop service for } \\
\text { international migration } \\
\text { - Provide skill training as per demands of } \\
\text { global market and the labour deficient } \\
\text { countries } \\
\text { - Take diplomatic drive for preventing } \\
\text { retrenchment and identifying new markets } \\
\text { for workers } \\
\text { - Simplify procedures to avail overseas }\end{array}$ \\
\hline
\end{tabular}




\begin{tabular}{|c|c|c|c|}
\hline Strategic Goals & Key Targets & Actions Taken/ Underway & PRSP Policy Agenda (2009-2011) \\
\hline \multirow[t]{2}{*}{1} & 2 & 3 & 4 \\
\hline & & & $\begin{array}{l}\text { employment } \\
\text { - Provide credit facilities for helping the } \\
\text { poor to bear the cost of overseas } \\
\text { employment } \\
\text { - Give orientation training to the job } \\
\text { seekers and finders on jobs and on } \\
\text { countries } \\
\text { - Provide training on the immigration laws } \\
\text { and labour laws of the employing countries } \\
\text { - Strengthen the monitoring of recruiting } \\
\text { agents } \\
\text { - Create language training opportunities } \\
\text { - Continue the existing demandable } \\
\text { training programme } \\
\text { - Enhance the training capacities in } \\
\text { existing TTCs } \\
\text { - Expand training programme in } \\
\text { housekeeping } \\
\text { - Establish Catering Training Institute in } \\
\text { Sylhet Technical Training Centre. }\end{array}$ \\
\hline $\begin{array}{l}\text { 3. Expanding potential sectors for overseas } \\
\text { employment }\end{array}$ & $\begin{array}{l}\text { - Increase export of nurses, carpenters, } \\
\text { plumbers, auto-mechanics, air-conditioning } \\
\text { technicians, IT engineers, and computer } \\
\text { experts by } 15 \%\end{array}$ & $\begin{array}{l}\text { - Some schedule banks and financial institutions have initiated an } \\
\text { expatriate lending project whereby the bank will advance money to the } \\
\text { prospective job seekers who will repay the loan from their remittances } \\
\text { - Demand in overseas employment has been explored through } \\
\text { Bangladesh missions abroad } \\
\text { - Bangladesh Bank is implementing a project to streamline and expedite } \\
\text { remittance transfer } \\
\text { - PKSF financing cost of migrant workers of Moraga areas }\end{array}$ & $\begin{array}{l}\text { - Expand and diversify of existing job } \\
\text { markets and explore new avenues for } \\
\text { overseas markets } \\
\text { - Examine and replicate overseas job loan } \\
\text { schemes of Financial Institutions (e.g. } \\
\text { Pubali Bank) } \\
\text { - Implement the 9-point strategies prepared } \\
\text { by the MEWOE } \\
\text { - Strengthen activities of the Bangladesh } \\
\text { Mission abroad regarding overseas labour } \\
\text { welfare and labour disputes } \\
\text { - Take adequate measures to ensure the } \\
\text { rights and interests of the work force } \\
\text { abroad } \\
\text { - Address particular concerns of women } \\
\text { workers in overseas employment } \\
\text { - Innovate schemes for prospective job } \\
\text { seekers abroad }\end{array}$ \\
\hline \multicolumn{4}{|c|}{ Lead Responsibility: MoLE Associate Responsibility: MoE, MoI, MoWCA, MoSW, MoEWOE, BMET, DoL, DIFE, BITAC, SCITI, BSCIC, SMEF, TSCs, TTCs, DTE, BTEB } \\
\hline $\begin{array}{l}\text { 4. Introducing training, support system, } \\
\text { and counselling for retrenched workers }\end{array}$ & - $100 \%$ retrenched workers & $\begin{array}{l}\text { - Skill retraining was organised } \\
\text { - Counselling for guidance was provided } \\
\text { - Loan through banks were distributed }\end{array}$ & $\begin{array}{l}\text { - Introduce skill development training for } \\
\text { self-employment and micro-entrepreneur } \\
\text { development } \\
\text { - Introduce skill training for jobs in } \\
\text { alternative sectors }\end{array}$ \\
\hline
\end{tabular}




\begin{tabular}{|c|c|c|c|}
\hline Strategic Goals & Key Targets & Actions Taken/ Underway & PRSP Policy Agenda (2009-2011) \\
\hline 1 & 2 & 3 & 4 \\
\hline & & & $\begin{array}{l}\text { - Introduce SSN programme for retrenched } \\
\text { workers and their family members }\end{array}$ \\
\hline \multicolumn{4}{|c|}{ Lead Responsibility: MoLE and MoEWOE Associate Responsibility: MoE, MoI, MoWCA, MoSW, BMET, DL, DIFE, BITAC, SCITI, BSCIC, SMEF, TSCs, TTCs, DTE, BTEB } \\
\hline $\begin{array}{l}\text { 5. Enhancing awareness and advocacy on } \\
\text { labour welfare issues including labour laws }\end{array}$ & $\begin{array}{l}\text { - Enforce labour laws } \\
\text { - Increase familiarity with BLA-2006 \& } \\
\text { other labour laws }\end{array}$ & $\begin{array}{l}\text { - Workshops, seminars \& symposiums were and are being arranged } \\
\text { - Leaflets and booklets were and are being prepared } \& \text { distributed }\end{array}$ & $\begin{array}{l}\text { - Re-evaluate and correct National Labour } \\
\text { Policy } \\
\text { - Enhance Industrial sector-wise labour } \\
\text { welfare trainings } \\
\text { - Ensure industrial compliance, minimum } \\
\text { wage payment, payment in time, minimize } \\
\text { labour disputes } \\
\text { - Increase labour welfare activities } \\
\text { - Arrange workshops, seminars and } \\
\text { symposiums } \\
\text { - Widen publicity on labour welfare } \\
\text { through mass media } \\
\text { - Ensure availability of labour related } \\
\text { publications to the workers' organization, } \\
\text { trade unions and workers }\end{array}$ \\
\hline $\begin{array}{l}\text { 6. Ensuring transparency and monitoring in } \\
\text { overseas job-related migration process }\end{array}$ & $\begin{array}{l}\text { - Strong monitoring mechanism in overseas } \\
\text { job related migration } \\
\text { - Bilateral and Multilateral agreement among } \\
\text { the labour sending and receiving countries. }\end{array}$ & $\begin{array}{l}\text { - Monitoring mechanisms have been developed both in MoEWOE and } \\
\text { BMET } \\
\text { - Existing rules and regulations are being reviewed. } \\
\text { - MOU has been signed with labour receiving countries to ensure workers' } \\
\text { rights and welfare }\end{array}$ & $\begin{array}{l}\text { - Implement the developed-monitoring- } \\
\text { mechanisms both in Ministry and BMET } \\
\text { - Review findings of Existing rules and } \\
\text { regulations } \\
\text { - Continue signing MOUs with the labour } \\
\text { receiving countries to ensure workers' } \\
\text { rights and welfare }\end{array}$ \\
\hline \multicolumn{4}{|c|}{ Lead Responsibility: MoLE and MoEWOE Associate Responsibility: MoE, MoI, MoWCA, MoSW, BMET, DoL, DIFE, BITAC, SCITI, BSCIC, SMEF, TSCs, MF, TTCs, DTE, BTEB } \\
\hline 7. Ensuring workers welfare & $\begin{array}{l}\text { - Ensure treatment \& medication at work } \\
\text { place in the formal sector } \\
\text { - Provide health, hygiene, safety \& OSH } \\
\text { training to all workers }\end{array}$ & $\begin{array}{l}\text { - Training on OSH are being provided } \\
\text { - Distribution of family planning materials is on going } \\
\text { - Time Bound Programme for elimination of WFCL is being } \\
\text { implemented }\end{array}$ & $\begin{array}{l}\text { - Create workers welfare facilities in the } \\
\text { Labour Welfare Centres (30) } \\
\text { - Build alliances and partnerships with local } \\
\text { govt. institutions, NGOs and international } \\
\text { organizations } \\
\text { - Establish workers welfare centres in new } \\
\text { industrial areas } \\
\text { - Increase recreational facilities and health } \\
\text { and family planning services }\end{array}$ \\
\hline $\begin{array}{l}\text { 8. Welfare for the migrant workers and } \\
\text { their families }\end{array}$ & $\begin{array}{l}\text { - Ensure Welfare for the Overseas workers } \\
\text { and their families }\end{array}$ & $\begin{array}{l}\text { - Monitoring Mechanism through and within Labour wings has been } \\
\text { enhanced. } \\
\text { - Welfare Officer has been recruited in Malaysia } \\
\text { - Welfare fund is used for the several important activities like repatriation } \\
\text { of mortal remains of workers from host countries, burials, and financial } \\
\text { assistance to the sick and distressed and to heirs of the deceased who are } \\
\text { not getting any compensation from the employer. } \\
\text { - Provision has been made to provide middle and lower-middle class }\end{array}$ & $\begin{array}{l}\text { - Recruit more Welfare Officers in other } \\
\text { - Strour wings in accordance with need. } \\
\text { - } \text { workers } \\
\text { - Establish 'Welfare Desks' at the remaining } \\
\text { Deputy Commissioners' Offices. } \\
\text { - Implement the provision of special } \\
\text { benefit for middle and lower-middle class }\end{array}$ \\
\hline
\end{tabular}




\begin{tabular}{|c|c|c|c|}
\hline Strategic Goals & Key Targets & Actions Taken/ Underway & PRSP Policy Agenda (2009-2011) \\
\hline 1 & 2 & 3 & 4 \\
\hline & & $\begin{array}{l}\text { remitters with special benefits. } \\
\text { - "Expatriates Welfare Desk" has been set up in } 29 \text { Deputy } \\
\text { - Commissioners' Offices } \\
\text { - Provision of special benefit for middle and lower-middle class remitters } \\
\text { has been made. } \\
\text { - Awareness creation among potential workers willing to have overseas job } \\
\text { - Expatriate welfare desk established at airports } \\
\text { - Grants provided to injured workers and for burial of expatriate workers }\end{array}$ & $\begin{array}{l}\text { remitters } \\
\text { - Strengthen awareness creation } \\
\text { - Involve Civil Societies and NGOs in } \\
\text { awareness raising programme. } \\
\text { - Make Pre-departure briefing mandatory } \\
\text { for all migrant workers } \\
\text { - Continue providing grants to expatriate } \\
\text { workers }\end{array}$ \\
\hline 9. Developing healthy industrial relations & $\begin{array}{l}\text { - Build decent work facilities } \\
\text { - Improve labour management relations } \\
\text { - Increase management capacity } \\
\text { - Eliminate gender based discrimination in } \\
\text { workplace } \\
\text { - Provide medical care to workers \& their } \\
\text { family members } \\
\text { - Create recreational facilities for workers }\end{array}$ & $\begin{array}{l}\text { - Massive training on industrial relations are being rolled out } \\
\text { - Renovation and modernization of existing factories are on going } \\
\text { - Providing medical \& recreational equipments in LWCs } \\
\text { - Setting up of Crisis Management Unit in RMG belt with one JDL, } 10 \\
\text { ADL \& LWC offices is taking place }\end{array}$ & $\begin{array}{l}\text { - Mitigate crisis in RMG sector } \\
\text { - Execute industrial relations and workers } \\
\text { education courses in IRIs and LWCs } \\
\text { - Provide training to the workers \& mid- } \\
\text { level management on labour law, industrial } \\
\text { relations, OSH, skill development } \\
\text { - Recognize and ensure workers } \\
\text { participation and ensure women leaders } \\
\text { participation } \\
\text { - Upgrade the Tongi Industrial Relations } \\
\text { Institute into "National Institute of } \\
\text { Labour Administration and Training" } \\
\text { - Ensure decent workplace incorporating } \\
\text { particular needs of women workers } \\
\end{array}$ \\
\hline \multicolumn{4}{|c|}{ Lead Responsibility: MoLE Associate Responsibility: MoE, MoI, MoWCA, MoSW, MoEWOE, BMET, DoL, DIFE, BITAC, SCITI, BSCIC, SMEF, TSCs, MF, TTCs, DTE, BTEB } \\
\hline $\begin{array}{l}\text { 10. Creating housing facilities for working } \\
\text { women }\end{array}$ & $\begin{array}{l}\text { - Safe accommodation for women workers } \\
\text { - Physical and social security for women } \\
\text { workers }\end{array}$ & $\begin{array}{l}\text { - Undertaken construction of } 10 \text {-storied buildings for creating } \\
\text { a. Accommodation } \\
\text { b. Treatment and recreational facilities }\end{array}$ & $\begin{array}{l}\text { - Ensure secured accommodation, medical } \\
\text { facilities and recreational facilities for } \\
\text { female workers } \\
\text { - Construct Multi-storied Female Worker's } \\
\text { Hostel \& Welfare centre at the present } \\
\text { LWC of Chasara, Tejgaon and Tongi }\end{array}$ \\
\hline \multicolumn{4}{|c|}{ Lead Responsibility: MoLE Associate Responsibility: MoE, MoI, MoWCA, MoSW, MoEWOE, BMET, DoL, DIFE, BITAC, SCITI, BSCIC, SMEF, TSCs, MF, TTCs, DTE, BTEB } \\
\hline $\begin{array}{l}\text { 11. Reconstructing Dhaka divisional labour } \\
\text { office for multipurpose usages }\end{array}$ & $\begin{array}{l}\text { - Create congenial and healthy working } \\
\text { environment for DL, DIFE \& Labour } \\
\text { Courts }\end{array}$ & - $\quad$ Construction of a multi-storied building (20-storied) on going & $\begin{array}{l}\text { - Provide better facilities for services by DL } \\
\text { \& DIEF \& Labour Courts } \\
\text { - Ensure better facilities for providing } \\
\text { services to the factory owners and workers }\end{array}$ \\
\hline \multicolumn{4}{|c|}{ Lead Responsibility: MoLE, Associate Responsibility: MoHFW, ME, MoI, MoWCA, MoSW, MoEWOE, BMET, DoL, DIFE, BITAC, SCITI, BSCIC, SMEF, TSCs, MF, TTCs, DTE, BTEB } \\
\hline $\begin{array}{l}\text { 12. Promoting awareness of reproductive } \\
\text { health, rights, gender equality \& prevention } \\
\text { of HIV/AIDS in tea garden \& RMG } \\
\text { workers, and potential overseas migrant } \\
\text { workers. }\end{array}$ & $\begin{array}{l}\text { - Increase knowledge, behaviour change \& } \\
\text { awareness of STD, HIV/AIDS prevention } \\
\text { etc. among the tea garden communities \& } \\
\text { RMG workers, and potential overseas } \\
\text { migrant workers. }\end{array}$ & $\begin{array}{l}\text { - Providing training to trade union leaders on these issues } \\
\text { - Orientation on(i) Gender/Reproductive Right (ii) Reproductive } \\
\text { health/STD/HIV/AIDS are being provided to various stakeholders } \\
\text { - Workshop for garden managers \& RMG mid-level management } \\
\text { organised }\end{array}$ & $\begin{array}{l}\text { - Create gender-friendly environment \& } \\
\text { ensure change of mindset of the workers } \\
\text { \& management } \\
\text { - Create awareness of gender equity, } \\
\text { reproductive health \& rights among the } \\
\text { management }\end{array}$ \\
\hline
\end{tabular}




\begin{tabular}{|c|c|c|c|}
\hline Strategic Goals & Key Targets & Actions Taken/ Underway & PRSP Policy Agenda (2009-2011) \\
\hline \multirow[t]{2}{*}{1} & 2 & 3 & 4 \\
\hline & & - Training for Service Providers organised & $\begin{array}{l}\text { - Undertake programmes to build awareness } \\
\text { of HIV/AIDS }\end{array}$ \\
\hline \multicolumn{4}{|c|}{ Lead Responsibility: MoLE Associate Responsibility: MoHFW, BEF/Private Sector, NGOs, MoYS, MoSW, MoWCA, DWA } \\
\hline $\begin{array}{l}\text { 13. Ensuring and enhancing occupational } \\
\text { safety and health }\end{array}$ & $\begin{array}{l}\text { - Improve multi-disciplinary services towards } \\
\text { ship-breaking workers } \\
\text { - Ensure OSH and eliminate CL in } \\
\text { bidi/tobacco industries, printing press and } \\
\text { book binding } \\
\text { - Task Force on Labour Welfare for RMG } \\
\text { - Task Force on Occupational Safety in RMG } \\
\text { - Formulate occupational safety and health } \\
\text { policy }\end{array}$ & $\begin{array}{l}\text { - Construction of Welfare Complex is underway } \\
\text { - Training programmes are underway } \\
\text { - A Social Compliance Forum (SCF) was constituted on } 11 \text { June } 2005 \text { by } \\
\text { the Government to ensure workers' welfare and security } \\
\text { - In order to meet various requirements on Social Compliance in the } \\
\text { RMG industry the government has constituted a Task Force on Labour } \\
\text { Welfare in RMG, and Compliance Monitoring Cell } \\
\text { - BGMEA has started crash programme on fire safety. The BGMEA } \\
\text { surveillance teams inspected } 682 \text { Garments Factories in Dhaka and } 587 \\
\text { Garments Factories in Chittagong to monitor safety measures }\end{array}$ & $\begin{array}{l}\text { - Build safety providing capacity of the } \\
\text { ship-breaking sector } \\
\text { - Ensure OSH and elimination of child } \\
\text { labour } \\
\text { - Establish Task Forces on Labour Welfare } \\
\text { and Occupational Safety \& Compliance } \\
\text { Monitoring Cells for other industries } \\
\text { - Ensure application of OSH within the } \\
\text { ambit of the Bangladesh Labour Act, } 2006 \\
\text { - Engage inspectors in order to ensure } \\
\text { complete health and safety inspection in a } \\
\text { factory } \\
\text { - Ensure safe building code for all industrial } \\
\text { buildings } \\
\text { - Introduce a system of sector-wise } \\
\text { inspection } \\
\text { - Establish an internal monitoring body } \\
\text { responsible for monitoring activities of } \\
\text { inspectors } \\
\text { - Augment technology capabilities to deal } \\
\text { with humidity, mine fires, ground control, } \\
\text { stability of illumination }\end{array}$ \\
\hline \multicolumn{4}{|c|}{ 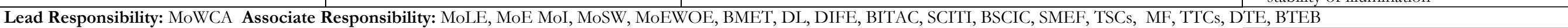 } \\
\hline $\begin{array}{l}\text { 14. Quickening elimination of child labour } \\
\text { and Worst Form of Child Labour (WFCL) }\end{array}$ & $\begin{array}{l}\text { - Reduce number of child workers } \\
\text { - Develop socio-economic indicators of } \\
\text { child workers }\end{array}$ & $\begin{array}{l}\text { - MoLE through its partnership with ILO/IPEC and other agencies are } \\
\text { engaged in projects and programmes intended to prevent and eliminate } \\
\text { the WFCL in the country } \\
\text { - BBS planned to conduct an Integrated Baseline Survey for determining } \\
\text { Hazardous Child Labour }\end{array}$ & $\begin{array}{l}\text { - Strengthen advocacy for eliminating child } \\
\text { labourers } \\
\text { - Expand poverty reduction programmes } \\
\text { for the families of child labourers } \\
\text { - Introduce education programmes for } \\
\text { working children } \\
\text { - Improve capacity to monitor and } \\
\text { implement programmes for child labour } \\
\text { - Adopt the national child labour policy }\end{array}$ \\
\hline \multicolumn{4}{|c|}{ Lead Responsibility: MoLE Associate Responsibility: MoE, MoI, MoWCA, MoSW, MoEWOE, BMET, DL, DIFE, BITAC, SCITI, BSCIC, SMEF, TSCs, MF, TTCs, DTE, BTEB } \\
\hline 15. Ensuring a better working environment & $\begin{array}{l}\text { - Raise awareness regarding the provisions of } \\
\text { labour laws among workers } \\
\text { - Improve professional skills among the } \\
\text { management and concerned government } \\
\text { officers regarding BLA-2006 }\end{array}$ & $\begin{array}{l}\text { - Short-term training courses in different sectors are conducted throughout } \\
\text { the country regarding labour welfare and employment provisions as } \\
\text { guaranteed in the BLA-2006. } \\
\text { - Workshops on OSH, labour welfare and employment conditions are held } \\
\text { throughout the country }\end{array}$ & $\begin{array}{l}\text { - Organize } 60 \text { courses in a year for } 3 \text { years } \\
\text { - Ensure } 50 \text { participants (workers) in a } \\
\text { course totalling } 9000 \text { participants in } 3 \text { years } \\
\text { - Organise one-day course with } 4 \text { sessions } \\
\text { - Organise } 5 \text {-days long } 24 \text { courses in a year } \\
\text { (6 courses quarterly) totalling } 72 \text { courses in } \\
3 \text { years }\end{array}$ \\
\hline
\end{tabular}




\begin{tabular}{|c|c|c|c|}
\hline Strategic Goals & Key Targets & Actions Taken/ Underway & PRSP Policy Agenda (2009-2011) \\
\hline 1 & 2 & 3 & 4 \\
\hline & & & $\begin{array}{l}\text { - Ensure } 30 \text { participants (officers) in each } \\
\text { course totalling } 2160 \text { participants in } 3 \text { years }\end{array}$ \\
\hline \multicolumn{4}{|c|}{ Lead Responsibility: MoWCA Associate Responsibility: MoLE, MoE MoI, MoSW, MoEWOE, BMET, DL, DIFE, BITAC, SCITI, BSCIC, SMEF, TSCs, MF, TTCs, DTE, BTEB } \\
\hline $\begin{array}{l}\text { 16. Ensuring women's participation in } \\
\text { international forums }\end{array}$ & $\begin{array}{l}\text { - Raise voices on women issues and } \\
\text { concerns in international forums } \\
\text { - Increase participation of women } \\
\text { representatives in international trade forums } \\
\text { - Increase in women's access to international } \\
\text { market }\end{array}$ & $\begin{array}{l}\text { - Negotiating market access under Mode- } 4 \\
\text { - Discussions on market access for trade in services under Mode-4 } \\
\text { continue. }\end{array}$ & $\begin{array}{l}\text { - Encourage participation of women's } \\
\text { groups in WTO negotiations and in various } \\
\text { committees of the Ministry of Commerce } \\
\text { - Ensure incorporation of women workers' } \\
\text { concerns in the Trade Policy Review } \\
\text { Mechanisms } \\
\text { - Adopt international labour migration as a } \\
\text { strategy of employment for retrenched } \\
\text { female workers } \\
\text { - Ensure coherence between the dominant } \\
\text { international economic agenda and the } \\
\text { international legal obligations }\end{array}$ \\
\hline \multicolumn{4}{|c|}{ 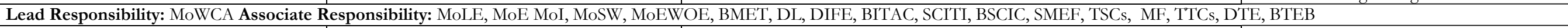 } \\
\hline 17. Advancing women workers' rights & $\begin{array}{l}\text { - Implement ILO labour standards in both } \\
\text { public and private sectors } \\
\text { - Make grassroots level institutions more } \\
\text { women-friendly } \\
\text { - Ensure women workers rights and dignity } \\
\text { - Promote equal pay in private sector to } \\
\text { address the gender gap in wages for men } \\
\text { and women }\end{array}$ & $\begin{array}{l}\text { Women-friendly strategies and policies are being adopted and } \\
\text { - } \\
\text { implemented } \\
\text { Ensuring women in ICT facilities and skill-oriented training } \\
\text { particularly in assembling and repairing cell phone, and software } \\
\text { development are underway } \\
\text { - Social protection of woman with disability and socially } \\
\text { disadvantaged women workers are being provided } \\
\text { - Introducing women-friendly policies and strategies in public \& } \\
\text { private sectors } \\
\text { - Implementing ILO labour standards in all areas of public and } \\
\text { private sectors } \\
\text { Making institutions at the grassroots level more women-friendly }\end{array}$ & $\begin{array}{l}\text { - Enforce existing labour laws to support } \\
\text { women } \\
\text { - Provide ID cards to all RMG workers } \\
\text { - Diversify training for nurses, RMG } \\
\text { workers, factory workers, cleaners and } \\
\text { housemaids } \\
\text { - Provide collateral-free loan and support } \\
\text { for exploration of opportunities in the } \\
\text { domestic and foreign markets } \\
\text { - Ensure economic growth, poverty } \\
\text { reduction and empowerment through } \\
\text { international trade } \\
\text { - Build linkages between public and private } \\
\text { sectors and NGO/CSOs for mitigating } \\
\text { risk and vulnerability of women workers } \\
\text { abroad } \\
\text { - Revise ICT Policy to incorporate women's } \\
\text { concerns } \\
\text { - Develop training programme on ICT } \\
\text { particularly in assembling and repairing } \\
\text { cell phone, and software development } \\
\text { insuring women's participation } \\
\text { - Ensure transparency \& accountability in } \\
\text { public and private sectors in all women } \\
\text { issues } \\
\text { - Make institutions more gender-friendly } \\
\text { - Increase health coverage and provide } \\
\text { insurance for reducing risks faced by }\end{array}$ \\
\hline
\end{tabular}




\begin{tabular}{|c|c|c|c|}
\hline Strategic Goals & Key Targets & Actions Taken/ Underway & PRSP Policy Agenda (2009-2011) \\
\hline 1 & 2 & 3 & 4 \\
\hline & & & $\begin{array}{l}\text { women workers during pregnancy, } \\
\text { childbirth and old age } \\
\text { - Introduce social security legislation for } \\
\text { women with disability and implement it } \\
\text { through community approaches } \\
\text { - Design contributory provident fund and } \\
\text { insurance coverage for RMG workers }\end{array}$ \\
\hline \multicolumn{4}{|c|}{ Lead Responsibility: MoLE Associate Responsibility: PC, MoEWOE, MoA, MoI, MoE, MoYS, MoWCA, SMEF, MoHFW, BOI } \\
\hline $\begin{array}{l}\text { 18. Mainstreaming employment into all } \\
\text { policies }\end{array}$ & $\begin{array}{l}\text { - Sector level policies (especially the case for } \\
\text { support to specific sectors and SME } \\
\text { development): } \\
\text { (i) Agriculture policy } \\
\text { (ii) Industrial policy } \\
\text { (iii) Labour policy/law } \\
\text { (iv) SME policy } \\
\text { (v) Gender specific employment policy } \\
\text { (vi) Education policy } \\
\text { (vii) Investment policy } \\
\text { - Develop a coordinated and harmonized } \\
\text { policy for employment and labour welfare }\end{array}$ & $\begin{array}{l}\text { - Actions undertaken } \\
\text { (i) Ex ante as well as ex post employment impact assessment of various } \\
\text { policies and programmes; } \\
\text { (ii) Programmes for SME development, and } \\
\text { (iii) Policies aimed at selected employment-intensive sectors. } \\
\text { - Labour Law } 2006 \text { passed } \\
\text { a) Labour Welfare Foundation } 2006 \text { approved } \\
\text { b) Private Road Transport Labour Welfare Fund Law-2005 approved } \\
\text { c) 'Overseas Employment Policy 2006' in } 2007 \text { approved } \\
\text { d) Employment generation is treated as one of the important areas of } \\
\text { strategic policy intervention for poverty alleviation }\end{array}$ & $\begin{array}{l}\text { - Undertake ex-ante and ex-post } \\
\text { employment impact assessment of policies } \\
\text { and programmes of all ministries } \\
\text { - Undertake programmes for SME } \\
\text { development and policies for selected } \\
\text { employment-intensive sectors } \\
\text { - Ensure that labour policy and law } \\
\text { combine flexibility in the labour market } \\
\text { and security for workers } \\
\text { - Develop appropriate policy to prevent a } \\
\text { further fall in labour intensity in various } \\
\text { activities } \\
\text { - Ensure technological upgrade, adaptation } \\
\text { and dissemination that are suitable for } \\
\text { local environment } \\
\text { - Develop and implement employment } \\
\text { policy in order to bring about gender } \\
\text { parity in employment } \\
\text { - Reformulate development strategies } \\
\text { focusing on the fact that service sector is } \\
\text { overtaking agriculture as the largest } \\
\text { provider of employment } \\
\text { - Adopt policies to facilitate development of } \\
\text { SMEs } \\
\text { - Adopt policies towards diversifying } \\
\text { manufacturing sectors } \\
\text { - Formulate agriculture and rural } \\
\text { development policies to reduce } \\
\text { vulnerability of agricultural labourers } \\
\text { - Develop an institutional arrangement } \\
\text { among key government agencies for } \\
\text { labour policy formulation and } \\
\text { implementation }\end{array}$ \\
\hline \multicolumn{4}{|c|}{ Lead Responsibility: MoLE and MoEWOE Associate Responsibility: MoE, MoI, MoWCA, MoSW, BMET, DL, DIFE, BITAC, SCITI, BSCIC, SMEF, TSCs, MF, TTCs, DTE, BTEB } \\
\hline 19. Creating jobs for men and women & $\begin{array}{l}\text { - Emergency Fund for employment } \\
\text { generation }\end{array}$ & $\begin{array}{l}\text { - Karmasangsthan (Employment) Bank } \\
\text { - PKSF }\end{array}$ & $\begin{array}{l}\text { - Emergency Social Fund for income } \\
\text { generating employment }\end{array}$ \\
\hline
\end{tabular}




\begin{tabular}{|c|c|c|c|}
\hline Strategic Goals & Key Targets & Actions Taken/ Underway & PRSP Policy Agenda (2009-2011) \\
\hline 1 & 2 & 3 & 4 \\
\hline & & - SMEF & $\begin{array}{l}\text { - Emergency employment programmes to } \\
\text { absorbs short-run shocks } \\
\text { - Employment }\end{array}$ \\
\hline 20. Creating jobs in poverty-prone Areas & $\begin{array}{l}\text { - All areas that are vulnerable to natural } \\
\text { calamities }\end{array}$ & $\begin{array}{l}\text { - } \mathrm{PKSF} \\
\text { - SMEF } \\
\text { - Overseas Employment-opportunity for people of Monga-prone areas. }\end{array}$ & $\begin{array}{l}\text { - Undertake job creation programmes in } \\
\text { the poverty-prone areas, especially the } \\
\text { Monga-prone districts } \\
\text { - Undertake special job creation measures } \\
\text { for women in poverty prone areas }\end{array}$ \\
\hline \multicolumn{4}{|c|}{ Lead Responsibility: MoLE and MoEWOE Associate Responsibility: MoF, Minimum Wages Board (MWB), Trade Bodies/Associations, BEF, NGOs, Trade Unions } \\
\hline 21. Ensuring increase in real wages & $\begin{array}{l}\text { - Increase real wage in agriculture, industrial } \\
\text { and service sectors }\end{array}$ & $\begin{array}{l}\text { - Government approved new wages scale in } 2006 \text { (National Wages and } \\
\text { Productivity Commission, 2005) }\end{array}$ & $\begin{array}{l}\text { - Permanent Wage Board is to be formed } \\
\text { - Increase real wages with linkage to labour } \\
\text { productivity } \\
\text { - Improve labour skills by providing } \\
\text { demand driven training } \\
\text { - Improve labour productivity by adopting } \\
\text { appropriate technology } \\
\text { - Ensure that minimum wages is fixed at } \\
\text { realistic level } \\
\text { - Develop monitoring system for minimum } \\
\text { wage implementation }\end{array}$ \\
\hline \multicolumn{4}{|c|}{ Lead Responsibility: Ministry of Law Associate Responsibility: , MoLE, MoEWOE, DL, DIFE, Regulatory Reforms Commission, SMEF, Recruiting Agencies, NGOs, MWB, Police Department } \\
\hline $\begin{array}{l}\text { 22. Reforming regulatory framework to } \\
\text { promote decent employment }\end{array}$ & $\begin{array}{l}\text { - Introduce minimum wage } \\
\text { - Regulate the overseas recruiting agencies } \\
\text { - Modernize labour legislation } \\
\text { - Modernize factory inspection }\end{array}$ & - Regulatory Reforms Commission is functioning & $\begin{array}{l}\text { - Strengthen supervisions by the GoB of } \\
\text { the recruitment agencies for avoiding } \\
\text { harassment and fraudulence activities } \\
\text { - Modernise labour legislation in } \\
\text { accordance with fundamental principles } \\
\text { and rights at work and other relevant ILO } \\
\text { standards } \\
\text { - Promote social dialogue among } \\
\text { governments, employers organization and } \\
\text { trade unions } \\
\text { - Introduce sector wise factory inspection }\end{array}$ \\
\hline \multicolumn{4}{|c|}{ Lead Responsibility: MoEWOE and MoLE Associate Responsibility: BMET, SMEF, Local Governments, Workers’ Associations, NGOs, BEF } \\
\hline $\begin{array}{l}\text { 23. Developing employment support } \\
\text { service }\end{array}$ & $\begin{array}{l}\text { - Establish twenty one (21) District } \\
\text { Employment and Manpower Offices } \\
\text { (DEMOs) }\end{array}$ & $\begin{array}{l}\text { - There is a network of } 21 \text { District Employment and Manpower } \\
\text { Offices in the country to provide news to job-seekers. }\end{array}$ & $\begin{array}{l}\text { - Create access to markets and business } \\
\text { development services for rural enterprises } \\
\text { - Enhance monitoring the activities of } \\
\text { DEMOs by the MoLE } \\
\text { - Reform DEMOs and prepare list of job } \\
\text { seekers and job openings regularly on } \\
\text { wage and self- employment } \\
\text { - Introduce Self-Employment schemes for } \\
\text { the registered unemployed job seekers to } \\
\text { provide credit }\end{array}$ \\
\hline
\end{tabular}




\begin{tabular}{|c|c|c|c|}
\hline Strategic Goals & Key Targets & Actions Taken/ Underway & PRSP Policy Agenda (2009-2011) \\
\hline \multirow[t]{2}{*}{1} & 2 & 3 & 4 \\
\hline & & & $\begin{array}{l}\text { - Collect and disseminate information on } \\
\text { employment in the organized sector on a } \\
\text { regular basis }\end{array}$ \\
\hline \multicolumn{4}{|c|}{ Lead Responsibility: MoF Associate Responsibility: MoWCA, MoSW, MoYS, MoLE, SMEF, BEF, Insurance Companies } \\
\hline $\begin{array}{l}\text { 24. Ensuring rights-based approach in the } \\
\text { labour market programmes and social } \\
\text { protection }\end{array}$ & $\begin{array}{l}\text { - Introduce insurance for workers } \\
\text { - Introduce social security for the worker } \\
\text { - Strengthen SSN for the workers } \\
\text { - Introduce rights-based employment } \\
\text { programmes }\end{array}$ & $\begin{array}{l}\text { - Five types of benefits are in practice in the public sector. These are: } \\
\text { (i)compensation pension; (ii)invalidity pension; (iii)superannuation } \\
\text { pension; (iv)retiring pension and (v)optional pension } \\
\text { - Government employees are socially protected also by Benevolent Fund } \\
\text { Scheme and Group Insurance Scheme } \\
\text { - Existing labour market policies and programmes underline the } \\
\text { importance of a right based approach to employment especially through } \\
\text { micro credit and employment based safety nets through public works } \\
\text { programmes }\end{array}$ & $\begin{array}{l}\text { - Introduce social protection for informal } \\
\text { workers } \\
\text { - Strengthening social security in the formal } \\
\text { private sector } \\
\text { - Undertake initiatives for providing } \\
\text { insurance to workers in unorganized } \\
\text { sector by forming workers' cooperatives } \\
\text { - Introduce SSN Programmes for socially } \\
\text { disadvantaged workers (cobblers, barbers, } \\
\text { sweepers, and others) } \\
\text { - Ensure greater job security, better } \\
\text { working conditions and bargaining } \\
\text { position for the rural workers } \\
\text { - Introduce employment based safety nets } \\
\text { programmes through public works } \\
\text { programmes }\end{array}$ \\
\hline \multicolumn{4}{|c|}{ 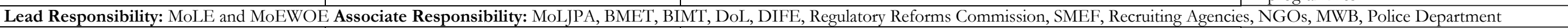 } \\
\hline $\begin{array}{l}\text { 25. Reforming/ } \\
\text { Restructuring/ } \\
\text { Strengthening Institutions involved in } \\
\text { employment generation, skill development } \\
\text { and labour welfare }\end{array}$ & $\begin{array}{l}\text { - Strengthen coordination and effectiveness } \\
\text { of training system }\end{array}$ & $\begin{array}{l}\text { - BMET offers training on as many as } 29 \text { areas including different trades of } \\
\text { industrial technology } \\
\text { - TTCs offer regular 2-year long vocational training course and } 6 \text { months } \\
\text { special course. Course contents of the TTCs \& TSCs meet the } \\
\text { requirements of National Skill Standard Grade-III, Grade-II \& Grade-I }\end{array}$ & $\begin{array}{l}\text { - Strengthen BMET's activities on human } \\
\text { resource export } \\
\text { - Introduce four new trades viz. computer } \\
\text { hardware, medical electronics, consumer } \\
\text { electronics and industrial electronics } \\
\text { - Make DIFE more efficient, accountable } \\
\text { and specialized } \\
\text { - Strengthen monitoring of the } \\
\text { performance of the existing } 60 \\
\text { polytechnic institutes } \\
\text { - Ensure quality trainers \& teachers in } \\
\text { polytechnic institutes } \\
\text { - Setup an expert group to look into the } \\
\text { issues relating to the vocational training } \\
\text { programmes } \\
\text { - Introduce variety of vocational courses of } \\
\text { different duration } \\
\text { - Establish new institutes for training the } \\
\text { teachers } \\
\text { - Improve the quality of trainers including } \\
\text { vocational teachers by providing both } \\
\text { overseas and domestic training } \\
\text { - Widen the coverage of training courses }\end{array}$ \\
\hline
\end{tabular}




\begin{tabular}{|c|c|c|c|}
\hline Strategic Goals & Key Targets & Actions Taken/ Underway & PRSP Policy Agenda (2009-2011) \\
\hline \multirow[t]{2}{*}{1} & 2 & 3 & 4 \\
\hline & & & $\begin{array}{l}\text { offered by TTCs } \\
\text { - Introduce training and advance courses } \\
\text { on glass and ceramics, plastic, light } \\
\text { engineering and electronics }\end{array}$ \\
\hline \multicolumn{4}{|c|}{ Lead Responsibility: MoLE and MoEWOE Associate Responsibility: MoLJPA, MoF, PC, SMEF, DoL, DIFE } \\
\hline 26. Ensuring public-private partnership & $\begin{array}{l}\text { - Enhance and harmonize service delivery } \\
\text { activities by both public and private sectors }\end{array}$ & $\begin{array}{l}\text { - Public-private partnership is introduced in several areas for example } \\
\text { Training and employment programme in collaboration with BGMEA, } \\
\text { BKMEA etc. }\end{array}$ & $\begin{array}{l}\text { - Develop a consultation process to foster } \\
\text { public-private partnership in employment } \\
\text { generation and labour welfare } \\
\text { - Strengthen linkages between the technical } \\
\text { training institutes and research institutes } \\
\text { - Enhance partnership with NGOs working } \\
\text { in labour welfare } \\
\text { - Expand and diversify vocational training } \\
\text { facilities, upgrade training, curricula } \\
\text { equipment and other infrastructure } \\
\text { - Involve TTCs and BMET for Public } \\
\text { Private Partnership with relevant } \\
\text { employers (BGMEA, BKMEA, Western } \\
\text { Marine Ltd and other potential Private } \\
\text { Organisations. } \\
\end{array}$ \\
\hline $\begin{array}{l}\text { 27. Integrating cleaner technology with } \\
\text { employment }\end{array}$ & $\begin{array}{l}\text { - Promoting cleaner technologies in work } \\
\text { places }\end{array}$ & $\begin{array}{l}\text { - Green technologies such as organic tea, municipal solid waste recycling, } \\
\text { bio-gas, bio-mass are being promoted }\end{array}$ & $\begin{array}{l}\text { - Strengthen advocacy for cleaner } \\
\text { technology } \\
\text { - Create incentive for cleaner technology }\end{array}$ \\
\hline \multicolumn{3}{|l|}{ Total Indicative Cost (in billion taka) } & Tk. 38.10 \\
\hline
\end{tabular}


Policy Matrix 7: Private Sector Development

\begin{tabular}{|c|c|c|c|}
\hline Strategic Goals & Key Targets & Actions Taken/ Underway & PRSP Policy Agenda (2009-2011) \\
\hline 1 & 2 & 3 & 4 \\
\hline \multicolumn{4}{|c|}{ Lead Responsibility: PM's Office, MoI, MoC, BOI, Privatization Commission } \\
\hline $\begin{array}{l}\text { 1. Creating enabling } \\
\text { policy environment } \\
\text { for PSD }\end{array}$ & $\begin{array}{l}\text { - Prepare strategic vision for } \\
\text { private sector development } \\
\text { (PSD) } \\
\text { - Review experience of other } \\
\text { countries to formulate PSD } \\
\text { strategy } \\
\text { - Set up national commission } \\
\text { consisting of policy makers and } \\
\text { private sector experts }\end{array}$ & $\begin{array}{l}\text { - A Strategic vision for Private Sector Development is completed and formulation of Private } \\
\text { Sector Development strategy is underway } \\
\text { - BBBF has been formed and RRC has been set up } \\
\text { - A national council for industrial development has been constituted } \\
\text { - Industrial policy of } 2005 \text { to encourage private sector participation undertaken } \\
\text { - Revised Privatization Policy } 2007 \text { is in place } \\
\text { - Export Policy 2006-09 and Import Policy 2006-have been declared }\end{array}$ & $\begin{array}{l}\text { - Experiences of Malaysia and Singapore would be } \\
\text { examined for adapting appropriate strategies for } \\
\text { PSD } \\
\text { - Undertaking investment climate assessments and } \\
\text { other firm-level surveys to provide analytical basis } \\
\text { for ongoing business environment reform } \\
\text { - Policy, strategies and programmes would be } \\
\text { formulated, implemented and monitored } \\
\text { - Incorporate feedback from private sector in } \\
\text { formulation of policies on various private sector } \\
\text { development issues } \\
\text { - BBBF to continue }\end{array}$ \\
\hline \multicolumn{4}{|c|}{ Lead Responsibility: MoLJPA, MoL, Chambers, BOI, MoLE, MoC, BEPZA,BSCIC, RRC } \\
\hline & $\begin{array}{l}\text { - Improve/streamline legal and } \\
\text { regulatory framework }\end{array}$ & $\begin{array}{l}\text { - BOI in support with SEDF-IFC conducted Administrative Barrier Review and identified } \\
\text { bottlenecks with suggestions } \\
\text { - MoI has undertaken an initiative to review all existing laws, rules and regulations of its different } \\
\text { corporations and departments } \\
\text { - The Privatization Regulations } 2007 \text { have been promulgated to identify bottlenecks and ensure } \\
\text { transparency } \\
\text { - The private sector investment guideline } 2004 \text { has been prepared and approved } \\
\text { - The Securities and Exchange Commission Rules has been adapted }\end{array}$ & $\begin{array}{l}\text { - Undertake measures to clear backlog of cases } \\
\text { - Reform the labour laws to prevent politicization } \\
\text { - Simplify land titling and transfer procedure } \\
\text { - Establish a policy analysis unit in each PSD } \\
\text { organization } \\
\text { - Streamline procedures, improve efficiency of } \\
\text { bonded warehouses, duty drawback system and IT } \\
\text { capacities } \\
\text { - Make the approval processes in BOI, BEPZA and } \\
\text { Registrar of JSCs transparent } \\
\text { - Streamline business regulations and enact an } \\
\text { appropriate competition law } \\
\text { - Improve enforcement of contracts and property } \\
\text { rights and streamline commercial justice system }\end{array}$ \\
\hline \multicolumn{4}{|c|}{ Lead Responsibility: Privatization Commission, PM Office, MoI, BBF, } \\
\hline & $\begin{array}{l}\text { - Expedite the process of } \\
\text { privatization }\end{array}$ & $\begin{array}{l}\text { - Total } 34 \text { SOEs were transferred / sold to private sector during the last PRSP period. This } \\
\text { process is being continued } \\
\text { - Programme for another } 26 \mathrm{SOEs} \text { has been developed } \\
\text { - Revised privatization policy has been published } \\
\text { - Privatization Regulation } 2007 \text { is promulgated }\end{array}$ & $\begin{array}{l}\text { - Encourage private sector investment including FDI } \\
\text { in privatization programme } \\
\text { - Introduce transparency in selecting SOEs, financing } \\
\text { \& valuing of assets \& liabilities and bidding for } \\
\text { privatization } \\
\text { - Minimize delays incurred in hand over of enterprises } \\
\text { - Make privatization process less complicated } \\
\text { - Provide counselling service to potential investors } \\
\text { - Build capacity of Privatization Commission to } \\
\text { ensure proper monitoring of post transfer support } \\
\text { - Train and rehabilitate retrenched workers }\end{array}$ \\
\hline
\end{tabular}




\begin{tabular}{|c|c|c|c|}
\hline Strategic Goals & Key Targets & Actions Taken/ Underway & PRSP Policy Agenda (2009-2011) \\
\hline 1 & 2 & 3 & 4 \\
\hline \multicolumn{4}{|c|}{ Lead Responsibility: MoF, BOI, NBR, RRC, BBF. } \\
\hline & $\begin{array}{l}\text { - Provide adequate and equitable } \\
\text { fiscal incentives }\end{array}$ & $\begin{array}{l}\text { - BOI in each year in interacting with the investors place recommendations to GOB for adequate } \\
\text { and equitable fiscal incentives to investors } \\
\text { - BSCIC of MOI is providing collateral free loan to the under privileged women and unemployed } \\
\text { youth. }\end{array}$ & $\begin{array}{l}\text { - Replace tax holiday by discounted tax rate } \\
\text { - Bring company tax in line with other regional } \\
\text { countries } \\
\text { - Implementing PERC's relevant recommendations } \\
\text { - Making PFI effective } \\
\text { - Undertake further reforms in tax administration, } \\
\text { company tax, PFI and PSI effectiveness }\end{array}$ \\
\hline \multicolumn{4}{|c|}{ Lead Responsibility: MoF, MoC, Tariff Commission, Trade bodies, Chambers, EPB, CPA, MPA,LPA, DOF, BSTI, TB, RRC, BBF, } \\
\hline & $\begin{array}{l}\text { - Trade policy reforms at right } \\
\text { pace and sequence. }\end{array}$ & $\begin{array}{l}\text { - SAFTA is being implemented from } 1 \text { July 2006. SAFTA has opened negotiations in service } \\
\text { sector } \\
\text { - A number of rounds of trade negotiation have taken placed under APTA } \\
\text { - Trade negotiation under BIMSTEC is underway } \\
\text { - Bangladesh signed agreement on TPS-OIC in November, } 2006 \\
\text { - Bangladesh signed the Preferential Trade Agreement among D-eight countries in the sixth } \\
\text { meeting of OIC held in May, } 2006 \\
\text { - Tariff Commission has already conducted studies on the issue of removal of anti export bias } \\
\text { accompanied by resolution of supply-side bottlenecks }\end{array}$ & $\begin{array}{l}\text { - Follow up bilateral and regional FTA } \\
\text { - Reduce cost of doing business and provide a level } \\
\text { playing field to domestic producers } \\
\text { - Frame a strategy to get benefit from global service } \\
\text { trade } \\
\text { - Reduce lead time in export by developing port, } \\
\text { transport system, infrastructure and simplifying } \\
\text { goods unloading } \\
\text { - Lobby in the USA for duty-free entry of RMG } \\
\text { exports } \\
\text { - Diversify export items and markets } \\
\text { - Undertake quality improvement and cost reduction } \\
\text { measures to increase competitiveness of the exports } \\
\text { - Establish product wise design centres } \\
\text { - Increase skills and capacity of EPB, custom } \\
\text { authorities, sea and land port authorities, BSTI, Tea } \\
\text { Board, different trade bodies } \\
\text { - Promote modern technology for promotion and } \\
\text { expansion of exports }\end{array}$ \\
\hline \multicolumn{4}{|c|}{ Lead Responsibility: MOI, MOC, MOL\&E, NBR, MOF, BSCIC, DCC } \\
\hline & $\begin{array}{l}\text { - Readymade Garments (RMG) } \\
\text { promotion by addressing the } \\
\text { challenges in the post MFA era }\end{array}$ & $\begin{array}{l}\text { - An initiative has been taken by the MOI through BSCIC to reallocate all garment industries } \\
\text { from Dhaka City to Munshigonj district. The name of the project is "Garment Shilpa Park". }\end{array}$ & $\begin{array}{l}\text { - Conduct study on the possible impact of EU Rules } \\
\text { of Origin (RoO) on Bangladesh } \\
\text { - Expand IT services to BMET's district level officers } \\
\text { - Diversify trainings for all including nurses, garment } \\
\text { workers, factory workers, cleaners, housemaid, etc. } \\
\text { - Give thrust on export of high quality garments }\end{array}$ \\
\hline \multicolumn{4}{|c|}{ Lead Responsibility: MoHPW, BOI, MoL, MoF.,BEPZA \& BSCIC } \\
\hline $\begin{array}{l}\text { 2. Easing supply } \\
\text { constraints }\end{array}$ & - Provide freehold land & $\begin{array}{l}\text { - BOI recommends to Land administration for arranging freehold land for investors and is taking } \\
\text { an inventory of freehold lands } \\
\text { - SEZ policy is being formulated to facilitate land for private investors } \\
\text { - BSCIC is providing infrastructure facilities including land to the entrepreneurs in } 72 \text { districts } \\
\text { - Studies on industrial Estates are underway }\end{array}$ & $\begin{array}{l}\text { - Make unused public lands available to private } \\
\text { investors } \\
\text { - Provide fiscal incentives to private industrial estates } \\
\text { - Acquire land and hand them over to potential } \\
\text { investors for setting up of new industries, SEZ, } \\
\text { Shilpa Park, etc. } \\
\text { - Modernise land registration processes } \\
\end{array}$ \\
\hline
\end{tabular}




\begin{tabular}{|c|c|c|c|}
\hline Strategic Goals & Key Targets & Actions Taken/ Underway & PRSP Policy Agenda (2009-2011) \\
\hline 1 & 2 & 3 & 8 \\
\hline & & & $\begin{array}{l}\text { - Increase transparency in location \& environmental } \\
\text { clearance certifications }\end{array}$ \\
\hline \multicolumn{4}{|c|}{ Lead Responsibility: PM Office., BEPZA, BSCIC ,MoI, MoL,BOI, MoC } \\
\hline & $\begin{array}{l}\text { - Improve Regulatory Framework } \\
\text { and Institutional Setup for } \\
\text { Development of Economic } \\
\text { Zones }\end{array}$ & & $\begin{array}{l}\text { - Institute new policy and regulatory frameworks to } \\
\text { enable private investment in economic zones } \\
\text { - Improve land zoning for industrial purpose, land } \\
\text { titling process and land registration } \\
\text { - Piloting master land zoning and infrastructure plans } \\
\text { for selected large scale zone developments } \\
\text { - Finalize licensing for proposed and future private } \\
\text { export processing zones } \\
\text { - Facilitate public-private partnerships for provision of } \\
\text { utilities to economic zone and industrial estates } \\
\text { - Assist BEPZA and BSCIC to undertake regulatory } \\
\text { role } \\
\text { - Support building of privately financed common } \\
\text { effluent treatment plants in economic zone and } \\
\text { industrial estates } \\
\text { - Adapt a comprehensive economic zone strategy } \\
\text { - Strengthen environmental compliance standards to } \\
\text { meet the standards of foreign buyers and investors } \\
\text { - Change BEPZA rules to accommodate importers so } \\
\text { that a manufacturer of local consumers goods gets } \\
\text { facilities of tax-free import of raw materials and } \\
\text { intermediate goods } \\
\text { - Implement "One Industry one Village" theme for } \\
\text { developing economically backward areas }\end{array}$ \\
\hline \multicolumn{4}{|c|}{ Lead Responsibility: BB, MOF } \\
\hline & $\begin{array}{l}\text { - Deepen and make more efficient } \\
\text { financial market }\end{array}$ & $\begin{array}{l}\text { - NCBs have been made into limited companies } \\
\text { - Supervision of banking sector has been strengthened } \\
\text { - Enforcement of bankruptcy and default legislation made stricter } \\
\text { - Regulation of improved governance of MFIs enacted. } \\
\text { - Financial intermediation made more effective, low cost and deeper, with special emphasis on } \\
\text { reaching SMEs and rural areas } \\
\text { - Functioning of capital and insurance markets and contractual savings, respective regulators } \\
\text { improved }\end{array}$ & $\begin{array}{l}\text { - New agency for loan recovery will be established } \\
\text { - Scale-up ultra-poor finance through PKSF and } \\
\text { donor programmes (CFPR, etc.) } \\
\text { - Provide license to start banking on the basis of } \\
\text { clearly defined objectives and criteria } \\
\text { - Establish Financial Reporting Council } \\
\text { - Adopt corporate governance for MFIs } \\
\text { - Increase market placement of securitized issues, } \\
\text { promote corporate bond markets for government } \\
\text { securities and establish reliable yield benchmarks } \\
\text { - Complete ongoing restructuring of NCBs } \\
\text { - Remove legal impediments for SEC to carry out its } \\
\text { oversight role }\end{array}$ \\
\hline
\end{tabular}




\begin{tabular}{|c|c|c|c|}
\hline Strategic Goals & Key Targets & Actions Taken/ Underway & PRSP Policy Agenda (2009-2011) \\
\hline 1 & 2 & 3 & 4 \\
\hline \multicolumn{4}{|c|}{ Lead Responsibility: BB, Chambers, SEC, MoF } \\
\hline & - Strengthen capital market & $\begin{array}{l}\text { - Opening of Beneficiary Owner's (BO) Account and Central Depository Systems (CDS) is } \\
\text { introduced } \\
\text { - Initial Public offering (IPO) floatation cost is reduced } \\
\text { - 'N'category is introduced and mutual fund is approved } \\
\text { - Investor's Education Programme has been conducted } \\
\text { - Government owned shares are being off-loaded } \\
\text { - Monetary requirements have been introduced to raise capital by limited companies } \\
\text { - Direct listing regulation of Dhaka/Chittagong Stock Exchange is approved } \\
\text { - Security Training Institute is established } \\
\text { - The project-“Improvement of Capital Market Governance" is under implementation } \\
\text { - Securities and Exchange Commission (Public Rules), 2006 } \\
\text { - SEC issued 'Corporate Governance Guidelines' on 'comply or explain' basis to elevate } \\
\text { corporate governance }\end{array}$ & $\begin{array}{l}\text { - Take measures to increase supply of good shares } \\
\text { - Strengthen regulatory \& supervisory frameworks for } \\
\text { capital \& insurance markets } \\
\text { - Strengthen the SEC with adequate and appropriate } \\
\text { professional human resources } \\
\text { - Establish efficient bond to encompass resourceful } \\
\text { primary and secondary markets, lucid rules and } \\
\text { regulations, well functioning settlement and custody } \\
\text { systems, reliable ratings and bench mark yield curve } \\
\text { - Deepen the scale and scope of the market, } \\
\text { particularly by introducing new concepts and } \\
\text { instruments such as risk-hedging and commodity } \\
\text { trading etc. }\end{array}$ \\
\hline \multicolumn{4}{|c|}{ Lead Responsibility: MoSICT, BOI, Chambers, Privatization Commission. BEPZA } \\
\hline & - Attract higher level of FDI & $\begin{array}{l}\text { - Bangladesh Better Business Forum has been formed } \\
\text { - Regulatory Reform Commission has been formed } \\
\text { - A large number of regulatory, legal and policy reforms have been made to create better business } \\
\text { environment and better investment climate }\end{array}$ & $\begin{array}{l}\text { - Business support services to be improved for } \\
\text { reducing cost of doing business and attracting FDI } \\
\text { - Privatization Commission continues to attract FDI } \\
\text { through SOE privatization programme } \\
\text { - Maintaining political stability } \\
\text { - Introduction of Equity Protection Law } \\
\text { - Easy the procedure for opening up branch or liaison } \\
\text { offices by the foreign investors/companies in } \\
\text { Bangladesh. } \\
\text { - Implement laws for establishing } \\
\text { EPZ/SEZ/Industrial Parks in private sector } \\
\text { - Encourage private investment in infrastructure } \\
\text { building } \\
\text { - Improve the negotiation skill and capacity of } \\
\text { Government }\end{array}$ \\
\hline \multicolumn{4}{|c|}{ Lead Responsibility: MOCM, MoS, MOPT BR, RHW, MoLJPA, ERC, CPA, MOEP, PMOffice. } \\
\hline & - Improve infrastructural facilities & $\begin{array}{l}\text { - Construction of Dhaka Metro in private sector on BOT basis has been approved by the Cabinet } \\
\text { Committee } \\
\text { - Jamuna Bridge Railway Link Construction Project (second revised) is being implemented since } \\
\text { July } 1997 \\
\text { - Two foreign companies have expressed their interest on the construction of the expressway } \\
\text { from Dhaka to Chittagong. PQ will be awarded soon } \\
\text { - A MOU is awaiting agreement signature between the GOB and a Chinese Company (CMEG) } \\
\text { for the construction of the Dhaka - Laksham Cord line. DPP is being prepared. } \\
\text { - Three large IPPs each of having } 150 \text { MW capacity are under process of implementation }\end{array}$ & $\begin{array}{l}\text { - Modernise management and operations of ports } \\
\text { - Improve railway container and cargo handling } \\
\text { - Implement necessary policy and institutional reforms } \\
\text { at Chittagong port } \\
\text { - Increase generation and distribution of electricity } \\
\text { and gas } \\
\text { - Address critical issue of pricing of power and gas } \\
\text { - Take policies/strategies to facilitate ship building in } \\
\text { private sector } \\
\text { - Develop coal mines activities } \\
\text { - Develop SEZ/industrial parks with public-private }\end{array}$ \\
\hline
\end{tabular}




\begin{tabular}{|c|c|c|c|}
\hline Strategic Goals & Key Targets & Actions Taken/ Underway & PRSP Policy Agenda (2009-2011) \\
\hline \multirow[t]{2}{*}{1} & 2 & 3 & 4 \\
\hline & & & $\begin{array}{l}\text { partnership } \\
\text { - Energy conservation and efficiency programmes } \\
\text { - Renewable energy development } \\
\text { - BRTC will be strengthened for effective regulation } \\
\text { and facilitating telecommunication services }\end{array}$ \\
\hline \multicolumn{4}{|c|}{ Lead Responsibility: MoPME, MoE, MoLE, MoT\&J, MoSICT. } \\
\hline & $\begin{array}{ll}\text { - } & \text { Address Skills } \\
& \text { Constraints }\end{array}$ & $\begin{array}{l}\text { - A new labour law } 2006 \text { has been formulated and approved by the government } \\
\text { - MoLE is providing technical trainings on different trades and creating skilled manpower } \\
\text { through technical training centres. } \\
\text { - A total no. of } 26 \text { technical centres is being established through implementation of } 4 \text { different } \\
\text { projects. Out of these } 6 \text { TTCs are being established solely for women } \\
\text { - A data base has been developed by BMET of Mo Expatriate Welfare and Overseas } \\
\text { Employment }\end{array}$ & $\begin{array}{l}\text { - Consolidate gains in primary and secondary } \\
\text { education with emphasis on improving the overall } \\
\text { quality } \\
\text { - Improve the quality and market relevance of the } \\
\text { vocational education and training (VET) system } \\
\text { - Develop a policy framework, in coordination with } \\
\text { the private sector, clarifying roles \& responsibilities } \\
\text { of various VET agencies } \\
\text { - Make available information on training programme } \\
\text { and facilitate regularly and independent impact } \\
\text { evaluations on training programme } \\
\text { - Allow greater autonomy for VET institutions and } \\
\text { Set-up an autonomous Board of VET }\end{array}$ \\
\hline \multicolumn{4}{|c|}{ Lead Responsibility: MoE, MoPME, MoLE, MoI, BSCIC, MOEE, } \\
\hline & - Develop Human resources & $\begin{array}{l}\text { - BITAC provides regular training on welding, machinery shopping, foundry, electrical and } \\
\text { electronics, plastic technology, heat treatment at a very low cost } \\
\text { - A special Institution named SCITI of BSCIC is imparting regular training on entrepreneurship } \\
\text { development } \\
\text { - Design centres of BSCIC are giving training on different trades for development of human } \\
\text { resources } \\
\text { - BSCIC imparted HRD training related to SMEs }\end{array}$ & $\begin{array}{l}\text { - Develop curriculum of education and training } \\
\text { programmes to reflect need of private sector } \\
\text { - Introduce internships and on the job training } \\
\text { facilities } \\
\text { - Improve entrepreneurial, managerial and labour } \\
\text { skills } \\
\text { - Strengthen technical and vocational teachers training } \\
\text { - Reform the legal base of universities for assessment } \\
\text { of performance and re-establishing accountability } \\
\text { - Separate integrated programme to be undertaken for } \\
\text { women entrepreneurship development } \\
\text { - Ensure quality higher education to meet the market } \\
\text { needs } \\
\text { - Undertake initiative for collaboration of all research } \\
\text { organizations and technical and higher educational } \\
\text { institutions with the service users }\end{array}$ \\
\hline \multicolumn{4}{|c|}{ Lead Responsibility: MoI, MoE, MoSICT, BOI, BEPZA, BITAC, BUET, Chambers/Trade Bodies. } \\
\hline & $\begin{array}{l}\text { - Facilitate technology } \\
\text { development }\end{array}$ & $\begin{array}{l}\text { - National Science and Technology Policy, } 1986 \text { is under review for updating } \\
\text { - ICT Act was enacted in October } 2006 \text { and preparation of Rules related to e-commerce is } \\
\text { underway } \\
\text { - National Institute of Bio-Technology has been set up } \\
\text { - Bio-Technology Laboratory and Research has been initiated } \\
\text { - BOI approved TT agreements by local and foreign investors }\end{array}$ & $\begin{array}{l}\text { - Prepare a technology development strategy } \\
\text { - Carry out, on a continuous basis, strategic reviews of } \\
\text { higher education and TEVT system to make it more } \\
\text { adaptable to employer and entrepreneurs needs } \\
\text { - Trade bodies will seek trade specific technology } \\
\text { development in collaboration with relevant public }\end{array}$ \\
\hline
\end{tabular}




\begin{tabular}{|c|c|c|c|}
\hline Strategic Goals & Key Targets & Actions Taken/ Underway & PRSP Policy Agenda (2009-2011) \\
\hline \multirow[t]{2}{*}{1} & 2 & 3 & 4 \\
\hline & & $\begin{array}{l}\text { - A new policy in TT is completed and initiative has been taken for collaboration between public } \\
\text { and private sector in setting up of a centre for transfer and diffusion of technologies. } \\
\text { - Officials of BITAC are receiving trainings to improve their technological knowledge for } \\
\text { developing new technology } \\
\text { - Experts from developed countries are regularly coming to provide training to the officials of } \\
\text { BITAC } \\
\text { - Developed an action plan on technology for selected SMEs }\end{array}$ & $\begin{array}{l}\text { and private institutions supported by appropriate } \\
\text { matching grant facility } \\
\text { - Provide policy support for technology transfer by } \\
\text { foreign investors } \\
\text { - Carry out strategic reviews of the incentive regimes } \\
\text { for public and private absorption of technology with } \\
\text { a focus on commercialization of pro-poor } \\
\text { innovations } \\
\text { - Identify gender gaps and concerns in policy } \\
\text { documents and strategy papers on technology }\end{array}$ \\
\hline \multicolumn{4}{|c|}{ Lead Responsibility: BBS,BOI,EPB, Chambers, MoSICT, BEPZA, BBF, RRC } \\
\hline $\begin{array}{l}\text { 3.Improving Business } \\
\text { Support Services }\end{array}$ & $\begin{array}{l}\text { - Create information and data base } \\
\text { for providing market information }\end{array}$ & $\begin{array}{l}\text { - The government developed a web portal to ensure access of information related for } \\
\text { improvement of the business. } \\
\text { - BOI has completed a web based MIS for keeping investment related data. } \\
\text { - A business registry has already been developed that will extend business support services. } \\
\text { - Possibility of bringing BOI and BEPZA under one umbrella is under examination. } \\
\text { - Efforts to separate the regulatory and service functions of EPB will be made }\end{array}$ & $\begin{array}{l}\text { - Strengthen industrial statistics wing of BBS } \\
\text { - Make registration of private investment mandatory } \\
\text { and improve coordination amongst pertinent } \\
\text { agencies } \\
\text { - Establish modern laboratories for controlling quality } \\
\text { of export products } \\
\text { - Ensure regular supply of updated information on } \\
\text { market and technology to producers } \\
\text { - Establish backward and forward industries } \\
\text { - Establish effluent treatment plants in industrial } \\
\text { zones } \\
\text { - Ensure easy access to raw materials for export } \\
\text { products } \\
\text { - Institute regulatory impact assessment mechanisms } \\
\text { and processes within Government } \\
\text { - Establish ongoing processes for reduction of } \\
\text { regulatory burden within Government } \\
\text { - Establish PSD inter -Agency Network } \\
\text { - Support development of GoB's capacity to monitor } \\
\text { the Bangladesh Investment Climate } \\
\text { - Implement e-Government framework, platform and } \\
\text { LAN (software only) and implement e-Government } \\
\text { pilots } \\
\text { - Conduct business process surveys of municipal } \\
\text { authorities' service functions }\end{array}$ \\
\hline \multicolumn{4}{|c|}{ Lead Responsibility: MoI, BSTI, MoLE, MoC, MoSICT } \\
\hline & $\begin{array}{l}\text { - Improve standard and quality } \\
\text { control }\end{array}$ & $\begin{array}{l}\text { - BSTI plays vital role in maintaining country's standard and quality control issue of different } \\
\text { products } \\
\text { - BSTI is implementing two projects to (a) upgrade the required technical infrastructure for } \\
\text { standards development and harmonization, metrology and testing laboratories required by the } \\
\text { selected sectors, and Standards for labelling and accreditation and/or certification of } \\
\text { laboratories and quality system and (b) develop national capacities for setting up Hazardous } \\
\text { Analysis Critical Control Point (HACCP) ISO } 9000 \text { and ISO } 14000 \text { schemes at enterprise level }\end{array}$ & $\begin{array}{l}\text { - Strengthen BSTI to meet the international standards } \\
\text { - The trade bodies to initiate setting up of trade } \\
\text { specific standards as per international requirements. } \\
\text { - Make arrangement for quality development of } \\
\text { Chambers and Business Associations. } \\
\text { - There should be more cooperation between public }\end{array}$ \\
\hline
\end{tabular}




\begin{tabular}{|c|c|c|c|}
\hline Strategic Goals & Key Targets & Actions Taken/ Underway & PRSP Policy Agenda (2009-2011) \\
\hline 1 & 2 & 3 & 4 \\
\hline & & $\begin{array}{l}\text { as well as the capacity of national certification bodies to assess such systems } \\
\text { - A consumer rights protection law has been approved on principle } \\
\text { - Actions are underway to reorganize and strengthening EPB, Bangladesh Tariff Commission and } \\
\text { CCI\&E }\end{array}$ & $\begin{array}{l}\text { and private sector on standard and environmental } \\
\text { issues }\end{array}$ \\
\hline \multicolumn{4}{|c|}{ Lead Responsibility: MoI, DPDT, MoC, EPB, BOI, BEPZA, Cambers } \\
\hline & $\begin{array}{l}\text { - Improve Intellectual Property } \\
\text { Rights environment }\end{array}$ & $\begin{array}{l}\text { - Department of Patent, Design and Trademarks (DPDT) is implementing a project to } \\
\text { strengthen national capacity to develop \& modernize the intellectual property (IP) system }\end{array}$ & $\begin{array}{l}\text { - Strengthen Department of Patent, Design and } \\
\text { Trademarks (DPDT) with appropriate human } \\
\text { resources } \\
\text { - Strengthen national capacity to develop \& } \\
\text { modernize the intellectual property (IP) system } \\
\text { - Strengthen Copyright Office with appropriate } \\
\text { technical and professional manpower }\end{array}$ \\
\hline \multicolumn{4}{|c|}{ Lead Responsibility: MoI, BSCIC, Cambers, MoWCA, WEAB, EPB, BOI, MoLE, MoYS, WEDP } \\
\hline $\begin{array}{l}\text { 4. Women } \\
\text { entrepreneurship } \\
\text { Development }\end{array}$ & $\begin{array}{l}\text { - Develop Women } \\
\text { entrepreneurship } \\
\text { - Ensure } 20 \% \text { increase of women } \\
\text { entrepreneurs }\end{array}$ & $\begin{array}{l}\text { - BSCIC provides training on 'Business Management' and Entrepreneurship Development to } \\
\text { the rural potential women entrepreneurs in all divisions and selected districts. } \\
\text { - BSCIC's project viz. 'women entrepreneurship development' for self-employment of potential } \\
\text { women since } 1984 \text { and so far imparted EDP training for } 93,621 \text { potential woman } \\
\text { entrepreneurs } \\
\text { - Recent policy of Government allows women entrepreneurs to receive } 10 \% \text { of credit facilities to } \\
\text { improve their business } \\
\text { - } 5 \text { percent industrial plots are being reserved for women entrepreneurs in various industrial parks } \\
\text { to ensure more participation } \\
\text { - Representatives of women entrepreneurs association are sent abroad for training, seminars and } \\
\text { workshops } \\
\text { - Women associations named 'Women Entrepreneurs Association of Bangladesh' Women } \\
\text { Chamber and Commerce Industries are the regular members of all activities of the MOI. } \\
\text { - EPB plans to create a trade portal that will help women entrepreneurs to participate in } \\
\text { economic activities. } \\
\text { - } 10 \% \text { of Small Enterprise Fund (SEF) created by the BB has been allocated for the women } \\
\text { entrepreneurs. }\end{array}$ & $\begin{array}{l}\text { - Provide tariff incentives to import of inputs in case } \\
\text { of cottage and handicraft activities } \\
\text { - Encourage women entrepreneurs in small \& } \\
\text { medium-scale production and business activities } \\
\text { - Give preferential treatment to women entrepreneurs } \\
\text { in trade fairs at home and abroad } \\
\text { - Develop linkages between women's associations and } \\
\text { credit institutions } \\
\text { - Undertake initiative for the development of women's } \\
\text { entrepreneurship in an integrated way } \\
\text { - Involve business association and chambers of } \\
\text { commerce \& Industries in women's entrepreneur's } \\
\text { development } \\
\text { - Encourage the Chambers to provide women } \\
\text { entrepreneurs with bankable project and } \\
\text { technology } \\
\text { - Ensure woman's association to work with apex } \\
\text { chamber and associations for promotion of } \\
\text { women entrepreneurs } \\
\text { - Implement gender Action Plan by the SMEF and } \\
\text { WEEF } \\
\text { - Established a design institutes for SMEs } \\
\text { - Provide special support (information, credit, } \\
\text { extension services, technology etc.) for women } \\
\text { entrepreneurs } \\
\text { - Ensure special allocation for women entrepreneurs } \\
\text { - Make the procedure of starting business easy for } \\
\text { women }\end{array}$ \\
\hline
\end{tabular}




\begin{tabular}{|c|c|c|c|}
\hline Strategic Goals & Key Targets & Actions Taken/ Underway & PRSP Policy Agenda (2009-2011) \\
\hline 1 & 2 & 3 & 4 \\
\hline \multicolumn{4}{|c|}{ Lead Responsibility: MoF, BB, MoA, MoFL, MOLG\&C, MoL, BSCIC, BARD, PM Office, NGO Bureau, MoT\&J, } \\
\hline $\begin{array}{l}\text { 5. Developing Rural } \\
\text { Non-Farm Sector } \\
\text { (RNFS) }\end{array}$ & $\begin{array}{l}\text { - Develop RNFS } \\
\text { - Make RNFS mainstream } \\
\text { - Make market function better }\end{array}$ & $\begin{array}{l}\text { - Public and private sectors are providing training to develop human resources involved in the } \\
\text { non-farm sector } \\
\text { - Credit facilities are given for product promotion and business expansion to RNFS } \\
\text { - Taxes and other financial and policy assistance are provided to RNFS } \\
\text { - Supports are being given to rural entrepreneurs to facilitate smooth business }\end{array}$ & $\begin{array}{l}\text { - Ensure physical infrastructure and rural } \\
\text { electrification } \\
\text { - Rationalize tax \& tariff structure to facilitate RNFS } \\
\text { - Create extensive data base on RNFE sector } \\
\text { - Reform NCBs for enhancing rural banks to support } \\
\text { RNFS } \\
\text { - Prepare and adopt a national RNFS development } \\
\text { policy } \\
\text { - Enforce transparent and consistent "rules of the } \\
\text { game" for agro enterprise development } \\
\text { - Improve marketing infrastructure to promote rural } \\
\text { non-farm and non-crop agriculture activities } \\
\text { - Address issues relating to quality and productivity of } \\
\text { outputs in RNFS } \\
\text { - Encourage private entrepreneurs to enter into buy- } \\
\text { back arrangement with RNFS }\end{array}$ \\
\hline \multicolumn{3}{|c|}{ Total Indicative Cost (in billion taka) } & Tk. 54.76 \\
\hline
\end{tabular}


Policy Matrix 8: Land Use Policy and Management

\begin{tabular}{|c|c|c|c|}
\hline Strategic Goals & Key Targets & Actions Taken/ Underway & PRSP Policy Agenda (2009-2011) \\
\hline 1 & 2 & 3 & 4 \\
\hline \multicolumn{4}{|l|}{ Lead Responsibility: MoL } \\
\hline $\begin{array}{l}\text { 1. Modernizing land records preparation and land } \\
\text { management system }\end{array}$ & $\begin{array}{l}\text { - Modernize land records of one city and } 60 \\
\text { Upazila }\end{array}$ & $\begin{array}{l}\text { - The pilot project taken up for computerization of land } \\
\text { records of Demra circle was completed successfully in } \\
2005 / 2006 \\
\text { - Programme of computerization of land records is going on in } \\
\text { another four circles in Dhaka city }\end{array}$ & $\begin{array}{l}\text { - Prepare and preserve land records using } \\
\text { ICT } \\
\text { - Establish a database to preserve and } \\
\text { manage all records electronically at all } \\
\text { tiers of land administration } \\
\text { - Preserve hard copies of all records for } \\
\text { checking authenticity } \\
\text { - Use satellite imageries for preparation of } \\
\text { land records } \\
\text { - Reorganize the offices of registration of } \\
\text { land transfer deed } \\
\text { - Integrate land survey, land records and } \\
\text { land management and digitise the whole } \\
\text { land administration }\end{array}$ \\
\hline $\begin{array}{l}\text { 2. Rehabilitating asset less and homeless people in } \\
\text { rural areas, poor female headed households, slum } \\
\text { dwellers and low income families in Dhaka and other } \\
\text { big cities and climate victims }\end{array}$ & $\begin{array}{l}\text { - Provide } 58000 \text { asset less and homeless families } \\
\text { with houses } \\
\text { - Provide } 114 \text { twin houses to homeless families } \\
\text { and land to } 3000 \text { other families } \\
\text { - Provide flats to } 7560 \text { slum dwellers } \\
\text { - Provide flats to } 5040 \text { low-income families }\end{array}$ & $\begin{array}{l}\text { - } 25385 \text { asset less and poor families have been provided with } \\
\text { houses, training and micro-credit for their rehabilitation } \\
\text { - Construction of } 12600 \text { flats is going on in Dhaka city. These } \\
\text { are being constructed on govt. land on public/private } \\
\text { ownership basis. These will be allotted to slum dwellers and } \\
\text { low income families at a reduced price } \\
\text { - Rehabilitation of climate victims through Guchcha Gram } \\
\text { started }\end{array}$ & $\begin{array}{l}\text { - Identify land filling of suitable Khas land } \\
\text { - Select beneficiary families } \\
\text { - Construct houses and transfer deed to } \\
\text { the beneficiaries } \\
\text { - Engage in I.G.As through training and } \\
\text { credit } \\
\text { - Construct flats by private investors to be } \\
\text { given to poor } \\
\text { - Start the process for selection of } \\
\text { beneficiaries, allotting of flats, sale and } \\
\text { transfer of flats and conduct deed of } \\
\text { transfer } \\
\text { - Rehabilitation of climate victims through } \\
\text { Guchcha Gram to continue }\end{array}$ \\
\hline 3. Providing agricultural Khas land & $\begin{array}{l}\text { - Settle } 33000 \text { acres of Khas land in favour of } \\
33000 \text { families. }\end{array}$ & $\begin{array}{l}\text { - Settlement of around } 15000 \text { acres, } 19000 \text { acres and } 15000 \\
\text { acres of agricultural Khas land has been completed in FY05, } \\
\text { FY06 and FY07. }\end{array}$ & $\begin{array}{l}\text { - Identify more Khas land suitable for } \\
\text { settlement } \\
\text { - Select beneficiary on the basis of } \\
\text { transparent criteria } \\
\text { - Provide Khas land on the basis of } \\
\text { existing policy }\end{array}$ \\
\hline 4. Ensuring proper and planned use of land & $\begin{array}{l}\text { - Complete land zoning in } 19 \text { Coastal districts } \\
\text { - Complete land zoning in } 2 \text { other districts }\end{array}$ & $\begin{array}{l}\text { - Preparation of a database based on land resources and of } \\
\text { Maps based on land zoning information is going on } \\
\text { - Land zoning maps based on land use in } 19 \text { coastal districts } \\
\text { and } 2 \text { other districts will be prepared }\end{array}$ & $\begin{array}{l}\text { - Prepare upazila land use plan } \\
\text { - Prepare database based on land } \\
\text { resources and of land zoning } \\
\text { information system } \\
\text { - Enact land zoning law and village } \\
\text { improvement Act } \\
\text { - Prepare a report on Char and } \\
\text { ecologically Critical Areas }\end{array}$ \\
\hline
\end{tabular}




\begin{tabular}{|c|c|c|c|}
\hline Strategic Goals & Key Targets & Actions Taken/ Underway & PRSP Policy Agenda (2009-2011) \\
\hline 1 & 2 & 3 & 4 \\
\hline $\begin{array}{l}\text { 5. Managing Jajmahal, Balumahal and Sairat mahals } \\
\text { for poverty reduction }\end{array}$ & - Modify and update relevant policies & $\begin{array}{l}\text { - Jalmahal management policy modified and updated } \\
\text { - Land use policy made effective } \\
\text { - Land Reforms Board rules introduced } \\
\text { - Formulation of Balumahal policy is going on }\end{array}$ & $\begin{array}{l}\text { - Modify /Update Jalmahal management } \\
\text { policy } \\
\text { - Modify /Update Balumahal management } \\
\text { policy } \\
\text { - Modify /Update other Sairat mahal } \\
\text { management policy } \\
\text { - Develop data management system for } \\
\text { public water bodies }\end{array}$ \\
\hline 6. Ensuring ownership/title through land survey & $\begin{array}{l}\text { - Print and publish } 1000000 \text { Khatians } \\
\text { - Print and publish } 300000 \text { Maps }\end{array}$ & $\begin{array}{l}\text { - } 1065631 \text { Khatians of } 2248 \text { Mouzas and } 655202 \text { maps of } 1949 \\
\text { Mouzas was printed and published } \\
\text { - Printing and publication of } 3000000 \text { Khatians of } 5400 \\
\text { Mouzas and } 1344000 \text { maps of } 5600 \text { Mouzas are under way }\end{array}$ & $\begin{array}{l}\text { - Selection of area for survey } \\
\text { - Employment of manpower for surveying } \\
\text { - Informing land owners through wide } \\
\text { publicity } \\
\text { - Preparation and supply of Khatians and } \\
\text { Maps } \\
\text { - Develop digital data base of land survey }\end{array}$ \\
\hline $\begin{array}{l}\text { 7. Ensuring maximum and efficient land related } \\
\text { service to people }\end{array}$ & $\begin{array}{l}\text { - Prepare recommendation for modification, } \\
\text { updating and simplification of land related acts, } \\
\text { ordinances, rules, regulations and policies }\end{array}$ & $\begin{array}{l}\text { - A workshop was held in March } 2006 \text { to prepare } \\
\text { recommendations } \\
\text { - RRC has been working on this issue }\end{array}$ & $\begin{array}{l}\text { - Constitute a committee of specialist } \\
\text { including lawyers } \\
\text { - Install close circuit camera in the land } \\
\text { ministry and attached departments }\end{array}$ \\
\hline \multicolumn{4}{|c|}{ 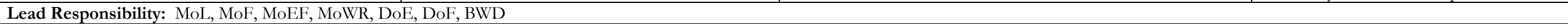 } \\
\hline $\begin{array}{l}\text { 8. Protecting and Conserving wetland, hilly areas, tea } \\
\text { and rubber gardens }\end{array}$ & $\begin{array}{l}\text { - Promulgate new laws/policies. } \\
\text { - Modification/updating of existing laws/policies }\end{array}$ & $\begin{array}{l}\text { - Department of fisheries, local govt. institutions closely } \\
\text { involved in the management of Jalmahals }\end{array}$ & $\begin{array}{l}\text { - Lease out rivers, canals, hoars etc. to } \\
\text { poor and fishing community } \\
\text { - Introduce special laws/policies for } \\
\text { protecting hilly areas, tea gardens, rubber } \\
\text { gardens }\end{array}$ \\
\hline 9. Taking measures for accretion of coastal land & $\begin{array}{l}\text { - Accrete land in Chittagong, Feni, Lakshmipur } \\
\text { and Noakhali areas }\end{array}$ & - Settlement of coastal land is underway & $\begin{array}{l}\text { - Take measure to consolidate accretion of } \\
\text { land in coastal areas and make it suitable } \\
\text { for afforestation, habitation and crop } \\
\text { production }\end{array}$ \\
\hline \multicolumn{3}{|l|}{ Total Indicative Cost (in billion taka) } & Tk. 3.78 \\
\hline
\end{tabular}




\begin{tabular}{|c|c|c|c|}
\hline Strategic Goals & Key Targets & Actions Taken/ Underway & PRSP Policy Agenda (2009-2011) \\
\hline 1 & 2 & 3 & 4 \\
\hline \multicolumn{4}{|c|}{ Lead Responsibility: MoHPW, city corporations, municipalities } \\
\hline $\begin{array}{l}\text { 1. Ensuring adequate and affordable } \\
\text { housing for different income groups, } \\
\text { especially low income and extreme } \\
\text { poor and vulnerable groups }\end{array}$ & $\begin{array}{l}\text { - Provide housing for families with } \\
\text { low-income in rural and urban areas, } \\
\text { landless and homeless families } \\
\text { - Discourage encroachment on public } \\
\text { land and formation of new slums and } \\
\text { unauthorized constructions } \\
\text { - Subsidize raising of plinth level and } \\
\text { construction of houses within the } \\
\text { Bheri-Bandh area in disaster prone } \\
\text { regions of Bangladesh } \\
\text { - Coordinate the National Housing } \\
\text { Policy with other development } \\
\text { policies }\end{array}$ & $\begin{array}{l}\text { - Rehabilitation scheme undertaken for } 60000 \\
\text { evicted slum dwellers } \\
\text { - Chittagong, Kushtia, Natore, Cox's Bazar, } \\
\text { Noakhali, Sylhet, Maulavi Bazar, Comilla, } \\
\text { Narsinghdi, Barisal Housing Estates initiated and } \\
\text { completed } \\
\text { - RAJUK's 'Purbachal' (26917 plots), 'Jhilmil' (1775), } \\
\text { 'Uttara Residential Model Town' (6640) } \\
\text { implemented and is in the third phase } \\
\text { - Annual REHAB housing Fair for members, clients, } \\
\text { financial institutions and providers of building } \\
\text { material takes place } \\
\text { - Adarsha Gram I benefited } 45,647 \text { families and } \\
\text { - Adarsha Gram II benefited 25,385 families } \\
\text { - Programme for the vagrant and elderly women are } \\
\text { being administered by MoSW } \\
\text { - Appropriate Resources for Improving Street } \\
\text { Children's' Environment (ARISE) } \\
\text { - Providing shelter with health services, education } \\
\text { and jobs for } 8,000 \text { vulnerable children } \\
\text { - For low-income GoB officials, } 5000 \text { flats in Mirpur } \\
\text { and } 1000 \text { flats in Mohammadpur were built and } \\
\text { construction of } 420 \text { flats in Motijhil is underway }\end{array}$ & $\begin{array}{l}\text { - Preparing Policy Guidelines for creating conducive environment for private } \\
\text { investment in housing } \\
\text { - Target the extremely impoverished in rural and urban areas for assisted } \\
\text { house building, community housing, mess etc. } \\
\text { - Establish housing, preferably multi-unit -high- rise, for the extreme poor } \\
\text { with essential facilities } \\
\text { - Speed up previous projects facing stagnation and complete on-going } \\
\text { development work } \\
\text { - Expansion of planned residential areas in Dhaka, Chittagong and other } \\
\text { divisional headquarters and in all the district towns for different income } \\
\text { groups } \\
\text { - In Dhaka, further development of Uttara-Gulshan-Banani and Baridhara } \\
\text { - Provide loans to low-income people to own houses on hire-purchase basis } \\
\text { - Build GO-NGO partnership and encourage the private sector to provide } \\
\text { housing for families with low-income in rural and urban areas, landless and } \\
\text { homeless } \\
\text { - Develop mechanism for mobilization of resources and new financing } \\
\text { mechanism } \\
\text { - Encourage research and development for new modes of housing technology } \\
\text { using indigenous materials } \\
\text { - Strengthen House and Building Research Institute (HBRI) for low cost } \\
\text { housing research }\end{array}$ \\
\hline \multicolumn{4}{|c|}{ Lead Responsibility: MoHPW, city corporations, municipalities, NGOs, private sector } \\
\hline $\begin{array}{l}\text { 2. Providing housing for rural and } \\
\text { urban homeless, landless and } \\
\text { vulnerable groups and poor female } \\
\text { headed households }\end{array}$ & $\begin{array}{l}\text { - Provide housing for all functionally } \\
\text { landless people by } 2025 \\
\text { - Ensure shelter for people who qualify } \\
\text { for safety net programmes } \\
\text { - Provide housing for Female HH } \\
\text { where women are widowed, deserted } \\
\text { or destitute }\end{array}$ & $\begin{array}{l}\text { - Establish Adarsha Grams, Abashan, Asrayan, } \\
\text { - Ghare Phera on Govt. khas lands } \\
\text { - Fund for housing for the distressed (grihayan } \\
\text { tahabil) established } \\
\text { - Under Abashan project a total of } 32,663 \text { houses } \\
\text { were built for } 163,315 \text { beneficiaries up to } 2005\end{array}$ & $\begin{array}{l}\text { - Identify financing institutions, agencies, NGOs and other organizations for } \\
\text { assisting house building } \\
\text { - Set up slum improvement cell in every municipality } \\
\text { - Extend solid waste collection service, efficient conservancy services } \\
\text { proportionate to population within communities and provide water points } \\
\text { and sanitary latrines } \\
\text { - Build more hostels, vagrant homes and also replicate projects like Asrayan, } \\
\text { Abashan, targeting single women, FHH, disaster affected families, vulnerable } \\
\text { groups, street children } \\
\text { - Ensure M\&O of new and rehabilitated structures } \\
\text { - Rural housing, ideal village and returning homes projects to continue }\end{array}$ \\
\hline \multicolumn{4}{|c|}{ Lead Responsibility: MoHPW, MoL, FD, PC, city corporations, municipalities, NGOs, private sector } \\
\hline $\begin{array}{l}\text { 3. Maximising utilization of land in } \\
\text { urban and rural areas }\end{array}$ & $\begin{array}{l}\text { - Reallocate the extreme poor living in } \\
\text { depressed areas } \\
\text { - Target people with threatened } \\
\text { livelihoods, hard-core poor people, } \\
\text { unemployed people in remote areas, }\end{array}$ & $\begin{array}{l}\text { - Provide housing including safe drinking water, } \\
\text { sanitation and electricity } \\
\text { - MoSW's Abashon project in } 180 \text { upazilas is } \\
\text { underway. } \\
\text { - } 6 \text { Sharkari Ashroy Kendra (Vagrant home) is }\end{array}$ & $\begin{array}{l}\text { - Introduce land zoning, enforce rules for sites and services, formulate policy } \\
\text { for inclusion of hard-core poor and women in income generating activities } \\
\text { related to construction materials, formulate new structure of duty (stamp } \\
\text { duty) and registration fees on the basis of economic categories } \\
\text { - Provide fiscal and other financial and competitive incentives to GO-NGO }\end{array}$ \\
\hline
\end{tabular}




\begin{tabular}{|c|c|c|c|}
\hline Strategic Goals & Key Targets & Actions Taken/ Underway & PRSP Policy Agenda (2009-2011) \\
\hline 1 & 2 & 3 & 4 \\
\hline & $\begin{array}{l}\text { monga areas, hoar and char areas } \\
\text { - Rehabilitate Disaster calamity victims } \\
\text { - Mitigate housing problems of } \\
\text { homeless poor } \\
\text { - Rehabilitate scattered slum dwellers } \\
\text { and pavement dwellers }\end{array}$ & $\begin{array}{l}\text { underway } \\
\text { - Training and Rehabilitation Centre for } \\
\text { disadvantaged girls, } 6 \text { Safe Home for the women } \\
\text { and adolescent girls are operating } \\
\text { - Formulated the National Plan for Disaster } \\
\text { Management } 2007-2015 \text { particularly addresses } \\
\text { specific housing needs of women and } \\
\text { disadvantaged vulnerable groups included within } \\
\text { CRA and RRAP } \\
\text { - Rehabilitated slum and lower income group in } \\
\text { Dhaka city in } 47.90 \text { acres of land by constructing } \\
\text { 15,024 flats in } 438 \text { multi-storied buildings } \\
\text { - Preparation of Master Plan/Land use plans for } 12 \\
\text { newly declared Paurashava underway } \\
\text { - Prepared layout plans of plots of land development } \\
\text { projects of National Housing Authority } \\
\text { - Bangladesh Country Urban Indicators Study } \\
\text { Projects for } 14 \text { cities undertaken } \\
\text { - Technical Assistance for Strengthening Capability } \\
\text { of the Urban Development Directorate for } \\
\text { updating upazila and District Town Master Plan } \\
\text { - Establishment of Building Technology } \\
\text { Dissemination, Testing and Trainings Centres at } \\
\text { Rajshai, Sylhet and Dhaka is underway } \\
\text { - Preparation of structure, Master and Area Plan for } \\
\text { Sylhet and Barisal and Cox's Bazar towns is } \\
\text { underway }\end{array}$ & $\begin{array}{l}\text { partnerships that encourage rehabilitation and reallocation schemes } \\
\text { - Develop Regional Plan for } 3 \text { Hill districts of Rangamati, Khagrachari and } \\
\text { Bandarban } \\
\text { - Develop land use clusters in rural areas (vertical expansion within specified } \\
\text { zones) and detailed area plans through land acquisition and zoning } \\
\text { - Create processes for land use planning and regulation } \\
\text { - Ensure M\&O of new and rehabilitated structures } \\
\text { - Institutionalize capacity development of local authority } \\
\text { - Prepare urban and rural Housing Policy for maximising land utilization of } \\
\text { land }\end{array}$ \\
\hline \multicolumn{4}{|c|}{ Lead Responsibility: MoHPW, MoL, MoEF, MoWR, PC, city corporations, municipalities } \\
\hline $\begin{array}{l}\text { 4. Facilitating/ promoting private } \\
\text { sector, NGOs and CBOs in house } \\
\text { building }\end{array}$ & $\begin{array}{l}\text { - Create processes for private sector } \\
\text { assisted building norms and system } \\
\text { for monitoring a GoB formulated } \\
\text { regulatory framework } \\
\text { - Formulate GoB body to evaluate } \\
\text { institutional capacity of local } \\
\text { authority } \\
\text { - Construct new houses, street lights, } \\
\text { roads and sidewalks }\end{array}$ & $\begin{array}{l}\text { - Community Risk Assessment (CRA) Guideline and } \\
\text { Risk Reduction Action Planning Process (RRAP) } \\
\text { are under implementation through sub-contracting } \\
\text { arrangements with NGOs }\end{array}$ & $\begin{array}{l}\text { - Improving/expanding basic amenities in urban slums } \\
\text { - Strengthen the Environment Cell to monitor conditions of urban slums and } \\
\text { related aspects } \\
\text { - Promote basic urban norms, neighbourhood and community feeling } \\
\text { - Provide housing and rooming houses for poor female working women, } \\
\text { single mothers and vulnerable }\end{array}$ \\
\hline \multicolumn{3}{|l|}{ Total Indicative Cost (in billion taka) } & Tk. 80.81 \\
\hline
\end{tabular}




\begin{tabular}{|c|c|c|c|}
\hline Strategic Goals & Key Targets & Action Taken/underway & PRSP Policy Agenda (2009-11) \\
\hline$(1)$ & $(2)$ & $(3)$ & $(4)$ \\
\hline \multicolumn{4}{|c|}{ Lead Responsibility: Bangladesh Power Development Board (BPDB) } \\
\hline $\begin{array}{l}\text { 1. Increasing efficiency accountability and } \\
\text { transparency }\end{array}$ & $\begin{array}{l}\text { - Complete unbundling of distribution sub-sector } \\
\text { - Create BPDB Holding Company } \\
\text { - Corporatise BPDB's remaining power plants } \\
\text { - Restore the sector financial viability and credit } \\
\text { worthiness } \\
\text { - Ensure good governance in the corporatised entities }\end{array}$ & $\begin{array}{l}\text { - North-West Zone Power Distribution Company (NWZPDC) } \\
\text { has started functioning. } \\
\text { - South Zone Power Distribution Company (SZPDC) } \\
\text { incorporated } \\
\text { - Unbundling of distribution to be complete with corporatisation } \\
\text { of Central Zone of BPDB } \\
\text { - Study completed for corporatisation of Central Zone } \\
\text { - Study for the creation of BPDB Holding Company is ongoing }\end{array}$ & $\begin{array}{l}\text { - Continue unbundling and } \\
\text { corporatisation } \\
\text { - Establish commercial arrangement } \\
\text { under Single Buyer power market } \\
\text { - Rationalize tariff according to Power } \\
\text { Pricing Framework and introduce life } \\
\text { line tariff for ultra-poor } \\
\text { - Strengthening sector regulation under } \\
\text { BERC } \\
\text { - Establish a power trading subsidiary for } \\
\text { bulk power management }\end{array}$ \\
\hline $\begin{array}{l}\text { 2. Ensuring least cost generation and } \\
\text { expansion }\end{array}$ & $\begin{array}{l}\text { - Expand installed capacity to } 7000 \mathrm{MW} \\
\text { - Increase per capita generation from } 170 \mathrm{kWh} \text { to } 200 \\
\mathrm{kWh}\end{array}$ & $\begin{array}{l}\text {-1000 MW capacity of power plants are under construction } \\
\text {-1700 MW capacity of power project is under procurement } \\
\text { process }\end{array}$ & $\begin{array}{l}\text { - Develop a least cost generation expansion } \\
\text { Plan } \\
\text { - Expand coal based power plants and power } \\
\text { generation by using safe and nuclear power } \\
\text { technology }\end{array}$ \\
\hline $\begin{array}{l}\text { 3. Expanding distribution and area } \\
\text { coverage }\end{array}$ & $\begin{array}{l}\text { - Increase coverage to realize GoB's vision to provide } \\
\text { electricity to all b } 2020 \\
\text { - Ensure access to electricity from } 45 \% \text { to } 60 \% \text { from } \\
\text { conventional and renewable sources } \\
\text { - Increase number of consumers by } 2.7 \text { million } \\
\text { - Increase no. of village electrification by } 6,000 \\
\text { - Expand distribution line ( } 33 \mathrm{kV} \text { and below) from } \\
275,000 \mathrm{~km} \text { to } 325,000 \mathrm{~km}\end{array}$ & & - Ensure expansion of distribution line \\
\hline 4. Expanding distribution by BPDB & $\begin{array}{l}\text { - } 6000 \mathrm{~km} \text { distribution line ( } 33 \mathrm{kV} \text { and below) } \\
\text { expansion } \\
\text { - New consumer connection: } 400,000\end{array}$ & & $\begin{array}{l}\text { - Ensure balance development in transmission } \\
\text { and distribution sub-sector } \\
\text { - Install telemeter for large customer's and } \\
\text { expand pre-paid metering system } \\
\end{array}$ \\
\hline 5. Improve operational Performance & $\begin{array}{l}\text { - Reduce BPDB's distribution loss to } 12.5 \text { percent } \\
\text { - Reduce retail customers accounts receivables to } 2.0 \\
\text { equivalent months } \\
\text { - Improve CI ratio more than } 87 \% \\
\end{array}$ & & - Continue efficiency improvement \\
\hline \multicolumn{4}{|c|}{ Lead Responsibility: Power Grid Company of Bangladesh (PGCB) } \\
\hline 6. Improving overall performance & $\begin{array}{l}\text { - Implement National Load Dispatch Centre } \\
\text { - Improve relay co-ordination and protection system } \\
\text { - Reduce transmission loss below } 3 \% \\
\text { - Reduce interruption on National Grid below } 30 \\
\text { per year and interruption time below } 30 \text { hours }\end{array}$ & $\begin{array}{l}- \text { NLDC project is in progress } \\
\text { - } 450 \text { MV AR Capacitor Bank are being installed; installation of } \\
\text { a } 600 \text { MVAR and a } 100 \text { MVAR Capacitor Banks are under } \\
\text { consideration } \\
\text { - Targeted reduction of transmission loss could be achieved in } \\
\text { the coming fiscal year }\end{array}$ & $\begin{array}{l}\text { - Enhanced technical coordination of power } \\
\text { system operation } \\
\text { - Improve Voltage profile by installing } \\
\text { 1150MVAR capacitor bank at } 132 \text { of } 33 \mathrm{kv} \\
\text { level }\end{array}$ \\
\hline
\end{tabular}




\begin{tabular}{|c|c|c|c|}
\hline Strategic Goals & Key Targets & Action Taken/underway & PRSP Policy Agenda (2009-11) \\
\hline$(1)$ & $(2)$ & $(3)$ & $(4)$ \\
\hline 7. Expanding Grid network capacity & $\begin{array}{l}\text { - Complete } 100 \mathrm{ckt} \mathrm{km} 400 \mathrm{kV} \text { transmission line } \\
\text { - Increase } 230 \mathrm{kV} \text { transmission line by } 936 \mathrm{ckt} \mathrm{km} \\
\text { - Increase } 132 \mathrm{kV} \text { transmission line by } 457 \mathrm{ckt} \mathrm{km} \\
\text { - Increase sub-station capacity by } 4587 \mathrm{MVA}\end{array}$ & $\begin{array}{l}\text { - Consultant has been engaged and bidding documents are } \\
\text { under preparation for } 400 \mathrm{kV} \text { line project } \\
\text { - } \quad 230 \mathrm{kV} \text { transmission line projects are under construction } \\
\text { - Bidding for construction of } 132 \mathrm{kV} \text { transmission line project } \\
\text { has been completed }\end{array}$ & $\begin{array}{l}\text { - Ensure balance development in the } \\
\text { transmission and distribution sub-sector }\end{array}$ \\
\hline \multicolumn{4}{|c|}{ Lead Responsibility: Ashugonj Power Station Company Ltd. (APSCL) } \\
\hline $\begin{array}{l}\text { 8. Improve corporate governance and } \\
\text { operating efficiency }\end{array}$ & $\begin{array}{l}\text { - Improve corporate culture } \\
\text { - Reduce outages time } \\
\text { - Increase plant availability to } 80 \%\end{array}$ & $\begin{array}{l}\text { - Modernization \& Rehabilitation of Unit-3,4 \& } 5 \text { of Ashuganj } \\
\text { Power Station is in progress }\end{array}$ & $\begin{array}{l}\text { - Improve plant efficiency by maintenance } \\
\text { and rehabilitation work } \\
\text { - Reduce auxiliary consumption and station } \\
\text { use }\end{array}$ \\
\hline \multicolumn{4}{|c|}{ Lead Responsibility: Electricity Generation Company of Bangladesh (EGCB) } \\
\hline $\begin{array}{l}\text { 9. Increasing generation of additional } \\
\text { electricity }\end{array}$ & $\begin{array}{l}\text { - Ensure plant availability more than } 85 \% \\
\text { Ensure energy conservation from the very } \\
\text { beginning of plant design }\end{array}$ & $\begin{array}{l}\text { - Construction of } 2 \times 120 \text { MW Peaking Power Generation } \\
\text { Plant at Siddhirganj is in progress } \\
\text { - Owner's Engineer engaged and bid document is under review } \\
\text { for } 2 \text { X } 150 \mathrm{MW} \text { peaking power project }\end{array}$ & $\begin{array}{l}\text { - Complete } 2 \times 150 \mathrm{MW} \text { peaking plant at } \\
\text { Siddhirganj } \\
\text { - Complete } 360 \mathrm{MW} \text { CC power plant at } \\
\text { Haripur } \\
\text { - Order } 100 \text { and } 150 \text { megawatt gas turbine } \\
\text { projects on an urgent basis } \\
\text { - Encourage construction of } 10,20 \text { and } 30 \\
\text { megawatt power stations in private sector } \\
\text { - Establish Rooppur Nuclear Power Plant }\end{array}$ \\
\hline \multicolumn{4}{|c|}{ Lead Responsibility: Dhaka Electric Supply Authority (DESA)/ Dhaka Power Distribution Company (DPDC) } \\
\hline 10. Improving operational performance & $\begin{array}{l}\text { - Reduce transmission loss to } 3.5 \% \\
\text { - Reduce distribution loss to } 11.5 \% \\
\text { - Reduce retail customer accounts receivable to } 2.5 \\
\text { equivalent months } \\
\text { - Improve CI ratio more than } 87 \%\end{array}$ & & - Continue efficiency improvement \\
\hline 11. Expanding facility & $\begin{array}{l}\text { - } 52 \mathrm{~km} 132 \mathrm{kV} \text { transmission line and cable expansion } \\
\text { - Expand pre-paid metering system }\end{array}$ & & $\begin{array}{l}\text { - Balance development in transmission and } \\
\text { distribution } \\
\text { - Expand } 1000 \mathrm{~km} \text { distribution line }(33 \mathrm{kV} \& \\
\text { less) } \\
\text { - Connect } 100,000 \text { new consumer }\end{array}$ \\
\hline \multicolumn{4}{|c|}{ Lead Responsibility: Dhaka Electric Supply Company (DESCO), West Zone Power Distribution Company Ltd. (WZPDC) } \\
\hline 12. Improving corporate governance & $\begin{array}{l}\text { - Improve corporate culture } \\
\text { - Introduce pre paid meter }\end{array}$ & & \\
\hline 13. Improving operational performance & $\begin{array}{l}\text { - Reduce distribution loss to } 12.5 \% \\
\text { - Reduce retail customer accounts receivable to } 2.5 \\
\text { equivalent months } \\
\text { - Improve CI ratio more than } 87 \%\end{array}$ & & - Continue efficiency improvement \\
\hline \multicolumn{4}{|c|}{ Lead Responsibility: Rural Electrification Board (REB) } \\
\hline 14. Improving overall governance & $\begin{array}{l}\text { - Improve management efficiency and innovative } \\
\text { arrangements for renewable energy expansion }\end{array}$ & $\begin{array}{l}\text { - Study programme for management improvement and corporate } \\
\text { governance improvement has been taken by Power Cell }\end{array}$ & \\
\hline
\end{tabular}




\begin{tabular}{|c|c|c|c|}
\hline Strategic Goals & Key Targets & Action Taken/underway & PRSP Policy Agenda (2009-11) \\
\hline$(1)$ & $(2)$ & $(3)$ & $(4)$ \\
\hline 15. Improving operational performance & $\begin{array}{l}\text { - Reduce distribution loss to } 11.5 \% \\
\text { - Reduce retail customer's accounts receivable to } 2.0 \\
\text { equivalent months }\end{array}$ & & - Continued efficiency improvement \\
\hline 16. Expanding distribution network & $\begin{array}{l}\text { - Expand 40,000 km distribution line ( } 33 \mathrm{kV} \& \text { less) } \\
\text { - Ensure 2,000,000 new consumer connection } \\
\text { - Provide electricity to 6,000 new village } \\
\text { - Install 20,000 new SHS }\end{array}$ & & $\begin{array}{l}\text { - Balanced development in the transmission } \\
\text { and distribution }\end{array}$ \\
\hline \multicolumn{4}{|c|}{ Lead Responsibility: Bangladesh Oil, Gas and Mineral Corporation (BOGMC) } \\
\hline $\begin{array}{l}\text { 17. Assessing non-renewable indigenous } \\
\text { resources and undertaking measures for } \\
\text { economic and efficient use of energy }\end{array}$ & $\begin{array}{l}\text { - Increase oil and gas reserves through extended } \\
\text { exploration in both land and sea } \\
\text { - Increase coal extraction to substitute increasing gas } \\
\text { demand. } \\
\text { - Expand national grid to cover western, north- } \\
\text { western and south-western zones. }\end{array}$ & $\begin{array}{l}\text { - Offshore PSC Bidding } 2008 \text { initiated to entertain private sector } \\
\text { investment widely } \\
\text { - In view of strengthening BAPEX, funds have been allocated for } \\
\text { extensive exploration works } \\
\text { - Coal Policy is under formulation } \\
\text { - Companies under Petrobangla are enjoying autonomy } \\
\text { - Offloading of shares of the companies has been initiated } \\
\text { - Expansion of gas network to the western and south-western } \\
\text { zone is ongoing } \\
\text { - Rajshahi city is being brought under gas network } \\
\text { - Private entrepreneurs are being encouraged to install CNG } \\
\text { filling stations }\end{array}$ & $\begin{array}{l}\text { - Commercialize gas sector } \\
\text { - Attract private sector investment } \\
\text { - Increase CNG usage as environment friendly } \\
\text { clean fuel } \\
\text { - Gas exploration both onshore and offshore } \\
\text { to be enhanced }\end{array}$ \\
\hline \multicolumn{4}{|c|}{ Lead Responsibility: Roads and Highways Department (RHD) } \\
\hline 18. Developing roads infrastructure & $\begin{array}{l}\text { - Construct new road : } 3160 \mathrm{~km} \\
\text { - Rehabilitate road: } 2090 \mathrm{~km} \\
\text { - Construct/recon bridge: } 21100 \text { meter }\end{array}$ & $\begin{array}{l}\text { - } 3786 \mathrm{~km} \text { of new road is constructed } \\
\text { - } 2406 \mathrm{~km} \text { of road improved and rehabilitated } \\
\text { - } 13476 \text { meter of bridge is constructed and reconstructed }\end{array}$ & $\begin{array}{l}\text { - Increase maintenance expenditures } \\
\text { - Construct coastal highway link } \\
\text { - Develop border roads } \\
\text { - Construct major bridges on national } \\
\text { highways } \\
\text { - Construct toll roads/ bridges } \\
\text { - Dhaka-Chittagong Second National Highway } \\
\text { to be constructed by private sector } \\
\text { - Establish road connection with neighbouring } \\
\text { countries under Asian Highways Scheme } \\
\text { - Construct Karnaphuli Extra Dose PC } \\
\text { Garder Bridge }\end{array}$ \\
\hline $\begin{array}{l}\text { 19. Improving institutional and policy } \\
\text { formulation capabilities of RHD }\end{array}$ & & $\begin{array}{l}\text { - National Land Transport Policy is in place } \\
\text { - Creation of an independent road fund is in final stage } \\
\text { - Road sector manual under Project Appraisal Framework is } \\
\text { introduced } \\
\text { - Improved institutional capabilities for planning policy and } \\
\text { reform are in place } \\
\text { - Road safety division is functioning } \\
\text { - RHD Management plan and manuals prepared } \\
\text { - A private sector investment policy for involving the private }\end{array}$ & $\begin{array}{l}\text { - Integrate road master plan with RHD, } \\
\text { DTCB and LGED } \\
\text { - Increase return-on- asset } \\
\text { - Establish a National Highway Authority } \\
\text { - Establish a Road Fund Authority }\end{array}$ \\
\hline
\end{tabular}




\begin{tabular}{|c|c|c|c|}
\hline Strategic Goals & Key Targets & Action Taken/underway & PRSP Policy Agenda (2009-11) \\
\hline (1) & $(2)$ & $(3)$ & $(4)$ \\
\hline & & $\begin{array}{l}\text { sector in the road sub-sector has been prepared } \\
\text { - Revised contracting procedures introduced } \\
\text { - E-governance, networking and database like Management } \\
\text { Information System, Geographical Information System , } \\
\text { Personnel Information Management System and Central } \\
\text { Management System, Road Asset Management System, Bridge } \\
\text { Maintenance \& Management System are in place } \\
\text { - Manual of Environment Impact Assessment of RHD Projects is } \\
\text { being prepared } \\
\text { - Integrated Multi-Modal Transport Policy (IMTP) has been } \\
\text { prepared }\end{array}$ & \\
\hline 20. Developing corridor based roads & $\begin{array}{l}\text { - Construct Dhaka-Southeast, Dhaka-Northeast, } \\
\text { Dhaka-Southwest, Dhaka-Northwest, Khulna- } \\
\text { Northwest corridor }\end{array}$ & $\begin{array}{l}\text { - Implementation work is in progress } \\
\text { - Creation of legal and financial environment through adoption of } \\
\text { an integrated multi modal transport policy awaiting approval }\end{array}$ & $\begin{array}{l}\text { - Upgrade Dhaka-Chittagong, Dhaka-Khulna, } \\
\text { Dhaka-Sylhet, Dhaka-Tangail roads into } 4 \\
\text { lanes } \\
\text { - Construct Padma Bridge } \\
\text { - Construct 2nd Meghna and 2nd Meghna- } \\
\text { Gumti Bridges } \\
\text { - Construct Karnaphuli Extra Dose PC } \\
\text { Garder Bridge } \\
\text { - Construct Bekutia Bridge }\end{array}$ \\
\hline 21. Ensuring rural-urban linkages & $\begin{array}{l}\text { - Construct road } 1100 \mathrm{~km} \text { and improve } 3000 \mathrm{~km} \\
\text { - Construct bridge } 8000 \text { meter }\end{array}$ & $\begin{array}{l}\text { - Being implemented under } 8 \text { numbers of feeder/ zila/ public } \\
\text { priority road projects }\end{array}$ & $\begin{array}{l}\text { - Implement several feeder/zila/ public } \\
\text { priority road projects }\end{array}$ \\
\hline $\begin{array}{l}\text { 22. Attaching higher priority on road } \\
\text { maintenance }\end{array}$ & - Periodic maintenance of $4500 \mathrm{~km}$ road & $\begin{array}{l}\text { - Routine maintenance and shoulder repair is carried out for } \\
\text { RHD road network and periodic maintenance is done } \\
\text { - National highway network is being reconstructed, rehabilitated } \\
\text { and improved } \\
\text { - Regional highway is overlaid and resealed } \\
\text { - The draft bill for the creation of Road Maintenance Fund is } \\
\text { being approved and brought under legislation }\end{array}$ & $\begin{array}{l}\text { - Upkeep of whole RHD network through } \\
\text { regular routine maintenance } \\
\text { - Enhance management budget } \\
\text { - Enhance budget for natural disaster }\end{array}$ \\
\hline 23. Construct bypass road and flyovers & $\begin{array}{l}\text { - Construct bypass road } \\
\text { - Construct flyovers }\end{array}$ & $\begin{array}{l}\text { - Bypasses have been constructed in major cities } \\
\text { - Construction of Kaliakoir, Khulna, 2nd Bagura Town, } \\
\text { Ambarkhana, Akhaura City, Osmani Airport, Jenaidah BISIC } \\
\text { Shilpa Nagar bypass roads are underway } \\
\text { - Flyover at Tongi rail crossing is in progress }\end{array}$ & $\begin{array}{l}\text { - Construct Satkhira, Faridpur, Mymensingh } \\
\text { town bypass roads } \\
\text { - Construct flyovers at } 10 \text { railway crossing } \\
\text { points on important national highways }\end{array}$ \\
\hline $\begin{array}{l}\text { 24. Building the missing links on the } \\
\text { national and regional highway network }\end{array}$ & & $\begin{array}{l}\text { - Construction of Hatikamrul-Bonpara road is completed } \\
\text { - Construction of Bhanga-Bhatiapara-Narail road is completed } \\
\text { - Construction of Barisal-Bhola-Laxmipur road is in progress }\end{array}$ & $\begin{array}{l}\text { - Complete construction of Barisal-Bhola- } \\
\text { Laxmipur road }\end{array}$ \\
\hline $\begin{array}{l}\text { 25. Construction, Operation and } \\
\text { maintenance of long bridges ( } 1500 \mathrm{~m} \text { or } \\
\text { above), toll roads, flyovers, causeways, ring } \\
\text { roads etc. }\end{array}$ & $\begin{array}{l}\text { - Preparation of Detailed Design for Padma } \\
\text { Bridge. } \\
\text { - Land acquisition and appointment of Contractors } \\
\text { for Padma Bridge. } \\
\text { - To start the construction work of Padma Bridge. } \\
\text { - Construction of Bekutia Bridge on Perojpur- }\end{array}$ & $\begin{array}{l}\text { - } 1521 \mathrm{~m} \text { long Mukterpur (6th Bangladesh-China Friendship) } \\
\text { bridge has been opened for traffic on } 18 \text { February, } 2008 . \\
\text { - Land acquisition and appointment of Consultant for Detailed } \\
\text { Design of Padma Bridge are under way. }\end{array}$ & $\begin{array}{l}\text { - Growth of SMEs, new business, agricultural } \\
\text { and industrial production, employment and } \\
\text { income, and thereby poverty reduction in the } \\
\text { south-eastern parts of the country }\end{array}$ \\
\hline
\end{tabular}




\begin{tabular}{|c|c|c|c|}
\hline Strategic Goals & Key Targets & Action Taken/underway & PRSP Policy Agenda (2009-11) \\
\hline \multirow[t]{2}{*}{$(1)$} & (2) & (3) & (4) \\
\hline & $\begin{array}{l}\text { Jhalakati road over the river Kocha under } \\
\text { Jhalakati District. }\end{array}$ & & \\
\hline \multicolumn{4}{|c|}{ Lead Responsibility: Dhaka Transport Coordination Board (DTCB) } \\
\hline $\begin{array}{l}\text { 26. Developing public transport system } \\
\text { for Dhaka city by integrating different } \\
\text { modes of transport }\end{array}$ & $\begin{array}{l}\text { - Mass transport system serving Dhaka, } \\
\text { Narayangonj, saver, Dhamrai, Gazipur and Kaliganj } \\
\text { - Development of bus rapid transit } \\
\text { - Development of arterial roads and footpaths } \\
\text { - Development of circular railway } \\
\text { - Improvement of traffic management }\end{array}$ & $\begin{array}{l}\text { - Construction of Dhaka City bypass road is completed } \\
\text { - Construction of flyover at Mohakhali is completed } \\
\text { - Construction of Moghbazar flyover } \\
\text { - Construction of bypass roads- Panthapath - Rampura, Malibagh } \\
\text { - Janapath, Zia colony - Mirpur }\end{array}$ & $\begin{array}{l}\text { - Construct elevated expressway in Dhaka city } \\
\text { - Construct ring road on the outskirts of } \\
\text { Dhaka city } \\
\text { - Construct flyover at Pragati Sarani } \\
\text { - Solve the traffic congestion in Dhaka city } \\
\text { - Provide better traffic management }\end{array}$ \\
\hline \multicolumn{4}{|c|}{ Lead Responsibility: Local Government Engineering Department (LGED) } \\
\hline \multirow[t]{2}{*}{ 27. Developing rural road communication } & $\begin{array}{l}\text { - Construct: Upazila Road: } 36166 \mathrm{~km} \\
\text { - Construct: Union Road: } 44418 \mathrm{~km} \\
\text { - Construct: Village Road: } 171335 \mathrm{~km}\end{array}$ & $\begin{array}{l}\text { - } 21803 \mathrm{~km} \\
\text { - } 13571 \mathrm{~km} \\
\text { - } 11980 \mathrm{~km}\end{array}$ & $\begin{array}{l}\text { - Ensure transportation of agricultural } \\
\text { products } \\
\text { - Ensure participation and involvement of } \\
\text { community, local government institutions, } \\
\text { NGOs and beneficiary groups } \\
\end{array}$ \\
\hline & $\begin{array}{l}\text { - Construct: Bridge/Culvert on Upazila Road: } 382293 \\
\text { m } \\
\text { - Construct: Bridge/Culvert on Union Road: } 330409 \\
\text { m } \\
\text { - Construct Bridge/Culvert on Village Road: } 695688 \\
\text { m } \\
\text { - Construct tree plantation: } 80584 \text { km } \\
\end{array}$ & $\begin{array}{l}-355374 \mathrm{~m} \\
-228329 \mathrm{~m} \\
-334580 \mathrm{~m} \\
\text { - } 29342 \mathrm{~km}\end{array}$ & $\begin{array}{l}\text { - Ensure community input in planning and } \\
\text { design } \\
\text { - Ensure quality control of construction and } \\
\text { maintenance } \\
\text { - Strengthen sustainable operation and } \\
\text { maintenance system }\end{array}$ \\
\hline $\begin{array}{l}\text { 28. Prioritising pro-growth infrastructure } \\
\text { (submersible road, ghats, growth centres, } \\
\text { hats, women's market section and union } \\
\text { parishad complex, cyclone shelters) }\end{array}$ & $\begin{array}{l}\text { - Growth centres: } 2100 \\
\text { - Other Important rural markets: } 6900 \\
\text { - Women's market sections: } 2300 \\
\text { - Union parishad complex: } 4489 \\
\text { - Cyclone shelter: } 500 \\
\text { - Ghats: } 300\end{array}$ & $\begin{array}{l}\text { - } 920 \text { growth centres are under construction } \\
\text { - } 214 \text { rural markets are under construction } \\
\text { - } 700 \text { women's market sections are under construction } \\
\text { - } 1494 \text { Union parishad complex are under construction } \\
\text { - } 380 \text { Cyclone shelter are under construction } \\
\text { - } 135 \text { Ghats are under construction }\end{array}$ & $\begin{array}{l}\text { - Ensure participation of community, local } \\
\text { government institutions, NGOs, beneficiary } \\
\text { and user communities } \\
\text { - Ensure community input in planning and } \\
\text { designing } \\
\text { - Ensure quality control of construction and } \\
\text { maintenance } \\
\text { - Strengthen sustainable operation and } \\
\text { maintenance system }\end{array}$ \\
\hline $\begin{array}{l}\text { 29. Ensuring women's participation and } \\
\text { emphasising their needs }\end{array}$ & & $\begin{array}{l}\text { - Ensure women's increased participation in road construction, } \\
\text { maintenance and building embankments }\end{array}$ & $\begin{array}{l}\text { - Incorporate women's participation } \& \text { needs } \\
\text { in building of infrastructure facilities and } \\
\text { project selection } \\
\text { - Encourage female participation in } \\
\text { labour/landless contracting societies grass } \\
\text { root committees }\end{array}$ \\
\hline \multicolumn{4}{|c|}{ Lead Responsibility: Bangladesh Road Transport Corporation (BRTC) } \\
\hline $\begin{array}{l}\text { 30. Making BRTC a viable institution and } \\
\text { ensuring affordable services to all }\end{array}$ & $\begin{array}{l}\text { - Increase number of vehicles and new depots/units } \\
\text { in different districts }\end{array}$ & $\begin{array}{l}\text { - } 200 \text { Single Decker and Double Decker buses repaired. } \\
\text { - New } 194 \text { Diesel operated and } 30 \text { CNG operated Single Decker }\end{array}$ & $\begin{array}{l}\text { - Procure } 595 \text { Double Decker buses } \\
\text { - Procure } 100 \text { CNG Single Decker buses. }\end{array}$ \\
\hline
\end{tabular}




\begin{tabular}{|c|c|c|c|}
\hline Strategic Goals & Key Targets & Action Taken/underway & PRSP Policy Agenda (2009-11) \\
\hline (1) & $(2)$ & (3) & (4) \\
\hline including the poor and women & $\begin{array}{l}\text { - Keep up the standard of services } \\
\text { - Minimize loss of property and lives because of } \\
\text { accidents } \\
\text { - Provide training for safe \& improved driving, } \\
\text { maintenance, repair, and operation } \\
\text { - Introduce CNG services and bus services with Euro } \\
\text { standard engines }\end{array}$ & $\begin{array}{l}\text { buses and } 10 \text { Diesel Trucks have been procured } \\
\text { - Procurement of } 100 \text { CNG Single Decker buses and } 300 \text { CNG } \\
\text { Single Decker buses are under process } \\
\text { - Already set up } 6 \text { driving Training Institutes and setting up of } 6 \\
\text { driving training Institutes are underway } \\
\text { - Establishment of } 10 \text { new CNG fuelling station cum petrol } \\
\text { pumps on going }\end{array}$ & $\begin{array}{l}\text { - Procure } 500 \text { Trucks } \\
\text { - Modernise road transport service network to } \\
\text { render satisfactory transport service } \\
\text { - Help reduction of poverty, unemployment, } \\
\text { pollution, accident, and economic maladies } \\
\text { of people } \\
\text { - Ensure women development and good } \\
\text { governance. }\end{array}$ \\
\hline 31. Ensuring private sector participation & - Introduce avenues for public private partnership & & - Public private partnership is to be ensured. \\
\hline \multicolumn{4}{|c|}{ Lead Responsibility: Bangladesh Railway (BR) } \\
\hline $\begin{array}{l}\text { 32. Extending \& improving railway } \\
\text { network }\end{array}$ & $\begin{array}{l}\text { - Construct } 77.19 \mathrm{Km} \text { new track. } \\
\text { - Procure/Replace } 21 \text { Locomotives } \\
\text { - Procure } 50 \text { Passenger Coaches } \\
\text { - Procure } 160 \text { Wagons \& brake vans } \\
\text { - Construction of new ICD }\end{array}$ & $\begin{array}{l}\text { - Construction of } 35.19 \mathrm{Km} \text { new track is on-going. } \\
\text { - Procurement of } 10 \text { Locomotives is under process } \\
\text { - Procurement of } 50 \text { passenger coaches is under process } \\
\text { - Procurement of } 55 \text { wagons \& brake vans has been taken and } \\
\text { - } \text { Procurement of } 105 \text { is under process } \\
\text { - Feasibility Studies for Padma bridge rail link, underground rail } \\
\text { link, 2nd Jamuna Rail Bridge, Dhaka-Laksam Chord line are } \\
\text { under preparation } \\
\text { - Twenty years Railway Master Plan preparation is in final stage }\end{array}$ & $\begin{array}{l}\text { - Prepare Railway Master Plan for next } 20 \\
\text { years } \\
\text { - Extend railway network } \\
\text { - Increase line capacity by track doubling in } \\
\text { Dhaka-Chittagong and Dhaka-Sylhet } \\
\text { corridor } \\
\text { - Improve the specification of rolling stocks } \\
\text { - Construct new ICD at Dhirasam } \\
\text { - Preparatory works for introducing advanced } \\
\text { \& improved technology such as } \\
\text { Underground rail, Surface \& Elevated rail, } \\
\text { circular rail etc. } \\
\text { - Construct underground rail in Dhaka city }\end{array}$ \\
\hline 33. Prioritising pro-poor growth & $\begin{array}{l}\text { - Rehabilitate } 375 \mathrm{Km} \text {. railway track along with other } \\
\text { infrastructures \& signalling system } \\
\text { - Remodel } 8 \text { Stations. } \\
\text { - Modernize } 12 \text { station's signalling systems } \\
\text { - Rehabilitate } 22 \text { locomotives. } \\
\text { - Rehabilitate } 260 \text { Passenger Coaches } \\
\text { - Rehabilitate } 277 \text { wagons \& brake vans }\end{array}$ & $\begin{array}{l}\text { - Rehabilitation of } 345 \mathrm{~km} \text { railway track along with other } \\
\text { infrastructure \& signalling system is ongoing } \\
\text { - Remodelling of } 8 \text { stations has been taken in hand. } \\
\text { - Financing for modernization of } 14 \text { station's signalling systems in } \\
\text { under process } \\
\text { - Rehabilitation of locomotives is going on } \\
\text { - DPP for rehabilitation of } 260 \text { Passenger Coaches has been } \\
\text { submitted } \\
\text { - Rehabilitation of } 277 \text { Wagons \& brake vans has taken place }\end{array}$ & $\begin{array}{l}\text { - Rehabilitate \& improve all Detroit railway } \\
\text { tracks, bridge, stations, yards, \& other } \\
\text { infrastructures } \\
\text { - Modernize signalling systems in the section } \\
\text { to ensure safe \& speedy running of trains } \\
\text { - Increase passenger amenities and ensure safe, } \\
\text { speedy \& comfortable train journey } \\
\text { - Adopt Public Service Obligation (PSO) } \\
\text { involving all branch lines to serve the poor } \\
\text { people in remote areas } \\
\text { - Provide transport facilities to large numbers } \\
\text { of poor passengers and for movement of } \\
\text { commodities }\end{array}$ \\
\hline $\begin{array}{l}\text { 34. Emphasising routine } \& \text { periodic } \\
\text { maintenance }\end{array}$ & $\begin{array}{l}\text { - Provide routine \& periodic maintenance } \\
\text { - Introduce mechanical track maintenance system in } \\
\text { BR. } \\
\text { - Improve Pahartali \& Saidpur Work shop. }\end{array}$ & $\begin{array}{l}\text { - Routine \& periodic has been enhanced and BR's maintenance } \\
\text { budget has been increased. } \\
\text { - Emphasis has been given to introduce mechanical track } \\
\text { maintenance system in BR } \\
\text { - Improvement of Pahartali workshop has started and DPP for } \\
\text { Saidpur Workshop improvement has been submitted }\end{array}$ & $\begin{array}{l}\text { - Provide adequate funds for maintenance } \\
\text { - Adopt modern track maintenance method } \\
\text { - Ensure routine \& periodic maintenance of all } \\
\text { infrastructures as per their standard } \\
\text { specification } \\
\text { - Rehabilitate \& replace plants and machineries }\end{array}$ \\
\hline
\end{tabular}




\begin{tabular}{|c|c|c|c|}
\hline Strategic Goals & Key Targets & Action Taken/underway & PRSP Policy Agenda (2009-11) \\
\hline$(1)$ & $(2)$ & (3) & $(4)$ \\
\hline & & & to enhance the maintenance works \\
\hline $\begin{array}{l}\text { 35. Opening avenues for private sector } \\
\text { participation }\end{array}$ & $\begin{array}{l}\text { - Improve operational efficiency through more } \\
\text { participation of private sector. } \\
\text { - Make the railway more responsive to market needs } \\
\text { and sound business practices. } \\
\text { - Explore commercially possibilities of surplus land } \\
\text { and other capacities of Railway. }\end{array}$ & $\begin{array}{l}\text { - Provision for private sector participation is in place for } \\
\text { infrastructure building and maintenance works } \\
\text { - Introduced computerized seat reservation and ticketing system } \\
\text { - Introduced on board services in } 16 \text { intercity trains, extra } \\
\text { capacity BR's Fibre optic Telecom System, commercial activities } \\
\text { of Mail/Express/Local train } \\
\text { - Repairing passenger coaches, cleaning locomotives and } \\
\text { converting non-AC coaches into AC on BOT basis are ongoing }\end{array}$ & $\begin{array}{l}\text { - Association of private sector and outsourcing } \\
\text { to be continued and new component would } \\
\text { be identified } \\
\text { - Explore possibilities of commercial use of } \\
\text { surplus land and other capacities of Railway }\end{array}$ \\
\hline 36. Strengthening organization of BR & $\begin{array}{l}\text { - Take various Organizational Strengthening } \\
\text { programmes }\end{array}$ & $\begin{array}{l}\text { - Organizational reform of Bangladesh railway has been taken in } \\
\text { hand }\end{array}$ & $\begin{array}{l}\text { - Implementation of organizational } \\
\text { strengthening programmes to improve } \\
\text { performance of BR }\end{array}$ \\
\hline \multicolumn{4}{|c|}{ Lead Responsibility: Mongla Port Authority (MPA) } \\
\hline $\begin{array}{l}\text { 37. Improving navigability in the Pussur } \\
\text { Channel }\end{array}$ & $\begin{array}{l}\text { - Dredge } 32.00 \text { lakh cum. silt to facilitate movement } \\
\text { of } 9 \mathrm{~m} \text { draft ship in the Pussur channel }\end{array}$ & $\begin{array}{l}\text { - DPP of the project "Dredging at the Outer Bar in the Pussur } \\
\text { Channel" has been approved }\end{array}$ & $\begin{array}{l}\text { - Implement the project "Dredging at the } \\
\text { Outer Bar in the Pussur Channel" }\end{array}$ \\
\hline $\begin{array}{l}\text { 38. Ensuring efficient service to shore } \\
\text { based cargo and container handling of the } \\
\text { port }\end{array}$ & $\begin{array}{l}\text { - Procure } 2 \text { Straddle Carrier- } 40 \text { ton capacity, } 4 \text { Low } \\
\text { mast forklift truck auto transmission-3 ton capacity, } \\
2 \text { Fork lift truck-5 ton, } 1 \text { Fork lift truck }-9 \text { ton, } 2 \\
\text { Terminal Tractor-50 ton, } 220^{\prime}-0 \text { ", } 840^{\prime}-0 \text { " trailer }\end{array}$ & $\begin{array}{l}\text { - The project has been approved and the project is at the } \\
\text { implementation stage. }\end{array}$ & $\begin{array}{l}\text { - Procure these equipments under the project } \\
\text { "Procurement of cargo handling equipment } \\
\text { for Mongla Port". }\end{array}$ \\
\hline $\begin{array}{l}\text { 39. Ensuring safe } 24 \text { hours ship movement } \\
\text { in the Pussur channel }\end{array}$ & $\begin{array}{l}\text { - Procure } \& \text { install } 62 \text { channel marking and lighted } \\
\text { buoys and other accessories } \\
\text { - Remove } 15 \text { of sunken wrecks of ships }\end{array}$ & $\begin{array}{l}\text { - A DPP of the project is being finalised by the Ministry of } \\
\text { Shipping }\end{array}$ & $\begin{array}{l}\text { - Implement project "Navigational Aids to } \\
\text { Mongla Port" } \\
\text { - Maintain the Pussur Channel for easy } \\
\text { movement of ships } \\
\text { - Procure A Cutter Suction Dredger for } \\
\text { Mongla Port }\end{array}$ \\
\hline $\begin{array}{l}\text { 40. Maintaining adequate depth in the } \\
\text { mooring area of the Pussur Channel }\end{array}$ & - Carry out 1.328 million cum dredging & $\begin{array}{l}\text { - The DPP of the project "Dredging in the Mooring areas of } \\
\text { Mongla Port" is under preparation }\end{array}$ & $\begin{array}{l}\text { - Improvement of navigability in the channel } \\
\text { will help to increase incoming ships in the } \\
\text { port }\end{array}$ \\
\hline \multicolumn{4}{|c|}{ Lead Responsibility: Chittagong Port Authority (CPA) } \\
\hline \multirow[t]{4}{*}{ 41. Increase port capacity/efficiency } & $\begin{array}{l}\text { - Construct a Container Terminal at New Mooring } \\
\text { area with } 1000 \mathrm{~m} \text { berth }\end{array}$ & $\begin{array}{l}\text { - Construction of } 5 \text { berths including 180,000 sq.m. back up area } \\
\text { completed and operating }\end{array}$ & - Enhance capacity \& service level of the port \\
\hline & $\begin{array}{l}\text { - Appoint Terminal Operator for New Mooring } \\
\text { Container Terminal }\end{array}$ & $\begin{array}{l}\text { - MTCC is constituted to determine technical \& commercial } \\
\text { parameters for Management \& Operation by private operator } \\
\text { - PQ document prepared }\end{array}$ & $\begin{array}{l}\text { - Promote Port Privatization Policy } \\
\text { - Ensure optimum utilization of facilities } \\
\text { created under NCT project } \\
\end{array}$ \\
\hline & $\begin{array}{l}- \text { Construct back up facilities behind NCT berths No. } \\
4 \& 5 \text {. }\end{array}$ & $\begin{array}{l}\text { - DPP for construction of back up facilities behind berth No. } 4 \& \\
5 \text { is prepared and is in the process of approval }\end{array}$ & $\begin{array}{l}\text { - Construct back up facilities and ensure } \\
\text { optimum utilization of NCT }\end{array}$ \\
\hline & $\begin{array}{l}\text { - Chittagong Port Trade Facilitation Project by } \\
\text { introducing CTMS/MIS, Environmental } \\
\text { Management } \\
\text { - Modernize cargo clearance procedure } \\
\text { - Construct internal roads/ bridges }\end{array}$ & $\begin{array}{l}\text { - Tenders invited for Computerization of Container Terminal } \\
\text { Management System } \\
\text { - Completed Oil Waste Reception and Oil-spill Protection } \\
\text { - Civil works for Environmental Management is in progress; } \\
\text { Prepared VCA and Anti-corruption policy } \\
\text { - Construction of internal roads/ bridges and Port Service road } \\
\text { and bridge over Moheskhal is in progress }\end{array}$ & $\begin{array}{l}\text { - Introduce CTMS, MIS, Environmental } \\
\text { Management system, modernise cargo } \\
\text { clearance procedure, } \\
\text { - Introduce anti-corruption policy, enhance } \\
\text { degree of transparency/security }\end{array}$ \\
\hline
\end{tabular}




\begin{tabular}{|c|c|c|c|}
\hline Strategic Goals & Key Targets & Action Taken/underway & PRSP Policy Agenda (2009-11) \\
\hline$(1)$ & $(2)$ & (3) & $(4)$ \\
\hline & $\begin{array}{l}\text { - Carry out Capital Dredging in Karnaphuli river and } \\
\text { Channel }\end{array}$ & $\begin{array}{l}\text { - The Consultant has been requested for submission of revised } \\
\text { cost estimates to prepare fresh DPP. }\end{array}$ & $\begin{array}{l}\text { - Ensure safe navigational channel in view of } \\
\text { the impact of construction of the 3rd } \\
\text { Karnaphuli bridge }\end{array}$ \\
\hline & $\begin{array}{l}\text { - Undertake a feasibility study for construction of a } \\
\text { new ICD near Dhirasrami railway station }\end{array}$ & $\begin{array}{l}\text { - Feasibility Study completed and the Final Report has been } \\
\text { accepted by the competent authority }\end{array}$ & $\begin{array}{l}\text { - Increased capacity for movement of } \\
\text { container through rail in Dhaka-Chittagong } \\
\text { Economic corridor }\end{array}$ \\
\hline & - Construct Inland Container Depot in Gazipur & $\begin{array}{l}\text { - TPP is prepared by Bangladesh Railway for Designing, } \\
\text { Tendering and Supervision services. }\end{array}$ & $\begin{array}{l}\text { - Handle increased number of containers and } \\
\text { provide adequate inter modal facilities }\end{array}$ \\
\hline & - Improve port efficiency & - Consultant submitted draft Strategy Plan for CPA. & $\begin{array}{l}\text { - Formulation of Port Efficiency } \\
\text { Improvement Plan }\end{array}$ \\
\hline & $\begin{array}{l}\text { - Improve transportation system of containers } \\
\text { through Inland Waterways for Chittagong Port }\end{array}$ & $\begin{array}{l}\text { - TEC's recommendation for package- } 3 \text { and package- } 4 \text { have } \\
\text { been approved }\end{array}$ & $\begin{array}{l}\text { - Construct Inland Container Terminal at } \\
\text { Pangoan }\end{array}$ \\
\hline & - Construct Karnaphuli container Terminal & - DPP prepared \& sent for approval. & $\begin{array}{l}\text { - Facilitate handling of } 4 \text { lakh TEUs of } \\
\text { containers per year }\end{array}$ \\
\hline & - Construct Patenga Container Terminal & - At conceptual stage & - Construct Patenga Container Terminal \\
\hline & $\begin{array}{l}\text { - Prepare a Comprehensive Master Plan for } \\
\text { development of Chittagong Port }\end{array}$ & & $\begin{array}{l}\text { - Assess requirement of further creation, } \\
\text { expansion and modernization of port } \\
\text { facilities }\end{array}$ \\
\hline \multicolumn{4}{|c|}{ Lead Responsibility: Civil Aviation Authority, Bangladesh (CAAB) } \\
\hline \multirow[t]{3}{*}{ 42. Expanding the existing Airports } & $\begin{array}{l}\text { - Up-grade Osmani Airport for operation of wide } \\
\text { body aircraft }\end{array}$ & - $100.00 \%$ Physical work has been completed by December 2008 & \\
\hline & $\begin{array}{l}\text { - Extend and modernize passenger Terminal building } \\
\text { at Osmani Airport }\end{array}$ & - Physical work is in progress & - Complete the rest by December 2008 \\
\hline & - Up-grade Zia International Airport & $\begin{array}{l}\text { - DPP of the project is under process for approval in the } \\
\text { Planning Commission. }\end{array}$ & $\begin{array}{l}\text { - Re-construct the taxi-way } \\
\text { - Replace primary radar and secondary radar } \\
\text { - Obtain communication, navigation and } \mathrm{E} / \mathrm{M} \\
\text { equipments }\end{array}$ \\
\hline \multicolumn{4}{|c|}{ Lead Responsibility: Biman Bangladesh Airlines Limited } \\
\hline $\begin{array}{l}\text { 43. Increasing scale of operation to serve } \\
\text { more passengers }\end{array}$ & $\begin{array}{l}\text { - Increase capacity through lease of aircraft } \\
\text { - Modernize Biman's fleet by acquiring new } \\
\text { generation aircraft } \\
\text { - Concentrate operation in the Gulf and Middle-East } \\
\text { region }\end{array}$ & $\begin{array}{l}\text { - Addition of aircraft on wet and dry lease is under process and } \\
\text { process is underway to modernize Biman fleet } \\
\text { - More frequencies to Gulf and Middle East being operated }\end{array}$ & $\begin{array}{l}\text { - Complete steps for acquisition of aircraft } \\
\text { - Improve passenger services continuously } \\
\text { - Increase frequencies to profitable ethnic } \\
\text { markets }\end{array}$ \\
\hline 44. Improve financial performance & $\begin{array}{l}\text { - Reduce operation cost in different areas } \\
\text { - Enter into high-yield markets } \\
\text { - Commercialize the organization } \\
\text { - Appoint operator under management contract } \\
\text { - Off-loading of Biman's } 49 \text { percent share } \\
\end{array}$ & $\begin{array}{l}\text { - Cost cutting measures have been implemented and still being } \\
\text { pursued } \\
\text { - Biman has been converted into a Public Limited Company } \\
\text { (PLC) to run on commercial basis } \\
\text { - Off-loading Biman's share is under consideration }\end{array}$ & $\begin{array}{l}\text { - Government to provide equity for } \\
\text { acquisition of new aircraft for Biman } \\
\text { - Protect Biman's traffic and handling rights as } \\
\text { a national carrier }\end{array}$ \\
\hline 45. Enhancing air cargo capacity & $\begin{array}{l}\text { - Establish joint freighter services with foreign airlines } \\
\text { - Procure freighter aircraft }\end{array}$ & & $\begin{array}{l}\text { - Formulate policy to carry perishable export } \\
\text { cargo }\end{array}$ \\
\hline
\end{tabular}




\begin{tabular}{|c|c|c|c|}
\hline Strategic Goals & Key Targets & Action Taken/underway & PRSP Policy Agenda (2009-11) \\
\hline (1) & (2) & (3) & (4) \\
\hline \multicolumn{4}{|c|}{ Lead Responsibility: Bangladesh Inland Water Transport Corporation (BIWTC) } \\
\hline 46. Enhance quality of Water Transport & $\begin{array}{l}\text { - Construct/Acquire } 2 \text { Container Vessels } \\
\text { - Rehabilitate } 2 \text { Coastal Passenger Vessels } \\
\text { - Rehabilitate } 6 \text { Ro-Ro Ferry, } 2 \text { K-type Ferry and } 6 \\
\text { Pontoons } \\
\text { - Construct } 4 \text { Sea-Trucks for carrying passengers in } \\
\text { coastal belt and risky routes } \\
\text { - Modify Passenger Steamer M.V. Sonargaon } \\
\text { - Construct/Procure } 2 \text { Ro-Ro ferry and } 2 \text { Ro-Ro } \\
\text { Pontoon for Mawa ferry } \\
\text { - Construct/Acquire of } 1 \text { passenger vessel of capacity } \\
\text { - Con for Kumira-Guptachara route } \\
\text { construct/Acquire of } 4 \text { self -propelled cellular } \\
\text { - Construct/Acquire } 2 \text { Coastal Ferries and } 2 \text { Pontoons } \\
\text { with Stable Ramp } \\
\text { - Construct/Procure } 2 \text { Nos. K-type ferries for } \\
\text { ensuring quick and efficient ferry services provided } \\
\text { by BIWTC in Mawa ferry sector } \\
\text { - Procure and Install Hi-Tech Navigation System at } \\
\text { Paturia and Mawa Ferry and } 4 \text { Ferry } \\
\text { - Procure/Construct Nos. Shallow Draft Oil Tankers } \\
\text { for BIWTC } \\
\text { - Procure/install modern equipments for increasing } \\
\text { efficiency of BIWTC's dockyards } \\
\text { - Rehabilitate } 4 \text { Nos. medium type ferries of BIWTC } \\
\text { - Construct/Procure a Salvage tug of capacity } 2000 \\
\text { H.P. }\end{array}$ & $\begin{array}{l}\text { - The project is under approval stage } \\
\text { - Rehabilitation work is being carried out } \\
\text { - One project is under implementation } \\
\text { - DPP of a project is at the approval stage. } \\
\text { - Work is going on in Khulna Shipyard Ltd. and is expected to be } \\
\text { completed by June, } 2008 \text {. } \\
\text { - The project is under approval stage. } \\
\text { - DPP is under preparation. } \\
\text { - Is being processed for foreign financing } \\
\text { - Is being processed for foreign financing } \\
\text { - Tender Notice has been published } \\
\text { - DPP is under preparation } \\
\text { - DPP is under preparation } \\
\text { - DPP is under preparation } \\
\text { - DPP is under preparation } \\
\text { - DPP is under preparation }\end{array}$ & $\begin{array}{l}\text { - Ensure efficient ferry services in Aricha and } \\
\text { - Aawa } \\
\text { - Add Water Taxi for operation in the circular } \\
\text { - Add container vessel for water born cargo } \\
\text { transportation } \\
\text { - Promote water transportation in the inland } \\
\text { and coastal water ways } \\
\text { - Provide better communication facilities } \\
\text { through waterways } \\
\text { - Provide cheaper transportation for people } \\
\text { - Provide safe and easy transportation for } \\
\text { woman } \\
\text { - Ensure efficient service in Dhaka-Khulna } \\
\text { inland water route } \\
\text { - Introduce Ro-Ro ferry services in Mawa } \\
\text { sector } \\
\text { - Provide uninterrupted ferry services during } \\
\text { foggy period }\end{array}$ \\
\hline 47. Expanding services & $\begin{array}{l}\text { - Open new ferry services at Laxmipur-Bhola and } \\
\text { Bhola-Barisal ferry route } \\
\text { - Open Chittagong-Cox's Bazar tourist services } \\
\text { - Open Dhaka-Bhola passenger services } \\
\text { - Open Sea-truck services where necessary }\end{array}$ & $\begin{array}{l}\text { - Laxmipur-Bhola and Bhola-Barisal ferry services are in } \\
\text { operation }\end{array}$ & $\begin{array}{l}\text { - Establish Bhola-Barisal and Laxmipur-Bhola } \\
\text { ferry services } \\
\text { - Promote water transportation in inland \& } \\
\text { coastal routes } \\
\text { - Promote transportation for poor people } \\
\text { living in the backward areas and movement } \\
\text { of commodities }\end{array}$ \\
\hline $\begin{array}{l}\text { 48. Opening avenues for private sector } \\
\text { participation }\end{array}$ & $\begin{array}{l}\text { - Organize reforms and sound business practice } \\
\text { - Meet up the market need } \\
\text { - Make the organization more responsive } \\
\text { - Charter cargo fleet and coastal passenger routes }\end{array}$ & - Will be done continuously & $\begin{array}{l}\text { - Provide better and efficient services to the } \\
\text { people at a competitive price } \\
\text { - Provide efficient customer facilities } \\
\text { - Contribute to the national economy by } \\
\text { providing efficient services }\end{array}$ \\
\hline $\begin{array}{l}\text { 49. Ensuring maintenance of BIWTC's } \\
\text { fleet }\end{array}$ & $\begin{array}{l}\text { - Identify the vessel on priority basis } \\
\text { - Prepare necessary schedule up to } 2008 \\
\text { - Introduce modern technology/machineries in }\end{array}$ & - Will be done continuously & $\begin{array}{l}\text { - Provide efficient and time bound services. } \\
\text { - Adequate modern technology for periodic } \\
\text { maintenance }\end{array}$ \\
\hline
\end{tabular}




\begin{tabular}{|c|c|c|c|}
\hline Strategic Goals & Key Targets & Action Taken/underway & PRSP Policy Agenda (2009-11) \\
\hline \multirow[t]{2}{*}{$(1)$} & $(2)$ & (3) & (4) \\
\hline & existing dockyards & & $\begin{array}{l}\text { - Provide modern facilities to the people on } \\
\text { board. }\end{array}$ \\
\hline $\begin{array}{l}\text { 50. Formulating pragmatic water transport } \\
\text { policies }\end{array}$ & - Prepare IW'T Master Plan & $\begin{array}{l}\text { - TSC wing of Planning Commission is working on IWT Master } \\
\text { Plan. }\end{array}$ & $\begin{array}{l}\text { - Implement Integrated Transport System } \\
\text { - Conduct Baseline survey } \\
\text { - Increase fund for IWT sector } \\
\text { - Provide better information and quicker } \\
\text { services }\end{array}$ \\
\hline \multirow[t]{2}{*}{ 51. Ensuring disaster risk reduction } & $\begin{array}{l}\text { - Reconstruct Infrastructures and other facilities } \\
\text { damaged by cyclone 'sidr' }\end{array}$ & - DPP of the project is at the approval stage & $\begin{array}{l}\text { - Take preventive measure for future disaster } \\
\text { risk reduction }\end{array}$ \\
\hline & $\begin{array}{l}\text { - Conversion of main engines of some major ferries of } \\
\text { BIWTC into CNG driven engines }\end{array}$ & - Project is included in the Medium Term Budget Framework & $\begin{array}{l}\text { - Reduce fuel consumption and fuel costs } \\
\text { - Keeping more polluted free water ways }\end{array}$ \\
\hline \multicolumn{4}{|c|}{ Lead Responsibility: Bangladesh Inland Water Transport Authority (BIWTA) } \\
\hline \multirow[t]{3}{*}{$\begin{array}{l}\text { 52. Ensuring smooth and safe navigation } \\
\text { of all vessels }\end{array}$} & $\begin{array}{l}\text { - Keep the inland waterways navigable for smooth } \\
\text { movement of all vessels }\end{array}$ & $\begin{array}{l}\text { - Master Plan for inland Water Transport system is under } \\
\text { preparation } \\
\text { - Several projects have already been undertaken }\end{array}$ & $\begin{array}{l}\text { - Dredge } 42.00 \text { lakh } \mathrm{m} 3 \text { and } 20.00 \text { lakh } \mathrm{m} 3 \\
\text { under } 4 \text { development projects } \\
\text { - Build circular waterways } \\
\text { - Build Inland Container River Terminal, } \\
\text { Pangaon }\end{array}$ \\
\hline & $\begin{array}{l}\text { - Dredge } 50.00 \text { lakh } \mathrm{m} 3 \text { in various routes and digging } \\
\text { of } 35.00 \text { lakh } \mathrm{m} 3 \text { in different rivers }\end{array}$ & - Action is underway & $\begin{array}{l}\text { - Develop infrastructure facilities for IWT } \\
\text { sector to provide cheapest transport cost for } \\
\text { carrying goods and services }\end{array}$ \\
\hline & - Procure 3 (three) dredgers & - Action is underway & $\begin{array}{l}\text { - Contribution to the Poverty Reduction by } \\
\text { providing cheapest transportation to the } \\
\text { rural people }\end{array}$ \\
\hline 53. Providing port facilities & & $\begin{array}{l}\text { - Action is being undertaken following the approval of the } \\
\text { project } \\
\text { - Approval process of the project is underway }\end{array}$ & $\begin{array}{l}\text { - Construct port facilities in Buriganga river } \\
\text { - Modernize Dhaka River Port } \\
\text { - Construct inland container river terminal } \\
\text { - Establish river ports at Nowapara, Bhairab- } \\
\text { Ashuganj and Borguna } \\
\text { - Develop and modernize Barisal River Port }\end{array}$ \\
\hline \multicolumn{4}{|c|}{ Lead Responsibility: Bangladesh Telephone and Telegraph Board (BTTB) } \\
\hline $\begin{array}{l}\text { 54. Expanding Internet Information } \\
\text { Network }\end{array}$ & $\begin{array}{l}\text { - Increase rural density mandatory for } \\
\text { ISP/Mobile/PSTN operators } \\
\text { - Fix and support targets of growth for internet } \\
\text { penetration for the ISP in rural areas }\end{array}$ & $\begin{array}{l}\text { - DPP approved for INFO-BAHAN Project } \\
\text { - Consultant selection process in going-on }\end{array}$ & $\begin{array}{l}\text { - Extend ICT facility to empowering rural } \\
\text { people } \\
\text { - Procure necessary hardware and software } \\
\text { - Develop ICT supportive infrastructure } \\
\text { - Serve the needs of Voice Video and Data } \\
\text { Communication } \\
\text { - Effective broadband policy and deployment } \\
\text { of a nationwide broadband network (Wired } \\
\text { and wireless) }\end{array}$ \\
\hline $\begin{array}{l}\text { 55. Installing digital telephone exchanges } \\
\text { at Upazila }\end{array}$ & & $\begin{array}{l}\text { - PP (1st revision) approved } \\
\text { - Approval of RDPP and underway }\end{array}$ & $\begin{array}{l}\text { - Extend digital telephone at Upazila \& growth } \\
\text { centre level } \\
\text { - Install RSU and MSU in } 178 \text { upazillas \& } 42\end{array}$ \\
\hline
\end{tabular}




\begin{tabular}{|c|c|c|c|}
\hline Strategic Goals & Key Targets & Action Taken/underway & PRSP Policy Agenda (2009-11) \\
\hline \multirow[t]{2}{*}{$(1)$} & $(2)$ & (3) & $(4)$ \\
\hline & & & $\begin{array}{l}\text { growth centres } \\
\text { - Install185 radio links and } 51 \text { towers } \\
\text { - Bring all Upazilas under internet connection } \\
\text { within next five years }\end{array}$ \\
\hline \multicolumn{4}{|c|}{ Lead Responsibility: Bangladesh Post Office (BPO) } \\
\hline 56. Automating the Postal Service & $\begin{array}{l}\text { - Procure necessary hardware, software and } \\
\text { connectivity for } 83 \text { offices } \\
\text { - Train the staffs for necessary operation } \\
\text { - Automate the services delivery process }\end{array}$ & - A project on this has been prepared & $\begin{array}{l}\text { - Counter automation } \\
\text { - Automation of Postal Accounting } \\
\text { Information System } \\
\text { - Automation of Management Information } \\
\text { System } \\
\text { - Automation of service delivery system }\end{array}$ \\
\hline 57. Providing training to BPO staff & - Impart training on state of the art technologies & - A project has already been prepared & $\begin{array}{l}\text { - Provide training to the officers and staffs of } \\
\text { BPO }\end{array}$ \\
\hline 58. Building infrastructure of $\mathrm{BPO}$ & - Facilitate ICT based service & - Two projects on this have been prepared & $\begin{array}{l}\text { - Develop Infrastructure development of BPO } \\
\text { - Ensure rural women's access to ICT facilities }\end{array}$ \\
\hline \multicolumn{3}{|l|}{ Total Indicative Cost (in billion taka) } & Tk. 536.66 \\
\hline
\end{tabular}


Policy Matrix 11: Social Safety Net, Food Security, Disaster Management, Scaling up of Micro-credit and Rural Non-farm Activities

\begin{tabular}{|c|c|c|c|}
\hline Strategic Goals & Key Targets & Actions Taken/ Underway & PRSP Policy Agenda (2009-2011) \\
\hline 1 & 2 & 3 & 4 \\
\hline \multicolumn{4}{|l|}{ I. Social Safety Net } \\
\hline \multicolumn{4}{|c|}{ Lead Responsibility: MoF, GED, MoSW, MoWCA, MoCHTA, MoLA, MoLE, } \\
\hline $\begin{array}{l}\text { 1. Forming and fostering an } \\
\text { enabling policy framework for } \\
\text { social protection }\end{array}$ & $\begin{array}{l}\text { - Prepare and adopt a coherent national } \\
\text { social protection policy }\end{array}$ & $\begin{array}{l}\text { - Each and every SSNP has its own } \\
\text { operational policy }\end{array}$ & $\begin{array}{l}\text { - Formulate and adopt a coherent, cost effective and women sensitive national social } \\
\text { protection policy addressing intra-household food security with focus on women and } \\
\text { children } \\
\text { - Enact relevant laws and prepare relevant rules of business } \\
\text { - Review social protection policies of various countries and their financial implications and } \\
\text { modes of financing }\end{array}$ \\
\hline \multicolumn{4}{|c|}{ Lead Responsibility: MoF, MoSW } \\
\hline $\begin{array}{l}\text { 2. Extending coverage of safety } \\
\text { net programmes }\end{array}$ & $\begin{array}{l}\text { - Cover } 75 \% \text { of ultra poor of which } 2 / 3 \\
\text { will be women with an emphasis on } \\
\text { women with disability and indigenous } \\
\text { groups } \\
\text { - Achieve } 90 \% \text { accuracy in targeting } \\
\text { - Ensure targeting } 100 \% \text { of seasonal } \\
\text { unemployed in Monga, Char,Coastal } \\
\text { areas and CHT areas } \\
\text { - For sustainable livelihood of poor } \\
\text { beneficiaries under employment } \\
\text { support schemes, micro insurance } \\
\text { facility will be built with SSNP such as } \\
\text { VGD, VGF, FFW, CFW etc. }\end{array}$ & $\begin{array}{l}\text { - Introduced an old age insurance to } \\
\text { gradually cover all deserving persons } \\
\text { - Amount of assistance raised for many } \\
\text { programmes } \\
\text { - Allowance for lactating mother and } \\
\text { stipend for students with disability } \\
\text { have been introduced } \\
\text { - Additional } 9 \text { State Orphanage has } \\
\text { been established } \\
\text { - Micro credit programme has been } \\
\text { introduced for persons with disability } \\
\text { - Introduced employment generation } \\
\text { for seasonally unemployed }\end{array}$ & $\begin{array}{l}\text { - Extend coverage of and enhance old age allowance, allowances for destitute women, } \\
\text { insolvent freedom fighters, insolvent-disabled, and lactating mothers, injured freedom } \\
\text { fighters, residents in government orphanage and other institution, pension for retired } \\
\text { government employees and their families, capitation grants for orphan students in non- } \\
\text { government orphanages, general relief activities, non-Bengali rehabilitation, distressed } \\
\text { cultural personalities/activities, stipend for disabled students, grants for the schools for the } \\
\text { disabled, housing support \& agricultural rehabilitation } \\
\text { - Keep block allocation for disaster management } \\
\text { - Redesign programmes for disadvantaged groups such as persons with disability, mental } \\
\text { patients, indigenous groups, and people in remote areas with special focus on women and } \\
\text { children } \\
\text { - Revive programmes such as returning home, one household, one farm programme } \\
\text { - Introduce the programmes entitled Employment Generation for the Hard Core Poor and } \\
\text { National Service for the unemployment youths } \\
\text { - Widen and deepen the existing SSNPs with maintaining gender balance and appropriate } \\
\text { targeting } \\
\text { - Adopt new programmes to cover ultra poor, pavement dwellers, extreme urban poor, } \\
\text { adolescent girls of poor families, and beggars } \\
\text { - Facilitate community based social safety net } \\
\text { - Extend coverage and enhance allocation for existing programmes for social empowerment as } \\
\text { well as undertake new programmes like participatory rural development project and small } \\
\text { farmer development foundation support project } \\
\text { - Assess the impacts of large safety net programmes } \\
\text { - Undertake employment generation for seasonally unemployed with a focus on women and } \\
\text { equal wage }\end{array}$ \\
\hline \multicolumn{4}{|l|}{ Lead Responsibility: MoLE } \\
\hline 3. Implementing labour laws & $\begin{array}{l}\text { - Put regulatory framework in place } \\
\text { - Amend laws as necessary }\end{array}$ & - Labour Law 2006 has been passed & $\begin{array}{l}\text { - Amend and implement labour law and other laws as necessary by considering gender issues } \\
\text { - Put regulatory framework in place } \\
\text { - Put fiscal mechanisms and operational procedures in place } \\
\text { - Form legal review bodies composed of government, civil society members, women groups, } \\
\text { employers and employees }\end{array}$ \\
\hline \multicolumn{3}{|c|}{ Sub-Total Indicative Cost (in billion taka) } & Tk. 140.00 \\
\hline
\end{tabular}




\begin{tabular}{|c|c|c|c|}
\hline Strategic Goals & Key Targets & Actions Taken/ Underway & PRSP Policy Agenda (2009-2011) \\
\hline 1 & 2 & 3 & 4 \\
\hline \multicolumn{4}{|l|}{ II. Food Security } \\
\hline \multicolumn{4}{|c|}{ Lead Responsibility: MoI, BSTI, MoFDM } \\
\hline $\begin{array}{l}\text { 4. Creating an enabling framework } \\
\text { for food security }\end{array}$ & $\begin{array}{l}\text { - Implement National Food Policy } 2006 \\
\text { and the Plan of Action } \\
\text { - Frame policy to ensure entitlement of } \\
\text { all excluded groups }\end{array}$ & $\begin{array}{l}\text { - Quality control of food products by } \\
\text { BSTI } \\
\text { - Mobile court for ensuring food quality } \\
\text { by BSTI. } \\
\text { - Implementation of 'National Food } \\
\text { Policy Plan of Action 2007-2015' } \\
\text { - Gender and disadvantaged included in } \\
\text { food policy }\end{array}$ & $\begin{array}{l}\text { - Strengthen BSTI's food quality control system } \\
\text { - Strengthen the food control system specially conformity assessment infrastructure } \\
\text { - Formulate and implement food safety policy } \\
\text { - Strengthen co- ordination, monitoring \& evaluation while implementing the PoA } \\
\text { - Implement National Food Policy Plan of Action 2007-2015 } \\
\text { - Enact consumer protection act } \\
\text { - Prepare beneficiary list of various programme using data base of national ID card } \\
\text { - Implement National Food Policy Capacity Strengthening Programme }\end{array}$ \\
\hline \multicolumn{4}{|l|}{ Lead Responsibility: MoFDM } \\
\hline $\begin{array}{l}\text { 5. Assuring low cost food supply } \\
\text { 6. Ensuring food security of the } \\
\text { poor and the vulnerable }\end{array}$ & $\begin{array}{l}\text { - Yearly distribution of } 1.5 \text { million tons } \\
\text { of food grain at reduced price } \\
\text { - Secure access to food } \\
\text { - Generate employment } \\
\text { - Maintain adequate food stock } \\
\text { - Smoothen distribution of food }\end{array}$ & $\begin{array}{l}\text { - Food distribution undertaken by } \\
\text { Ministry of Food and Disaster } \\
\text { management (MFDM) during } \\
\text { emergency } \\
\text { - Food security programmes }\end{array}$ & $\begin{array}{l}\text { - Purchases food from domestic and international markets } \\
\text { - Ensure enough food-stock for stabilizing the market } \\
\text { - Expand food safety net } \\
\text { - Enhance storage capacity for food grains } \\
\text { - Enhance allocation for subsidy for open market Sales, VGD, VGF, TR, GR, FFW and food } \\
\text { assistance in CTG-Hill Tracts. }\end{array}$ \\
\hline \multicolumn{4}{|l|}{ Lead Responsibility: MoFDM } \\
\hline $\begin{array}{l}\text { 7. Smoothening fluctuations in } \\
\text { food consumption }\end{array}$ & & $\begin{array}{l}\text { - Ministry of Food and Disaster } \\
\text { Management is trying to maintain } \\
\text { food security by maintaining } 1.0 \\
\text { million MT of food stock at the } \\
\text { beginning of the FY } \\
\text { - Private import of food grain has been } \\
\text { liberalized to improve the private } \\
\text { stock for market supply } \\
\text { - Food grain has been allocated for } \\
\text { targeted programmes } \\
\text { - Market price of food grain rationalized }\end{array}$ & $\begin{array}{l}\text { - Modernization of food management to continue } \\
\text { - Stabilize market price by improving market supply } \\
\text { - Modernization of food stock management for speedy distribution/release in times of need } \\
\text { - Ensure national and local level stocks of critical food items at public and private levels } \\
\text { - Undertake targeted food operations, price stabilization, price support, open market sales and } \\
\text { selected rationing }\end{array}$ \\
\hline $\begin{array}{l}\text { 8. Increasing } \\
\text { purchasing power of poor and } \\
\text { entitlement of disadvantaged } \\
\text { women and men }\end{array}$ & $\begin{array}{l}\text { - Increase real wage } \\
\text { - Ensure targeted distribution with } \\
\text { emphasis on women headed poor } \\
\text { households } \\
\text { - Maintain low inflation rate }\end{array}$ & $\begin{array}{l}\text { - Pro-poor growth firmly on the agenda } \\
\text { - Various food based infrastructure } \\
\text { development programmes underway } \\
\text { - Employment generation programme } \\
\text { worth Tk. } 11.56 \text { billion starts from FY } \\
\text { 2009-10 }\end{array}$ & $\begin{array}{l}\text { - Encourage investment in labour- intensive sectors } \\
\text { - Ensure easy access to credit } \\
\text { - Pursue canal maintenance programme } \\
\text { - Review impact of various macro-economic policies on the poor for policy adjustments } \\
\text { - Target sector specific (garment, shrimp, tea plantation etc.) women workers for subsidized } \\
\text { food }\end{array}$ \\
\hline $\begin{array}{l}\text { 9. Ensuring better food utilization } \\
\text { and more nutritious food to all } \\
\text { particularly poor children and }\end{array}$ & $\begin{array}{l}\text { - Increase awareness of nutrition, food } \\
\text { safety and food hygiene } \\
\text { - Include food safety, nutrition and } \\
\end{array}$ & $\begin{array}{l}\text { - School feeding programme on a } \\
\text { relatively small scale } \\
\text { - Providing technical input for food }\end{array}$ & $\begin{array}{l}\text { - Evaluate the existing programmes and options for new programmes } \\
\text { - Ensure an effective capacity for long term planning of balanced food in building a healthy } \\
\text { nation }\end{array}$ \\
\hline
\end{tabular}




\begin{tabular}{|c|c|c|c|}
\hline Strategic Goals & Key Targets & Actions Taken/ Underway & PRSP Policy Agenda (2009-2011) \\
\hline 1 & 2 & 3 & 4 \\
\hline women & $\begin{array}{l}\text { hygiene issues in school curricula } \\
\text { - Increase nutrition for pre-school } \\
\text { children } \\
\text { - Improve nutrition for pregnant and } \\
\text { lactating women }\end{array}$ & $\begin{array}{l}\text { safety activities/ programmes. } \\
\text { - A study on "Determination of food } \\
\text { availability and consumption patterns } \\
\text { and setting up of nutritional standards } \\
\text { in Bangladesh" is underway }\end{array}$ & $\begin{array}{l}\text { - Monitor nutritional status of pregnant and lactating mother (expansion of NNP) in } \\
\text { disadvantaged position }\end{array}$ \\
\hline \multicolumn{3}{|c|}{ Sub-Total Indicative Cost (in billion taka) } & Tk. 110.00 \\
\hline \multicolumn{4}{|l|}{ III. Disaster Management } \\
\hline \multicolumn{4}{|l|}{ Lead Responsibility: MoFDM } \\
\hline $\begin{array}{l}\text { 10. Mainstreaming disaster } \\
\text { management and risk reduction } \\
\text { into national policies, institutions } \\
\text { and development process }\end{array}$ & $\begin{array}{l}\text { - Introduce disaster management and } \\
\text { risk reduction in all development } \\
\text { activities } \\
\text { - Include disaster risk management in } \\
\text { the development project validation } \\
\text { process through Disaster Impact and } \\
\text { Risk Assessment (DIRA) }\end{array}$ & $\begin{array}{l}\text { - Disaster Management Plan finalized } \\
\text { - SAARC Regional framework for } \\
\text { Disaster Management established and } \\
\text { modelled on Bangladesh disaster } \\
\text { Management framework } \\
\text { - Established Working Committee to } \\
\text { identify the sectoral intervention for } \\
\text { mainstreaming risk reduction } \\
\text { - Climate change research underway to } \\
\text { determine impacts } \\
\text { - Actions underway to mainstream } \\
\text { disaster risk reduction issues in the } \\
\text { education curriculum }\end{array}$ & $\begin{array}{l}\text { - Develop tools to facilitate implementation of the ECNEC decisions of } 2007 \\
\text { - Include disaster risk reduction including climate change impacts in all the sectoral policies, } \\
\text { - } \text { - Implems and projects } \\
\text { - Undertake strong advocacy to ensure implementation of local level risk reduction action plan } \\
\text { - Establish monitoring and evaluation framework } \\
\text { - Introduce property insurance } \\
\text { - Project future activities and growth targets incorporating risk scenario } \\
\text { - Incorporate climate change into disaster management and risk reduction plans, policies, } \\
\text { - Unogrammes and projects } \\
\text { focusing on women and children }\end{array}$ \\
\hline \multicolumn{4}{|c|}{ Lead Responsibility: MoFDM, DoE } \\
\hline $\begin{array}{l}\text { 11. Strengthening disaster } \\
\text { management and risk reduction } \\
\text { capacity }\end{array}$ & $\begin{array}{l}\text { - Build capacity of national institutions } \\
\text { for disaster management }\end{array}$ & $\begin{array}{l}\text { - Disaster Management Plan prepared } \\
\text { and endorsed } \\
\text { - Draft Disaster Management Act is } \\
\text { prepared } \\
\text { - Draft National Policy on Disaster } \\
\text { Management Act is prepared } \\
\text { - MoFDM Allocation of Business has } \\
\text { been revised } \\
\text { - Standing orders on disaster } \\
\text { management is being revised } \\
\text { - Strategy for MoFDM and DoE on } \\
\text { Climate Change drafted } \\
\text { - Training needs assessment undertaken } \\
\text { for disaster Management committees } \\
\text { and programme implementers } \\
\text { - Procurement of equipment for search } \\
\text { for and rescue of earthquake and } \\
\text { other disaster victims are underway } \\
\text { - Flood monitoring and damage } \\
\text { assessment using satellite data } \\
\text { undertaken } \\
\text { - Constructed poverty parameter spatial }\end{array}$ & $\begin{array}{l}\text { - Finalize and obtain approval of all key policy documents } \\
\text { - Strengthen the disaster management system including capacity building of disaster } \\
\text { management committees at all levels to enhance knowledge and understanding of policy } \\
\text { change impacts } \\
\text { - Provide adequate and regular budgetary support commensurate with assigned responsibility } \\
\text { - Revise plan of action for disaster management } \\
\text { - Revise Allocation of Business in relation to MoFDM mandates } \\
\text { - Prepare Plan of Action or Manual for disaster management for agriculture sector with a } \\
\text { focus on women } \\
\text { - Increase capacity of disaster forecasting } \\
\text { - Conduct earthquake and tsunami risk assessment for big cities and costal districts } \\
\text { - Strengthen search and rescue capabilities of first responding institutions } \\
\text { - Establish a local level disaster management contributory fund with contribution from } \\
\text { government, private sector and donors } \\
\text { - Implement disaster management related programmes. }\end{array}$ \\
\hline
\end{tabular}




\begin{tabular}{|c|c|c|c|}
\hline Strategic Goals & Key Targets & Actions Taken/ Underway & PRSP Policy Agenda (2009-2011) \\
\hline 1 & 2 & 3 & 4 \\
\hline & & $\begin{array}{l}\text { database in GIS } \\
\text { - Crop monitoring using satellite data } \\
\text { received at the ground station of } \\
\text { SPARRSO } \\
\text { - Installed satellite based cyclone } \\
\text { monitoring system } \\
\text { - MoFDM undertaken 2005-2009 } \\
\text { framework for action } \\
\text { - Developed strategic plan for DMB, } \\
\text { DRR and DGoF } \\
\text { - Developing Annual plans of DMB, } \\
\text { DRR and DGoF }\end{array}$ & \\
\hline \multicolumn{4}{|l|}{ Lead Responsibility: MoFDM } \\
\hline $\begin{array}{l}\text { 12. Ensuring knowledge } \\
\text { management (acquiring sharing } \\
\text { and applying) on disaster risk } \\
\text { reduction }\end{array}$ & $\begin{array}{l}\text { - Identify and disseminate indigenous } \\
\text { knowledge and best practices } \\
\text { - Build network among local, regional } \\
\text { and international stakeholders } \\
\text { - Strengthen Institute of Disaster Risk } \\
\text { Management \& Research (IDRMR) }\end{array}$ & $\begin{array}{l}\text { - Disaster Management Information } \\
\text { Centre established and being } \\
\text { progressively strengthened through } \\
\text { databases and other information } \\
\text { networks } \\
\text { - Partnership being established with } \\
\text { information providers } \\
\text { - Flood forecasting, warning and } \\
\text { cyclone warning system is in place } \\
\text { - Agro meteorological cell established } \\
\text { - NAPA for climate change adaptation } \\
\text { is in process } \\
\text { - Development of drought prediction } \\
\text { model initiated } \\
\text { - Initiated activities to establish the } \\
\text { disaster management information centre } \\
\text { - Started poverty parameter spatial } \\
\text { database in GIS }\end{array}$ & $\begin{array}{l}\text { - Establish standing operating procedure (SOP) of DMIC } \\
\text { - Expand information networks and data bases on all hazards } \\
\text { - Establish network among local, regional and national stakeholders ensuring involvement of } \\
\text { women groups at all levels } \\
\text { - Establish a Disaster Management Cell and training provision } \\
\text { - Establish an institute of disaster management research } \\
\text { - Develop drought prediction model in agromet division in BMD } \\
\text { - Build capacity of BMD in warning and forecasting system } \\
\text { - Make mandatory disaster management education in all public training programme } \\
\text { - Establish a national disaster management training policy and strategy framework } \\
\text { - Expand the risk reduction and emergency management training programme to cover all the } \\
\text { DMCs of the high and medium risk districts }\end{array}$ \\
\hline \multicolumn{4}{|l|}{ Lead Responsibility: MoFDM } \\
\hline $\begin{array}{l}\text { 13.Enhancing community level } \\
\text { capacity for disaster risk reduction } \\
\text { (preparedness, recovery and } \\
\text { rehabilitation) with a focus on } \\
\text { women }\end{array}$ & $\begin{array}{l}\text { - Strengthen community based } \\
\text { programmes for risk reduction } \\
\text { - Reduce loss of lives of children, } \\
\text { women, elderly people and livestock } \\
\text { and damage to crops and household } \\
\text { savings in disasters }\end{array}$ & $\begin{array}{l}\text { - Developed community risk } \\
\text { assessment (CRA) guideline and risk } \\
\text { reduction action plan (RRAP) } \\
\text { - CRA and RRAPs are under } \\
\text { implementation by NGOs } \\
\text { - Achieved high level of community } \\
\text { involvement in CRA and risk } \\
\text { management } \\
\text { - Revised roles and responsibilities of } \\
\text { disaster management committees and } \\
\text { incorporated in new Standing Orders } \\
\text { - ICT training programme implemented }\end{array}$ & $\begin{array}{l}\text { - Create hazard awareness programmes to increase knowledge of risk and understanding of } \\
\text { actions to manage risk } \\
\text { - Expand the focus of risk reduction down to the household level through the development of } \\
\text { Household Action Plans } \\
\text { - Identify most vulnerable groups/assets (children, women, elderly people, livestock, crops, } \\
\text { household savings) and include them in risk reduction plan } \\
\text { - Establish the CRA guideline to prepare the risk reduction action plans for high and medium } \\
\text { risk upazila and districts }\end{array}$ \\
\hline
\end{tabular}




\begin{tabular}{|c|c|c|c|}
\hline Strategic Goals & Key Targets & Actions Taken/ Underway & PRSP Policy Agenda (2009-2011) \\
\hline 1 & 2 & 3 & 4 \\
\hline & & $\begin{array}{l}\text { for all MoFDM staff } \\
\text { - LAN/ WAN network established } \\
\text { within the MoFDM and with BMD } \\
\text { - Funds made available to document and } \\
\text { disseminate indigenous best practice } \\
\text { - Disaster management in school } \\
\text { curriculum is being revised } \\
\text { - Exploring and promoting different } \\
\text { livelihood adaptation options } \\
\text { - Constructed } 25 \text { flood shelters } \\
\text { - Construction of } 74 \text { flood shelters are } \\
\text { ongoing }\end{array}$ & \\
\hline \multicolumn{4}{|c|}{ Lead Responsibility: MoSW , MoFDM, MoWCA } \\
\hline $\begin{array}{l}\text { 14. Ensuring protection of } \\
\text { women, children, elderly, people } \\
\text { with disability and other } \\
\text { vulnerable groups }\end{array}$ & $\begin{array}{l}\text { - Ensure } 20 \% \text { housing facilities for } \\
\text { female headed household in public } \\
\text { housing projects } \\
\text { - Build working women's hostel in every } \\
\text { district town }\end{array}$ & $\begin{array}{l}\text { - The national plan for disaster } \\
\text { management 2007-2015 approved } \\
\text { - Gender mainstreaming policy for all } \\
\text { disaster management and risk } \\
\text { reduction initiatives is being drafted } \\
\text { - Considerations for vulnerable groups } \\
\text { like women and children are included } \\
\text { within the CRA process } \\
\text { - Ensure shelters have necessary } \\
\text { facilities for the person with disability } \\
\text { and elderly }\end{array}$ & $\begin{array}{l}\text { - Finalize and implement the gender mainstreaming policy and establish effective monitoring } \\
\text { mechanisms to ensure conformity } \\
\text { - Develop a national damage and loss estimation system that considers the specific needs of } \\
\text { the vulnerable and women's groups } \\
\text { - Continue and strengthen the ongoing programmes }\end{array}$ \\
\hline $\begin{array}{l}\text { 15. Strengthening governance in } \\
\text { the sector }\end{array}$ & & $\begin{array}{l}\text { - Implementation of comprehensive } \\
\text { training programme } \\
\text { - Establishment of the policy, planning } \\
\text { and regulatory framework underway } \\
\text { - Establishment of the SAARC } \\
\text { framework for comprehensive disaster } \\
\text { management } \\
\text { - Development of central relief } \\
\text { management information system } \\
\text { underway }\end{array}$ & $\begin{array}{l}\text { - Establish the disaster management policy and regulatory framework } \\
\text { - Establish a Go-NGO coordination mechanism for timely and effective response } \\
\text { - Strengthen monitoring and evaluation system focusing on women and children }\end{array}$ \\
\hline \multicolumn{3}{|c|}{ Sub-Total Indicative Cost (in billion taka) } & Tk. 9.19 \\
\hline \multicolumn{4}{|c|}{ IV. Micro-credit } \\
\hline \multicolumn{4}{|c|}{ Lead Responsibility: MoF, MoSW , RD\&C, Micro-credit programme implementing ministry/division/agencies } \\
\hline $\begin{array}{l}\text { 16. Reaching micro-credit to the } \\
\text { ultra poor with a focus on women, } \\
\text { women with disability and } \\
\text { indigenous groups }\end{array}$ & $\begin{array}{l}\text { - Provide pre-credit maintenance and } \\
\text { training support } \\
\text { - Streamline credit delivery and diversify } \\
\text { financial and non-financial services } \\
\text { - } 30 \% \text { ultra poor women and men are } \\
\text { reached through financial and HRD } \\
\text { support }\end{array}$ & $\begin{array}{l}\text { - Implementation of extensive micro } \\
\text { credit programme of various public } \\
\text { organizations and NGOs } \\
\text { - Efforts are being made for reaching } \\
\text { the ultra poor through GO-NGO } \\
\text { collaboration } \\
\text { - MOI is providing micro credit to the }\end{array}$ & $\begin{array}{l}\text { - Formalize multi-purpose credit society with better functional policy with a focus on women } \\
\text { - Extend GO-NGO collaboration } \\
\text { - Review delivery systems of major micro credit providers } \\
\text { - Channel more resources for micro credit with a focus on women }\end{array}$ \\
\hline
\end{tabular}




\begin{tabular}{|c|c|c|c|}
\hline Strategic Goals & Key Targets & Actions Taken/ Underway & PRSP Policy Agenda (2009-2011) \\
\hline 1 & 2 & 3 & 4 \\
\hline & & ultra poor & \\
\hline $\begin{array}{l}\text { 17. Supporting mature clients, } \\
\text { entrepreneurs and tomorrow's } \\
\text { poor }\end{array}$ & $\begin{array}{l}\text { - Provide larger amount micro credit in } \\
\text { place }\end{array}$ & $\begin{array}{l}\text { - Government policy recommended for } \\
\text { providing collateral free larger sized } \\
\text { loans to small entrepreneurs } \\
\text { - Several NGOs providing larger sized } \\
\text { loans to entrepreneurs }\end{array}$ & $\begin{array}{l}\text { - Continue up to } 2011 \\
\text { - Extend larger sized credit to small entrepreneurs graduating from micro credit based } \\
\text { operations }\end{array}$ \\
\hline $\begin{array}{l}\text { 18. Using credit as a development } \\
\text { tool for the poor }\end{array}$ & $\begin{array}{l}\text { - Provide non-financial services such as } \\
\text { technology, marketing and risk } \\
\text { management } \\
\text { - Establish a network of specialized } \\
\text { service agencies (public bodies, NGOs } \\
\text { and private organizations) }\end{array}$ & $\begin{array}{l}\text { - Micro-credit activities are being } \\
\text { undertaken by NGOs } \\
\text { - Extensive micro-credit programmes in } \\
\text { place through BRDB and PDBF } \\
\text { - Volume and ceiling of micro-credit } \\
\text { has been expanded } \\
\text { - BSCIC is implementing different } \\
\text { micro-credit programmes } \\
\text { - Self-employment programmes for small } \\
\text { and cottage industries are in place } \\
\text { - BSCIC is distributing micro-credit to } \\
\text { the potential poor entrepreneurs }\end{array}$ & $\begin{array}{l}\text { - Reaching the needy men and women freedom fighters } \\
\text { - Make micro credit available to the employment seeker dependents of freedom fighters } \\
\text { - Collaborating with the GO \& NGO service providers at the local level } \\
\text { - Develop innovative idea for covering the non-bankable poor } \\
\text { - Introduce special credit-programme for vulnerable women }\end{array}$ \\
\hline $\begin{array}{l}\text { 19. Making micro-credit } \\
\text { operationally more effective }\end{array}$ & $\begin{array}{l}\text { - Flexible rules for credit disbursements } \\
\text { and repayment } \\
\text { - Package offer of the agencies } \\
\text { - } 50 \% \text { increase in the supply of funds } \\
\text { for expanding micro-credit }\end{array}$ & $\begin{array}{l}\text { - Some NGOs claim sustainability } \\
\text { through dependence on own depositors' } \\
\text { funds and low operational cost } \\
\text { - Repayment rules made somewhat } \\
\text { more flexible than before } \\
\text { - Offered some package to the clients }\end{array}$ & $\begin{array}{l}\text { - A nationwide micro credit policy must be framed with a focus and analysis of impacts on } \\
\text { women } \\
\text { - Regulatory framework for streamlining the activities of the micro credit programme } \\
\text { - Avoid overlapping and reduce interest rates } \\
\text { - Introduce uniform approach of operation both the NGOs and public sector } \\
\text { - Regulate savings mobilization and utilization in a flexible manner }\end{array}$ \\
\hline $\begin{array}{l}\text { 20. Using micro-credit for social } \\
\text { empowerment and social } \\
\text { protection }\end{array}$ & $\begin{array}{l}\text { - Increase women self employment } \\
\text { - Assist acid burn and disabled } \\
\text { - Generate employment } \\
\text { - Assist poor farmers and poultry farm }\end{array}$ & $\begin{array}{l}\text { - Micro credit programmes for social } \\
\text { empowerment }\end{array}$ & $\begin{array}{l}\text { - Enhance micro-credit for women self employment and increase fund for micro-credit } \\
\text { through PKSF } \\
\text { - Establish social development foundation and NGO foundation } \\
\text { - Create new funds for social protection }\end{array}$ \\
\hline $\begin{array}{l}\text { 21. Developing women's self help } \\
\text { groups }\end{array}$ & $\begin{array}{l}\text { - Increase the number of women's self- } \\
\text { help groups }\end{array}$ & $\begin{array}{l}\text { - Micro credit operation } \\
\text { - Weekly savings } \\
\text { - Training and motivation }\end{array}$ & $\begin{array}{l}\text { - Strengthen rural financing for non-farm activities by women } \\
\text { - Women's entrepreneurship development } \\
\text { - Create increased access to markets for women } \\
\text { - Improve delivery of services }\end{array}$ \\
\hline $\begin{array}{l}\text { 22. Transferring technology and } \\
\text { develop human resource with } \\
\text { emphasis on women }\end{array}$ & $\begin{array}{l}\text { - Increase in production oriented } \\
\text { technology and their transfer } \\
\text { - Increase capacity of different } \\
\text { institutions to develop human resource }\end{array}$ & $\begin{array}{l}\text { - Promotion of promising technologies } \\
\text { for increasing production } \\
\text { - Human resource development } \\
\text { through training and service delivery }\end{array}$ & $\begin{array}{l}\text { - Develop database on emerging sectors } \\
\text { - Establish institutional linkage for technological dissemination with a focus on women } \\
\text { - Ensure sustainable rural technology transfer in favour of women }\end{array}$ \\
\hline $\begin{array}{l}\text { 23. Developing human resources } \\
\text { of CBOs }\end{array}$ & $\begin{array}{l}\text { - Identify CBOs having potential of } \\
\text { human resources development }\end{array}$ & $\begin{array}{l}\text { - Formation of } \mathrm{CBOs} / \mathrm{VBO} \\
\text { - Mobilization of capital through } \\
\text { cooperatives and groups } \\
\text { - Human resource development } \\
\text { through training }\end{array}$ & $\begin{array}{l}\text { - Establish Linkage with govt. nation building departments and other local level organizations } \\
\text { - Development of } \mathrm{CBO} \text { and local organizations }\end{array}$ \\
\hline \multicolumn{3}{|c|}{ Sub-Total Indicative Cost (in billion taka) } & Tk. 50.00 \\
\hline
\end{tabular}




\begin{tabular}{|c|c|c|c|}
\hline Strategic Goals & Key Targets & Actions Taken/ Underway & PRSP Policy Agenda (2009-2011) \\
\hline 1 & 2 & 3 & 4 \\
\hline \multicolumn{4}{|l|}{ V. Rural Non-farm Activities } \\
\hline \multicolumn{4}{|c|}{ Lead Responsibility: BSCIC, LGED, BKB, BNFE, MRA, LGD } \\
\hline $\begin{array}{l}\text { 24. Targeting RNFE development } \\
\text { with a focus on women }\end{array}$ & $\begin{array}{l}\text { - Foster Rural Non Farm (RNF) Sector } \\
\text { - Strengthen key drivers of RNFE } \\
\text { growth } \\
\text { - Make market function better } \\
\text { - Increase women participation by } 15 \%\end{array}$ & $\begin{array}{l}\text { - BSCIC is providing training to } \\
\text { develop human resource in the non- } \\
\text { farm sector } \\
\text { - Credit facilities are given by BSCIC } \\
\text { for product promotion and business } \\
\text { expansion of RNF activities } \\
\text { - BSCIC is supporting preparation of } \\
\text { project proposal for entrepreneurs to } \\
\text { facilitate smooth business. } \\
\text { - Establishment of growth centres for } \\
\text { improvement of rural trade with } \\
\text { special focus on women. } \\
\text { - Provided training to } 214,826 \text { persons } \\
\text { and self employment to } 168,891 \\
\text { persons through Community Based } \\
\text { Resource Management. } \\
\text { - Generated employment through rural } \\
\text { road construction and earth work } \\
\text { - Work identified through PRA and } \\
\text { fund mobilized: } 31819 \text { person days. } \\
\text { - Need assessed and placed with BKB } \\
\text { for non farm loans: Tk. } 5 \text { core } \\
\text { - Formation of village based } \\
\text { organization } \\
\text { - Promotion of human resource } \\
\text { development through training } \\
\text { - Increased participation of women in } \\
\text { training on non-crop agriculture }\end{array}$ & $\begin{array}{l}\text { - Strengthen rural communication for fostering RNFA } \\
\text { - Give high priority to rural infrastructure and electrification with a focus on women } \\
\text { entrepreneurs } \\
\text { - Ensure capital formation through share and savings of the cooperatives } \\
\text { - Strengthen support to multi-purpose credit society such as MFI and improve rural financing } \\
\text { - Form cooperative service delivery organizations at the village level including women } \\
\text { - Develop local government institutions to support RNFA } \\
\text { - Promote business development service and product diversification for RNF sector focusing } \\
\text { on women's needs } \\
\text { - Explore domestic and international market for RNF product } \\
\text { - Pursue technology upgrade and strengthen vocational training with focus of women } \\
\text { - Encourage agro-processing and cottage industries by providing incentives particularly to } \\
\text { - } \text { women } \\
\text { - Drovide business advisory services to RNFP } \\
\text { - Facilitate women's access to new equipments for and knowledge about handicraft production } \\
\text { - Review periodically the lending policy of commercial banks and MFIs from a gender } \\
\text { - Create credit/special fund particularly for women in RNFA }\end{array}$ \\
\hline \multicolumn{3}{|c|}{ Sub-Total Indicative Cost (in billion taka) } & Tk. 10.20 \\
\hline \multicolumn{3}{|c|}{ Total Indicative Cost (in billion taka) } & Tk. 309.19 \\
\hline
\end{tabular}


Policy Matrix 12: Improving Knowledge Base: Education, Training, and Research

\begin{tabular}{|c|c|c|c|}
\hline Strategic Goals & Key Targets & Actions Taken/ Underway & PRSP Policy Agenda (2009-2011) \\
\hline 1 & 2 & 3 & 4 \\
\hline \multicolumn{4}{|c|}{ I. Early childhood and pre-school education } \\
\hline \multicolumn{4}{|c|}{ Lead Responsibility: MoPME, MoSW, MoWCA, MoLGRD\&C; NGO Affairs Bureau, NGOs } \\
\hline $\begin{array}{l}\text { 1. Introducing and strengthening early } \\
\text { childhood and pre-school education } \\
\text { (ECDP) }\end{array}$ & $\begin{array}{l}\text { - Introduce ECDP for all rural poor children in regular and } \\
\text { community schools for at least six months } \\
\text { - Introduce ECDP for the children in remote areas } \\
\text { - Ensure participation of parents in ECDP }\end{array}$ & $\begin{array}{l}\text { - Early childhood development programme } \\
\text { - Study for developing ECDP curriculum } \\
\text { - A number of national and international NGOs } \\
\text { have been working on community-based early } \\
\text { child care and development activities } \\
\text { - NPA for children is under preparation (MWCA) } \\
\text { aiming at children's right to growth and } \\
\text { development } \\
\text { - NPA and EFA are awaiting GoB's approval } \\
\text { aiming to introduce and promote ECD } \\
\text { programmes } \\
\text { - } 30,000 \text { Imams have been working as teachers in } \\
\text { pre primary education and the Holy Quran } \\
\text { learning } \\
\text { - Provide pre-school education among 9,000 Hill } \\
\text { Tracts children }\end{array}$ & $\begin{array}{l}\text { - Develop a core curriculum for ECDP to be used in all } \\
\text { ECDP centres } \\
\text { - Provide developmental care to children from birth } \\
\text { and provide it free to all urban and rural children } \\
\text { from poor families including indigenous groups } \\
\text { - Adopt a policy of encouraging preschools attached to } \\
\text { primary and community level schools to be operated } \\
\text { by the Government, NGOs and community } \\
\text { organizations } \\
\text { - Expand learning centres for children } \\
\text { - Introduce certificate course for pre-school teachers } \\
\text { - Introduce mid-day meal programme in the ECDP } \\
\text { centres } \\
\text { - Continue } 18,000 \text { mosque-based, } 2,687 \text { temple-based } \\
\text { pre primary education centres and } 12,000 \text { the Holy } \\
\text { Quran learning centres } \\
\text { - Expand mosque-based pre-primary education by } \\
\text { adding } 24,000 \text { centres by } 2013\end{array}$ \\
\hline \multicolumn{4}{|l|}{ II. Primary and Madrasha education } \\
\hline $\begin{array}{l}\text { 2. Introducing a unified and common } \\
\text { primary education opportunity for all } \\
\text { children }\end{array}$ & - Introduce unified education for all & $\begin{array}{l}\text { - Principle recognised and recommendations } \\
\text { made in NEC } 2003 \text { and other documents } \\
\text { - Revised curricula and learning materials focusing } \\
\text { on the foundation of functional literacy in } \\
\text { Bangla, numeracy skills (learning skills) and basic } \\
\text { life skills for all children }\end{array}$ & $\begin{array}{l}\text { - Continuation of ongoing programmes } \\
\text { - Revise primary education curriculum on a continuous } \\
\text { basis to make it unified and modernised }\end{array}$ \\
\hline 3. Increasing access to primary education & $\begin{array}{l}\text { - Increase net primary school enrolment rate to } 100 \text { percent } \\
\text { by } 2011 \\
\text { - Increase school attendance and completion rate to } 80 \\
\text { percent } \\
\text { - Increase completion of } 5 \mathrm{yr} \text { primary cycle from } 68 \text { to } 80 \\
\text { percent } \\
\text { - Introduce primary education for drop-out and left-out } \\
\text { children }\end{array}$ & $\begin{array}{l}\text { - A project offering basic education to } 350,000 \\
\text { urban working children is scheduled to be } \\
\text { completed this year } \\
\text { - A follow-up project has been undertaken } \\
\text { - A project to Reach Out of School Children } \\
\text { (ROSC) to serve } 500,000 \text { children through } \\
\text { community-based centres, NGO collaboration, } \\
\text { and incentives for children to attend is planned } \\
\text { - Implementation of Second Primary Education } \\
\text { Development Programme (2003-2009) PEDP-II } \\
\text { - An NPA for EFA with targets and strategies to } \\
\text { achieve internationally set goals for } 2015 \text { is } \\
\text { under preparation. }\end{array}$ & $\begin{array}{l}\text { - Improve infrastructure and other facilities of the } \\
\text { primary schools } \\
\text { - Make all classrooms inclusive for all children, i.e., } \\
\text { girls, children from indigenous groups, children with } \\
\text { disabilities } \\
\text { - Ensure necessary supports so that children with } \\
\text { disabilities (about } 10 \text { percent of the primary school } \\
\text { goers) can be a part of mainstream education } \\
\text { - Introduce programmes for providing education to } \\
\text { street and working children } \\
\text { - Increase the amount and coverage of stipend } \\
\text { programme for the students from poor families } \\
\text { - Introduce } 100 \text { percent subvention to registered and }\end{array}$ \\
\hline
\end{tabular}




\begin{tabular}{|c|c|c|c|}
\hline Strategic Goals & Key Targets & Actions Taken/ Underway & PRSP Policy Agenda (2009-2011) \\
\hline 1 & 2 & 3 & 4 \\
\hline & & $\begin{array}{l}\text { - } 71 \text { schools run by the Shishu Kallayan Trust } \\
\text { (Child Welfare Trust) provide formal primary } \\
\text { education and technical training to the under- } \\
\text { privileged working children } \\
\text { - School feeding programme under which a child } \\
\text { is provided with } 75 \text { grams of fortified biscuits in } \\
\text { eight poverty-stricken upazilas of three selected } \\
\text { districts to } 0.525 \text { million children. }\end{array}$ & $\begin{array}{l}\text { primary community school teachers in deserving cases } \\
\text { - Expand school feeding programme to } \\
\text { Adibashi/remote area schools all over the country } \\
\text { - Introduce teaching of mother tongues at the Pre-and } \\
\text { primary level for indigenous children }\end{array}$ \\
\hline $\begin{array}{l}\text { 4. Improving quality of education at } \\
\text { primary level }\end{array}$ & $\begin{array}{l}\text { - Introduce competency test after completion of five years } \\
\text { of primary cycle and provide completion certificate. } \\
\text { - Reduce teacher student ratio to :35 } \\
\text { - Improve competency so that more than } 70 \text { percent of } \\
\text { students who complete the } 5 \text {-year cycle of primary } \\
\text { education can pass the minimum competency test }\end{array}$ & $\begin{array}{l}\text { - Implementation of PEDP II } \\
\text { - Quality of education for three quarters of } \\
\text { primary school students being improved }\end{array}$ & $\begin{array}{l}\text { - Strengthen training and retraining programme for the } \\
\text { primary teachers on a continuous basis to improve } \\
\text { their pedagogical methods } \\
\text { - Ensure one primary school for every } 1500 \text { persons or } \\
\text { in places where students do not have to travel more } \\
\text { that } 2 \text { kilometres } \\
\text { - Apply quality standards like learning aids, and } \\
\text { involvement of the community in all primary } \\
\text { institutions } \\
\text { - Increase recruitment of female qualified teachers and } \\
\text { ensure safe housing facilities } \\
\text { - Ensure supply of teaching aid in the classroom for } \\
\text { making learning attractive to the students } \\
\text { - Improve and ensure maximum teacher-student } \\
\text { contact hours } \\
\text { - Introduce sports, cultural programmes, reading } \\
\text { competition etc. as extra curricular activities } \\
\text { - Undertake measures to improve the capacity of DPE, } \\
\text { BNFE, NAPE and NCTB } \\
\text { - Establish Primary Education Cadre }\end{array}$ \\
\hline $\begin{array}{l}\text { 5. Ensuring equality and equity in education } \\
\text { at the primary level }\end{array}$ & $\begin{array}{l}\text { - Ensure } 100 \text { percent enrolment of all children (boys and } \\
\text { girls) } \\
\text { - Sustain achieved gender equality }\end{array}$ & $\begin{array}{l}\text { - Cash for education is introduced for the children } \\
\text { of poor families } \\
\text { - GAD cell established at NCTB }\end{array}$ & $\begin{array}{l}\text { - Undertake community based efforts to encourage } \\
\text { families to send their children particularly girls to } \\
\text { schools } \\
\text { - Ensure incentive system so that children from poor } \\
\text { families do not dropout from primary education } \\
\text { - Make education life-oriented so that the guardians are } \\
\text { motivated to send children to school } \\
\text { - Introduce an equity (gender, ethnicity, disability etc. } \\
\text { aspects) and productivity oriented curriculum }\end{array}$ \\
\hline $\begin{array}{l}\text { 6. Improving quality of madrasha } \\
\text { education at the primary level }\end{array}$ & - Improve competency by 100 percent from current level & $\begin{array}{l}\text { - Madrasha Teachers' training programmes are } \\
\text { being implemented }\end{array}$ & $\begin{array}{l}\text { - Provide training to } 33 \text { percent of the Madrasha } \\
\text { teachers every year for } 3 \text { years } \\
\text { - Provide retaining on a continuous basis } \\
\text { - Harmonise curriculum of regular primary and } \\
\text { madrasha education } \\
\text { - Support modernization and quality improvement of } \\
\text { ibtidayee madrashas }\end{array}$ \\
\hline
\end{tabular}




\begin{tabular}{|c|c|c|c|}
\hline Strategic Goals & Key Targets & Actions Taken/ Underway & PRSP Policy Agenda (2009-2011) \\
\hline 1 & 2 & 3 & 4 \\
\hline 7. Improving primary school inspection & $\begin{array}{l}\text { - Every school should be subject to visit by inspection team } \\
6 \text { times a year }\end{array}$ & & $\begin{array}{l}\text { - Inspection team needs to meet with the teachers, } \\
\text { students and guardians } \\
\text { - Inspection needs to be further strengthened involving } \\
\text { representative of local government, member of SMCs } \\
\text { and member of local level NGOs or CBOs }\end{array}$ \\
\hline \multicolumn{4}{|c|}{ III. Secondary Education: General and Madrasha } \\
\hline \multicolumn{4}{|l|}{ Lead Responsibility: MoE, MoWCA } \\
\hline 8. Increasing access to secondary education & $\begin{array}{l}\text { - Increase gross enrolment rates by } 50 \text { percent for all levels } \\
\text { of secondary education. } \\
\text { - Gross enrolment for the junior secondary level should } \\
\text { increase from } 60 \text { percent to } 90 \text { percent; for the secondary } \\
\text { level it should increase from } 44 \text { percent to } 66 \text { percent and } \\
\text { for the higher secondary level it should increase from } 17 \\
\text { percent to } 25 \text { percent } \\
\text { - Reduce dropouts by half for general and madrasha } \\
\text { education at all levels } \\
\text { - Provide secondary education through residential schools } \\
\text { to } 6,600 \text { Hill Tracts students }\end{array}$ & $\begin{array}{l}\text { - SESIP (1999-2006) has been implemented } \\
\text { towards strengthening accountability in } \\
\text { management, enhancing quality and improving } \\
\text { equity of access } \\
\text { - Secondary Education Sector Development } \\
\text { Project (SESDP) has started in } 2007 \text { to enhance } \\
\text { quality by implementing the assessment and } \\
\text { examination reforms and improving equity of } \\
\text { access } \\
\text { - An English language teaching improvement } \\
\text { project (2nd phase) has been completed, and the } \\
\text { third phase has started } \\
\text { - Teaching Quality Improvement in Secondary } \\
\text { Education Project(TQI-SEP), a new project, is } \\
\text { under implementation } \\
\text { - A boost to female participation in secondary and } \\
\text { higher secondary level has been given by various } \\
\text { stipend projects } \\
\text { - PROMOTE project has been completed with } \\
\text { the aim at raising the ratio of female teachers in } \\
\text { secondary schools } \\
\text { - A Non-government Teachers' Registration and } \\
\text { Certification Agency (NTRCA) has been } \\
\text { established and started its activities } \\
\text { - School-based assessment (SBA) and Schools' } \\
\text { Performance Based Management System } \\
\text { (SPBMS) have been introduced to improve } \\
\text { learning assessment } \\
\text { - Secondary Education Quality and Access } \\
\text { Enhancement Project (SEQAEP) aims at } \\
\text { providing stipend to both girls and boys of } \\
\text { poor families is under implementation }\end{array}$ & $\begin{array}{l}\text { - Develop a sub-sector development programme for } \\
\text { the under-served groups } \\
\text { - Apply common minimum standards of inputs and } \\
\text { performance in all types of schools } \\
\text { - Increase resources linked to school performance, } \\
\text { student attendance; reduction of direct household } \\
\text { costs for the poor families } \\
\text { - Undertake quality improvement measures including } \\
\text { increased teachers' remuneration and incentives based } \\
\text { on performance; improved training and supervision of } \\
\text { teachers } \\
\text { - Introduce a common core curriculum for madrasha } \\
\text { and general education } \\
\text { - Ensure sufficient and improved supply of teaching- } \\
\text { learning materials } \\
\text { - Better assessment of student achievement } \\
\text { - Greater authority and accountability at the } \\
\text { institutional level } \\
\text { - Introduce stipends for boy students from poor } \\
\text { families to prevent dropouts } \\
\text { - Identify ways to discourage the practice of private } \\
\text { tutoring } \\
\text { - Introduce technology such as computer, internet, TV, } \\
\text { and radio to increase the reach of secondary education } \\
\text { - Bring new educational institutions under MPO system } \\
\text { - Establish more secondary schools in capital city }\end{array}$ \\
\hline $\begin{array}{l}\text { 9. Improving quality of education at } \\
\text { secondary level }\end{array}$ & $\begin{array}{l}\text { - Improve SSC pass rate from } 60 \text { percent to } 75 \text { percent and } \\
\text { the HSC pass rate from } 64 \text { percent to } 80 \text { percent both for } \\
\text { male and female students } \\
\text { - Change and modernize competency test examination } \\
\text { structure (SSC, HSC) }\end{array}$ & $\begin{array}{l}\text { - Government has taken the decision to change } \\
\text { SSC and HSC examination structure and will } \\
\text { start piloting it in class VIII exam this year }\end{array}$ & $\begin{array}{l}\text { - Provide effective teaching aid including access to } \\
\text { computer facilities to the teachers } \\
\text { - Improve benefit package for teachers in general with } \\
\text { special package for certain subjects (math, English, } \\
\text { and science subjects) and rural and remote areas }\end{array}$ \\
\hline
\end{tabular}




\begin{tabular}{|c|c|c|c|}
\hline Strategic Goals & Key Targets & Actions Taken/ Underway & PRSP Policy Agenda (2009-2011) \\
\hline 1 & 2 & 3 & 4 \\
\hline & $\begin{array}{l}\text { - Reduce teacher student ratio from 1:60 to 1:40 } \\
\text { - Ensure maximum teacher student contact hour per week }\end{array}$ & & $\begin{array}{l}\text { - Improve learning environment by developing } \\
\text { infrastructure. } \\
\text { - Ensure quality production and timely supply of } \\
\text { textbooks } \\
\text { - Introduce sports, cultural events, debate competitions, } \\
\text { book reading competition etc. for the students } \\
\text { - Consider abolishing science, commerce and } \\
\text { humanities streams and develop a common } \\
\text { curriculum up to class X } \\
\text { - Establish separate service commission for teachers } \\
\text { - Establish model secondary schools at all upazillas } \\
\text { - Establish permanent pay commission for teachers }\end{array}$ \\
\hline 10. Revising curriculum on a regular basis & $\begin{array}{l}\text { - Revise and modernize textbooks and curriculum every } \\
\text { three years }\end{array}$ & $\begin{array}{l}\text { - Some attention has been given to make } \\
\text { curriculum and textbooks free of gender biases }\end{array}$ & $\begin{array}{l}\text { - Intensify work on gender stereotyping of social and } \\
\text { cultural roles }\end{array}$ \\
\hline $\begin{array}{l}\text { 11. Ensuring a gender balance in the } \\
\text { formulation of curriculum }\end{array}$ & $\begin{array}{l}\text { - Revise and upgrade curriculum to remove negative images } \\
\text { if any and ensure presence of positive images of women } \\
\text { and household activities in the curriculum }\end{array}$ & $\begin{array}{l}\text { - Environmental issues are included in secondary } \\
\text { curriculum }\end{array}$ & $\begin{array}{l}\text { - Continue curriculum, textbook and learning materials } \\
\text { review and development }\end{array}$ \\
\hline $\begin{array}{l}\text { 12. Ensuring gender parity in Secondary } \\
\text { Education }\end{array}$ & $\begin{array}{l}\text { - Male female student enrolment ratios become equal at all } \\
\text { levels } \\
\text { - Ensure gender equality in enrolment and completion rates } \\
\text { - Reduce dropout rate by } 50 \text { percent among girls at all } \\
\text { secondary levels }\end{array}$ & $\begin{array}{l}\text { - Recruitment criteria have been relaxed for } \\
\text { women } \\
\text { - PROMOTE project encouraged women's } \\
\text { recruitment in secondary school teaching (at } \\
\text { least } 30 \% \text { ) } \\
\text { - Nationwide female stipend programme for both } \\
\text { secondary and higher secondary levels has been } \\
\text { introduced } \\
\text { - A stipend programme is being processed to } \\
\text { address poor male and female students in } \\
\text { metropolitan areas } \\
\text { - Higher secondary level girls are being provided } \\
\text { stipends in all over the country }\end{array}$ & $\begin{array}{l}\text { - Make classroom environment and schools facilities } \\
\text { girl friendly } \\
\text { - Continue affirmative action to increase female ratio in } \\
\text { teaching and management positions } \\
\text { - Introduce stipend programme for female secondary } \\
\text { students from poor urban families } \\
\text { - Undertake a project to establish toilet and drinking } \\
\text { water facilities in all secondary schools } \\
\text { - Introduce school transportation facilities / allowance } \\
\text { for girl students } \\
\text { - Build hostel facilities for girl students } \\
\text { - Reduce leakages in female secondary school } \\
\text { scholarship }\end{array}$ \\
\hline $\begin{array}{l}\text { 13. Improving enrolment, attendance and } \\
\text { completion rate of students of poor } \\
\text { families }\end{array}$ & $\begin{array}{l}\text { - Identify drop-out rate among students from poor families } \\
\text { - Ensure drop-out rate to decline by } 50 \text { percent for students } \\
\text { from poor families }\end{array}$ & $\begin{array}{l}\text { - Pro-poor targeting stipend projects addressing } \\
\text { both poor girls and boys are going to be } \\
\text { undertaken }\end{array}$ & $\begin{array}{l}\text { - Introduce and expand pro-poor stipend programme } \\
\text { for male and female secondary students from poor } \\
\text { families. }\end{array}$ \\
\hline $\begin{array}{l}\text { 14. Ensuring } 80 \% \text { common curriculum of } \\
\text { Madrasha and general education }\end{array}$ & $\begin{array}{l}\text { - Revise and introduce new Madrasha curriculum within } \\
\text { next two years }\end{array}$ & & $\begin{array}{l}\text { - Establish commission for re-orientation of madrasha } \\
\text { education }\end{array}$ \\
\hline $\begin{array}{l}\text { 15. Improving the quality of Madrasha } \\
\text { education }\end{array}$ & $\begin{array}{l}\text { - Provide training to } 33 \text { percent of the Madrasha teachers } \\
\text { every year for } 3 \text { years }\end{array}$ & & $\begin{array}{l}\text { - Introduce accreditation system for the private schools } \\
\text { and create a competitive environment that will lead to } \\
\text { improved performance of the MPO schools }\end{array}$ \\
\hline $\begin{array}{l}\text { 16. Making Madrasha education job market } \\
\text { oriented }\end{array}$ & $\begin{array}{l}\text { - Introduce technical education in } 10 \text { percent schools on a } \\
\text { pilot basis. }\end{array}$ & & $\begin{array}{l}\text { - Develop vocational education curriculum for } \\
\text { Madrasha education }\end{array}$ \\
\hline
\end{tabular}




\begin{tabular}{|c|c|c|c|}
\hline Strategic Goals & Key Targets & Actions Taken/ Underway & PRSP Policy Agenda (2009-2011) \\
\hline 1 & 2 & 3 & 4 \\
\hline \multicolumn{4}{|c|}{ IV. Technical and Vocational Education and Training (TVET) } \\
\hline \multicolumn{4}{|c|}{ Lead Responsibility: MoSW , MoE, MoLE, MoWCA, MoPME, MOYS, MoTJ } \\
\hline $\begin{array}{l}\text { 17. Introducing and expanding TVET for } \\
\text { adolescents, young adults and adult males } \\
\text { and females and make provision for TVET } \\
\text { after class vi, vii and equivalent grades }\end{array}$ & $\begin{array}{l}\text { - Increase enrolment by } 50 \text { percent } \\
\text { - Ensure three extensive monitoring and supervision of all } \\
\text { institutions every year } \\
\text { - Build six nursing training institutes in six divisions }\end{array}$ & $\begin{array}{l}\text { - Both men and women are receiving skill training } \\
\text { from BITAC on } 26 \text { trades. About } 10 \% \\
\text { participants are women in all training courses } \\
\text { - BSCIC through Design Centres is offering } \\
\text { regular skill training on different trades to } \\
\text { develop entrepreneurship and self-employment } \\
\text { - Skill training is also being given at district level } \\
\text { by undertaking new projects by BITAC } \\
\text { - 2nd shift programme in the technical and } \\
\text { vocational institute are running from academic } \\
\text { session 2004-2005 }\end{array}$ & $\begin{array}{l}\text { - Establish residential/non-residential TVET institutes } \\
\text { in under served districts and areas } \\
\text { - Ensure sufficient equipments and facilities for all } \\
\text { students to have effective practical experiences } \\
\text { - Provide training of the teachers including foreign } \\
\text { training to improve their quality } \\
\text { - Introduce course for medical technicians } \\
\text { - Design and introduce in collaboration with NGOs } \\
\text { and entrepreneurs, modular course in income } \\
\text { generating and self-employment skills linked to local } \\
\text { market prospects for underprivileged groups including } \\
\text { girls and women } \\
\text { - Provide support to skill development in the informal } \\
\text { sector } \\
\text { - Improve coordination and develop a common policy } \\
\text { and regulatory framework among various public and } \\
\text { private sector (including NGOs) providers of TVET } \\
\text { - Formalise informal sector by providing GOB support } \\
\text { through technical, financial and infrastructure } \\
\text { assistance } \\
\text { - Introduce and expand ICT Training including } \\
\text { hardware and software development } \\
\text { - Formalise informal sector's training institutions by } \\
\text { providing GOB support through technical, financial } \\
\text { and infrastructure assistance } \\
\text { - Set up technical institutes in each upazila }\end{array}$ \\
\hline $\begin{array}{l}\text { 18. Introducing vocational training for } \\
\text { boys and girls after completion of primary } \\
\text { cycle }\end{array}$ & $\begin{array}{l}\text { - Ensure catching } 50 \% \text { of the primary graduates (boys and } \\
\text { girls) not going to secondary level. }\end{array}$ & & $\begin{array}{l}\text { - Undertake need assessment and mapping exercise for } \\
\text { identifying areas where to establish vocational } \\
\text { institutes }\end{array}$ \\
\hline $\begin{array}{l}\text { 19. Increasing female participation in } \\
\text { vocational, and technical education }\end{array}$ & - Increase female enrolment by 60 percent & $\begin{array}{l}\text { - Establishment of three new polytechnic } \\
\text { institutes for women } \\
\text { - Establishment of six more Technical School \& } \\
\text { College for girls is underway } \\
\text { - Programme is being taken to set up more } \\
\text { polytechnic institutes for women } \\
\text { - } 30 \% \text { seats are reserved for female participants in } \\
\text { all training course }\end{array}$ & $\begin{array}{l}\text { - Introduce female stipend programme for TVET } \\
\text { education for all students } \\
\text { - Introduce measures (tuition fee waiver, placemen } \\
\text { facilities etc.) to attract larger female entrance into } \\
\text { under-represented fields } \\
\text { - Introduce measures such as residential facilities to } \\
\text { attract larger female entrance } \\
\text { - Adopt measures and targets for teaching and } \\
\text { management positions in vocational, technical, tertiary } \\
\text { professional education. }\end{array}$ \\
\hline
\end{tabular}




\begin{tabular}{|c|c|c|c|}
\hline Strategic Goals & Key Targets & Actions Taken/ Underway & PRSP Policy Agenda (2009-2011) \\
\hline 1 & 2 & 3 & 4 \\
\hline $\begin{array}{l}\text { 20. Providing market-related effective } \\
\text { education linked to the industrial sector } \\
\text { both in the domestic and international } \\
\text { market }\end{array}$ & $\begin{array}{l}\text { - Graduates find jobs within shortest possible time (6 } \\
\text { months of graduation) }\end{array}$ & $\begin{array}{l}\text { - Skill development project under the assistance } \\
\text { of ADB already taken to make TVET more } \\
\text { relevant and responsive to the job market } \\
\text { - EU and ILO expressed interest in making } \\
\text { TVET more relevant }\end{array}$ & $\begin{array}{l}\text { - Review TVET curriculum and course of all TVET } \\
\text { providers } \\
\text { - Involve business communities in designing of course } \\
\text { offerings and develop and revise curriculum and } \\
\text { course offerings based on market demand } \\
\text { - Introduce apprenticeship, job placement etc. in } \\
\text { collaboration with the private sector } \\
\text { - Upgrade curriculum and equipments in the VT } \\
\text { institutes }\end{array}$ \\
\hline $\begin{array}{l}\text { 21. Raise the percentage of vocational and } \\
\text { technical graduates obtaining employment } \\
\text { in the domestic and international markets }\end{array}$ & $\begin{array}{l}\text { - Ensure that } 80 \text { percent of the graduates gets jobs within } \\
\text { six months of graduation }\end{array}$ & $\begin{array}{l}\text { - Quality Manual has been developed to improve } \\
\text { academic and administrative activities of the } \\
\text { TVET institutes } \\
\text { - Monitoring activities of TVET has been } \\
\text { increased } \\
\text { - Skill training of TVET teachers is continuing }\end{array}$ & $\begin{array}{l}\text { - Develop job bank and placement service for graduates } \\
\text { of the technical and vocational graduates } \\
\text { - Develop network with the trade bodies and human } \\
\text { resource export agencies } \\
\text { - Introduce training provider's agreements with } \\
\text { industries, companies and NGOs } \\
\text { - Develop competency based training and training } \\
\text { standards } \\
\text { - Revitalise Technical Teachers Training College in } \\
\text { Dhaka and Vocational Teachers Training Institute in } \\
\text { Bogra } \\
\text { - Introduce short training course for teachers and } \\
\text { technical staff in specific skill areas/industries } \\
\text { - Strengthen teachers' training for TVET } \\
\end{array}$ \\
\hline \multicolumn{4}{|l|}{ V. Tertiary Education } \\
\hline \multicolumn{4}{|c|}{ Lead Responsibility: MoE, UGC, NAEM, Public and Private Universities, MoTJ } \\
\hline $\begin{array}{l}\text { 22. Increase opportunities and facilities of } \\
\text { higher education }\end{array}$ & $\begin{array}{l}\text { - Establish universities in Barisal, Rangamati and } \\
\text { Gopalganj }\end{array}$ & $\begin{array}{l}\text { - Universities in Jessore, Pabna and Rangpur are } \\
\text { operational }\end{array}$ & $\begin{array}{l}\text { - Build medical and engineering colleges / universities } \\
\text { in underserved areas } \\
\text { - Build nursing institutes in all divisions and old } \\
\text { districts } \\
\text { - Revise and develop modern nursing training } \\
\text { curriculum } \\
\text { - Enhance infrastructural facilities in established } \\
\text { universities } \\
\text { - Provide free education up to degree level } \\
\text { - Enhance budgetary allocation to education sector. } \\
\text { Current allocation ( } 2.5 \% \text { of GDP) must be raised to } \\
\text { the developing country average level of } 4.5 \% \text { of GDP } \\
\text { by } 2011\end{array}$ \\
\hline $\begin{array}{l}\text { 23. Increasing enrolment of male and } \\
\text { female students in professional degree } \\
\text { education }\end{array}$ & $\begin{array}{l}\text { - Increase enrolment of male and female students by } 50 \\
\text { percent in professional degree education }\end{array}$ & $\begin{array}{l}\text { - Programme planned for improvement of } \\
\text { infrastructure like teaching aid, research facilities } \\
\text { for different public universities }\end{array}$ & $\begin{array}{l}\text { - Give preferential consideration for admission of } \\
\text { female students } \\
\text { - Introduce } 5 \text { percent quota provision for female } \\
\text { students }\end{array}$ \\
\hline
\end{tabular}




\begin{tabular}{|c|c|c|c|}
\hline Strategic Goals & Key Targets & Actions Taken/ Underway & PRSP Policy Agenda (2009-2011) \\
\hline 1 & 2 & 3 & 4 \\
\hline $\begin{array}{l}\text { 24. Ensuring gender equality in higher } \\
\text { education }\end{array}$ & - Ensure that 40 percent of university students are women & $\begin{array}{l}\text { - Establishing an international university for } \\
\text { women in Chittagong }\end{array}$ & $\begin{array}{l}\text { - Introduce higher number of merit scholarship for } \\
\text { female students } \\
\text { - Build hostel facilities for female students } \\
\text { - Recruit more women faculties and ensure } \\
\text { accommodation facilities for them particularly in } \\
\text { universities out of metropolitan cities. } \\
\text { - Introduce stipend programme for } 30 \text { percent female } \\
\text { students from poor families }\end{array}$ \\
\hline $\begin{array}{l}\text { 25. Creating greater opportunities for the } \\
\text { students from poor families }\end{array}$ & $\begin{array}{l}\text { - Ensure } 30 \text { percent of university students are from poor } \\
\text { families }\end{array}$ & & $\begin{array}{l}\text { - Introduce merit based scholarship for the students } \\
\text { from poor families } \\
\text { - Introduce stipend programme for } 100 \text { percent } \\
\text { students from poor families } \\
\text { - Make education free for students from poor families } \\
\text { - Introduce provision for education loans from public } \\
\text { and private sources } \\
\text { - Introduce a rule for the private universities to provide } \\
\text { free education to } 10 \text { percent of the students from } \\
\text { poor families }\end{array}$ \\
\hline $\begin{array}{l}\text { 26. Achieving better balance in enrolment } \\
\text { among humanities, applied and pure } \\
\text { sciences and technology and commerce }\end{array}$ & $\begin{array}{l}\text { - } 50 \text { percent increase in enrolment of both boys and girls in } \\
\text { non-humanities subjects and professional areas }\end{array}$ & $\begin{array}{l}\text { - Proposal has already been initiated to strengthen } \\
\text { commerce and science departments }\end{array}$ & $\begin{array}{l}\text { - Build capacity in providing education in the area of } \\
\text { applied and pure sciences and technology and } \\
\text { commerce }\end{array}$ \\
\hline $\begin{array}{l}\text { 27. Improving the examination } \\
\text { performance of the general undergraduate } \\
\text { and graduate students }\end{array}$ & $\begin{array}{l}\text { - Pass rates in degree and master's examinations need to } \\
\text { improve by } 50 \text { percent }\end{array}$ & & $\begin{array}{l}\text { - Ensure teacher's presence in the campus by the } \\
\text { management } \\
\text { - Introduce and strengthen teachers training } \\
\text { programme } \\
\text { - Make training compulsory and link it to career } \\
\text { development }\end{array}$ \\
\hline $\begin{array}{l}\text { 28. Strengthening the knowledge generation } \\
\text { role of the universities }\end{array}$ & $\begin{array}{l}\text { - Link promotion and career development with research } \\
\text { and publications }\end{array}$ & $\begin{array}{l}\text { - UGC appoints a small working group with } \\
\text { researchers from public and private universities } \\
\text { to: } \\
\text { - Compile the list of publications of all } \\
\text { universities in the past ten years } \\
\text { - Develop standards of publications } \\
\text { - Recommend policy measures to ensure } \\
\text { budgetary allocations to support research } \\
\text { - Work out standard number of hours that } \\
\text { university teachers ought to teach and to } \\
\text { generate research publications }\end{array}$ & $\begin{array}{l}\text { - Create research endowment fund in collaboration } \\
\text { with private sector, university alumni and } \\
\text { development partners } \\
\text { - Create a research fund for undertaking action research } \\
\text { by faculties of Universities / colleges } \\
\text { - Link promotion to research activities undertaken and } \\
\text { publication by the teachers at the tertiary level }\end{array}$ \\
\hline $\begin{array}{l}\text { 29. Introducing opportunities for } \\
\text { continuing education at higher level }\end{array}$ & $\begin{array}{l}\text { - } 5 \text { percent of total students in higher education are } \\
\text { returning or restarting students }\end{array}$ & & $\begin{array}{l}\text { - Introduce rules for entering or re-entering into higher } \\
\text { education for those who dropped out, took a break } \\
\text { and want to continue } \\
\text { - Introduce provision of distance learning for } \\
\text { continuing education. Use of ICT, TV and }\end{array}$ \\
\hline
\end{tabular}




\begin{tabular}{|c|c|c|c|}
\hline Strategic Goals & Key Targets & Actions Taken/ Underway & PRSP Policy Agenda (2009-2011) \\
\hline 1 & 2 & 3 & 4 \\
\hline & & & community radio can be considered. \\
\hline $\begin{array}{l}\text { 30. Increasing internal efficiency of public } \\
\text { sector higher education }\end{array}$ & $\begin{array}{l}\text { - Achieve parity with regional standards in tertiary education } \\
\text { - Make the National University effective }\end{array}$ & $\begin{array}{l}\text { - Apply full quality-criteria to all tertiary } \\
\text { educational institutions }\end{array}$ & $\begin{array}{l}\text { - UGC will take an initiative to identify effective } \\
\text { mechanism for monitoring of performance in higher } \\
\text { education } \\
\text { - Introduce a system of review and revision of } \\
\text { curriculum every four-five years consistent with } \\
\text { regional standard }\end{array}$ \\
\hline $\begin{array}{l}\text { 31.Increasing cost recovery in higher } \\
\text { education }\end{array}$ & $\begin{array}{l}\text { - Increase university fees and accommodation cost every } \\
\text { year keeping in view the rate of inflation in the country }\end{array}$ & & $\begin{array}{l}\text { - Undertake consultation with various stakeholders to } \\
\text { build consensus on this issue } \\
\text { - Mobilize funds in terms of donations from private } \\
\text { sectors, alumni and foreign donations }\end{array}$ \\
\hline \multicolumn{4}{|l|}{ VI. Literacy and Non-formal Education } \\
\hline \multicolumn{4}{|c|}{ Lead Responsibility: MoPME, MoWCA, MoLGRD\&C, NGO Affairs Bureau, NGOs } \\
\hline 32. Increasing effective literacy rate & $\begin{array}{l}\text { - Increase literacy rate from about } 53 \text { percent to } 100 \text { percent } \\
\text { by } 2014 \text {. }\end{array}$ & $\begin{array}{l}\text { - A Non-formal Education Policy has been } \\
\text { finalised } \\
\text { - Bureau of Non-formal Education has been } \\
\text { established for management and governance of } \\
\text { the NFE sub-sector. } \\
\text { - Basic Education for Hard to Reach Urban } \\
\text { Working Children" is under implementation. } \\
\text { Post-literacy and Continuing Education I Project } \\
\text { has been completed. }\end{array}$ & $\begin{array}{l}\text { - Build a nationwide network of community-based, } \\
\text { community-managed and multi-purpose non-formal } \\
\text { and adult learning centres } \\
\text { - Develop parental continuing education opportunities } \\
\text { and make it accessible through the network of } \\
\text { community learning centres } \\
\text { - Involve beneficiaries in planning and managing } \\
\text { programmes } \\
\text { - Improve women's participation by encouraging them, } \\
\text { promoting representation of women in management } \\
\text { and engendering the teaching content }\end{array}$ \\
\hline $\begin{array}{l}\text { 33. Expanding the scope of non-formal } \\
\text { education beyond the literacy movement on } \\
\text { a pilot basis particularly targeted at the } \\
\text { extreme poor and remote areas }\end{array}$ & $\begin{array}{l}\text { - Ensure non-formal education with life skill for fifty } \\
\text { percent of the illiterate }\end{array}$ & $\begin{array}{l}\text { - Education Project II is under implementation. } \\
\text { It will cover } 1.6 \text { million neo-literates in } 29 \\
\text { districts. Under the project, literacy and income- } \\
\text { earning skills will be provided } \\
\text { - Two post-literacy and continuing education } \\
\text { project targeting three million potential clients } \\
\text { are designed to combine training in literacy and } \\
\text { income-earning skills }\end{array}$ & $\begin{array}{l}\text { - Assess the size and locational concentration of } \\
\text { illiterate population } \\
\text { - Ensure equivalency between formal and non-formal } \\
\text { education } \\
\text { - Link of the second chance programmes with skill } \\
\text { development and formal education } \\
\text { - Target marginal sections of the population to address } \\
\text { their specific needs } \\
\text { - Undertake targeted social mobilization in NFE area to } \\
\text { support participation of stakeholders }\end{array}$ \\
\hline \multicolumn{4}{|l|}{ VII. Education Governance } \\
\hline \multicolumn{4}{|c|}{ Lead Responsibility: MoE, MoPME, MoWCA, NCTB, MoLE } \\
\hline 34. Strengthening education governance & $\begin{array}{l}\text { - Undertake monitoring and supervision of all educational } \\
\text { institutes by authority every } 3 \text { months on a regular basis } \\
\text { - All institutions at secondary, vocational and tertiary level } \\
\text { should be rated by private agencies } \\
\text { - Develop a longer term (2015) perspective for educational } \\
\text { development and reform that provide the context and } \\
\text { framework for short-term and medium-term actions }\end{array}$ & $\begin{array}{l}\text { - Some monitoring and academic institution } \\
\text { inspection mechanism is in place whose } \\
\text { effectiveness needs improvement } \\
\text { - Performance based incentive like sanction of } \\
\text { academic building, scientific equipment, } \\
\text { teaching aid, library etc. have been initiated. }\end{array}$ & $\begin{array}{l}\text { - Strengthen monitoring mechanism and develop } \\
\text { criteria for monitoring performance of the } \\
\text { institutions, management, teachers and students } \\
\text { - Develop monitoring and supervision criteria for all } \\
\text { levels of education } \\
\text { - Effective coordination in education sector for Human } \\
\text { Development }\end{array}$ \\
\hline
\end{tabular}




\begin{tabular}{|c|c|c|c|}
\hline Strategic Goals & Key Targets & Actions Taken/ Underway & PRSP Policy Agenda (2009-2011) \\
\hline 1 & 2 & 3 & 4 \\
\hline & - Decentralize educational planning and management & & $\begin{array}{l}\text { - Greater decentralization of educational planning and } \\
\text { management } \\
\text { - Increased, targeted and managed allocation of } \\
\text { resources for access with equity and quality in } \\
\text { education } \\
\text { - Rating agency needs to make this information } \\
\text { available to the public } \\
\text { - Take an initiative to publish a book on rules and } \\
\text { regulations applicable to MPO schools and also make } \\
\text { this available on the website } \\
\text { - Provide management training at different levels of } \\
\text { education } \\
\text { - Strengthen the SMCs by depoliticizing them. The } \\
\text { members need to fulfil well defined criteria such as } \\
\text { education, social involvement, standing in the } \\
\text { community etc. } \\
\text { - Develop policy, delegate authority and accountability } \\
\text { at district, upazila, local and institution levels } \\
\text { - Develop an action plan for implementing this policy } \\
\text { - Establish a permanent National Commission on } \\
\text { Education for pre-tertiary education answerable to the } \\
\text { Parliamentary standing Committee on Education and } \\
\text { also to the parliament }\end{array}$ \\
\hline $\begin{array}{l}\text { 35. Reducing education divides in terms of } \\
\text { content and standard between different } \\
\text { streams }\end{array}$ & $\begin{array}{l}\text { - Reduce education divides in term of contents between } \\
\text { general and madrasha, and between Bengali and English } \\
\text { medium schools } \\
\text { - Reduce education divides in terms of standard between urban } \\
\text { and rural school, and between public and private schools } \\
\end{array}$ & & $\begin{array}{l}\text { - Undertake a survey to identify the degree and extent } \\
\text { of educational divides between different streams } \\
\text { - Prepare an action plan to reduce education divides } \\
\text { between different streams }\end{array}$ \\
\hline $\begin{array}{l}\text { 36. Reducing disparity between over-served } \\
\text { and underserved areas and between rural } \\
\text { and urban areas }\end{array}$ & $\begin{array}{l}\text { - Complete building schools, colleges technical institutes } \\
\text { and universities in more than } 50 \% \text { of the underserved } \\
\text { areas } \\
\text { - Complete building and repairing of all schools and } \\
\text { colleges in the cyclone "Sidr" affected areas }\end{array}$ & $\begin{array}{l}\text { - School mapping is already done } \\
\text { - Primary schools have their own guidelines }\end{array}$ & $\begin{array}{l}\text { - Build educational institutes for various levels and } \\
\text { kinds of education in the underserved areas } \\
\text { - Build residential facilities for students, teachers and } \\
\text { staff for educational institutes in the remote areas }\end{array}$ \\
\hline $\begin{array}{l}\text { 37. Reducing corruption and system-loss in } \\
\text { education }\end{array}$ & $\begin{array}{l}\text { - Reduce leakages in the school subvention and stipend } \\
\text { payments by } 75 \text { percent } \\
\text { - Inspection must take place every two months for the } \\
\text { secondary schools, three times for the degree college and } \\
\text { twice a year for universities and professional institutes }\end{array}$ & $\begin{array}{l}\text { - Performance based subvention at the secondary } \\
\text { level has already been introduced }\end{array}$ & $\begin{array}{l}\text { - Strengthen monitoring and inspection system for all } \\
\text { levels and kinds of educational institutes } \\
\text { - Create monitoring and inspection provisions by } \\
\text { creating a local level committee involving local } \\
\text { stakeholders } \\
\text { - Introduce monitoring and inspection by local level } \\
\text { stakeholders } \\
\text { - Develop a code of conduct for the teachers and } \\
\text { include that in their training programme } \\
\text { - Develop a guide about the rights and entitlements for } \\
\text { the students and their families }\end{array}$ \\
\hline
\end{tabular}




\begin{tabular}{|c|c|c|c|}
\hline Strategic Goals & Key Targets & Actions Taken/ Underway & PRSP Policy Agenda (2009-2011) \\
\hline 1 & 2 & 3 & 4 \\
\hline 38. Improving the quality of teachers & - All teachers will be trained and certified & - Teacher training is already in place & $\begin{array}{l}\text { - Teacher training must be mandatory every two years } \\
\text { and training capacity must be strengthened } \\
\text { - Link salary increase, and promotion of teachers to } \\
\text { performance at all levels of education } \\
\text { - Performance evaluation criteria and system needs to } \\
\text { be defined in a transparent manner and needs to } \\
\text { include students evaluation of the teachers }\end{array}$ \\
\hline $\begin{array}{l}\text { 39. Strengthening financial management of } \\
\text { all educational institutions }\end{array}$ & $\begin{array}{l}\text { - Every institution needs to produce an annual audit report } \\
\text { and submit to the management } \\
\text { - Every educational institute needs to develop an annual } \\
\text { budget and be approved by relevant management } \\
\text { authorities }\end{array}$ & & $\begin{array}{l}\text { - Annual financial auditing needs to take place for all } \\
\text { educational institutes by private auditors } \\
\text { - Make mandatory for all schools to have annual budget } \\
\text { and it approved by SMC } \\
\text { - Revised and improved education package under } \\
\text { PEDP II will be piloted in } 2010 \\
\text { - Provide reward for group performance } \\
\end{array}$ \\
\hline $\begin{array}{l}\text { 40. Enhancing resource mobilisation by all } \\
\text { educational institutes }\end{array}$ & $\begin{array}{l}\text { - Public universities and higher level professional institutes } \\
\text { need to mobilize } 20 \text { percent of total funds from private } \\
\text { sector and donors }\end{array}$ & & $\begin{array}{l}\text { - Make it mandatory for the management to undertake } \\
\text { initiatives for raising funds from non-government } \\
\text { sources }\end{array}$ \\
\hline \multicolumn{4}{|l|}{ VIII. Continuing Training } \\
\hline \multicolumn{4}{|c|}{ Lead Responsibility: MoE, UGC, Public and Private Universities } \\
\hline $\begin{array}{l}\text { 41. Creating opportunities for continuing } \\
\text { education and training }\end{array}$ & $\begin{array}{l}\text { - Introduce provision for knowledge and skills to be } \\
\text { updated }\end{array}$ & $\begin{array}{l}\text { - Some private universities introduced limited } \\
\text { provisions for continuing education in selected } \\
\text { areas }\end{array}$ & $\begin{array}{l}\text { - Introduce courses on need based skill retraining } \\
\text { programmes in the already existing educational } \\
\text { institutes in the evenings }\end{array}$ \\
\hline $\begin{array}{l}\text { 42. Expanding language courses particularly } \\
\text { English/Arabic etc. }\end{array}$ & - Introduce provision for language courses to be updated & $\begin{array}{l}\text { - Various embassies and private organizations } \\
\text { offer language courses } \\
\text { - Foreign Language Laboratory has been set up in } \\
\text { selected } 11 \text { colleges / centres. } \\
\text { - English Language Teaching Improvement } \\
\text { Project (ELTIP) is being implemented } \\
\end{array}$ & $\begin{array}{l}\text { - Provide government financial support to the private } \\
\text { language teaching institutions on the basis of their } \\
\text { performance } \\
\text { - Improve the language programmes in the public } \\
\text { universities }\end{array}$ \\
\hline \multicolumn{4}{|l|}{ IX. Building Research Capacity } \\
\hline \multicolumn{4}{|c|}{ Lead Responsibility: MoE, UGC, Public and Private Universities and Degree Colleges, Government and Private Think-Tanks } \\
\hline $\begin{array}{l}\text { 43. Creating of new knowledge and } \\
\text { information }\end{array}$ & & & $\begin{array}{l}\text { - Strengthen writing of term-paper, thesis and } \\
\text { dissertation in the curriculum of tertiary education } \\
\text { - Create a national endowment of undertaking action- } \\
\text { based and result-oriented research } \\
\text { - Encourage research among the teachers of tertiary } \\
\text { education and link it to promotion } \\
\text { - Develop BIDS as the think tank of the government } \\
\text { - Encourage establishment of / formation of private } \\
\text { sector think tank/research organizations } \\
\text { - Develop and strengthen BBS as an independent } \\
\text { competent and functional organization }\end{array}$ \\
\hline \multicolumn{3}{|l|}{ Total Indicative Cost (in billion taka) } & Tk. 582.30 \\
\hline
\end{tabular}


Policy Matrix 13: Health, Nutrition, Population, and Food Safety

\begin{tabular}{|c|c|c|c|}
\hline Strategic Goals & Key Targets & Actions Taken/ Underway & PRSP Policy Agenda (2009-2011) \\
\hline 1 & 2 & 3 & 4 \\
\hline \multicolumn{4}{|c|}{ Lead Responsibility: DGHS and DGFP Associate Responsibility: MOHFW, MOLGRD\&C, LGIs, UPHCP, SSFP, MOP\&ME, M/O Education, MOSW, NGOs, CBOs, CSOs } \\
\hline $\begin{array}{l}\text { 1. Improve Child } \\
\text { Health }\end{array}$ & $\begin{array}{l}\text { - Reduce Infant Mortality Rate per } 1000 \text { Live Births from } \\
52 \text { in } 2007 \text { to } 37 \text { in } 2011 \\
\text { - Reduce Under } 5 \text { Mortality Rate per } 1000 \text { Live Births } \\
\text { from } 65 \text { in } 2007 \text { to } 52 \text { in } 2011\end{array}$ & $\begin{array}{l}\text { - Essential Services Delivery } \\
\text { - Expanded Programme on Immunization } \\
\text { - Control of Acute Respiratory Tract Infection } \\
\text { - Control of Diarrhoeal Diseases } \\
\text { - Integrated Management of Childhood Illness } \\
\text { - School Health services } \\
\text { - Limited curative care } \\
\text { - Updated National Health Policy } \\
\text { - National Nutrition Program }\end{array}$ & $\begin{array}{l}\text { - Further strengthening of EPI } \\
\text { - Full coverage of facility IMCI } \\
\text { - Further strengthening of control of ARI and DD } \\
\text { - Strengthening ESD } \\
\text { - Continuation of HNPSP till } 2011 \\
\text { - National Health Policy will be re-evaluated and adjusted }\end{array}$ \\
\hline \multicolumn{4}{|c|}{ 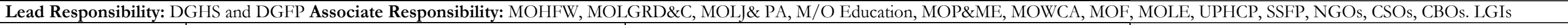 } \\
\hline $\begin{array}{l}\text { 2. Improve maternal } \\
\text { and reproductive health }\end{array}$ & $\begin{array}{l}\text { - Reduce MMR per 100,000 LB from } 275 \text { in } 2005 \text { to } 240 \\
\text { in } 2011 \\
\text { - Increase proportion of births attended by skilled health } \\
\text { personnel from } 18 \% \text { in } 2007 \text { to } 43 \% \text { in } 2011 \\
\text { - Utilization of ANC and PNC for pregnant women } \\
\text { increased from } 41 \text { to } 60 \% \text { and from } 18 \text { to } 30 \% \\
\text { respectively } \\
\text { - Proportion of institutional deliveries increased from } 9 \text { to } \\
30 \% \\
\text { - Net need for obstetric complications increased from } 35 \\
\text { to } 50 \%\end{array}$ & $\begin{array}{l}\text { - Provision of ANC services for all pregnant women including TT } \\
\text { - Training of CSBAs } \\
\text { - Expansion of CEmOC in more upazila health complexes } \\
\text { - Piloting of demand-side financing through providing maternal } \\
\text { vouchers } \\
\text { - Demand creation for utilization of ANC, PNC and institutional } \\
\text { deliveries }\end{array}$ & $\begin{array}{l}\text { - Enforce legal age of marriage particularly for girls } \\
\text { - Strictly enforce birth registration } \\
\text { - Girls' education } \\
\text { - Women employment } \\
\text { - Expansion of CSBA } \\
\text { - Women status in family and society } \\
\text { - Ensure nutrition and mothers welfare } \\
\text { - Ensure community participation in the management and } \\
\text { promotion of reproductive health }\end{array}$ \\
\hline \multicolumn{4}{|c|}{ 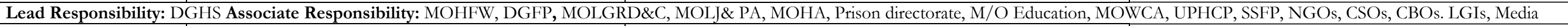 } \\
\hline $\begin{array}{l}\text { 3. Control of } \\
\text { Communicable } \\
\text { Diseases }\end{array}$ & $\begin{array}{l}\text { - HIV prevalence continue to be }<1 \% \text { among high risks } \\
\text { groups } \\
\text { - Sustain TB case detection rate of } 70 \% \text { achieving } \\
\text { geographical and socio-economic parity } \\
\text { - Sustain TB treatment success rate of } 85 \% \text { achieving } \\
\text { geographical and socioeconomic parity } \\
\text { - Decrease of leprosy endemic districts (prevalence } \\
>1 / 10,000 \text { population) from } 8 \text { to } 0 . \\
\text { - Reduce malaria specific mortality and morbidity } 50 \% \text { by } \\
2011 \\
\text { - Reduce kal-azar incidence as less than } 1 \text { per } 10,000 \\
\text { population at upazila level by } 2011 \\
\text { - Reduce case fatality rate of dengue below } 1 \% \text { by } 2011 \\
\text { - Mass drug administration for filariasis elimination } \\
\text { coverage } 100 \% \text { by } 2011\end{array}$ & $\begin{array}{l}\text { - National AIDS/STD Programme } \\
\text { - Targeted HIV/AIDS interventions with high risks groups like sex } \\
\text { workers, injectable drug users, migrant workers, transport } \\
\text { workers, HIV positive etc. and young people } \\
\text { - National TB programme } \\
\text { - DOTS programme in TB } \\
\text { - Leprosy elimination programme } \\
\text { - Malaria control programme } \\
\text { - Early diagnosis and prompt treatment of malaria } \\
\text { - Distribution of insecticide treated mosquito nets in selected areas } \\
\text { - Kal-azar elimination programme } \\
\text { - Filariasis control programme } \\
\text { - Dengue control programme }\end{array}$ & $\begin{array}{l}\text { - Supportive laws and law-enforcing agencies for effective } \\
\text { HIV/AIDS prevention programme } \\
\text { - Supportive prison authorities for effective TB programme } \\
\text { - Supportive local government institutions (union councils, } \\
\text { municipalities, city corporations) for environment cleaning } \\
\text { for controlling vectors } \\
\text { - Prevention of parent to child transmission of HIV } \\
\text { - Couple counselling for HIV testing } \\
\text { - National Tuberculosis control programme aims at halving } \\
\text { the prevalence and mortality of TB in line with MDGs }\end{array}$ \\
\hline \multicolumn{4}{|c|}{ Lead Responsibility: DGHS Associate Responsibility: MOHFW, NBR, MoIn, M/O Education, MOP\&ME, Media, NGOs, CSOs, CBOs, M/O Commerce, BSTI } \\
\hline $\begin{array}{l}\text { 4. Control of Non- } \\
\text { communicable diseases }\end{array}$ & $\begin{array}{l}\text { - Reduction of prevalence of smoking in adults to } 15 \% \text { by } \\
2011\end{array}$ & $\begin{array}{l}\text { - Strategic plan for surveillance and prevention of non- } \\
\text { communicable diseases in Bangladesh }\end{array}$ & $\begin{array}{l}\text { - High taxation on tobacco } \\
\text { - Public information campaign }\end{array}$ \\
\hline
\end{tabular}




\begin{tabular}{|c|c|c|c|}
\hline Strategic Goals & Key Targets & Actions Taken/ Underway & PRSP Policy Agenda (2009-2011) \\
\hline \multirow[t]{2}{*}{1} & 2 & 3 & 4 \\
\hline & $\begin{array}{l}\text { - Reduction of prevalence of smokeless tobacco use in } \\
\text { adults to } 15 \% \text { by } 2011 \\
\text { - Increase screening for early detection of cancer (cervix, } \\
\text { breast and oral) to } 30 \% \text { of the eligible women by } 2011 \\
\text { - Increase detection of hypertension with awareness } \\
\text { raising to } 20 \% \text { by } 2011\end{array}$ & - Public information campaign for awareness creation & \\
\hline \multicolumn{4}{|c|}{ Lead Responsibility: NNP, IPHN Associate Responsibility: UPHCP, SSFP,MOHFW, MOWCA, MOIn, M/O Commerce, MOP\&ME, M/O Education, Media, NGOs, CBOs, CSOs, } \\
\hline 5. Nutrition & $\begin{array}{l}\text { - Reduction of percent of underweight children age } 6 \text { to } \\
59 \text { months from } 46.3 \% \text { in } 2007 \text { to } 36 \% \text { in } 2011 \\
\text { - Reduction of percent of severely underweight children } \\
\text { age } 6 \text { to } 59 \text { months from } 10.9 \% \text { in } 2007 \text { to }<2 \% \text { in } \\
2011 \\
\text { - Reduce the prevalence of low birth weight }(<2500 \mathrm{~g}) \\
\text { from } 36 \% \text { to } 20 \% \text { or less by } 2011 \\
\text { - Maintain the prevalence of night blindness among } \\
\text { children aged } 12-59 \text { months below } 0.5 \% \\
\text { - Reduction of the night blindness among pregnant } \\
\text { women to below } 5 \% \text { by } 2011 \\
\text { - Reduction of the prevalence of anaemia in }<5 \text { years } \\
\text { children from } 49 \text { to } 40 \% \text {, adolescents from } 30 \text { to } 20 \% \\
\text { and in pregnant women from } 46 \text { to } 30 \% \text { by } 2011 \text {. } \\
\text { - Reduction of the prevalence of iodine deficiency from } \\
43 \text { to } 23 \% \text { of all school children by } 2011\end{array}$ & $\begin{array}{l}\text { - National Nutrition Programme } \\
\text { - Control of Vitamin A deficiency disorders } \\
\text { - Control of iron deficiency anaemia } \\
\text { - Control of iodine deficiency disorders } \\
\text { - Micronutrient fortification } \\
\text { - Behaviour change communication } \\
\text { - Breast feeding promotion and protection for improved nutrition } \\
\text { - } \text { - Gractices }\end{array}$ & $\begin{array}{l}\text { - Role of women's status in family and society for ensuring } \\
\text { her own and child's nutrition } \\
\text { - Adapt NNP on the basis of lessons learnt } \\
\text { - Urban nutrition } \\
\text { - Promotion of breast feeding, supplementary feeding and } \\
\text { nutrition } \\
\text { - Special nutrition needs for people and children living with } \\
\text { AIDS } \\
\text { - Address nutritional needs of people living with AIDS } \\
\text { including men }\end{array}$ \\
\hline \multicolumn{4}{|c|}{ Lead Responsibility: MOHFW, MOLGRD\&C, M/O Commerce Associate Responsibility: MOHA, MOA, MOF\&DM, MOF\&L, MOIn, LGIs, Media, NGOs, CBOs, CSOs } \\
\hline $\begin{array}{l}\text { 6. Food safety and } \\
\text { quality }\end{array}$ & $\begin{array}{l}\text { - Setting definite food standard } \\
\text { - Review and update of all existing food safety laws } \\
\text { - Examine the need of setting authority to deal with food } \\
\text { safety and quality }\end{array}$ & $\begin{array}{l}\text { - Standardization of different food items including adoption of } \\
\text { Codex standard of } 29 \text { food items } \\
\text { - Consumers' protection act under finalization } \\
\text { - Awareness rising on food safety and quality }\end{array}$ & $\begin{array}{l}\text { - Coordination among the concerned ministries for } \\
\text { enforcement of food safety } \\
\text { - Examine the need of setting authority to deal with food } \\
\text { safety and quality }\end{array}$ \\
\hline \multicolumn{4}{|c|}{ 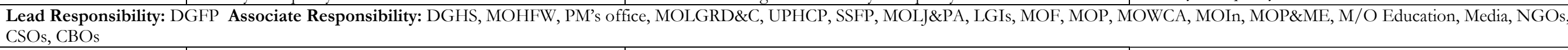 } \\
\hline 7. Population planning & $\begin{array}{l}\text { - Reduction of total fertility rate from } 2.7 \text { in } 2007 \text { to } 2.2 \text { in } \\
2011 \\
\text { - Reduction of population growth rate from } 1.40 \% \text { to } \\
1.20 \% \text { in } 2011 \\
\text { - Increase CPR from } 54 \% \text { to } 72 \% \text { by } 2011 \\
\text { - Long acting and permanent methods constitute most in } \\
\text { method mix }\end{array}$ & $\begin{array}{l}\text { - FP programme constituting field workers at household level } \\
\text { backed by network of facilities at different levels } \\
\text { - National population policy } \\
\text { - Emphasis on long acting and permanent methods } \\
\text { - Focused activities in low performing areas }\end{array}$ & $\begin{array}{l}\text { - Update Population Policy and ensure birth control and } \\
\text { reproductive health care } \\
\text { - Effective FP programme in urban areas } \\
\text { - Enforce legal age at marriage } \\
\text { - Women's employment }\end{array}$ \\
\hline \multicolumn{4}{|c|}{ Lead Responsibility: DGHS Associate Responsibility: MOHFW, MOIn, MOP\&ME, M/O Education, Media, NGOs, CSOs, CBOs } \\
\hline $\begin{array}{l}\text { 8. Health Education } \\
\text { and promotion }\end{array}$ & $\begin{array}{l}\text { - Improve health seeking behaviour of the community } \\
\text { with the emphasis of health education for the vulnerable } \\
\text { groups } \\
\text { - Strengthen community participation in health promotion } \\
\text { activities and ensure optimum use of health services }\end{array}$ & $\begin{array}{l}\text { - Programmes undertaken by Bureau of Health Education under } \\
\text { DGHS } \\
\text { - Programmes undertaken by IEM unit under DGFP } \\
\text { - Outsourced promotion to non-state agencies }\end{array}$ & $\begin{array}{l}\text { - Multi-sectoral collaboration for health promotion } \\
\text { - Inclusion in school curricula }\end{array}$ \\
\hline
\end{tabular}




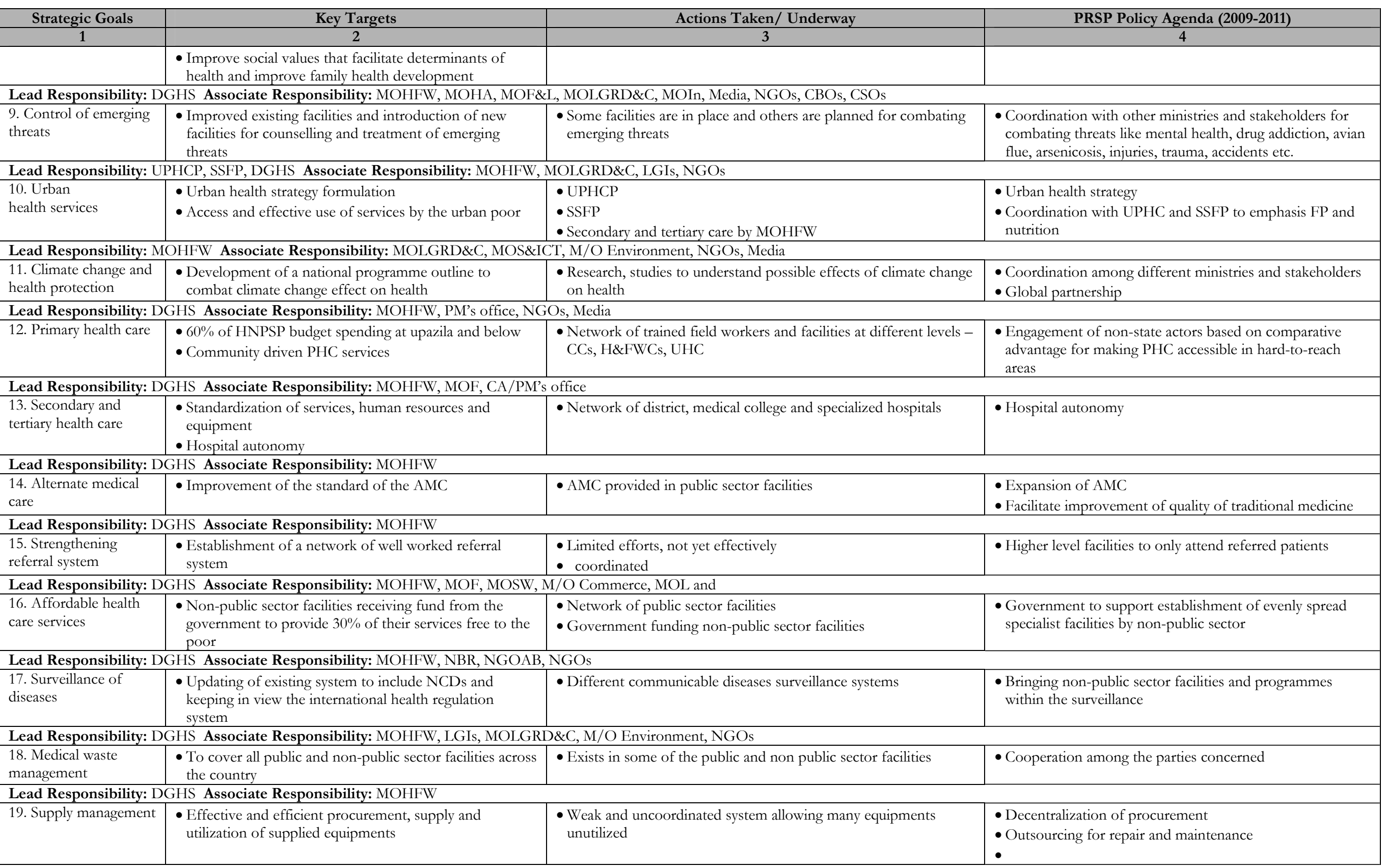




\begin{tabular}{|c|c|c|c|}
\hline Strategic Goals & Key Targets & Actions Taken/ Underway & PRSP Policy Agenda (2009-2011) \\
\hline 1 & 2 & 3 & 4 \\
\hline \multicolumn{4}{|c|}{ Lead Responsibility: MOHFW Associate Responsibility: PM's office } \\
\hline 20. Health governance & $\begin{array}{l}\text { - Practice of transparency and accountability in all acts at } \\
\text { all levels }\end{array}$ & $\begin{array}{l}\text { - PPP } \\
\text { - Citizens charter }\end{array}$ & $\begin{array}{l}\text { - Stewardship role of the public sector } \\
\text { - Regulation of the non-public sector }\end{array}$ \\
\hline \multicolumn{4}{|c|}{ Lead Responsibility: MOHFW Associate Responsibility: MOF, MOP, PM’s office } \\
\hline 21. Sector reforms & $\begin{array}{l}\text { - Continuation and further strengthening of on-going } \\
\text { reforms }\end{array}$ & $\begin{array}{l}\text { - Decentralized planning and budgeting } \\
\text { - Diversification of service provisions }\end{array}$ & $\begin{array}{l}\text { - Single plan and budget in MOHFW } \\
\text { - Decentralized planning and budgeting }\end{array}$ \\
\hline \multicolumn{4}{|c|}{ Lead Responsibility: MOHFW Associate Responsibility: MOWCA, NGOs, CSOs, CBOs } \\
\hline $\begin{array}{l}\text { 22. Gender equality in } \\
\text { health }\end{array}$ & $\begin{array}{l}\text { - Ensuring women's health rights throughout their life } \\
\text { cycle }\end{array}$ & $\begin{array}{l}\text { - Women friendly facilities } \\
\text { - Network of facilities }\end{array}$ & - Women's status in family and society \\
\hline \multicolumn{4}{|c|}{ Lead Responsibility: MOHFW Associate Responsibility: MOLJ\&PA, PM’s office } \\
\hline $\begin{array}{l}\text { 23. Stewardship role of } \\
\text { the public sector }\end{array}$ & $\begin{array}{l}\text { - MOHFW gradually assume strategic stewardship and } \\
\text { governance roles for policy management } \\
\text { - MOHFW strengthens its regulatory and supervisory roles } \\
\text { - Public sector to ensure proper safety net for the poor, } \\
\text { vulnerable and marginalized } \\
\text { - MOHFW assumes responsibilities for proper information } \\
\text { generation, collection and effective management feeding into } \\
\text { policy formulation and planning }\end{array}$ & $\begin{array}{l}\text { - Updating of the national health policy } \\
\text { - Revised BMDC ordinance } \\
\text { - PPP }\end{array}$ & - Role of public sector in direct service delivery \\
\hline $\begin{array}{l}\text { 24. Human resources } \\
\text { for health }\end{array}$ & $\begin{array}{l}\text { - Formulation of long-term comprehensive Human } \\
\text { Resource strategy }\end{array}$ & - Private sector participation in medical education & $\begin{array}{l}\text { - Career plan } \\
\text { - Uniform accreditation of all medical education by public } \\
\text { and private sector } \\
\text { - Handling the large number of informal service providers }\end{array}$ \\
\hline \multicolumn{4}{|c|}{ Lead Responsibility: DDA Associate Responsibility: MOHFW, BMA } \\
\hline 25. Drug issues & $\begin{array}{l}\text { - Ensuring easy access to essential drugs at fair price } \\
\text { - Promote drug export } \\
\text { - Availability of antiretroviral drugs(ARVDs) }\end{array}$ & - National Drug Policy & $\begin{array}{l}\text { - Rational use of drugs } \\
\text { - Attain self-sufficiency in production of medicine of } \\
\text { international standard } \\
\text { - Revise the drugs pricing mechanism as stated in the } \\
\text { National Drugs Policy } 2005 \\
\text { - Formulate National Pharmaceutical Policy } \\
\end{array}$ \\
\hline \multicolumn{4}{|c|}{ Lead Responsibility: MOLGRD\&C Associate Responsibility: WASAs, DPHE, LGIs, MOIn, Media, NGOs, CSOs, CBOs } \\
\hline $\begin{array}{l}\text { 26. Water and } \\
\text { sanitation }\end{array}$ & $\begin{array}{l}\text { - Universal access to pure drinking water by } 2011 \\
\text { - Sanitation facilities in every household by } 2013\end{array}$ & $\begin{array}{l}\text { - DPHE } \\
\text { - WASAs } \\
\text { - LGIs } \\
\text { - National Sanitation Policy }\end{array}$ & - Sanitized railway and reverie transports \\
\hline \multicolumn{4}{|c|}{ Lead Responsibility: MOHFW Associate Responsibility: MOF, MOP, CA/PM's office, M/O Commerce } \\
\hline $\begin{array}{l}\text { 27. Financing of HNP } \\
\text { sector }\end{array}$ & $\begin{array}{l}\text { - Share of HNP allocation to national budget be raise to } \\
12 \% \text { by } 2011 \\
\text { - Introduce incentive systems for HNP service providers } \\
\text { working in rural, underserved and remote areas }\end{array}$ & $\begin{array}{l}\text { - Participation of non-public sectors } \\
\text { - Contribution from donors }\end{array}$ & $\begin{array}{l}\text { - Acquire, retain and use of resources by the health facilities } \\
\text { - Health insurance }\end{array}$ \\
\hline $\begin{array}{l}\text { Total Indicative Cost } \\
\text { (in billion taka) }\end{array}$ & & & Tk. 207.94 \\
\hline
\end{tabular}


Policy Matrix 14: Social Inclusion and Empowerment- (a) Women's Advancement and Rights

\begin{tabular}{|c|c|}
\hline Strategic Goals & Key Targets \\
\hline 1 & 2 \\
\hline \multicolumn{2}{|c|}{ Lead Responsibility: MoWCA Associate Responsibility: PMO, MoLJPA } \\
\hline $\begin{array}{l}\text { 1. Putting policy and legal framework in } \\
\text { place toward achieving equal rights for } \\
\text { women }\end{array}$ & $\begin{array}{l}\text { - Make constitution the basis for ensuring women's } \\
\text { rights and advancement } \\
\text { - Introduce official circular to all ministries to } \\
\text { identify ways to enhance women's advancement }\end{array}$ \\
\hline
\end{tabular}

- Ratified CEDAW with some reservation

\section{Ensuring women's full participation}

in mainstream economic activities

3. Eliminating all social discriminations against women in all economic activities

\section{- Reduce poverty of $50 \%$ of poor women}

- Increase number of women beneficiaries to credit facilities by $10 \%$ annually

- Provide marketable technical and skills training to 2.5 lakh women

- Issue Government order for the provision of 5 months' Maternity Leave with full pay for women workers both at public and private level

- Raise the number of day care centres to 42 from

32 and provide day care services to 3000 children

- Provide training and credit facilities for retrenched women workers

- Create opportunities for productive employment of women

\section{- MoWCA distibuted widowed, deserted and destiute women} allowance in the amount of Tk. 21780 Lakhs to 650,000 beneficiaries during FY08

- 95,400 rural women are getting training and micro-credit and taka 29.35 Core is distributed to the beneficiarie

- 5169 sewing machines were distributed among poor women

- VGD beneficiaries are getting taka 7.5 Lakhs in one cycle

- BSCIC is regularly giving entrepreneurship training to ensure that more women participate in small and cottage industries and micro enterprise

- BITAC is providing skills training for mainstreaming women entrepreneurs

- SMESDP has taken a project to develop facilities for increasing women participation in the economic activities

- A project "Social Protection for the Poor Female Workers of the Garments Sector" was undertaken to reduce employment risks associated with the Multi Fibber Agreement

- Provision for 5 months' Maternity Leave with full pay for women has been incorporated in the National Women Development Policy 2008

- The Bureau of Manpower, Employment and Training (BMET) provided skill training to rural poor women in eight upazilas

- A project "Community Based Training for Employment and Income Generation for Rural Poor Women" was undertaken

- Withdraw reservation and ensure full ratification of CEDAW

- Address explicitly women's advancement and rights issues in all national and sectoral policies

- Revive Women Development Policy formulated in 1997

- Implement CEDAW

- Amend Section 1(2) of the Family Courts

Ordinance of 1985 to include the whole of

Bangladesh

- Amend citizenship act to ensure equality

between women and men citizens

- Adopt a uniform family code in order to protect the rights of all women

- Enforce equal pay for equal work and ensure inflation adjusted wage

- Ensure marketable skills development training for the retrenched garment workers

- Ensure safe \& secure working environment for women

- Ensure 5 months' Maternity Leave with full pay for women worker in both public and

private sectors

- Ensure women access and entry into foreign employment

- Set up migrant resource centre paying attention to women's need

- Encourage the private sector to recruit more women and monitor employers' behaviour towards female employee through developing a code of conduct

- Establish more childcare facilities for working mothers

- Ensure credit facilities for retrenched workers and provide alternative employment

- Develop a national system of Contributory

Provident Funds and Pension Funds for working women (garments, other industries)

- Provide life and disability insurance for the protection of women workers and female headed 


\begin{tabular}{|c|c|c|c|}
\hline Strategic Goals & Key Targets & Actions Taken/ Underway & PRSP Policy Agenda (2009-2011) \\
\hline 1 & 2 & 3 & 4 \\
\hline & & & $\begin{array}{l}\text { households } \\
\text { - Provide market-based and diversified skill- } \\
\text { training to women } \\
\text { - Link credit with entrepreneurship development } \\
\text { programme and provide need based training to } \\
\text { women }\end{array}$ \\
\hline \multicolumn{4}{|l|}{ II. Technology } \\
\hline \multicolumn{4}{|c|}{ Lead Responsibility: MoWCA, MoSICT Associate Responsibility: NGOs, Private sector } \\
\hline $\begin{array}{l}\text { 4. Ensuring women's access to } \\
\text { technology }\end{array}$ & $\begin{array}{l}\text { - Ensure participation of } 50 \text { percent of women in } \\
\text { the key sectors in technology adoption for } \\
\text { enhancing competitiveness } \\
\text { - Ensure that those who receive training in e- } \\
\text { commerce, e-business, ICT and skill development } \\
50 \% \text { are women }\end{array}$ & $\begin{array}{l}\text { - Ministry has keen interest in enlarging the programme in } 30 \\
\text { more districts for 24,000 women } \\
\text { - Through the Computer Training Centres of DWA and JMS } 4518 \\
\text { women are getting ICT training every year }\end{array}$ & $\begin{array}{l}\text { - Provide women training with on e-commerce, e- } \\
\text { business, ICT and create job banks for women } \\
\text { - Encourage making and disseminating } \\
\text { inexpensive domestic appliances to reduce } \\
\text { women's household workload } \\
\text { - Establish ICT centres for women in all districts } \\
\text { - Ensure that women benefit from new } \\
\text { technology }\end{array}$ \\
\hline \multicolumn{4}{|l|}{ III. Social Protection } \\
\hline \multicolumn{4}{|c|}{ Lead Responsibility: MoSW, MoLJPA, MoWCA, MoHA, Associate Responsibility: MoF, MoLE, MoHFW, MoCHTA and NGO/CSOs } \\
\hline $\begin{array}{l}\text { 5. Ensuring } \\
\text { social protection for } \\
\text { women against } \\
\text { vulnerability and risks }\end{array}$ & $\begin{array}{l}\text { - Expand social protection to cover all disadvantaged } \\
\text { women and children } \\
\text { - Increase health coverage and provide insurance for } \\
\text { reducing risks faced in pregnancy, childbirth, and } \\
\text { old age for destitute women }\end{array}$ & $\begin{array}{l}\text { - Social protection for disadvantaged and older women (VGF, } \\
\text { FSVGD, VGD-UP, Widow \& Old age allowance, WTC, NNP) } \\
\text { - Social Protection Projects taking relevant initiatives }\end{array}$ & $\begin{array}{l}\text { - Ensure access of women to government Legal } \\
\text { Aid Fund } \\
\text { - Increase budgetary allocation for economic, } \\
\text { external and health risk management for female } \\
\text { - Introduce social security legislation for disabled } \\
\text { women and implement through community } \\
\text { approaches } \\
\text { - Undertake programmes for disadvantaged } \\
\text { women including poor destitute and elderly } \\
\text { - Strengthen GO/NGO/CSOs coordination to } \\
\text { provide basic information about the status of } \\
\text { ethnic women and men } \\
\text { - Promote enforcement of National Woman } \\
\text { Development policy } 2008 \\
\end{array}$ \\
\hline \multicolumn{4}{|l|}{ IV. Finance and Banking } \\
\hline \multicolumn{4}{|c|}{ Lead Responsibility: MoWCA, MoSW, BB Associate Responsibility: BOI, MoI, MoF, MoLGRDC, } \\
\hline $\begin{array}{l}\text { 6. Ensuring women's easy access to } \\
\text { finance and credit for full participation } \\
\text { in mainstream economic activities }\end{array}$ & $\begin{array}{l}\text { - Provide } 10 \% \text { of total bank credit to women, } \\
\text { including indigenous women with disability } \\
\text { - Expand coverage of bank credit including micro- } \\
\text { credit for women in underdeveloped areas } \\
\text { - Enhance effectiveness of village based cooperatives } \\
\text { to address the economic vulnerability caused by } \\
\text { floods, droughts and cyclones } \\
\text { - Provide soft credit including rescheduling facilities } \\
\text { and loan waiver/ exemption for victims of } \\
\text { conflicts }\end{array}$ & $\begin{array}{l}\text { - Ministry creates opportunities for ensuring social protection } \\
\text { against vulnerability through providing micro credit/ bank credit } \\
\text { by utilizing government machineries and various } \\
\text { nongovernmental organizations covering a large number of poor } \\
\text { women. }\end{array}$ & $\begin{array}{l}\text { - Introduce soft loan, collateral free loan, low } \\
\text { interest rate and longer repayment scheme from } \\
\text { bank and other financial sources } \\
\text { - Provide banking facilities to garment workers } \\
\text { near their workplace } \\
\text { - Allocate budgetary funds for providing small- } \\
\text { scale loans to women } \\
\text { - Provide policy and financial supports for the } \\
\text { sustainability of women's involvement in } \\
\text { entrepreneurship }\end{array}$ \\
\hline
\end{tabular}




\begin{tabular}{|c|c|c|c|}
\hline Strategic Goals & Key Targets & Actions Taken/ Underway & PRSP Policy Agenda (2009-2011) \\
\hline 1 & 2 & 3 & 4 \\
\hline & & & $\begin{array}{l}\text { - Expand micro-credit for women in small and } \\
\text { marginal farm households } \\
\text { - Provide one-stop service with credit, market } \\
\text { information, legal services, and technology for } \\
\text { micro-credit borrowers and women } \\
\text { entrepreneurs } \\
\text { - Develop savings incentives for working women } \\
\text { - Strengthen village based cooperatives to address } \\
\text { the economic vulnerability caused by natural } \\
\text { calamities }\end{array}$ \\
\hline \multicolumn{4}{|l|}{ V. Housing Facilities and Shelter } \\
\hline \multicolumn{4}{|l|}{ Lead Responsibility: : MoHFW, MoI } \\
\hline $\begin{array}{l}\text { 7. Ensuring safe and affordable shelter } \\
\text { and housing for women at risk and } \\
\text { vulnerable women }\end{array}$ & $\begin{array}{l}\text { - Ensure } 50 \% \text { housing facilities for female headed } \\
\text { households in public housing projects } \\
\text { - Build working women's hostels in every district } \\
\text { town }\end{array}$ & $\begin{array}{l}\text { - } 7 \text { hostels are in operation to provide safe housing for the } \\
\text { working women } \\
\text { - Vagrants home and Abasan housing programme are in place } \\
\text { - Construction of two hostels at Barisal and Sylhet is underway } \\
\text { - Expansion of Housing Facility of Working Women of Jatioyo } \\
\text { Mohila Sangstha is on going }\end{array}$ & $\begin{array}{l}\text { - Provide safe affordable housing facilities for } \\
\text { single women and female headed households } \\
\text { - Build homes for elderly women particularly poor } \\
\text { women } \\
\text { - Give priority to lower level women government } \\
\text { staff while allocating housing } \\
\text { - Ensure that buildings have necessary facilities for } \\
\text { women with disability and elderly women } \\
\text { - Build hostels for working women especially } \\
\text { garments workers near their workplace }\end{array}$ \\
\hline \multicolumn{4}{|c|}{ VI. Political empowerment \& decision making } \\
\hline \multicolumn{4}{|c|}{ Lead Responsibility: MoLJPA, MoWCA Associate Responsibility: PMO, MoLGRDC, MoE, MoPME, NGO/CSOs, EC, political parties, media } \\
\hline $\begin{array}{l}\text { 8. Enhancing women's } \\
\text { political empowerment } \\
\text { 9. Improving women's participation } \\
\text { in decision making }\end{array}$ & $\begin{array}{l}\text { - Ensure } 100 \text { seats of the Parliament reserved for } \\
\text { women for direct election } \\
\text { - Increase participation of women in the committees } \\
\text { of political parties by at least } 1 / 3^{\text {rd }} \\
\text { - Enhance capacity of women members of the local } \\
\text { government institutions }\end{array}$ & $\begin{array}{l}\text { - Women representation in local bodies } \\
\text { - Government order issued for clarifying duties \& responsibilities } \\
\text { of local government representatives in the reserve seats }\end{array}$ & $\begin{array}{l}\text { - Ensure } 100 \text { seats of the Parliament reserved for } \\
\text { women for direct election } \\
\text { - Ensure full and effective participation of women } \\
\text { in national parliament and local government } \\
\text { institutions } \\
\text { - Include women MPs in all Standing Committees } \\
\text { - Encourage political parties to include women in } \\
1 / 3^{\text {rd }} \text { of their committee membership } \\
\text { - Arrange gender sensitization for Parliamentarians } \\
\text { - Encourage women leaders to participate in the } \\
\text { politics } \\
\text { - Take initiatives towards making women } \\
\text { politically more conscientious } \\
\text { - Ensure political commitment of all political } \\
\text { parties to address the issue of direct election of } \\
\text { women in parliament with specific constituencies } \\
\text { - Integrate positive image of women leaders in the } \\
\text { school curriculum from historical evidence } \\
\text { - Make the duties and responsibilities of elected }\end{array}$ \\
\hline
\end{tabular}




\begin{tabular}{|c|c|c|c|}
\hline Strategic Goals & Key Targets & Actions Taken/ Underway & PRSP Policy Agenda (2009-2011) \\
\hline 1 & 2 & 3 & 4 \\
\hline & & & $\begin{array}{l}\text { women local government representative in the } \\
\text { reserve seats clear }\end{array}$ \\
\hline \multicolumn{4}{|l|}{ VII. Violence Against Women(VAW) } \\
\hline \multicolumn{4}{|c|}{ Lead Responsibility: MoSW , MoWCA, MoLJPA, MoHA, MoHFW Associate Responsibility: MoI, NGO,CSOs, media } \\
\hline $\begin{array}{l}\text { 11. Eliminating all forms of } \\
\text { exploitation and legal and socio- } \\
\text { cultural discriminations against women }\end{array}$ & $\begin{array}{l}\text { - Increase reporting of violence against women cases } \\
\text { - Reduce incidence of VAW at least } 50 \text { percent } \\
\text { - Increase support and rehabilitation measures for } \\
\text { VAW victims } \\
\text { - Increase allocation for the police service and } \\
\text { judiciary system aimed at counteracting VAW } \\
\text { - Continue support for training of police and law } \\
\text { enforcement officers } \\
\text { - Increase support of legal aid and proper protection } \\
\text { for women victims of violence }\end{array}$ & $\begin{array}{l}\text { - } 6 \text { One-Stop Crisis Centre (OCC)" have been established in } \\
\text { Medical College Hospitals at divisional level } \\
\text { - The MoWCA has a Central Cell to prevent violence against } \\
\text { women and children. The Cell works in close collaboration with } \\
\text { other ministries and departments } \\
\text { "Safe Home" for the victims has been established at Gazipur } \\
\text { - Ministry will undertake Multi Sectoral Programme on VAW (2nd } \\
\text { phase) and this project will strengthen the Central Cell for } \\
\text { Violence against Women and Children of MoWCA }\end{array}$ & $\begin{array}{l}\text { - Include domestic violence as a punishable crime } \\
\text { in Women and Children Repression Prevention } \\
\text { Act } 2000 \\
\text { - Ensure protection of women in the custody of } \\
\text { law enforcement agencies } \\
\text { - Provide VAW training to police and medical } \\
\text { personnel } \\
\text { - Raise awareness of services, resources with } \\
\text { Deputy Commissioner, Judges of the courts and } \\
\text { tribunals to get support for women and children } \\
\text { victims of violence } \\
\text { - Sensitize judiciary to apply CEDAW provisions } \\
\text { in cases affecting women's rights } \\
\text { - Implement laws in VAW and provide psycho- } \\
\text { social supports and facilities for the victims } \\
\text { - Enhance congenial male attitude towards females } \\
\text { - Raise gender awareness among male officials of } \\
\text { law enforcement agencies through providing } \\
\text { trainings } \\
\text { - Ensure positive role of media in creation of } \\
\text { gender sensitivity among people especially on } \\
\text { VAW } \\
\text { - Develop integrated strategy for combating VAW } \\
\text { and improve coordination between GO and } \\
\text { NGOs } \\
\text { - Create mass awareness for combating VAW } \\
\text { - Allocate adequate funds for preventing VAW } \\
\text { and supporting the victims } \\
\text { - Ensure strictest legal measures against } \\
\text { oppression of women }\end{array}$ \\
\hline \multicolumn{4}{|c|}{ VIII. Gender Mainstreaming in policy, programmes and project } \\
\hline \multicolumn{4}{|c|}{ Lead Responsibility: MoWCA, MoF, PC, PMO, Cabinet Division, Line Ministries } \\
\hline $\begin{array}{l}\text { 12. Strengthening institutions for } \\
\text { coordination and monitoring women's } \\
\text { advancements and rights }\end{array}$ & $\begin{array}{l}\text { - Maintain regular liaison with Cabinet and PM } \\
\text { office regarding priority policy issues on women's } \\
\text { advancements and rights } \\
\text { - Hold regular meetings of NCWD } \\
\text { - Hold regular meetings of WID FPs } \\
\text { - Provide additional human resource to MoWCA to } \\
\text { strengthen its role for coordination and monitoring } \\
\text { of GE/GM commitments }\end{array}$ & $\begin{array}{l}\text { - All sectors implement the policies stated in the NAP \& all } \\
\text { project proposals address women's issues } \\
\text { - WID focal points are in ministries and departments } \\
\text { - Ensure women issue as one of major activities of WID Focal } \\
\text { point. Sub/associate focal point will ensure if women } \\
\text { advancement activities are being implemented, } \\
\text { - Ensure regular meeting of NCWD and parliamentary committee }\end{array}$ & $\begin{array}{l}\text { - Form a high level committee to evaluate the } \\
\text { weakness in the existing women's institutional } \\
\text { setup in the government and to make } \\
\text { recommendation for making it effective } \\
\text { - Implement international agreements regarding } \\
\text { women issues } \\
\text { - Strengthen linkages of MoWCA with all }\end{array}$ \\
\hline
\end{tabular}




\begin{tabular}{|c|c|c|c|}
\hline Strategic Goals & Key Targets & Actions Taken/ Underway & PRSP Policy Agenda (2009-2011) \\
\hline 1 & 2 & 3 & 4 \\
\hline & & & $\begin{array}{l}\text { Ministries, CSOs, NGOs, gender PRSP group } \\
\text { for monitoring of progress in the area of } \\
\text { women's advancements and rights } \\
\text { - Include MoWCA in various committees of the } \\
\text { Government } \\
\text { - Develop and strengthen WID FP as an effective } \\
\text { mechanism } \\
\text { - Strengthen capacity of WID focal } \\
\text { points/Associate WID focal points on } \\
\text { monitoring implementation of GE/GM } \\
\text { policies, strategies, programmes and projects }\end{array}$ \\
\hline \multicolumn{4}{|c|}{ Lead Responsibility: MoWCA, MoE, MoF, relevant Line Ministries } \\
\hline $\begin{array}{l}\text { 13. Strengthening capacity for Gender } \\
\text { Responsive Planning and Gender } \\
\text { Responsive Budgeting } \\
\text { 14. Institutionalizing Gender Training } \\
\text { in the Training Institutions }\end{array}$ & $\begin{array}{l}\text { - Develop/strengthen capacity of relevant ministries } \\
\text { for GRP, GRB and GE/GM policies } \\
\text { - Institutionalize gender in the training curricula of } \\
\text { BPATC, Planning Academy, JATI, NILG, BIM, } \\
\text { APD, BCSAA, SCITI, NIPORT, NAEM and } \\
\text { other training institutions } \\
\text { - Produce tools on GRP and GRB and develop } \\
\text { capacity to utilize them } \\
\text { - Ensure gender parity in planning the social safety } \\
\text { net initiatives }\end{array}$ & $\begin{array}{l}\text { - Strengthen Capacity of relevant Government officials including } \\
\text { MoF for gender responsive budgeting(GRB) } \\
\text { - Integration of gender training with regular curriculum of training } \\
\text { institutes } \\
\text { - Analyze training policy from gender perspective } \\
\text { - Review and update existing course curriculum of the Training } \\
\text { Institutions to incorporate gender equality concerns } \\
\text { - Adopt/customize GAD manual in the institution }\end{array}$ & $\begin{array}{l}\text { - Build/strengthen capacity of relevant } \\
\text { Government officials for gender responsive } \\
\text { planning (GRP) and gender-responsive } \\
\text { budgeting (GRB) } \\
\text { - Provide more user-friendly support } \\
\text { materials/tools on GRP/GRB and GE/GM } \\
\text { policies for enhancing understanding and } \\
\text { implementation of commitments } \\
\text { - Enhance capacity of the Trainers to impart } \\
\text { gender training in the training institutions } \\
\text { - Effective integration of gender training with } \\
\text { regular curriculum of training institutes }\end{array}$ \\
\hline \multicolumn{4}{|c|}{ Lead Responsibility: MOWCA, BBS and other relevant ministries } \\
\hline $\begin{array}{l}\text { 15. Developing capacity for the } \\
\text { production, dissemination and use of } \\
\text { sex-disaggregated statistics }\end{array}$ & $\begin{array}{l}\text { - Introduce fundamentals of gender statistics and } \\
\text { make them understood by key stakeholders } \\
\text { - Develop standard list of sex- disaggregated } \\
\text { statistics and indicators } \\
\text { - Establish, upload and maintain sex disaggregated } \\
\text { data base in MoWCA's website and ensure access }\end{array}$ & $\begin{array}{l}\text { - Materials on gender statistics made available } \\
\text { - Develop and adapt a general gender statistics guidebook } \\
\text { - Identify a set of indicators to be incorporated in the national } \\
\text { statistics system from gender perspective, in relation to national } \\
\text { commitment and policy }\end{array}$ & $\begin{array}{l}\text { - Make available sex dis-aggregated data for } \\
\text { policy planning and make assessment of } \\
\text { progress of PRSP } \\
\text { - Develop sex disaggregated data base and upload } \\
\text { data in MoWCA's website and ensure access } \\
\text { and updating the system } \\
\text { - Capacity building of ministries in generating and } \\
\text { processing sex disaggregated data } \\
\text { - Develop list of sex disaggregated statistics and } \\
\text { indicators } \\
\text { - Include in the census items/questions to } \\
\text { capture sex disaggregated data for gender based } \\
\text { analysis }\end{array}$ \\
\hline $\begin{array}{l}\text { 16. Integrating gender concerns into all } \\
\text { National Policies/ } \\
\text { Programmes/Projects of all Ministries }\end{array}$ & $\begin{array}{l}\text { - Integrate gender concerns into all National } \\
\text { Policies/ Programmes/Projects of } \\
\text { Ministries/Agencies } \\
\text { - Issue circular for integration of gender concerns in }\end{array}$ & $\begin{array}{l}\text { - Institutionalize women's needs in training programmes of } \\
\text { government officials }\end{array}$ & $\begin{array}{l}\text { - Develop guidelines for gender responsive } \\
\text { planning and review } \\
\text { - Ensure gender responsiveness in } \\
\text { programme/project planning and reviewing }\end{array}$ \\
\hline
\end{tabular}




\begin{tabular}{|c|c|c|c|}
\hline Strategic Goals & Key Targets & Actions Taken/ Underway & PRSP Policy Agenda (2009-2011) \\
\hline \multirow[t]{2}{*}{1} & 2 & 3 & 4 \\
\hline & $\begin{array}{l}\text { all programmes and projects } \\
\text { - Integrate gender equality issues into all policies } \\
\text { and programmes as stated in NAP }\end{array}$ & & $\begin{array}{l}\text { through integrating guidelines into TPP/DPP } \\
\text { process/mechanism }\end{array}$ \\
\hline $\begin{array}{l}\text { 17. Strengthening GRB mechanism in } \\
\text { MTBF }\end{array}$ & $\begin{array}{l}\text { - Include new ministries under MTBF } \\
\text { - Allocation and expenditure of funds in favour of } \\
\text { benefiting women }\end{array}$ & $\begin{array}{l}\text { - Integration of Poverty and Gender impact assessment criteria } \\
\text { under section } 3 \text { of BC1 of MTBF }\end{array}$ & $\begin{array}{l}\text { - Build capacity of relevant officials on poverty } \\
\text { and gender impact assessment criteria of BC1 } \\
\text { - Integrate gender and poverty impact assessed in } \\
\text { an effective manner } \\
\text { - Strengthen understanding of GRB among other } \\
\text { stakeholders }\end{array}$ \\
\hline \multicolumn{3}{|l|}{ Total Indicative Cost (in billion taka) } & Tk. $\mathbf{3 5 . 5 5}$ \\
\hline
\end{tabular}


Policy Matrix 14: Social Inclusion and Empowerment- (b) Children's Advancement and Rights

\begin{tabular}{|c|c|c|c|}
\hline Strategic Goals & Key Targets & Actions Taken/ Underway & PRSP Policy Agenda (2009-2011) \\
\hline 1 & 2 & 3 & 4 \\
\hline \multicolumn{4}{|l|}{ I. Children's Health } \\
\hline \multicolumn{4}{|c|}{ Lead Responsibility: MoHFW, DGHS, DGFP, EPI Programme, NGOs } \\
\hline $\begin{array}{l}\text { 1. Reducing infectious diseases and } \\
\text { improving immunization and vaccination }\end{array}$ & $\begin{array}{l}\text { - Reduce Infant mortality rate to } 37 \text { per } 1000 \\
\text { LB } \\
\text { - Reduce under-five mortality rate to } 52 \text { per } \\
1000 \mathrm{LB} \\
\text { - Reduce female U5MR to } 97 \text { per } 1000 \mathrm{LB}\end{array}$ & $\begin{array}{l}\text { - Essential Services Package-Expanded Programme on } \\
\text { Immunization (EPI) is operating } \\
\text { - Initiatives are taken through the implementation of 'Early } \\
\text { Learning Child Development Programme' and Sisimpur Project }\end{array}$ & - Ongoing and continue up to 2011 \\
\hline \multicolumn{4}{|c|}{ Lead Responsibility: MoHFW, DGHS’s DDC Programme and NGOs MoHFW, DGHS’s ARI Programme, NGOs MoWCA } \\
\hline $\begin{array}{l}\text { 2. Improving Acute Respiratory Infection } \\
\text { management and ensuring prompt } \\
\text { medical care }\end{array}$ & & - Essential Services Package-Acute Respiratory Infection Control & - Ongoing and continue up to 2011 \\
\hline $\begin{array}{l}\text { 3. Reducing morbidity and mortality from } \\
\text { the diarrhoeal diseases }\end{array}$ & $\begin{array}{l}\text { - Maintain immunization coverage at } 90 \% \\
\text { - Extend Oral Re-hydration Therapy (ORT) } \\
\text { facilities at the union level }\end{array}$ & - Essential Services Package-Diarrhoeal Disease Control (DDC) & - Ongoing and continue up to 2011 \\
\hline $\begin{array}{l}\text { 4. Improving access, quality and equity of } \\
\text { health services for children }\end{array}$ & $\begin{array}{l}\text { - Increase knowledge and skills of public IMCI } \\
\text { service providers to } 50 \text { percent } \\
\text { - Eliminate gender disparity in child mortality rate }\end{array}$ & - Essential Services Package-Child Health Care & - Ongoing and continue up to 2011 \\
\hline $\begin{array}{l}\text { 5. Increasing use of Integrated } \\
\text { Management of Childhood Illness }\end{array}$ & $\begin{array}{l}\text { - Increase use of Integrated Management of } \\
\text { Childhood Illness at the union level }\end{array}$ & $\begin{array}{l}\text { - Essential Services Package-Integrated Management of } \\
\text { Childhood Illness }\end{array}$ & - Ongoing and continue up to 2011 \\
\hline \multicolumn{4}{|c|}{ Lead Responsibility: MoE, MoPME, MoI, MoHFW, IEM of DGF, HEP Programme of DGHS MoHFW, Health education Bureau MoWCA } \\
\hline $\begin{array}{l}\text { 6. Strengthening child health education } \\
\text { and promotional activities }\end{array}$ & $\begin{array}{l}\text { - Increase massive awareness of child health } \\
\text { education }\end{array}$ & $\begin{array}{l}\text { - Essential Services Package-Health Education and Promotion (HEP) } \\
\text { - Formative research, monitoring and evaluation }\end{array}$ & - Ongoing and continue up to 2011 \\
\hline $\begin{array}{l}\text { 7. Creating wide awareness of child health } \\
\text { education }\end{array}$ & - Increase awareness of child health education & $\begin{array}{l}\text { - Initiatives are taken through the implementation of 'Early } \\
\text { Learning Child Development Programme' } \\
\text { - Developed child health education curriculum } \\
\end{array}$ & - Ongoing and continue up to 2011 \\
\hline \multicolumn{4}{|c|}{ Lead Responsibility: MoI, MoE, MoPME, MoHFW, DGHS’s School Health Programme, MoWCA, DGHS, DGFP, LGD, MoYS } \\
\hline $\begin{array}{l}\text { 8. Improving school health services and } \\
\text { supplying iron and folic acid for girls }\end{array}$ & $\begin{array}{l}\text { - Increase coverage of school health } \\
\text { programme during FY08-FY11 }\end{array}$ & $\begin{array}{l}\text { - Essential Services Package-School Health Programme extended } \\
\text { up to } 2011\end{array}$ & $\begin{array}{l}\text { - Increase coverage of school health Programme } \\
\text { during FY 08-FY } 11 \\
\text { - Provide health training on various relevant } \\
\text { adolescent issues }\end{array}$ \\
\hline $\begin{array}{l}\text { 9. Ensuring access to reproductive health } \\
\text { care services for adolescents }\end{array}$ & $\begin{array}{l}\text { - Ensure access to reproductive health care } \\
\text { services for all adolescents, }\end{array}$ & $\begin{array}{l}\text { - Essential Services Package-Reproductive Health Care } \\
\text { - Initiatives are taken through the implementation of } \\
\text { "Empowerment and Protection of Children" project. }\end{array}$ & - Ongoing and continue up to 2011 \\
\hline $\begin{array}{l}10 \text { Reducing mortality of children in } \\
\text { urban areas }\end{array}$ & $\begin{array}{l}\text { - Increase coverage of urban health services by } \\
85 \text { percent } \\
\text { - Train MO and municipal health staff } \\
\end{array}$ & - Essential Services Package-Urban Health services & - Ongoing and continue up to 2011 \\
\hline \multicolumn{4}{|l|}{ II. Food and Nutrition } \\
\hline \multicolumn{4}{|c|}{ Lead Responsibility: MoA, MoF MoWR, NGOs } \\
\hline $\begin{array}{l}\text { I1. Providing energy to children, } \\
\text { adolescent girls, pregnant and lactating } \\
\text { women }\end{array}$ & $\begin{array}{l}\text { - Reduce prevalence of night blindness in } \\
\text { children and postpartum women problem } \\
(1 \% \text { for children and } 5 \% \text { for women during }\end{array}$ & $\begin{array}{l}\text { - A Project of BSCIC established } 265 \text { salt iodization plants under } \\
\text { BITAC and BUET for mixing iodine with edible salt in different } \\
\text { areas }\end{array}$ & $\begin{array}{l}\text { - Ongoing and continue up to } 2011 \\
\text { - Use anthropometry to target households at risk of } \\
\text { malnutrition with social safety net programme }\end{array}$ \\
\hline
\end{tabular}




\begin{tabular}{|c|c|c|c|}
\hline Strategic Goals & Key Targets & Actions Taken/ Underway & PRSP Policy Agenda (2009-2011) \\
\hline 1 & 2 & 3 & 4 \\
\hline & $\begin{array}{l}\text { pregnancy) } \\
\text { - } 90 \% \text { coverage of iodized salt } \\
\text { - Sustain elimination of iodine deficiency } \\
\text { disorders } \\
\text { - Reduce iron deficiency/anaemia by } 33 \% \\
\end{array}$ & $\begin{array}{l}\text { - Regular motivation and orientation programme is undertaken } \\
\text { for taking iodized salt } \\
\text { - Increase and maintain cereal production } \\
\text { - Increase non-cereal production (Pulses, Oilseeds, Vegetables } \\
\text { and Animal Food) }\end{array}$ & $\begin{array}{l}\text { such as VGD } \\
\text { - Build awareness of the role of vegetables, fruits, } \\
\text { aroids and pulses for improving malnutrition } \\
\text { - Diversify food habits by raising awareness at the } \\
\text { family level particularly of women }\end{array}$ \\
\hline \multicolumn{4}{|c|}{ Lead Responsibility: MoA, MoF, MoWR, MoI, MoLGRDC, MoFL, MoWCA, CBO, NGOs } \\
\hline $\begin{array}{l}\text { 12. Obtaining plant and animal protein, } \\
\text { vitamins, minerals and increasing oil } \\
\text { consumption among children }\end{array}$ & $\begin{array}{l}\text { - Provide plant and animal proteins and } \\
\text { mineral } \\
\text { - Increase consumption of oil among children }\end{array}$ & $\begin{array}{l}\text { - Increase non-cereal production (Pulses, Oilseeds, Vegetables } \\
\text { and Animal Food) } \\
\text { - To create awareness of nutritious food among poor women } \\
\text { MoWCA is implementing a programme using local NGOs and } \\
\text { each year } 4050 \text { women are getting nutrition training. }\end{array}$ & - Ongoing and continue up to 2011 \\
\hline $\begin{array}{l}\text { 13. Reducing severe and moderate } \\
\text { malnutrition among children under } 2 \text { and } \\
\text { pregnant and lactating women }\end{array}$ & & - Improvement of nutritional status & - Ongoing and continue up to 2011 \\
\hline \multicolumn{4}{|c|}{ Lead Responsibility: MoHFW, MoWCA, MoI, NGOs } \\
\hline $\begin{array}{l}\text { 14. Ensuring nutrition in primary health } \\
\text { care for all poor children }\end{array}$ & $\begin{array}{l}\text { - Involve relevant sectors for nutrition and } \\
\text { primary health care }\end{array}$ & $\begin{array}{l}\text { - Community Nutrition Programme } \\
\text { - Initiatives are taken through the implementation of 'Early } \\
\text { Learning Child Development Programme and a Programme for } \\
\text { pregnant and lactating mothers }\end{array}$ & - Ongoing and continue up to 2011 \\
\hline \multicolumn{4}{|c|}{ Lead Responsibility: MoHFW , MoI, MoWCA, NGOs MoWCA, BFF } \\
\hline $\begin{array}{l}\text { 15. Ensuring supply of iron tablets, } \\
\text { iodised salt and vitamin A among children } \\
1-5 \text { years. }\end{array}$ & OIncrease exclusive breastfeeding rate & $\begin{array}{l}\text { - National Nutrition Programme } \\
\text { - Promotion and Support of Breast Feeding }\end{array}$ & $\begin{array}{l}\text { - Ongoing and continue up to } 2011 \\
\text { - Ongoing and continue up to } 2011\end{array}$ \\
\hline \multicolumn{4}{|c|}{ Lead Responsibility: MoHFW, MoWCA, MoI, NGOs, BSCIC MoSW, MoA, MoF, MoWR, MoFL } \\
\hline 16. Eliminating iodine deficiency & & $\begin{array}{l}\text { - A special project is being undertaken by MOI targeting to } \\
\text { reduce nutritional gap by adding vitamin A in the flour and } \\
\text { edible oil }\end{array}$ & $\begin{array}{l}\text { - Awareness programme for taking iodised salt } \\
\text { ongoing and continue up to } 2011\end{array}$ \\
\hline \multicolumn{4}{|c|}{ Lead Responsibility: MoA, MoF, MoI, MoWR, MoFL, MoLGRDC, MoWCA } \\
\hline $\begin{array}{l}\text { 17. Creating nutritional awareness of } \\
\text { children }\end{array}$ & $\begin{array}{l}\text { - Reduce prevalence of anaemia by } 20 \% \text { in all } \\
\text { children and pregnant women }\end{array}$ & - Nutrition Education for School Children & - Ongoing and continue up to 2011 \\
\hline $\begin{array}{l}\text { 18. Distributing nutritionally balanced diet } \\
\text { for disaster victims especially for children }\end{array}$ & $\begin{array}{l}\text { oPlan of Action for disaster management for } \\
\text { agriculture sector to be formulated }\end{array}$ & $\begin{array}{l}\text { - MOWCA implementing a project to create nutrition awareness } \\
\text { of mothers of children through local NGOs. About } 4050 \\
\text { women are getting nutrition awareness training each year. } \\
\text { - Strengthened emergency food distribution during and after } \\
\text { disaster } \\
\text { - Diversified food habits approach undertaken }\end{array}$ & $\begin{array}{l}\text { - Ongoing and continue up to } 2011 \\
\text { - Increase purchasing power of women for changing } \\
\text { food habits } \\
\text { - Increase non-cereal production (Pulses, Oilseeds, } \\
\text { Vegetables and Animal Food) }\end{array}$ \\
\hline \multirow{2}{*}{\multicolumn{4}{|c|}{$\begin{array}{l}\text { III. Children with disability } \\
\text { Lead Responsibilitv: MoSW. MoHFW, MoPME, MoE, MoLE, MoWCA }\end{array}$}} \\
\hline & & & Lead Responsibility: MoSW. MoHFW, MoPME, MoE, MoLE, MoWCA \\
\hline $\begin{array}{l}\text { 19. Developing right based approach for } \\
\text { children with disability }\end{array}$ & $\begin{array}{l}\text { - Undergo blood testing of intending couple } \\
\text { - Increase nutritional service for pregnant } \\
\text { mothers } \\
\text { - Increase sensitizations to the rights of }\end{array}$ & $\begin{array}{l}\text { - National Policy on disability is approved. } \\
\text { - National Action Plan on disability is approved } \\
\text { - Provide access to all kinds of facilities to children and person } \\
\text { with disability in health, education and other areas }\end{array}$ & $\begin{array}{l}\text { - Ensure access of children with disabilities to health, } \\
\text { education, social education, sanitation and safe water } \\
\text { and appropriate training, employment and } \\
\text { rehabilitation } \\
\text { - Conduct a survey on people with disability }\end{array}$ \\
\hline
\end{tabular}




\begin{tabular}{|c|c|c|c|}
\hline Strategic Goals & Key Targets & Actions Taken/ Underway & PRSP Policy Agenda (2009-2011) \\
\hline 1 & 2 & 3 & 4 \\
\hline & persons with disability and reduce the stigma & & $\begin{array}{l}\text { - Improve health and education facilities for children } \\
\text { with disability } \\
\text { - Develop awareness of decision makers to include } \\
\text { children's disability issues in policies and } \\
\text { programmes }\end{array}$ \\
\hline $\begin{array}{l}\text { 20. Preventing accidents and injuries } \\
\text { caused to children }\end{array}$ & $\begin{array}{l}\text { - Increase awareness of accidents and injuries } \\
\text { - Reduce injury related mortality and morbidity } \\
\text { by } 30 \%\end{array}$ & $\begin{array}{l}\text { - All policies relating to road, building and other physical facilities } \\
\text { should take into consideration the needs and concern of child } \\
\text { with disability }\end{array}$ & $\begin{array}{l}\text { - Ensure prevention of accidents and injuries caused } \\
\text { to children by taking into consideration the needs } \\
\text { and concerns of children with disabilities }\end{array}$ \\
\hline \multicolumn{4}{|l|}{ IV. Education } \\
\hline \multicolumn{4}{|c|}{ Lead Responsibility: MoPME, BBS, MoSW, NGOs, MoWCA, Mica } \\
\hline $\begin{array}{l}\text { 21. Developing and implementing early } \\
\text { childhood development (ECD) policies } \\
\text { and programmes } \\
\text { 22. Reducing inequity and disparity in } \\
\text { ECD programme }\end{array}$ & - ECD for all children under 5 years & $\begin{array}{l}\text { - Ongoing and continue up to } 2011 \\
\text { - Early Childhood Development Programme, Pre-School } \\
\text { Programme, Day-Care Centre for Children } \\
\text { - Early Childhood Development Programme has been taken for } \\
\text { the period 2006/07-2010/11 }\end{array}$ & $\begin{array}{l}\text { - Ensure ECD to develop a positive influence on } \\
\text { preparedness for school and later performances and } \\
\text { achievement of children in school } \\
\text { - Ongoing and continue up to } 2011\end{array}$ \\
\hline \multicolumn{4}{|c|}{ Lead Responsibility: MoPME, MoWCA, IER-DU, MoLGRDC, NGOs MoWCA, MoPME } \\
\hline $\begin{array}{l}\text { 23. Increasing enrolment in primary } \\
\text { school and improving quality } \\
\text { 24. Improve access, retention and equity } \\
\text { at the primary level } \\
\text { 25. Increase equity of outcome }\end{array}$ & $\begin{array}{l}\text { - Net enrolment at primary level to increase to } \\
90 \% \\
\text { - Primary school drop-out rate to decrease } 20 \\
\% \\
\text { - Children reaching grade } 5 \text { to increase to } 75 \% \\
\text { - Train } 100 \% \text { teacher } \\
\text { - Attendance increases by } 20-25 \% \\
\text { - Increase contact hours by } 20 \% \text {. }\end{array}$ & $\begin{array}{l}\text { - Institutionalize community, parent and student consultation and } \\
\text { participation in the development and performance measure of } \\
\text { local school } \\
\text { - Build more school/class with safe and play safe } \\
\text { - Introduce core curricula to be delivered by all PE providers } \\
\text { - Develop improved learning materials for marginalized and } \\
\text { people with disability and indigenous children } \\
\text { - Maintain gender parity in access and achievement } \\
\text { - Make maximum class size of } 46 \text { students }\end{array}$ & - Ongoing and continue up to 2011 \\
\hline \multicolumn{4}{|l|}{ V. Excluded children } \\
\hline \multicolumn{4}{|c|}{ Lead Responsibility: MoPME, MoWCA, MoSW, MoYS, MoLE, NGOs } \\
\hline $\begin{array}{l}\text { 26. Formulating programmes for street, } \\
\text { indigenous, working children without } \\
\text { parental care and under-privileged } \\
\text { children }\end{array}$ & $\begin{array}{l}\text { - Increase coverage of education for the } \\
\text { excluded children to } 75 \text { percent }\end{array}$ & $\begin{array}{l}\text { - Universal primary education Programme } \\
\text { - Education for the Excluded Children } \\
\text { - National Policy for NFE }\end{array}$ & $\begin{array}{l}\text { - Strengthen Education Programme for street, } \\
\text { indigenous, working and under-privileged children } \\
\text { - Programme will be continued up to } 2011 \\
\text { - Expand the opportunity for enrolment/retention, } \\
\text { educational performances of excluded children } \\
\text { - Set up Child Development Centres to provide } \\
\text { security and shelter to children }\end{array}$ \\
\hline \multicolumn{4}{|c|}{ Lead Responsibility: MoE, MoPME, MoWCA, MoCA, MoYS, MoSW, NCTB, PTIs, NGOs, } \\
\hline $\begin{array}{l}\text { 27. Equipping all children with basic } \\
\text { education to develop life skills }\end{array}$ & $\begin{array}{l}\text { - } 25 \text { percent children gets education with life } \\
\text { skills }\end{array}$ & $\begin{array}{l}\text { - Education for the excluded children } \\
\text { - MoSW has taken education Programme for street and } \\
\text { underprivileged children through its Programmes and projects } \\
\text { - For all children "Formulation of Qualitative Basic Education } \\
\text { Programme" a project for enhancing communicative English } \\
\text { skill has been included in the ADP 2007-2008. }\end{array}$ & $\begin{array}{l}\text { - Ongoing and continue up to } 2011 \\
\text { - Process of promoting basic education Programme } \\
\text { for youth will be continued }\end{array}$ \\
\hline
\end{tabular}




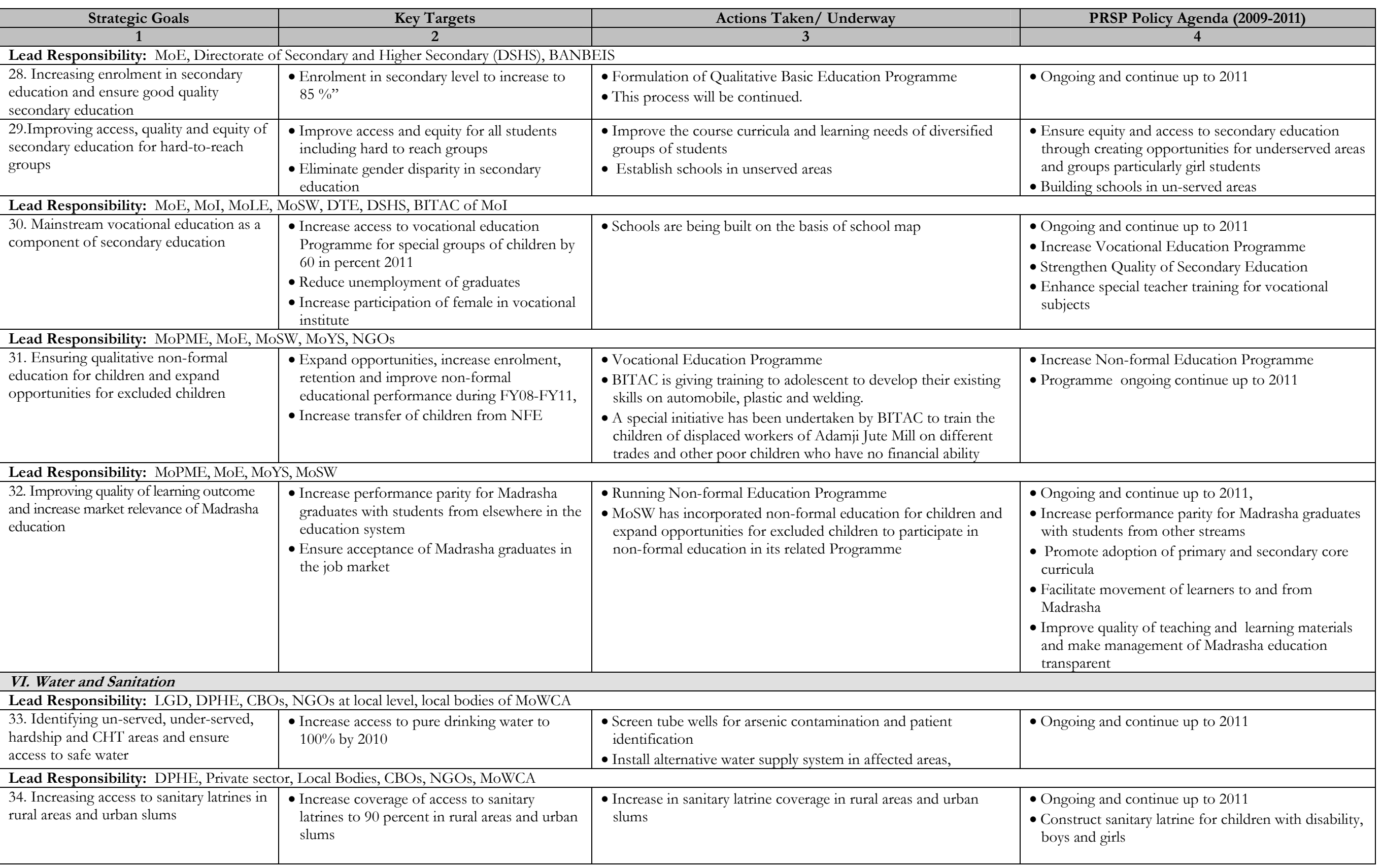




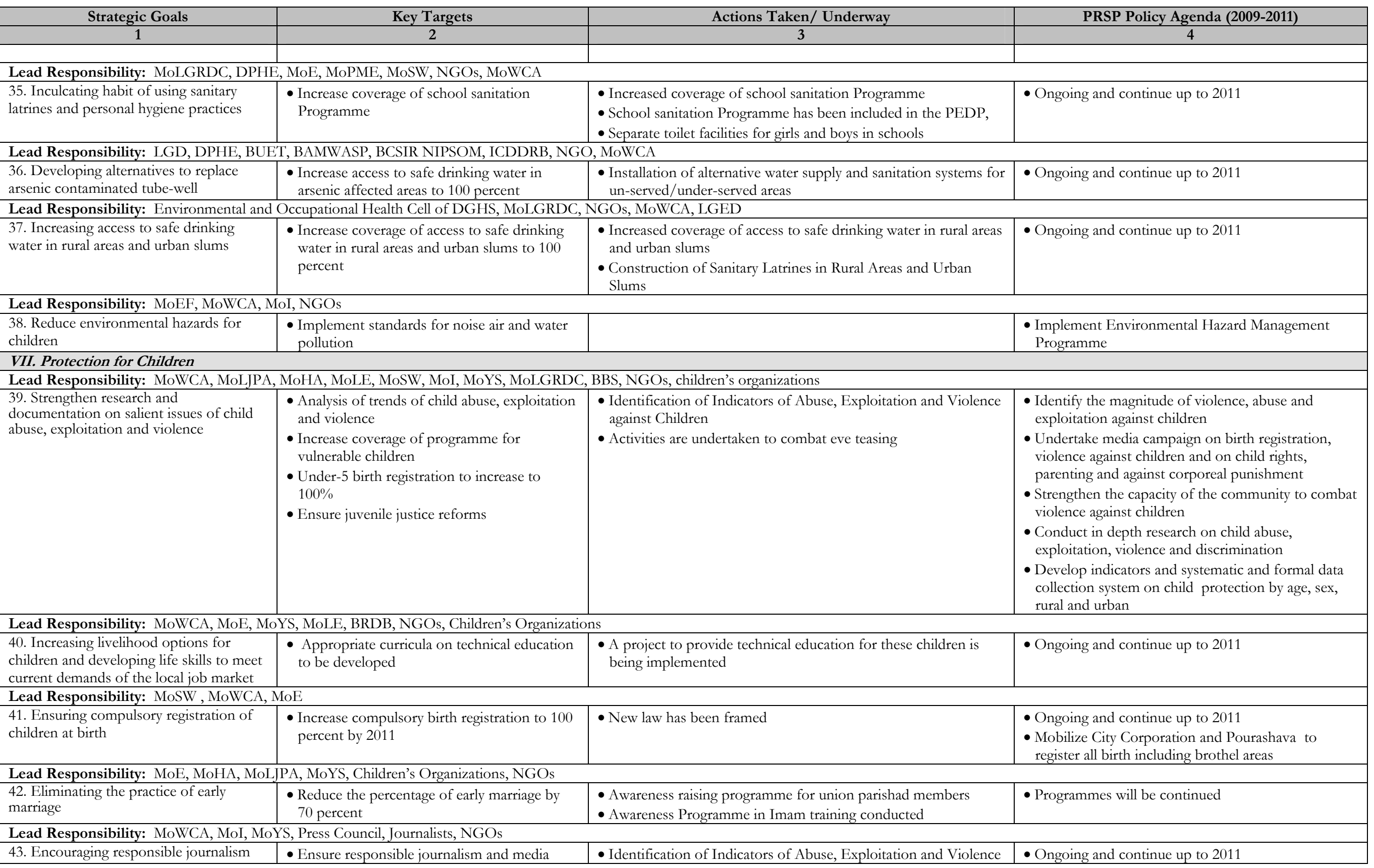




\begin{tabular}{|c|c|c|c|}
\hline Strategic Goals & Key Targets & Actions Taken/ Underway & PRSP Policy Agenda (2009-2011) \\
\hline 1 & 2 & 3 & 4 \\
\hline and media reporting & reporting to protect child rights & $\begin{array}{l}\text { - Against Children } \\
\text { with the assistance of UNICEF for the period 2006-2010 is } \\
\text { under process }\end{array}$ & $\begin{array}{l}\text { - Conduct awareness raising programme in } \\
\text { community school and work place on children } \\
\text { rights and protection issues }\end{array}$ \\
\hline \multicolumn{4}{|c|}{ Lead Responsibility: MoHA, MoSW, MoYS ,MoHFW, MoWCA, MoLJPA, NGOs } \\
\hline $\begin{array}{l}\text { 44. Ensuring the best interests of children } \\
\text { who come into contact with the law }\end{array}$ & $\begin{array}{l}\text { - Raise awareness of law enforcing officials } \\
\text { and judicial officers } \\
\text { - Develop scheme involving the courts social } \\
\text { workers and probation officers as an } \\
\text { alternative to custodial sentences } \\
\text { - Prevent arbitrary arrest and detention of } \\
\text { children }\end{array}$ & $\begin{array}{l}\text { - Strengthen Livelihood Options to Decrease Children's } \\
\text { Vulnerability } \\
\text { - MoSW has taken steps to address the problem of children who } \\
\text { come in contact with law by improving the juvenile justice } \\
\text { system with the help of concerned ministries }\end{array}$ & $\begin{array}{l}\text { - Ongoing and continue up to } 2011 \\
\text { - Develop community mechanism to deal with under } \\
\text { age petty offenders } \\
\text { - "Domestic Violence" must be clearly defined for } \\
\text { proper response }\end{array}$ \\
\hline \multicolumn{4}{|c|}{ Lead Responsibility: MoWCA, PMO, MoYS, MoHA, MoLJPA MOI } \\
\hline $\begin{array}{l}\text { 45. Establishing mechanisms to prevent } \\
\text { and protect children from all forms of } \\
\text { abuse, exploitation and violence }\end{array}$ & $\begin{array}{l}\text { - Improve monitoring mechanism of child } \\
\text { rights and child welfare } \\
\text { - Review existing legislation with the aim of } \\
\text { prohibiting all forms of punitive physical and } \\
\text { mental violence }\end{array}$ & - Ministry of information working on awareness raising & $\begin{array}{l}\text { - Ongoing and continue up to } 2011 \\
\text { - Establish procedure and mechanism to monitor, } \\
\text { investigate complaints, and intervene where } \\
\text { necessary } \\
\text { - Develop a mechanism for monitoring the } \\
\text { implementation of laws and regulation in relation to } \\
\text { child rights } \\
\text { - Harmonize the national legislation according to } \\
\text { CRC } \\
\text { - Provide working and street children with } \\
\text { information on HIV/AIDS } \\
\text { - Prohibit use of children in political and other } \\
\text { activities through coercion/enticement } \\
\end{array}$ \\
\hline \multicolumn{4}{|c|}{ Lead Responsibility: MoWCA, PMO, MoSW, MoYS, MoHA } \\
\hline $\begin{array}{l}\text { 46. Building awareness of children about } \\
\text { trafficking and abduction }\end{array}$ & $\begin{array}{l}\text { - Increase awareness about safe migration, } \\
\text { trafficking and abduction } \\
\text { - Eliminate sale and hiring of children for } \\
\text { begging purposes }\end{array}$ & & $\begin{array}{l}\text { - Reduce child sale for trafficking } \\
\text { - Develop and enforce strict employment and } \\
\text { recruitment procedure }\end{array}$ \\
\hline \multicolumn{4}{|c|}{ Lead Responsibility: MoI, MoSW, MoHFW, MoYS, MoWCA, MoLJPA, NGOs } \\
\hline $\begin{array}{l}\text { 47. Protecting children against torture and } \\
\text { other cruel, inhuman punishment. }\end{array}$ & $\begin{array}{l}\text { - Reduce all forms of ill-treatment and violence } \\
\text { against children }\end{array}$ & $\begin{array}{l}\text { - Encouragement of Responsible Journalism and Media Reporting } \\
\text { to Protect Child Rights } \\
\text { - To serve the interest of children MoWCA is implementing a } \\
\text { television programme 'Sisimpur' }\end{array}$ & $\begin{array}{l}\text { - Amend laws to prohibit all forms of punitive } \\
\text { physical and mental violence } \\
\text { - Develop a mechanism for monitoring } \\
\text { implementation of laws and regulation relating to } \\
\text { child rights } \\
\text { - Enact a separate juvenile justice system, and a } \\
\text { children code of conduct } \\
\text { - Undertake measures to prevent and punish } \\
\text { perpetrators } \\
\text { - Conduct nationwide awareness campaign about the } \\
\text { negative consequences of ill treatment of children }\end{array}$ \\
\hline
\end{tabular}




\begin{tabular}{|c|c|c|c|}
\hline Strategic Goals & Key Targets & Actions Taken/ Underway & PRSP Policy Agenda (2009-2011) \\
\hline 1 & 2 & 3 & 4 \\
\hline \multicolumn{4}{|c|}{ Lead Responsibility: MoWCA, MoE, MoI, MoYS MoSW, MoHA, Madrasha Education Boards, NGOs } \\
\hline $\begin{array}{l}\text { 48. Protecting children from corporal } \\
\text { punishment in home, schools and other } \\
\text { institutions }\end{array}$ & $\begin{array}{l}\text { - Increase awareness and protect children from } \\
\text { physical punishment } \\
\text { - Incorporate appropriate materials in teacher } \\
\text { training and enforce the issue }\end{array}$ & $\begin{array}{l}\text { - Existing Juvenile Justice Reforms in its Treatment of Children } \\
\text { - MoSW has taken bold steps to address the problem of the } \\
\text { children who come in contact with law through improving the } \\
\text { juvenile justice administration system with the help of } \\
\text { concerned ministries and development partners }\end{array}$ & $\begin{array}{l}\text { - Ongoing and continue up to } 2011 \\
\text { - Undertake campaign against all forms of corporal } \\
\text { - } \text { Eunishment at home and educational institutions } \\
\text { - Enact consolidated children code } \\
\text { - Harmonize national legislation according to CRC } \\
\end{array}$ \\
\hline \multicolumn{4}{|c|}{ Lead Responsibility: MoLE, MoWCA, MoYS, MoSW, BBS, NGOs } \\
\hline \multicolumn{4}{|c|}{ Lead Responsibility: MoWCA, MoHA, MoSW, MoYS, MoLJPA, MoLE, MoI, MoLGRDC, NGOs } \\
\hline \multicolumn{4}{|c|}{ Lead Responsibility: MoWCA, MoHA, MoHFW, MoYS, MoSW, MoLJPA, NGOs } \\
\hline $\begin{array}{l}\text { 51.Improving the plight of children who } \\
\text { live under difficult situation }\end{array}$ & $\begin{array}{l}\text { - Increase necessary support to children under } \\
\text { difficult circumstances, } \\
\text { - Introduce regulation regarding minimum } \\
\text { wage and protective standard for health, } \\
\text { leisure and education for working children } \\
\text { - Ensure child domestic workers to attend } \\
\text { school up to grade V }\end{array}$ & $\begin{array}{l}\text { - Motivational work for protect children against torture and other } \\
\text { cruel, inhuman or degrading treatment or punishment through } \\
\text { one foreign aided project and } 130 \text { training centres ongoing by } \\
\text { DYD. } \\
\text { - MoSW has been working to protect children against torture and } \\
\text { other cruel, inhuman or degrading treatment or punishment in } \\
\text { collaboration with other ministries and organizations }\end{array}$ & $\begin{array}{l}\text { - Improve the plight of children who live under } \\
\text { difficult circumstances } \\
\text { - Ensure the access of working children to learning } \\
\text { opportunity such as formal and non formal facilities } \\
\text { - Make guardians and employers aware of the need to } \\
\text { give working children time off to attend school } \\
\text { - Develop an effective mechanism for enforcing the } \\
\text { law in favour of child domestic workers } \\
\text { - Ensure working children's rights to be protected } \\
\text { from exploitation, cruel treatment, and right to } \\
\text { education } \\
\text { - Establish Child Development Centre in big cities to } \\
\text { provide security and shelter and learning } \\
\text { opportunities }\end{array}$ \\
\hline \multicolumn{4}{|c|}{ Lead Responsibility: MoFDM, MoLGRDC, MoYS, MoHFW, NGOs } \\
\hline $\begin{array}{l}\text { 52. Protecting children affected by natural } \\
\text { disasters }\end{array}$ & $\begin{array}{l}\text { - Increase coverage of Safety Nets Programme } \\
\text { for children displaced by natural disasters }\end{array}$ & $\begin{array}{l}\text { - Certain innovative NGO intervention is ongoing } \\
\text { - Identify children affected by disaster including perso }\end{array}$ & $\begin{array}{l}\text { - Ongoing and continue up to } 2011 \\
\text { - Develop a guideline for protection of mother and }\end{array}$ \\
\hline
\end{tabular}




\begin{tabular}{|c|c|c|c|}
\hline Strategic Goals & Key Targets & Actions Taken/ Underway & PRSP Policy Agenda (2009-2011) \\
\hline 1 & 2 & 3 & 4 \\
\hline & & $\begin{array}{l}\text { disability and other less visible group } \\
\text { - Allocate and distribute relief to children affected by disasters } \\
\text { - Ensure children from vulnerable and stigmatized group receive } \\
\text { relief and support }\end{array}$ & children from the effects of natural disaster \\
\hline \multicolumn{4}{|c|}{ Lead Responsibility: MoSW , MoCHTA, MoWCA, MoEF, MoHFW, MoYS, NGOs } \\
\hline $\begin{array}{l}\text { 53. Safeguarding the interests of } \\
\text { indigenous children }\end{array}$ & $\begin{array}{l}\text { - Ensure the basic needs of indigenous } \\
\text { children }\end{array}$ & $\begin{array}{l}\text { - MoLE is processing a 'National Policy" on child labour and } \\
\text { indigenous children issue has been covered in the policy } \\
\text { - Promotion of development and confidence building in CHT } \\
\text { - Integrated community development project in CHT }\end{array}$ & $\begin{array}{l}\text { - Ongoing and continue up to } 2011 \\
\text { - Develop a guideline to safeguard the needs and } \\
\text { interest of Adivasi/indigenous children }\end{array}$ \\
\hline \multicolumn{4}{|c|}{ Lead Responsibility: MoSW, MoWCA, MoHA, MoYS, Children Organization, NGOs } \\
\hline $\begin{array}{l}\text { 54. Protect children who are orphan, } \\
\text { abandoned and are vulnerable to abuse, } \\
\text { exploitation and violence }\end{array}$ & $\begin{array}{l}\text { - Increase protection of children deprived of } \\
\text { parental care }\end{array}$ & $\begin{array}{l}\text { - Protection of orphaned, abandoned and street children from } \\
\text { abuse and exploitation } \\
\text { - A new project in collaboration with UNICEF entitled } \\
\text { "Protection of Children at Risk" is going to be undertaken }\end{array}$ & $\begin{array}{l}\text { - Ongoing and continue up to } 2011 \\
\text { - Adopt a draft social policy for care and protection of } \\
\text { children out of parental care }\end{array}$ \\
\hline \multicolumn{4}{|c|}{ Lead Responsibility: MoSW, MoWCA, MoHFW, MoLE, MoI, MoLJPA, NGOs } \\
\hline $\begin{array}{l}55 . \text { Ensuring child victims' speedy } \\
\text { recovery and smooth social reintegration }\end{array}$ & $\begin{array}{l}\text { - Increase } 100 \% \text { support services to child } \\
\text { victims for recovery and social reintegration }\end{array}$ & $\begin{array}{l}\text { - Necessary support services to child victims for recovery and } \\
\text { social reintegration } \\
\text { - Create and strengthen community support services with } \\
\text { appropriate and quality family support services } \\
\text { - Take children's views into account for their reintegration }\end{array}$ & $\begin{array}{l}\text { - Ongoing and continue up to } 2011 \\
\text { - Develop bilateral, regional and multilateral } \\
\text { agreement to prevent trafficking and ensure } \\
\text { recovery and reintegration } \\
\text { - Ensure psycho-social support, health services } \\
\text { treatment short stay shelters, legal assistance etc to } \\
\text { the victims }\end{array}$ \\
\hline \multicolumn{4}{|c|}{ Lead Responsibility: MoLJPA, MoHA, MoSW, MoWCA, MoI, Private Media, NGOs MoHA, Media, NGOs } \\
\hline $\begin{array}{l}\text { 56. Assisting the recovery and } \\
\text { reintegration of children who were } \\
\text { detained or imprisoned }\end{array}$ & $\begin{array}{l}\text { - Increase assistance in the recovery and } \\
\text { reintegration of children who come into } \\
\text { contact with the law }\end{array}$ & $\begin{array}{l}\text { - Safety Nets Programme for children displaced by natural } \\
\text { disasters } \\
\text { - Recovery and reintegration of children who come into contact } \\
\text { with the law } \\
\text { - MoSW has been working to assist in the recovery and } \\
\text { reintegration of children (accused or victim) who are imprisoned } \\
\text { and suffer from labelling effects }\end{array}$ & $\begin{array}{l}\text { - Ongoing and continue up to } 2011 \\
\text { - Juvenile justice system must be more clearly } \\
\text { separated from the rest of the justice system }\end{array}$ \\
\hline $\begin{array}{l}\text { 57. Prosecuting alleged perpetrators of } \\
\text { sexual abuse and trafficking of children }\end{array}$ & - Ensure strict enforcement of law & - Mobilize public support against the perpetrators & - Ongoing and continue up to 2011 \\
\hline \multicolumn{4}{|c|}{ Lead Responsibility: MoWCA, MoSW, LEBs, NGOs, MoHFW, MoHA, MoI, MoYS, MoSW, MoWCA, NCTF, NGOs, MoE, MoPME, NGOs } \\
\hline $\begin{array}{l}\text { 58. Improving local communities } \\
\text { awareness of the incidents of abuse and } \\
\text { exploitation }\end{array}$ & $\begin{array}{l}\text { - Increase awareness about incidents of abuse, } \\
\text { exploitation and existing and potential } \\
\text { perpetrators }\end{array}$ & $\begin{array}{l}\text { - Protection of children deprived of parental care } \\
\text { - MoSW is running } 82 \text { Sarkari Shishu Paribar and } 6 \text { Baby Homes } \\
\text { for the orphans and abandoned children }\end{array}$ & $\begin{array}{l}\text { - Ongoing and continue up to } 2011 \\
\text { - Improve social awareness of the potential } \\
\text { perpetrators for protecting children from all abuse } \\
\text { and exploitation } \\
\text { - Ensure recreational and emotional services for the } \\
\text { victims } \\
\text { - Train service providers on child protection and build } \\
\text { capacity to provide victims with psycho social } \\
\text { support } \\
\text { - Formulated Social Policy for care and protection of }\end{array}$ \\
\hline
\end{tabular}




\begin{tabular}{|c|c|c|c|}
\hline Strategic Goals & Key Targets & Actions Taken/ Underway & PRSP Policy Agenda (2009-2011) \\
\hline 1 & 2 & 3 & 4 \\
\hline & & & children out of paternal care \\
\hline $\begin{array}{l}\text { 59. Reducing health consequences of } \\
\text { sexual abuse and exploitation }\end{array}$ & $\begin{array}{l}\text { - Reduce } 100 \% \text { negative health impacts of } \\
\text { sexual abuse and exploitation through } \\
\text { providing appropriate services } \\
\text { - Ensure information about voluntary testing } \\
\text { and treatment to } 100 \% \text { children victims of } \\
\text { sexual abuse }\end{array}$ & $\begin{array}{l}\text { - Strengthen information about sexuality, sexual hygiene } \\
\text { - HIV/AIDS policy and strategy developed and approved } \\
\text { - Support services to child victims for recovery and reintegration } \\
\text { is in place } \\
\text { - In 'One Stop Crisis Centre' girl victims' issues are addressed } \\
\text { - MoSW is working to increase the support services for the child } \\
\text { victims in cooperation with other ministries }\end{array}$ & $\begin{array}{l}\text { - Programme will be continued. } \\
\text { - Efforts will be continued .up to } 2011 \\
\text { - Support sexually abused children for voluntary } \\
\text { testing and treatment of STDs, HIV, AIDS } \\
\text { - Ongoing and continue up to } 2011\end{array}$ \\
\hline \multicolumn{4}{|c|}{ Lead Responsibility: MoYS, MoHFW, NASP of DGHS, NGOs } \\
\hline $\begin{array}{l}\text { 60. Ensuring prevention of transmission } \\
\text { of STDs, HIV, AIDS in under18 age } \\
\text { group }\end{array}$ & - Prevent the transmission of HIV/AIDS & $\begin{array}{l}\text { - The Department of Youth Development has been implementing } \\
\text { awareness programme for preventing the transmission of STD } \\
\text { including HIV/AIDS among children under } 18 \text { years of age } \\
\text { - Behaviour Change Communication Service for youth under } 18 \\
\text { year age group to prevent HIV/AIDS }\end{array}$ & $\begin{array}{l}\text { - Prevent transmission of HIV/AIDS through safe } \\
\text { blood supply } \\
\text { - Ensure social mobilization for prevention of } \\
\text { HIV/AIDS } \\
\text { - Help child victims of exploitation and abuse } \\
\text { - Prevention of transmission of HIV/AIDS }\end{array}$ \\
\hline \multicolumn{4}{|c|}{ Lead Responsibility: MoYS, MoWCA, MoHA, MoSW, MoHFW, MoI, MoLJPA, MoFA, MoEWOE, NGOs } \\
\hline $\begin{array}{l}\text { 61. Reducing sexual abuse and trafficking } \\
\text { of children }\end{array}$ & $\begin{array}{l}\text { - Measures to combat sexual abuse, } \\
\text { exploitation and trafficking of children } \\
\text { - Increase coverage and impact of these efforts }\end{array}$ & $\begin{array}{l}\text { - Organizing protest involving Community Groups against abuse } \\
\text { - 'Empowerment and Protection of Children' is on underway to } \\
\text { increase awareness of incidents of abuse and of existing and } \\
\text { potential perpetrators }\end{array}$ & $\begin{array}{l}\text { - Efforts will be continued up to } 2011 \\
\text { - Provide appropriate training to all law enforcing } \\
\text { agencies to combat the sexual abuse, exploitation } \\
\text { and trafficking of children }\end{array}$ \\
\hline $\begin{array}{l}\text { 62. Increasing efficiency, coverage and } \\
\text { welfare of children }\end{array}$ & $\begin{array}{l}\text { - Better reporting for national, international } \\
\text { and UN agencies } \\
\text { - Strengthen inter-ministerial coordination }\end{array}$ & $\begin{array}{l}\text { - MoWCA submitted CRC report } \\
\text { - Preparing final evaluation report of WFCL in } 2010\end{array}$ & $\begin{array}{l}\text { - Strengthen Coordination and Cooperation among } \\
\text { the ministries and NGOs working on children } \\
\text { - Organize regular inter-ministerial meeting to review } \\
\text { children development issues }\end{array}$ \\
\hline \multicolumn{4}{|c|}{ Lead Responsibility: MoYS, MoWCA, MoHFW, MoE, MoHA, MoLE, MoSW, MoLJPA, NCTF, NGOs, Bangladesh Shishu Academy } \\
\hline $\begin{array}{l}\text { 63. Developing indicators to monitor } \\
\text { Implementation of NPA for children }\end{array}$ & $\begin{array}{l}\text { - Ensure monitoring of indicators of } \\
\text { implementation of NPA }\end{array}$ & $\begin{array}{l}\text { - Ministry of Women and Children Affairs already developed } \\
\text { 'National Plan of Action for children for 2005-2010 } \\
\text { - Indicators for monitoring implementation of NPA developed }\end{array}$ & $\begin{array}{l}\text { - Establish an independent monitoring system and } \\
\text { mechanism to assess the performances of the NPA } \\
\text { - Strengthen the coordination wing of the MoWCA } \\
\text { - Establish Directorate of Children under the } \\
\text { MoWCA }\end{array}$ \\
\hline \multicolumn{4}{|c|}{ Lead Responsibility: MoYS, MoWCA, MoE, MoHA, MoHFW, MoSW, MoPME, NGOs } \\
\hline $\begin{array}{l}\text { 64. Developing database for children } \\
\text { development }\end{array}$ & $\begin{array}{l}\text { - Develop mechanism to collect and store } \\
\text { information }\end{array}$ & $\begin{array}{l}\text { - MoSW is providing information about STIs, HIV/AIDS } \\
\text { - MIS is underway under project Capacity Building for Monitoring } \\
\text { Child Rights }\end{array}$ & $\begin{array}{l}\text { - Develop a Management Information System (MIS) } \\
\text { - Disseminate data among other stakeholder }\end{array}$ \\
\hline \multicolumn{3}{|l|}{ Total Indicative Cost (in billion taka) } & Tk. 0.46 \\
\hline
\end{tabular}


Policy Matrix 14: Social Inclusion and Empowerment- (c) Indigenous People, People with Disability, and other Disadvantaged and Extreme Poor Groups

\begin{tabular}{|c|c|c|c|}
\hline Strategic Goals & Key Targets & Actions Taken/ Underway & PRSP Policy Agenda (2009-2011) \\
\hline 1 & 2 & 3 & 4 \\
\hline \multicolumn{4}{|l|}{ I. Indigenous people } \\
\hline \multicolumn{4}{|c|}{ Lead Responsibility: MoCHTA. MoLJPA, MoL, MPO, Cabinet Division } \\
\hline $\begin{array}{l}\text { 1. Developing a national policy on } \\
\text { indigenous people }\end{array}$ & - Adopts National Indigenous People’s Policy & & $\begin{array}{l}\text { - Form a committee with balanced representations from both } \\
\text { hilly areas and plain land indigenous groups to formulate a } \\
\text { "National Indigenous People's Policy" } \\
\text { - Consider ratifying and implementing the ILO convention } 169 \\
\text { and UN Declaration on Indigenous People's Rights } 2007 \\
\text { - Form a committee with representation from hilly areas and } \\
\text { plain land indigenous people to disburse the fund allocated for } \\
\text { the development of indigenous people }\end{array}$ \\
\hline $\begin{array}{l}\text { 2. Ensuring full implementation of the } \\
\text { Chittagong Hill Tracts Peace Accord }\end{array}$ & - Implement Peace Accord fully by 2009 & $\begin{array}{l}\text { - Amended CHT regulation, } 1900 \text { and other } \\
\text { acts according to the CHT peace accord } \\
\text { - The Land Commission started functioning }\end{array}$ & $\begin{array}{l}\text { - Improve the socio-economic conditions of indigenous people } \\
\text { in CHT districts } \\
\text { - Hold election of the Hill District Council }\end{array}$ \\
\hline $\begin{array}{l}\text { 3. Formulating land policy for indigenous } \\
\text { people }\end{array}$ & $\begin{array}{l}\text { - Secure rights on land for indigenous people in hilly } \\
\text { areas and plain land } \\
\text { - Reduce } 80 \% \text { land degradation by } 2011\end{array}$ & - Undertaking land survey & $\begin{array}{l}\text { - Introduce secure land tenure system for indigenous people } \\
\text { - Reduce land degradation for sustainable development } \\
\text { - Form a Land Commission to settle land disputes of indigenous } \\
\text { people in the plain land } \\
\text { - Address the land problems of plain land indigenous people } \\
\text { - Consider repealing Attia Forest (Protection) Ordinance 1982: } \\
\text { Ordinance no. XXXIII of } 1982 \\
\text { - Take action to deal with cases filed by Forest Department } \\
\text { against indigenous people }\end{array}$ \\
\hline \multicolumn{4}{|c|}{ Lead Responsibility: MoCHTA, MoFE, MoI, CHTB } \\
\hline $\begin{array}{l}\text { 4. Ensuring community involvement in } \\
\text { conservation of technology }\end{array}$ & $\begin{array}{l}\text { - } 100 \% \text { community involvement in conservation of } \\
\text { technologies }\end{array}$ & $\begin{array}{l}\text { - Recognition of traditional knowledge of } \\
\text { indigenous communities } \\
\text { - Fostering local government in areas inhabited } \\
\text { by } \\
\text { indigenous people }\end{array}$ & $\begin{array}{l}\text { - Improving functional, managerial and organizational } \\
\text { capabilities of indigenous communities } \\
\text { - Identify indigenous technologies which can be preserved and } \\
\text { adopted for improving the lives of indigenous people } \\
\text { - Promote awareness of rights and customary laws }\end{array}$ \\
\hline \multicolumn{4}{|c|}{ Lead Responsibility: MoCHTA Cabinet Division, Line Ministries } \\
\hline $\begin{array}{l}\text { 5. Mobilising other ministries to ensure } \\
\text { indigenous community's access to basic } \\
\text { services }\end{array}$ & $\begin{array}{l}\text { - Declare MoCHTA as lead ministry to coordinate } \\
\text { all development activities of indigenous people }\end{array}$ & $\begin{array}{l}\text { - Include need and concern of indigenous } \\
\text { people in the routine activities of officials of } \\
\text { relevant ministries }\end{array}$ & $\begin{array}{l}\text { - Amend the charter of duties of respective ministries } \\
\text { - Incorporate indigenous including plain land indigenous } \\
\text { people's needs, interest, and priorities in policies of relevant } \\
\text { ministries on human and other resources in an equitable } \\
\text { manner. }\end{array}$ \\
\hline \multicolumn{4}{|c|}{ Lead Responsibility: MoCHTA, MoPME, MoE, MoCA } \\
\hline $\begin{array}{l}\text { 6. Preserving the identity of life and culture } \\
\text { and the languages of indigenous communities }\end{array}$ & $\begin{array}{l}\text { - Take action to preserve the language by } 2009 \\
\text { - Ensure } 75 \% \text { of indigenous student in HSC and } \\
\text { higher education obtains stipend for certain period }\end{array}$ & $\begin{array}{l}\text { - Increase number of scholarship/ stipend } \\
\text { from block allocation of PMO and CHTDC } \\
\text { fund } \\
\text { - Provide learning materials free of cost to } \\
\text { indigenous students }\end{array}$ & $\begin{array}{l}\text { - Formulate national language policy to safeguard the indigenous } \\
\text { languages and culture } \\
\text { - Form a committee with linguistic expert to safeguard the } \\
\text { languages of indigenous communities } \\
\text { - Increase number of stipends for male and female students of } \\
\text { indigenous communities including the plain land communities }\end{array}$ \\
\hline
\end{tabular}




\begin{tabular}{|c|c|c|c|}
\hline Strategic Goals & Key Targets & Actions Taken/ Underway & PRSP Policy Agenda (2009-2011) \\
\hline 1 & 2 & 3 & 4 \\
\hline \multicolumn{4}{|l|}{ Lead Responsibility: MoCHTA. MoF MoFDM } \\
\hline $\begin{array}{l}\text { 7. Ensure food assistance to cope with food } \\
\text { insecurity }\end{array}$ & $\begin{array}{l}\text { - Provide food assistance to the victims of damage } \\
\text { of Jhum crops }\end{array}$ & $\begin{array}{l}\text { - Undertake awareness of mutual cooperation } \\
\text { to fight against natural calamities }\end{array}$ & $\begin{array}{l}\text { - Ensure safety net and food security programme for CHTs, and } \\
\text { plain land indigenous communities } \\
\text { - Increase food support during food deficit } \\
\text { - Arrange institutional credit at low rate of interest }\end{array}$ \\
\hline \multicolumn{4}{|c|}{ Lead Responsibility: MoCHTA, MoPEMR, MoLGRDC } \\
\hline $\begin{array}{l}\text { 8. Ensuring electricity supply and } \\
\text { telecommunication network } \\
\text { 9. Ensuring sanitation and water supply }\end{array}$ & $\begin{array}{l}\text { - Cover } 50 \% \text { people in upazila in CHTD } \\
\text { - Cover all municipalities and upazila towns by } \\
\text { telecommunication } \\
\text { - Provide safe water to at least } 70 \% \text { people in } \\
\text { different CHT districts and plain land indigenous } \\
\text { areas }\end{array}$ & $\begin{array}{l}\text { - "Chittagong Hill Tracts Electrification } \\
\text { Project"- Third Phase } \\
\text { - Chittagong Hill Tracts Electrification } \\
\text { Project"- Kaptai and Belaichari }\end{array}$ & $\begin{array}{l}\text { - Expand national power grid and distribution system in } \\
\text { different upazilas } \\
\text { - Expand solar electric supply } \\
\text { - Establish mobile phone network in the municipal areas in hill } \\
\text { tracts districts } \\
\text { - Set up digital telephone exchange at the upazila towns } \\
\text { - Provide safe water and hygienic sanitation facilities }\end{array}$ \\
\hline \multicolumn{4}{|c|}{ Lead Responsibility: MoCHTA MoFE, MoI, CHTB, MoLE } \\
\hline $\begin{array}{l}\text { 10. Ensuring indigenous people's economic } \\
\text { activities }\end{array}$ & $\begin{array}{l}\text { - Increase their participation in non-farm activities } \\
\text { - Develop small and cottage industries } \\
\text { - Develop poultry and livestock rearing and small } \\
\text { trade } \\
\text { - Facilitate access of agriculture and other ethnic } \\
\text { products of indigenous people to national and } \\
\text { international market }\end{array}$ & & $\begin{array}{l}\text { - Create employment opportunities for hilly and plain land } \\
\text { indigenous people } \\
\text { - Expand micro-credit activities } \\
\text { - Expand appropriate technology for promotion of crop and } \\
\text { other agricultural produce } \\
\text { - Develop communication facilities } \\
\text { - Create favourable environment for private sector to invest in } \\
\text { food/fruit processing industry } \\
\text { - Involve private sectors in tourism and other income generating } \\
\text { activities } \\
\text { - Develop rural roads and hat-bazars in indigenous areas } \\
\text { - Consider quota system for hilly and plain land indigenous } \\
\text { people for government jobs }\end{array}$ \\
\hline \multicolumn{4}{|l|}{ II. People with Disability } \\
\hline \multicolumn{4}{|c|}{ Lead Responsibility: MoSW, MoPME, MoE, MOI } \\
\hline $\begin{array}{l}\text { 11. Ensuring access to normal education for } \\
\text { students with disability } \\
\text { 12. Ensuring special education to hearing } \\
\text { impaired and mentally retarded students }\end{array}$ & $\begin{array}{l}\text { - Increase enrolment of mentally retarded children } \\
\text { in school to } 10 \% \text { in primary level and } 6 \% \text { in } \\
\text { secondary level } \\
\text { - Ensure 3\% participation in HSC and university } \\
\text { level education }\end{array}$ & $\begin{array}{l}\text { - Develop right based approach for children } \\
\text { with disability } \\
\text { - Conduct social mobilization about rights of } \\
\text { children with disability to have access to } \\
\text { special education/ education, training, } \\
\text { - Provision for stipend at primary, secondary, } \\
\text { higher secondary and university levels }\end{array}$ & $\begin{array}{l}\text { - Expand existing educational institutes for children with } \\
\text { disability (both male and female) to increase coverage } \\
\text { - Expand access of learners with disability to mainstream } \\
\text { schools } \\
\text { - Expand NCSE for training teachers, social workers and health } \\
\text { workers } \\
\text { - Increase number of stipends and hostel facilities for students } \\
\text { with disability ( both male and female) in higher education }\end{array}$ \\
\hline
\end{tabular}




\begin{tabular}{|c|c|c|c|}
\hline Strategic Goals & Key Targets & Actions Taken/ Underway & PRSP Policy Agenda (2009-2011) \\
\hline 1 & 2 & 3 & 4 \\
\hline \multicolumn{4}{|c|}{ Lead Responsibility: MoSW. MoHFW, MoL GRDC } \\
\hline $\begin{array}{l}\text { 13. Ensuring adequate medical services and } \\
\text { counselling for both boys and girls with } \\
\text { disabilities }\end{array}$ & $\begin{array}{l}\text { - Reduce prevention of disability } \\
\text { - Reduce morbidity among persons } \\
\text { - Increase no of beds and equipment in hospitals } \\
\text { for persons with disability }\end{array}$ & $\begin{array}{l}\text { - Strengthen early detection of symptoms of } \\
\text { disability } \\
\text { - Test blood of couple before marriage to } \\
\text { avoid the birth of children with disability }\end{array}$ & $\begin{array}{l}\text { - Expand EPI programme and distribution of vitamin A capsule } \\
\text { - Strengthen essential service package } \\
\text { - Strengthen integrated management of childhood illness } \\
\text { - Provide assistive devices and equipment at the health centre }\end{array}$ \\
\hline \multicolumn{4}{|l|}{ Lead Responsibility: MoSW, MoLE } \\
\hline \multicolumn{4}{|l|}{ Lead Responsibility: MoSW, MoC, MoHPW } \\
\hline \multicolumn{4}{|l|}{ Lead Responsibility: MoSW, MoHFW, MoPME } \\
\hline $\begin{array}{l}\text { 18. Providing door step service to persons } \\
\text { with disabilities according to their needs }\end{array}$ & $\begin{array}{l}\text { - Provide disability related services to all people } \\
\text { with disabilities in the community }\end{array}$ & $\begin{array}{l}\text { - Ensure that rural areas alleviate the suffering } \\
\text { of rural people with disability through } \\
\text { friendly environment in own community }\end{array}$ & $\begin{array}{l}\text { - Detection and timely medical intervention } \\
\text { - Fitment of artificial aids and appliances } \\
\text { - Educational services in integrated schools } \\
\text { - Provide vocational training and micro credit } \\
\text { - Create awareness in the community of peoples with disabilities } \\
\text { especially women's survival, protection and rights }\end{array}$ \\
\hline \multicolumn{4}{|c|}{ Lead Responsibility: MoSW. MoL\&JPA, Cabinet Division } \\
\hline $\begin{array}{l}\text { 19. Amending the disability Act in } \\
\text { accordance with the UN Convention }\end{array}$ & $\begin{array}{l}\text { - Ensure disability Act as a reflection of right based } \\
\text { approach } \\
\text { - Ensure the Act to incorporate accountability of } \\
\text { government employees }\end{array}$ & $\begin{array}{l}\text { - Prepare the draft Act by panel of experts- } \\
\text { jurist, educators, sociologists psychologists, } \\
\text { psychiatrists, doctor and the like }\end{array}$ & $\begin{array}{l}\text { - Clarify definitions of disability and specify the diverse needs } \\
\text { and rights of people with disability } \\
\text { - Amend allocation of business of different ministries } \\
\text { incorporating the disability issues to address the disability by } \\
\text { them }\end{array}$ \\
\hline
\end{tabular}




\begin{tabular}{|c|c|c|c|}
\hline Strategic Goals & Key Targets & Actions Taken/ Underway & PRSP Policy Agenda (2009-2011) \\
\hline 1 & 2 & 3 & 4 \\
\hline & & different ministries & $\begin{array}{l}\text { - Amend the charter of duties of department to address disability } \\
\text { issues }\end{array}$ \\
\hline \multicolumn{4}{|l|}{ Lead Responsibility: MoSW, BBS } \\
\hline $\begin{array}{l}\text { 21. Developing a data base for persons with } \\
\text { disabilities }\end{array}$ & - Undertake and complete survey by 2010 & - Prepare TPP for the survey & $\begin{array}{l}\text { - Constitute a committee with professionals having expertise in } \\
\text { socio-economic survey } \\
\text { - Undertake survey to have reliable data for planning }\end{array}$ \\
\hline \multicolumn{4}{|c|}{ III. Other Disadvantaged and Extreme Poor Group } \\
\hline \multicolumn{4}{|c|}{ Lead Responsibility: MoSW. MoLGRDC, NGOs } \\
\hline $\begin{array}{l}\text { 22. Ensure access to basic services of the } \\
\text { disadvantaged group }\end{array}$ & $\begin{array}{l}\text { - Provide } 60 \% \text { disadvantaged and extreme poor } \\
\text { group access to basic social services }\end{array}$ & $\begin{array}{l}\text { - Rural social services are being provided } \\
\text { - Rural development programmes } \\
\text { - Char development project and other national } \\
\text { programmes }\end{array}$ & $\begin{array}{l}\text { - Constitute coordination committees at the national and } \\
\text { grassroots levels to ensure that disadvantaged groups benefit } \\
\text { from development activities } \\
\text { - Provide skill development training }\end{array}$ \\
\hline \multicolumn{4}{|l|}{ Lead Responsibility: MoSW, MoHFW, MoL } \\
\hline $\begin{array}{l}\text { 23. Ensuring housing especially for tea } \\
\text { garden workers, sweepers, and homeless } \\
\text { people due to river erosion } \\
\text { 24. Ensuring proper rehabilitation of sex } \\
\text { workers }\end{array}$ & $\begin{array}{l}\text { - Provide Bede khas land } \\
\text { - Provide land to sweeper and tea garden workers in } \\
\text { their working place i.e. in municipality/ } \\
\text { corporation and tea garden respectively, } \\
\text { - Rehabilitate and provide alternative job option to } \\
25,000 \text { sex-workers }\end{array}$ & $\begin{array}{l}\text { - Sweepers live in temporary shed } \\
\text { - Tea garden workers live nearby tea garden } \\
\text { - Some Bede live in their constructed houses } \\
\text { - Department of social services is } \\
\text { implementing a project on sex-workers }\end{array}$ & $\begin{array}{l}\text { - Make extensive survey and make a need assessment of housing } \\
\text { - Ensure housing for all disadvantaged and extreme poor } \\
\text { including Bede, sweeper, teagarden worker } \\
\text { - Empower and vocationally train sex-workers and their } \\
\text { children } \\
\text { - Socialize the children who came in contact with crime and } \\
\text { facilitate them to reintegrate with family and society } \\
\text { - Allocate khas land to victims of river erosion }\end{array}$ \\
\hline \multicolumn{4}{|c|}{ Lead Responsibility: MoSW, MoF, MoLGRDC, NGOs } \\
\hline $\begin{array}{l}\text { 25. Provide occupational group with micro- } \\
\text { credit and skill training }\end{array}$ & $\begin{array}{l}\text { - Bring } 80 \% \text { disadvantaged and extreme poor } \\
\text { group under the purview of micro credit and skill } \\
\text { training programme }\end{array}$ & $\begin{array}{l}\text { - Government and NGOs are implementing } \\
\text { micro credit and skill training programmes }\end{array}$ & $\begin{array}{l}\text { - Facilitate occupational mobility } \\
\text { - Ensure improvement of their occupational situation with } \\
\text { modern equipment } \\
\text { - Provide credit at low rate of interest and skill training }\end{array}$ \\
\hline \multicolumn{4}{|l|}{ Lead Responsibility: MoSW, BBS } \\
\hline $\begin{array}{l}\text { 26. Undertaking a national survey on } \\
\text { disadvantaged and extreme poor groups }\end{array}$ & - Complete a survey & $\begin{array}{l}\text { - Prepare TPP for the survey for undertaking } \\
\text { the survey }\end{array}$ & $\begin{array}{l}\text { - Constitute a committee with professionals having expertise in } \\
\text { socio - economic survey } \\
\text { - Undertake survey to have reliable data for planning }\end{array}$ \\
\hline \multicolumn{3}{|l|}{ Total Indicative Cost (in billion taka) } & Tk. 12.65 \\
\hline
\end{tabular}


Policy Matrix 15: Promoting Good Governance

\begin{tabular}{|c|c|c|c|}
\hline Strategic Goals & Key Targets & Actions Taken/ Underway & PRSP Policy Agenda (2009-2011) \\
\hline 1 & 5 & 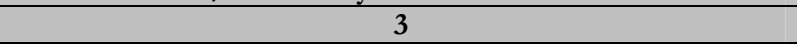 & 4 \\
\hline \multicolumn{4}{|c|}{ Lead Responsibility: MoLJPA, MoI, BTV, Radio } \\
\hline \multirow[t]{3}{*}{$\begin{array}{l}\text { 1. Making parliamentary } \\
\text { process effective }\end{array}$} & $\begin{array}{l}\text { - Develop capacity for policy formulation } \\
\text { and improved legislation }\end{array}$ & $\begin{array}{l}\text { - "Strengthening Parliamentary Democracy" project ongoing } \\
\text { - Bangladesh Institute of Parliamentary Studies established to } \\
\text { improve the efficacy of Parliamentary business } \\
\text { - Parliament Secretariat Act, } 1994 \text { passed } \\
\text { - Inter-ministerial committee is working on amendment of } \\
\text { Rules of procedure } \\
\text { - Local area network (LAN) established }\end{array}$ & $\begin{array}{l}\text { - Make all MPs aware of policies and their responsibilities with respect to } \\
\text { their implementation } \\
\text { - Make all MPs aware about the constitution of the country and } \\
\text { government's commitment to uphold global development agendas } \\
\text { - Sensitize the MPs about poverty reduction and women's advancement } \\
\text { issues } \\
\text { - Ensure freedom of conscience by making Rules of Procedures more } \\
\text { effective } \\
\text { - Ensure elimination of culture of boycott, absenteeism and delayed } \\
\text { attendance in sessions of the parliament } \\
\text { - Introduce code of conduct and code of ethics for MPs to ensure respect } \\
\text { and tolerance among parliamentarians } \\
\text { - Establish a resource centre in the parliament with sufficient human } \\
\text { resources so that MPs can obtain national and international information as } \\
\text { per need } \\
\text { - Sensitize MPs in 'Gender Budgeting' }\end{array}$ \\
\hline & - Improve oversight function & $\begin{array}{l}\text { - Replacement of ministers as chairman from the Parliamentary } \\
\text { Committees by the MPs } \\
\text { - Permanent staffs recruited for the committees }\end{array}$ & $\begin{array}{l}\text { - Make parliamentary parties more active and effective in policy formulation } \\
\text { - Making parliamentary parties more active and effective in formulation of } \\
\text { laws } \\
\text { - Popularise effective practicing of shadow government } \\
\text { - Ensure that some Standing Committees and Public Accounts Committees } \\
\text { may be chaired by MPs from opposition } \\
\text { - Strengthen Parliamentary Standing Committees } \\
\text { - Implement the recommendations/decisions made by oversight committees } \\
\text { - Increasing access to media on standing committee reports/ activities } \\
\text { - Ensure that MPs don't get involved or intervene in the administration of } \\
\text { their constituencies } \\
\text { - Ensure that standing Committees can enforce the decisions taken by them } \\
\text { - Ensure participation in Parliamentary Standing Committee } \\
\text { - Recruit } 50 \% \text { women in the parliamentary staff } \\
\text { - Discussion of Annual Audit Report of C\&AG by the MPs and reporting on } \\
\text { recovery }\end{array}$ \\
\hline & - Ensure right to information & - 'Right to Information Act' is already in place. & $\begin{array}{l}\text { - Establish legal framework of Right to Information } \\
\text { - Ensure dissemination of information on government's policies, rules and } \\
\text { regulations, peoples rights and obligations to the grassroots level } \\
\text { - Make provision for "town-hall" kind of open forum meeting where public } \\
\text { representative will face questions of the public } \\
\text { - Introduce the system of public hearing for undertaking major projects and } \\
\text { programmes } \\
\text { - Develop a constituency-based interface between MPs and citizens in order } \\
\text { to develop a mechanism for accountability and give women priority in this }\end{array}$ \\
\hline
\end{tabular}




\begin{tabular}{|c|c|c|c|}
\hline Strategic Goals & Key Targets & Actions Taken/ Underway & PRSP Policy Agenda (2009-2011) \\
\hline 1 & 2 & 3 & 4 \\
\hline & & & $\begin{array}{l}\text { body } \\
\text { - Make public media more independent and use it to make people aware of } \\
\text { government's policy and activities } \\
\text { - More authority of BTV and Radio in broadcasting substantive information }\end{array}$ \\
\hline \multicolumn{4}{|c|}{ Lead Responsibility: MoE Associate Responsibility: Cabinet Division, PMO, Finance Division, PATC, APD and all other ministries controlling cadres } \\
\hline \multirow[t]{4}{*}{$\begin{array}{l}\text { 2. Improving public } \\
\text { service management }\end{array}$} & - Enhance human resource development & - A new comprehensive career plan is under consideration & $\begin{array}{l}\text { - Introduce merit based recruitment process } \\
\text { - Introduce quota for women, persons from lagging regions, indigenous } \\
\text { people for next ten years } \\
\text { - Provide need based on-the-job training and scope for professional } \\
\text { development } \\
\text { - Ensure development of ethical sense among the public officials } \\
\text { - Recruit top talents in the service and fast track them in the service } \\
\text { - Include gender dimension in job description } \\
\text { - Update and modernize personnel policies and management systems } \\
\text { - Ensure effective service delivery by public officials } \\
\text { - Strengthen training of the government officials to improve public service } \\
\text { delivery to meet the demands of the citizens }\end{array}$ \\
\hline & - Institutional development & $\begin{array}{l}\text { - Citizen's charter introduced } \\
\text { - New system of performance appraisal is under active } \\
\text { consideration }\end{array}$ & $\begin{array}{l}\text { - Encourage proactive, responsive and trust worthy role of the officers } \\
\text { - Introduce safeguard against political influences on government officials } \\
\text { - Undertake target oriented activities and performance based evaluation } \\
\text { - Ensure that women sensitive citizen's charters are introduced and } \\
\text { effectively implemented } \\
\text { - Ensure women representation in high-level government decision making forum } \\
\text { - Revamp governance of Public Service Commission } \\
\text { - Incorporate ICT/ e-governance at all levels }\end{array}$ \\
\hline & - Procedural change & - Clustering of ministries and divisions is underway & $\begin{array}{l}\text { - Conventional ministerial responsibility would be reformulated making } \\
\text { politicians responsible for 'policy' decisions and civil servants responsible } \\
\text { for clearly defined 'operational' ones } \\
\text { - Ensure timely and friendly service delivery in fair and transparent manner } \\
\text { - Monitor implementation of "Citizen's Charter" } \\
\text { - Ensure that time-bound decision making system is introduced and } \\
\text { government procedures are streamlined and simplified }\end{array}$ \\
\hline & $\begin{array}{l}\text { - Create healthy and enabling working } \\
\text { environment }\end{array}$ & & $\begin{array}{l}\text { - Introduce attractive compensation package } \\
\text { - Introduce Performance award, Quality award, Innovation award, etc. } \\
\text { - Introduce code of conduct addressing harassments including sexual } \\
\text { harassments and include them in service rules }\end{array}$ \\
\hline \multicolumn{4}{|c|}{ Lead Responsibility: MoLJPA Associate Responsibility: MoSICT, MoE, FD } \\
\hline $\begin{array}{l}\text { 3. Improving legal and } \\
\text { judicial system }\end{array}$ & $\begin{array}{l}\text { - Simplify, improve and modernize laws } \\
\text { - Establishment of National Human Rights } \\
\text { Commission }\end{array}$ & $\begin{array}{l}\text { - Lower criminal judiciary separated from the executive } \\
\text { - New appointments of judicial officers is underway } \\
\text { - Training for the Judges is in progress } \\
\text { - Legal Aid mechanism reviewed and enhanced to increase } \\
\text { effectiveness }\end{array}$ & $\begin{array}{l}\text { - Ensure quick and low cost legal access to justice } \\
\text { - Incorporate the ICT in legal process and Case Management and Court } \\
\text { Administration (CMCA) automation } \\
\text { - Appoint a court Ombudsman to ensure transparency and accountability in } \\
\text { the process of justice and reduction of time and cost in case disposal }\end{array}$ \\
\hline
\end{tabular}




\begin{tabular}{|c|c|c|c|}
\hline Strategic Goals & Key Targets & Actions Taken/ Underway & PRSP Policy Agenda (2009-2011) \\
\hline \multirow[t]{3}{*}{1} & $\begin{array}{ll}2 \\
\end{array}$ & 3 & 4 \\
\hline & & - Alternative Dispute Resolution mechanism is introduced & $\begin{array}{l}\text { - Support Judicial Service Commission and its Secretariat by introducing a } \\
\text { research cell for assessing performance, posting, promotion, and transfer of } \\
\text { judges } \\
\text { - Ensure that all judges reveal their assets and the assets/properties of their } \\
\text { family members periodically } \\
\text { - Ensure open law-making process including consultation with people } \\
\text { - Strengthen the law drafting capacity } \\
\text { - Include CSOs and women's groups in implementing open law- making process } \\
\text { - Give proper consideration to gender equality issues in law revision }\end{array}$ \\
\hline & $\begin{array}{l}\text { - Reduce backlog of cases by } 25 \text { percent to } \\
\text { ensure access to justice }\end{array}$ & $\begin{array}{l}\text { - Law revision is under process } \\
\text { - Establishment of booths for public information in the } \\
\text { Supreme Court premises is in progress }\end{array}$ & $\begin{array}{l}\text { - Simplify procedural laws } \\
\text { - Encourage and strengthen alternate dispute resolution (ADR) } \\
\text { - Expand access to law through e-publication and real time updating of cases } \\
\text { - Improve the physical facilities of the court } \\
\text { - Develop website for public information and establish front/help desk to } \\
\text { supply desired information to the clients } \\
\text { - Take measures in accessing legal aid fund by women and poor } \\
\text { - Provide training to judges on CEDAW and NWDP } 2008 \\
\end{array}$ \\
\hline \multicolumn{4}{|c|}{ Lead Responsibility: MoHA Associate Responsibility: MoLJPA, MoWCA, NGOs and Civil Society Organisations } \\
\hline \multirow[t]{2}{*}{$\begin{array}{l}\text { 4. Changing role of law } \\
\text { enforcing agencies }\end{array}$} & - Impartial application of law & $\begin{array}{l}\text { - New Police Act is underway } \\
\text { - Citizen Charter (police) has been launched }\end{array}$ & $\begin{array}{l}\text { - Establish right to information } \\
\text { - Establish mechanism for civil society scrutiny } \\
\text { - Establish an integrated and dedicated investigation cell under Attorney } \\
\text { General } \\
\text { - Set up an Independent Police Complaints Authority with a published } \\
\text { National Policy Plan } \\
\text { - Formulate and implement gender policy for the police } \\
\text { - Undertake rigorous human resource management and intensive training of } \\
\text { the police force } \\
\text { - Ensure transparency in police investigation } \\
\text { - Amend old laws and introduce laws to address new situation } \\
\text { - Ensure that police are not used to serve partisan purpose } \\
\text { - Ensure post mortem report within } 24 \text { hours } \\
\text { - Introduce nationwide network of criminal case information } \\
\text { - Include gender training as part of police training and retraining }\end{array}$ \\
\hline & $\begin{array}{l}\text { - Proper investigation procedure to be in } \\
\text { place }\end{array}$ & & $\begin{array}{l}\text { - Upgrade skills and knowledge of investigators } \\
\text { - Ensure development of ethical values among the law enforcers } \\
\text { - Establish sophisticated laboratory for DNA test in greater districts HQs } \\
\text { - Introduce gender dimension in all police investigations } \\
\text { - Include women in the team of investigators and provide training to develop } \\
\text { gender sensitivity }\end{array}$ \\
\hline \multicolumn{4}{|c|}{ Lead Responsibility: LGD, RDCD Associate Responsibility: Cabinet Division, FD, MoE, NGOs and Civil Society Organisations } \\
\hline $\begin{array}{l}\text { 5. Strengthening local } \\
\text { governments }\end{array}$ & $\begin{array}{l}\text { - Devolution of power and transfer of } \\
\text { resources, capacity building for local }\end{array}$ & $\begin{array}{l}\text { - Fund transfer and budgeting process reformed } \\
\text { - Project planning and implementation in some Union }\end{array}$ & $\begin{array}{l}\text { - Introduce clear mandate of job responsibility including job description of } \\
\text { the women members }\end{array}$ \\
\hline
\end{tabular}




\begin{tabular}{|c|c|c|c|}
\hline Strategic Goals & Key Targets & Actions Taken/ Underway & PRSP Policy Agenda (2009-2011) \\
\hline \multirow[t]{4}{*}{1} & 2 & 3 & 4 \\
\hline & government representatives & $\begin{array}{l}\text { Parishads under a Project } \\
\text { - 25\% of Union Parishad complex built and another } 30 \% \\
\text { under process } \\
\text { - Training for local government representative and staff on } \\
\text { capacity development and resource mobilization is ongoing } \\
\text { under LGS Project } \\
\text { - Training on leadership development and attitudinal change is } \\
\text { in progress } \\
\text { - Partnership building with NGOs and CBOs } \\
\text { - Initiatives for providing training to elected upazila officials } \\
\text { and policy input for strengthening upazila parishad under } \\
\text { upazila strengthening project have undertaken }\end{array}$ & $\begin{array}{l}\text { - Develop capacity and incentive for local resource mobilization } \\
\text { - Ensure recognition for commendable works at the local level } \\
\text { - Forge partnership with NGOs/CBOs } \\
\text { - Provide poverty sensitization through leadership and gender training to the } \\
\text { local government representatives } \\
\text { - Delegate more authority to the local government bodies to solve their own } \\
\text { problems } \\
\text { - Provide more training to the local government bodies in terms of building } \\
\text { their capacity in formulating plans and budgeting } \\
\text { - Finding avenues for enhancing cooperation and coordination between the } \\
\text { UPZ and local MPs and also with union parishad, pourashava and zila } \\
\text { parishad } \\
\text { - Finding mechanism for ensuring people's participation in local } \\
\text { development planning and monitoring }\end{array}$ \\
\hline & - Effective local government & $\begin{array}{l}\text { - Establishment of Local Government Commission is } \\
\text { underway } \\
\text { - Revision and updating of the Laws and Acts are under } \\
\text { process } \\
\text { - Unified legislation for LGIs } \\
\text { - Supply of the ICT material and training in progress } \\
\text { - Encouraging local level need based training }\end{array}$ & $\begin{array}{l}\text { - Uniform application of rules and procedures } \\
\text { - Introduce gradually e-governance at local government level } \\
\text { - Allow flexibility and operational independence to LGIs to address the local } \\
\text { needs } \\
\text { - Promote local level needs assessments and initiatives } \\
\text { - Allow the local government bodies to directly deal with the national } \\
\text { investors and donors } \\
\text { - Establish separate career development plans for the officials and employees } \\
\text { directly employed by the local government } \\
\text { - Activate the standing committees and create scope for women members to } \\
\text { take part in the decision making process of the local government } \\
\text { institutions } \\
\text { - Promote local needs and initiatives considering women's advancement and } \\
\text { rights perspective } \\
\text { - Introduce gender sensitive budgeting and planning at the local level } \\
\text { - Include women and different minority groups in developing LG's } \\
\text { development programmes }\end{array}$ \\
\hline & - Transparency and oversight & $\begin{array}{l}\text { - Citizens' charter introduced } \\
\text { - Access to information enhanced } \\
\text { - Performance and financial auditing introduced } \\
\text { - Website for Local Government Division established }\end{array}$ & $\begin{array}{l}\text { - Ensure full access to service delivery information to the users } \\
\text { - Introduce performance/financial auditing for all LGIs } \\
\text { - Evaluate overall performance by Local Government Commission } \\
\text { - Provide technical and consultancy support by nation building departments } \\
\text { - Introduce local level planning and budgeting and ensure budget } \\
\text { implementation } \\
\text { - Introduce a well-defined gender-sensitive code of conducts for the local } \\
\text { government officials } \\
\text { - Introduce gender and social-audit for local government institutions }\end{array}$ \\
\hline \multicolumn{4}{|c|}{ Lead Responsibility: Cabinet Division Associate Responsibility: MoLJPA, MoSICT and PMO. } \\
\hline $\begin{array}{l}\text { 6. Promoting e- } \\
\text { Governance in the }\end{array}$ & $\begin{array}{l}\text { - e- Access to all the services } \\
\text { - System integration }\end{array}$ & $\begin{array}{l}\text { - Provision for ICT materials for all local government } \\
\text { institutions }\end{array}$ & $\begin{array}{l}\text { - Introduce a legal framework for e- Governance } \\
\text { - Introduce and gradually promote e-governance in all walks of life }\end{array}$ \\
\hline
\end{tabular}




\begin{tabular}{|c|c|c|c|}
\hline Strategic Goals & Key Targets & Actions Taken/ Underway & PRSP Policy Agenda (2009-2011) \\
\hline 1 & 2 & 3 & 4 \\
\hline government & & - ICT policy is in place & $\begin{array}{l}\text { - Ensure public/private partnership and outsourcing } \\
\text { - Establish a nation-wide Third Generation wireless broad-band network to } \\
\text { ensure a High-Speed Down Link Packet Access (HSDPA) } \\
\text { - Simplify policy issues and publicise online for consultations } \\
\text { - Initiate a strategy to get information online } \\
\text { - Involve women in ICT/e-governance } \\
\end{array}$ \\
\hline \multicolumn{4}{|c|}{ Lead Responsibility: Anti Corruption Commission Associate Responsibility: MoHA and MoLJPA } \\
\hline $\begin{array}{l}\text { 7. Combating Corruption } \\
\text { effectively }\end{array}$ & - Establish a corruption free society & $\begin{array}{l}\text { - Legal actions ongoing } \\
\text { - Anti-corruption committee in all districts formed } \\
\text { - Awareness campaign ongoing }\end{array}$ & $\begin{array}{l}\text { - Identify and eliminate legal and procedural loopholes } \\
\text { - Suppress corruption through enforcement of the regulatory framework } \\
\text { - Promote awareness building and undertake advocacy } \\
\text { - Introduce zero tolerance to corruption } \\
\text { - Form citizens groups and ensure women's participation in the anti- } \\
\text { corruption committees at grassroots level } \\
\text { - Strengthening anti-corruption drive }\end{array}$ \\
\hline \multicolumn{4}{|c|}{ Lead Responsibility: MoLJPA Associate Responsibility: MoHA, MoWCA, NGOs and CSOs } \\
\hline $\begin{array}{l}\text { 8. Establishing Human } \\
\text { rights }\end{array}$ & $\begin{array}{l}\text { - Ensure protection of human rights } \\
\text { - Prevention of extra - judicial killings }\end{array}$ & $\begin{array}{l}\text { - Universal Declaration of Human Right ratified } \\
\text { - Government has promulgated 'National Human Rights } \\
\text { Commission' ordinance }\end{array}$ & $\begin{array}{l}\text { - Ensure implementation of law against anti-trafficking of human } \\
\text { - Establish Human Rights Commission } \\
\text { - Establish the office of Ombudsperson } \\
\text { - Establish child right commission } \\
\text { - Undertake public awareness campaign on women's legal rights } \\
\text { - Ensure access to alternative dispute resolution (ADR) and/or legal aid for } \\
\text { domestic violence cases and other forms of human rights violation } \\
\text { - Introduce zero tolerance to VAW and violation of human rights } \\
\text { - Recognize domestic violence as a punishable crime }\end{array}$ \\
\hline \multicolumn{4}{|c|}{ Access to information and awareness building at the grassroots level } \\
\hline \multicolumn{4}{|c|}{ Lead Responsibility: Ministry of Information, other relevant ministries, NGOs, Media, Film Makers } \\
\hline $\begin{array}{l}\text { 9. Ensuring correct } \\
\text { information reaches people }\end{array}$ & $\begin{array}{l}\text { - Disseminate information to people } \\
\text { - Dispel mis-information, prejudicial } \\
\text { believes particularly in the rural areas and } \\
\text { among the poor } \\
\text { - Building greater awareness among people } \\
\text { of physiological disorders }\end{array}$ & $\begin{array}{l}\text { - Provided funds to make good quality films } \\
\text { - Community based radio broadcasting has been approved }\end{array}$ & $\begin{array}{l}\text { - Make documentary films on various social and development issues in } \\
\text { cooperation with stakeholders and view them in the villages, schools, } \\
\text { colleges, clubs etc. } \\
\text { - Ensure that radio and televisions make awareness building programmes } \\
\text { which are innovative, creative, attractive, educational and also } \\
\text { entertainment oriented } \\
\text { - Introduce a new terrestrial information TV channel to improve peoples } \\
\text { awareness of their rights and obligations }\end{array}$ \\
\hline $\begin{array}{l}\text { 10. Empowering people by } \\
\text { giving them information } \\
\text { and } \\
\text { encouraging socially } \\
\text { responsible behaviour }\end{array}$ & $\begin{array}{l}\text { - Increase awareness among people of } \\
\text { their rights, obligations and socially } \\
\text { responsible behaviour }\end{array}$ & & $\begin{array}{l}\text { - Undertake nation wide road-shows, area-based information fair on various } \\
\text { development issues } \\
\text { - Introduce citizens' charters in every government office } \\
\text { - Encourage NGOs to strengthen their roles in a cohesive manner in } \\
\text { disseminating information at the grassroots level }\end{array}$ \\
\hline \multicolumn{3}{|c|}{ Total Indicative Cost (in billion taka) } & Tk. 300.95 \\
\hline
\end{tabular}


Policy Matrix 16: Utility Services Development including Water, Sanitation and Urban Services

\begin{tabular}{|c|c|c|c|}
\hline Strategic goal(s) & Key targets & Action taken/Underway & PRSP policy agenda (FY09-FY11) \\
\hline 1 & 2 & 3 & 4 \\
\hline \multicolumn{4}{|c|}{ I. Water Supply and Sanitation } \\
\hline \multicolumn{4}{|c|}{ Lead Responsibility: LGD, DoPE, } \\
\hline $\begin{array}{l}\text { 1. Ensuring safe water } \\
\text { facilities for all }\end{array}$ & $\begin{array}{l}\text { - Ensure access to safe water for all } \\
\text { - Reduce water borne morbidity \& } \\
\text { mortality } \\
\text { - Reduce proportion of population to } \\
\text { arsenic contamination } \\
\text { - Ensure safe water supply in } 80 \% \text { of } \\
\text { the slum areas } \\
\text { - Identify un-/under-served and } \\
\text { hardship areas to ensure access to safe } \\
\text { water } \\
\text { - Provide arsenic free water supply in } \\
\text { 10,000 villages }\end{array}$ & $\begin{array}{l}\text { - Govt. declared to achieve water for all by } 2011 \\
\text { - National Policy for Arsenic Mitigation formulated } \\
\text { - Plan for Arsenic Mitigation adopted } \\
\text { - Sector Development Framework for Water Supply and Sanitation } \\
\text { (WSS) plan adopted } \\
\text { - Arsenic-testing kits introduced } \\
\text { - Installation of safe water supply systems for un-served/ under- } \\
\text { served areas started } \\
\text { - Developed partnership with NGOs, PVOs, CSOs etc. } \\
\text { - Installation of Deep Tube Wells and Construction of water } \\
\text { reservoirs for Rain Water Harvesting } \\
\text { - Storage of water in reserved ponds } \\
\text { - Creating awareness of people on arsenic issues } \\
\text { - Water supply through pipelines is being provided } \\
\end{array}$ & $\begin{array}{l}\text { - Expand and improve safe water supply facilities in urban and rural areas } \\
\text { - Establish laboratory network for water quality monitoring \& surveillance } \\
\text { programme } \\
\text { - Intensify awareness programme on hygiene practices at the grassroots level } \\
\text { - Strengthen capacities of LGIs and other stakeholders in WSS sector } \\
\text { - Develop alternative technological options to replace arsenic contaminated } \\
\text { tube wells } \\
\text { - Continue ongoing activities }\end{array}$ \\
\hline $\begin{array}{l}\text { 2. Providing hygienic } \\
\text { sanitation facilities }\end{array}$ & $\begin{array}{l}\text { - Ensure access to sanitation for all } \\
\text { - Identify unserved/under-served and } \\
\text { hardship areas to ensure access to } \\
\text { hygienic sanitation } \\
\text { - Ensure access to sanitary community } \\
\text { latrines in village } \\
\text { - Ensure sanitation facilities in } 80 \% \\
\text { slum areas bazar, mosques and } \\
\text { schools }\end{array}$ & $\begin{array}{l}\text { - Govt. declared to achieve sanitation facilities for all by } 2010 \\
\text { - Construction of sanitary latrines in rural areas and urban slums } \\
\text { - } \text { started } \\
\text { - Installation of sanitary latrines in } 32,400 \text { schools started } \\
\text { - Awareness building among the students on hygiene } \\
\text { - Installation of sanitary latrines in slum areas }\end{array}$ & $\begin{array}{l}\text { - Ongoing and Continue up to } 2011 \\
\text { - Ensure women's hygienic sanitation facilities in public spaces } \\
\text { - Increase coverage of school sanitation programme } \\
\text { - Expand and improve sanitation facilities in urban and rural areas }\end{array}$ \\
\hline \multicolumn{4}{|c|}{ Lead Responsibility: MoLGRDC, MoFDM, MoPME, MoE, DPHE, LGED, WASAs, LGIs, NGOs, CSOs, CBOs, CAB } \\
\hline $\begin{array}{l}\text { 3. Strengthening disaster } \\
\text { management and risk } \\
\text { reduction capacity }\end{array}$ & $\begin{array}{l}\text { - Strengthen national disaster } \\
\text { management }\end{array}$ & $\begin{array}{l}\text { - Disaster Management and mitigation system in place } \\
\text { - Formed a Committee and redrafted the Allocation of Business in } \\
\text { relation to MoFDM Mandates } \\
\text { - Formed a Committee for revising the Standing Orders on } \\
\text { Disaster Management } \\
\text { - Flood forecasting and warning and cyclone warning systems in } \\
\text { place } \\
\text { - Agro-meteorological cell established } \\
\text { - Adoption of NAPA for climate change is in process } \\
\text { - Development of drought prediction model initiated } \\
\text { - Launched the MoFDM Website }\end{array}$ & $\begin{array}{l}\text { - Ensure knowledge management on disaster risk reduction (acquiring, } \\
\text { sharing and applying) } \\
\text { - Establish strong local, regional and national networks among stakeholders } \\
\text { - Establish a Disaster Management Cell } \\
\text { - Initiate activities to establish the Disaster Management Information } \\
\text { Centre (DMIC) } \\
\text { - Update disaster management booklet of DPHE }\end{array}$ \\
\hline \multicolumn{4}{|c|}{ II. Environmental improvement for Water \& Sanitation } \\
\hline \multicolumn{4}{|c|}{ Lead Responsibility: MoLGRDC, DPHE, City Corporations, LGED, WASAs, LGIs, NGOs, CSOs, CBOs, CAB } \\
\hline $\begin{array}{l}\text { 4. Improving solid waste } \\
\text { management system }\end{array}$ & $\begin{array}{l}\text { - Introduce efficient collection and } \\
\text { transportation of municipal waste to } \\
\text { the disposal site }\end{array}$ & $\begin{array}{l}\text { - DCC has prepared a Master Plan for sustainable solid waste } \\
\text { management } \\
\text { - A modern land fill site developed \& another is underway }\end{array}$ & $\begin{array}{l}\text { - Develop framework and build capacity to handle trans-boundary } \\
\text { hazardous waste under Basel Convention } \\
\text { - Continue with the initiatives and interventions taken during 2005-2007 }\end{array}$ \\
\hline
\end{tabular}




\begin{tabular}{|c|c|c|c|}
\hline Strategic goal(s) & Key targets & Action taken/Underway & PRSP policy agenda (FY09-FY11) \\
\hline \multirow[t]{2}{*}{1} & 2 & 3 & 4 \\
\hline & $\begin{array}{l}\text { - Segregate at source and introduce safe } \\
\text { disposal of hazardous waste } \\
\text { - Improve solid waste disposal method } \\
\text { in all towns }\end{array}$ & $\begin{array}{l}\text { - Community based urban solid waste management by Waste } \\
\text { - Poncern under SEMP is in progress } \\
\text { - Promoting alternative environment friendly shopping bags } \\
\text { Pilots are ongoing in secondary towns on solid waste management }\end{array}$ & - Construct modern land fill sites as per requirement in all cities \& towns \\
\hline $\begin{array}{l}\text { 5.Improving living } \\
\text { environment in the slums }\end{array}$ & $\begin{array}{l}\text { - Reduce drainage congestions in cities } \\
\text { - Reduce pollution }\end{array}$ & $\begin{array}{l}\text { - Secondary towns improvement project ongoing } \\
\text { - Other metropolitan city investments proposed and ongoing }\end{array}$ & $\begin{array}{l}\text { - Continue with the initiatives and interventions taken during 2005-2007 } \\
\text { - Ensure a regulatory framework for treating industrial pollution }\end{array}$ \\
\hline $\begin{array}{l}\text { 6. Improving open water } \\
\text { quality }\end{array}$ & $\begin{array}{l}\text { - Reduce pollution load in water } \\
\text { ecosystem } \\
\text { - Enact and enforce laws to control } \\
\text { emissions of toxic matter into water }\end{array}$ & $\begin{array}{l}\text { - Installation of Effluent Treatment Plant (ETP) in polluting } \\
\text { industry has been made mandatory and many enterprises have } \\
\text { installed ETP }\end{array}$ & $\begin{array}{l}\text { - Establish water quality monitoring \& surveillance programme and establish } \\
\text { laboratory network } \\
\text { - Take appropriate measures for people-centred pollution-free rivers } \\
\text { through awareness raising and voluntary labour mobilization }\end{array}$ \\
\hline \multicolumn{4}{|c|}{ III. Road Transportation and Communication } \\
\hline \multicolumn{4}{|c|}{ Lead Responsibility: MoC, BRTC } \\
\hline $\begin{array}{l}\text { 7. Improving quality of } \\
\text { city transportation }\end{array}$ & $\begin{array}{l}\text { - Activate DTCB for City transportation } \\
\text { improvement } \\
\text { - Ensure improved road transportation } \\
\text { \& road safety }\end{array}$ & $\begin{array}{l}\text { - Manpower \& organisational set up approved } \\
\text { - Improvement of traffic regulation being undertaken } \\
\text { - Road sign and signal manual is introduced } \\
\text { - Road safety addressed in all projects } \\
\text { - Developed computerized accident database } \\
\text { - Provide input/support to National Road Safety Council }\end{array}$ & $\begin{array}{l}\text { - Develop DTCB as per approved set up } \\
\text { - Undertake action programme as per STP } \\
\text { - Further improve road \& traffic regulation in the city to reduce travel time } \\
\text { - Construct } 18 \text { overload control station }\end{array}$ \\
\hline \multicolumn{4}{|c|}{ IV. Bangladesh Railway (BR) } \\
\hline \multicolumn{4}{|c|}{ Lead Responsibility: MoC, BR, MoC, PSOs } \\
\hline $\begin{array}{l}\text { 8. Developing railways as } \\
\text { mass transport }\end{array}$ & $\begin{array}{l}\text { - Improve customer service \& } \\
\text { operational efficiency } \\
\text { - Make railway responsive to market } \\
\text { needs and sound business practices }\end{array}$ & $\begin{array}{l}\text { - Computerized seat reservation and ticketing system } \\
\text { - Commercial activities of mail, express and local train have been } \\
\text { privatized } \\
\text { - On board services of } 16 \text { intercity trains privatized } \\
\text { - Extra capacity BR's fibre optic telecom system leased out } \\
\text { - Repairing and cleaning of locomotives and passenger carriages } \\
\text { and conversion of non-AC into AC coaches on BOT basis are } \\
\text { underway }\end{array}$ & $\begin{array}{l}\text { - Continue and identify ways to increase association of private sector and } \\
\text { outsourcing } \\
\text { - Continue with actions already taken }\end{array}$ \\
\hline \multicolumn{4}{|c|}{ V. Bangladesh Road Transport Corporation (BRTC) } \\
\hline \multicolumn{4}{|c|}{ Lead Responsibility: MoC, BRTC } \\
\hline $\begin{array}{l}\text { 9. Modernising road } \\
\text { transport service \& } \\
\text { enhance services to } \\
\text { people, especially the } \\
\text { poor and persons with } \\
\text { disability }\end{array}$ & $\begin{array}{l}\text { - Improve passenger services } \\
\text { - Promote safe \& improved driving, } \\
\text { maintenance, repair, operation and } \\
\text { management of vehicles }\end{array}$ & $\begin{array}{l}\text { - Repaired \& rehabilitated double and single Decker buses } \\
\text { - Procured new bus \& truck fleet } \\
\text { - Procurement of single Decker and double Decker CNG buses is } \\
\text { under process } \\
\text { - } 6 \text { Driving Training Institutes setup and } 6 \text { more Driving Training } \\
\text { Institutes are underway }\end{array}$ & $\begin{array}{l}\text { - Procure } 600 \text { Double Decker buses } \\
\text { - Procure } 100 \mathrm{CNG} \text { Single Decker buses } \\
\text { - Procure } 500 \text { trucks } \\
\text { - Open new bus depots/units in different districts } \\
\text { - Increase inspection and monitoring of activities at all levels } \\
\text { - Ensure expansion of private sector participation }\end{array}$ \\
\hline \multicolumn{4}{|c|}{ VI. Bangladesh Road Transport Authority (BRTA) } \\
\hline \multicolumn{4}{|c|}{ Lead Responsibility: MoC, BRTA } \\
\hline $\begin{array}{l}\text { 10. Ensuring road safety } \\
\text { \& better service in road } \\
\text { transportation }\end{array}$ & $\begin{array}{l}\text { - Ensure discipline in road } \\
\text { transportation }\end{array}$ & $\begin{array}{l}\text { - Road permits issued depending on road condition } \\
\text { - Fixing uniform rates for different types of transport } \\
\text { - Implementing speed and weight limits } \\
\text { - Ordinance \& rules are under modification }\end{array}$ & $\begin{array}{l}\text { - Set up weigh bridge in all important positions } \\
\text { - Ensure that no transport ply with weight and speed beyond legal } \\
\text { limit } \\
\text { - Fix distance at the time of issuing the route permit }\end{array}$ \\
\hline
\end{tabular}




\begin{tabular}{|c|c|c|c|}
\hline Strategic goal(s) & Key targets & Action taken/Underway & PRSP policy agenda (FY09-FY11) \\
\hline \multirow[t]{7}{*}{1} & 2 & 3 & 4 \\
\hline & & & - Set up weighing machines at least in 7 important positions \\
\hline & $\begin{array}{l}\text { - Ensure environment friendly transport } \\
\text { in Bangladesh }\end{array}$ & $\begin{array}{l}\text { - 2- stroke three wheelers phased out from Dhaka metropolitan } \\
\text { area } \\
\text { - Increasingly introducing CNG/Euro engine }\end{array}$ & $\begin{array}{l}\text { - Ban 2-stroke three wheelers all over the country } \\
\text { - Ban buses older than } 20 \text { years and trucks older than } 25 \text { years in Dhaka } \\
\text { metropolitan area }\end{array}$ \\
\hline & $\begin{array}{l}\text { - Bring discipline in issuing driving } \\
\text { license and registration certificates }\end{array}$ & $\begin{array}{l}\text { - Laminated driving license \& registration certificates are } \\
\text { introduced }\end{array}$ & $\begin{array}{l}\text { - Introduce retro-reflective registration plate with hologram } \\
\text { - Embody security mark in the registration certificates }\end{array}$ \\
\hline & $\begin{array}{l}\text { - Introduce automation and share } \\
\text { information with all concerned }\end{array}$ & $\begin{array}{l}\text { - A central server set up \&WAN established partially in Dhaka } \\
\text { south and Dhaka north } \\
\text { - LAN has been completed at HQ }\end{array}$ & $\begin{array}{l}\text { - Bring Zonal offices under WAN } \\
\text { - Extend network to related offices - police, banks/post offices etc. } \\
\text { - Introduce auto-input output activities of all works in auto backup }\end{array}$ \\
\hline & $\begin{array}{l}\text { - Preserve all information in computer } \\
\text { database }\end{array}$ & $\begin{array}{l}\text { - Old data has already been taken into the database } \\
\text { - Developing auto back-up system in circle \& zonal offices }\end{array}$ & $\begin{array}{l}\text { - Complete auto back-up system of data in zonal and circle offices } \\
\text { - Update entry of all data relating to activities of BRTA }\end{array}$ \\
\hline & $\begin{array}{l}\text { - Introduce road safety education and } \\
\text { training }\end{array}$ & $\begin{array}{l}\text { - Trained drivers and conductors of } 4 \text { old districts } \\
\text { - Made short films for awareness building on road safety }\end{array}$ & $\begin{array}{l}\text { - Cover all old districts within the period } \\
\text { - Continue with awareness building of children \& pedestrians }\end{array}$ \\
\hline \multicolumn{4}{|c|}{ VII. Biman Bangladesh Airlines Limited } \\
\hline \multicolumn{4}{|c|}{ Lead Responsibility: MoCAT, Biman Bangladesh } \\
\hline $\begin{array}{l}\text { 11. Increasing scale of } \\
\text { operation }\end{array}$ & $\begin{array}{l}\text { - Modernize Biman's fleet } \\
\text { - Improve financial performance } \\
\text { - Enhance air cargo capacity for } \\
\text { promoting export }\end{array}$ & $\begin{array}{l}\text { - Addition of aircraft on wet and dry lease is under process } \\
\text { - Cost cutting measures have been implemented } \\
\text { - Biman converted into a Public Limited Company } \\
\text { - More frequent Gulf \& Middle-East flights are being operated }\end{array}$ & $\begin{array}{l}\text { - Increase capacity through leasing of aircraft } \\
\text { - Improve passenger services } \\
\text { - Provide equity for acquisition of new aircraft } \\
\text { - Protect Biman's traffic and handling rights as a national carrier } \\
\text { - Concentrate operation in the Gulf and Middle-East region } \\
\text { - Allow carrying perishable export cargo by foreign carriers }\end{array}$ \\
\hline \multicolumn{4}{|c|}{ VIII. Bangladesh Inland Water Transport Corporation (BIWTC) } \\
\hline \multicolumn{4}{|c|}{ Lead Responsibility: MoS, BIWTC, Private sector MoS, BIWTC, PSOs } \\
\hline $\begin{array}{l}\text { 12. Enhancing quality of } \\
\text { Water Transport }\end{array}$ & $\begin{array}{l}\text { - Promote water transportation in } \\
\text { the inland and coastal water ways } \\
\text { - Provide safe and cheaper } \\
\text { transportation for the mass people } \\
\text { including woman } \\
\text { - Emphasize efficient passenger service } \\
\text { in long distance inland water routes } \\
\text { - Provide uninterrupted ferry services }\end{array}$ & $\begin{array}{l}\text { - Rehabilitation of } 2 \text { Coastal Passenger Vessels for BIWTC is } \\
\text { being carried out } \\
\text { - Rehabilitation of } 6 \text { Ro-Ro Ferry, } 2 \text { K-type Ferry, } 6 \text { Pontoons and } \\
\text { modification of Passenger Steamer M.V. Sonargaon are on going } \\
\text { - Construction/Procurement of } 2 \text { K-type ferries for Mawa ferry } \\
\text { ghat } \\
\text { - Construction/Procurement of } 2 \text { Ro-Ro ferries and } 2 \text { Ro-Ro } \\
\text { Pontoon in Mawa ferry sector } \\
\text { - Construction of steel jetty at Sandwip is underway } \\
\text { - Construction/Acquisition of } 2 \text { Container Vessels is under } \\
\text { - Epproval }\end{array}$ & $\begin{array}{l}\text { - Procure Water Taxi for operation in the circular water route } \\
\text { - Procure container vessel for cargo transportation } \\
\text { - Introduce Ro-Ro ferry services in Mawa sector } \\
\text { - Construct } 4 \text { Sea-Trucks for carrying passengers in the coastal belt and in } \\
\text { the risky inland water routes } \\
\text { - Construct/Procure } 1 \text { passenger vessel of capacity } 500 \text { suitable for } \\
\text { operation in all seasons } \\
\text { - Construct/Procure } 4 \text { self propelled cellular container vessels of } 100 \text { TEU } \\
\text { - Construct/Procure } 2 \text { Coastal Ferries and } 2 \text { Pontoons with Stable Ramp } \\
\text { - for operation in Bhola-Laxmipur Ferry route } \\
\text { - Install Hi-Tech Navigation System at Paturia and Mawa Ferry Route and } 4 \\
\text { Ferry ships for uninterrupted operation } \\
\text { - Construct/Procure } 2 \text { Shallow Draft Oil Tankers } \\
\text { - Procure/install modern equipments/facilities for increasing the efficiency } \\
\text { - Rehabilitate } 4 \text { medium type ferries } \\
\text { - Construct/Procure a Salvage tug of capacity } 2000 \text { H.P. }\end{array}$ \\
\hline $\begin{array}{l}\text { 13. Expanding Water } \\
\text { Transport services }\end{array}$ & $\begin{array}{l}\text { - Establish Bhola-Barisal and Laxmipur- } \\
\text { Bhola ferry services }\end{array}$ & $\begin{array}{l}\text { - Opening new ferry services at Laxmipur-Bhola and Bhola-Barisal } \\
\text { ferry route }\end{array}$ & - Continue with the ongoing actions \\
\hline
\end{tabular}




\begin{tabular}{|c|c|c|c|}
\hline Strategic goal(s) & Key targets & Action taken/Underway & PRSP policy agenda (FY09-FY11) \\
\hline \multirow[t]{7}{*}{1} & 2 & 3 & 4 \\
\hline & $\begin{array}{l}\text { - Promote transportation facilities in the } \\
\text { remote areas }\end{array}$ & & $\begin{array}{l}\text { - Opening Sea-truck services as and where necessary } \\
\text { - Open Chittagong-Cox's Bazar tourist services } \\
\text { - Open Dhaka-Bhola passenger services } \\
\end{array}$ \\
\hline & $\begin{array}{l}\text { - Open avenues for private sector } \\
\text { participation }\end{array}$ & $\begin{array}{l}\text { - Organizational reforms and sound business practice in effect } \\
\text { - Charter out cargo fleet and coastal passenger routes }\end{array}$ & - Make the organization more responsive \\
\hline & $\begin{array}{l}- \text { Emphasize routine periodic } \\
\text { maintenance of BIWTC's fleet }\end{array}$ & - Identify the vessel on priority basis \& prepare necessary schedule & - Introduce modern technology and machineries in existing dockyards \\
\hline & $\begin{array}{l}\text { - Ensure environment protection and } \\
\text { disaster risk reduction }\end{array}$ & - Infrastructures damaged by 'SIDR' are being rehabilitated. & $\begin{array}{l}\text { - Continue with the actions } \\
\text { - Take preventive measures for future disaster risk reduction }\end{array}$ \\
\hline & - Ensure cost reduction & - Make CNG conversion of main engines of major ferries & - Implement a project to ensure cost reduction \\
\hline & $\begin{array}{l}\text { - Introduce waterways in and around } \\
\text { Dhaka city }\end{array}$ & - Construction of cargo and passenger facilities & - Undertake action following the approval of the project \\
\hline \multicolumn{4}{|c|}{ Lead Responsibility: Energy Division, Petroleum \& Mineral Resources Division Associate Responsibility: DESA, DESCO, West Zone Power Distribution Company (WZPDC), REB } \\
\hline $\begin{array}{l}\text { 14. Ensuring reliable } \\
\text { power supply }\end{array}$ & $\begin{array}{l}\text { - Define service standard } \\
\text { - Improve financial performance } \\
\text { - Reduce power interruption } \\
\text { - Reduce System Loss to } 11 \% \\
\text { - Maintain bill collection ratio at } 98 \% \\
\text { - Improve C.I. ratio to } 87 \%\end{array}$ & $\begin{array}{l}\text { - Reduced interruption to } 6 \mathrm{hrs} / \mathrm{yr} / \text { consumer } \\
\text { - Reduced frequency of interruption to } 10 \mathrm{hrs} / \mathrm{yr} / \text { feeder } \\
\text { - Reduced each interruption to not more than } 1 \mathrm{hr} \\
\text { - Ensuring feeder wise functioning in all companies } \\
\text { - Installing one stop service in all divisions } \\
\text { - Operation \& Maintenance of the feeder applying TQM } \\
\text { - Introducing E-governance and MIS in all companies } \\
\end{array}$ & $\begin{array}{l}\text { - All distribution companies to work to achieve these targets } \\
\text { - Improve load management to distribute peak demand on } 24 \mathrm{hrs} \text {. } \\
\text { - Monitor power distribution feeder wise } \\
\text { - Establish feeders as strategic business units (cost centres) } \\
\text { - Establish one stop service centres } \\
\text { - Establish feeder wise maintenance and service centres } \\
\text { - Operationalise prepaid metering }\end{array}$ \\
\hline \multicolumn{4}{|c|}{ IX. Tourism Development } \\
\hline \multicolumn{4}{|c|}{ Lead Responsibility: MoCAT Associate Responsibility: all relevant ministries } \\
\hline \multirow[t]{6}{*}{$\begin{array}{l}\text { 15. Expanding tourism } \\
\text { for growth }\end{array}$} & $\begin{array}{l}\text { - Improve institutional arrangement for } \\
\text { tourism }\end{array}$ & $\begin{array}{l}\text { - Beach Management Committees formed } \\
\text { - Approved Destination Status from China obtained to facilitate } \\
\text { arrival of more Chinese tourists } \\
\text { - NTO being reformed }\end{array}$ & $\begin{array}{l}\text { - Institutionalize participation in Tourism Satellite Accounts of World } \\
\text { Tourism Organization } \\
\text { - Establish a regulatory framework to protect tourists interests }\end{array}$ \\
\hline & $\begin{array}{l}\text { Develop new tourism sites in } \\
\text { collaboration with other agencies/ } \\
\text { private sector }\end{array}$ & $\begin{array}{l}\text { - Prepared Integrated Tourism Development Plan for inter } \\
\text { ministerial Cooperation for Tourism Development such as - } \\
\text { Environment, Forest, LGED, Roads \& Highways, } \\
\text { Archaeological Department etc. }\end{array}$ & $\begin{array}{l}\text { - Develop Kuakata Buddist Temple } \\
\text { - Establish Mirinja Tourism Centre } \\
\text { - Establish Safari Park at Gazipur, Eco-park at Madhabkunda, Charkukri- } \\
\text { Mukri with Department of Forest } \\
\text { - Develop more archaeological sites for cultural tourism }\end{array}$ \\
\hline & - Develop infrastructure for tourism & - Special Tourism Zone and Exclusive Tourism Zones taken up & $\begin{array}{l}\text { - Develop special and exclusive tourist zones } \\
\text { - Establish meeting, conference and exposition facilities } \\
\text { - Procure transports and other crafts for reverie and beach tourism }\end{array}$ \\
\hline & - Promote private sector for Tourism & $\begin{array}{l}\text { - Bank loan and micro-credit facilities extended } \\
\text { - Land allotted at Cox's Bazar for hotel, motel }\end{array}$ & $\begin{array}{l}\text { - Diversify tourism products in collaboration with private sector } \\
\text { - Continue promotion of private sector through different incentives }\end{array}$ \\
\hline & $\begin{array}{l}\text { - Develop human resources for tourism } \\
\text { services }\end{array}$ & $\begin{array}{l}\text { - National Hotel and Tourism Training Institute is being upgraded } \\
\text { and training activities intensified }\end{array}$ & $\begin{array}{l}\text { - Prepare annual work plan of NHTTI based on training needs } \\
\text { - Consider establishing training facilities in other areas }\end{array}$ \\
\hline & $\begin{array}{l}\text { - Ensure safety in important tourist } \\
\text { spots }\end{array}$ & - Established a special police unit in Cox’s Bazar sea beach & $\begin{array}{l}\text { - Evaluation of beach outposts completed \& implementation undertaken by } \\
\text { Police Reform Programme }\end{array}$ \\
\hline
\end{tabular}




\begin{tabular}{|c|c|c|c|}
\hline Strategic goal(s) & Key targets & Action taken/Underway & PRSP policy agenda (FY09-FY11) \\
\hline 1 & 2 & 3 & 4 \\
\hline \multicolumn{4}{|l|}{ X. Post, Telecom \& ICT } \\
\hline \multicolumn{4}{|c|}{ Lead Responsibility: MoPT\&T, PT\&T, BPO, PSOs } \\
\hline \multirow[t]{2}{*}{$\begin{array}{l}\text { 16. Improving access to } \\
\text { ICT, Telecom \& Postal } \\
\text { services }\end{array}$} & $\begin{array}{l}\text { - Expand internet network } \\
\text { - Facilitate voice video data } \\
\text { communications } \\
\text { - Minimize digital gap } \\
\end{array}$ & $\begin{array}{l}\text { - Tender invited for installation of fibre optic line under BOO- } \\
\text { BOT }\end{array}$ & $\begin{array}{l}\text { - Expand ICT facility } \\
\text { - Empower rural people through diffusion of ICT in rural areas } \\
\text { - Continue with the action } \\
\text { - Develop ICT infrastructure under BOO-BOT }\end{array}$ \\
\hline & $\begin{array}{l}\text { - Set up digital telephone exchanges in } \\
\text { Upazilas \& growth centres }\end{array}$ & $\begin{array}{l}\text { - Approval of revised DPP is underway } \\
\text { - Extension of project up to } 2007 \text { is under consideration } \\
\text { - Installation of RSU \& MSU in } 178 \text { Upazila \& } 42 \text { growth centres } \\
\text { is underway } \\
\text { - Installation of } 37 \text { towers is under process }\end{array}$ & $\begin{array}{l}\text { - Continue expansion of digital telephone facilities in Upazilas \& growth } \\
\text { centres }\end{array}$ \\
\hline $\begin{array}{l}\text { 17. Modernising postal } \\
\text { services for better service } \\
\text { to people }\end{array}$ & $\begin{array}{l}\text { - Automate postal services } \\
\text { - Capacity building of BPOs through } \\
\text { HRD }\end{array}$ & $\begin{array}{l}\text { - Initiative is taken for automation of postal services } \\
\text { - HRD initiative is in process }\end{array}$ & $\begin{array}{l}\text { - Service counters and postal accounting to be automated } \\
\text { - Automatise service delivery } \\
\text { - Create staff capacity for automation \& improved service } \\
\end{array}$ \\
\hline \multicolumn{4}{|c|}{ XI. Safety, Security and Protection of Life, Liberty and Wealth } \\
\hline \multirow{2}{*}{\multicolumn{2}{|c|}{\begin{tabular}{l|l}
\multicolumn{2}{|l}{ Lead Responsibility: MoHA, Bangladesh Police, Criminal Justice \& } \\
$\begin{array}{l}\text { 18. Ensuring safety \& } \\
\text { security of life, liberty \& }\end{array}$ & $\bullet$ Criminal Justice reform \\
wealth for all &
\end{tabular}}} & 1 Associate Responsibility: Criminal Justice \& Jail MoHA, BP, MoI & PA, DoFSCD, Ansar, BDR, NGOs, CSOs \\
\hline & & $\begin{array}{l}\text { - Speedy Trial Act, } 2002 \text { passed } \\
\text { - } 9 \text { Speedy Trial Tribunals established } \\
\text { - Acid Offences Act, } 2002 \text { enacted } \\
\text { - Monitoring cell established in Home Ministry } \\
\text { - Rapid Action Battalion established in } 2004 \\
\text { - Independent public prosecution service proposed } \\
\text { - Project to enhance criminal justice and access of the poor to } \\
\quad \text { justice undertaken }\end{array}$ & $\begin{array}{l}\text { - Complete meaningful separation of judiciary from executive } \\
\text { - Promote ADR utilizing community capacities including local governments } \\
\text { - Implement independent public prosecution service } \\
\text { - Strengthen safeguards in implementation of speedy solutions } \\
\text { - Standards setting in lower judiciary } \\
\text { - Promote legal literacy and strengthen legal assistance for poor }\end{array}$ \\
\hline & - Police reform & $\begin{array}{l}\text { - Police Regulations of Bengal is being replaced by new act } \\
\text { - Committee to update Jail Code established } \\
\text { - Developing national protocols for victim referrals } \\
\text { - Drafting Code of Ethics and Code of Conduct for Police } \\
\text { - Developed a new Crime Prevention and Community Safety } \\
\text { system }\end{array}$ & $\begin{array}{l}\text { - Revision of the Bengal Police Regulation will be completed } \\
\text { - Gender Guide Lines will be introduced } \\
\text { - New law to curb domestic violence is under process } \\
\text { - Make a new THB Act to tackle Trafficking of Human Beings } \\
\text { - Develop a programme for integrating the thana and the chowkidari } \\
\text { systems and promote community policing }\end{array}$ \\
\hline & - Develop and modernize police & $\begin{array}{l}\text { - Construction of the } 6 \text { new model thanas are underway } \\
\text { - A Model Victim Support Centre is being established at the } \\
\text { Teigaon Women Police station } \\
\text { - Establishment of a Crime Prevention Centre is underway } \\
\text { - ICT initiatives for capacity building of BP are under way }\end{array}$ & $\begin{array}{l}\text { - Establish an IT (Cyber) Crime Investigation Facility at CID HQ } \\
\text { - Establish beach outposts at Cox's Bazar }\end{array}$ \\
\hline & - Reform Jail & $\begin{array}{l}\text { - } 2 \text { central jails and } 34 \text { district jails are under construction } \\
\text { - Established } 4 \text { correctional and rehabilitation centres for children } \\
\text { and } 1 \text { under construction } \\
\text { - Established } 1 \text { safe-home for women inmates in each division } \\
\text { - Computerisation of prison administration is under process }\end{array}$ & $\begin{array}{l}\text { - Provide vocational training for inmates, particularly female inmates } \\
\text { - Ensure Safe Homes for women to ensure their safety and well-being }\end{array}$ \\
\hline & - Promote ADR for rural population & - Pilot experiences are being accumulated & - Collate pilot experiences for wider replication \\
\hline
\end{tabular}




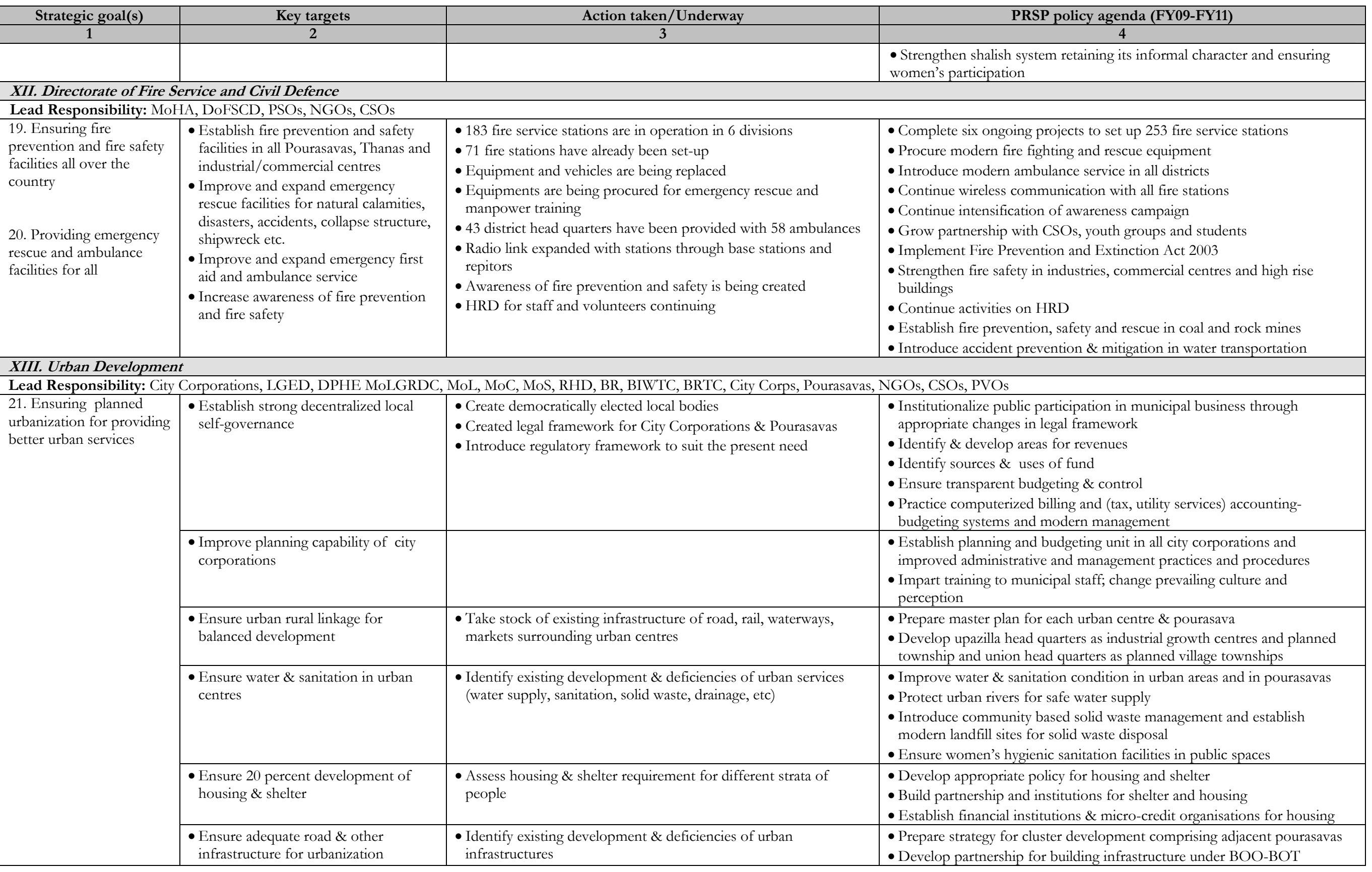




\begin{tabular}{|c|c|c|c|}
\hline Strategic goal(s) & Key targets & Action taken/Underway & PRSP policy agenda (FY09-FY11) \\
\hline 1 & 2 & 3 & 4 \\
\hline & & & $\begin{array}{l}\text { - Establish mechanism for coordination involving all agencies, NGOs, } \\
\text { CSOs, PVOs etc. }\end{array}$ \\
\hline & - Provide recreational facilities & $\begin{array}{l}\text { - Identify existing \& future recreational requirements like parks, } \\
\text { playground, auditoriums, libraries etc }\end{array}$ & $\begin{array}{l}\text { - Identify land for joint venture development of recreational facilities } \\
\text { - Utilize urban river banks for development of linear park \& other } \\
\text { recreational facilities under BOO-BOT basis }\end{array}$ \\
\hline \multicolumn{3}{|c|}{ Total Indicative Cost (in billion taka) } & Tk. 168.00 \\
\hline
\end{tabular}




\begin{tabular}{|c|c|c|c|}
\hline Strategic Goals & Key Targets & Actions Taken/ Underway & PRSP Policy Agenda (2009-2011) \\
\hline 1 & 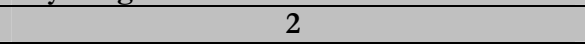 & 3 & 4 \\
\hline & $\begin{array}{l}\text { - Participatory and co-management of NRM } \\
\text { - Equity and benefit sharing of natural } \\
\text { resources among population }\end{array}$ & & $\begin{array}{l}\text { management experts } \\
\text { - Develop the organizational capacity for a well defined set up of organogram } \\
\text { - Develop environmental accountability in all sectors } \\
\text { - Develop mandatory participatory and co-management approach in all CPRs } \\
\text { - Include } 50 \% \text { women in all organization, agencies, sectors to ensure compliance and } \\
\text { good governance } \\
\text { - Build capacity for international negotiations through training, database, analytical } \\
\text { research, documentation and reporting } \\
\text { - Develop the alternative project option to phase-out the ODS }\end{array}$ \\
\hline \multicolumn{4}{|c|}{ 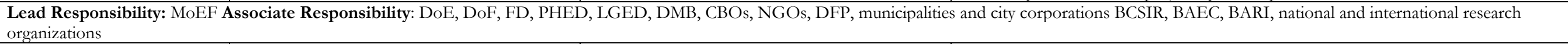 } \\
\hline $\begin{array}{l}\text { 5. Strengthening the process } \\
\text { of environmental analysis in } \\
\text { project design and } \\
\text { implementation }\end{array}$ & $\begin{array}{l}\text { - All environmental laws, regulations are } \\
\text { applied } \\
\text { - DoE's activity at the district levels } \\
\text { - Public participation in all environment } \\
\text { related decisions }\end{array}$ & $\begin{array}{l}\text { - Public participation in environment related } \\
\text { project formulation and implementation is } \\
\text { being practiced } \\
\text { - Internet service has been established in many } \\
\text { environmental organizations and is under way } \\
\text { in rest of the organizations } \\
\text { - An environmental analysis framework for } \\
\text { project design and implementation has been } \\
\text { developed } \\
\text { - State of Environment is publishing Reports on } \\
\text { a regular basis }\end{array}$ & $\begin{array}{l}\text { - Recruit professional staff in DoE } \\
\text { - Continue awareness programmes among scientific, technical and managerial } \\
\text { personnel } \\
\text { - Expand the DoE activities up to the district levels } \\
\text { - Develop a website for environmental clearance certificate (ECC) and EMP } \\
\text { procedures } \\
\text { - Establish mandatory public consultation process in all EIA, EMP, ETP and other } \\
\text { relevant activities } \\
\text { - Create awareness about the importance of EIA among women entrepreneurs }\end{array}$ \\
\hline \multicolumn{4}{|c|}{ Lead Responsibility: MoEF Associate Responsibility: All relevant Ministries, CBOs, NGOs, DFP, media } \\
\hline $\begin{array}{l}\text { 6. Ensuring sustainable land } \\
\text { management }\end{array}$ & $\begin{array}{l}\text { - Reduce the rate of shifting cultivation from } \\
51 \% \text { to } 30 \%\end{array}$ & $\begin{array}{l}\text { - Food for work based river excavation and } \\
\text { development of embankment have been } \\
\text { conducted }\end{array}$ & $\begin{array}{l}\text { - Enforce land zoning and control measures } \\
\text { - Restore khas land, polluted water bodies and ecosystem for common usages } \\
\text { - Continue the community-based earth excavation work involving poor peoples } \\
\text { - Increase the extension activities to produce improved seeds of local plant species } \\
\text { - Establish monitoring and evaluation systems with the help of concerned authorities } \\
\text { - Conduct } 64 \text { workshops and training programmes for 200,000 peoples from } \\
\text { different stakeholder groups in each district }\end{array}$ \\
\hline \multicolumn{4}{|c|}{ 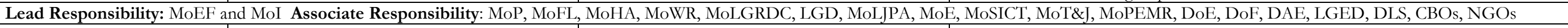 } \\
\hline $\begin{array}{l}\text { 7. Controlling Industrial } \\
\text { pollution }\end{array}$ & $\begin{array}{l}\text { - } 50 \% \text { of all amber-b and red category } \\
\text { industries under Environmental clearance } \\
\text { systems and proper maintenance of EMP } \\
\text { - Environmental management plan (EMP), } \\
\text { effluent treatment plant (ETP) and health } \\
\text { management system in all polluting } \\
\text { industries } \\
\text { - EMP in occupational health risk bearing } \\
\text { industries } \\
\text { - Initial environmental examination (IEE) and } \\
\text { environmental impact assessment (EIA) of } \\
100 \% \text { industries prior to their establishment }\end{array}$ & $\begin{array}{l}\text { - Pilot schemes to carry out the improvement of } \\
\text { environmental management in textile sectors } \\
\text { - Developed a committee to recommend } \\
\text { measures for highly polluted industries } \\
\text { - MoI is implementing BOILER ACT, } \\
\text { regulation and rules } \\
\text { - BSCIC has taken an initiative to relocate } \\
\text { tanneries, garments industries and } \\
\text { pharmaceuticals industries that exist in the } \\
\text { residential area and inside the main cities } \\
\text { - For industrial waste water treatment, researches } \\
\text { are going on in some universities }\end{array}$ & $\begin{array}{l}\text { - Continue to enforce all environmental policies, rules and regulations to the } \\
\text { polluting industries } \\
\text { - Introduce mandatory environmental friendly solid and other wastes management } \\
\text { system } \\
\text { - Develop sector specific EIA guidelines } \\
\text { - Amend Environment Conservation Rules, } 1997 \text { keeping provision of public } \\
\text { participation in EIA approval. } \\
\text { - Enforce to develop Common Effluent Treatment Plant (CETP) in all private sector } \\
\text { run industrial parks } \\
\text { - Develop the Environmental Management Programme } \\
\text { - Set up a strong networking system among all relevant industries through } \\
\text { establishing a database with relevant information }\end{array}$ \\
\hline
\end{tabular}




\begin{tabular}{|c|c|c|c|}
\hline Strategic Goals & Key Targets & Actions Taken/ Underway & PRSP Policy Agenda (2009-2011) \\
\hline 1 & 2 & 3 & 4 \\
\hline & $\begin{array}{l}\text { - Polluter-to-pay applied to } 100 \text { percent } \\
\text { industries }\end{array}$ & $\begin{array}{l}\text { - Implementations of ECC, IEE, EIA, EMP and } \\
\text { ETP has been initiated }\end{array}$ & $\begin{array}{l}\text { - Create awareness of women and men labour force on health hazard from industrial } \\
\text { pollution and take safeguard measures }\end{array}$ \\
\hline \multicolumn{4}{|c|}{ 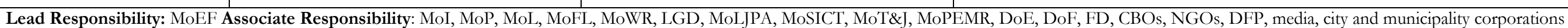 } \\
\hline $\begin{array}{l}\text { 8. Controlling air } \\
\text { pollution in major } \\
\text { metropolitan cities and rural } \\
\text { settings }\end{array}$ & $\begin{array}{l}\text { - Reduce current ambient air quality of } 138 \\
\mu \mathrm{m} 3 / \text { year for PM } 10 \text { to } 100 \mu \mathrm{m} 3 / \text { year and } \\
77 \mu \mathrm{m} 3 / \text { year for PM } 2.5 \text { to } 40 \mu \mathrm{m} 3 / \text { year in } \\
\text { major metropolitan cities including Dhaka } \\
\text { - Reduce the emissions at the national } \\
\text { standard level of } 4,000 \text { motorized vehicles } \\
\text { running outside Dhaka and } 50 \% \text { of total } \\
\text { vehicles inside Dhaka } \\
\text { - Control of GHG emission from } 60 \% \text { of } \\
\text { automobiles and } 20 \% \text { of brick kiln sources } \\
\text { in all urban areas } \\
\text { - Motor Vehicle Ordinance and } \\
\text { Environmental Court } 2000 \text { in major } \\
\text { metropolitan cities enforced } \\
\text { - Establish CAMPS }\end{array}$ & $\begin{array}{l}\text { - Banned two-stroke three-wheeler in Dhaka city } \\
\text { since September, } 2002 \text { and switched to CNG } \\
\text { - Installed the Catalytic Converter and Diesel } \\
\text { Particulate Filter becomes mandatory } \\
\text { - Installed the Continuous Air Monitoring } \\
\text { Station in Dhaka and other metropolitan cities } \\
\text { - Invented fuel-efficient cooking stoves for the } \\
\text { poor } \\
\text { - Limited diffusion of efficient stoves } \\
\text { - Two-stroke engine vehicles replaced with four- } \\
\text { stroke, CNG run ones in Dhaka } \\
\text { - Vehicular Emission Standard and Ambient Air } \\
\text { Quality Standard updated under AQMP } \\
\text { Project } \\
\text { - Initiated the improvement of brick kiln } \\
\text { - Initiated the EMP in all polluting industries } \\
\text { - Developed monitoring and evaluation systems } \\
\text { both inside and outside the stakeholders } \\
\text { - Implemented CASE project }\end{array}$ & $\begin{array}{l}\text { - Implement the procedures of the State Air Quality Standard (AQS) in the vehicles } \\
\text { of urban areas and all polluting industries } \\
\text { - Ensure mandatory use of four-stroke engine in all cities } \\
\text { - Arrange campaign, workshop and training programmes among owners and drivers } \\
\text { of vehicles and relevant managers of polluting industries for utilizing the clean and } \\
\text { renewable energies } \\
\text { - Establish vehicle inspection and maintenance programmes in all metropolitan cities } \\
\text { - Identify industries including brick kiln which are responsible for air pollution and } \\
\text { - } \text { set permissible limit for polluted air emissions } \\
\text { - Dentinue tree plantation and green belt in each industry. } \\
\text { - Ensure } 70 \% \text { an appropriate dust control system in each major city } \\
\text { - Eacilities } \\
\text { - Establish } 5 \text { refinery stations for lead and sulphur free vehicular fuel oil } \\
\text { - Introduce polluted emission tax }\end{array}$ \\
\hline \multicolumn{4}{|c|}{ Lead Responsibility: MoEF Associate Responsibility: MoI, MoP, MoFL, MoWR, MoLGRDC, LGD, MoLJPA, MoSICT, MoT\&J, DoE, DoF, DAE, LGED, BWDB, DPH, BSTI, CBOs, NGOs, media } \\
\hline $\begin{array}{l}\text { 9. Controlling toxic chemical } \\
\text { and radioactive pollution }\end{array}$ & $\begin{array}{l}\text { - Database of existing radioactive pollution } \\
\text { with network system in place } \\
\text { - Monitor radioactivity in metropolitan cities } \\
\text { in place }\end{array}$ & $\begin{array}{l}\text { - Bangladesh Atomic Energy Commission has } \\
\text { established a framework to determine the } \\
\text { radioactivity of different materials }\end{array}$ & $\begin{array}{l}\text { - Develop a committee for the assessment of existing toxic chemical and radioactive } \\
\text { pollution } \\
\text { - Develop a monitoring and evaluation system in the major metropolitan cities } \\
\text { - Develop guideline on the training programmes for the safe use of toxic chemical } \\
\text { and radioactive matters } \\
\text { - Undertake awareness programmes for safe use of toxic chemical and radioactive } \\
\text { matters } \\
\text { - Take protective measures against the impact of toxic chemical and radioactive } \\
\text { pollution on pregnant women and children }\end{array}$ \\
\hline \multicolumn{4}{|c|}{ Lead Responsibility: MoEF Associate Responsibility: MoI, MoP, MoL, MoFL, MoHA, MoSICT, MoLJPA, MoT\&J, MoPEMR, DoE, DoF, DMB, CBOs, NGOs, media, city and municipality corporations } \\
\hline $\begin{array}{l}\text { 10. Controlling noise } \\
\text { pollution }\end{array}$ & $\begin{array}{l}\text { - Reduce the noise pollution level from 90- } \\
110 \text { decibel to } 45-55 \text { decibel in metropolitan } \\
\text { cities } \\
\text { - National noise level database } \\
\text { - Noise pollution policy and regulatory } \\
\text { framework }\end{array}$ & $\begin{array}{l}\text { - Initiated the banning of the hydraulic horns } \\
\text { from motor vehicles } \\
\text { - Developed the national noise level standards } \\
\text { by DoE } \\
\text { - Developed a noise inventory of Khulna district }\end{array}$ & $\begin{array}{l}\text { - Ban the use of hydraulic horns and apply restrictions on the use of horns in areas } \\
\text { like academic and religious institutions and residential areas } \\
\text { - Complete procedures and implement the Noise Level Standard (NLS) in } \\
\text { metropolitan cities, vehicles and industries } \\
\text { - Undertake awareness and motivational activities } \backslash \text { for maintaining a NLS for } \\
\text { vehicles and industries } \\
\text { - Develop a national noise inventory, database and networking system } \\
\text { - Set up noise taxes and registration fees that have a potential health risk }\end{array}$ \\
\hline
\end{tabular}




\begin{tabular}{|c|c|c|c|}
\hline Strategic Goals & Key Targets & Actions Taken/ Underway & PRSP Policy Agenda (2009-2011) \\
\hline 1 & 2 & 3 & 4 \\
\hline and hill cutting & $\begin{array}{l}\text { - Develop } 100 \mathrm{~km} \text { erosion prove } \\
\text { embankment }\end{array}$ & $\begin{array}{l}\text { of regulatory framework against illegal hill } \\
\text { cutting }\end{array}$ & $\begin{array}{l}\text { - Establish monitoring and evaluation systems with the help of concerned authorities } \\
\text { - Continue community-based earth excavation work under Food For Work } \\
\text { Programme for more integration of poor people }\end{array}$ \\
\hline \multicolumn{4}{|c|}{ 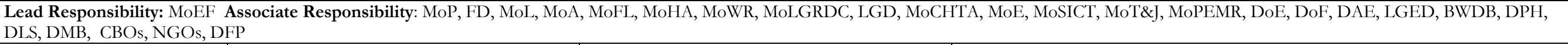 } \\
\hline $\begin{array}{l}\text { 14. Mainstreaming the } \\
\text { climate change issues into } \\
\text { national and sectoral } \\
\text { development plans and } \\
\text { policies }\end{array}$ & $\begin{array}{l}\text { - Develop a national guideline on Bali Action } \\
\text { Plan } \\
\text { - Sector wise survey to identify sector-specific } \\
\text { risks to climate change } \\
\text { - A national data base of different CC issues, } \\
\text { their status and possible mitigation and / or } \\
\text { adaptation measures } \\
\text { - Climate change training and education in } \\
\text { primary, secondary, tertiary levels } \\
\text { - Awareness and motivational activities in the } \\
\text { high risk areas } \\
\text { - A national inventory of ozone depleting } \\
\text { substances (ODS) and preparation of a } \\
\text { national strategy } \\
\text { - Reduce } 30 \% \text { of ODS by } 2011 \text { that exist in } \\
2007\end{array}$ & $\begin{array}{l}\text { - Inventory of GHG emission along with the } \\
\text { Country Programme has been initiated } \\
\text { - Developed a separate CC Cell in DoE from } \\
\text { which different training and awareness } \\
\text { programme on CC and their possible } \\
\text { adaptation / mitigation measures are being } \\
\text { undertaken } \\
\text { - Study entitled 'Vulnerability and Adaptation to } \\
\text { Climate Change and Probable Mitigation } \\
\text { Measures' has been initiated } \\
\text { - National Adaptation Programme of Action } \\
\text { (NAPA) to climate change has been completed } \\
\text { - CC issues incorporated in the Coastal Zone } \\
\text { Policy } \\
\text { - CC documentation centre has been established } \\
\text { in the Department of Environment } \\
\text { - Integration of CC issues into concerned cross- } \\
\text { sectoral Ministries / Agencies is being } \\
\text { continued } \\
\text { - Initiated various CC adaptations and mitigation } \\
\text { researches by DoE, DoF, concerned } \\
\text { departments/disciplines of the public } \\
\text { universities and other research organizations } \\
\text { - CDMP is focusing on the CC issues in the } \\
\text { concerned coastal and other disaster-prone } \\
\text { areas } \\
\text { - A national steering and working committee has } \\
\text { been formed to develop a National Bali Action } \\
\text { Plan for Bangladesh } \\
\text { - Bangladesh Climate Change Strategy and } \\
\text { Action Plan (BCCSAP) has been adopted }\end{array}$ & $\begin{array}{l}\text { - Set up high level committee to coordinate and monitor national policies and actions } \\
\text { of climate adaptation/ mitigation and coordinate donor assistance } \\
\text { - Continue dialogue among the ministries / agencies on integration of CC issues } \\
\text { - Coordinate NAPA with all public, private and community level stakeholders } \\
\text { - Provide policy and institutional framework for integration of CC issues in all } \\
\text { relevant public and private investments } \\
\text { - Set up a network and develop a national database on CC issues } \\
\text { - Develop community level CC mitigation strategy with involvement of local } \\
\text { government authority } \\
\text { - Introduce CC issues and its possible mitigation and adaptation measures in the } \\
\text { curricula at all levels of education } \\
\text { - Develop and implement projects for CC adaptation and mitigation in coastal } \\
\text { communities, socio-cultural, political norms and values } \\
\text { - Develop and implement projects on technology development to support CC } \\
\text { - Ortigation and adaptation with women perspective } \\
\text { affected areas can adapt and mitigate } \\
\text { - Develop a CC research and information network } \\
\text { - Develop at least one permanent CC proved integrated sustainable infrastructure } \\
\text { - Develop a model on how the post CC situation can adapt a more sustainable } \\
\text { infrastructure in the coastal districts } \\
\text { - Complete the National Bali Action Plan and commence its implementation } \\
\text { - Introduce insurance system for exposed households with local multi-donor trust } \\
\text { funds } \\
\text { - Implement Bangladesh Climate Change Strategy and Action Plan (BCCSAP) }\end{array}$ \\
\hline \multicolumn{4}{|c|}{ 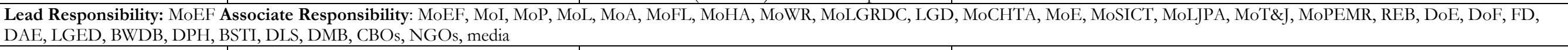 } \\
\hline $\begin{array}{l}\text { 16. Conserving bio-diversity } \\
\text { of the country }\end{array}$ & $\begin{array}{l}\text { - } 160 \text { regenerate/propagate native endangered } \\
\text { plant species along with gene-bank among } \\
\text { ecologically critical areas (ECAs) } \\
\text { - } 200 \text { regenerate/propagate native endangered } \\
\text { animal species along with gene-bank from } \\
\end{array}$ & $\begin{array}{l}\text { - Biodiversity conservation through afforestation } \\
\text { has been initiated in the areas in coastal and hill } \\
\text { districts } \\
\text { - Established } 16 \text { Protected Areas (PAs) covering } \\
0.244 \text { million hectares throughout Bangladesh } \\
\end{array}$ & $\begin{array}{l}\text { - Develop and implement the guidelines on regeneration and conservation of } \\
\text { endangered and rare species in ECAs and PAs } \\
\text { - Complete the survey on floral and faunal biodiversity in } 20 \text { floral and faunal } \\
\text { ecosystems } \\
\text { - Develop protected areas and wild life management system }\end{array}$ \\
\hline
\end{tabular}




\begin{tabular}{|c|c|c|c|}
\hline Strategic Goals & Key Targets & Actions Taken/ Underway & PRSP Policy Agenda (2009-2011) \\
\hline 1 & 2 & 3 & 4 \\
\hline & $\begin{array}{l}\text { critical ecosystems } \\
\text { - } 10,000 \text { acres of forest land to be recovered } \\
\text { - } 25 \% \text { of the river embankment to be } \\
\text { recovered from illegal encroachment } \\
\text { - Stop further destruction of habitat and } \\
\text { overexploitation of flora and fauna from all } \\
\text { natural forest areas and water bodies } \\
\text { - Stop further encroachment of the natural } \\
\text { forests and inland waters } \\
\text { - Protected areas and wild life management to } \\
\text { be established } \\
\text { - } 30 \% \text { expansion of social and agro forestry }\end{array}$ & $\begin{array}{l}\text { and } 8 \text { Ecologically Critical Areas (ECAs) } \\
\text { - Development of co-management model on } \\
\text { afforestation along with ox-bow lake and baor } \\
\text { management process } \\
\text { - Development of Wildlife Policy and Act are in } \\
\text { the process } \\
\text { - Finalized the Bio-safety Protocol and } \\
\text { Guidelines } \\
\text { - Finalized the NBSAP } \\
\text { - Formulation of National Biodiversity } \\
\text { Framework for the development of the } \\
\text { Sundarbans Biodiversity Conservation Act is in } \\
\text { process } \\
\text { - Coastal and Wetland Biodiversity Management } \\
\text { at Cox's Bazar and Hakaluki Haor Project is in } \\
\text { progress } \\
\text { Preparation of Encyclopaedia on flora and } \\
\text { fauna of Bangladesh }\end{array}$ & $\begin{array}{l}\text { - Develop appropriate social and agro forestry } \\
\text { - Initiate a national biodiversity data base } \\
\text { - Develop and initiate the bio-safety regulatory regime } \\
\text { - Develop a framework to mitigate the biodiversity loss } \\
\text { - Introduce and implement quarantine law in port areas } \\
\text { - Ban cultivation of exotic fish, flora and fauna that have adverse effects on the } \\
\text { environment } \\
\text { - Stop unethical and immature inbreeding activities in fisheries and livestock sectors } \\
\text { - Initiate the reintroduction of } 20 \text { aquatic and } 20 \text { terrestrial extinct species from } \\
\text { ECAs and PAs } \\
\text { - Introduce participatory-co-management with local communities including poor and } \\
\text { women of all natural forest and inland waters bodies } \\
\text { - Initiate the national bio-safety protocol and National Bio-diversity Strategy Policy } \\
\text { and Action Plan (NBSAP) } \\
\text { - Ensure afforestation of } 20 \text { percent of land area by } 2015\end{array}$ \\
\hline \multicolumn{4}{|c|}{ Lead Responsibility: MoEF Associate Responsibility: MoI, MoE, MoPEMR, DoE, DoF, Universities, CBOs, NGOs, Text Book Board, DFP, media, national \& international research organizations } \\
\hline $\begin{array}{l}\text { 17. Enhancing education and } \\
\text { awareness activities for } \\
\text { sustainable development }\end{array}$ & $\begin{array}{l}\text { - Establish environmental education at } \\
\text { primary, secondary and tertiary levels } \\
\text { - Increase awareness and motivational } \\
\text { programmes at the community levels } \\
\text { through electronic and print media } \\
\text { - Offer special degree on climate change } \\
\text { /disaster management issues }\end{array}$ & $\begin{array}{l}\text { - Environmental education has been introduced } \\
\text { into the syllabus at primary and secondary } \\
\text { levels } \\
\text { - Academic programmes on Environmental } \\
\text { Science are offered by Public Universities and } \\
\text { Government Polytechnic Institutes } \\
\text { - Initiated environmental training programmes } \\
\text { for the relevant Training Academy }\end{array}$ & $\begin{array}{l}\text { - Arrange at least } 1 \text { environmental management training, seminar and symposium in } \\
\text { each district } \\
\text { - Advertise environmental awareness and motivational activities in road side poster } \\
\text { and media } \\
\text { - Develop a national network of environmental management curriculum, modules } \\
\text { and books }\end{array}$ \\
\hline \multicolumn{4}{|c|}{ Lead Responsibility: MoEF Associate Responsibility: MoP, MoL, MoA, MoFL, MoWR, LGD, MoT\&J, DoE, DoF, BWDB, DPH, BSTI, national and international research organizations } \\
\hline $\begin{array}{l}\text { 18. Improving research and } \\
\text { development activities }\end{array}$ & & $\begin{array}{l}\text { - Some demonstration projects are going on } \\
\text { - DoE has already been established its one } \\
\text { central and several divisional environmental } \\
\text { analysis laboratories } \\
\text { - Developed air quality monitoring centres in } \\
\text { Dhaka and other divisions under AQMP } \\
\text { project } \\
\text { - Developed } 3 \text { trans boundary air quality } \\
\text { monitoring stations }\end{array}$ & $\begin{array}{l}\text { - Develop collaborative research programme including academic, research } \\
\text { organizations and MoEF } \\
\text { - Publish and distribute research-based periodicals and journals on a regular basis } \\
\text { - Develop research to innovate tools on SWM, air quality improvement, soil } \\
\text { reclamation and noise remediation } \\
\text { - Develop a network of environmental organizations }\end{array}$ \\
\hline \multicolumn{3}{|c|}{ Total Indicative Cost (in billion taka) } & Tk. 125.03 \\
\hline
\end{tabular}


Policy Matrix 18: Technology Policy including ICT and Biotechnology

\begin{tabular}{|c|c|c|c|}
\hline Strategic Goals & Key Targets & Actions Taken/ Underway & PRSP Policy Agenda (2009-2011) \\
\hline 1 & 2 & 3 & 4 \\
\hline \multicolumn{4}{|l|}{ Lead Responsibility: MoSICT } \\
\hline $\begin{array}{l}\text { 1. Developing ICT Policy and } \\
\text { Infrastructure }\end{array}$ & $\begin{array}{l}\text { - Update national Policy on ICT } \\
\text { - ICT Road Map/Policy Implementation Plan and } \\
\text { formulation of e-Government strategy } \\
\text { - Rules and regulations related to the } \\
\text { implementation of ICT Act } 2006 \\
\text { - Connect the ministries/divisions, departments, } \\
\text { districts and Upazilas to establish the public } \\
\text { network } \\
\text { - Country web portal and delivery of public service } \\
\text { through the web portal } \\
\text { - Establish Office of the Controller of Electronic } \\
\text { Signature Certifying Authority } \\
\text { - Establish Cyber Tribunal as per the ICT Act } 2006 \\
\text { - Construct BCC Bhaban as proposed up to 15th } \\
\text { floor for expansion of ICT activities } \\
\text { - New technology and standard of Internet } \\
\text { Protocol version } 6 \text { (IPv6) } \\
\text { - Reorganize and strengthen MoSICT and BCC } \\
\text { - Establish Bangladesh as a BPO/Call Centres } \\
\text { outsourcing destination }\end{array}$ & $\begin{array}{l}\text { - National Policy on Science and Technology } \\
\text { (S\&T) has been formulated } \\
\text { - National Policy on ICT has been formulated } \\
\text { and National Task Force on ICT has been } \\
\text { formed } \\
\text { - ICT Act has been enacted } \\
\text { - Formed a Committee for the implementation } \\
\text { of World Summit on Information Society } \\
\text { (WSIS) Declaration of Principles and Plan of } \\
\text { Action } \\
\text { - Copyright Act has been amended } \\
\text { - Exemption of VAT and taxes for ICT related } \\
\text { equipment, tax holidays, creation of equity } \\
\text { funds were undertaken } \\
\text { - ICT incubator centre has been established } \\
\text { - Opened a shared-office in the Silicon Valley } \\
\text { (USA) } \\
\text { - Taken measures to establish a High-Tech Park } \\
\text { - Bangladesh is connected to the Information } \\
\text { Superhighway through submarine fibre-optic } \\
\text { cable } \\
\text { - ICT Business Promotion Council has been } \\
\text { established to expand the development of IT } \\
\text { industries of Bangladesh in Global Market } \\
\text { - International Gateway (IGW) and } \\
\text { Interconnection Exchange (ICX) is being } \\
\text { established } \\
\text { - Decision taken to open up Voice Over } \\
\text { Internet Protocol (VoIP) to the private sector } \\
\text { - Established training labs with internet } \\
\text { connectivity in } 128 \text { Institutions in } 64 \text { Districts } \\
\text { - BTRC has already formulated guidelines for } \\
\text { setting up of Call Centres and has invited } \\
\text { application for license }\end{array}$ & $\begin{array}{l}\text { - Update regularly National Policy on ICT } \\
\text { - Prepare ICT Road Map/Policy Implementation Plan through "Support for } \\
\text { Development of Public Sector use of ICT under EMTAP Project" } \\
\text { - Formulate e-Government work plan to transform to e-governance by } 2014 \\
\text { - Frame rules and regulations related to the implementation of ICT Act } 2006 \\
\text { - Extended support for running ICT incubator } \\
\text { - Establish new ICT incubator } \\
\text { - Introduce national Infra-network project for the government } \\
\text { (BanglaGovNet) to connect the ministries, divisions, departments, districts } \\
\text { and upazilas } \\
\text { - Develop country web portal and deliver public services through the web } \\
\text { portal gradually } \\
\text { - Establish ICT Centres (Data Resource Centre) in all districts and limited } \\
\text { - Espazilas } \\
\text { - Authority. } \\
\text { - Establish Cyber Tribunal as per the ICT Act 2006 } \\
\text { - Construct BCC Bhaban as proposed } \\
\text { - Gradually upgrade new technology and standard of Internet Protocol } \\
\text { version } 6 \text { (IPv6) } \\
\text { - Reorganize and strengthen MoSICT and BCC } \\
\text { - Initiate necessary policy provision for mass-scale public sector use } \\
\text { - Take measures to establish Bangladesh as a BPO/Call Centres }\end{array}$ \\
\hline \multicolumn{4}{|c|}{ Lead Responsibility: MoSICT, MoE, PMO, PC } \\
\hline $\begin{array}{l}\text { 2. Promoting human resource } \\
\text { development for ICT }\end{array}$ & $\begin{array}{l}\text { - Provide ICT training to } 10 \% \text { of Secondary \& } \\
\text { Higher Secondary teachers every year } \\
\text { - } 50 \text { percent of the government officials will be } \\
\text { trained } \\
\text { - } 50 \text { percent of the students in secondary education } \\
\text { level will receive ICT training } \\
\text { - Study on the Job/International Market for }\end{array}$ & $\begin{array}{l}\text { - IT training institutions have been set up at } \\
\text { divisional headquarters to disseminate } \\
\text { knowledge of ICT } \\
\text { - ICT education has been introduced in schools } \\
\text { and colleges } \\
\text { - ICT training for teachers of Schools and } \\
\text { Colleges has been introduced }\end{array}$ & $\begin{array}{l}\text { - Develop curriculum and provide training to Secondary \& Higher Secondary } \\
\text { Level Teachers on ICT usage } \\
\text { - Introduce internship programme for ICT graduates } \\
\text { - Furnish } 128 \text { Computer Training Labs and train } 768 \text { teachers from schools } \\
\text { and colleges in ICT } \\
\text { - Provide government officials with ICT training }\end{array}$ \\
\hline
\end{tabular}




\begin{tabular}{|c|c|c|c|}
\hline Strategic Goals & Key Targets & Actions Taken/ Underway & PRSP Policy Agenda (2009-2011) \\
\hline 1 & 2 & 3 & 4 \\
\hline & $\begin{array}{l}\text { Bangladeshi ICT Professionals } \\
\text { - ICT Professional Skill Assessment and } \\
\text { Enhancement (IPSAEP) Programme in place }\end{array}$ & $\begin{array}{l}\text { - PGD courses on ICT have been introduced in } \\
\text { selected universities and at BCC } \\
\text { - National Science and Technology Fellowships } \\
\text { are being given to students for carrying out } \\
\text { higher studies } \\
\text { - Bangladesh-Korea Institute of Information } \\
\text { and Communication Technology has been set } \\
\text { up to produce ICT professionals } \\
\text { - Study on the Job/International Market for } \\
\text { Bangladeshi ICT Professionals is being } \\
\text { introduced/explored } \\
\text { - Internship programme has been launched for } \\
\text { ICT graduates }\end{array}$ & $\begin{array}{l}\text { - Initiate ICT Professional Skill Assessment and Enhancement (IPSAEP) } \\
\text { programme } \\
\text { - Expand infrastructure facilities of the ICT sector and explore alternative } \\
\text { submarine connectivity }\end{array}$ \\
\hline \multicolumn{4}{|l|}{ Lead Responsibility: MoSICT } \\
\hline 3. Promoting use of ICT & $\begin{array}{l}\text { - Ensure e-Governance for delivery of public } \\
\text { services to the people } \\
\text { - Provide broadband internet connectivity to ICT } \\
\text { incubator and to important } \\
\text { Ministries/Divisions/Departments } \\
\text { - Promote and assist computerization in the } \\
\text { Government Ministries, Divisions, Departments } \\
\text { etc. } \\
\text { - Coordinate the public and private sectors to make } \\
\text { easy access to information for the citizen } \\
\text { - Increase export of Software and ITES } \\
\text { - ICT based services available to all citizens }\end{array}$ & $\begin{array}{l}\text { - e-Governance cell has been established in the } \\
\text { Prime Minister's Office and e-Governance } \\
\text { initiatives have been taken } \\
\text { - Gradual introduction of ICT in all public } \\
\text { agencies is being undertaken by the } \\
\text { Government } \\
\text { - BCC is providing broadband internet services } \\
\text { to ICT incubator and a number of Ministries } \\
\text { and agencies } \\
\text { - Measures have been taken to make all } \\
\text { government forms available on the net } \\
\text { - In some government departments online file } \\
\text { tracking system has been established } \\
\text { - Dynamic and interactive websites have been } \\
\text { developed for government offices } \\
\text { - Some key ministries have been connected } \\
\text { with the Prime Minister's Office and Planning } \\
\text { Commission } \\
\text { - Computerization of a few Government offices } \\
\text { is in progress } \\
\text { - BCC is fully connected to the Local Area } \\
\text { Network (LAN) and Internet }\end{array}$ & $\begin{array}{l}\text { - Promote e-Governance for delivery of ICT to ensure public services to } \\
\text { people } \\
\text { - Convert BCC website to a Web Portal } \\
\text { - Connect the Ministries, Divisions, Departments, Districts, Upazilas under a } \\
\text { public network (BanglaGovNet) } \\
\text { - Broadband internet connectivity will be provided to ICT incubator and to } \\
\text { all Ministries/Divisions/Departments } \\
\text { - Promote and assist computerization in the Government Ministries, } \\
\text { Divisions and Departments } \\
\text { - Coordinate public and private sector activities to make easy access to } \\
\text { information for the citizens } \\
\text { - Promote ICT industry to increase export of Software and ITES } \\
\text { - Facilitate ICT industry and NGOs for delivery of ICT based services to the } \\
\text { citizen } \\
\text { - Create ICT awareness among all the citizens } \\
\text { - Promote good governance through ICT and undertake mass awareness } \\
\text { campaign involving telecommunication tools such as SMS and MMS } \\
\text { - Ensure proper maintenance of ICT infrastructure for quality service } \\
\text { - Promote telemedicine and e-health at upazilla level } \\
\text { - Ensure effective broadband policy and deployment of a nation-wide } \\
\text { broadband network (wired and wireless) }\end{array}$ \\
\hline \multicolumn{4}{|c|}{ Lead Responsibility: MoSICT, NGOs, district administrations } \\
\hline $\begin{array}{l}\text { 4. Increasing access to ICT } \\
\text { among disadvantaged groups } \\
\text { including women }\end{array}$ & $\begin{array}{l}\text { - Establish tele-centres throughout the country to } \\
\text { deliver services in the rural areas including remote } \\
\text { areas } \\
\text { - Establish several e-Community Centres across the } \\
\text { country }\end{array}$ & $\begin{array}{l}\text { - E-Commerce initiatives have been taken } \\
\text { - A Programme has been undertaken for } \\
\text { upgrading, modernizing and expanding } \\
\text { information services for promoting awareness } \\
\text { of people } \\
\text { - MoSICT has already taken up some } \\
\text { development projects for opening e- }\end{array}$ & $\begin{array}{l}\text { - Promote ICT industry and NGOs to establish tele-centres throughout the } \\
\text { country to deliver services to the rural and remote areas } \\
\text { - Promote ICT to provide public services in the remote, e.g., e-Learning, e- } \\
\text { Agriculture, e-Health etc. } \\
\text { - Establish e-Community Centres with help for women users } \\
\text { - Strengthen the capacity of BTRC } \\
\text { - Provide mobile in the hands of the poor and women and use it for }\end{array}$ \\
\hline
\end{tabular}




\begin{tabular}{|c|c|c|c|}
\hline Strategic Goals & Key Targets & Actions Taken/ Underway & PRSP Policy Agenda (2009-2011) \\
\hline 1 & 2 & 3 & 4 \\
\hline & & Community Centres & providing information to them \\
\hline \multicolumn{4}{|c|}{ Lead Responsibility: MoSICT, MoE, MoF, Cabinet Division } \\
\hline $\begin{array}{l}\text { 5. Enhancing Research \& } \\
\text { Development in ICT } \\
\text { Applications }\end{array}$ & $\begin{array}{l}\text { - Develop and disseminate Multimedia based } \\
\text { courseware for SSC level } \\
\text { - Ensure Local Content development for easy } \\
\text { access to information in the rural areas } \\
\text { - Ensure quality education using ICT (Education } \\
\text { Olympiad) } \\
\text { - Establish centre of Excellence for ICT }\end{array}$ & $\begin{array}{l}\text { - Multimedia based courseware development } \\
\text { and dissemination is being undertaken by } \\
\text { "Implementation of Computer Training } \\
\text { Programme in } 128 \text { Educational Institutions in } \\
\text { 64 Districts" Project } \\
\text { - Independent groups and private organizations } \\
\text { are working on Unicode compliant Bangla } \\
\text { solutions using open source }\end{array}$ & $\begin{array}{l}\text { - Develop and disseminate multimedia based courseware for SSC level } \\
\text { - Develop local Content for easy access to information for the rural people } \\
\text { - Build capacity for quality education through creation of competitive } \\
\text { environment using ICT } \\
\text { - Establish Centre of Excellence for ICT } \\
\text { - Research and training centre will be established in the SASEC countries }\end{array}$ \\
\hline \multicolumn{4}{|l|}{ Lead Responsibility: MoSICT } \\
\hline $\begin{array}{l}\text { 6. Using Nuclear Technology for } \\
\text { Power Generation }\end{array}$ & - Complete Rooppur Nuclear Power Plant by 2010 & $\begin{array}{l}\text { - A development project entitled } \\
\text { "Accomplishment of Essential Activities to } \\
\text { Implement } 600 \mathrm{MW}(\mathrm{e}) \text { Rooppur Nuclear } \\
\text { Power Plant" is considered by the } \\
\text { Government for the FY } 2008 \text { - } 2010 \\
\end{array}$ & - Mobilize resources for establishing $600 \mathrm{MW}$ Nuclear Power Plant \\
\hline \multicolumn{4}{|l|}{ Lead Responsibility: MoSICT } \\
\hline $\begin{array}{l}\text { 7. Developing nuclear service } \\
\text { related infrastructure }\end{array}$ & $\begin{array}{l}\text { - Provide services in industrial sectors } \\
\text { - Screen Congenital Hypothyroidism in Newborn } \\
\text { Babies } \\
\text { - Develop Tissue Banking services } \\
\text { - Ensure chemical analysis of products of } \\
\text { agriculture, industry, medicine etc. }\end{array}$ & $\begin{array}{l}\text { - Atomic Energy Commission has established } \\
\text { one Institute and fourteen Nuclear Medicine } \\
\text { Centres (NMC) in different Medical College } \\
\text { Hospitals } \\
\text { - Some of the radio-isotopes are already being } \\
\text { produced by the research reactor and a } \\
\text { project has been taken } \\
\text { - A laboratory has been set up in INMU and } \\
\text { samples are being collected } \\
\text { - Tissue Banking and Biomaterial Research Unit } \\
\text { has been established, services are being } \\
\text { provided according to demands and training } \\
\text { are being provided to develop skilled human } \\
\text { resources } \\
\text { - A nuclear laboratory has already been set up } \\
\text { and projects are proposed for more } \\
\text { laboratories } \\
\text { - Temperature controller, Nuclear Pulse } \\
\text { Generator, Radiation Survey Meters etc. have } \\
\text { been developed }\end{array}$ & $\begin{array}{l}\text { - Expand and modernise NMC's through procurement and installation of } \\
\text { modern equipment } \\
\text { - Establish PET CT facility in the country which will ensure early detection } \\
\text { of cancer } \\
\text { - Establish more Nuclear Medicine Centres under BAEC to meet the } \\
\text { demand of radioisotopes for the increasing number of general patients } \\
\text { - Design and develop special electronic instruments according to the needs } \\
\text { of BAEC and also as of other organizations of the country. }\end{array}$ \\
\hline \multicolumn{4}{|c|}{ Lead Responsibility: MoSICT, MoP\&T } \\
\hline $\begin{array}{l}\text { 8. Improving technology for } \\
\text { Telecommunication }\end{array}$ & $\begin{array}{l}\text { - Install additional Submarine Cable for redundancy } \\
\text { and capacity building } \\
\text { - Expand Data Communication Networks } \\
\text { - Infrastructure sharing by the telecom operators } \\
\text { - Install IP Telephony and Video Conferencing } \\
\text { Services }\end{array}$ & $\begin{array}{l}\text { - Major cities are already covered by telecom } \\
\text { services and further work is continuing } \\
\text { - All access service networks are advised to } \\
\text { share network with other service providers } \\
\text { and BTRC is formulating a guideline in this } \\
\text { regard }\end{array}$ & $\begin{array}{l}\text { - Install additional Submarine Cable for redundancy and capacity building } \\
\text { - Expand Data Communication Networks } \\
\text { - Promote infrastructure sharing by the telecom operators } \\
\text { - Promote latest Technology, Value Added Services Content generation and } \\
\text { - Promote/facilitate content service providers } \\
\text { - Facilitate IP Telephony and Video Conferencing Services }\end{array}$ \\
\hline
\end{tabular}




\begin{tabular}{|c|c|c|c|}
\hline Strategic Goals & Key Targets & Actions Taken/ Underway & PRSP Policy Agenda (2009-2011) \\
\hline \multirow[t]{2}{*}{1} & 2 & 3 & 4 \\
\hline & $\begin{array}{l}\text { - Establish a National Monitoring Centre (NMC) } \\
\text { - Construct a "Telecom Tower" as BTRC Head } \\
\text { Quarter in Dhaka by } 2010\end{array}$ & $\begin{array}{l}\text { - BTRC is finalizing a guideline on issuing } \\
\text { license for IP telephony } \\
\text { - NMC has been established, BTRC and NMC } \\
\text { officials have been trained and monitoring } \\
\text { equipment are being imported } \\
\text { - Land has been allotted for BTRC and } \\
\text { necessary preparation is being taken to } \\
\text { construct "Telecom Tower" }\end{array}$ & $\begin{array}{l}\text { - Establish Telecom Network for National Monitoring System and National } \\
\text { Monitoring Centre (NMC) } \\
\text { - Construct a "Telecom Tower" building by } 2010 \text { as BTRC Head Quarter } \\
\text { building in Dhaka } \\
\text { - Promote rural density mandatory for ISP/Mobile/PSTN operators } \\
\text { - Fix and support target of growth for internet penetration for the ISP } \\
\text { especially in rural area. }\end{array}$ \\
\hline \multicolumn{4}{|c|}{ Lead Responsibility: MoA, MoSICT, BARI, Agriculture University } \\
\hline $\begin{array}{l}\text { 9. Developing agriculture and } \\
\text { food technology }\end{array}$ & $\begin{array}{l}\text { - Ensure High quality food } \\
\text { - Preservation of foodstuff and agriculture produces } \\
\text { - Control and manage pesticide residues in plants } \\
\text { and crops }\end{array}$ & - Various R\&D works are being carried out & $\begin{array}{l}\text { - Expand R \& D works to develop high protein content food, food items } \\
\text { with extended shelf life, tissue culture techniques for improving } \\
\text { economically important and endangered plants, to establish generic } \\
\text { transformation techniques for obtaining transgenic plants with improved } \\
\text { and desired characteristics } \\
\text { - Develop nation-wide bio-fertilizer }\end{array}$ \\
\hline \multicolumn{4}{|l|}{ Lead Responsibility: MoSICT } \\
\hline $\begin{array}{l}\text { 10. Developing nuclear safety } \\
\text { administration }\end{array}$ & $\begin{array}{l}\text { - Ensure Nuclear Safety and Radiation control } \\
\text { - Adequate Nuclear Regulatory Infrastructure for } \\
\text { the implementation of nuclear power programme }\end{array}$ & $\begin{array}{l}\text { - BAEC is issuing license to handle, use, } \\
\text { import, export, transport, store, and trade in } \\
\text { radioactive materials and equipments } \\
\text { - BAEC is monitoring and providing training } \\
\text { and expert services to the clients } \\
\text { - All radiation sources/materials have been } \\
\text { taken under regulatory control of BAEC } \\
\text { - Personnel dosimeters are being supplied to } \\
\text { monitor radiation workers } \\
\text { - Radiation monitoring instruments are being } \\
\text { standardized, and spent sources are being } \\
\text { collected, stored and disposed }\end{array}$ & $\begin{array}{l}\text { - Implement Nuclear Safety Act, } 1993 \\
\text { - Expand BAEC's regulatory activities to fulfil the requirements for safety } \\
\text { and security of nuclear materials/sources as well as the regulatory } \\
\text { requirements for introduction and expansion of nuclear power programme }\end{array}$ \\
\hline \multicolumn{4}{|c|}{ Lead Responsibility: MoWR, MoSICT } \\
\hline $\begin{array}{l}\text { 11. Introducing new technology } \\
\text { for water resources development } \\
\text { and management }\end{array}$ & $\begin{array}{l}\text { - Identify proper geologic aquifer of clean and safe } \\
\text { drinking water sources }\end{array}$ & $\begin{array}{l}\text { - Samples are being collected from different } \\
\text { places of the country and are being analyzed. }\end{array}$ & $\begin{array}{l}\text { - Ensure sustainable development of groundwater resources for use in } \\
\text { domestic, agriculture and industrial purposes } \\
\text { - Identify efficient management of water resources technology }\end{array}$ \\
\hline \multicolumn{4}{|c|}{ Lead Responsibility: MoSICT, MoI, MoEF } \\
\hline $\begin{array}{l}\text { 12. Developing new sustainable } \\
\text { and appropriate technologies for } \\
\text { production and preservation of } \\
\text { food }\end{array}$ & $\begin{array}{l}\text { - Lease-out commercial processes to local } \\
\text { entrepreneurs and industrialists } \\
\text { - Provide full technical support for establishing } \\
\text { cost-effect small and medium industries and } \\
\text { producing safe and quality food products }\end{array}$ & $\begin{array}{l}\text { - Activities have been undertaken for } \\
\text { processing and preserving of fruits, } \\
\text { vegetables, fish and meat products } \\
\text { - Developing nutritious foods for } \\
\text { undernourished children and women } \\
\text { - Developing of solar drying technology for } \\
\text { producing dehydrated food products } \\
\text { - Developing fermented food, sources and } \\
\text { other value added products by utilizing local } \\
\text { raw materials } \\
\text { - Utilizing food and agricultural wastes/by }\end{array}$ & $\begin{array}{l}\text { - Improve food safety, quality and food security status } \\
\text { - Create and promote cost-effective food processing technologies } \\
\text { - Undertake need based research and development for developing indigenous } \\
\text { technologies for various activities } \\
\text { - Provide technical support for establishing cost-effective small and medium } \\
\text { industries and producing safe and quality food products }\end{array}$ \\
\hline
\end{tabular}




\begin{tabular}{|c|c|c|c|}
\hline Strategic Goals & Key Targets & Actions Taken/ Underway & PRSP Policy Agenda (2009-2011) \\
\hline 1 & 2 & 3 & 4 \\
\hline & & $\begin{array}{l}\text { products for production of feed and other } \\
\text { value added products }\end{array}$ & \\
\hline \multicolumn{4}{|c|}{ Lead Responsibility: MoWR, MoSICT } \\
\hline $\begin{array}{l}\text { 13. Introducing cost effective } \\
\text { technology for irrigation }\end{array}$ & - Increase use of $\mathrm{CNG}$ & $\begin{array}{l}\text { - Developing dual/fuel (CNG/Diesel) kit to } \\
\text { use in irrigation system with shallow water } \\
\text { pumps }\end{array}$ & - Develop dual fuel shallow water pump \\
\hline \multicolumn{4}{|l|}{ Lead Responsibility: MoSICT } \\
\hline $\begin{array}{l}\text { 14. Improving energy } \\
\text { technology }\end{array}$ & $\begin{array}{l}\text { - Reduce energy crisis of rural people } \\
\text { - Reduce Greenhouse Gas (GHG) emission. }\end{array}$ & $\begin{array}{l}\text { - Institute of Fuel Research and Development } \\
\text { (IFRD) of BCSIR has already set up about } \\
21,858 \text { biogas plants } \\
\text { - Different models of fuel efficient mud stoves } \\
\text { were developed and about } 0.3 \text { million were } \\
\text { disseminated } \\
\text { - Different models of Solar Oven have been } \\
\text { developed and being further modified }\end{array}$ & $\begin{array}{l}\text { - Set up Biogas plants throughout the country utilizing all sources of bio- } \\
\text { degradable waste } \\
\text { - Develop demand based improved stoves and help people to set up } \\
\text { improved mud stoves instead of conventional stoves } \\
\text { - Disseminate different types of solar oven throughout the country }\end{array}$ \\
\hline \multicolumn{4}{|c|}{ Lead Responsibility: MoHFW, MoSICT } \\
\hline $\begin{array}{l}\text { 15. Developing and promoting } \\
\text { alternative medical care (AMC) }\end{array}$ & $\begin{array}{l}\text { - Reduce dependence on the allopathic system of } \\
\text { medicine }\end{array}$ & $\begin{array}{l}\text { - Propagation and plantation of medicinal } \\
\text { plants, extraction and laboratory study are } \\
\text { being undertaken } \\
\text { - Traditional drugs are also being studied in the } \\
\text { laboratory }\end{array}$ & - Develop alternative medicine particularly to address women's health needs \\
\hline \multicolumn{4}{|c|}{ Lead Responsibility: MoSICT, MoA, MoEF, Universities, Researchers } \\
\hline $\begin{array}{l}\text { 16. Developing biotechnology } \\
\text { policy for socioeconomic } \\
\text { development }\end{array}$ & $\begin{array}{l}\text { - Apply biotechnology to improve agricultural } \\
\text { crops, marine sciences and aquaculture, } \\
\text { environment, pharmacy, forensics, and public } \\
\text { health }\end{array}$ & $\begin{array}{l}\text { - Researches have been initiated on plant tissue } \\
\text { culture, rice bio fertilizer, DNA finger } \\
\text { printing, artificial breeding of indigenous } \\
\text { fishes, industrial micro organisms, PPR virus } \\
\text { of goat etc. } \\
\text { - Bangladesh has adopted the National Policy } \\
\text { Guidelines on Biotechnology to accelerate } \\
\text { multidimensional biotechnological research }\end{array}$ & $\begin{array}{l}\text { - Provide DNA finger printing services for investigation } \\
\text { - Develop biotechnology based legal framework for Intellectual Property } \\
\text { Rights } \\
\text { - Prepare work plan for the implementation of National Biotechnology } \\
\text { Policy } \\
\text { - Strengthen R\&D on biotechnology to identify efficient, eco-friendly and } \\
\text { economically viable options }\end{array}$ \\
\hline \multicolumn{4}{|c|}{ Lead Responsibility: MoSICT, MoA, MoEF } \\
\hline $\begin{array}{l}\text { 17. developing Eco-friendly } \\
\text { appropriate biotechnology }\end{array}$ & $\begin{array}{l}\text { - Ensure wide use of tissue culture for regeneration } \\
\text { and rapid multiplication of nearly extinct plants, } \\
\text { economically important and medicinal plants } \\
\text { - Develop and transfer technology to the grassroots } \\
\text { level for income generation }\end{array}$ & $\begin{array}{l}\text { - Developed protocol technology for plant } \\
\text { regeneration, multiplication and cultivation } \\
\text { - Number of processes on Spirulina have been } \\
\text { leased out } \\
\text { - A new process has been developed for } \\
\text { cultivation of Spirulina }\end{array}$ & $\begin{array}{l}\text { - Develop biotechnology based small and medium industry } \\
\text { - Generate income through economic and medicinal plant cultivation } \\
\text { - Develop nursery for the rural people } \\
\text { - Develop genetically modified (GM) pest resistant varieties of fruits and } \\
\text { vegetables } \\
\text { - Conduct training programme for the production of Spirulina }\end{array}$ \\
\hline \multicolumn{3}{|c|}{ Total Indicative Cost (in billion taka) } & Tk. 50.72 \\
\hline \multicolumn{3}{|l|}{ Grand Total (in billion taka) } & Tk. 2814.81 \\
\hline
\end{tabular}


Social Safety Net Budget FY 2008 - 09

\begin{tabular}{|c|c|c|c|c|c|c|c|c|}
\hline & (A.1) Cash Transfer & (Allowanc & es) Progra & & & & & \\
\hline \multirow[t]{2}{*}{ S1. } & \multirow[t]{2}{*}{$\begin{array}{c}\text { Program } \\
\text { (Ministry/Division) }\end{array}$} & \multicolumn{3}{|c|}{$\begin{array}{c}\text { Target Group Coverage } \\
\text { (in Lac) }\end{array}$} & \multicolumn{2}{|c|}{$\begin{array}{l}\text { Budget } \\
\text { (in Crore) }\end{array}$} & & \\
\hline & & $2007-08$ & $2008-09$ & $\begin{array}{c}\text { Increase } \\
(\%)\end{array}$ & $\begin{array}{c}\text { Revised } \\
(2007-08)\end{array}$ & $\begin{array}{l}\text { Proposed } \\
(2008-09)\end{array}$ & \multicolumn{2}{|c|}{ Increase (\%) } \\
\hline 1 & $\begin{array}{l}\text { Old Age Allowance } \\
\text { (MOSW) }\end{array}$ & 17.00 & 20.00 & $17.65 \%$ & 448.80 & 600.00 & $34 \%$ & $\begin{array}{l}\text { Rate has been } \\
\text { increased from } \\
\text { Tk. } 220 \text { to } \\
\text { Tk. } 250 \text { per } \\
\text { person per } \\
\text { month }\end{array}$ \\
\hline 2 & $\begin{array}{l}\text { Allowances for the } \\
\text { Widowed, Deserted } \\
\text { and Destitute } \\
\text { Women (MOWCA) }\end{array}$ & 8.25 & 9.00 & $9.09 \%$ & 184.80 & 270.00 & $46 \%$ & $-\mathrm{Do}-$ \\
\hline 3 & $\begin{array}{l}\text { Allowances for the } \\
\text { Financially Insolvent } \\
\text { Disabled } \\
\text { (MOWSW) }\end{array}$ & 2.00 & 2.00 & $0.00 \%$ & 52.80 & 60.00 & $14 \%$ & -Do- \\
\hline 4 & $\begin{array}{l}\text { Maternity allowance } \\
\text { program for the } \\
\text { Poor Lactating } \\
\text { Mothers (MOWCA) }\end{array}$ & 0.45 & 0.60 & $33.33 \%$ & 17.00 & 21.60 & $27 \%$ & \\
\hline 5 & $\begin{array}{l}\text { Honorarium for } \\
\text { Insolvent Freedom } \\
\text { Fighters (MOFWA) }\end{array}$ & 1.00 & 1.00 & $0.00 \%$ & 72.00 & 108.00 & $50 \%$ & $\begin{array}{l}\text { Rate has been } \\
\text { raised from } \\
\text { Tk.600 to } \\
\text { Tk.900 }\end{array}$ \\
\hline 6 & $\begin{array}{l}\text { Honorarium for } \\
\text { Injured Freedom } \\
\text { Fighters (MOFWA) }\end{array}$ & 0.08 & 0.08 & $0.00 \%$ & 27.30 & 44.00 & $61 \%$ & $\begin{array}{l}\text { Different types } \\
\text { of allowances } \\
\text { may be } \\
\text { increased by } \\
50 \%\end{array}$ \\
\hline 7 & $\begin{array}{l}\text { Grants for } \\
\text { Residents in } \\
\text { Government } \\
\text { Orphanages and } \\
\text { other institutions } \\
\text { (MOSW) }\end{array}$ & 0.16 & 0.16 & $0.00 \%$ & 19.44 & 22.14 & $14 \%$ & $\begin{array}{l}\text { The rate has } \\
\text { been raised } \\
\text { from Tk.1200 } \\
\text { to Tk.1500 }\end{array}$ \\
\hline 8 & $\begin{array}{l}\text { Capitation Grants } \\
\text { for Orphan } \\
\text { Students in non- } \\
\text { gov. orphanges } \\
\text { (MOSW) }\end{array}$ & 0.42 & 0.45 & $7.14 \%$ & 30.24 & 37.80 & $25 \%$ & $\begin{array}{l}\text { Monthly rate } \\
\text { may be } \\
\text { increased from } \\
\text { Tk. } 600 \text { to } \\
\text { Tk. } 700\end{array}$ \\
\hline 9 & $\begin{array}{l}\text { Gratuitous Relief } \\
\text { (Cash) (MOFDM) }\end{array}$ & 5.30 & 5.30 & $0.00 \%$ & 26.53 & 10.00 & & $\begin{array}{l}\text { Additional } \\
\text { support will be } \\
\text { provided from } \\
\text { the block } \\
\text { allocation for } \\
\text { disaster } \\
\text { management. }\end{array}$ \\
\hline 10 & $\begin{array}{l}\text { General Relief } \\
\text { Activities } \\
\text { (MOFDM) }\end{array}$ & 5.00 & 5.00 & $0.00 \%$ & 10.00 & 10.00 & & $\begin{array}{l}\text { Clothes, } \\
\text { Blanket, Biscuit, } \\
\text { dry food and } \\
\text { others in kinds. }\end{array}$ \\
\hline 11 & Block Allocation for $I$ & isaster $\mathrm{Ma}$ & lagement & & 10.00 & 100.00 & & \\
\hline
\end{tabular}




\begin{tabular}{|c|c|c|c|c|c|c|c|c|}
\hline 12 & $\begin{array}{l}\text { Non-Bengali } \\
\text { Rehabilitation } \\
\text { (MOFDM) }\end{array}$ & 1.10 & 1.10 & $0.00 \%$ & 30.10 & 35.00 & $16 \%$ & $\begin{array}{l}\text { Expenses for } \\
\text { payment of } \\
\text { Water and } \\
\text { Electricity bill } \\
\text { for Bihari } \\
\text { Camps. } \\
\end{array}$ \\
\hline 13 & $\begin{array}{l}\text { Allowances for } \\
\text { Distressed Cultural } \\
\text { Personalities/ } \\
\text { Activitists (MOCA) }\end{array}$ & 0.01 & 0.01 & $0.00 \%$ & 0.75 & 0.75 & & \\
\hline 14 & $\begin{array}{l}\text { Allowances for } \\
\text { beneficiaries in Ctg. } \\
\text { Hill Tract area. }\end{array}$ & 0.54 & 0.54 & $0.00 \%$ & 1.50 & 1.50 & & $\begin{array}{l}\text { Non-tribal, } \\
\text { Refugees from } \\
\text { India and } \\
\text { Jonosanghati } \\
\text { Members. }\end{array}$ \\
\hline 15 & $\begin{array}{l}\text { Pension for Retired } \\
\text { Government } \\
\text { Employees or their } \\
\text { families }\end{array}$ & 3.12 & 3.25 & $4.17 \%$ & 3381.00 & 3584.00 & $6 \%$ & \\
\hline & Total (A.1.i) $=$ & 44.43 & 48.49 & $9.09 \%$ & 4312.26 & 4904.79 & $14 \%$ & \\
\hline \multicolumn{9}{|c|}{$\begin{array}{c}\text { ii) Social } \\
\text { Empowerment }\end{array}$} \\
\hline 1 & $\begin{array}{l}\text { Stipend for Disabled } \\
\text { Students (MOSW) }\end{array}$ & 0.12 & 0.12 & $0.00 \%$ & 5.00 & 5.00 & $0 \%$ & $\begin{array}{l}\text { Rates for } \\
\text { primary level } \\
\text { Tk.300, } \\
\text { Secondary level } \\
\text { Tk.450, Higher } \\
\text { Secondary } \\
\text { Tk.600 \& } \\
\text { Higher studies } \\
\text { Tk.1000 }\end{array}$ \\
\hline 2 & $\begin{array}{l}\text { Grants for the } \\
\text { Schools for the } \\
\text { Disabled (MOSW) }\end{array}$ & 0.12 & 0.12 & $0.00 \%$ & 1.80 & 1.80 & $0 \%$ & $\begin{array}{l}\text { Teachers' } \\
\text { benefit. }\end{array}$ \\
\hline & Total (A.1.ii) $=$ & 0.24 & 0.24 & $0.00 \%$ & 6.80 & 6.80 & $0 \%$ & \\
\hline & Total (A.1) $=$ & 44.67 & 48.73 & & 4319.06 & 4911.59 & $14 \%$ & \\
\hline \multicolumn{9}{|c|}{ (A.2) Cash Transfer (Special) Program } \\
\hline \multicolumn{9}{|c|}{ (A.2.i) Social Protection } \\
\hline \multirow[t]{2}{*}{ S1. } & Program & \multicolumn{3}{|c|}{ Coverage (in Lac) } & \multicolumn{3}{|c|}{ Budget (in Crore) } & \\
\hline & & $2007-08$ & $2008-09$ & $\begin{array}{c}\text { Increas } \\
\text { e }(\%)\end{array}$ & $\begin{array}{c}\text { Revised } \\
(2007-08)\end{array}$ & $\begin{array}{l}\text { Proposed } \\
(2008-09)\end{array}$ & & crease $(\%)$ \\
\hline 1 & $\begin{array}{l}\text { Cash For Work } \\
\text { (MOFDM) }\end{array}$ & 67.00 & 0.00 & & 100.00 & 0.00 & & $\begin{array}{l}\text { New } \\
\text { Program, } \\
\text { Only for } \\
\text { FY 08 }\end{array}$ \\
\hline & & $\begin{array}{l}\text { (Man- } \\
\text { Month) }\end{array}$ & \multicolumn{2}{|c|}{ (Man-Month) } & & & & \\
\hline & Total (A.2.i) = & 67.00 & 0.00 & & 100.00 & 0.00 & & \\
\hline \multicolumn{9}{|c|}{$\begin{array}{l}\text { (A.2.ii) Social } \\
\text { Empowerment }\end{array}$} \\
\hline 1 & $\begin{array}{l}\text { Housing Support } \\
\text { (MOFDM) }\end{array}$ & 63.00 & 10.00 & & 63.00 & 10.00 & & $\begin{array}{l}\text { Additional } \\
\text { requiremen } \\
\mathrm{t} \text { will be } \\
\text { fulfilled } \\
\text { from the } \\
\text { block } \\
\text { allocation }\end{array}$ \\
\hline
\end{tabular}




\begin{tabular}{|c|c|c|c|c|c|c|c|c|}
\hline 2 & $\begin{array}{l}\text { Agriculture } \\
\text { Rehabilitation } \\
\text { (MOA) }\end{array}$ & & & & 180.00 & 10.00 & & \\
\hline & Total (A.2.ii) $=$ & 63.00 & 10.00 & & 243.00 & 20.00 & & \\
\hline & Total (A.2) $=$ & 130.00 & 10.00 & & 343.00 & 20.00 & & \\
\hline \multicolumn{9}{|c|}{$\begin{array}{l}\text { (B) Food Security Programs: Social } \\
\text { Protection }\end{array}$} \\
\hline \multirow[t]{2}{*}{1} & $\begin{array}{l}\text { Subsidy for Open } \\
\text { Market Sales (OMS) } \\
\text { (MOFDM) }\end{array}$ & 76.00 & 94.44 & $19.53 \%$ & 1849.00 & 2674.95 & $45 \%$ & \multirow[t]{2}{*}{$\begin{array}{l}\text { Per head } 90 \\
\mathrm{~kg} \text { rice is } \\
\text { sold, } \\
\text { considering } \\
\text { daily } 5 \mathrm{~kg}, 3 \\
\text { Days in a } \\
\text { month for } \\
6 \text { months. }\end{array}$} \\
\hline & & $\begin{array}{l}\text { (Man } \\
\text { Month) }\end{array}$ & \multicolumn{2}{|c|}{ (Man Month) } & $(6.84)$ & $(8.50)$ & $(24 \%)$ & \\
\hline \multirow[t]{2}{*}{2} & \multirow[t]{2}{*}{$\begin{array}{l}\text { Vulnerable Group } \\
\text { Development } \\
\text { (VGD) (MOWCA) }\end{array}$} & 7.50 & 7.50 & $0.00 \%$ & 721.00 & 836.64 & $16 \%$ & \multirow[t]{2}{*}{$\begin{array}{l}\text { WFP } \\
\text { assisted } \\
\text { program. } \\
30 / \text { person/ } \\
\text { month. } \\
\text { Beneficiarie } \\
\text { s } 7.5 \text { Lacs. }\end{array}$} \\
\hline & & $\begin{array}{r}\text { (Man- } \\
\text { Month) } \\
\end{array}$ & \multicolumn{2}{|c|}{ (Man-Month) } & $(2.65)$ & $(2.65)$ & & \\
\hline \multirow[t]{2}{*}{3} & \multirow[t]{2}{*}{$\begin{array}{l}\text { Vulnerable Group } \\
\text { Feeding (VGF) } \\
\text { (MOFDM) }\end{array}$} & 104.67 & 75.00 & & 855.00 & 708.08 & & \multirow[t]{2}{*}{$\begin{array}{l}10 \\
\mathrm{~kg} / \text { person/ } \\
\text { month. } 3 \\
\text { months } \\
\text { program }\end{array}$} \\
\hline & & $\begin{array}{r}\text { (Man- } \\
\text { Month) }\end{array}$ & \multicolumn{2}{|c|}{ (Man-Month) } & $(3.14)$ & $(2.25)$ & & \\
\hline \multirow[t]{2}{*}{4} & \multirow[t]{2}{*}{$\begin{array}{l}\text { Test Relief (TR) } \\
\text { Food (MOFDM) }\end{array}$} & 12.50 & 50.00 & & 411.00 & 631.47 & $54 \%$ & \multirow[t]{2}{*}{$\begin{array}{l}3.5 \mathrm{~kg} / \text { day. } \\
30 \text { days } 105 \\
\mathrm{~kg} / \text { person. }\end{array}$} \\
\hline & & $\begin{array}{r}\text { (Man- } \\
\text { Month) } \\
\end{array}$ & \multicolumn{2}{|c|}{ (Man-Month) } & $(1.50)$ & $(2.00)$ & $(33 \%)$ & \\
\hline \multirow[t]{2}{*}{5} & \multirow[t]{2}{*}{$\begin{array}{l}\text { Gratuitous Relief } \\
\text { (GR)- Food } \\
\text { (MOFDM) }\end{array}$} & 64.00 & 64.00 & $0.00 \%$ & 174.00 & 201.41 & $16 \%$ & \multirow[t]{2}{*}{$\begin{array}{l}10 \\
\mathrm{~kg} / \text { person }\end{array}$} \\
\hline & & $\begin{array}{r}\text { (Man in } \\
\mathrm{Lac})\end{array}$ & \multicolumn{2}{|c|}{ (Man in Lac) } & $(0.64)$ & $(0.64)$ & & \\
\hline \multirow[t]{2}{*}{6} & \multirow[t]{2}{*}{$\begin{array}{l}\text { Food Assistance in } \\
\text { CTG-Hill tracts } \\
\text { Area }\end{array}$} & 75.00 & 75.00 & $0.00 \%$ & 204.00 & 237.88 & $17 \%$ & \multirow[t]{2}{*}{$\begin{array}{l}3.5 \mathrm{~kg} / \text { day. } \\
30 \text { days } 105 \\
\mathrm{~kg} / \text { person. }\end{array}$} \\
\hline & & $\begin{array}{r}\text { (Man- } \\
\text { Month) } \\
\end{array}$ & \multicolumn{2}{|c|}{ (Man-Month) } & $(0.75)$ & $(0.75)$ & & \\
\hline 7 & \multirow[t]{2}{*}{$\begin{array}{l}\text { Food For Work } \\
(\text { FFW) }\end{array}$} & 17.62 & 47.62 & $63.00 \%$ & 503.00 & 1577.63 & $214 \%$ & \\
\hline & & $\begin{array}{r}\text { (Man- } \\
\text { Month) }\end{array}$ & \multicolumn{2}{|c|}{ (Man-Month) } & $(1.85)$ & $(5.00)$ & $(170 \%)$ & \\
\hline & Total $(B)=$ & 357.29 & 413.56 & $15.75 \%$ & 4717.00 & 6868.05 & $46 \%$ & \\
\hline \multicolumn{9}{|c|}{$\begin{array}{l}\text { (C.1) Micro-Credit Programs: Social } \\
\text { Empowerment }\end{array}$} \\
\hline 1 & Fund through PKSF & 2.00 & 2.00 & $0 \%$ & 217.61 & 271.37 & & $\begin{array}{l}\text { World } \\
\text { Bank } \\
\text { Supported. } \\
\text { Tk. } 382 \\
\end{array}$ \\
\hline
\end{tabular}




\begin{tabular}{|c|c|c|c|c|c|c|c|c|}
\hline & & & & & & & & $\begin{array}{l}\text { crore has } \\
\text { been } \\
\text { allocation } \\
\text { till FY08 }\end{array}$ \\
\hline 2 & \begin{tabular}{|l|} 
Special fund for \\
Employment \\
Generation for \\
Hard-core Poor in \\
SIDR Area (PKSF)
\end{tabular} & 0.50 & 1.00 & $\begin{array}{r}100.00 \\
\%\end{array}$ & 130.00 & 0.00 & & \\
\hline 3 & $\begin{array}{l}\text { Social Development } \\
\text { Foundation }\end{array}$ & & & & 30.00 & 40.00 & $33 \%$ & $\begin{array}{l}\text { World } \\
\text { Bank } \\
\text { Supported. } \\
200 \\
\text { projects are } \\
\text { under } \\
\text { implementa } \\
\text { tion in FY } \\
08 . \text { In FY } \\
09267 \\
\text { projects } \\
\text { would be } \\
\text { supported. }\end{array}$ \\
\hline 4 & NGO Foundation & & & & 0.00 & 15.00 & & $\begin{array}{l}\text { Accumulate } \\
\text { d Capital } \\
\text { Tk.127 } \\
\text { Crore }\end{array}$ \\
\hline 5 & $\begin{array}{l}\text { Micro-credit for } \\
\text { Women Self- } \\
\text { employment } \\
\text { (MOWCA) }\end{array}$ & 0.68 & 0.70 & $2.94 \%$ & 20.00 & 10.00 & $-50.0 \%$ & $\begin{array}{l}\text { The } \\
\text { Programme } \\
\text { coverage is } \\
\text { in } 333 \\
\text { Upazilas of } \\
64 \text { districts, } \\
\text { Tk. } 42.75 \\
\text { has been } \\
\text { disbursed } \\
\text { till FY } \\
2007-08 \\
\end{array}$ \\
\hline 6 & \begin{tabular}{|l} 
Fund for \\
Development of \\
Fisheries and \\
Livestock sector \\
(MOFL)
\end{tabular} & & 1.00 & & 0.00 & 0.00 & & $\begin{array}{l}\text { Accumulate } \\
\text { d capital } \\
\text { Tk.15 } \\
\text { crore. }\end{array}$ \\
\hline 7 & \begin{tabular}{|l|} 
Freedom Fighters' \\
Self Employment \\
Support (MOFWA)
\end{tabular} & 0.10 & 0.10 & $0.00 \%$ & 0.00 & 10.00 & & $\begin{array}{l}\text { Accumulate } \\
\text { d Capital } \\
\text { Tk. } 42.50 \\
\text { Crore. }\end{array}$ \\
\hline 8 & Micro Credit for Self & loymer & f Youth & MOYS) & 0.05 & 0.00 & & $\begin{array}{l}\text { Accumulate } \\
\text { d Capital } \\
\text { Tk.164 } \\
\text { Crore. }\end{array}$ \\
\hline 9 & $\begin{array}{l}\text { Micro-Credit in } \\
\text { Social sector Service } \\
\text { (RSS, RMC, UCD) } \\
\text { (MOSW) }\end{array}$ & 4.30 & 4.50 & & 0.00 & 0.00 & & $\begin{array}{l}\text { Interest } \\
\text { free loan. } \\
\text { Accumulated } \\
\text { Capital } \\
\text { Tk.265 crore }\end{array}$ \\
\hline 10 & $\begin{array}{l}\text { Micro-credit by } \\
\text { BRDB (RDCD) }\end{array}$ & & & & & & & $\begin{array}{l}\text { Accumulate } \\
\text { d Capital } \\
\text { Tk.611.28 } \\
\text { Crore } \\
\end{array}$ \\
\hline 11 & $\begin{array}{l}\text { Infrastructure } \\
\text { Development } \\
\text { Company }\end{array}$ & & & & 115.00 & 140.00 & & $\begin{array}{l}\text { WB } \\
\text { supported }\end{array}$ \\
\hline
\end{tabular}




\begin{tabular}{|c|c|c|c|c|c|c|c|c|}
\hline 12 & \begin{tabular}{|l} 
Infrastructure \\
Investment \\
Facilitation Centre \\
(IIFC) \\
\end{tabular} & & & & 1.83 & 0.00 & & $\begin{array}{l}\text { WB } \\
\text { supported }\end{array}$ \\
\hline 13 & $\begin{array}{l}\text { Municipal } \\
\text { Development Fund }\end{array}$ & & & & 116.75 & 294.56 & & $\begin{array}{l}\text { WB } \\
\text { supported }\end{array}$ \\
\hline & Total $($ C.1) $=$ & 7.58 & 9.30 & $22.69 \%$ & 631.19 & 780.93 & $23.72 \%$ & \\
\hline \multicolumn{9}{|c|}{ (C.2) Miscellaneous Funds: Social Empowerment } \\
\hline \multirow[t]{2}{*}{ S1. } & \multirow{2}{*}{$\begin{array}{c}\text { Program } \\
\text { (Ministry/Division } \\
\text { ) }\end{array}$} & \multicolumn{3}{|c|}{ Coverage (in Lac) } & \multicolumn{3}{|c|}{ Budget (in Crore) } & \\
\hline & & $2007-08$ & 2008-09 & $\begin{array}{c}\text { Increas } \\
\text { e }(\%)\end{array}$ & $\begin{array}{l}\text { Revised } \\
(2007-08)\end{array}$ & $\begin{array}{l}\text { Proposed } \\
(2008-09) \\
\end{array}$ & \multicolumn{2}{|c|}{ Increase (\%) } \\
\hline 1 & $\begin{array}{l}\text { Fund for the } \\
\text { Welfare of Acid } \\
\text { Burnt and Disables } \\
\text { (MOSW) }\end{array}$ & 0.70 & 0.75 & $7 \%$ & 5.00 & 10.00 & & $\begin{array}{l}\text { Accumulate } \\
\text { d Capital } \\
\text { Tk. } 60.50 \\
\text { Crore } \\
\end{array}$ \\
\hline 2 & $\begin{array}{l}\text { Fund for Garment } \\
\text { workers Training } \\
\text { and support (MOC) }\end{array}$ & 0.50 & 1.00 & $100 \%$ & 20.00 & 0.00 & & $\begin{array}{l}\text { Tk.20 } \\
\text { Crore has } \\
\text { been } \\
\text { allocated in } \\
\text { this fund in } \\
\text { FY 2007- } \\
08 \text {. }\end{array}$ \\
\hline 3 & $\begin{array}{l}\text { Fund for Assistance } \\
\text { to the Small Farmer } \\
\text { and Poultry Farms } \\
\text { (FD) }\end{array}$ & 1.00 & 1.00 & $0 \%$ & 0.00 & 100.00 & & \\
\hline 4 & $\begin{array}{l}\text { Employment } \\
\text { Generation for } \\
\text { Hard-core Poor } \\
\text { (PKSF) }\end{array}$ & 1.00 & 1.00 & $0 \%$ & 100.00 & 0.00 & & \\
\hline 5 & $\begin{array}{l}\text { Support to Small } \\
\text { Entrepreneurship } \\
(\mathrm{PKSF})\end{array}$ & 1.00 & 2.00 & $100 \%$ & 100.00 & 100.00 & & $\begin{array}{l}\text { Accumulate } \\
\text { d Capital } \\
\text { Tk. } 275 \\
\text { Crore }\end{array}$ \\
\hline 6 & $\begin{array}{l}\text { Mitigation of Risk } \\
\text { of Natural Disaster } \\
\text { (pre and post) } \\
\text { (MOFDM) }\end{array}$ & & & & 20.00 & 0.00 & & $\begin{array}{l}\text { Total } \\
\text { disburseme } \\
\text { nt } 147 \\
\text { Crore ( } 40 \% \\
\text { Grant and } \\
60 \% \text { Loan) } \\
\end{array}$ \\
\hline 7 & $\begin{array}{l}\text { Housing Loan for } \\
\text { Homeless (BB) }\end{array}$ & & 1.75 & & 0.00 & 10.00 & & $\begin{array}{l}\text { Accumulate } \\
\text { d Capital } \\
\text { Tk.160 } \\
\text { Crore. } \\
\end{array}$ \\
\hline 8 & $\begin{array}{l}\text { Swanirvar Training } \\
\text { Program }\end{array}$ & & & & 1.25 & 1.50 & $20 \%$ & \\
\hline 9 & \multicolumn{4}{|c|}{$\begin{array}{l}\text { Jatio Pratibandhi Unnayan Foundation (JPUF) } \\
\text { (MOSW) }\end{array}$} & & & & $\begin{array}{l}\text { Tk.25 } \\
\text { Crore } \\
\text { disbursed } \\
\text { as seed } \\
\text { money.WB } \\
\text { assistance is } \\
\text { in the } \\
\text { pipeline }\end{array}$ \\
\hline 10 & $\begin{array}{l}\text { Shamaj Kallyan } \\
\text { Parishad }\end{array}$ & 0.14 & 0.14 & & 8.00 & 8.00 & & \\
\hline 11 & $\begin{array}{l}\text { Renewable Fuel } \\
\text { Development } \\
\text { Assistance }\end{array}$ & & 1.00 & & 20.00 & 50.00 & $150 \%$ & \\
\hline
\end{tabular}




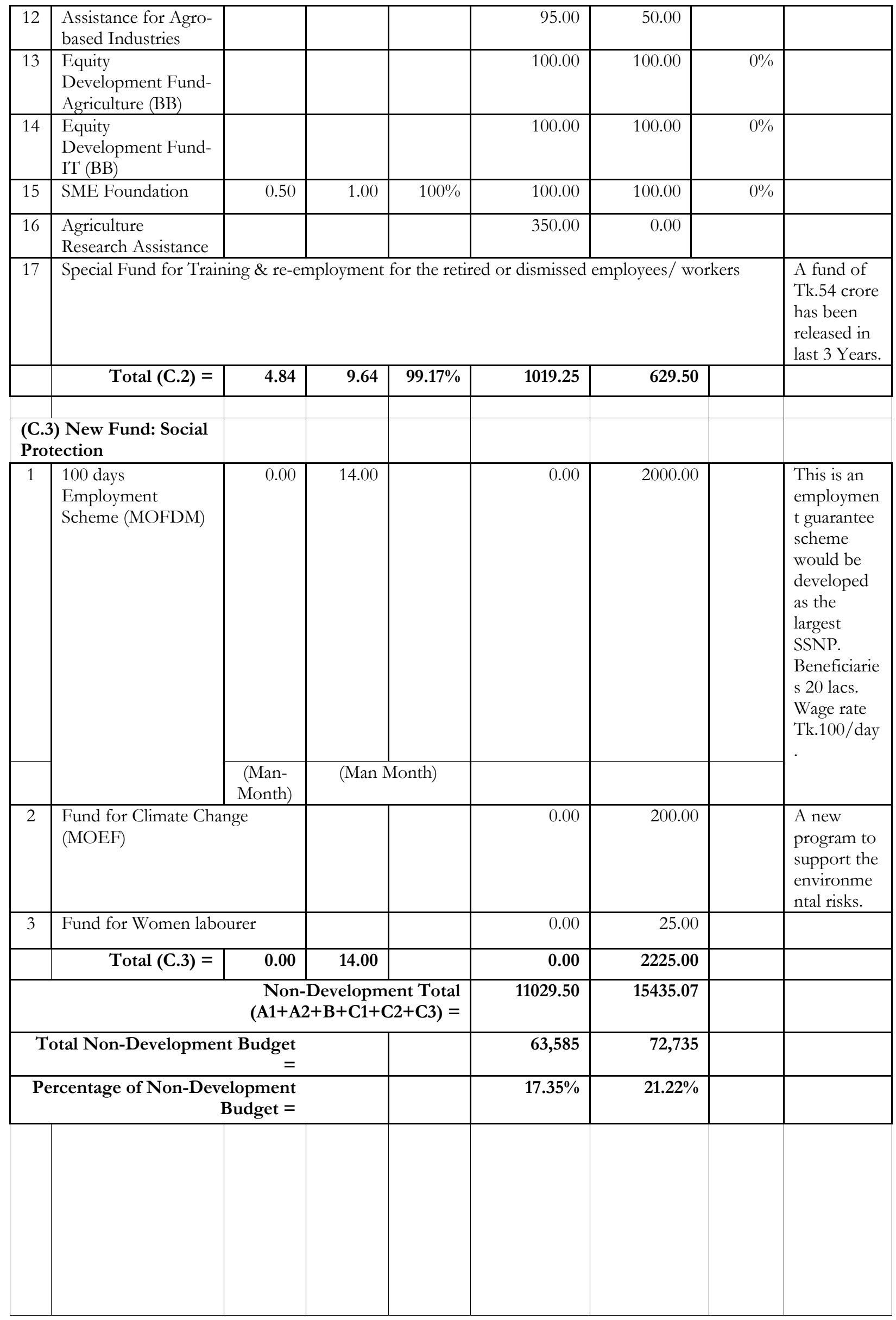




\begin{tabular}{|c|c|c|c|c|c|c|c|c|}
\hline \multicolumn{5}{|c|}{$\begin{array}{l}\text { (D) Development Sector Programs: Social } \\
\text { Empowerment }\end{array}$} & & & & \\
\hline \multicolumn{3}{|c|}{$\begin{array}{l}\text { (D.1) Running Development } \\
\text { Programs }\end{array}$} & & & & & & \\
\hline \multirow[t]{2}{*}{ S1. } & \multirow{2}{*}{$\begin{array}{c}\text { Program } \\
\text { (Ministry/Division } \\
\text { ) }\end{array}$} & \multicolumn{3}{|c|}{ Coverage (in Lac) } & \multicolumn{3}{|c|}{ Budget (in Crore) } & \\
\hline & & $2007-08$ & $2008-09$ & $\begin{array}{c}\text { Increas } \\
\text { e }(\%)\end{array}$ & $\begin{array}{l}\text { Revised } \\
(2007-08)\end{array}$ & $\begin{array}{l}\text { Proposed } \\
(2008-09)\end{array}$ & Incr & ease $(\%)$ \\
\hline 1 & $\begin{array}{l}\text { Stipend for Primary } \\
\text { Students } \\
\text { (MOPMED) }\end{array}$ & 55.00 & 55.00 & $0.00 \%$ & 468.00 & 468.00 & & $\begin{array}{l}\text { The stipend } \\
\text { is provided } \\
\text { to } 58 \text { lacs } \\
\text { students. }\end{array}$ \\
\hline 2 & $\begin{array}{l}\text { School Feeding } \\
\text { Program } \\
\text { (MOPMED) }\end{array}$ & 6.00 & 6.00 & $0.00 \%$ & 50.00 & 0.00 & & $\begin{array}{l}\text { Each } \\
\text { student is } \\
\text { provided } 75 \\
\text { gram } \\
\text { nutritant } \\
\text { biscuits. }\end{array}$ \\
\hline 3 & $\begin{array}{l}\text { Stipend for Dropout } \\
\text { Students } \\
\text { (MOPMED) }\end{array}$ & 5.00 & 5.00 & $0.00 \%$ & 151.54 & 151.54 & & $\begin{array}{l}\text { Stipend is } \\
\text { issued to } \\
\text { about } 5 \text { lacs } \\
\text { schools }\end{array}$ \\
\hline 4 & $\begin{array}{l}\text { Stipend for } \\
\text { Secondary and } \\
\text { Higher } \\
\text { Secondary/Female } \\
\text { Student (MOE) } \\
\end{array}$ & 28.00 & 28.00 & $0.00 \%$ & 340.00 & 340.00 & & \\
\hline 5 & $\begin{array}{l}\text { Stipend for Poor } \\
\text { Boys in secondary } \\
\text { school }\end{array}$ & 0.00 & 1.39 & & & 150.00 & & \\
\hline 6 & $\begin{array}{l}\text { Maternal Health } \\
\text { Voucher Scheme } \\
\text { (MOHFP) }\end{array}$ & 1.00 & 1.00 & $0.00 \%$ & 17.95 & 17.95 & & $\begin{array}{l}\text { Implement } \\
\text { ation under } \\
\text { HNPSP } \\
\text { project. }\end{array}$ \\
\hline 7 & $\begin{array}{l}\text { Rural Employment } \\
\text { Opportunities for } \\
\text { Protection of Public } \\
\text { Property (REOPA) } \\
\text { (LGD) }\end{array}$ & 0.24 & 0.24 & 0.00 & 26.00 & 26.00 & $0 \%$ & $\begin{array}{l}\text { EC \& } \\
\text { UNDP } \\
\text { supported }\end{array}$ \\
\hline 8 & $\begin{array}{l}\text { Community } \\
\text { Nutrition Program } \\
\text { (MOHFA) }\end{array}$ & 1.20 & 1.76 & $46.67 \%$ & 115.00 & 200.00 & $74 \%$ & $\begin{array}{l}\text { Mixture of } \\
\text { rice, pulse, } \\
\text { Ghur, } \\
\text { Soybean, } \\
\text { nutrient } \\
\text { packet and } \\
\text { vitamin A } \\
\text { Capsul. } \\
\end{array}$ \\
\hline 9 & Shouhardo Program & 4.00 & 4.00 & & 17.03 & 19.40 & & $\begin{array}{l}18 \\
\text { Districts. } \\
\text { GoB } \\
\text { Financed }\end{array}$ \\
\hline 10 & $\begin{array}{l}\text { Accommodation } \\
\text { (Poverty Alleviation } \\
\text { \& Rehabilitation) } \\
\text { Project (Prime } \\
\text { Minister's Office) } \\
\end{array}$ & 0.40 & & & 91.39 & 110.49 & & $\begin{array}{l}\text { Abashan } \\
\text { Project. }\end{array}$ \\
\hline 11 & School Children ... & & & & 84.30 & 96.86 & & \\
\hline & Total (D.1) = & 96.44 & 97.00 & & 1142.49 & 1246.69 & & \\
\hline
\end{tabular}




\begin{tabular}{|c|c|c|c|c|c|c|c|c|}
\hline \multicolumn{9}{|c|}{ (D.2) New Programs } \\
\hline 1 & $\begin{array}{l}\text { Rural Employment } \\
\text { and Rural } \\
\text { Maintenance } \\
\text { Program (LGD) }\end{array}$ & 0.00 & 50.00 & & 0.00 & 190.00 & & $\begin{array}{l}\text { It's a new } \\
\text { Program } \\
\text { fully GoB } \\
\text { financed Tk } \\
943 \text { Crore } \\
\text { has been } \\
\text { allocated } \\
\text { for } 5 \text { years } \\
\text { period. }\end{array}$ \\
\hline 2 & \multicolumn{2}{|c|}{$\begin{array}{l}\text { VGD-UP (8 District on Monga } \\
\text { Area) (MOWCA) }\end{array}$} & 0.40 & & & 19.20 & & $\begin{array}{l}\text { A new } \\
\text { project } \\
\text { would be } \\
\text { implemente } \\
\text { d under EC } \\
\text { assistance. }\end{array}$ \\
\hline & Total (D.2) $=$ & 0.00 & 50.40 & & 0.00 & 209.20 & & \\
\hline & $\begin{array}{c}\text { Development } \\
\text { Total }(\mathrm{D})=\end{array}$ & 96.44 & 147.40 & $52.84 \%$ & 1168.49 & 1462.69 & $\begin{array}{r}25.18 \\
\%\end{array}$ & \\
\hline \multicolumn{2}{|c|}{$\begin{array}{r}\text { Grand Total Safety net } \\
(\mathrm{A} 1+\mathrm{A} 2+\mathrm{B}+\mathrm{C} 1+\mathrm{C} 2+\mathrm{C} 3 \\
+\mathrm{D} 1+\mathrm{D} 2)=\end{array}$} & 640.82 & 652.63 & & 12197.99 & $16,897.76$ & $\begin{array}{r}38.53 \\
\%\end{array}$ & \\
\hline \multicolumn{3}{|c|}{ Grand Total Budget $=$} & & & 86,085 & 97735 & $\begin{array}{r}13.53 \\
\%\end{array}$ & \\
\hline \multicolumn{4}{|c|}{ Percentage of Total Budget $=$} & & $14.17 \%$ & $17.29 \%$ & & \\
\hline \multicolumn{4}{|c|}{ GDP $=$} & & 535,415 & 611400 & $14.19 \%$ & \\
\hline \multicolumn{4}{|c|}{ Percentage of GDP = } & & $2.28 \%$ & $2.76 \%$ & & \\
\hline
\end{tabular}


M\&E Indicators 1: Macroeconomic Environment for Pro-poor Growth

\begin{tabular}{|c|c|c|c|}
\hline Strategic Goal & Input Indicators/Policy Change & Output Indicators & Outcome/Impact indicators \\
\hline \multicolumn{4}{|c|}{ Macroeconomic Stability and Pro-poor Economic Growth } \\
\hline $\begin{array}{l}\text { 1. Maintaining stable } \\
\text { macroeconomic environment }\end{array}$ & $\begin{array}{l}\text { - maintain budget deficit at not more } 5 \% \text { of GDP } \\
\text { - maintain growth of money supply to support higher growth and } \\
\text { stable price level } \\
\text { - maintain sustainable current account deficit }\end{array}$ & & $\begin{array}{l}\text { - growth rate } \\
\text { - rate of inflation } \\
\text { - employment for men and women } \\
\text { - head count ratio }\end{array}$ \\
\hline $\begin{array}{l}\text { 2. Increasing funding for pro-poor } \\
\text { growth }\end{array}$ & - increase pro-poor public expenditure & & $\begin{array}{l}\text { - head-count ratio } \\
\text { - Gini-coefficient } \\
\text { - employment for men and women } \\
\end{array}$ \\
\hline 3. Ensuring financial sector reform & $\begin{array}{l}\text { - restructure NCBs } \\
\text { - improve bank regulation/supervision } \\
\text { - improve corporate governance of banks and NBFIs } \\
\text { - ensure flow of credit to agriculture, SMEs, low cost housing \& } \\
\text { women entrepreneurs }\end{array}$ & & $\begin{array}{l}\text { - interest rate } \\
\text { - flow of credit to private sector } \\
\text { - proportion of NPLs }\end{array}$ \\
\hline $\begin{array}{l}\text { 4. Reforming SOEs to reduce } \\
\text { losses and improve their } \\
\text { efficiency }\end{array}$ & $\begin{array}{l}\text { - budget allocation of SOEs as percentage of total budget } \\
\text { - privatize more public enterprises } \\
\text { - downsize BADC and BCIC }\end{array}$ & & $\begin{array}{l}\text { - profit of individual SOEs } \\
\text { - number of employees in SOEs }\end{array}$ \\
\hline $\begin{array}{l}\text { 5. Promoting ready made garment } \\
\text { exports }\end{array}$ & $\begin{array}{l}\text { - implement recommendations of NCC on RMG } \\
\text { - examine the contentious issues like ROO } \\
\text { - improve ports and customs services further }\end{array}$ & & $\begin{array}{l}\text { - share of RMG as \% of total export } \\
\text { - employment in RMG sector }\end{array}$ \\
\hline $\begin{array}{l}\text { 6. Improving international } \\
\text { competitiveness of exports }\end{array}$ & $\begin{array}{l}\text { - implement export policy (2006-09) to promote competitiveness and } \\
\text { diversification of exports } \\
\text { - provide cash incentives to SMEs } \\
\text { - develop entrepreneurship training to promote SMEs }\end{array}$ & & $\begin{array}{l}\text { - total exports } \\
\text { - composition of exports } \\
\text { - exchange rate }\end{array}$ \\
\hline $\begin{array}{l}\text { 7. Providing freer trade } \\
\text { environment }\end{array}$ & $\begin{array}{l}\text { - reduce average protective tariff to } 20 \text { percent } \\
\text { - rationalize number of QRs }\end{array}$ & & $\begin{array}{l}\text { - balance of payment } \\
\text { - foreign exchange reserve }\end{array}$ \\
\hline $\begin{array}{l}\text { 8. Enhancing inflows of } \\
\text { remittances }\end{array}$ & $\begin{array}{l}\text { - strengthen anti money laundering surveillance } \\
\text { - increase remittance flows through official channel }\end{array}$ & & $\begin{array}{l}\text { - remittance as } \% \text { of foreign exchange } \\
\text { earnings } \\
\text { - foreign exchange reserve }\end{array}$ \\
\hline
\end{tabular}


M\&E Indicators 2: Resource Mobilisation (Domestic and Foreign)

\begin{tabular}{|c|c|c|c|}
\hline Strategic Goal & Input Indicators/Policy Change & Output Indicators & Outcome/Impact indicators \\
\hline 1. Enhancing tax effort & $\begin{array}{l}\text { - further modernise and rationalise the taxation system } \\
\text { - establish separate tax policy unit } \\
\text { - decentralise tax collection efforts }\end{array}$ & & $\begin{array}{l}\text { - total revenue as a percent of GDP } \\
\text { - share of direct tax in total revenue }\end{array}$ \\
\hline 2. Improving tax administration & $\begin{array}{l}\text { - pursue capacity building of revenue administration } \\
\text { - reduce discretionary power in tax laws and build trust in tax payers } \\
\text { - create tax friendly environment and provide more client oriented } \\
\text { services } \\
\text { - establish networking of VAT and income tax offices with NBR } \\
\text { - reduce number of items under VAT exemption } \\
\text { - implement customs MIS } \\
\text { - link shipping agents, port authority \& customs using ASYCUDA }\end{array}$ & & - total revenue as percentage of GDP \\
\hline $\begin{array}{l}\text { 3. Generating more revenue from } \\
\text { non-tax sources }\end{array}$ & $\begin{array}{l}\text { - rationalize non-tax revenue rate of fees and charges } \\
\text { - rationalize prices of gas, electricity, petroleum and fertilizers }\end{array}$ & & - non-tax revenue/total revenue \\
\hline $\begin{array}{l}\text { 4. Ensuring increased donor fund } \\
\text { inflow }\end{array}$ & - ensure better aid harmonisation & & $\begin{array}{l}\text { - inflow of foreign official resources as } \\
\text { a share of GDP }\end{array}$ \\
\hline $\begin{array}{l}\text { 5. Strengthening aid management } \\
\text { and implementation capacity }\end{array}$ & $\begin{array}{l}\text { - streamline field administration of implementation } \\
\text { - strengthen implementation, monitoring and feedback into policy }\end{array}$ & & $\begin{array}{l}\text { - timely disbursement of resources and } \\
\text { implementation of activities }\end{array}$ \\
\hline
\end{tabular}

\section{M\&E Indicators 3: Agricultural Growth towards Poverty Reduction}

\begin{tabular}{|c|c|c|c|}
\hline Strategic Goal & Input Indicators/Policy Change & Output Indicators & Outcome/Impact indicators \\
\hline $\begin{array}{l}\text { 1. Increasing productivity and } \\
\text { profitability of agriculture (crops } \\
\text { and non-crops) }\end{array}$ & $\begin{array}{l}\text { - expenditure on agriculture by sub-sectors as percentage of total } \\
\text { public expenditure } \\
\text { - expenditure on agricultural research and extension services } \\
\text { - expenditure on irrigation } \\
\text { - expenditure on marketing services } \\
\text { - expenditure on agro-processing and agro-business development } \\
\text { - expenditure for subsidies in agriculture } \\
\text { - timely availability of agricultural inputs } \\
\text { - expenditure on production of quality seeds } \\
\text { - disbursement of agricultural credit by sub-sectors and farm size } \\
\text { - protect crop lands from non-agricultural uses } \\
\text { - improve land resource base }\end{array}$ & $\begin{array}{l}\text { - new varieties of seeds } \\
\text { - supply of inputs in the market } \\
\text { - pro-poor extension services focused } \\
\text { - irrigation infrastructure } \\
\text { - supply of quality seeds }\end{array}$ & $\begin{array}{l}\text { - per capita consumption of food grains, } \\
\text { vegetables, protein, milk and milk products } \\
\text { - agricultural wage rate by male/female } \\
\text { - agricultural growth rate } \\
\text { - household food security } \\
\text { - employment by sub-sector and by male and } \\
\text { female } \\
\text { - head-count ratio } \\
\text { - regional and temporal price variation } \\
\text { - agricultural output by sub-sectors } \\
\text { - reduction of yield gap } \\
\text { - production of cash crops and high value crops } \\
\text { - output of agro-processing industries }\end{array}$ \\
\hline
\end{tabular}


M\&E Indicators 4: Water Resources Development and Management

\begin{tabular}{|c|c|c|c|}
\hline Strategic Goal & Input Indicators/Policy Change & Output Indicators & Outcome/Impact indicators \\
\hline $\begin{array}{l}\text { 1. Expanding utilization of surface } \\
\text { water including coastal polders } \\
\text { and arsenic prone areas }\end{array}$ & $\begin{array}{l}\text { - increase expenditure on surface water as } \% \text { of water resource } \\
\text { sector expenditure } \\
\text { - handover of O\&M of the existing projects to the beneficiaries } \\
\text { - cost sharing/cost recovery from the beneficiaries }\end{array}$ & $\begin{array}{l}\text { - use of surface water for agricultural } \\
\text { - development of WMO } \\
\text { - handover of O\&M to the WMO } \\
\text { - cost recovery }\end{array}$ & $\begin{array}{l}\text { - } \text { cost of production } \\
\text { - impact on environment } \\
\text { - reduced O\&M burden } \\
\text { - employment generation for men and } \\
\text { women }\end{array}$ \\
\hline $\begin{array}{l}\text { 2. Augmenting utilization of } \\
\text { surface water all over the } \\
\text { country for efficient water } \\
\text { management }\end{array}$ & $\begin{array}{l}\text { - expenditure on surface water as } \% \text { of expenditure on water } \\
\text { resource sector } \\
\text { - negotiations for augmenting trans-boundary water resources with } \\
\text { neighbouring countries }\end{array}$ & $\begin{array}{l}\text { - no. of small/large water retention structures } \\
\text { - diversion of surface water from main river } \\
\text { - rivers and rainwater harvest } \\
\text { - barrages/rubber dams constructed } \\
\text { - trans-boundary water sources assured }\end{array}$ & $\begin{array}{l}\text { - production of agricultural output } \\
\text { - habitat protection } \\
\text { - impact on environment } \\
\text { - employment generation } \\
\text { - trans-boundary river flow during dry } \\
\text { period }\end{array}$ \\
\hline $\begin{array}{l}\text { 3. Rationalising utilization of } \\
\text { ground water }\end{array}$ & $\begin{array}{l}\text { - monitor quality \& quantity of groundwater regularly } \\
\text { - execute Control Measures }\end{array}$ & $\begin{array}{l}\text { - implementation of GW management plans } \\
\text { - region-wise threshold established }\end{array}$ & $\begin{array}{l}\text { - use of ground water } \\
\text { - } \mathrm{GW} \text {-use optimization }\end{array}$ \\
\hline $\begin{array}{l}\text { 4. Ensuring maximum protection } \\
\text { from flood and reducing } \\
\text { vulnerability to water related } \\
\text { disasters }\end{array}$ & $\begin{array}{l}\text { - increase expenditure on flood protection, drainage system etc. } \\
\text { - \% of functional/total no of FCD system } \\
\text { - drought management plans preparation } \\
\text { - riverbank protection and town protection measures } \\
\text { - construct more cyclone shelters } \\
\text { - plan adaptation needs for climate change } \\
\text { - expenditure on maintenance and upgrading of FFWC systems }\end{array}$ & $\begin{array}{l}\text { - FCD projects rehabilitated } \\
\text { - river banks protected at critical sites } \\
\text { - benefited area enlarged due to forecasts } \\
\text { - more cyclone shelters constructed } \\
\text { - climate change adaptation needs assessed } \\
\text { - no. of projects for drought mitigation } \\
\text { - improvement of reliability of forecasts }\end{array}$ & $\begin{array}{l}\text { - flood free area } \\
\text { - coastal polders safe from sea-level } \\
\text { rise } \\
\text { - value of protected assets } \\
\text { - lives saved from disaster } \\
\text { - safety of coastal population from } \\
\text { cyclone } \\
\text { - agricultural droughts mitigated } \\
\end{array}$ \\
\hline $\begin{array}{l}\text { 5. Protecting haors/baors/ } \\
\text { wetland/ sundarban, saline } \\
\text { water intrusion and promote } \\
\text { accretion of land }\end{array}$ & $\begin{array}{l}\text { - make accreted land habitable and suitable for crop production } \\
\text { - implement Integrated Costal Zone Management Plan } \\
\text { - undertake haor/baor development plans }\end{array}$ & $\begin{array}{l}\text { - } \% \text { of protected wetland to total wet land } \\
\text { area } \\
\text { - proportion of area accreted } \\
\text { - salinity controlled } \\
\end{array}$ & $\begin{array}{l}\text { - crop area } \\
\text { - habitat improvement } \\
\text { - employment generation for men and } \\
\text { women }\end{array}$ \\
\hline $\begin{array}{l}\text { 6. Managing erosion of major } \\
\text { rivers and protect towns }\end{array}$ & $\begin{array}{l}\text { - expenditure on control erosion of major rivers and protection of } \\
\text { large and small towns as } \% \text { of water resource sector expenditure }\end{array}$ & $\begin{array}{l}\text { - towns protected } \\
\text { - river bank protected }\end{array}$ & $\begin{array}{l}\text { - property saved } \\
\text { - employment generation for men and } \\
\text { women }\end{array}$ \\
\hline $\begin{array}{l}\text { 7. Ensuring extension and } \\
\text { maintenance of navigation } \\
\text { routes }\end{array}$ & $\begin{array}{l}\text { - expenditure on survival, extension and maintenance of safe } \\
\text { navigation routes }\end{array}$ & $\begin{array}{l}\text { - length of navigational routes } \\
\text { - density of boat traffic }\end{array}$ & $\begin{array}{l}\text { - cost of water transportation } \\
\text { - time saved in commuting }\end{array}$ \\
\hline \multicolumn{4}{|l|}{ Non-structural Goals } \\
\hline $\begin{array}{l}\text { 8. Enhancing access of the poor } \\
\text { to water and common property } \\
\text { resources }\end{array}$ & $\begin{array}{l}\text { - undertake programmes to lease out water and common property } \\
\text { resources } \\
\text { - engage the poor in maintenance of canal and embankment }\end{array}$ & $\begin{array}{l}\text { - area leased out for the poor community for } \\
\text { settlement (Ha.) } \\
\text { - labour Contracting Societies }\end{array}$ & $\begin{array}{l}\text { - employment generation for men and } \\
\text { women } \\
\text { - no. projects leased } \\
\text { - no. of households settled } \\
\end{array}$ \\
\hline $\begin{array}{l}\text { 9. Strengthening human resources } \\
\text { of BWDB }\end{array}$ & $\begin{array}{l}\text { - undertake projects with WMOs } \\
\text { - register WMOs } \\
\text { - provide training to WMOs personnel } \\
\text { - provide WMOs with source to earn revenue for their operational }\end{array}$ & $\begin{array}{l}\text { - WMOs taking O\&M responsibilities as per } \\
\text { GPWM } \\
\text { - training events completed }\end{array}$ & $\begin{array}{l}\text { - surface water use without cross- } \\
\text { cutting conflicts of users }\end{array}$ \\
\hline
\end{tabular}




\begin{tabular}{|c|c|c|c|}
\hline Strategic Goal & Input Indicators/Policy Change & Output Indicators & Outcome/Impact indicators \\
\hline & cost & & \\
\hline $\begin{array}{l}\text { 10. Conducting research and } \\
\text { development for improved } \\
\text { regional water balance }\end{array}$ & $\begin{array}{l}\text { - expenditure on research and development (\% of ADP/year). } \\
\text { - contracts with specialized trusts/research institutions } \\
\text { - cost incurred for climate change adaptation measures }\end{array}$ & $\begin{array}{l}\text { - research/study reports } \\
\text { - no. of EIA/SIA for all water sector projects } \\
\text { - ground water quality and status of regional } \\
\text { thresholds }\end{array}$ & $\begin{array}{l}-\% \text { of additional area free from } \\
\text { drought } \\
\text { - no. of prioritized river training works }\end{array}$ \\
\hline $\begin{array}{l}\text { 11. Ensuring monitoring of } \\
\text { hydrological, climate and } \\
\text { maritime data }\end{array}$ & $\begin{array}{l}\text { - install required telemetry stations } \\
\text { - procure equipment and vehicles } \\
\text { - ensure pro-poor system improvement } \\
\text { - undertake community training on these issues }\end{array}$ & $\begin{array}{l}\text { - lead time of forecasting } \\
\text { - upgrading of FFWC system } \\
\text { - reliability of forecasts } \\
\text { - forecast coverage increased } \\
\text { - customized warning data and information }\end{array}$ & $\begin{array}{l}\text { - homestead saved from flood loss } \\
\text { - savings of agricultural damage } \\
\text { - savings of infrastructural damage }\end{array}$ \\
\hline $\begin{array}{l}\text { 12. Reviewing the existing policy } \\
\text { and finalising the National } \\
\text { Water Act }\end{array}$ & $\begin{array}{l}\text { - strengthen and update WARPO for discharging its clearing house } \\
\text { functions for all water related agencies }\end{array}$ & $\begin{array}{l}\text { - WARPO updates NWRD database and } \\
\text { undertakes macro and micro planning } \\
\text { - \% of feasibility and project studies have } \\
\text { IWRM concepts adequately analyzed }\end{array}$ & $\begin{array}{l}\text { - sustainable, conflict-free and } \\
\text { equitable water resources } \\
\text { development }\end{array}$ \\
\hline
\end{tabular}

M\&E Indicators 5: Small and Medium Enterprises (SMEs) Development

\begin{tabular}{|c|c|c|c|}
\hline Strategic Goal & Input Indicators & Output Indicators & Outcome /Impact indicators \\
\hline $\begin{array}{l}\text { 1. Creating enabling environment to ensure level } \\
\text { playing field for enterprises of all sizes }\end{array}$ & $\begin{array}{l}\text { - undertake pro-SME policies and provide } \\
\text { incentives to SME sector } \\
\text { - undertake pro-SME import and export } \\
\text { policies } \\
\text { - undertake pro-SME credit policy for both } \\
\text { urban and rural areas } \\
\text { - ensuring financing from alternative sources }\end{array}$ & $\begin{array}{l}\text { - flow of credit to SMEs by sector, gender and } \\
\text { areas } \\
\text { - incentives to SMEs } \\
\text { - beneficiaries of export and import policies } \\
\text { - rate of interest }\end{array}$ & $\begin{array}{l}- \text { growth of SMEs } \\
\text { - growth of exports } \\
\text { - rate of employment creation for men and } \\
\text { women } \\
\text { - head count ratio }\end{array}$ \\
\hline 2. Easing regulatory barriers for SME development & $\begin{array}{l}\text { - introduce regulatory reforms in the favour } \\
\text { of SMEs } \\
\text { - ensure support services to SMEs } \\
\text { - Strengthening advocacy for SME } \\
\text { development }\end{array}$ & $\begin{array}{l}\text { - no. of trade license issued to men and women } \\
\text { entrepreneurs } \\
\text { - tax and VAT reduction } \\
\text { - no. of boiler certificate issued } \\
\text { - no. of product certification issued } \\
\text { - no. of trademarks and fire license issued } \\
\text { - no. of BSCIC registration of SMEs } \\
\text { - no. of enterprise registration by the Registrar of } \\
\text { Joint Stock Companies and Firms } \\
\text { - no. of environment certificate issued }\end{array}$ & $\begin{array}{l}\text { - growth of SMEs } \\
\text { - growth of women owned SMEs }\end{array}$ \\
\hline $\begin{array}{l}\text { 3. Creating a database for SMEs for investors and } \\
\text { service providers }\end{array}$ & $\begin{array}{l}\text { - SME definition } \\
\text { - creation of SME database and SME Web } \\
\text { portal } \\
\text { - create Help Line Centre in } 64 \text { BSCIC } \\
\text { industrial service centres }\end{array}$ & $\begin{array}{l}\text { - no. of visitors on SME WEB Portal } \\
\text { - no. of users of the help line centre facilities }\end{array}$ & $\begin{array}{l}\text { - availability of data and information to the } \\
\text { SMEs related stakeholders }\end{array}$ \\
\hline
\end{tabular}




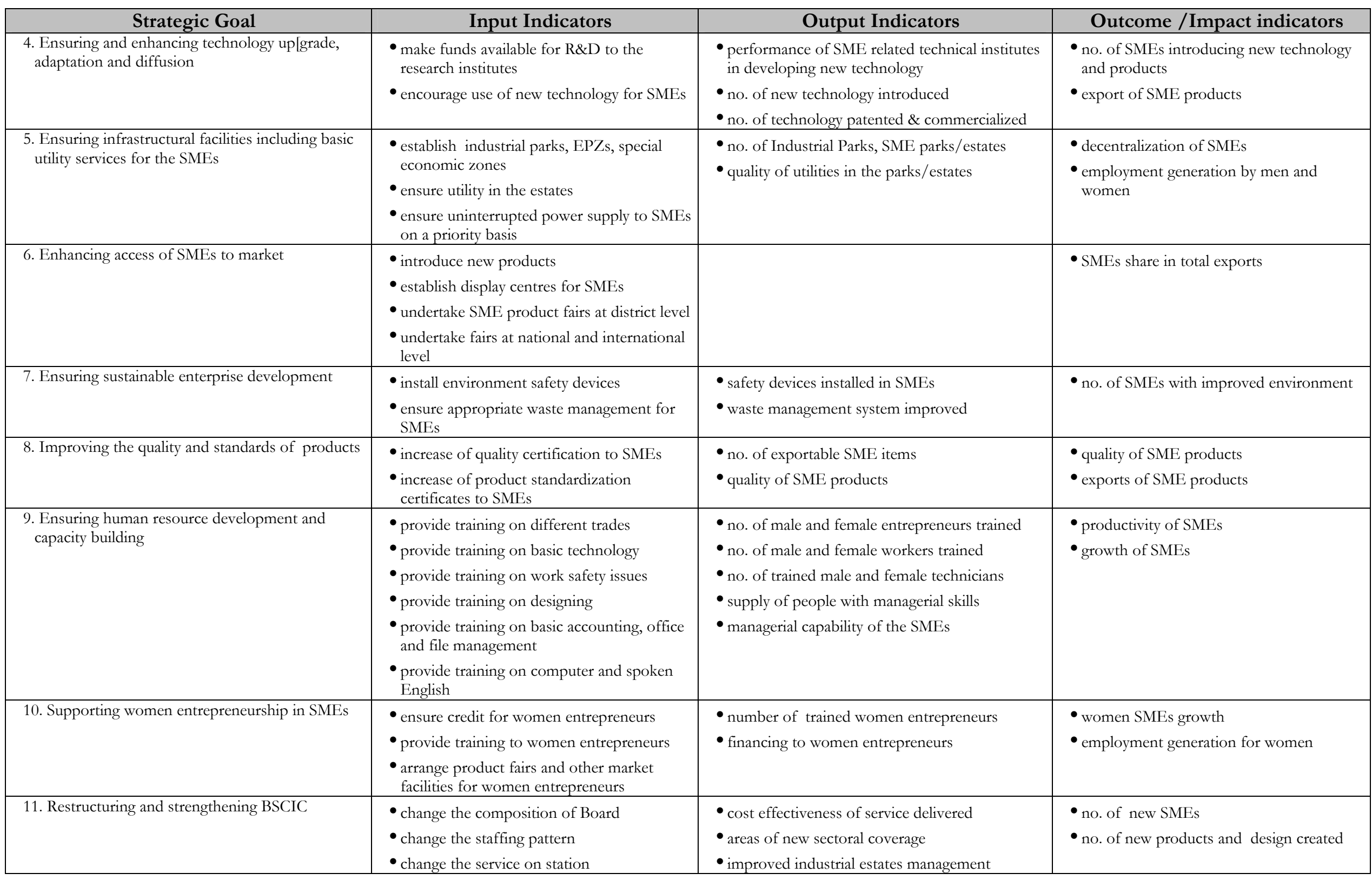




\begin{tabular}{|c|c|c|c|}
\hline Strategic Goal & Input Indicators & Output Indicators & Outcome /Impact indicators \\
\hline 12. Strengthening BSTI & $\begin{array}{l}\text { - increase the no. of regional BSTI offices } \\
\text { - increase testing facilities in BSTI } \\
\text { - increase the no. of qualified staffs in the } \\
\text { regional offices }\end{array}$ & - decentralised and efficient services from BSTI & - quality and standard of SMEs \\
\hline 13. Supporting BCSIR & $\begin{array}{l}\text { - increase flow of funds for R\&D specially on } \\
\text { SMEs } \\
\text { - ensure marketing of new technologies, } \\
\text { processes and products }\end{array}$ & $\begin{array}{l}\text { - no. of new processes and products developed } \\
\text { - technology diffusion and adoption }\end{array}$ & $\begin{array}{l}\text { - } \text { product diversification } \\
\text { - technological advancement }\end{array}$ \\
\hline 14. Strengthening DPDT & $\begin{array}{l}\text { - establish offices of IPRs } \\
\text { - undertake projects to strengthen DPDT }\end{array}$ & $\begin{array}{l}\text { - awareness on IPR issues } \\
\text { - coverage and outreach } \\
\text { - services from DPDT } \\
\end{array}$ & - no. of patented products and IPRs \\
\hline 15. Strengthening SMEF & $\begin{array}{l}\text { - decentralise service delivery } \\
\text { - increase partnership building with private } \\
\text { sector }\end{array}$ & $\begin{array}{l}\text { - Expansion of coverage and outreach } \\
\text { - Extent of networking }\end{array}$ & - no. of SME client served \\
\hline 16. Coordinating policy formulation & $\begin{array}{l}\text { - formulate National Coordination } \\
\text { Committee } \\
\text { - develop indicators for measuring policy and } \\
\text { programmes }\end{array}$ & $\begin{array}{l}\text { - no. of coordination meetings held } \\
\text { - no. of impact output indicators formulated }\end{array}$ & - harmonized national development policies \\
\hline
\end{tabular}

\section{M \&E Indicators 6: Employment Generation and Labour Welfare}

\begin{tabular}{|c|c|c|c|}
\hline Strategic Goal & Input Indicators/Policy Change & Output Indicators & Outcome/Impact indicators \\
\hline $\begin{array}{l}\text { 1. Generating productive } \\
\text { employment }\end{array}$ & $\begin{array}{l}\text { - improve training on existing trades, and introducing training on } \\
\text { new trades in growing demand } \\
\text { - train basic technology and improve technology } \\
\text { - improve working condition for higher productivity } \\
\text { - translate higher productivity into higher wages/earnings } \\
\text { - reform TVET System to make it more responsive to the needs of } \\
\text { women and disadvantaged groups } \\
\text { - draft Child Labour Policy to be finalised and adopted }\end{array}$ & $\begin{array}{l}\text { - no. of trained male and female entrepreneurs } \\
\text { and graduates } \\
\text { - no. of trained male and female workers } \\
\text { - no. male and female technicians } \\
\text { - policies \& guidelines for TVET reform } \\
\text { - no. of quality trainers and graduates } \\
\text { - public-private sector partnerships } \\
\text { - Child Labour Unit at MLE made operational }\end{array}$ & $\begin{array}{l}\text { - availability and absorption of trained } \\
\text { human resources } \\
\text { - number of child labour in hazardous } \\
\text { sectors }\end{array}$ \\
\hline $\begin{array}{l}\text { 2. Undertaking special initiative for } \\
\text { the export of workers from } \\
\text { Monga Area }\end{array}$ & $\begin{array}{l}\text { - create and manage institutional, technical and financial } \\
\text { infrastructure for proper training and to meet initial expenses for } \\
\text { overseas employment }\end{array}$ & $\begin{array}{l}\text { - National Steering Committee and } \\
\text { Implementation Committees at the local level } \\
\text { formed to monitor training \& loan programmes }\end{array}$ & $\begin{array}{l}\text { - overseas employment for Monga } \\
\text { affected people }\end{array}$ \\
\hline $\begin{array}{l}\text { 3. Promoting overseas } \\
\text { employment }\end{array}$ & $\begin{array}{l}\text { - provide training to the workforce including women for overseas } \\
\text { employment } \\
\text { - provide one-stop service for international women migration } \\
\text { - take diplomatic drive for sending human resources abroad } \\
\text { - strengthen the monitoring of recruiting agents }\end{array}$ & $\begin{array}{l}\text { - trained pool of male and female workforce } \\
\text { identified for overseas market } \\
\text { - one-stop-service for women migrants } \\
\text { - no. of labour export agreement signed by the } \\
\text { government } \\
\text { - recruitment agents are well monitored }\end{array}$ & $\begin{array}{l}\text { - no. of overseas employment } \\
\text { generated for men and women } \\
\text { - flow of remittance } \\
\text { - no. of complaints against recruitment } \\
\text { agencies }\end{array}$ \\
\hline
\end{tabular}




\begin{tabular}{|c|c|c|c|}
\hline Strategic Goal & Input Indicators/Policy Change & Output Indicators & Outcome/Impact indicators \\
\hline 4. Promoting wage employment & $\begin{array}{l}\text { - improve capacity in the TTCs, TSCs and other technical institutes } \\
\text { and undertake modernization of training courses }\end{array}$ & - no. of students receiving improved training & - wage employment \\
\hline 5. Promoting self-employment & - provide bank loans to trained male and female entrepreneurs & - no. of self-employment created in a year & $\begin{array}{l}\text { - unemployment rate } \\
\text { - share of self-employment in total } \\
\text { employment }\end{array}$ \\
\hline $\begin{array}{l}\text { 6. Mainstreaming employment } \\
\text { into policy making }\end{array}$ & $\begin{array}{l}\text { - develop sector level employment policies and mainstream } \\
\text { employment generation as a cross-cutting issue }\end{array}$ & - sector level action plans for employment & $\begin{array}{l}\text { - employment by sectors } \\
\text { - unemployment rate }\end{array}$ \\
\hline $\begin{array}{l}\text { 7. Undertaking job creation } \\
\text { programmes through public } \\
\text { works }\end{array}$ & - increase resource allocation for public works programme & $\begin{array}{l}\text { - employment in public work programmes in } \\
\text { poor especially in Monga-prone areas }\end{array}$ & $\begin{array}{l}\text { - severity of seasonal unemployment } \\
\text { reduced, especially in the Monga-prone } \\
\text { districts }\end{array}$ \\
\hline $\begin{array}{l}\text { 8. Improving resilience to } \\
\text { livelihood shocks due to natural } \\
\text { disasters in the coastal areas }\end{array}$ & • establish Coastal Development Authority (CDA) & $\begin{array}{l}\text { - existing programmes are administered by the } \\
\text { proposed CDA }\end{array}$ & $\begin{array}{l}\text { Mitigation of shocks due to natural } \\
\text { disasters in the coastal areas }\end{array}$ \\
\hline 9. Improving labour welfare & $\begin{array}{l}\text { - establish Labour Welfare Foundation (LWF) } \\
\text { - train OSH, reproductive rights, HIV/AIDS, STD and distributing } \\
\text { family planning materials } \\
\text { - establish labour recreational facilities } \\
\text { - undertake time bound programmes for elimination of WFCL } \\
\text { - improve management and workers education courses in IRIs and } \\
\text { LWCs }\end{array}$ & $\begin{array}{l}\text { - Labour Welfare Centres established } \\
\text { - partnerships with local govt. institutions, and } \\
\text { NGOs established } \\
\text { - improved capacity to monitor and implement } \\
\text { programmes on child labour } \\
\text { - adoption of the National Child Labour Policy } \\
\text { - BLA-2006 enforced }\end{array}$ & $\begin{array}{l}\text { - labour welfare in terms of health care, } \\
\text { recreation, family welfare } \\
\text { - labour productivity } \\
\text { - industrial relations } \\
\text { - no. of disruptions in factories }\end{array}$ \\
\hline
\end{tabular}

M\&E Indicators 7: Private Sector Development

\begin{tabular}{|c|c|c|c|}
\hline Strategic Goal & Input Indicators/Policy Change & Output Indicators & Outcome/Impact indicators \\
\hline $\begin{array}{l}\text { 1. Creating an enabling policy } \\
\text { environment }\end{array}$ & $\begin{array}{l}\text { - streamline the legal and regulatory framework } \\
\text { - clear the backlog of cases in the courts } \\
\text { - simplify and make the land titling procedure corruption free } \\
\text { - ensure compliance of labour laws with international standards } \\
\text { - reduce time for issuing trade licenses \& enterprise registrations } \\
\text { - enact competition law and declare competition policy } \\
\text { - strengthen One-Stop Service of the BOI } \\
\text { - formulate wage legislation responsive to productivity growth } \\
\text { - replace tax holiday by a system of discount tax rate } \\
\text { - increase tax exemption ceiling and lower VAT rates } \\
\text { - bring company tax in line with other countries in the region } \\
\text { - enhance privatization and public enterprise reform } \\
\text { - ensure effective implementation of PSI } \\
\text { - create an atmosphere to attract FDIs }\end{array}$ & $\begin{array}{l}\text { - no. of backlog of cases relating to contract } \\
\text { enforcement } \\
\text { - easy compliance of regulatory requirements } \\
\text { - land/asset transfer time and cost } \\
\text { - corporate tax system rationalized } \\
\text { - privatization \& public enterprise reform } \\
\text { - time \& costs for issuing a trade license and } \\
\text { enterprise registration } \\
\text { - better business environment created } \\
\text { - labour productivity improved }\end{array}$ & $\begin{array}{l}\text { - private investment growth } \\
\text { - employment growth both for male } \\
\text { and female } \\
\text { - no. of new enterprises } \\
\text { - no. of new women owned } \\
\text { enterprises } \\
\text { - growth of industry } \\
\text { - increase in FDI inflow } \\
\text { - no. of people receiving efficient } \\
\text { service from BOI 'one stop services' }\end{array}$ \\
\hline $\begin{array}{l}\text { 2. Increasing and providing } \\
\text { policy support for PSD }\end{array}$ & $\begin{array}{l}\text { - ensure public expenditure on research and support services } \\
\text { - stimulate private investment with guidance and counselling }\end{array}$ & $\begin{array}{l}\text { - credit availability to small/and women } \\
\text { entrepreneurs become easy }\end{array}$ & $\begin{array}{l}\text { - entrepreneurship growth including } \\
\text { women entrepreneurs }\end{array}$ \\
\hline
\end{tabular}




\begin{tabular}{|c|c|c|c|}
\hline & $\begin{array}{l}\text { - stimulate sub-contracting activities } \\
\text { - create database for PSD } \\
\text { - channel funds to the women and small entrepreneurs without } \\
\text { collateral and keep interest rate low at maximum of } 10 \% \\
\text { - form cluster village } \\
\text { - establish training and design centres } \\
\text { - streamline foreign loan registry system }\end{array}$ & $\begin{array}{l}\text { - sub-contracting facilities strengthened } \\
\text { - information related to PSD is available } \\
\text { - public -private partnership established. } \\
\text { - skill development facilities are available. } \\
\text { - marketing facilities are created. } \\
\text { - foreign loan registry time reduced }\end{array}$ & $\begin{array}{l}\text { - private investment growth } \\
\text { - employment growth for men and } \\
\text { women }\end{array}$ \\
\hline $\begin{array}{l}\text { 3. Improving access to land for } \\
\text { private sector }\end{array}$ & $\begin{array}{l}\text { - formulate an economic zones (EZ) policy and regulatory } \\
\text { - } \text { devework } \\
\text { - restructure ans existing public sector industrial estates portfolio } \\
\text { - undertake rigorous economic analysis of new investments in EZs } \\
\text { - undertake institutional development and capacity building within } \\
\text { government }\end{array}$ & - Special Economic Zones (SEZs) established & $\begin{array}{l}\text { - output and export from SEZs } \\
\text { - employment for men and women }\end{array}$ \\
\hline 4. Easing supply constraints & $\begin{array}{l}\text { - create new agency for loan recovery } \\
\text { - establish new leasing companies } \\
\text { - reduce infrastructural constraints }\end{array}$ & $\begin{array}{l}\text { - new industrial estates set up } \\
\text { - loan recovery rate improved } \\
\text { - no. of firms benefiting from leasing } \\
\text { companies }\end{array}$ & - level of private investment \\
\hline $\begin{array}{l}\text { 5. Undertake systematic dialogue } \\
\text { between the public and private } \\
\text { sectors }\end{array}$ & $\begin{array}{l}\text { - strengthen government secretariat for BBBF } \\
\text { - establish private sector secretariat for BBBF } \\
\text { - continue identifying issues faced by the private sector and find } \\
\text { - solution through working groups } \\
\text { - monitor implementation of solutions }\end{array}$ & $\begin{array}{l}\text { - no. of meetings of working groups } \\
\text { - no. of plenary meetings } \\
\text { - no. of recommendations made and } \\
\text { implemented }\end{array}$ & $\begin{array}{l}\text { - domestic and foreign private } \\
\text { investment } \\
\text { - employment for men and women }\end{array}$ \\
\hline $\begin{array}{l}\text { 6.Promoting women } \\
\text { entrepreneurship (WE) } \\
\text { development }\end{array}$ & $\begin{array}{l}\text { - strengthen women entrepreneurships development of BSCIC } \\
\text { - strengthen one stop services of BOI } \\
\text { - take steps to ensure higher growth of WE } \\
\text { - build capacity of women garment workers for foreign job } \\
\text { markets } \\
\text { - link women's associations and credit institutions } \\
\text { - ensure preferential access to support services for WE } \\
\text { - provide industrial plots to WE on a preferential basis }\end{array}$ & $\begin{array}{l}\text { - quality of business support services } \\
\text { - BSCIC's women entrepreneurships } \\
\text { development programmes strengthened } \\
\text { - more credit and business services are } \\
\text { available for women entrepreneurs } \\
\text { - women entrepreneur's forum strengthened }\end{array}$ & $\begin{array}{l}\text { - growth of PSD } \\
\text { - growth of women entrepreneurships } \\
\text { - growth of women employment and } \\
\text { income }\end{array}$ \\
\hline
\end{tabular}

M\&E Indicators 8: Land Use Management including Land Reform

\begin{tabular}{|c|c|c|c|}
\hline Strategic Goal & Input Indicators/Policy Change & Output Indicators & Outcome/Impact indicators \\
\hline $\begin{array}{l}\text { 1.Modernising land records and } \\
\text { land management system }\end{array}$ & $\begin{array}{l}\text { - increase expenditure on procurement of materials } \\
\text { - increase expenditure on employment and training of manpower. }\end{array}$ & $\begin{array}{l}\text { - no. of Upazilas with modernised and } \\
\text { computerised land records system }\end{array}$ & - no. of land related disputes and cases \\
\hline $\begin{array}{l}\text { 2. Rehabilitating and improving } \\
\text { socioeconomic condition of } \\
\text { asset less and homeless poor } \\
\text { people }\end{array}$ & $\begin{array}{l}\text { - increase expenditure on construction of houses } \\
\text { - increase expenditure on training } \\
\text { - increase amount of micro credit }\end{array}$ & $\begin{array}{l}\text { - no. of families provided with land \& housing } \\
\text { - no. of families provided with training } \\
\text { - no. of families provided with micro credit }\end{array}$ & $\begin{array}{l}\text { - change of status of these people } \\
\text { - employment generation }\end{array}$ \\
\hline $\begin{array}{l}\text { 3. Distributing agricultural Khas } \\
\text { land to poor }\end{array}$ & $\begin{array}{l}\text { - take measure for identifying Khas land } \\
\text { - take measure for selection of beneficiaries }\end{array}$ & $\begin{array}{l}\text { - no. of families provided with agricultural } \\
\text { Khas land }\end{array}$ & $\begin{array}{l}\text { - crop production by concerned } \\
\text { families }\end{array}$ \\
\hline $\begin{array}{l}\text { 4. Ensuring proper and planned } \\
\text { use of land }\end{array}$ & $\begin{array}{l}\text { - increase expenditure on procurement of materials, employment } \\
\text { and training of human resources }\end{array}$ & $\begin{array}{l}\text { - no. of completed land zoning maps and } \\
\text { promulgation }\end{array}$ & - optimum use of land \\
\hline
\end{tabular}




\begin{tabular}{|c|c|c|c|}
\hline Strategic Goal & Input Indicators/Policy Change & Output Indicators & Outcome/Impact indicators \\
\hline & $\begin{array}{l}\text { - take measures for enactment of laws } \\
\text { - take measures for preparation of reports, maps } \\
\text { - increase expenditure on awareness building of local people and } \\
\text { LG bodies }\end{array}$ & & \\
\hline $\begin{array}{l}\text { 5. Managing Jajmahal, Balumahal } \\
\text { and other Sairat mahals for } \\
\text { poverty reduction }\end{array}$ & $\begin{array}{l}\text { - take measure for identification of genuine fishermen } \\
\text { - taken measure for involving NGOs and the Union Parishad }\end{array}$ & $\begin{array}{l}\text { - no. of fishermen/ fishermen societies } \\
\text { provided with Jalmahals }\end{array}$ & $\begin{array}{l}\text { - socioeconomic conditions of } \\
\text { fishermen } \\
\text { - growth of inland capture fishery }\end{array}$ \\
\hline $\begin{array}{l}\text { 6. Ensuring ownership/title } \\
\text { through land survey }\end{array}$ & $\begin{array}{l}\text { - take measure for selection of area } \\
\text { - employ sufficient employees for survey } \\
\text { - increase expenditure on procurement of materials }\end{array}$ & $\begin{array}{l}\text { - no. of Khatians and Mauza Maps printed } \\
\text { and published } \\
\text { - no. of Khatians and Mouza Maps supplied } \\
\text { to the owners }\end{array}$ & - reduction in the land related cases \\
\hline $\begin{array}{l}\text { 7. Ensuring maximum land } \\
\text { related service to the people }\end{array}$ & $\begin{array}{l}\text { - constitute committee of experts including lawyers } \\
\text { - take measure for modification, updating and simplification of } \\
\text { land related acts, ordinances, rules, regulations and policies }\end{array}$ & $\begin{array}{l}\text { - no. of land related acts, ordinances, rules, } \\
\text { regulations and policies modified, updated, } \\
\text { simplified or cancelled }\end{array}$ & $\begin{array}{l}\text { - no of people receiving delivery of } \\
\text { services }\end{array}$ \\
\hline $\begin{array}{l}\text { 8. Protecting and conserving wet } \\
\text { land, hilly areas, tea gardens, } \\
\text { rubber gardens }\end{array}$ & $\begin{array}{l}\text { - take measure to protect wet land from land grabbers } \\
\text { - take measure to make the accreted land suitable for afforestation, } \\
\text { habitation and crop production }\end{array}$ & $\begin{array}{l}\text { - proportion of wet land area protected } \\
\text { - development of accreted land }\end{array}$ & $\begin{array}{l}\text { - crop area } \\
\text { - impact on environment }\end{array}$ \\
\hline $\begin{array}{l}\text { 9. Take measures to help } \\
\text { accretion of coastal land }\end{array}$ & - identify potential areas for accretion process & & $\begin{array}{l}\text { - quantity of land accreted } \\
\text { - new habitat }\end{array}$ \\
\hline
\end{tabular}

M\&E Indicators 9: Housing Development

\begin{tabular}{|c|c|c|c|}
\hline Strategic Goal & Input Indicators/Policy Change & Output Indicators & Outcome/Impact indicators \\
\hline $\begin{array}{l}\text { 1. Providing adequate and } \\
\text { affordable housing for different } \\
\text { income groups, especially low } \\
\text { income and extreme poor and } \\
\text { vulnerable group }\end{array}$ & $\begin{array}{l}\text { - identify rent to income ratio } \\
\text { - identify per square feet cost of housing in different cities } \\
\text { - ensure access to credit/housing finance } \\
\text { - reduce duty and fees for registration of homes/ apartments } \\
\text { - encourage building of multi-unit houses } \\
\text { - ensure decrease in the no. of squatters and slums } \\
\text { - provide tenurial rights }\end{array}$ & $\begin{array}{l}\text { - systems of innovative housing finance, } \\
\text { cognizant of middle and low-income } \\
\text { households } \\
\text { - stamp duty and fees for registration of } \\
\text { homes/apartments } \\
\text { - housing for elderly, FHH, slum and poor } \\
\text { people } \\
\text { - facilitators who will empower local } \\
\text { communities } \\
\text { - eviction frequency }\end{array}$ & $\begin{array}{l}\text { - increase in \% of new homes for all } \\
\text { especially hard-core poor } \\
\text { - new housing communities for hard- } \\
\text { core poor and wage workers in } \\
\text { rented/leased buildings facilitated by } \\
\text { GoB/Cooperative Housing Societies } \\
\text { - housing for elderly, FHH, slum } \\
\text { dwellers and poor people } \\
\text { - } \% \text { of owned houses in urban areas }\end{array}$ \\
\hline $\begin{array}{l}\text { 2. Provide housing for rural and } \\
\text { urban homeless, landless and } \\
\text { vulnerable groups }\end{array}$ & $\begin{array}{l}\text { - build hostels and dormitories for working women in all district } \\
\text { towns } \\
\text { - include women especially in public housing projects } \\
\text { - reduce old slums and attrition rate of new slums } \\
\text { - undertake group-lending schemes } \\
\text { - recapture public land occupied by squatters }\end{array}$ & $\begin{array}{l}\text { - low-cost homes with efficient land utilization } \\
\text { - housing for communities in distress } \\
\text { - select disaster-prone, food insecure rural } \\
\text { areas for targeted home building assistance } \\
\text { - develop systems of innovative housing } \\
\text { finance } \\
\text { - recaptured public land occupied by squatters } \\
\text { - new housing policies based on equality and } \\
\text { capability criteria }\end{array}$ & $\begin{array}{l}\text { - no. of people with housing in } \\
\text { disaster-prone, food insecure rural } \\
\text { areas } \\
\text { - no. of poor and female headed } \\
\text { household with housing } \\
\text { - no. of working women with housing } \\
\text { facility } \\
\text { - no. of high-rise buildings with } \\
\text { minimum } 450 \text { square feet flats }\end{array}$ \\
\hline
\end{tabular}




\begin{tabular}{|c|c|c|c|}
\hline Strategic Goal & Input Indicators/Policy Change & Output Indicators & Outcome/Impact indicators \\
\hline $\begin{array}{l}\text { 3. Ensuring maximum utilization } \\
\text { of land in urban and rural areas } \\
\text { and providing finance }\end{array}$ & $\begin{array}{l}\text { - increase in budgetary allocation for the housing sector } \\
\text { - acquire land for reorganizing land use } \\
\text { - increase in number of industries to produce construction } \\
\text { materials } \\
\text { - support construction of social housing/mess etc. } \\
\text { - setup advisory services on housing } \\
\text { - invest in local, regional and national level research organizations } \\
\text { for housing standards } \\
\text { - introduce national guidelines for effective utilization of land } \\
\text { - provide conditional loans to housing association for building } \\
\text { housing for poor and destitute women } \\
\text { - identify households in rural and urban areas capable of paying } 5 \\
\text { \% interest rate on housing loans }\end{array}$ & $\begin{array}{l}\text { - increase access to inputs in rural areas } \\
\text { - ensure quality testing for locally produced } \\
\text { building materials } \\
\text { - housing fund management association } \\
\text { including BB, NGOs, local govt. and GoB } \\
\text { - loans for housing with community } \\
\text { homesteads } \\
\text { - numbers of permanent structures } \\
\text { - no. of updated land use plans } \\
\text { - no. of completed regional plans } \\
\text { - price of land and housing } \\
\text { - amount of urban land provided with services }\end{array}$ & $\begin{array}{l}\text { - } \text { micro-finance institutions for } \\
\text { housing } \\
\text { - financing mechanisms } \\
\text { - national guidelines for effective } \\
\text { utilization of land } \\
\text { - conditional cash transfer } \\
\text { - legal aid and counselling on home } \\
\text { building } \\
\text { - grievance and redressal mechanisms } \\
\text { related to land and housing } \\
\text { - no. of people able to afford self } \\
\text { owned houses }\end{array}$ \\
\hline $\begin{array}{l}\text { 4. Facilitating private sector } \\
\text { (formal and informal) house } \\
\text { building, NGOs and CBOs }\end{array}$ & $\begin{array}{l}\text { - provide loans for housing with community homesteads } \\
\text { - coordinate between local govt. NGOs and CBOs for housing, } \\
\text { transportation, employment, industry } \\
\text { - support for less literate population, vulnerable, destitute, disaster } \\
\text { affected and women }\end{array}$ & $\begin{array}{l}\text { - advisory services on housing information } \\
\text { - improved funding opportunities at local level } \\
\text { for house building and "Compact } \\
\text { townships" }\end{array}$ & $\begin{array}{l}\text { - no. of people able to afford self } \\
\text { owned houses } \\
\text { - compact township }\end{array}$ \\
\hline
\end{tabular}

M\&E Indicators 10: Infrastructural Development including Power, Energy and Communications

\begin{tabular}{|c|c|c|c|}
\hline Strategic Goals & Input Indicators & Output Indicators & Outcome/Impact indicators \\
\hline \multicolumn{4}{|c|}{ Infrastructure Development including Power, Energy \& Communications } \\
\hline $\begin{array}{l}\text { Power: } \\
\text { 1. Developing capacity for power } \\
\text { generation, transmission and } \\
\text { distribution }\end{array}$ & $\begin{array}{l}\text { - increase expenditure on power sector } \\
\text { - rationalize tariffs } \\
\text { - adopt transparent power-pricing framework } \\
\text { - encourage private sector power generation }\end{array}$ & $\begin{array}{l}\text { - power generation capability }(\mathrm{MW}) \\
\text { - transmission line }(\mathrm{km}) \\
\text { - distribution line }(\mathrm{km})\end{array}$ & $\begin{array}{l}\text { - area coverage } \\
\text { - no. of consumer by types } \\
\text { - access of poor households } \\
\text { - manufacturing and crop outputs } \\
\text { - employment generation } \\
\text { - head-count ratio }\end{array}$ \\
\hline $\begin{array}{l}\text { Energy: } \\
\text { 2. Assessing non-renewable } \\
\text { indigenous resources } \\
\text { 3. Ensuring conservation } \\
\text { measures for efficient use }\end{array}$ & $\begin{array}{l}\text { - increase expenditure on oil, gas and mineral exploration in land } \\
\text { - and sea } \\
\text { - attract private sector investment in exploration } \\
\text { - } \text { strengthen the hydrocarbon unit (HCU) } \\
\text { - introduce meters for domestic gas supply } \\
\text { - ensure marketing of LPG and CNG } \\
\text { - formulate coal policy }\end{array}$ & $\begin{array}{l}\text { - discovery of new fields and assessment of } \\
\text { potential reserve } \\
\text { - no. of households using LPG } \\
\text { - no. of CNG using motor vehicles } \\
\text { - coal exploration and extraction }\end{array}$ & $\begin{array}{l}\text { - } \text { manufacturing sector growth } \\
\text { - } \text { stable power generation } \\
\text { - } \text { output of gas based industries } \\
\text { - thermal power generation }\end{array}$ \\
\hline $\begin{array}{l}\text { Roads: } \\
\text { 4. Developing roads } \\
\text { infrastructure }\end{array}$ & $\begin{array}{l}\text { - } \text { increase expenditure on transport sector } \\
\text { - prepare an integrated road sector Master Plan } \\
\text { - update legislation mainly Highways Act } 1925 \\
\text { - adopt integrated multimodal transport policy } \\
\text { - prepare and implement private sector investment policy in the }\end{array}$ & $\begin{array}{l}\text { - construction of roads by categories } \\
\text { - constructions of bridges/culverts/flyovers } \\
\text { - access to areas by roads } \\
\text { - no. of growth centres linked } \\
\text { - no. of ferry ghats linked }\end{array}$ & $\begin{array}{l}\text { - } \text { private investment } \\
\text { - employment generation (by sector- } \\
\text { sub-sector, male-female, } \\
\text { rural/urban) } \\
\text { - production and domestic trade }\end{array}$ \\
\hline
\end{tabular}




\begin{tabular}{|c|c|c|c|}
\hline Strategic Goals & Input Indicators & Output Indicators & Outcome/Impact indicators \\
\hline & road sub-sector development & & $\begin{array}{l}\text { - women's market sections } \\
\text { - export }\end{array}$ \\
\hline $\begin{array}{l}\text { 5. Developing road } \\
\text { communication to link growth } \\
\text { centres, union and upazila } \\
\text { headquarters and national roads }\end{array}$ & $\begin{array}{l}\text { - } \text { expenditure on link roads and pro-growth infrastructure } \\
\text { - involve community, local government institutions (LGI), } \\
\text { NGOs and beneficiary groups } \\
\text { - provide community input in planning, design and } \\
\text { implementation }\end{array}$ & - construction of rural roads & $\begin{array}{l}\text { - rate of growth of rural economy } \\
\text { - head count index in rural areas } \\
\text { - social indicators in rural areas }\end{array}$ \\
\hline $\begin{array}{l}\text { 6. Emphasising maintenance of } \\
\text { roads and other physical } \\
\text { infrastructure }\end{array}$ & $\begin{array}{l}\text { - } \text { earmark separate fund for road maintenance } \\
\text { - } \quad \text { enhance maintenance fund } \\
\text { - involve local government \& NGOs in operation \& maintenance }\end{array}$ & - maintenance of roads/bridges/culverts & - rate of growth of rural economy \\
\hline $\begin{array}{l}\text { Railways: } \\
\text { 7. Increasing access to the railway } \\
\text { service }\end{array}$ & $\begin{array}{l}\text { - } \text { increase expenditure on railways } \\
\text { - rehabilitate and reopen closed branch lines } \\
\text { - } \text { adopt public service obligation (PSO) involving all branch lines } \\
\text { to serve the local poor in backward/remote areas } \\
\text { - provide transport facilities to poor passengers }\end{array}$ & $\begin{array}{l}\text { - no. of branch lines } \\
\text { - construction of double track lines }\end{array}$ & $\begin{array}{l}\text { - cost effective and efficient railway } \\
\text { system } \\
\text { - no. of passengers by classes } \\
\text { - railway freight by types of goods }\end{array}$ \\
\hline $\begin{array}{l}\text { Inland water transport: } \\
\text { 8. Enhancing quality of water } \\
\text { transport }\end{array}$ & $\begin{array}{l}\text { - expenditure on inland water transport as } \% \text { of transport sector } \\
\text { - } \text { expenditure } \\
\text { - cormulate pragmatic water transport policies } \\
\text { - develop sustainable water transport system }\end{array}$ & $\begin{array}{l}\text { - no. of container vessels for waterborne } \\
\text { cargo transportation and water taxi } \\
\text { - ro-ro ferries, } 2 \mathrm{~K} \text {-type ferries, landing } \\
\text { stations and coastal passenger vessels } \\
\text { - navigation services } \\
\text { - launch terminal/ghats facilities } \\
\end{array}$ & $\begin{array}{l}\text { - travel/transport cost and time } \\
\text { - system loss at various level } \\
\text { - employment generation by } \\
\text { male/female, rural/urban } \\
\text { - head-count ratio }\end{array}$ \\
\hline $\begin{array}{l}\text { Airway: } \\
\text { 9. Increasing scale of operation to } \\
\text { serve more passengers and } \\
\text { enhance air cargo capacity }\end{array}$ & $\begin{array}{l}\text { - increase expenditure on airway } \\
\text { - acquire aircrafts for long-haul and regional routes } \\
\text { - off-load Biman's share } \\
\text { - implement cost cutting measures } \\
\text { - facilitate private sector participation in aviation } \\
\text { - undertake policy for foreign carriers for perishable export cargo } \\
\text { - expand and modernise ZIA. }\end{array}$ & $\begin{array}{l}\text { - no. of new destinations and frequency } \\
\text { - modern Biman's fleet } \\
\text { - Modernise airport facilities }\end{array}$ & $\begin{array}{l}\text { - volume of export } \\
\text { - employment generation } \\
\text { - profit of Biman }\end{array}$ \\
\hline
\end{tabular}

M\&E Indicators 11: Social Safety Net, Food Security, Disaster Management, Scaling up of Micro-credit and Rural Non-farm Activities

\begin{tabular}{|c|c|c|c|}
\hline Strategic Goal & Input Indicators/Policy Change & Output Indicators & Outcome/Impact indicators \\
\hline \multicolumn{4}{|l|}{ Social Safety Net } \\
\hline $\begin{array}{l}\text { 1. Extending coverage of social } \\
\text { safety net }\end{array}$ & $\begin{array}{l}\text { - increase cash and kind transfers as \% of GDP } \\
\text { - increase SSN expenditure as } \% \text { of total public expenditure }\end{array}$ & $\begin{array}{l}\text { - increase in income and consumption } \\
\text { - increase in employment generation }\end{array}$ & $\begin{array}{l}\text { - head count rate } \\
\text { - incidence of extreme poverty by } \\
\text { socio-economic groups and region }\end{array}$ \\
\hline \multicolumn{4}{|l|}{ Food Security } \\
\hline 2. Ensuring food entitlement & $\begin{array}{l}\text { - keep food price within peoples' purchasing power } \\
\text { - increase total food distribution }\end{array}$ & - increase food consumption & $\begin{array}{l}\text { - } \text { no. of people enduring hunger } \\
\text { - } \text { nutrition status of poor people }\end{array}$ \\
\hline \multicolumn{4}{|l|}{ Disaster Management } \\
\hline $\begin{array}{l}\text { 3. Improving risk reduction } \\
\text { capacity }\end{array}$ & $\begin{array}{l}\text { - increase public expenditure on disaster management } \\
\text { - involve NGOs, LGIs in disaster management }\end{array}$ & $\begin{array}{l}\text { - protection and rehabilitation of all groups } \\
\text { of people }\end{array}$ & $\begin{array}{l}\text { - loss of life and property } \\
\text { - credit to poor and SMEs }\end{array}$ \\
\hline
\end{tabular}




\begin{tabular}{|c|c|c|c|}
\hline \multicolumn{4}{|l|}{ Micro-credit } \\
\hline $\begin{array}{l}\text { 4. Reaching the ultra poor and } \\
\text { under served areas }\end{array}$ & $\begin{array}{l}\text { - ensure disbursement of micro-credit to ultra poor } \\
\text { - expand disbursement to underserved areas } \\
\text { - upscale micro-credit to served capable entrepreneurs }\end{array}$ & $\begin{array}{l}\text { - increased coverage of the ultra poor, under } \\
\text { served areas and capable entrepreneurs' }\end{array}$ & $\begin{array}{l}\text { - head count index } \\
\text { - graduation rate }\end{array}$ \\
\hline $\begin{array}{l}\text { 5. Scaling up micro-credit for } \\
\text { poverty reduction }\end{array}$ & $\begin{array}{l}\text { - reduce interest rate } \\
\text { - ensure disbursement of collateral free larger micro credit } \\
\text { - provide non-financial services on need basis } \\
\text { - extend and deepen GO-NGO collaboration } \\
\text { - make rules for credit disbursement and repayment more flexible } \\
\text { - ensure supply of loanable funds } \\
\text { - strengthen Micro-Finance Regulatory Authority }\end{array}$ & $\begin{array}{l}\text { - } \% \text { of poor and ultra poor with access to } \\
\text { micro credit } \\
\text { - coverage of non financial services } \\
\text { - no. of borrowers and size of credit } \\
\text { - lower interest rate and longer grace period } \\
\text { - governance of micro-finance institutions }\end{array}$ & $\begin{array}{l}\text { - head-count ratio } \\
\text { - employment generation by } \\
\text { male/female and rural /urban } \\
\text { - household income of micro credit } \\
\text { recipients and the other poor } \\
\text { - graduation rate }\end{array}$ \\
\hline \multicolumn{4}{|l|}{ Rural Non Farm Activities } \\
\hline $\begin{array}{l}\text { 6. Accelerating growth of Rural } \\
\text { Non-Farm Enterprises (Runes) } \\
\text { sector }\end{array}$ & $\begin{array}{l}\text { - increase expenditure on RNF as \% of total public expenditure } \\
\text { - increase expenditure on rural electrification } \\
\text { - improve delivery of utility services for RNF enterprises } \\
\text { - provide credits, incentives and non financial supports for Runes } \\
\text { - undertake measures to improve rural investment climate }\end{array}$ & $\begin{array}{l}\text { - kilometres of rural roads by quality category } \\
\text { - no. of entrepreneurs with access to } \\
\text { electricity in rural areas } \\
\text { - increased growth of rural enterprises }\end{array}$ & $\begin{array}{l}\text { - rural employment } \\
\text { - rural non-farm wage rate } \\
\text { - growth of income in rural non-farm } \\
\text { activities }\end{array}$ \\
\hline
\end{tabular}

M\&E Indicators 12: Improving Knowledge Base: Education, Training, Research, Access to Information and Building Awareness at the Grassroots Level

\begin{tabular}{|c|c|c|c|}
\hline Strategic Goal & Input Indicators/Policy Change & Output Indicators & Outcome/Impact indicators \\
\hline $\begin{array}{l}\text { 1. Strengthening early childhood } \\
\text { development (ECD) } \\
\text { programmes }\end{array}$ & $\begin{array}{l}\text { - increase expenditure for ECD education } \\
\text { - undertake pre-school programmes for children from poor families } \\
\text { - establish day-care centres for children }\end{array}$ & $\begin{array}{l}\text { - coverage of pre-school programmes for } \\
\text { children } \\
\text { - } \% \text { of children getting day-care facilities }\end{array}$ & $\begin{array}{l}\text { - \% of households with access to } \\
\text { ECDP } \\
\text { • 'quality' of ECDP }\end{array}$ \\
\hline $\begin{array}{l}\text { 2. Ensure all boys and girls } \\
\text { complete a full course of primary } \\
\text { schooling } \\
\text { 3. Improving access and equity to } \\
\text { secondary education }\end{array}$ & $\begin{array}{l}\text { - increase expenditure on primary and secondary education } \\
\text { - establish/renovate school buildings and other infrastructure } \\
\text { - provide teaching materials, teacher's training } \\
\text { - develop uniform curriculum } \\
\text { - equity, quality and access to primary and secondary education } \\
\text { - ensure selection of teachers on the basis of merit } \\
\text { - make learning enjoyable in the classroom }\end{array}$ & $\begin{array}{l}\text { - no. of schools built/renovated } \\
\text { - no. of texts books supplied } \\
\text { - no. of teachers trained } \\
\text { - pupil-teacher ratio } \\
\text { - competency evaluation test } \\
\text { - coverage of stipends for female students }\end{array}$ & $\begin{array}{l}\text { - enrolment rates for boys and girls } \\
\text { - dropout and repetition rates for boys } \\
\text { and girls by age groups } \\
\text { - no. of boys and girls reaching grade- } 5 \\
\text { - passing rate of boys and girls at } \\
\text { secondary level } \\
\text { - 'quality' of education }\end{array}$ \\
\hline $\begin{array}{l}\text { 4. Strengthening education } \\
\text { programmes for excluded } \\
\text { children }\end{array}$ & $\begin{array}{l}\text { - increase expenditure on education for the excluded children } \\
\text { - establish/renovate school buildings and other infrastructure } \\
\text { - provide necessary materials, teacher's training, stipends and } \\
\text { incentives }\end{array}$ & $\begin{array}{l}\text { - no. of schools built/renovated } \\
\text { - no. of teachers trained } \\
\text { - no. of text books supplied }\end{array}$ & $\begin{array}{l}\text { - enrolment rate of excluded boy and } \\
\text { girl children } \\
\text { - dropout and repetition rates for boys } \\
\text { and girls by age groups } \\
\text { - proportion of excluded children who } \\
\text { achieved education }\end{array}$ \\
\hline $\begin{array}{l}\text { 5. Enhancing technical and } \\
\text { vocational education for children }\end{array}$ & $\begin{array}{l}\text { - establish/renovate school buildings and other infrastructure } \\
\text { - provide necessary materials, teacher's training, stipends and } \\
\text { incentives } \\
\text { - develop uniform curriculum } \\
\text { - ensure equity and quality of education }\end{array}$ & $\begin{array}{l}\text { - no. of schools built } \\
\text { - no. of teachers trained } \\
\text { - development and use of uniform curriculum }\end{array}$ & $\begin{array}{l}\text { - proportion of poor children access to } \\
\text { TVET } \\
\text { - enrolment rate in TVET for men and } \\
\text { women } \\
\text { - dropout and repetition rates } \\
\text { - } \% \text { of men and women students }\end{array}$ \\
\hline
\end{tabular}




\begin{tabular}{|c|c|c|c|}
\hline Strategic Goal & Input Indicators/Policy Change & Output Indicators & Outcome/Impact indicators \\
\hline & & & $\begin{array}{l}\text { completed TVET } \\
\text { - 'quality' of education }\end{array}$ \\
\hline $\begin{array}{l}\text { 6. Strengthening madrasa } \\
\text { education including core } \\
\text { curriculum }\end{array}$ & $\begin{array}{l}\text { - provide teaching materials and teacher's training } \\
\text { - develop and improve core curriculum } \\
\text { - integrate madrasa into a unified primary \& secondary education } \\
\text { system }\end{array}$ & $\begin{array}{l}\text { - no. of teachers trained } \\
\text { - integrated curriculum for madrasha }\end{array}$ & $\begin{array}{l}\text { - enrolment rate in madrasah education } \\
\text { - } \% \text { of students accessing madrasah } \\
\text { education } \\
\text { - passing rate } \\
\text { - 'quality' and market relevance of } \\
\text { madrasah education } \\
\text { - performance parity for madrasah } \\
\text { students with other educational } \\
\text { system }\end{array}$ \\
\hline $\begin{array}{l}\text { 7. Empowering children through } \\
\text { social integration and inclusion }\end{array}$ & $\begin{array}{l}\text { - expenditure on children empowerment as percentage of child } \\
\text { development expenditure } \\
\text { - increase access, equity and participation in relevant sectors } \\
\text { - enhance opportunity for and capacity of girl child }\end{array}$ & $\begin{array}{l}\text { - \% of children with participation and access to } \\
\text { relevant sectors and institutions }\end{array}$ & - empowerment of children \\
\hline $\begin{array}{l}\text { 8. Creating opportunities for } \\
\text { continuing education and } \\
\text { training }\end{array}$ & $\begin{array}{l}\text { - introduce courses on need based skill retraining programmes in } \\
\text { the existing educational institutes in the evenings }\end{array}$ & $\begin{array}{l}\text { - no. of retraining and continuing education } \\
\text { programme introduced }\end{array}$ & $\begin{array}{l}\text { - no. of men and women enrolled in } \\
\text { and completed continuing education } \\
\text { and training }\end{array}$ \\
\hline $\begin{array}{l}\text { 9. Creating of new knowledge and } \\
\text { information }\end{array}$ & $\begin{array}{l}\text { - create a national endowment to support undertaking action-based } \\
\text { and result-oriented research } \\
\text { - encourage research among the teachers of tertiary education and } \\
\text { link it to promotion } \\
\text { - develop and strengthen BBS as an independent organization }\end{array}$ & $\begin{array}{l}\text { - national endowment for research } \\
\text { - no. of action and result oriented research } \\
\text { - recommendation identified for dealing with } \\
\text { national and local level socio-economic and } \\
\text { technology related problems }\end{array}$ & $\begin{array}{l}\text { - policy formulated on the basis of } \\
\text { research findings }\end{array}$ \\
\hline $\begin{array}{l}\text { 10. Empowering people by giving } \\
\text { them information and } \\
\text { encouraging socially responsible } \\
\text { behaviour }\end{array}$ & $\begin{array}{l}\text { - undertake nation wide road-shows, area-based information } \\
\text { fair on various development issues } \\
\text { - } \quad \text { introduce citizens' charters in every government office } \\
\text { in disseminating information at the grassroots level } \\
\text { - make documentary films on various social issues }\end{array}$ & $\begin{array}{l}\text { - no. of road-shows, area-based information } \\
\text { fairs } \\
\text { - citizens' charters in every government office } \\
\text { - availability of information at the grassroots } \\
\text { level } \\
\text { - no. of documentary film produced }\end{array}$ & $\begin{array}{l}\text { - socially responsible behaviour among } \\
\text { men and women } \\
\text { - } \% \text { of population viewing } \\
\text { documentary films } \\
\text { - change in attitude of people }\end{array}$ \\
\hline
\end{tabular}


M\&E Indicators 13: Health, Population, Nutrition, Water and Sanitation and Food Safety Sector

\begin{tabular}{|c|c|c|c|}
\hline Strategic Goal & Input Indicators/Policy Change & Output Indicators & Outcome/Impact indicators \\
\hline $\begin{array}{l}\text { 1. Improving child and mother } \\
\text { health } \\
\text { 2. Improving reproductive health } \\
\text { 3. Improving adolescent health } \\
\text { 4. Ensuring health facilities for the } \\
\text { elderly } \\
\text { 5. improve access of poor to heath } \\
\text { services and quality of services }\end{array}$ & $\begin{array}{l}\text { - increase expenditure on health as \% of total govt expenditure } \\
\text { - increase expenditure on ESP as percentage of total health } \\
\text { expenditure } \\
\text { - increase expenditure on cash/voucher/health card system for } \\
\text { poor pregnant women } \\
\text { - increase expenditure on prevention of STD including HIV/AIDS } \\
\text { - increase expenditure on control of communicable diseases } \\
\text { - distribute insecticide treated mosquito nets in malaria prone areas } \\
\text { - strengthen and expand BCC } \\
\text { - design supervision and monitoring mechanism for the availability, } \\
\text { - quality and accessibility of health services } \\
\text { - introduce citizens charter in hospitals } \\
\text { - undertake awareness campaign }\end{array}$ & $\begin{array}{l}\text { - coverage of EPI } \\
\text { - percentage of children covered by IMCI } \\
\text { - percentage of population covered by ESP } \\
\text { - percentage of births attended by skilled } \\
\text { personnel/TBA } \\
\text { - coverage of EOC services } \\
\text { - contraceptive prevalence rate } \\
\text { - coverage of preventive services against } \\
\text { - communicable diseases } \\
\text { - numberage of ANC and PNC } \\
\text { - number of hualified doctors per } 1000 \text { persons } \\
\text { - number of trained nurses per } 1000 \text { persons } \\
\text { - availability of doctors and nurses on duty }\end{array}$ & $\begin{array}{l}\text { - infant mortality rate of boys and girls } \\
\text { - child (U-5) mortality rate of boys and } \\
\text { girls } \\
\text { - maternal mortality rate } \\
\text { - population growth rate } \\
\text { - no. of death caused by TB, Malaria } \\
\text { and other communicable diseases of } \\
\text { men and women } \\
\text { - total fertility rate } \\
\text { - quality' of health services } \\
\text { - life expectancy of men and women } \\
\text { - proportion of poor patients }\end{array}$ \\
\hline $\begin{array}{l}\text { 6. Improving child and mother } \\
\text { nutrition }\end{array}$ & $\begin{array}{l}\text { - increase expenditure on child and mother nutrition } \\
\text { - strengthen } \mathrm{ABCN} \text { in rural and urban areas } \\
\text { - fortify common food with vitamin A, irons and iodine } \\
\text { - strengthen nutrition education and school nutrition programmes } \\
\text { - implement national nutrition programmes } \\
\text { - undertake awareness campaign }\end{array}$ & $\begin{array}{l}\text { - coverage of vitamin A, iron tablets, iodized } \\
\text { salt/testing kits, de-worming and other micro } \\
\text { nutrient supplementation } \\
\text { - coverage of home gardening } \\
\text { - coverage of national nutrition programmes } \\
\text { for poor children }\end{array}$ & $\begin{array}{l}\text { - PEM } \\
\text { - height-for-age (stunting rate) of boys } \\
\text { and girls } \\
\text { - weight-for-height (wasting rate) of } \\
\text { boys and girls } \\
\text { - weight-for-age (underweight BMI) of } \\
\text { boys and girls }\end{array}$ \\
\hline $\begin{array}{l}\text { 7. Ensuring food quality and } \\
\text { access to safe food for all }\end{array}$ & $\begin{array}{l}\text { - increase number of food items standardized by BSTI } \\
\text { - introduce Consumers' Protection Act } \\
\text { - introduce policy for quality control of street vended food } \\
\text { - develop food borne diseases surveillance system } \\
\text { - update Pure Food Act } \\
\text { - strengthen BSTI to expand market monitoring systems } \\
\text { - undertake awareness campaign }\end{array}$ & $\begin{array}{l}\text { - number of PHLs at divisional and district } \\
\text { headquarters } \\
\text { - number of adulterated food items } \\
\text { - incidence of food related diseases }\end{array}$ & $\begin{array}{l}\text { - life expectancy of men and women by } \\
\text { expenditure group }\end{array}$ \\
\hline $\begin{array}{l}\text { 8. Ensuring safe water and } \\
\text { sanitation facilities for all }\end{array}$ & $\begin{array}{l}\text { - increase expenditure on supply of safe water and sanitation } \\
\text { - install alternative water supply and sanitation systems for un- } \\
\text { served/under-served areas } \\
\text { - introduce water quality monitoring and surveillance programme }\end{array}$ & $\begin{array}{l}\text { - } \% \text { of population with access to safe water } \\
\text { - } \% \text { of population with access to sanitary } \\
\text { latrines }\end{array}$ & $\begin{array}{l}\text { - incidence of water borne morbidity } \\
\text { and mortality } \\
\text { - life expectancy of men and women }\end{array}$ \\
\hline
\end{tabular}


M\&E Indicators 14: Social Inclusion and Empowerment- (a) Women's Advancement and Rights

\begin{tabular}{|c|c|c|c|}
\hline Strategic Goal & Input Indicators/Policy Change & Output Indicators & Outcome/Impact Indicators \\
\hline $\begin{array}{l}\text { 1. Ensuring women's full } \\
\text { participation in mainstream } \\
\text { economic activities }\end{array}$ & $\begin{array}{l}\text { - increase expenditure on women development as \% of public } \\
\text { expenditure } \\
\text { - increase women's participation in farm \& non-farm agricultural } \\
\text { activities and provide 'khas' land \& agricultural credit } \\
\text { - improve participation in manufacturing, banking, physical } \\
\text { infrastructure and service sectors including government jobs } \\
\text { - provide training, credit and fiscal incentives for small and } \\
\text { medium-scale enterprises } \\
\text { - ensure day care facilities for working women } \\
\text { - implement full quota for women } \\
\text { - make institutions women friendly }\end{array}$ & $\begin{array}{l}\text { - } \% \text { of women in farm \& non-farm } \\
\text { agriculture, manufacturing, banking, } \\
\text { physical infrastructure and service sectors } \\
\text { - } \% \text { of poor women with access to } \\
\text { agricultural inputs and credit } \\
\text { - } \% \text { of women with access to training, } \\
\text { credit and fiscal incentives for SMEs } \\
\text { - day care facilities for working women } \\
\text { - clean toilet facilities for women in public } \\
\text { spaces, offices, markets and factories }\end{array}$ & $\begin{array}{l}-\% \text { of female-headed households below } \\
\text { the poverty line } \\
-\% \text { of Women /man aged } 15+ \\
\text { employed as paid employees } \\
-\% \text { of Women /man aged } 15+\text { who are } \\
\text { self-employed or employers }\end{array}$ \\
\hline $\begin{array}{l}\text { 2. Improving women's efficiency } \\
\text { (reducing time use) in } \\
\text { performing their household and } \\
\text { reproductive roles and } \\
\text { responsibilities }\end{array}$ & $\begin{array}{l}\text { - increase expenditure on women to reduce time by providing } \\
\text { water, gas, electricity facilities } \\
\text { - ensure social and maternal services } \\
\text { - provide subsidy to poor households } \\
\text { - raise awareness to improve men's contribution to household } \\
\text { activities }\end{array}$ & $\begin{array}{l}\text { - proportion of households getting water, } \\
\text { gas, electricity facilities } \\
\text { - proportion of women getting social and } \\
\text { maternal services }\end{array}$ & $\begin{array}{l}\text { - average no. of hours per week spent by } \\
\text { women/men on unpaid housework } \\
\text { and care of family members }\end{array}$ \\
\hline $\begin{array}{l}\text { 3. Building women's capacity in } \\
\text { health and education to } \\
\text { improve entrance into labour } \\
\text { market and productivity }\end{array}$ & $\begin{array}{l}\text { - provide necessary health, nutrition, educational services and } \\
\text { appropriate training } \\
\text { - achieve and sustain gender balance in primary, secondary and } \\
\text { tertiary education } \\
\text { - improve quality, equity and access to health, nutrition, } \\
\text { educational services and training for women }\end{array}$ & $\begin{array}{l}\text { - } \text { no. of doctors per } 1,000 \text { persons } \\
\text { - } \text { proportion of women with access to } \\
\text { EOC, ANC, PNC services } \\
\text { - } \text { proportion of births attended by skilled } \\
\text { - } \text { health personnel /TBA } \\
\text { STD \& AIDS/HIV prevalence among } \\
\text { - } \text { comen } \\
\text { - contraceptive prevalence rate } \\
\text { tablets and nutritious food } \\
\text { - } \text { supplementation } \\
\text { stipends }\end{array}$ & $\begin{array}{l}\text { - maternal mortality ratio } \\
\text { - ratio of girls to boys in primary, } \\
\text { secondary and tertiary education } \\
\text { - malnutrition among girls and women } \\
\text { - enrolment rates of girls at primary, } \\
\text { secondary and tertiary education } \\
\text { - ratio of adult literate females to males } \\
\text { - employment generation for women } \\
\text { - share of women in wage employment } \\
\text { - head-count ratio of female-headed } \\
\text { households without remittance }\end{array}$ \\
\hline $\begin{array}{l}\text { 4. Ensuring social protection for } \\
\text { women against vulnerability and } \\
\text { risk }\end{array}$ & $\begin{array}{l}\text { - strengthen social protection (e.g. VGF, FSVGD, RMP, WTC, } \\
\text { NNP, widow \&old age allowance etc) for disadvantaged women } \\
\text { - ensure access of women victims to govt. legal aid fund } \\
\text { - provide VAW training, one-stop services, media coverage, } \\
\text { rehabilitation programmes } \\
\text { - eliminate leakages of safety net programmes } \\
\text { - introduce reform (where necessary) and enforce existing } \\
\text { women laws strictly to support women }\end{array}$ & $\begin{array}{l}\text { - } \quad \text { no. marriage with dowry } \\
\text { - } \quad \text { retrenched female workers due to phase- } \\
\text { out of MFA } \\
\text { - } \text { no. of trafficking of women } \\
\text { - } \% \text { of women getting protection against } \\
\text { vulnerability and risk } \\
\text { - } \% \text { of women victims reintegrated in the } \\
\text { - } \quad \% \text { ofiety poor women covered by safety net }\end{array}$ & $\begin{array}{l}\text { - } \% \text { of female/male headed households } \\
\text { under the poverty line } \\
\text { - no. of violence recorded against } \\
\text { women }\end{array}$ \\
\hline $\begin{array}{l}\text { 5. Enhancing women's political } \\
\text { empowerment and participation } \\
\text { in decision-making process }\end{array}$ & $\begin{array}{l}\text { - strengthen political empowerment of women at national and local } \\
\text { level and ensure participation in decision-making process } \\
\text { - include women members of parliament in all standing }\end{array}$ & $\begin{array}{l}\text { - no. of women candidates at national and } \\
\text { local level regular election } \\
\text { - } \% \text { of women's representation in }\end{array}$ & $\begin{array}{l}\text { - } \quad \text { no. of women elected at national } \\
\text { and local level regular election } \\
\text { - } \quad \% \text { of women in decision-making }\end{array}$ \\
\hline
\end{tabular}




\begin{tabular}{|c|c|c|c|}
\hline Strategic Goal & Input Indicators/Policy Change & Output Indicators & Outcome/Impact Indicators \\
\hline & $\begin{array}{l}\text { committees } \\
\text { - make women politically and socially more conscientious } \\
\text { - develop women empowerment index every three years }\end{array}$ & $\begin{array}{l}\text { parliament, public, private and NGO } \\
\text { services } \\
\text { - women empowerment index made public }\end{array}$ & $\begin{array}{l}\text { in parliament and public sector } \\
\quad \text { women empowerment index }\end{array}$ \\
\hline $\begin{array}{l}\text { 6. Ensuring women's } \\
\text { participation in the } \\
\text { international forums }\end{array}$ & $\begin{array}{l}\text { - provide diversified training, one-stop services etc. for } \\
\text { international migration of women } \\
\text { - increase women's access and participation at international level } \\
\text { - ensure safe and secured working environment for women at } \\
\text { international level } \\
\text { - create opportunities for women's participation in overseas } \\
\text { employment }\end{array}$ & $\begin{array}{l}\text { - no. of women's participation in the } \\
\text { international forums } \\
\text { - proportion of women proficient in } \\
\text { language } \\
\text { - no. of women getting diversified training } \\
\text { to compete at the international level }\end{array}$ & $\begin{array}{l}\text { - overseas employment generation } \\
\text { - remittances by women } \\
\text { - head-count ratio of female-headed } \\
\text { households }\end{array}$ \\
\hline $\begin{array}{l}\text { 7. Strengthen institutions for } \\
\text { coordination and monitoring of } \\
\text { gender equality issues }\end{array}$ & $\begin{array}{l}\text { - implementation of women's NPA } 2008 \\
\text { - review the effectiveness of the current institutional setup to } \\
\text { address women advancement issues } \\
\text { - establish a coordination wing in MoWCA to act as secretariat of } \\
\text { NCWD and WDIEC } \\
\text { - develop a database on reported cases of violence against women } \\
\text { - introduce PBA system }\end{array}$ & $\begin{array}{l}\text { - Coordination wing in MoWCA } \\
\text { established } \\
\text { - gender disaggregated statistics generated } \\
\text { - indicators for monitoring progress in } \\
\text { implementation of (NPA) for women } \\
\text { - recommendation for reorganising } \\
\text { institutional setup to address women } \\
\text { advancement issues }\end{array}$ & $\begin{array}{l}\text { - women empowerment } \\
\text { - new institutional setup to address } \\
\text { - } \text { incmen advancement issues } \\
\text { - ince of violence against women }\end{array}$ \\
\hline
\end{tabular}

\section{M\&E Indicators 14: Social Inclusion and Empowerment- (b) Children's Advancement and Rights}

\begin{tabular}{|c|c|c|c|}
\hline Strategic Goal & Input Indicators/Policy Change & Output Indicators & Outcome/Impact Indicators \\
\hline $\begin{array}{l}\text { 1. Reduce infant and under-five } \\
\text { mortality rates }\end{array}$ & $\begin{array}{l}\text { - increase expenditure for children on health } \\
\text { - maintain expanded programme on immunization (EPI) } \\
\text { - ensure prompt care for diarrhoeal disease control (DDC) } \\
\text { - improve acute respiratory infection (ARI) } \\
\text { - increase use of integrated management of childhood illness } \\
\text { (IMCI) at union level } \\
\text { - strengthen health education promotion (HEP) and school health } \\
\text { programmes } \\
\text { - access to reproductive health services } \\
\text { - access to health services for disadvantaged children } \\
\text { - develop strategies for prevention of accidents and injuries }\end{array}$ & $\begin{array}{l}\text { - no. of doctors per } 1,000 \text { children } \\
\text { - \% of children covered by BCG, DPT, } \\
\text { POLIO, MEASLES } \\
\text { - } \% \text { of children covered by ARI } \\
\text { - } \% \text { of children covered by IMCI } \\
\text { - coverage of school health programme for } \\
\text { poor children } \\
\text { - coverage of reproductive health care for } \\
\text { adolescent } \\
\text { - coverage of urban and rural primary health } \\
\text { services for poor children }\end{array}$ & $\begin{array}{l}\text { - male/female infant mortality rate ( } \\
\text { per } 1000 \text { live births ) } \\
\text { - male/female under-five mortality } \\
\text { rate ( per } 1000 \text { live births ) } \\
\text { - male/female child mortality rate( } \\
\text { - 'quality' of health services for } \\
\text { children }\end{array}$ \\
\hline $\begin{array}{l}\text { 3. Reduce malnutrition among } \\
\text { children }\end{array}$ & $\begin{array}{l}\text { - increase expenditure for children on nutrition } \\
\text { - fortify common food with vitamin A, irons and iodine } \\
\text { - strengthen nutrition education and school nutrition } \\
\text { programmes } \\
\text { - implement national nutrition programmes }\end{array}$ & $\begin{array}{l}\text { - coverage of vitamin A, iodized salt, iron, } \\
\text { folic acid tablets and nutritious food } \\
\text { supplements especially for girl children of } \\
\text { poor families } \\
\text { - coverage of nutrition programmes for poor } \\
\text { children }\end{array}$ & $\begin{array}{l}\text { - } \text { malnutrition rate among children } \\
\text { - } \text { height-for-age (stunting rate) } \\
\text { - weight-for-height (wasting rate) } \\
\text { - weight-for-age (underweight) }\end{array}$ \\
\hline $\begin{array}{l}\text { 4. Provide safe water, healthy } \\
\text { sanitation and environment for } \\
\text { children }\end{array}$ & $\begin{array}{l}\text { - increase expenditure for children on safe water and sanitation } \\
\text { - install alternative water supply and sanitation systems for un- } \\
\text { served/under-served areas }\end{array}$ & $\begin{array}{l}\text { - coverage of alternative water supply and } \\
\text { sanitation systems for un-served/under- } \\
\text { served areas }\end{array}$ & $\begin{array}{l}\text { - proportion of children with } \\
\text { access to safe water, healthy } \\
\text { sanitation and environment }\end{array}$ \\
\hline
\end{tabular}




\begin{tabular}{|c|c|c|c|}
\hline Strategic Goal & Input Indicators/Policy Change & Output Indicators & Outcome/Impact Indicators \\
\hline $\begin{array}{l}\text { 5. Strengthening early childhood } \\
\text { development (ECD) programmes }\end{array}$ & - increase expenditure on ECDP & - $\%$ of household with access to ECDP & $\begin{array}{l}\bullet \% \text { of children from poor families in } \\
\text { pre-school programmes } \\
\bullet \% \text { of children from poor families } \\
\text { getting day-care facilities }\end{array}$ \\
\hline $\begin{array}{l}\text { 6. Ensuring all boys and girls } \\
\text { complete a full course of primary } \\
\text { schooling } \\
\text { 7. Improving access and equity to } \\
\text { secondary education }\end{array}$ & $\begin{array}{l}\text { - establish/renovate school buildings and other infrastructure } \\
\text { - provide necessary materials, teacher's training, stipends etc } \\
\text { - develop uniform curriculum } \\
\text { - ensure equity, quality and access to primary and secondary } \\
\text { education }\end{array}$ & $\begin{array}{l}\text { - no. of schools built/renovated } \\
\text { - no. of texts books supplied } \\
\text { - no. of teachers trained } \\
\text { - pupil-teacher ratio } \\
\text { - competency evaluation test } \\
\text { - coverage of stipends for female students }\end{array}$ & $\begin{array}{l}\text { - enrolment rates at primary \& } \\
\text { secondary level by boys and girls } \\
\text { - dropout and repetition rates at } \\
\text { primary and secondary level by boys } \\
\text { and girls and age group } \\
\text { - } \% \text { of children reaching grade } 5 \\
\text { - passing rate at secondary level } \\
\end{array}$ \\
\hline $\begin{array}{l}\text { 8. Strengthening education } \\
\text { programmes for excluded } \\
\text { children }\end{array}$ & $\begin{array}{l}\text { - establish/renovate school buildings and other infrastructure } \\
\text { - provide necessary materials, teacher's training, stipends and } \\
\text { incentives }\end{array}$ & $\begin{array}{l}\text { - } \% \text { of excluded children access to education } \\
\text { - no. of schools built/renovated } \\
\text { - no. of teachers trained } \\
\text { - no. of text books supplied }\end{array}$ & $\begin{array}{l}\text { - enrolment rate of excluded children } \\
\text { - dropout and repetition rates } \\
\text {-\% of excluded children achieved } \\
\text { education }\end{array}$ \\
\hline $\begin{array}{l}\text { 9. Enhancing technical and } \\
\text { vocational education for children }\end{array}$ & $\begin{array}{l}\text { - } \text { establish/renovate school buildings and other infrastructure } \\
\text { - provide necessary materials, teacher's training, stipends etc. } \\
\text { - develop need-based curriculum }\end{array}$ & $\begin{array}{l}\text { - } \% \text { of poor children with access to TVET } \\
\text { - no. of schools built } \\
\text { - no. of teachers trained }\end{array}$ & $\begin{array}{l}- \text { enrolment rate in TVET } \\
\bullet \text { dropout and repetition rates } \\
\bullet \% \text { of student achieved TVET }\end{array}$ \\
\hline $\begin{array}{l}\text { 10. Strengthening madrasah } \\
\text { education including core } \\
\text { curriculum }\end{array}$ & $\begin{array}{l}\text { - provide necessary materials, teacher's training, stipends and } \\
\text { incentives } \\
\text { - develop and improve core curriculum } \\
\text { - integrate madrasah into a unified national primary and } \\
\text { secondary education system }\end{array}$ & $\begin{array}{l}\text { - percentage of children with access to } \\
\text { madrasah education } \\
\text { - no. of teachers trained } \\
\text { - performance parity for madrasah students } \\
\text { with other educational system }\end{array}$ & $\begin{array}{l}\text { - enrolment rate in madrasah } \\
\text { education } \\
\text { - passing rate } \\
\text { - 'quality' and market relevance of } \\
\text { madrasah education } \\
\end{array}$ \\
\hline $\begin{array}{l}\text { 11. Empowering children through } \\
\text { social integration and inclusion }\end{array}$ & $\begin{array}{l}\text { - increase expenditure on children empowerment } \\
\text { - increase access, equity and participation in relevant sectors } \\
\text { and institutions } \\
\text { - enhance opportunity and capacity for girl child }\end{array}$ & $\begin{array}{l}\bullet \% \text { of children with participation and access to } \\
\text { relevant sectors and institutions } \\
\bullet \% \text { of children's representation in parliament, } \\
\text { public \& private institutions and NGOs }\end{array}$ & • empowerment of children \\
\hline $\begin{array}{l}\text { 12. Reducing social violence } \\
\text { against children } \\
\text { 13. Ensuring child victims' access } \\
\text { to all necessary support services } \\
\text { for speedy recovery and smooth } \\
\text { social reintegration } \\
\text { 14. Preventing transmission of } \\
\text { STD including HIV/AIDS } \\
\text { within children }\end{array}$ & $\begin{array}{l}\text { - increase expenditure on violence against children } \\
\text { - introduce reform (where necessary) and enforce existing child } \\
\text { laws strictly to support children }\end{array}$ & $\begin{array}{l}\text { - proportion of early marriage } \\
\text { - no. of trafficking of children } \\
\text { - } \text { no. of violence recorded against children } \\
\text { - proportion of children getting protection } \\
\text { against violence, vulnerability and risk } \\
\text { - } \% \text { children victims reintegrated in the society } \\
\text { - } \% \text { of poor children covered under safety net } \\
\text { - prevalence of STD \& AIDS/HIV among } \\
\text { children }\end{array}$ & - socio-economic climate for children \\
\hline
\end{tabular}


M\&E Indicators 14: Social Inclusion and Empowerment- (c) Indigenous people, Persons with Disability, and Other Disadvantaged and Extreme Poor Groups

\begin{tabular}{|c|c|c|c|}
\hline Strategic Goal & Input Indicators/Policy Change & Output Indicators & Outcome/Impact indicators \\
\hline \multicolumn{4}{|l|}{ Indigenous people } \\
\hline $\begin{array}{l}\text { 1. Establishing peace in hill } \\
\text { districts }\end{array}$ & - increasing public expenditure for indigenous people & $\begin{array}{l}\text { - better development atmosphere in hill } \\
\text { districts } \\
\text { - secure land tenure system for indigenous } \\
\text { people }\end{array}$ & - living standard in the hill districts \\
\hline $\begin{array}{l}\text { 2. Involving community } \\
\text { in adoption and conservation of } \\
\text { technologies }\end{array}$ & $\begin{array}{l}\text { - increase expenditure for community involvement } \\
\text { - preserve traditional knowledge of indigenous communities } \\
\text { - ensure participation of local government in indigenous } \\
\text { community development } \\
\text { - build awareness of rights, legal affairs, customary laws of } \\
\text { indigenous community }\end{array}$ & $\begin{array}{l}\text { - no. of indigenous people participated } \\
\text { in conservation of technologies in managerial } \\
\text { and organizational affairs of indigenous } \\
\text { communities } \\
\text { - awareness of their right, legal affairs, } \\
\text { customary laws }\end{array}$ & $\begin{array}{l}\text { - empowerment of indigenous } \\
\text { community }\end{array}$ \\
\hline $\begin{array}{l}\text { 3. Mobilising other Ministries } \\
\text { to ensure indigenous } \\
\text { community's access to basic } \\
\text { services such as health, } \\
\text { education, sanitation, safe } \\
\text { water, electricity etc. }\end{array}$ & $\begin{array}{l}\text { - ensure education for indigenous people } \\
\text { - ensure health and reproductive health for indigenous community } \\
\text { - ensure sanitation and water supply for indigenous community } \\
\text { - ensure electricity supply for indigenous community } \\
\text { - incorporate indigenous affairs in respective national policies }\end{array}$ & $\begin{array}{l}\text { - } \% \text { of indigenous people covered in } \\
\text { education } \\
\text { - } \% \text { of indigenous people covered by health } \\
\text { services } \\
\text { - } \% \text { of indigenous people covered by water } \\
\text { and sanitation } \\
\text { - no. of national policies incorporating needs } \\
\text { of indigenous community }\end{array}$ & $\begin{array}{l}\text { - education among indigenous people } \\
\text { - mortality and morbidity among } \\
\text { indigenous people } \\
\text { - literacy rate among indigenous } \\
\text { people } \\
\text { - indigenous household access to } \\
\text { electricity } \\
\text { - Indigenous language preserved }\end{array}$ \\
\hline $\begin{array}{l}\text { 4. Ensuring safety net and food } \\
\text { security in indigenous areas }\end{array}$ & $\begin{array}{l}\text { - increase expenditure on safety net programme for indigenous } \\
\text { people }\end{array}$ & $\begin{array}{l}\text { - no. of beneficiaries form safety net } \\
\text { - effectiveness of safety net programme }\end{array}$ & - head count \\
\hline $\begin{array}{l}\text { 5. Creating employment } \\
\text { opportunity for indigenous } \\
\text { community }\end{array}$ & $\begin{array}{l}\text { - ensure indigenous people's participation in economic activities } \\
\text { - support private sectors in developing rural roads and hat-bazars } \\
\text { and construction of physical facilities, tourism and food/fruit } \\
\text { processing industry } \\
\text { - expand micro-credit suited to conditions of indigenous people } \\
\text { for income generating activities and employment }\end{array}$ & $\begin{array}{l}\text { - } \% \text { of indigenous people in farm and non- } \\
\text { farm physical activities, tourism and } \\
\text { food/ fruit processing industry } \\
\text { - indigenous people's access to micro-credit }\end{array}$ & $\begin{array}{l}\text { - employment generation for } \\
\text { indigenous people } \\
\text { - income of indigenous people }\end{array}$ \\
\hline \multicolumn{4}{|l|}{ Persons with Disabilities } \\
\hline $\begin{array}{l}\text { 6. Providing access to normal } \\
\text { education to children with } \\
\text { physical disabilities and visually } \\
\text { impaired and special education } \\
\text { to hearing impaired and } \\
\text { mentally retarded students }\end{array}$ & $\begin{array}{l}\text { - increase expenditure for persons with disabilities } \\
\text { - increase expenditure on education/special education of children } \\
\text { with disability } \\
\text { - expand coverage of stipend for students with disability } \\
\text { - make special learning materials for students with disability }\end{array}$ & $\begin{array}{l}\text { - } \% \text { of students with disability covered in } \\
\text { education facilities } \\
\text { - } \% \text { of visually impaired children covered in } \\
\text { education facilities } \\
\text { - } \% \text { of hearing impaired children covered in } \\
\text { education facilities } \\
\text { - } \% \text { of mentally retarded children covered in } \\
\text { education facilities }\end{array}$ & $\begin{array}{l}\text { - literacy rate among people with } \\
\text { disability } \\
\text { - passing rate in national standard } \\
\text { examinations }\end{array}$ \\
\hline $\begin{array}{l}\text { 7. Ensuring adequate provision } \\
\text { of medical/ health care services }\end{array}$ & $\begin{array}{l}\text { - increase expenditures on education/special education of } \\
\text { children with disability }\end{array}$ & $\begin{array}{l}\text { - no. of persons with disabilities of different } \\
\text { category received health/ medical services }\end{array}$ & $\begin{array}{l}\text { - prevention of disability } \\
\text { - life expectancy of people with }\end{array}$ \\
\hline
\end{tabular}




\begin{tabular}{|c|c|c|c|}
\hline Strategic Goal & Input Indicators/Policy Change & Output Indicators & Outcome/Impact indicators \\
\hline and counselling etc & $\begin{array}{l}\text { - make blood tests of couple compulsory } \\
\text { - increase no. of beds in hospital for people with disability } \\
\text { - introduce integrated management of childhood illness }\end{array}$ & & $\begin{array}{l}\text { disability } \\
\text { - morbidity of people with disability }\end{array}$ \\
\hline $\begin{array}{l}\text { 8. Ensuring implementation of } \\
\text { quota for employment of } \\
\text { persons with disability in } \\
\text { NGOs and public and private } \\
\text { sector }\end{array}$ & $\begin{array}{l}\text { - ensure employment and rehabilitation of people with disability } \\
\text { - increase expenditure on development activities undertaken for } \\
\text { providing housing facilities } \\
\text { provide credit facilities for people with disability } \\
\text { - provide skill training in computer and soft ware development }\end{array}$ & $\begin{array}{l}\text { - no. of persons with disabilities of different } \\
\text { category employed and } \\
\text { - no. of persons with disabilities rehabilitated }\end{array}$ & $\begin{array}{l}\text { - self-employment of people with } \\
\text { disability } \\
\text { - wage employment of people with } \\
\text { disability } \\
\text { - income of people with disability } \\
\end{array}$ \\
\hline $\begin{array}{l}\text { 9. Ensuring accessibility to all } \\
\text { physical facilities } \\
\text { 10. Ensuring participation in } \\
\text { social functions, sports and } \\
\text { cultural activities }\end{array}$ & $\begin{array}{l}\text { - ensure accessibility to physical facilities of people with disability, } \\
\text { by building ramps in public buildings, ticket counter, seat and } \\
\text { toilet facilities in buses, waterways, rail stations, cinema halls } \\
\text { - provide play ground, sports materials, incentives etc. for persons } \\
\text { with disabilities as percentage of total expenditure on their } \\
\text { development activities. }\end{array}$ & $\begin{array}{l}\text { - ramps in public buildings, ticket counter, } \\
\text { seat and toilet facilities in buses, waterways, } \\
\text { rail stations, cinema halls }\end{array}$ & $\begin{array}{l}\text { - no. of persons with disabilities of } \\
\text { different category availing their } \\
\text { accessibility to all physical facilities } \\
\text { - no. of person with disability of } \\
\text { different category participated in } \\
\text { social, sport and cultural activities } \\
\end{array}$ \\
\hline $\begin{array}{l}\text { 11. Providing services to persons } \\
\text { with disabilities according to } \\
\text { their needs at the door step }\end{array}$ & $\begin{array}{l}\text { - ensure service to persons with disabilities according to their } \\
\text { needs at their door step } \\
\text { - increase expenditure for artificial aids and appliances } \\
\text { - provide micro credit for income generating activities }\end{array}$ & $\begin{array}{l}\text { - no. of person with disability of different } \\
\text { category provided community based service } \\
\text { according to their needs at their door step }\end{array}$ & - integration with mainstream society \\
\hline $\begin{array}{l}\text { 12. Amending the disability act } \\
\text { according to standard set out by } \\
\text { the international organization }\end{array}$ & $\begin{array}{l}\text { - undertake measures to amend the disability act } \\
\text { - form a expert committee } \\
\text { - hold series of meeting }\end{array}$ & $\begin{array}{l}\text { - disability is defined and diverse needs and } \\
\text { rights of person with disability are specified } \\
\text { - responsibility of government employee for } \\
\text { disability issue is defined }\end{array}$ & $\begin{array}{l}\text { - rights of persons with disabilities } \\
\text { established }\end{array}$ \\
\hline $\begin{array}{l}\text { 13. Strengthening coordination } \\
\text { and monitoring mechanism to } \\
\text { review the progress } \\
\text { 14. Mobilising other ministries/ } \\
\text { divisions to ensure access to } \\
\text { education of persons with } \\
\text { disability }\end{array}$ & $\begin{array}{l}\text { - ensure coordination and monitoring of progress of activities for } \\
\text { people with disability } \\
\text { - form a National Coordination Committee } \\
\text { - hold review meetings to coordinate activities of different } \\
\text { ministries } \\
\text { - mainstream disability issues in the activities of all ministries }\end{array}$ & $\begin{array}{l}\text { - formation of a National Coordination } \\
\text { Committee } \\
\text { - no. of coordination and monitoring meting } \\
\text { held } \\
\text { - government circular with instruction for } \\
\text { every ministry to address disability issues }\end{array}$ & $\begin{array}{l}\text { - } \text { proper implementation } \\
\text { - measures taken by different } \\
\text { ministries }\end{array}$ \\
\hline $\begin{array}{l}\text { 15. Ensuring data base on } \\
\text { persons with disability }\end{array}$ & - undertake survey on people with disability & - reliable data on people with disability & $\begin{array}{l}\text { - programme and planning for people } \\
\text { with disability }\end{array}$ \\
\hline \multicolumn{4}{|c|}{ Disadvantaged and Extreme poor group } \\
\hline $\begin{array}{l}\text { 16. Ensuring access of } \\
\text { disadvantaged and extreme } \\
\text { poor group to health, sanitation } \\
\text { and safe water, education, and } \\
\text { know-how that will make them } \\
\text { able to change their situations }\end{array}$ & $\begin{array}{l}\text { - provide all basic services for other disadvantaged and extreme } \\
\text { poor group } \\
\text { - ensure access to health and family welfare related services } \\
\text { - ensure access to education and technical training } \\
\text { - ensure access to sanitation and water supply }\end{array}$ & $\begin{array}{l}\text { - disadvantaged and extreme poor people } \\
\text { covered by health services, } \\
\text { - people covered by educational facilities } \\
\text { - people covered by water and sanitation } \\
\text { - people provided with technical know-how }\end{array}$ & $\begin{array}{l}\text { - life expectancy } \\
\text { - morbidity } \\
\text { - literacy rate } \\
\text { - standard of life }\end{array}$ \\
\hline $\begin{array}{l}\text { 17. Ensuring housing facilities } \\
\text { especially for tea garden } \\
\text { workers, sweepers, and people } \\
\text { who are homeless due to river } \\
\text { erosion }\end{array}$ & $\begin{array}{l}\text { - ensure housing and rehabilitation facilities for other } \\
\text { disadvantaged and extreme poor group } \\
\text { - develop housing for sweeper, Bede, home-less people }\end{array}$ & $\begin{array}{l}\text { - \% of sweeper, Bede and other } \\
\text { disadvantaged communities receiving } \\
\text { housing facilities } \\
\text { - \% of homeless people received housing }\end{array}$ & - head-count poverty reduction \\
\hline
\end{tabular}




\begin{tabular}{|c|c|c|c|}
\hline Strategic Goal & Input Indicators/Policy Change & Output Indicators & Outcome/Impact indicators \\
\hline $\begin{array}{l}\text { 18. Ensuring rehabilitation of sex } \\
\text { workers and children }\end{array}$ & - rehabilitate sex-workers and their children & - \% sex workers and children rehabilitated & \\
\hline $\begin{array}{l}\text { 19. Providing micro credit and } \\
\text { skill training to disadvantaged } \\
\text { and extreme poor group }\end{array}$ & $\begin{array}{l}\text { - provide micro-credit and skill training for development of other } \\
\text { disadvantaged and extreme poor community } \\
\text { - ensure skill training on social forestry, poultry etc } \\
\text { - provide facilities to develop cottage industry }\end{array}$ & $\begin{array}{l}\text { - \% of people receiving micro credit } \\
\text { - \% of people receiving skill training on } \\
\text { different trades }\end{array}$ & $\begin{array}{l}\text { - employment of men and women } \\
\text { - income of men and women }\end{array}$ \\
\hline $\begin{array}{l}\text { 20. Improving data base of } \\
\text { disadvantaged and extreme } \\
\text { poor communities }\end{array}$ & $\begin{array}{l}\text { - undertake survey of various disadvantaged and extreme poor } \\
\text { communities } \\
\text { - use data and information for developing support facilities }\end{array}$ & - availability of data & $\begin{array}{l}\text { - appropriate policy decision } \\
\text { - programme planning and } \\
\text { implementation }\end{array}$ \\
\hline
\end{tabular}

M\&E Indicators 15: Improvement of Governance including Civil Service Reforms, Judicial Reforms and Law and Order

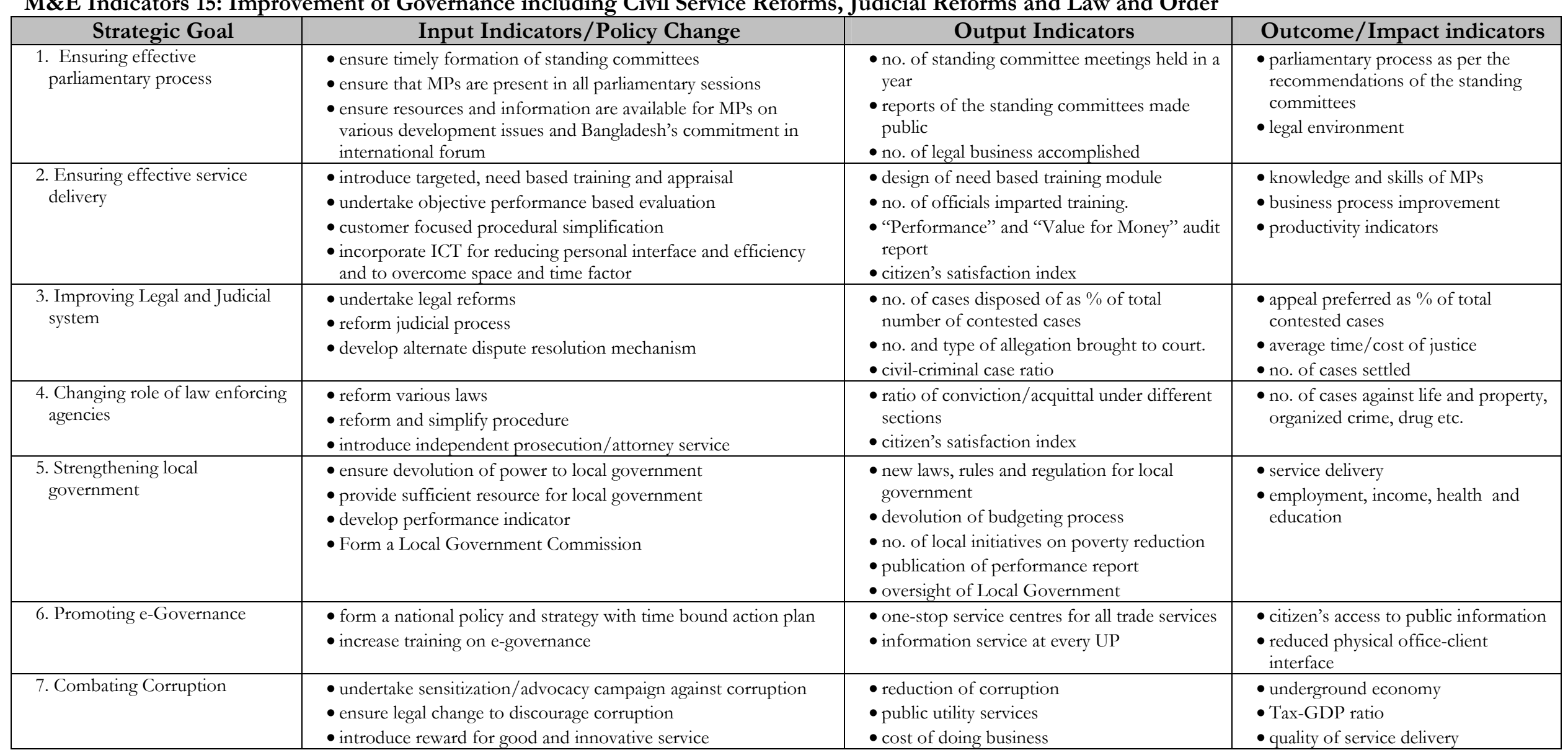




\begin{tabular}{|c|l|l|c|}
\hline Strategic Goal & \multicolumn{1}{|c|}{ Input Indicators/Policy Change } & Output Indicators & Outcome/Impact indicators \\
\hline 8. Promoting Human rights & $\begin{array}{l}\bullet \text { make Human Rights Commission functional } \\
\bullet \text { undertake extensive advocacy/media campaign }\end{array}$ & $\begin{array}{l}\bullet \text { laws in line with the UDHR } \\
\bullet \text { better human rights situation }\end{array}$ \\
\hline
\end{tabular}

M\&E Indicators 16: Utility Services Development including Safe Water Supply/Urban Development

\begin{tabular}{|c|c|c|c|}
\hline Strategic Goal & Input Indicators/Policy Change & Output Indicators & Outcome/Impact indicators \\
\hline \multicolumn{4}{|l|}{ Water \& Sanitation } \\
\hline $\begin{array}{l}\text { 1. Ensuring safe water supply and } \\
\text { sanitation for all }\end{array}$ & $\begin{array}{l}\text { - increase expenditure on supply of safe water and sanitation } \\
\text { - increase use of surface water exploring perennial surface water } \\
\text { source } \\
\text { - implement water safety plan } \\
\text { - increase water-testing capacity through networking up to district } \\
\text { levels } \\
\text { - expand utilization of surface water } \\
\text { - rationalise utilization of ground water }\end{array}$ & $\begin{array}{l}\text { - no. of water users per water point } \\
\text { - safe water coverage through pipelines } \\
\text { - use of ground \& surface water } \\
\text { - knowledge and capability for design of } \\
\text { future water resources management plans } \\
\text { - institutional development for WATSAN } \\
\text { sector agencies }\end{array}$ & $\begin{array}{l}\text { - safe water coverage } \\
\text { - population not having access to } \\
\text { sanitation } \\
\text { - water borne morbidity \& mortality } \\
\text { - population exposed to arsenic } \\
\text { contamination. } \\
\text { - access to sanitary community latrines } \\
\text { including women in village, bazar, } \\
\text { mosques, health clinics and schools }\end{array}$ \\
\hline \multicolumn{4}{|c|}{ Bangladesh Road Transport Authority } \\
\hline $\begin{array}{l}\text { 2. Ensuring better control in the } \\
\text { road transport sector in issuing } \\
\text { route permits and fixing } \\
\text { rates/fares of buses and trucks } \\
\text { and environment friendly } \\
\text { transport }\end{array}$ & $\begin{array}{l}\text { - increase expenditure on BRTA } \\
\text { - modify BRTA rules and ordinance to cope with emerging } \\
\text { situations } \\
\text { - fix uniform rates for different types of transport } \\
\text { - ensure plying of vehicles within specified speed and with } \\
\text { approved weight } \\
\text { - phase out all two-stroke engines from major cities } \\
\text { - introduce CNG and euro engine } \\
\text { ensure auto back-up system of all data entry done in the circle } \\
\text { and zonal offices }\end{array}$ & $\begin{array}{l}\text { - no. of route permits issued } \\
\text { - no. of banned buses older than } 20 \text { years } \\
\text { and trucks older than } 25 \text { years from } \\
\text { metropolitan area } \\
\text { - no. of major cities with phased out two- } \\
\text { stroke engines }\end{array}$ & $\begin{array}{l}\text { - } \text { regulated bus and truck fares } \\
\text { - traffic management } \\
\text { - road accident } \\
\text { - air pollution }\end{array}$ \\
\hline $\begin{array}{l}\text { 3. Introducing road safety } \\
\text { education \& training and bring } \\
\text { discipline in issuing driving } \\
\text { licenses and registration } \\
\text { certificates }\end{array}$ & $\begin{array}{l}\text { - educate drivers and conductors about road safety } \\
\text { - educate children and pedestrians on road safety } \\
\text { - issue laminated licenses to drivers and registration certificates to } \\
\text { vehicle owners }\end{array}$ & $\begin{array}{l}\text { - no. of drivers and conductors trained } \\
\text { - no. of laminated driving licenses and } \\
\text { registration certificates issued }\end{array}$ & $\begin{array}{l}\text { - no. of road accident } \\
\text { - no. of death and injury due to road } \\
\text { accident }\end{array}$ \\
\hline \multicolumn{4}{|c|}{ Infrastructure Development including Power, Energy \& Communications } \\
\hline $\begin{array}{l}\text { Power: } \\
\text { 4. Improving quality of service }\end{array}$ & $\begin{array}{l}\text { - build sub-stations and corresponding distribution lines } \\
\text { - introduce and expand coverage of pre-paid metering system } \\
\text { - unbundle the power sector operation } \\
\text { - strengthen institutional capacities } \\
\text { - execute reward and punishment system }\end{array}$ & $\begin{array}{l}\text { - no. of sub-stations and corresponding lines } \\
\text { installed } \\
\text { - one stop desk service counter } \\
\text { - pre-paid metering system }\end{array}$ & $\begin{array}{l}\text { - } \text { power interruption and load } \\
\text { shedding } \\
\text { - } \text { revenues } \\
\text { - manufacturing \& agriculture output }\end{array}$ \\
\hline $\begin{array}{l}\text { Energy: } \\
\text { 5. Assessing non-renewable } \\
\text { indigenous resources }\end{array}$ & $\begin{array}{l}\text { - strengthen the hydrocarbon unit (HCU) of the energy and } \\
\text { mineral resources division. } \\
\text { - introduce meters for domestic gas consumption }\end{array}$ & $\begin{array}{l}\text { - discovery of new gas fields } \\
\text { - potential reserve } \\
\text { - no. of households using LPG }\end{array}$ & $\begin{array}{l}\text { - } \text { potential reserve } \\
\text { - system loss } \\
\text { - Revenue earning }\end{array}$ \\
\hline
\end{tabular}




\begin{tabular}{|c|c|c|c|}
\hline Strategic Goal & Input Indicators/Policy Change & Output Indicators & Outcome/Impact indicators \\
\hline $\begin{array}{l}\text { 6. Ensuring conservation } \\
\text { measures for economic and } \\
\text { efficient use of energy }\end{array}$ & - ensure marketing of LPG and CNG. & - no. of CNG using motor vehicles & \\
\hline $\begin{array}{l}\text { Inland water transport: } \\
\text { 8. Enhancing quality of water } \\
\text { transport }\end{array}$ & $\begin{array}{l}\text { - } \text { increase expenditure on inland water transport } \\
\text { - formulate pragmatic water transport policies } \\
\text { - carry out base line survey covering all water transport areas }\end{array}$ & $\begin{array}{l}\text { - no. of container vessels for cargo } \\
\text { transportation and water taxi } \\
\text { - Ro-ro ferries, } 2 \mathrm{~K} \text {-type ferries, landing } \\
\text { stations and coastal passenger vessels } \\
\text { rehabilitated } \\
\text { - navigation services } \\
\text { - launch terminal/ghats facilities } \\
\end{array}$ & $\begin{array}{l}\text { - travel/transport cost and time } \\
\text { - system loss at various level } \\
\text { - production \& employment generation } \\
\text { by sector/sub-sector, male/female, } \\
\text { rural/urban } \\
\text { - no. of passenger by male/female } \\
\text { - volume of cargo transportation } \\
\end{array}$ \\
\hline $\begin{array}{l}\text { Airway: } \\
\text { 9. Increasing scale of operation to } \\
\text { serve more passengers and } \\
\text { enhance air cargo capacity }\end{array}$ & $\begin{array}{l}\text { - increase \& modernize Biman's fleet } \\
\text { - implement cost cutting measures } \\
\text { - facilitate private sector participation in aviation }\end{array}$ & $\begin{array}{l}\text { - no. of new destinations and frequency } \\
\text { - policies in place for foreign carriers to carry } \\
\text { perishable export cargo }\end{array}$ & $\begin{array}{l}\text { - travel/transport cost and time } \\
\text { - volume of export by air } \\
\text { - no. of passenger by male/female } \\
\text { - revenue earning } \\
\text { - employment generation by male } \\
\text { / female }\end{array}$ \\
\hline \multicolumn{4}{|c|}{ Tourism for Poverty Reduction } \\
\hline $\begin{array}{l}\text { 10. Developing infrastructure for } \\
\text { tourism industry }\end{array}$ & $\begin{array}{l}\text { - increase expenditure on tourism related infrastructure } \\
\text { - provide loans to private sector for investing in tourism industry } \\
\text { - include tourism sector under small credit scheme }\end{array}$ & $\begin{array}{l}\text { - no. of Tourist Complexes Constructed } \\
\text { - MICE (Meeting, Incentive, Conference And } \\
\text { Exposition) Facilities }\end{array}$ & $\begin{array}{l}\text { - no. of tourists disaggregated by } \\
\text { country / period of time/gender } \\
\text { - employment generation by } \\
\text { sector/sub- sector, male/female } \\
\text { - head-count ratio } \\
\end{array}$ \\
\hline $\begin{array}{l}\text { 11. Scaling-up marketing of } \\
\text { tourism }\end{array}$ & $\begin{array}{l}\text { - increase fund for promotion of Tourism } \\
\text { - prepare Inventory Of Tourist Destinations/Attractions } \\
\text { - upgrade Strategic Tourism Master Plan } \\
\text { - participate in Tourism Satellite Account of World Tourism } \\
\text { Organization } \\
\text { - provide training facilities on hotel management and tourism } \\
\text { - Improve Law and Order situation }\end{array}$ & $\begin{array}{l}\text { - no. of tourist Information centres } \\
\text { - leaflets, posters and brochures distributed } \\
\text { internationally } \\
\text { - no. of tourist spots especially with } \\
\text { archaeological and religious attractions } \\
\text { developed and conserved } \\
\text { - participation in International Tourist Fairs }\end{array}$ & $\begin{array}{l}\text { - no. of foreign and national tourist } \\
\text { - contribution to GDP } \\
\text { - contribution to foreign exchange } \\
\text { earnings }\end{array}$ \\
\hline $\begin{array}{l}\text { 13. Modernising postal services } \\
\text { for better service to people }\end{array}$ & $\begin{array}{l}\text { - automate postal services } \\
\text { - capacity building of BPOs through HRD }\end{array}$ & $\begin{array}{l}\text { - modern and efficient postal system with new } \\
\text { functions }\end{array}$ & - improved postal service delivery \\
\hline
\end{tabular}




\begin{tabular}{|c|c|c|c|}
\hline Strategic Goal & Input Indicators/Policy Change & Output Indicators & Outcome/Impact indicators \\
\hline \multicolumn{4}{|c|}{ Safety, Security, Protection of Life, Liberty \& Wealth } \\
\hline $\begin{array}{l}\text { 14. Ensuring safety \& security of } \\
\text { life \& property }\end{array}$ & $\begin{array}{l}\text { - increase expenditure on Bangladesh police to modernize them } \\
\text { - police reforms are in place }\end{array}$ & $\begin{array}{l}\text { - institutions for improved policing created } \\
\text { - no. of model Thanas } \\
\text { - victim support centre with Crime } \\
\text { Investigation Facility } \\
\text { - beach outposts are functional } \\
\text { - citizens' charter in place \& operational } \\
\end{array}$ & $\begin{array}{l}\text { - no. of crimes } \\
\text { - efficient \& speedy criminal } \\
\text { investigation } \\
\text { - safety of life \& property } \\
\text { - police image }\end{array}$ \\
\hline $\begin{array}{l}\text { 15. Ensuring fire prevention and } \\
\text { fire safety facilities }\end{array}$ & $\begin{array}{l}\text { - ensure fire prevention and fire safety service particularly in } \\
\text { industrial areas } \\
\text { - ensure emergency rescue and ambulance facilities all over the } \\
\text { country } \\
\text { - procure vehicles and equipment including rescue equipment } \\
\text { - ensure sufficient funds for operation and maintenance }\end{array}$ & $\begin{array}{l}\text { - fire service stations in pourasavas and } \\
\text { upazilas } \\
\text { - facilities for fire prevention, safety and } \\
\text { rescue } \\
\text { - fire prevention and safety for mines } \\
\text { - communication network between HQ and } \\
\text { peripheries }\end{array}$ & $\begin{array}{l}\text { - incidence of fire accidents } \\
\text { - loss of life and property due to fire, } \\
\text { disasters and accidents } \\
\text { - access of people to ambulance } \\
\text { facilities }\end{array}$ \\
\hline \multicolumn{4}{|l|}{ Urban Development } \\
\hline $\begin{array}{l}\text { 16. Establishing local self } \\
\text { governance }\end{array}$ & - create legal framework for self governance \& urban development & $\begin{array}{l}\text { - democratic local bodies functioning with } \\
\text { regularity }\end{array}$ & $\begin{array}{l}\text { - improved local urban governance } \\
\text { - service delivery } \\
\text { - urban issues addressed on a sustainable } \\
\text { basis }\end{array}$ \\
\hline $\begin{array}{l}\text { 17. Building capacity for planning } \\
\text { in city corporations \& ministry }\end{array}$ & $\begin{array}{l}\text { - initiate actions for establishing planning unit in all city corporations } \\
\text { - strengthen LGD planning outfit } \\
\text { - improve mass public communication system }\end{array}$ & $\begin{array}{l}\text { - plans prepared for all cities \& municipalities } \\
\text { on a continuous basis }\end{array}$ & $\begin{array}{l}\text { - urban facilities } \\
\text { - traffic congestion in the cities } \\
\text { - time/cost of public transportations }\end{array}$ \\
\hline $\begin{array}{l}\text { 18. Establishing viable urban } \\
\text { centres }\end{array}$ & $\begin{array}{l}\text { - undertake studies \& identify key focus areas in each centre } \\
\text { - generate revenue from designated sources } \\
\text { - ensure performance based funds from the central government }\end{array}$ & $\begin{array}{l}\text { - budgeting \& control mechanism in place } \\
\text { - transparent tax \& revenue raising system } \\
\text { - government grant support based on } \\
\text { performance }\end{array}$ & $\begin{array}{l}\text { - viable urban centres } \\
\text { - urban facilities }\end{array}$ \\
\hline 19. Ensuring urban-rural linkage & $\begin{array}{l}\text { - ensure linkage infrastructure } \\
\text { - increase expenditure on urban-rural linkage as percentage of } \\
\text { urban budget }\end{array}$ & $\begin{array}{l}\text { - urban-rural linkages } \\
\text { - time/cost for commuting between various } \\
\text { urban and rural areas }\end{array}$ & $\begin{array}{l}\text { - mutually supporting cities \& towns } \\
\text { developed }\end{array}$ \\
\hline $\begin{array}{l}\text { 20. Ensuing water \& sanitation in } \\
\text { urban areas }\end{array}$ & $\begin{array}{l}\text { - increase expenditure on WATSAN infrastructure as percentage } \\
\text { of urban budget } \\
\text { - create partnership-GO-NGO-Private sector for waste disposal }\end{array}$ & $\begin{array}{l}\text { - people with access to water-sanitation } \\
\text { - water-sanitation conditions in urban slums } \\
\text { - modern land fill sites }\end{array}$ & $\begin{array}{l}\text { - water borne diseases } \\
\text { - water and sanitation availability in } \\
\text { domestic and public space }\end{array}$ \\
\hline $\begin{array}{l}\text { 21. Ensuring adequate urban } \\
\text { infrastructure including housing } \\
\& \text { shelter }\end{array}$ & $\begin{array}{l}\text { - ensure housing facilities for low income, poor and working women } \\
\text { - ensure private-public cooperation in providing urban shelter with } \\
\text { special attention to working women's need } \\
\text { - ensure strategies for cluster development of adjacent pourasavas } \\
\text { - implement BOO-BOT for developing urban housing } \\
\end{array}$ & $\begin{array}{l}\text { - master plan for urban infrastructure } \\
\text { - housing-shelter plan } \\
\text { - institutions \& partnership developed for } \\
\text { construction \& finance }\end{array}$ & $\begin{array}{l}\text { - urban infrastructure limitations } \\
\text { - housing \& shelter facilities in the } \\
\text { urban areas }\end{array}$ \\
\hline 22. Ensuring recreational facilities & $\begin{array}{l}\text { - introduce a legal framework authorising urban control on all } \\
\text { common land \& water bodies } \\
\text { - develop a Master Plan for recreational needs like parks, } \\
\text { playground, libraries, auditoriums, etc. } \\
\text { - create partnership for development on BOO-BOT }\end{array}$ & $\begin{array}{l}\text { - urban river \& common lands developed for } \\
\text { common use } \\
\text { - cities \& towns created with urban amenities }\end{array}$ & $\begin{array}{l}\text { - city living conditions improved } \\
\text { - affordable recreational activities }\end{array}$ \\
\hline
\end{tabular}


M\&E Indicators 17: Environment and Tackling Climate Change for Sustainable Development

\begin{tabular}{|c|c|c|c|}
\hline Strategic Goal & Input Indicators/Policy Change & Output Indicators & Outcome/Impact indicators \\
\hline $\begin{array}{l}\text { 1. Increasing access of the poor } \\
\text { to common property resources } \\
\text { (CPRs) }\end{array}$ & $\begin{array}{l}\text { - increase access of the poor to CPRs } \\
\text { - establish property rights of ownership and use of water bodies, } \\
\text { natural resources, wetlands, chars and harvesting forests } \\
\text { - prepare a new regulatory framework for environmental } \\
\text { protection } \\
\text { - develop public-private and community-based participatory co- } \\
\text { management for NRM }\end{array}$ & $\begin{array}{l}\text { - utilization of CPRs } \\
\text { - health of CPRs } \\
\text { - participatory co-management of NRM }\end{array}$ & $\begin{array}{l}\text { - status of common property } \\
\text { resources } \\
\text { - head-count ratio } \\
\text { - ecosystem health } \\
\text { - safe environment } \\
\text { - \% of poor people with access to } \\
\text { CPRs }\end{array}$ \\
\hline $\begin{array}{l}\text { 2. Conserving bio-diversity of the } \\
\text { country }\end{array}$ & $\begin{array}{l}\text { - discourage monoculture and increase practices of multicultural } \\
\text { approaches including crop rotation } \\
\text { - increase diversified land-use patterns } \\
\text { - implement policies, rules and regulations for biodiversity } \\
\text { - reduce destruction of habitat and overexploitation of flora and } \\
\text { fauna } \\
\text { - stop encroachment of natural forests and water bodies } \\
\text { - stop invasion of exotic flora and fauna in the CPRs } \\
\text { - establish biodiversity conservation areas and sanctuaries }\end{array}$ & $\begin{array}{l}\text { - destruction of habitat and overexploitation } \\
\text { of flora and fauna } \\
\text { - CPRs health } \\
\text { - encroachment of the natural forests and } \\
\text { water bodies and its surroundings } \\
\text { - invasion of exotic flora and fauna } \\
\text { - new biodiversity conservation areas and } \\
\text { sanctuaries }\end{array}$ & $\begin{array}{l}\text { - balance in biodiversity } \\
\text { - participatory co-management in the } \\
\text { area of CPRs } \\
\text { - biodiversity conservation and } \\
\text { sanctuaries } \\
\text { - encroachment of the natural forests } \\
\text { and water bodies and its } \\
\text { surroundings } \\
\text { - invasion of exotic flora and fauna }\end{array}$ \\
\hline $\begin{array}{l}\text { 3. Controlling air pollution in } \\
\text { major metropolitan cities and } \\
\text { rural settings }\end{array}$ & $\begin{array}{l}\text { - increase access of energy efficient cooking stoves in rural and } \\
\text { urban areas } \\
\text { - increase conversion of natural gas to compressed natural gas in } \\
\text { motor vehicles } \\
\text { - increase use of sulpher and lead free fuel in motor vehicles } \\
\text { - control indoor polluted air emission } \\
\text { - implement policies, rules and regulations to reduce air pollution } \\
\text { - monitor and disseminate air quality information every day } \\
\text { - promote more research and development to change building and } \\
\text { construction standards } \\
\text { - reduce polluted air emission from brick kiln and other sources } \\
\text { - increase access to clean and renewable energy }\end{array}$ & $\begin{array}{l}\text { - } \% \text { of rural household using fuel efficient } \\
\text { cooking stoves } \\
\text { - per capita carbon dioxide emissions } \\
\text { - vehicle inspection and maintenance } \\
\text { programmes } \\
\text { - fuel quality with respect to lead and sulpher } \\
\text { content } \\
\text { - compulsory annual tests of vehicle emission } \\
\text { - emission related taxes } \\
\text { - clean technologies and renewable energies } \\
\text { for power generation } \\
\text { - clean air quality of our surroundings } \\
\end{array}$ & $\begin{array}{l}\text { - status of health of people } \\
\text { - emission efficiency in both indoor } \\
\text { and outdoor environment } \\
\text { - respiratory patients in urban and } \\
\text { rural areas } \\
\text { - ambient air quality at the national } \\
\text { standard level } \\
\text { - air quality information }\end{array}$ \\
\hline $\begin{array}{l}\text { 4. Improving solid waste } \\
\text { management system }\end{array}$ & $\begin{array}{l}\text { - increase segregation at source and safe disposal of hazardous } \\
\text { - wastes } \\
\text { - increase public-private partnership for solid waste management } \\
\text { - strengthen the regulatory measures for solid waste management } \\
\text { - introduce sanitary landfill in all urban cities } \\
\text { - introduce waste to resource recovery system } \\
\text { - introduce landfill leachate collection and treatment system } \\
\text { - develop tools and techniques that could bring monetary value of } \\
\text { the solid waste to the market }\end{array}$ & $\begin{array}{l}\text { - solid wastes collection with efficient } \\
\text { resource recovery, recycle, reuse and safe } \\
\text { disposal to the sanitary landfill } \\
\text { - safe disposal/reuse of hazardous wastes } \\
\text { - public-private partnership for } \\
\text { environmentally friendly SWM system } \\
\text { - environmentally friendly SWM master plan } \\
\text { - environmentally friendly solid and other } \\
\text { wastes management system in the industry } \\
\text { - network system among relevant } \\
\text { organizations }\end{array}$ & $\begin{array}{l}\text { - sanitized status of waste } \\
\text { management } \\
\text { - hygienic situation of the surrounding } \\
\text { environment } \\
\text { - skin diseased patients in urban and } \\
\text { rural areas } \\
\text { - income generation activities of poor } \\
\text { people }\end{array}$ \\
\hline
\end{tabular}




\begin{tabular}{|c|c|c|c|}
\hline Strategic Goal & Input Indicators/Policy Change & Output Indicators & Outcome/Impact indicators \\
\hline 5. Controlling industrial pollution & $\begin{array}{l}\text { - develop a data base of all existing and up coming industry } \\
\text { - ensure environmental clearance certificate (ECC) of all industries } \\
\text { - ensure EMP, ETP and environmental health management system } \\
\text { to all polluting industries } \\
\text { - ensure IEE/EIA of all industries prior to its establishment } \\
\text { - use alternative technologies that use cleaner energy } \\
\text { - encourage water recycling } \\
\text { - create a separate Environmental Cell for conducting EMP and } \\
\text { developing ETP } \\
\text { - establish polluter-to-pay approach to the industries those have } \\
\text { already damaged ecosystem/environment } \\
\text { - relocate tanneries of Hazaribagh and other polluting industries to } \\
\text { environmentally managed EPZ sites } \\
\text { - strengthen regulatory measures against industrial emissions }\end{array}$ & $\begin{array}{l}\text { - } \% \text { of industries and other enterprises into } \\
\text { ECC procedures } \\
\text { - tanneries and other polluting industries in } \\
\text { environmentally managed isolated areas } \\
\text { - environmental rules and regulations } \\
\text { - CETP in the industrial parks } \\
\text { - EIA report available to public } \\
\text { - mandatory environmentally friendly wastes } \\
\text { - management in all industry } \\
\text { - environmentally friendly management } \\
\text { - environs } \\
\text { the industries with a database system }\end{array}$ & $\begin{array}{l}\text { - environmentally friendly sustainable } \\
\text { industrial development } \\
\text { - hygienic environment in and around } \\
\text { the industry. } \\
\text { - safe occupational health in the } \\
\text { industry }\end{array}$ \\
\hline $\begin{array}{l}\text { 6. Improving water supply and } \\
\text { sanitation status for healthy } \\
\text { environment }\end{array}$ & $\begin{array}{l}\text { - introduce hanging toilet in the wetlands areas and coastal districts } \\
\text { - reduce effluent discharges from mechanized vessels and } \\
\text { industries into rivers and other inland waters } \\
\text { - enforce laws and regulations to control hazardous/toxic wastes } \\
\text { - develop a network of monitoring and evaluation systems } \\
\text { - develop drainage congestions in all MCC and major cities } \\
\text { - Ensure access to safe water supply both for drinking and other } \\
\text { - ensure hygienic public toilet and sanitation facilities in urban } \\
\text { areas } \\
\text { - dredge and excavate the rivers, haors and baors }\end{array}$ & $\begin{array}{l}\text { - sustainable access of improved water supply } \\
\text { and sanitation facilities } \\
\text { - conservancy laws and regulatory frameworks } \\
\text { - polluter-to-pay principles } \\
\text { - capacity for research and development in } \\
\text { collaboration with universities, research } \\
\text { institutions and other relevant organizations } \\
\text { - network among all relevant organizations } \\
\text { - ETP for effluent treatment in the industries }\end{array}$ & $\begin{array}{l}\text { - water-borne diseases } \\
\text { - life expectancy } \\
\text { - safe water supply and hygienic } \\
\text { sanitation }\end{array}$ \\
\hline $\begin{array}{l}\text { 7. Improving hazardous waste } \\
\text { management }\end{array}$ & $\begin{array}{l}\text { - increase expenditure on hazardous waste management } \\
\text { - ensure efficient collection, treatment and safe disposal medical, } \\
\text { ship breaking and chemical wastes } \\
\text { - ban trans boundary hazardous wastes dumping } \\
\text { - strengthen the regulatory measures against hazardous waste } \\
\text { management }\end{array}$ & $\begin{array}{l}\text { - efficient segregation and safe disposal of } \\
\text { hazardous wastes } \\
\text { - entrance of trans boundary hazardous wastes } \\
\text { - effective and efficient collection, treatment } \\
\text { and safe disposal of medical, ship breaking } \\
\text { and chemical wastes } \\
\text { - networking system among relevant } \\
\text { organizations }\end{array}$ & $\begin{array}{l}\text { - hazardous wastes pollution and } \\
\text { contamination } \\
\text { - infectious diseases }\end{array}$ \\
\hline $\begin{array}{l}\text { 8. Introducing and enforcing } \\
\text { Quarantine Law }\end{array}$ & $\begin{array}{l}\text { - increase expenditure on invasion management } \\
\text { - develop cells for monitoring of all sea, land and air ports to } \\
\text { protect the entrance of foreign matters or organisms } \\
\text { - strengthen regulatory measures against entrance of any foreign } \\
\text { matters or organisms }\end{array}$ & $\begin{array}{l}\text { - entrance of foreign matters or organisms in } \\
\text { the country } \\
\text { - quarantine of all marine ships, land vehicles } \\
\text { and airplane } \\
\text { - native indigenous species for flora and fauna }\end{array}$ & $\begin{array}{l}\text { - invasion risk } \\
\text { - health of flora and fauna }\end{array}$ \\
\hline $\begin{array}{l}\text { 9. Introducing environmental } \\
\text { education at all levels }\end{array}$ & $\begin{array}{l}\text { - incorporate EE in the curricula at all education levels } \\
\text { - develop environmentally friendly technical know-how among } \\
\text { populations } \\
\text { - develop safe and hygienic habitation knowledge in all activities of }\end{array}$ & $\begin{array}{l}\text { - expertise of environmentally friendly } \\
\text { resource management } \\
\text { - environmentally friendly technical know- } \\
\text { how on the rights and responsibilities }\end{array}$ & $\begin{array}{l}\text { - knowledge of environmentally } \\
\text { friendly sustainable development }\end{array}$ \\
\hline
\end{tabular}




\begin{tabular}{|c|c|c|c|}
\hline Strategic Goal & Input Indicators/Policy Change & Output Indicators & Outcome/Impact indicators \\
\hline & daily life & $\begin{array}{l}\text { - capacity of research in public universities, } \\
\text { research institutions and other organizations }\end{array}$ & \\
\hline $\begin{array}{l}\text { 10. Introducing environmental } \\
\text { awareness and motivational } \\
\text { programmes up to the grass } \\
\text { root levels of all stakeholders }\end{array}$ & $\begin{array}{l}\text { - incorporating environmental awareness and motivational } \\
\text { knowledge up to the grass root levels of all stakeholders. } \\
\text { - developing environmentally friendly programmes and activities of } \\
\text { technical know-how among different societies to make them well } \\
\text { informed choices and exercise on the rights and responsibilities. }\end{array}$ & $\begin{array}{l}\text { - expertise of resource management of } \\
\text { environmentally friendly for sustainable } \\
\text { development. } \\
\text { - environmentally friendly technical know- } \\
\text { how on the rights and responsibilities. } \\
\end{array}$ & $\begin{array}{l}\text { - knowledge of environmentally } \\
\text { friendly sustainable development }\end{array}$ \\
\hline $\begin{array}{l}\text { 11. Ensuring environmental } \\
\text { issues in good governance }\end{array}$ & $\begin{array}{l}\text { - ensuring technical and managerial competence, organizational } \\
\text { capacity, reliability, predictability and the rule of law } \\
\text { - ensuring accountability, transparency and open information } \\
\text { systems } \\
\text { - ensuring participatory co-management }\end{array}$ & $\begin{array}{l}\text { - technical and managerial competence, } \\
\text { organizational capacity, reliability, } \\
\text { predictability and the rule of law } \\
\text { - open information systems } \\
\text { - participatory co-management approach }\end{array}$ & $\begin{array}{l}\text { - reliability, predictability, rule of law, } \\
\text { accountability and transparency in } \\
\text { environmental friendly development }\end{array}$ \\
\hline
\end{tabular}

M\&E Indicators 18: Technology Policy including ICT and Bio-technology

\begin{tabular}{|c|c|c|c|}
\hline Strategic goal & Input indicators & Output indicators & Outcome/Impact indicators \\
\hline $\begin{array}{l}\text { 1. Developing power sector } \\
\text { through implementation of } \\
\text { Nuclear Power Project }\end{array}$ & $\begin{array}{l}\text { - arrange adequate financing for construction and implementation } \\
\text { of Nuclear Power Project } \\
\text { - improve HRD }\end{array}$ & $\begin{array}{l}\text { - contact signing with potential supplier for } \\
\text { Nuclear Power Plant \& Technology } \\
\text { - construction of Nuclear Power Plant }\end{array}$ & $\begin{array}{l}\text { - generation of electricity from nuclear } \\
\text { source }\end{array}$ \\
\hline $\begin{array}{l}\text { 2. Developing nuclear service } \\
\text { related infrastructure }\end{array}$ & $\begin{array}{l}\text { - ensure government funding and IAEA technical support } \\
\text { - procure necessary equipment and ensure HRD }\end{array}$ & - establishment of R\&D facilities & $\begin{array}{l}\text { - health services, analytical services } \\
\text { - NDT services and environmental } \\
\text { monitoring }\end{array}$ \\
\hline $\begin{array}{l}\text { 3. Developing technologies and } \\
\text { industrial processes for } \\
\text { production and preservation of } \\
\text { food items }\end{array}$ & $\begin{array}{l}\text { - hire competent scientists and technical workers } \\
\text { - procure scientific equipments } \\
\text { - increase expenditure for research and development (R\&D) } \\
\text { activities }\end{array}$ & $\begin{array}{l}\text { - no, of commercial process } \\
\text { - no. of leased out of process } \\
\text { - no of patent } \\
\text { - services provided in research } \\
\text { - technical assistance }\end{array}$ & $\begin{array}{l}\text { - no. of SMEs } \\
\text { - technology for food industries } \\
\text { - food safety and food quality status } \\
\text { - employment generation for poor } \\
\text { - development of R\&D skill }\end{array}$ \\
\hline $\begin{array}{l}\text { 4. Reducing irrigation cost } \\
\text { through dual fuel shallow water } \\
\text { pump }\end{array}$ & $\begin{array}{l}\text { - hire competent engineers \& technicians } \\
\text { - procure scientific equipment and machine tools }\end{array}$ & $\begin{array}{l}\text { - no. of medium lifting shallow tube-wells run } \\
\text { by dual fuel kit }\end{array}$ & $\begin{array}{l}\text { - Using the duel/fuel kit } \\
\text { - production cost of crops }\end{array}$ \\
\hline $\begin{array}{l}\text { 5. Introducing new energy } \\
\text { technology }\end{array}$ & $\begin{array}{l}\text { - provide training on improved stoves, biogas technologies and } \\
\text { solar oven in urban and rural areas } \\
\text { - organise seminar and exhibition in rural areas } \\
\text { - provide technical support to people to establish new technologies } \\
\text { - undertake loop research }\end{array}$ & $\begin{array}{l}\text { - no. of biogas plant established by BCSIR } \\
\text { - no. of new model of improved stoves } \\
\text { innovated } \\
\text { - no. of new model of solar oven innovated }\end{array}$ & $\begin{array}{l}\text { - use of sustainable energy } \\
\text { - environment pollution control } \\
\text { - green house gas emission } \\
\text { - employment generation }\end{array}$ \\
\hline $\begin{array}{l}\text { 6. Developing and promoting of } \\
\text { alternative medicine care } \\
\text { (AMC) }\end{array}$ & $\begin{array}{l}\text { - develop scientists and technical workers in area of AMC } \\
\text { - increase expenditure on R\&D }\end{array}$ & $\begin{array}{l}\text { - new medicinal use of plants innovated and } \\
\text { cultivated } \\
\text { - new industries for AMC products }\end{array}$ & $\begin{array}{l}\text { - no. of people use and benefits form } \\
\text { AMC }\end{array}$ \\
\hline $\begin{array}{l}\text { 7. Increased agricultural } \\
\text { productivity through the } \\
\text { innovative application of } \\
\text { genetic engineering and }\end{array}$ & $\begin{array}{l}\text { - increase expenditure on R\&D, infrastructure, scientists, technical } \\
\text { personnel etc. } \\
\text { - innovate DNA technology for transgenic plants and } \\
\text { environmentally safe rice bio-fertilizer }\end{array}$ & $\begin{array}{l}\text { - technology for crop improvement, plant } \\
\text { tissue culture, DNA finger printing, } \\
\text { identification of GMOs } \\
\text { - DNA technology for transgenic plants and }\end{array}$ & $\begin{array}{l}\text { - technology transfer to no. of } \\
\text { stakeholders and farmers }\end{array}$ \\
\hline
\end{tabular}




\begin{tabular}{|c|c|c|c|}
\hline Strategic goal & Input indicators & Output indicators & Outcome/Impact indicators \\
\hline biotechnology & & environmentally safe rice bio-fertilizer & \\
\hline $\begin{array}{l}\text { 8. Innovating building materials } \\
\text { appropriate for coastal areas }\end{array}$ & $\begin{array}{l}\text { - increase expenditure on } \mathrm{R} \& \mathrm{D} \text {, engineers, technical personnel } \\
\text { - undertake research activities }\end{array}$ & $\begin{array}{l}\text { - developed technology that withstands strong } \\
\text { tidal waves }\end{array}$ & $\begin{array}{l}\text { - new material and technology for } \\
\text { construction of infrastructures in } \\
\text { coastal areas }\end{array}$ \\
\hline $\begin{array}{l}\text { 9. Developing and disseminating } \\
\text { products and processes for } \\
\text { SMEs. }\end{array}$ & $\begin{array}{l}\text { - ensure hiring of competent engineers/technologists/scientists } \\
\text { - procure technical and scientific equipments. } \\
\text { - increase expenditure on R\&D }\end{array}$ & $\begin{array}{l}\text { - no. of new products } \\
\text { - availability of process for manufacturing of } \\
\text { products } \\
\text { - operation of process in a cost effective way }\end{array}$ & $\begin{array}{l}\text { - no. of new industries and product } \\
\text { lines } \\
\text { - generation of new employment } \\
\text { - minimum production cost through } \\
\text { less resource use }\end{array}$ \\
\hline $\begin{array}{l}\text { 10. Establishing technology } \\
\text { transfer centre for SMEs and } \\
\text { ensuring SME technology } \\
\text { incubation }\end{array}$ & $\begin{array}{l}\text { - establish technology transfer centre for SMEs in all districts } \\
\text { - employ sufficient human resources for technology dissemination }\end{array}$ & $\begin{array}{l}\text { - dissemination of technology for SMEs } \\
\text { promotion } \\
\text { - gap between research and commercial } \\
\text { organizations } \\
\text { - training for skill development and other } \\
\text { necessary facilities } \\
\text { - services for technology adaptation }\end{array}$ & $\begin{array}{l}\text { - competitive production costs } \\
\text { - production by SMEs including SMEs } \\
\text { owned by women } \\
\text { - employment generation for men and } \\
\text { women }\end{array}$ \\
\hline 11. Developing ICT for mass use & $\begin{array}{l}\text { - develop ICT Policy and Infrastructure } \\
\text { - develop human resource development for ICT } \\
\text { - enhance Research \& Development in ICT applications } \\
\text { - promote use of ICT } \\
\text { - ensure e-Governance for delivery of public services to the people } \\
\text { - provide broadband internet connectivity to ICT Incubator and to } \\
\text { important Ministries / Divisions / Departments } \\
\text { - provide ICT based services for available to all citizen } \\
\text { - increase access to ICT among disadvantaged groups including } \\
\text { women } \\
\text { - increase export of Software and ITES }\end{array}$ & $\begin{array}{l}\text { - access to related information for RNFA and } \\
\text { SME } \\
\text { - development/Improvement of operational } \\
\text { system } \\
\text { - implementation of e-business for access } \\
\text { market } \\
\text { - employment data base } \\
\text { - use of ICT for education } \\
\text { - Centre of excellence for ICT }\end{array}$ & $\begin{array}{l}\text { - access of product to global and local } \\
\text { markets } \\
\text { - employment generation in ICT (men } \\
\text { and women) } \\
\text { - e-Community centres in Upazila and } \\
\text { growth centres with provision for } \\
\text { women } \\
\text { - e-Governance to ensure public } \\
\text { services to people } \\
\text { - no. of rural population (male/female) } \\
\text { with access to ICT } \\
\text { - multimedia courseware for SSC level } \\
\text { - ICT awareness among all the citizens } \\
\text { - use of ICT to provide services in } \\
\text { remote areas for e-learning, e- } \\
\text { agriculture, e-health etc. }\end{array}$ \\
\hline
\end{tabular}


Thematic Committees and Their Composition

\begin{tabular}{|c|c|c|}
\hline $\begin{array}{l}\text { S1. } \\
\text { No. }\end{array}$ & $\begin{array}{l}\text { Names of the } \\
\text { Thematic } \\
\text { Committees }\end{array}$ & Composition of Committees \\
\hline 1. & $\begin{array}{l}\text { Macroeconomic } \\
\text { Management for } \\
\text { Pro-poor growth } \\
\text { including } \\
\text { Financial Sector } \\
\text { and Trade } \\
\text { Development }\end{array}$ & $\begin{array}{l}\text { Chair: Member, General Economics Division, Planning Commission } \\
\begin{array}{ll}\text { Committee Members } \\
\text { i) } & \text { Chief, GED, Planning Commission } \\
\text { ii) } & \text { Chief, Programming Division, Planning Commission } \\
\text { iii) } & \text { DG, Bangladesh Bureau of Statistics } \\
\text { iv) } & \text { Representative, Finance Division } \\
\text { v) } & \text { Representative, NBR } \\
\text { vi) } & \text { Representative, Ministry of Commerce } \\
\text { vii) } & \text { Representative, Bangladesh Bank } \\
\text { viii) } & \text { Representative, Export Promotion Bureau } \\
\text { ix) } & \text { Representative, BEPZA } \\
\text { x) } & \text { Representative, Securities Exchange Commission } \\
\text { xi) } & \text { Representative, ERD } \\
\text { xii) } & \text { Representative, BSTI }\end{array}\end{array}$ \\
\hline 2. & $\begin{array}{l}\text { Resources } \\
\text { Mobilization } \\
\text { (Domestic and } \\
\text { Foreign) }\end{array}$ & $\begin{array}{l}\text { Chair: Secretary, Internal Resources Division } \\
\begin{array}{cl}\text { Committee Members: } \\
\text { i) } & \text { Chief, Programming Division, Planning Commission } \\
\text { ii) } & \text { Representative, Finance Division } \\
\text { iii) } & \text { Representative, ERD, Ministry of Finance } \\
\text { iv) } & \text { Director General, National Savings Directorate } \\
\text { v) } & \text { Director General, Department of Postal Service } \\
\text { vi) } & \text { Representatives, Other concerned Ministries/Agencies }\end{array}\end{array}$ \\
\hline 3. & $\begin{array}{l}\text { Improvement of } \\
\text { Governance } \\
\text { including Civil } \\
\text { Service Reforms, } \\
\text { Judicial Reforms } \\
\text { and Law and Order } \\
\text { Improvement }\end{array}$ & $\begin{array}{l}\text { Chair: Secretary, Ministry of Establishment } \\
\text { Committee Members: } \\
\begin{array}{cl}\text { i) } & \text { Chief, SEI Division, Planning Commission } \\
\text { ii) } & \text { Representative, Chief Advisor's Office } \\
\text { iii) } & \text { Representative, Local Government Division } \\
\text { iv) } & \text { Representative, Ministry of Home Affairs } \\
\text { v) } & \text { Representative, Finance Division } \\
\text { vi) } & \text { Representative, GED, Planning Commission }\end{array}\end{array}$ \\
\hline 4. & $\begin{array}{l}\text { Health including } \\
\text { Nutrition, } \\
\text { Sanitation and } \\
\text { Population } \\
\text { Planning }\end{array}$ & 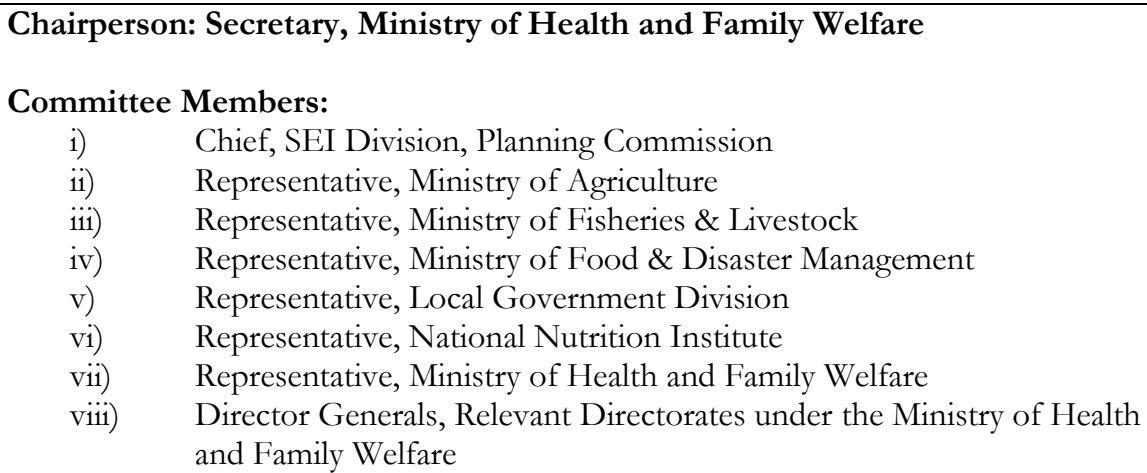 \\
\hline 5. & $\begin{array}{l}\text { Education } \\
\text { including Primary } \\
\text { and Mass } \\
\text { Education, Female } \\
\text { Education, } \\
\text { Vocational and } \\
\text { Technical } \\
\text { Education }\end{array}$ & $\begin{array}{l}\text { Chair: Secretary, Ministry of Education } \\
\begin{array}{cl}\text { Committee } & \text { Members: } \\
\text { i) } & \text { Chief. SEI Division, Planning Commission } \\
\text { ii) } & \text { Representative, Ministry of Primary and Mass Education } \\
\text { iii) } & \text { Representative, Ministry of Women and Children Affairs } \\
\text { iv) } & \text { Representative, Ministry of Youth and Sports } \\
\text { v) } & \text { Representative, Ministry of Labour and Employment } \\
\end{array}\end{array}$ \\
\hline
\end{tabular}




\begin{tabular}{|c|c|c|}
\hline $\begin{array}{l}\text { Sl. } \\
\text { No. }\end{array}$ & $\begin{array}{l}\text { Names of the } \\
\text { Thematic } \\
\text { Committees }\end{array}$ & Composition of Committees \\
\hline & & $\begin{array}{ll}\text { vi) } & \text { Representative, Ministry of Expatriate Welfare and Overseas } \\
& \text { Employment } \\
\text { vii) } & \text { Representative, Ministry of Science and Information \& Communication } \\
& \text { Technology } \\
\text { viii) } & \text { Representative, Ministry of Religion Affairs } \\
\text { ix) } & \text { Director General of Technical Education }\end{array}$ \\
\hline 6. & $\begin{array}{l}\text { Employment } \\
\text { Generation and } \\
\text { Labour Welfare }\end{array}$ & $\begin{array}{l}\text { Chair: Secretary, Ministry of Labour and Employment } \\
\text { Committee Members: } \\
\begin{array}{ll}\text { i) } & \text { Chief, SEI Division, Planning Commission } \\
\text { ii) } & \text { Representative, Programming Division } \\
\text { iii) } & \text { Representative, Ministry of Expatriate, Welfare and Overseas Employment } \\
\text { iv) } & \text { Representative, Finance Division } \\
\text { v) } & \text { Representative, Ministry of Social Welfare } \\
\text { vi) } & \text { Representative, Ministry of Woman and Children Affairs }\end{array}\end{array}$ \\
\hline 7. & $\begin{array}{l}\text { Women's and } \\
\text { Children's } \\
\text { Advancement and } \\
\text { Rights Including } \\
\text { Social Inclusion } \\
\text { and } \\
\text { Empowerment. }\end{array}$ & $\begin{array}{l}\text { Chair: Secretary, Ministry of Women and Children Affairs } \\
\begin{array}{cl}\text { Committee Members: } \\
\text { i) } & \text { Chief, SEI Division, Planning Commission } \\
\text { ii) } & \text { Representative, Ministry of Law, Justice and Parliamentary Affairs } \\
\text { iii) } & \text { Representative, Ministry of Social Welfare } \\
\text { iv) } & \text { Representative, Ministry of Home Affairs } \\
\text { v) } & \text { Representative, Ministry of Labour and Employment } \\
\text { vi) } & \text { Representative, Ministry of Expatriates Welfare and Overseas } \\
& \text { Employment } \\
\text { vii) } & \text { Representative, Ministry of Primary and Mass Education }\end{array}\end{array}$ \\
\hline 8. & $\begin{array}{l}\text { Social Safety Net } \\
\text { including Food } \\
\text { Security, Disaster } \\
\text { Management, } \\
\text { Micro credit and } \\
\text { Rural Development } \\
\text { / Non-farm } \\
\text { Activities }\end{array}$ & $\begin{array}{l}\text { Chair: Secretary, Ministry of Food and Disaster Management } \\
\text { Committee Members: } \\
\begin{array}{cl}\text { i) } & \text { Chief, Agriculture, Rural Institution and Water Resources Division } \\
\text { ii) } & \text { Representative, Rural Development and Cooperatives Division } \\
\text { iii) } & \text { Representative, Local Government Division } \\
\text { iv) } & \text { Representative, Ministry of Social Welfare } \\
\text { v) } & \text { Representative, Ministry of Labour and Employment } \\
\text { vi) } & \text { Representative, Ministry of Youth \& Sports } \\
\text { vii) } & \text { Representative, Ministry of Industries } \\
\text { viii) } & \text { Representative, Finance Division } \\
\text { ix) } & \text { Chairman, BRDB } \\
\text { x) } & \text { MD, PKSF }\end{array}\end{array}$ \\
\hline 9. & $\begin{array}{l}\text { Agriculture (Crops, } \\
\text { Fisheries and } \\
\text { Livestock) } \\
\text { including Forestry }\end{array}$ & $\begin{array}{l}\text { Chair: Secretary, Ministry of Agriculture } \\
\begin{array}{ll}\text { Committee } & \text { Members: } \\
\text { i) } & \text { Chief, Agriculture, Rural Institution and Water Resources Division } \\
\text { ii) } & \text { Representative, Ministry of Land } \\
\text { iii) } & \text { Representative, Ministry of Fisheries and Livestock } \\
\text { iv) } & \text { Representative, Ministry of Water Resources } \\
\text { v) } & \text { Representative, Local Government Division } \\
\text { vi) } & \text { Representative, Ministry of Industries }\end{array}\end{array}$ \\
\hline 10 & $\begin{array}{l}\text { Land Use } \\
\text { Management } \\
\text { including Land } \\
\text { Reform }\end{array}$ & $\begin{array}{l}\text { Chair: Secretary, Ministry of Land } \\
\text { Committee Members: } \\
\text { i) Chief, Agriculture, Rural Development and Water Resources Division } \\
\text { ii) Representative, Ministry of Land } \\
\text { iii) Representative, Ministry of Agriculture }\end{array}$ \\
\hline
\end{tabular}




\begin{tabular}{|c|c|c|}
\hline $\begin{array}{l}\text { S1. } \\
\text { No. }\end{array}$ & $\begin{array}{l}\text { Names of the } \\
\text { Thematic } \\
\text { Committees }\end{array}$ & Composition of Committees \\
\hline & & $\begin{array}{l}\text { iv) Representative, Ministry of Fisheries and Livestock } \\
\text { v) Representative, Ministry of Water Resources } \\
\text { vi) Representative, Local Government Division } \\
\text { vii) Representative, Ministry of Industries }\end{array}$ \\
\hline 11. & $\begin{array}{l}\text { Water Resources } \\
\text { Development and } \\
\text { Management }\end{array}$ & $\begin{array}{l}\text { Chair: Secretary, Ministry of Water Resources } \\
\begin{array}{cl}\text { Committee } & \text { Members: } \\
\text { i) } & \text { Chief, Agriculture, Water Resource and Rural Institution Division, } \\
& \text { Planning Commission } \\
\text { ii) } & \text { Representative, Ministry of Agriculture } \\
\text { iii) } & \text { Representative, Ministry of Fisheries \& Livestock } \\
\text { iv) } & \text { Representative, Ministry of Land } \\
\text { v) } & \text { Representative, Ministry of Finance } \\
\text { vi) } & \text { Representative, Local Governments Division } \\
\text { vii) } & \text { Representative, Rural Development \& Cooperatives Division } \\
\text { viii) } & \text { Representative, Ministry of Environment and Forest } \\
\text { ix) } & \text { Representative, Programming Division, Planning Commission }\end{array}\end{array}$ \\
\hline 12. & $\begin{array}{l}\text { Private Sector } \\
\text { Development }\end{array}$ & $\begin{array}{l}\text { Chair: Secretary, Prime Minister's/Chief Advisor's Office } \\
\text { Committee Members: } \\
\begin{array}{cl}\text { i) } & \text { Chief, Industries Division, Planning Commission } \\
\text { ii) } & \text { Representative, Ministry of Industries } \\
\text { iii) } & \text { Chairman, BOI } \\
\text { iv) } & \text { Executive Chairman, BEPZA } \\
\text { v) } & \text { Chairman, BTRC } \\
\text { vi) } & \text { Representative, Energy Regulatory Commission } \\
\text { vii) } & \text { Executive Director, Privatization Commission } \\
\text { viii) } & \text { Chairman, BSCIC } \\
\text { ix) } & \text { Executive Director, Bangladesh Shilpa Bank } \\
\text { x) } & \text { Chief, Controller of Insurance } \\
\text { xi) } & \text { Managing Director, BASIC }\end{array}\end{array}$ \\
\hline 13. & $\begin{array}{l}\text { Small and Medium } \\
\text { Enterprise (SME) } \\
\text { Development }\end{array}$ & $\begin{array}{l}\text { Chair: Secretary, Ministry of Industries } \\
\text { Committee Members: } \\
\begin{array}{ll}\text { i) } & \text { Chief, Industries Division } \\
\text { ii) } & \text { Representation, Ministry of Commerce } \\
\text { iii) } & \text { Representative, Ministry of Woman and Children Affairs } \\
\text { iv) } & \text { Representative, Board of Investment } \\
\text { v) } & \text { Representative, Bangladesh Bank }\end{array}\end{array}$ \\
\hline 14. & $\begin{array}{l}\text { Infrastructural } \\
\text { Development } \\
\text { including Power, } \\
\text { Energy and } \\
\text { Communications } \\
\text { (Roads, Railways, } \\
\text { Ports, Shipping, } \\
\text { Inland Water } \\
\text { Transport and } \\
\text { Telecommunication) }\end{array}$ & $\begin{array}{l}\text { Chair: Secretary, Power Division } \\
\begin{array}{cl}\text { Committee Members: } \\
\text { i) } & \text { Chief, Physical Infrastructure Division, Planning Commission } \\
\text { ii) } & \text { Representative, Ministry of Communication } \\
\text { iii) } & \text { Representative, Energy Division } \\
\text { iv) } & \text { Representative, Ministry of Commerce } \\
\text { v) } & \text { Representative, Ministry of Shipping } \\
\text { vi) } & \text { Representative, Ministry of Civil Aviation and Tourism } \\
\text { vii) } & \text { Representative, Ministry of Post and Telecommunications } \\
\text { viii) } & \text { Representatives from concerned agencies }\end{array}\end{array}$ \\
\hline
\end{tabular}




\begin{tabular}{|c|c|c|}
\hline $\begin{array}{l}\text { Sl. } \\
\text { No. }\end{array}$ & $\begin{array}{l}\text { Names of the } \\
\text { Thematic } \\
\text { Committees }\end{array}$ & Composition of Committees \\
\hline 15. & $\begin{array}{l}\text { Technology Policy } \\
\text { including } \\
\text { Information and } \\
\text { Communication } \\
\text { Technology }\end{array}$ & $\begin{array}{l}\text { Chair: Secretary, Ministry of Science and Information \& Communication } \\
\text { Technology } \\
\text { Co-Chair: Member, SEI Division, Planning Commission } \\
\text { Committee Members: } \\
\begin{array}{ll}\text { i) } & \text { Chief, SEI Division, Planning Commission } \\
\text { ii) } & \text { Representative, Ministry of Education } \\
\text { iii) } & \text { Representative, Ministry of Post and Telecommunications } \\
\text { iv) } & \text { Representative, Ministry of Health and Family Welfare } \\
\text { v) } & \text { Chairman, BTRC } \\
\text { vi) } & \text { Chairman, BCSIR } \\
\text { vii) } & \text { Representative, Bangladesh Atomic Energy Commission, and } \\
\text { viii) } & \text { Chairman, Bangladesh Computer Council }\end{array}\end{array}$ \\
\hline 16 & $\begin{array}{l}\text { Housing } \\
\text { Development (both } \\
\text { urban and rural) }\end{array}$ & $\begin{array}{l}\text { Chair: Secretary, Ministry of Housing and Public works } \\
\begin{array}{ll}\text { Committee Members: } \\
\text { i) } & \text { Chief, SEI Division, Planning Commission } \\
\text { ii) } & \text { Representative, Ministry of Social Welfare } \\
\text { iii) } & \text { Representative, Ministry of Women and Children Affairs } \\
\text { iv) } & \text { Representative, Ministry of Land } \\
\text { v) } & \text { Representative, Local Government Division, } \\
\text { vi) } & \text { Representative, Rural development and Co-operatives Division } \\
\text { vii) } & \text { Representative, Ministry of Water Resources }\end{array}\end{array}$ \\
\hline 17 & $\begin{array}{l}\text { Utility Services } \\
\text { Development } \\
\text { including Safe } \\
\text { Water Supply }\end{array}$ & $\begin{array}{l}\text { Chair: Secretary, Local Government Division } \\
\begin{array}{cl}\text { Committee } & \text { Members: } \\
\text { i) } & \text { Chief, Agriculture, Water Resource and Rural Institution Division } \\
& \text { Planning Commission } \\
\text { ii) } & \text { Representative, Ministry of Primary and Mass Education } \\
\text { iii) } & \text { Representative, Ministry of Education } \\
\text { iv) } & \text { Representative, Ministry of Health and Family Welfare } \\
\text { v) } & \text { Representative, Power Division } \\
\text { vi) } & \text { Representative, Ministry of Land } \\
\text { vii) } & \text { Representative, Roads and Railway Division } \\
\text { viii) } & \text { Representative, Ministry of Post and Telecommunications } \\
\text { ix) } & \text { Representative, Energy and Mineral Resources Division } \\
\text { x) } & \text { Representative, Ministry of Civil Aviation and Tourism } \\
\text { xi) } & \text { Representatives, All concerned Agencies }\end{array}\end{array}$ \\
\hline 18 & $\begin{array}{l}\text { Environment for } \\
\text { Sustainable } \\
\text { Development }\end{array}$ & $\begin{array}{l}\text { Chair: Secretary, Ministry of Environment and Forest } \\
\begin{array}{cl}\text { Committee } & \text { Members: } \\
\text { i) } & \text { Chief, Agriculture, Water Resource and Rural Institution Division, } \\
& \text { Planning Commission } \\
\text { ii) } & \text { Representative, Ministry of Agriculture } \\
\text { iii) } & \text { Representative, Ministry of Fisheries \& Livestock } \\
\text { iv) } & \text { Representative, Ministry of Land } \\
\text { v) } & \text { Representative, Ministry of Water Resources } \\
\text { vi) } & \text { Representative, Ministry of Home Affairs } \\
\text { vii) } & \text { Representative, Ministry of Defence } \\
\end{array}\end{array}$ \\
\hline
\end{tabular}




\section{Summary Proceedings of NSAPR II Consultation Meetings}

The NPFP (National Poverty Focal Point) of the GED (General Economics Division) organized several consultations with a cross-section of stakeholders to make the NSAPR II (revised) a truly country owned document. The first consultation was held with academics, researchers, CBOs and NGOs on the structure of the document. The National Steering Committee for the preparation of PRSP then finalized the structure of NSAPR on 17 September 2007. After the draft thematic reports were prepared, a three-day national-level consultation attended by academics, researchers, CBOs, NGOs, and trade bodies, was held in Dhaka on 18 -20 March 2008. This was followed by a two-day regional consultation at Barisal on 29 - 30 March 2008 which was participated by concerned local government officials, representatives from chambers of commerce and industry, professional organizations, NGOs, media, different occupational groups, and thematic experts. The recommendations of these consultations were reflected in the final thematic reports.

The draft NSAPR was prepared drawing on the 18 thematic reports produced by the thematic groups. The endeavour was supported by thematic experts. A two-day long consultation was held in Dhaka on $1-2$ June 2008 which was participated in by academics, researchers, and representatives from the Chamber of Commerce and Industry, professional organizations, CBOs, NGOs and concerned ministries. A consultation on the draft was also held with the development partners in Dhaka on 10 June 2008. Two more consultations on the draft were held- one at Rangamati on 21 June 2008 and the other at Rajshahi on 28 June 2008. The participants in these consultations included local people representing various stakeholders and local government functionaries. The consultations outside Dhaka were facilitated by the district administration while that with the development partners was facilitated by the Economic Relations Division of the Finance Ministry. Valuable comments were received in the consultations and these were supplemented by written comments sent afterwards.

The participants discussed both general and sectoral issues. The rationale of preparing the NSAPR II by the caretaker government instead of extending it for another year was questioned and it was suggested that the strategy must be owned by the future elected government through appropriate process. The logic of abandoning five-year plans and shifting to the three-year PRS was also questioned. A more broad based consultation was recommended to reflect the aspirations and opinions of people from all walks of life. Some participants questioned the relevance of the strategies followed by successive governments for the poor and opined that they were not pro-poor and inclusive as claimed.

Some participants opined that the current development paradigm in Bangladesh is termed as market friendly but it is actually corporate friendly. The economy is gradually shifting to a corporate economy culture. The focus on growth rather than distribution was also questioned. While growth may be good for some people it may exclude the poor. When bottled water is sold it enhances growth but the poor do not have access to this water.

The sectoral recommendations obtained from the consultations are briefly presented below:

\section{Macroeconomic Environment for Pro-Poor Economic Growth}

- Suitable policies are needed for promoting development in different regions of the country, especially the regions having high incidence of poverty or chronic poverty. The policies should include special incentives like tax holidays and low interest loans for industries, promoting development of exports following the "one district one product policy", and promoting export of manpower from the regions lagging behind by providing appropriate skill training.

- Establishment and operation of training institutes by the manpower recruiting agencies should be made mandatory. For migrant workers passports should be issued for 10 years.

- For private sector development some thrust sectors should be identified. 
- The government should avoid adopting anti-poor policies like banning rickshaws on major city roads.

- Automation of income tax administration is needed.

- Bangladesh should reap the benefits of regional trade. It should establish industrial clusters of SMEs near the land ports to serve the regional markets.

\section{Critical Areas of Focus for Pro-Poor Economic Growth}

\subsection{Agriculture}

- Development of agriculture should be promoted through supply of modern seeds, introduction of crops suitable for particular regions, like drought resistant and less water intensive rice in the north-western region and salinity resistant rice in coastal areas, fruits, spices and medicinal plants in CHT districts, promotion of livestock and fisheries sub-sectors through provision of research and extension services, and promotion of the cultivation of local fruits and spices.

- Awareness about bird flu and similar devastating diseases should be created in order to have a sustainable poultry industry.

- Increased agricultural production should be based on the use of more organic fertilizers and compost and less chemical fertilizers.

- In order to stop the distress sale of rice by small farmers and ensure fair price for them, cooperative marketing along the lines of Thailand can be introduced.

- In coastal districts cultivation of three crops in a year instead of the current single crop should be promoted through the development of agriculture.

\subsection{Water resources Development and Management}

- Over exploitation of underground water for irrigation and other uses which has a severe adverse impact on environment should be discouraged. Rather, use of surface water for irrigation and other purposes should be encouraged.

- Existing heights of embankments have to be raised as per engineering studies in view of the apprehended sea-level rise. Compaction of sea-facing embankments has to be ensured. Plantation of trees with long roots well outside the toe line of embankments has to be ensured.

- Awareness of water use and its economic importance needs to be created.

\subsection{Small and Medium Enterprises}

- Development of SMEs should be promoted, especially in the regions lagging behind and regions outside Dhaka through the provision of tax incentives, low-interest credit and adequate and uninterrupted supply of electricity and tax-free import of raw materials.

- In order to sustain the silk industry in Rajshahi, the establishment of reeling factories should be encouraged and the reeling sections in the Resham Board should be restarted.

- ICT should come under the purview of SME.

- Women entrepreneurs should be given training on marketing, accounting and pricing.

- Rescheduling of loans is needed in enterprises affected by natural disasters.

- Women entrepreneurs should have easy access to credit and mortgage-free loan. They should be exempted from requirements like trade license or tax certificate and should given loans on individual security.

- There should not be any restrictions on the movement of goods produced in the hill districts and forest products to facilitate growth of SMEs and agriculture in the region. 


\subsection{Land Use Policy and Administrative Issues}

- Implementation of the Land Use Policy 2002 will be able to put a stop to the nonagricultural use of agricultural land.

- Implementation of the land policy is needed to promote development in hill districts.

- Land administration and related issues should be adequately dealt with as land disputes are an important problem for the poor.

\section{Essential Infrastructure for Pro-Poor Economic Growth}

\subsection{Power and Energy}

- Measures should be taken to construct a nuclear power plant at Rooppur for generating electricity. Another plant can be constructed in a less populated area of Rangpur district.

- The capacity of the hydroelectric power plant at Kaptai should be increased and the provision of $15 \mathrm{MW}$ electricity sub-stations for hill districts should be assured, especially in view of the sacrifice of the people in this region for electricity.

- Gas should be supplied to yet un-served areas, especially in the western region. In case of gas connections priority should be given to industries over households.

- Low cost and environment friendly energy supply for the poor should be assured.

- Use of solar energy, wind energy and bio-gas to reduce the magnitude of the energy problem should be emphasized.

\subsection{Transport}

- Road transport network should continue to develop connecting Upazilas with district towns. Quality of construction and maintenance of roads should be ensured.

- Two bridges, one at Maoa over the Padma and another near Bahadurabad over the Jamuna, should be constructed to integrate the eastern region with the western region of the country.

- The toll for crossing the Jamuna Bridge should be drastically reduced to facilitate the flow of goods between the two regions.

- Measures should be taken to prevent road accidents which impose heavy costs on people.

- Road communication should be expanded in coastal districts to connect important places which are not yet connected. Construction and maintenance work should be completed before the advent of the rainy season.

- The railway should be developed as a relatively cheap and comfortable means of transport for people and goods. Double tracks should be provided on major routes like the Dhaka-Chittagong route.

- In coastal areas the dredging of rivers should be undertaken to facilitate year- round navigation and pontoons should constructed at all launch/steamer ghats. Security of river routes should be ensured.

\subsection{Post and telecommunication}

Telecommunication facilities should be expanded to link Upazilas with district towns in Rangamati, Banderban, and Khagrachari hill districts.

\subsection{Housing and Shelter}

- Loss of agricultural land through various non-agricultural uses should be minimized; loss owing to housing can be reduced by encouraging building clusters of houses in villages and providing them with infrastructural facilities.

- In coastal areas the poor should be provided with houses built on RCC pillars, more cyclone shelters at cyclone prone coastal districts should be constructed and old shelters should be properly maintained.

- The middle-class people in coastal areas should be provided with housing loans on easy terms to construct houses that can tolerate cyclone and tidal surges.

- The extreme poor and distressed people should be accommodated in clustered homes. 


\section{Effective Social Protection for Vulnerable People}

\subsection{Social Safety Net Programmes (SSNPs)}

People living in remote char areas should be brought under SSNPs. The coverage of the Char Livelihood Project should be expanded to all char areas.

\subsection{Micro Credit}

Zakat fund should be mobilized for poverty alleviation.

\subsection{Rural development}

Mosque-based employment generation activities can contribute to poverty reduction and they should be supported.

\subsection{Disaster Management}

Community radio should be established to provide early warning of cyclones and other natural disasters.

\section{Human Development}

\subsection{Education}

- General education should be discouraged while technical and vocational education should be encouraged so that young people can find jobs both within and outside the country; they can also start their own business. However, the current state of technical and vocational education should be assessed in terms of their success in generating self or wage employment.

- Students outside major metropolitan cities are in general weak in English; special programmes should be undertaken to promote effective English teaching in the country.

- Administration of primary education should be handed over to the local governments. There is no example of running primary education by the central bureaucracy in the world.

- Arrangements should be made to impart primary education to indigenous people in their own languages beside Bengali and English.

- Researches in science laboratories should be evaluated in terms of their contribution to the country's industrial development and future research programmes should be linked to the solution of the country's specific problems.

- A Knowledge Council should be established along the lines of India to facilitate creation of a knowledge-based society.

- More attention should be given to promoting quality education at all levels especially for the poor.

- Demand-based training should be given to cater to the domestic as well as international markets.

\subsection{Health}

- Administration of primary healthcare should be handed over to the local governments. Community clinics and other health facilities at union level should be made fully operational.

- Quality of healthcare services should be improved in the rural areas. The private sector should be encouraged alongside with the public sector to offer healthcare in rural areas.

- Government should regulate public health services so that private practice by public hospitals doctors must not affect the public hospital services.

\section{Ensuring Participation, Social Inclusion and Empowerment}

- The term 'indigenous people' should be used to mean people of different ethnic communities living in CHTs as well as on the plains. Similarly, 'people with disabilities' should be used instead of 'disabled people'. 
- Education of domestic servants and street children should be ensured; domestic servants should be given some training in household work.

- Inclusive education should be provided to people with disabilities.

- The post of Vice President of Upazila Parishad should be reserved for women.

- The implementation strategy of the Women Policy 2008 should be articulated.

\section{Promoting Good Governance}

- Access of people to government offices should be made easier and the citizens' charter should be displayed in all offices.

- Promotion of government officials should be based on efficiency, honesty, seniority, merit and commitment.

- The media should play an impartial, constructive and objective role to ensure good governance.

- In post-disaster management, activities of the government and NGOs should be coordinated so that some families do not receive more than the usual share of relief goods while many other families do not receive any relief at all.

- Peace in CHTs is the basic requirement for development in this region. Peace has to be maintained and promoted through creating a relationship of trust between the Paharies and Bengalee and by looking after the interests of all people living in the hill districts. Local government offices should be placed under the hill councils in line with the Peace accord.

- Local government elections in hill districts, which are long overdue, should be held to institutionalize democratic local government.

- Local government institutions should be strengthened.

\section{Ensuring Effective Service delivery}

\subsection{Water and Sanitation}

People in CHT suffer from lack of safe drinking water and access to sanitation. Adequate measures need to be taken to ensure access of all people in this region to water and sanitation.

\subsection{Development of Tourism}

The government should support the development of tourism by the private sector in Rangamati, Banderban and Khagrachari hill districts and other potential tourist areas.

\section{Caring for Environment and Tackling Climate Change for Sustainable Development}

- Environmental sustainability should be ensured through social forestry and by maintaining reserve forests.

- Globally the climate change issue puts emphasis on adaptation mechanisms. As a potential worst sufferer from climate change Bangladesh should ask for global prohibition on pollutions causing climate change and for adequate compensation.

- Climate change issues should be mainstreamed in the development discourse.

10. Increasing Productivity through technology including ICT and Bio-technology

- All government offices from the ministry to the field level should be brought under the Wide Area Network.

\section{NSAPR II Implementation Monitoring and Evaluation}

- PRS implementation monitoring and evaluation is weak and should be strengthened. Monitoring indicators should be small in number so that relevant data can be generated.

- Independent research organizations in collaboration with GED should be encouraged to undertake monitoring of NSAPR II.

- Social Auditing can be introduced to monitor the access of the poor to resources. 